\title{
Advanced Fuel Cycle Economic Tools, Algorithms, and Methodologies
}

\author{
David E. Shropshire
}

May 2009

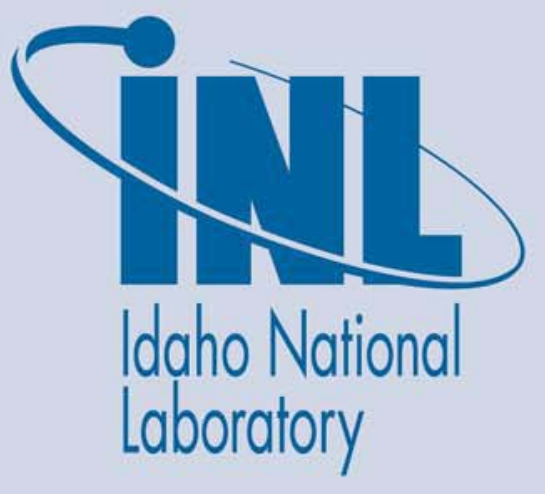

The INL is a U.S. Department of Energy National Laboratory operated by Battelle Energy Alliance 
INL/EXT-09-15483

\title{
Advanced Fuel Cycle Economic Tools, Algorithms, and Methodologies
}

\author{
David E. Shropshire
}

May 2009

\section{Idaho National Laboratory Advanced Nuclear Energy Systems Idaho Falls, Idaho 83415}

http://www.inl.gov

Prepared for the

U.S. Department of Energy

Office of Nuclear Energy

Under DOE Idaho Operations Office

Contract DE-AC07-05ID14517 


\section{DISCLAIMER}

This information was prepared as an account of work sponsored by an agency of the U.S. Government. Neither the U.S. Government nor any agency thereof, nor any of their employees, makes any warranty, expressed or implied, or assumes any legal liability or responsibility for the accuracy, completeness, or usefulness, of any information, apparatus, product, or process disclosed, or represents that its use would not infringe privately owned rights. References herein to any specific commercial product, process, or service by trade name, trade mark, manufacturer, or otherwise, does not necessarily constitute or imply its endorsement, recommendation, or favoring by the U.S. Government or any agency thereof. The views and opinions of authors expressed herein do not necessarily state or reflect those of the U.S. Government or any agency thereof. 
INL/EXT-09-15483 


\section{FOREWORD}

This report describes a compendium of integrated work activities that provide the basic tools and methods for the Advanced Fuel Cycle Initiative (AFCI) Systems Analysis to prepare an economic analysis. As a work in progress, this report contains the general content and description of the economic methodology as currently defined. Since the initial draft report was completed in September 2007, several changes have occurred to the systems analysis process described in this report, AFCI option space and assumptions, economic related data, cost models, and assumptions. 
iv

INL/EXT-09-15483 


\section{EXECUTIVE SUMMARY}

The Advanced Fuel Cycle Initiative (AFCI) Systems Analysis supports engineering economic analyses and trade studies, and requires a requisite reference cost basis to support adequate analysis rigor. In this regard, the AFCI program has created a reference set of economic documentation. The documentation consists of the "Advanced Fuel Cycle (AFC) Cost Basis" report (Shropshire, et al. 2007), "AFCI Economic Analysis" report, and the "AFCI Economic Tools, Algorithms, and Methodologies Report." Together, these documents provide the reference cost basis, cost modeling basis, and methodologies needed to support AFCI economic analysis.

The "AFC Cost Basis" report provides a comprehensive set of reactor and fuel cycle cost data supporting the AFCI economic analysis. The "AFC Cost Basis" report will be updated to include available information from the AFCI facility scoping studies (e.g., the GenIV Economic Modeling Working Group), the Economic Cooperation and Development (OECD) study on market competition in the nuclear industry, and new data and feedback received from industry and international collaborators.

The application of the reference cost data in the cost and econometric systems analysis models will be supported by this report. These methodologies include: the energy/environment/economic evaluation of nuclear technology penetration in the energy market - domestic and internationally - and impacts on AFCI facility deployment, uranium resource modeling to inform the front-end fuel cycle costs, facility first-of-a-kind to nth-of-a-kind learning with application to deployment of AFCI facilities, cost tradeoffs to meet nuclear non-proliferation requirements, and international nuclear facility supply/demand analysis.

The economic analysis will be performed using two cost models. VISION.ECON will be used to evaluate and compare costs under dynamic conditions, consistent with the cases and analysis performed by the AFCI Systems Analysis team. Generation IV Excel Calculations of Nuclear Systems (G4-ECONS) will provide static (snapshot-in-time) cost analysis and will provide a check on the dynamic results.

The AFCI engineering economic analysis will consist of system cost comparisons between closed fuel cycle variations/alternatives, and the current once-through fuel cycle alternative. The cost comparisons include reactor capital, operating, and decontamination and decommissioning (D\&D) costs, and fuel cycle front-end, recycling, and back-end (including disposal) costs. System cost comparisons will be presented in terms of cost distributions and/or ranges rather than single point values. The analysis will state all applicable general and case assumptions regarding the front-end, reactor, back-end, and recycling requirements. The economic analysis will contain cost sensitivity analysis, including cost distributions and the cost sensitivity due to specific variables of interest. The analysis will identify key cost drivers that have the greatest impact on economic discrimination between alternatives. System uncertainties, such as process performance, which have a large influence on costs, are identified and evaluated in combination with the uncertainties that are intrinsically associated with the input cost values. 
Cost comparisons will include the total fuel cycle costs and the total cost of electricity (TCOE) including reactor-associated life cycle costs. Nuclear energy costs will be compared to the costs projected for other future base-load electricity producing technologies, and an energy systems analysis will be carried out to determine real market competitiveness of AFCI technologies compared to fossil fuel derived electrical energy (particularly if carbon is taxed or carbon sequestration is required).

In future analyses, additional AFCI measures may be developed to show the value of AFCI in closing the fuel cycle. Comparisons can show AFCI in terms of reduced global proliferation (e.g., reduction in enrichment), greater sustainability through preservation of a natural resource (e.g., reduction in uranium ore depletion), value from weaning the U.S. from energy imports (e.g., measures of energy self-sufficiency), and minimization of future high level waste (HLW) repositories world-wide. 


\section{ACKNOWLEDGEMENTS}

The AFCI Systems Analysis wishes to acknowledge those who contributed to this report: David Shropshire, INL, report architect and integrator, project manager, and technical contributor; Ann Marie Phillips, INL, report production coordinator; Kent Williams, ORNL, G4-ECONS modeling and analysis and contributor to many of the AFCI Systems Analysis studies; Ann Reisman, John Lee, and Vatsal Bhatt, BNL, domestic and international market analysis; J. D. Smith, SNL and Ed Hoffman, ANL, AFCI economic studies and contributions to economic model development; Jake Jacobson, INL and J'Tia Taylor, University of Illinois-Champaign/Urbana, dynamic modeling and economic analysis; Trond Bjornard, INL, Tom Wood and Steven Short, PNNL, economic and nuclear security tradeoffs; Jennifer Morton, INL, international nuclear system data and configurations; Bob Cherry, INL, evaluation of new non-nuclear electricity generation alternatives; Erich Schneider and Anthony Scopatz, U of TexasAustin, uranium resource modeling and secondary uranium supplies; Geoffrey Rothwell, Stanford University, international fuel supply market structure analysis and method development for first-of-a kind to nth-of-a-kind systems. 
INL/EXT-09-15483 


\section{CONTENTS}

FOREWORD

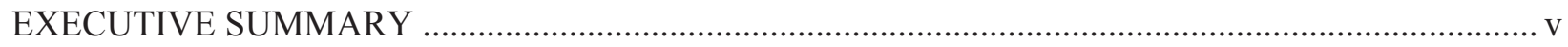

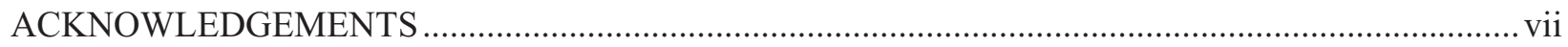

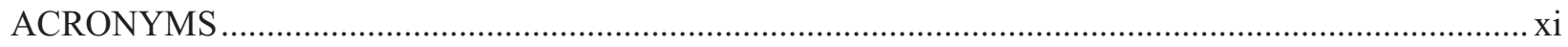

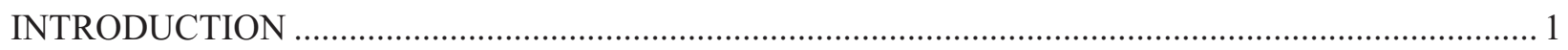

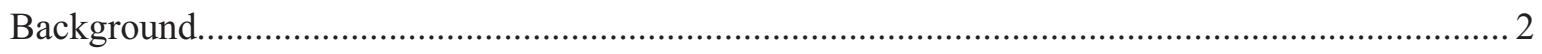

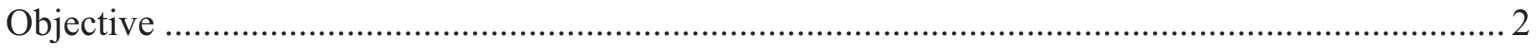

Define Scenarios and Bounding Parameters …..................................................................... 3

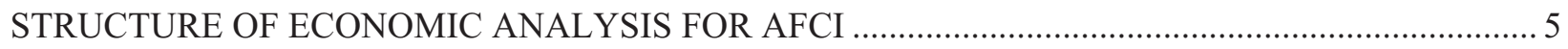

1. AFCI TECHNOLOGY PENETRATION IN U.S. AND INTERNATIONAL MARKETS .............. 7

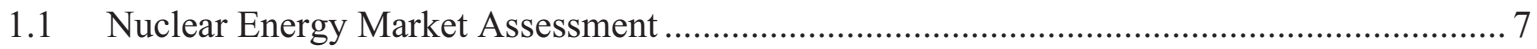

1.2 Comparison of Energy Options and Technology Challenges .......................................... 9

2. AFCI DEPLOYMENT WITHIN REACTOR AND FUEL CYCLE FACILITY SYSTEM

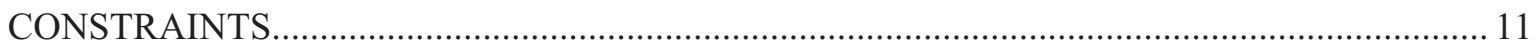

$2.1 \quad$ VISION Model Analysis at Various Deployment Rates................................................... 11

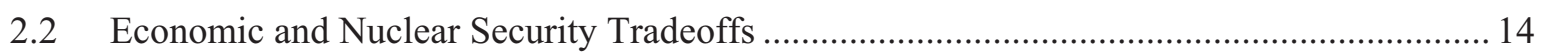

2.3 Nuclear Materials Exchange Database Description and Methodology ............................... 15

3. FAST REACTOR AND FUEL CYCLE ECONOMIC MEASURES AND MARKET

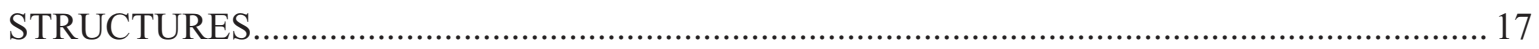

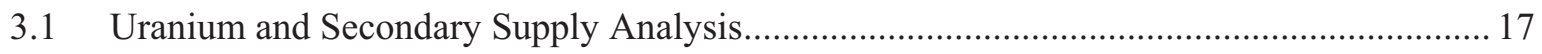

3.2 Enrichment and Fuel Fabrication Market Structure Economics ......................................... 19

3.3 AFCI Facility Deployment Analysis........................................................................... 20

4. SYSTEM LEVEL STATIC AND DYNAMIC ECONOMIC ANALYSIS UNDER

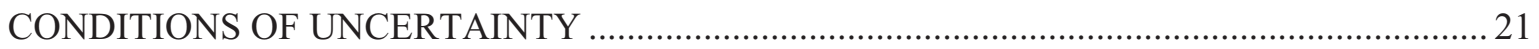

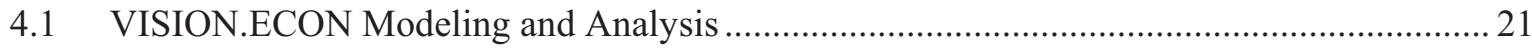

4.2 G4-ECONS MODELING AND ANALYSIS ............................................................... 23

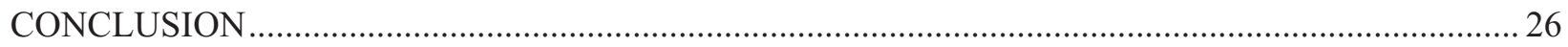

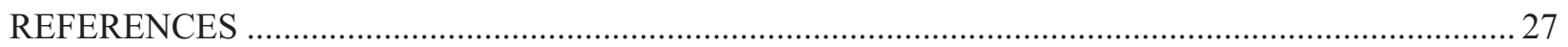

Attachment A- A Market-based Methodology to Project Future Deployment of AFCI Technologies in the U.S. and Nuclear Energy in the World......................................................

Attachment B-Comparison of Nuclear to Future New Electricity Generation Alternatives ................. B-1

Attachment C-Economics and Nuclear Security White Paper - Achieving Nonproliferation Objectives While Considering Cost Trade-offs. 
Attachment D_Nuclear Materials Exchange Database Description and Methodology ........................ D-1

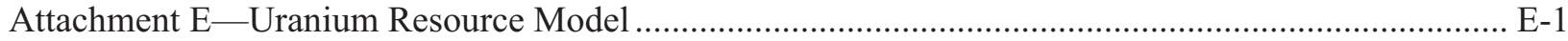

Attachment F-Cost and Market Structure Economics of the International Nuclear Fuel Cycle ..............F-1

Attachment G-The Cost Economics of Advanced Nuclear Power Technologies with Application

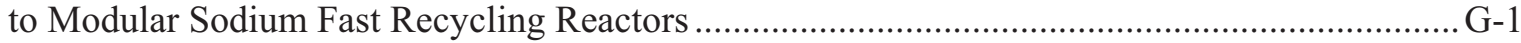

Attachment H-VISION Economic (VISION.ECON) Submodel Description and Methodology ........... H-1

Attachment I-The Static Analysis and Uncertainty Analysis Toolbox for the Spreadsheet Economic Evaluation of Reactor/Fuel Cycle Scenarios

\section{FIGURES}

Figure 1. Systems analysis option space for economic calculation and comparison ................................. 3

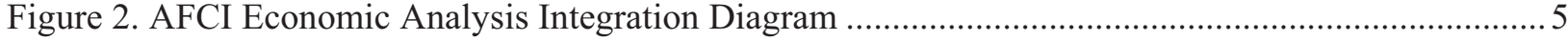

Figure 3. Schematic of the VISION Model flow control..................................................................... 12 


\section{ACRONYMS}

\begin{tabular}{|c|c|}
\hline ABR & Advanced Burner Reactor \\
\hline $\mathrm{AFC}$ & Advanced Fuel Cycle \\
\hline $\mathrm{AFCI}$ & Advanced Fuel Cycle Initiative \\
\hline BNL & Brookhaven National Laboratory \\
\hline CFTC & Consolidated Fuel Treatment Center \\
\hline $\mathrm{COEX}^{\mathrm{TM}}$ & co-extraction \\
\hline $\mathrm{CR}$ & conversion ratio \\
\hline D\&D & decontamination and decommissioning \\
\hline DOE & Department of Energy \\
\hline DOE-NA & Department of Energy-National Nuclear Security Administration \\
\hline DOE-NE & Department of Energy-Nuclear Energy \\
\hline DPL & Decision Programming Language \\
\hline DU & depleted uranium \\
\hline EAS & Engineering Alternative Study \\
\hline EIA & Energy Information Administration of DOE \\
\hline EMWG & Economic Modeling Working Group \\
\hline ETP & Energy Technology Perspectives \\
\hline FCF & fuel cycle facility \\
\hline FOAK & first-of-a-kind \\
\hline FR & Fast Reactor \\
\hline G4-ECONS & Generation IV Excel Calculations of Nuclear Systems \\
\hline GIF & Generation IV International Forum \\
\hline HLW & high-level waste \\
\hline IEA & International Energy Agency \\
\hline IGCC & integrated gasification combined cycle \\
\hline IMEP & Industrial Materials Exchange Planner \\
\hline IMF & inert matrix fuels \\
\hline INL & Idaho National Laboratory \\
\hline LEU & low-enriched uranium \\
\hline LUEC & levelized unit electricity cost \\
\hline LWR & light water reactor \\
\hline MA & minor actinide \\
\hline MARKAL & Market Allocation model \\
\hline
\end{tabular}




$\begin{array}{ll}\text { MOX } & \text { mixed uranium-plutonium oxide } \\ \text { NDC } & \text { Nuclear Development Committee } \\ \text { NME } & \text { nuclear materials exchange } \\ \text { NOAK } & \text { nth-of-a-kind } \\ \text { NPP } & \text { nuclear power plant } \\ \text { NU } & \text { new uranium } \\ \text { O\&M } & \text { operations and maintenance } \\ \text { OECD } & \text { Organization of Economic Cooperation and Development } \\ \text { ORNL } & \text { Oak Ridge National Laboratory } \\ \text { PEIS } & \text { Programmatic Environmental Impact Statement } \\ \text { PNNL } & \text { Pacific Northwest National Laboratory } \\ \text { PRISM } & \text { Power Reactor Innovative Small Module } \\ \text { PUREX } & \text { plutonium uranium extraction } \\ \text { R\&D } & \text { Research and Development } \\ \text { RU } & \text { reprocessed or reprocessable uranium } \\ \text { SF } & \text { spent fuel } \\ \text { TCOE } & \text { total cost of electricity } \\ \text { UOX } & \text { uranium oxide fuel } \\ \text { UREX } & \text { uranium extraction } \\ \text { VISION } & \text { Verifiable Fuel Cycle Simulation } \\ & \end{array}$




\section{Advanced Fuel Cycle Economic Tools, Algorithms, and Methodologies}

\section{INTRODUCTION}

The Advanced Fuel Cycle Initiative (AFCI) Systems Analysis supports engineering economic analyses and trade studies, and requires a requisite reference cost basis to support adequate analysis rigor. In this regard, the AFCI program has created a reference set of economic documentation. The documentation consists of the "Advanced Fuel Cycle (AFC) Cost Basis" report (Shropshire, et al. 2007), "AFC Economic Analysis" report, and the "AFC Economic Tools, Algorithms, and Methodologies" report. Together, these documents provide the reference cost basis, cost modeling basis, and methodologies needed to support AFCI economic analysis.

The "AFC Cost Basis" report provides a comprehensive set of reactor and fuel cycle cost data supporting the AFCI economic analysis. The "AFC Cost Basis" report will be updated to include available information from the AFCI facility scoping studies (e.g., the GenIV Economic Modeling Working Group), the Organization of Economic Cooperation and Development (OECD) study on market competition in the nuclear industry, and new data and feedback received from industry and international collaborators.

The application of the reference cost data in the cost and econometric systems analysis models will be supported by this report. These methodologies include the energy/environment/economic evaluation of nuclear technology penetration in the energy market - domestic and internationally - and impacts on AFCI facility deployment, uranium resource modeling to inform the front-end fuel cycle costs, facility first-of-a-kind to nth-of-a-kind learning with application to deployment of AFCI facilities, cost tradeoffs to meet nuclear non-proliferation requirements, and international nuclear facility supply/demand analysis.

The economic analysis will be performed using two cost models. VISION.ECON will be used to evaluate and compare costs under dynamic conditions, consistent with the cases and analysis performed by the AFCI Systems Analysis team. Generation IV Excel Calculations of Nuclear Systems (G4-ECONS) will provide static (snapshot-in-time) cost analysis and will provide a check on the dynamic results.

The AFCI engineering economic analysis will consist of system cost comparisons between closed fuel cycle variations/alternatives, and the current once-through fuel cycle alternative. The cost comparisons include reactor capital, operating, and decontamination and decommissioning (D\&D) costs, and fuel cycle front-end, recycling, and back-end (including disposal) costs. System cost comparisons will be presented in terms of cost distributions and/or ranges rather than single point values. The analysis will state all applicable general and case assumptions regarding the front-end, reactor, back-end, and recycling requirements. The economic analysis will contain cost sensitivity analysis, including cost distributions and the cost sensitivity due to specific variables of interest. The analysis will identify key cost drivers that have the greatest impact on economic discrimination between alternatives. System uncertainties, such as process performance, which have a large influence on costs, are identified and evaluated in combination with the uncertainties that are intrinsically associated with the input cost values.

Cost comparisons will include the total fuel cycle costs and the total cost of electricity (TCOE), including reactor-associated life-cycle costs. Nuclear energy costs will be compared to the costs projected for other future base-load electricity producing technologies, and an energy systems analysis will be carried out to determine real market competitiveness of AFCI technologies compared to fossil fuelderived electrical energy (particularly if carbon is taxed or carbon sequestration is required). 
In future analyses, additional AFCI measures may be developed to show the value of AFCI in closing the fuel cycle. Comparisons can show AFCI in terms of reduced global proliferation (e.g., reduction in enrichment), greater sustainability through preservation of a natural resource (e.g., reduction in uranium ore depletion), value from weaning the U.S. from energy imports (e.g., measures of energy selfsufficiency), and minimization of future high-level waste (HLW) repositories worldwide.

The main body of this report describes the background, objectives, description of the option space for economic scenario analysis, structure of the economic analysis, and summaries for each of the studies, methodologies, and models. A description is also provided to indicate how each of the activities interrelate and will be integrated in the AFCI economic analysis. Each of the activities is described in full detail in the attachments following the main report. The reader is directed to the latest 2008 "AFC Cost Basis" report for details on the estimating cost basis (Shropshire, et al. 2008).

\section{Background}

Since 2004, the Advanced Fuel Cycle Initiative Program has been developing an economic cost basis and developing capabilities to perform engineering economic comparisons of advanced fuel cycles. The initial "AFC Cost Basis" report was produced in 2004, with annual updates in 2005, 2006, and 2007. The most current "AFC Cost Basis" report was completed in March 2008 and contains 614 pages (12 MB of PDF text), and contains approximately 400 reference citations. In Fiscal Year 2008, the Department of Energy (DOE) released the report to the public.

Cost models were developed to support the economic analysis under conditions of uncertainty of both the costs and system parameters. The first tools used were a spreadsheet model developed by the GenIV Program, called G4-ECONS, and decision analysis software, called DPL (Decision Programming Language). The initial advanced fuel cycle economic sensitivity analysis was completed in 2006 (Shropshire, et al. 2006). In 2007, a dynamic system model called Verifiable Fuel Cycle Simulation (VISION) was developed with an economic submodel for more advanced economic analysis. Preliminary economic analysis was performed using VISION and was then compared to the static results produced using G4-ECONS, resulting in very similar costs and uncertainty ranges.

The Advanced Fuel Cycle Initiative (AFCI) Systems Analysis has been closely integrated with the GenIV Economic Modeling Working Group (EMWG). Kent Williams (Oak Ridge National Laboratory [ORNL]) has been a U.S. representative on the group since its initiation in 2003, and David Shropshire (Idaho National Laboratory [INL]) became involved in the EMWG as the AFCI Program representative in 2004. The AFCI program adopted the EMWG cost estimating guidelines (EMWG 2005) and G4-ECONS model (Williams 2007) for use and application to advanced fuel cycles. The joint work and participation is planned to continue in 2009 and for the foreseeable future.

\section{Objective}

The purpose of this report is to describe the economic analysis, modeling tools, and methodologies under development that will support the engineering economic analysis. Some example applications are provided in the analysis to illustrate how the tools and methods may be used. These economic analysis capabilities are used by the AFCI Systems Analysis to evaluate the economic ramifications of various AFCI fuel cycle scenarios, including determination of which components have the largest uncertainty, and which components have the largest impact on overall cost. The results of this work can help to provide insight to the economic conditions needed to keep nuclear energy (including closed fuel cycles) economically competitive in the U.S. and globally. 


\section{Define Scenarios and Bounding Parameters}

The economic analysis will be required to support the evaluation of AFCI in a number of variations. This analysis covers a broad "option space" including variations on thermal and fast reactors, fuel types, separation processes, fast reactor conversion ratios, thermal reactor burn-ups, and waste management alternatives. Due to the vastness of the potential number of combinations for analysis, there must be boundary conditions established for the option space (see Figure 1) for management of the separated waste streams. To date, two types or reactors have been evaluated: thermal light water and fast recycling reactors. Thermal reactors can use either a uranium oxide (UOX) fuel or a mixed uranium-plutonium oxide (MOX) fuel. Fast reactors can be operated in a converter mode or a breeder mode. Fuel separation technologies that are evaluated for both thermal light water reactors and fast reactors, or that are evaluated for UOX and MOX fuel, include uranium extraction (UREX) processing variations (e.g., UREX $+1 A$ ), co-extraction $\left(\mathrm{COEX}^{\mathrm{TM}}\right)$, and plutonium uranium extraction (PUREX). In the case of fast reactor metal fuels, electrochemical (pyrolytic) processing is also evaluated. In addition, the wet fuel storage time (2-30 years), thermal burn-up, and fast reactor conversion ratios could cover a wide range.

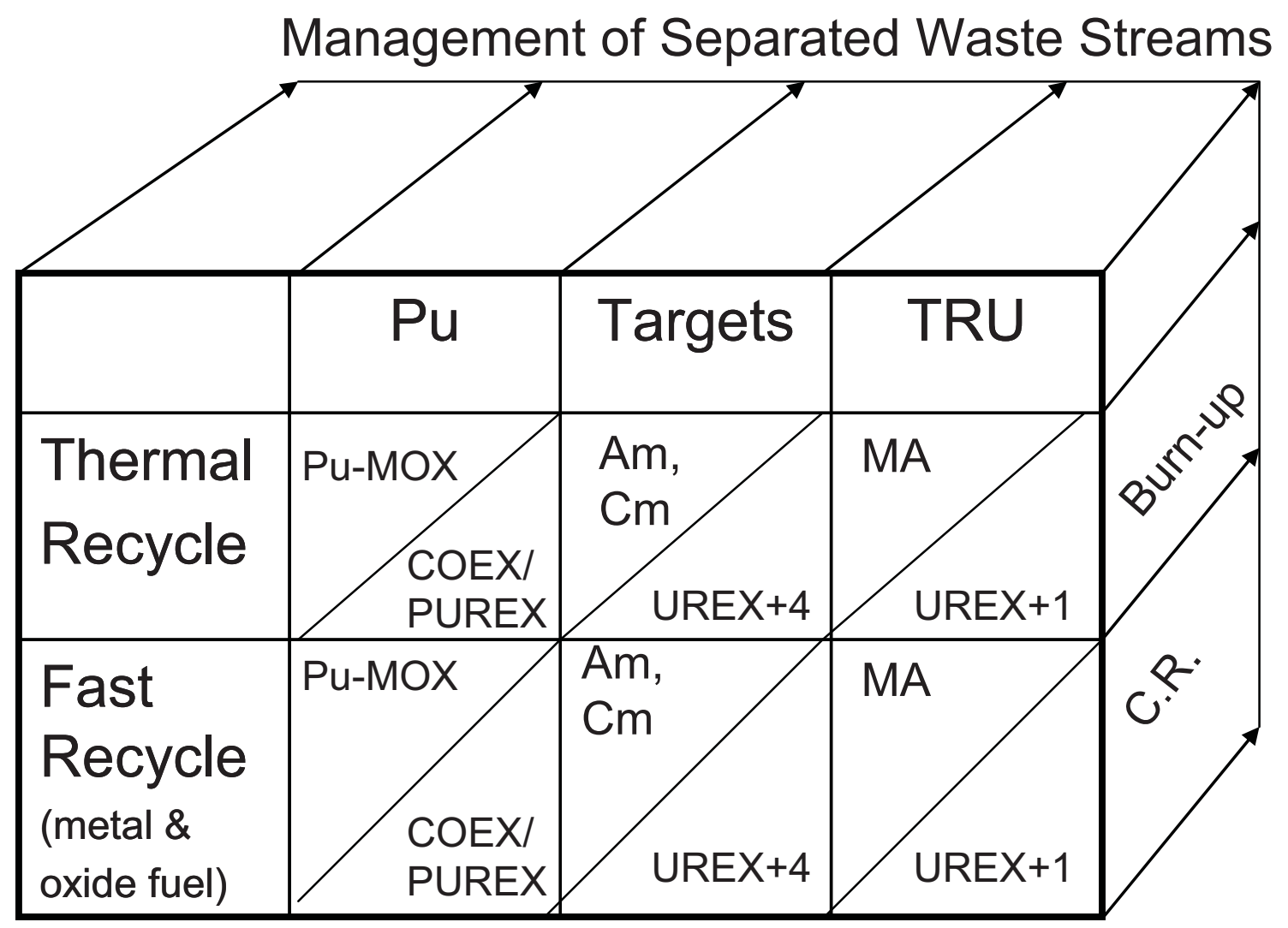

Figure 1. Systems analysis option space for economic calculation and comparison.

The economic analysis is used to compare cases such as the following:

- Closed fuel cycles versus the current open fuel cycle operating in the U.S.

- Single (only fast recycle) and double-tier (thermal recycle followed by fast recycle) systems

- Varying fuels in thermal reactors (e.g., UOX, Pu-MOX, targets) and fast reactors (oxide, metal)

- Varying separations technologies (e.g., PUREX, $\mathrm{COEX}^{\mathrm{TM}}$, UREX+, Electrochemical) and resulting streams 
- Varying thermal burnup and fast reactor conversion or breeding ratios

- Varying waste management options (wet storage time, recycled product storage, waste forms, and disposition).

In addition, timing issues can be examined by changing startup dates for the various facilities and reactors types. The timing and cost effects from deploying various facility capacities are also to be studied. From a global standpoint, the analysis should understand the effects (timing, capacities, etc.) from supplying new fuel to user countries and associated demands on system economics arising from used fuel take back.

Not all cost information required to compare these cases may be available. For example, the cost differentials for various UREX $+1,2,3,4$ separation schemes, fuel fabrication costs for mixed oxide fuels with transuranics and inert matrix fuels, new waste forms for reprocessed streams, and pyroprocessing (electrochemical) costs are not well defined. The reprocessing economic analysis can only proceed by using a broad cost range until design information on reprocessing facilities of various types becomes available, bottom-up cost analyses are performed on these designs, and the resulting cost estimates become part of the basis for new reprocessing economic models with higher "fidelity" than those presently available. 


\section{STRUCTURE OF ECONOMIC ANALYSIS FOR AFCI}

The AFCI economic analysis is integrated into four functional areas, as shown in Figure 2, each representing a key concentration of activities that, when integrated, provide the cost basis and methods required to prepare the economic analysis for the AFCI decision package. The functional areas are composed of various studies and assessments, new economic estimating methods, cost bases, and engineering cost models. Within each functional area, interfaces to other key activities are identified that are supported by the AFCI Systems Analysis, other activities within the DOE system, and international collaborators. The information flow between these functional areas is generally from top to bottom as indicated by the flow arrows originating at the circle labeled 1 and proceeding sequentially to the circle labeled 4 in Figure 2. The level of detail within the economic analysis is most coarse at the highest level and gains additional definition progressing downward through the functional areas. Information feedbacks are also included to allow new information and analysis defined at the fourth level to feedback to the higher levels to allow refinement of assumptions and re-assessment of the study results.

The first functional level assesses the potential for AFCI technology penetration into domestic and international energy markets. This is achieved through energy market assessment with domestic and international market models, which evaluate the future deployment potential for nuclear technologies based on the market competitiveness of nuclear energy compared to other energy sources. The market analysis is further supported by a comparison of nuclear to future new electricity generation technology alternatives.

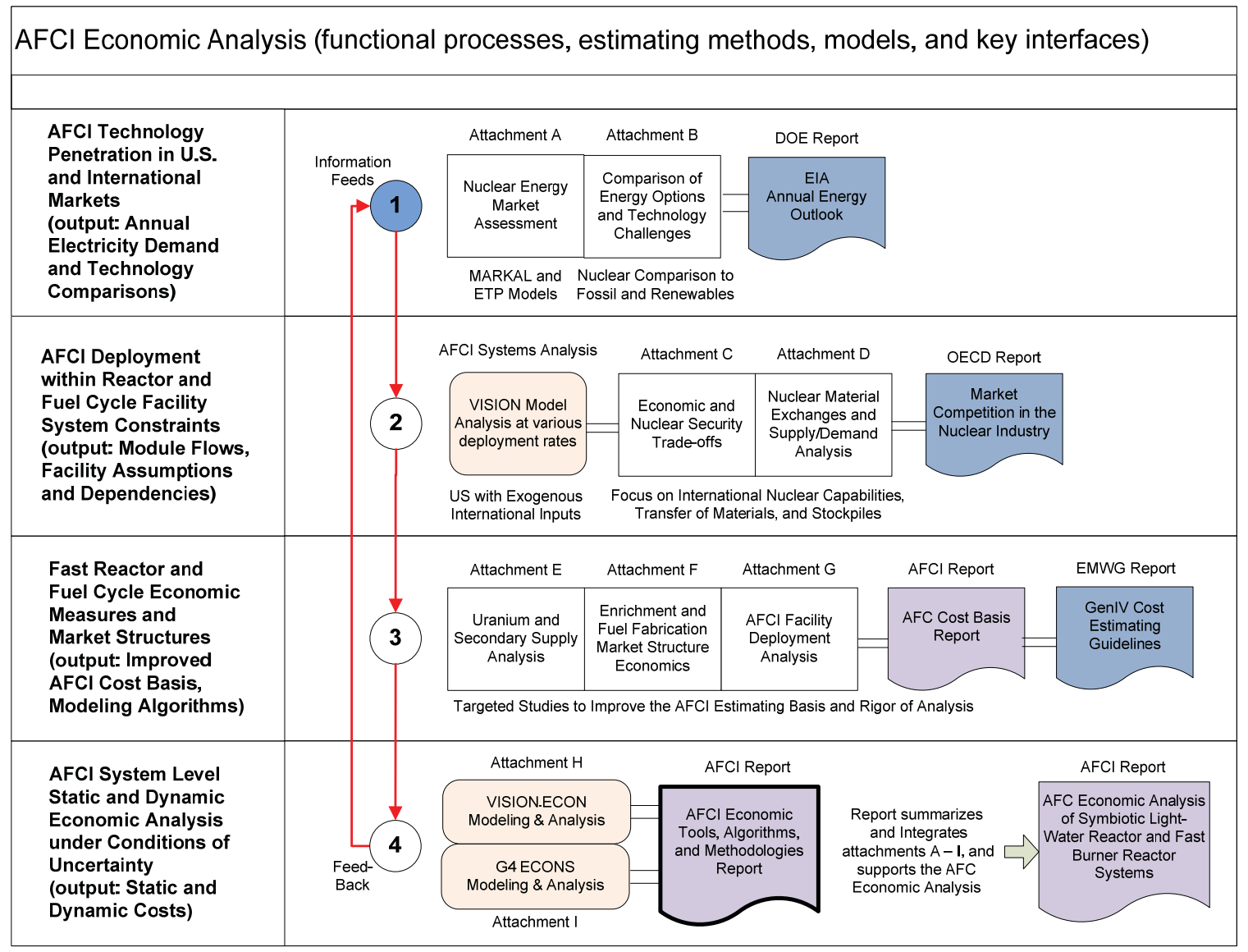

Figure 2. AFCI Economic Analysis Integration Diagram. 
The second functional level addresses the flows and constraints related to deployment of AFCI reactors and fuel cycles facilities. A system dynamics model was developed to evaluate facility deployment rates as supported by the AFCI technology penetration into the domestic and international markets. From an international perspective, the nuclear capabilities, transfer of materials and stockpile buildups are directly related to potential physical protection and nonproliferation concerns. A white paper study was developed to evaluate when economics and nonproliferation have common and conflicting objectives. A nuclear materials exchange capability was developed to evaluate current and potential future reactor and fuel cycle capacities globally, create linkages between current/future users and suppliers, and evaluate new supplier arrangements (e.g., fuel bank, multi-lateral facility).

In the third functional level, targeted studies were developed to improve the AFCI estimating cost basis and rigor of analysis. This level includes a study of uranium ore prices and secondary supplies of uranium from re-enrichment of depleted uranium (DU) and use of reprocessed uranium (RU) recycle in light water reactors (LWRs). An analysis of the international market structure economics for enrichment and fuel fabrication of LWR fuel was prepared. A method was created for incorporating learning effects from first-of-a-kind to nth-of-a-kind facilities. A study was prepared to identify the key economic questions/issues and data requirements needed to define the costs for new AFCI facilities.

Supported by the first three functional areas, the fourth functional level includes creation of static and dynamic models with uncertainty analysis to evaluate the economics of various fuel cycle and reactor scenarios. The G4-ECONS spreadsheet-based model provides a static analysis (or "snapshot in time" view) of the economics and mass flows for various reactor and fuel cycle scenarios. VISION.ECON provides dynamic analysis of fuel cycle and reactor scenarios, so that cost variations over time can be analyzed. Both of these models use data from the "AFC Cost Basis" report, which provides unit cost ranges for fuel cycle capabilities and capital and operating cost ranges for thermal and fast reactors (Shropshire, et al. 2008).

These four functional areas support AFCI economic analysis by providing the estimating basis, methods/algorithms, modeling tools, and interfaces needed to support system trade-off studies. The functional levels and their associated components are further described in the following sections. These sections include a description of the each of the tasks including their objectives, accomplishments to date, interfaces, and gaps. The next four major sections of this report are formatted with numbered headings that correspond with the four functional areas described above and shown in Figure 2. The reader is encouraged to read the summary sections, understand the general context of the studies, and refer to the attachments for the details. 


\section{AFCI TECHNOLOGY PENETRATION IN U.S. AND INTERNATIONAL MARKETS}

The first functional level assesses the potential for AFCI technology penetration into domestic and international energy markets. This is achieved through energy market assessment with domestic and international market models, which evaluate the future deployment potential for nuclear technologies based on the market competitiveness of nuclear energy compared to other energy sources. The market analysis is further supported by a comparison of nuclear to future new electricity generation technology alternatives. The types of output created by this function include annual electricity demands and assessment of technology deployment issues for nuclear, fossil, and renewable technologies.

A key report supporting this function is the Energy Information Administration (EIA) "Annual Energy Outlook" (EIA 2006a). This report provides the key baseline assumptions for nuclear energy market assessment and the comparison of future energy options. The "EIA" report includes information on reference energy markets (e.g., new capacity installation, number of plants, fuel usage, and other technology and resource assumptions).

These assessments will provide insights into how the competing energy technologies are changing and how this may change the future competitive environment for deployment of AFCI.

\subsection{Nuclear Energy Market Assessment}

The objective of the work described in Attachment A, "A Market Based Methodology to Project Future Deployment of AFCI Technologies in the U.S. and Nuclear Energy in the World," is to apply and test a market-based methodology to examine the growth of nuclear energy and the future deployment of AFCI technologies in the context of the overall energy market. The projected deployment of nuclear generating capacity is based on from market competition, and in some cases market intervention, to meet the future electricity demand.

This study has accomplished an initial sensitivity evaluation of the market penetration of AFCI nuclear energy systems in the domestic energy markets, and assessed the demand for nuclear energy in the world. Based on these results, the international AFCI case was tested with additional demand on U.S. resources (for supplying fresh reactor fuel and taking back spent fuel) from a representative small and large user country in FY-07.

The methodology uses two separate modeling frameworks: the U.S. Market Allocation Model (MARKAL) model for domestic AFCI technology deployment and the Energy Technology Perspectives (ETP) model - a MARKAL variant for global penetration of advanced nuclear reactors. The U.S. MARKAL model is a partial equilibrium model of the U.S. energy system that is executed in 5-year intervals extending from 2005 through 2050 and integrates both energy demand and supply technologies into a single energy market. In the solution, the energy system cost is minimized over the analysis period. In particular, U.S. MARKAL tracks new investments and existing capital stocks of competing electricity generating technologies over the forecast period to meet electricity demand endogenously determined in the model. These investments determine the projected deployment paths for individual technologies, including advanced nuclear reactor and fuel cycle technologies. The ETP model is a global version of MARKAL developed and maintained by the International Energy Agency (IEA), in which the world energy and associated commodity flows are modeled into 15 trade regions with major countries, such as the U.S., Canada, Russia, China, Mexico, and India defined as separate regions.

For this report, several scenarios were analyzed for the U.S. to illustrate the capability of the methodology. In all the scenarios, the cost data for AFCI-related technologies were taken from the "AFC Cost Basis" report (Shropshire, et al. 2008). The analysis varied the discount rate for AFCI technologies 
to see when the Fast Reactors (FR) became competitive. In addition, various levels of carbon tax were examined to determine the level of penetration of FRs. The ETP model evaluated the potential for advanced nuclear technologies in the world energy market. In addition, the global analysis considered a potential international deployment scenario (with the mechanisms of a supplier nation and consumer nations), to estimate impacts on the U.S. nuclear market of a hypothetical nuclear material supply to a large and a small consumer region, and subsequent return of spent fuel to the U.S., in which the U.S. was considered a supplier nation. The impact (of the fresh reactor fuel provision to each region and spent fuel return) on the U.S. nuclear fuel cycle, FR deployment, and high-level waste repository were examined.

The interaction of this work with the other tasks described in this report is potentially extensive. The comparison of energy options and technology challenges (main report-Section 1.2 and Attachment B,) and G4-ECONS modeling and analysis (main report-Section 4.2 and Attachment I) can be used to crosscheck the costs of competing electric generation technologies in MARKAL analyses. This MARKAL work could provide yearly market nuclear energy growth rates for the VISION model (Section 2.1) calculations of the module fuel cycle demands. The module demand data can be compared to the available/projected fuel cycle supplies in the nuclear materials exchange database (main report-Section 2.3 and Attachment D). The detailed uranium supply analysis (main report-Section 3.1 and Attachment E) and enrichment and fuel fabrication market structure economic analysis (main report-Section 3.2 and Attachment F) can be used to refine the representation of the market conditions to produce shadow prices at market equilibrium for uranium enrichment, and fabrication, respectively. The learning effects described in the AFCI facility deployment analysis (main report-Section 3.3 and Attachment G) can be used to produce projections of technology learning that would affect the market competitiveness of AFCI technologies. MARKAL and ETP models may be coupled with the VISION dynamic flow model to support a variety of growth scenarios. VISION (Section 2.1) takes as input external demand growth for nuclear technology over time, which could be provided by the nuclear energy market assessment. The nuclear growth rates used by VISION.ECON (main report-Section 4.1 and Attachment H) could be input to the MARKAL analyses to evaluate options for market deployment of nuclear and AFCI technologies that meet these rates over time. An iterative process can be established, in which VISION/VISION.ECON could run various scenarios, then supply MARKAL/ETP with the projected number of facilities (reactors, fuel fabrication, and separation). Subsequently, MARKAL/ETP could run analyses to determine the market conditions that are necessary to support those levels of growth. The results from MARKAL and ETP could then be fed back to VISION/VISION.ECON for additional analysis.

Future development areas for AFCI include:

1. Provide input to the AFCI Economic Analysis utilizing the modeling capabilities and initial sensitivity analysis. Integrate results from the global nuclear (ETP) analysis to incrementally evaluate additional international scenarios.

2. Evaluate AFCI technology deployment in the U.S. energy market, in consideration of financial options and policy tools. Identify (using U.S. MARKAL) the conditions (e.g., financial incentives and carbon constraints) where AFCI fuel-cycle technologies and reactors will penetrate the market. Select several scenarios of interest to examine competitiveness under alternative polices for taxes, subsidies, and other government mechanisms, and estimate the net cost to the government under each alternative. Finally, for the most viable scenarios, provide information to VISION/VISION.ECON for analysis of impacts to facility deployment, material flows, and costs.

3. Examine the impact of AFCI on the overall deployment of nuclear facilities in the world, supply and demand mechanisms of nuclear fuel (fresh and spent), and technologies in the world energy market, including the U.S. nuclear market. Work would involve integration of IEA-vetted MARKAL ETP model and the INL Nuclear Materials Exchange database. 
See Attachment A, "A Market-based Methodology to Project Future Deployment of AFCI Technologies in the U.S. and Nuclear Energy in the World," for more details.

\subsection{Comparison of Energy Options and Technology Challenges}

The objective of the work described in Attachment B, "Comparison of Nuclear to Future New Electricity Generation Alternatives," is to provide a realistic look at the technology challenges for all future sources of electricity and create improved understanding of the comparative economics and other measures of increasing importance (e.g., carbon dioxide production, natural resource utilization, energy self sufficiency, and waste challenges).

This study has produced in FY-07 a high-level comparison between nuclear and competing electricity generation options, accounting for future technology challenges and cost penalties if carbon controls become mandatory.

The decision to build new nuclear power generation facilities will not be made solely on the pros and cons of nuclear technology itself, but also on how those factors compare among the alternatives to nuclear energy. A range of new fossil and renewable energy technologies are now being demonstrated and will likely be commercially feasible choices in the near future. How these compare to nuclear power is reviewed in Attachment B.

The announced plans for power plants to be built in 2006-2010 show that fossil fuels are, by far, the favored source of energy. A number of advanced technologies for fossil fuel use are in development, and these are briefly reviewed. Integrated gasification combined cycle (IGCC) plants can offer both higher thermal efficiency as well as better pollutant control. Their process configuration makes them especially suitable for capturing $\mathrm{CO}_{2}$ to prevent its release to the atmosphere. Two tests of sequestering $\mathrm{CO}_{2}$ in underground formations have begun, with more planned.

Attachment B also discusses several sources of risk for potential users of these new fossil fuel technologies. There is an evident technical risk associated with being an early user of a new technology. Aggravating this problem, these plants are expensive because of their large size, so a large capital investment is at risk in building them before their performance is known. Even after they begin operation, because fuel costs are significant for a fossil fueled plant, unanticipated fluctuations in coal or natural gas prices can hurt the plant's economic performance. Finally, expected future limitations or penalties on emission of $\mathrm{CO}_{2}$ to the atmosphere will greatly affect fossil-fired plants by requiring process changes to capture that greenhouse gas. Coal-fired plants are particularly at risk because of their relatively high emissions per unit of power production. Cogeneration and poly-generation of multiple forms of energy (electricity, heat, hydrogen, or shaft work) in one plant from multiple sources of energy may be useful in addressing some of nuclear and fossil energy's issues.

This task integrates primarily with the nuclear energy market assessment (Attachment A, Section 1.1) by providing an independent comparison of energy choices, their timing, competition, and impacts due to carbon taxes. This task brings in additional sources of information that can be used to describe the competitive electricity market, future energy resources, and G4-ECONS modeling and analysis (main report-Section 4.2 and Attachment I).

Future development areas for AFCI include:

1. Provide applicable updates to competing projected energy costs and deployment schedules, accounting for recent plant cost increases.

2. Account for projected costs and implementation issues associated with carbon capture and sequestration. 
See Attachment B, "Comparison of Nuclear to Future New Electricity Generation Alternatives," for more details. 


\section{AFCI DEPLOYMENT WITHIN REACTOR AND FUEL CYCLE FACILITY SYSTEM CONSTRAINTS}

The second functional level addresses the flows and constraints related to deployment of AFCI reactors and fuel cycles facilities. A system dynamics model was developed to evaluate facility deployment rates as supported by the AFCI technology penetration into the domestic and international markets. From an international perspective, the nuclear capabilities, transfer of materials, and stockpile buildups are directly related to potential physical protection and nonproliferation concerns. A white paper study was developed to evaluate when economics and nonproliferation have common and conflicting objectives. A nuclear materials exchange capability was developed to evaluate current and potential future reactor and fuel cycle capacities globally, create linkages between current/future users and suppliers, and evaluate new supplier arrangements (e.g., fuel bank, multi-lateral facility). The types of output created by this function include material flows between facilities, facility capacities and deployment rates, and dependencies between users and suppliers.

A key report supporting this function is an international study on market competition in the nuclear industry that is sponsored by the Nuclear Development Committee (NDC) of the OECD. David Shropshire, co-chair of the study, expects that information from the study will be available by the end of 2007 and may be used in conjunction with the final AFCI economic analysis produced in FY-08. The OECD study will cover the competition in the supply of goods, materials, and services for the entire fuel cycle, for the design and construction of new nuclear power plants (NPPs), and for the maintenance, back fitting, and upgrading of existing nuclear power plants. Key markets are identified for more in-depth assessment. The analysis determines if effective competition exists in these markets, and the various constraints that limit competition. With the potential for nuclear expansion in the OECD countries, the study will assess the possible future trends in response to likely increases in demand over the next 10-15 years. A reference report is available through the OECD NEA.

These assessments will provide insight on the domestic and international linkages within global fuel cycle markets, the calculation of facility capacity demands and deployment schedules, the demands for international suppliers and opportunities for new market entrants.

\subsection{VISION Model Analysis at Various Deployment Rates}

The objective of the work described in the "VISION: Verifiable Fuel Cycle Simulation Model" report (Jacobson, et al. 2006) is to develop a dynamic systems model that can be used to analyze advanced fuel cycle and reactor concepts. An economic submodel was developed in conjunction with the systems model to evaluate the economic comparisons of different scenarios. A description of the economic submodel can be found in the main report's Section 4.1 and Attachment H.

This model development effort completed release 2.0 of VISION with documentation to the VISION user community in FY-07.

VISION is the AFCI's nuclear fuel cycle systems code. It is a dynamic stock and flow model that tracks the mass of materials through the entire nuclear fuel cycle. VISION tracks the isotopic mass-flows of uranium, plutonium, minor actinides, and fission products throughout the fuel cycle and accounts for the decay of those isotopes. The current VISION model focuses on the U.S. reactor fleet, with planned expansion to handle the international power fleet in the future.

Figure 3 shows a schematic of the structure of the VISION model, which is organized into a series of modules that include all of the major facilities and processes involved in the fuel cycle, starting with uranium mining and ending with waste management and disposal. The arrows in the diagram indicate the mass flow of the fuel; VISION provides an isotopic mass balance of fuel and an element mass balance of 
fuel by-products, such as cladding. Not shown, but included in each model, are the information and requirement flows among the modules that form the logic for the mass flow in VISION. VISION currently tracks 70 isotopes; it tracks all decay chain isotopes with a half-life greater than 0.5 years, and fission products relevant to repository heat, hypothetical repository dose, and radiotoxicity. The mass flows are combined with cost and waste packaging data to provide insight into economics and transportation issues of the fuel cycle.

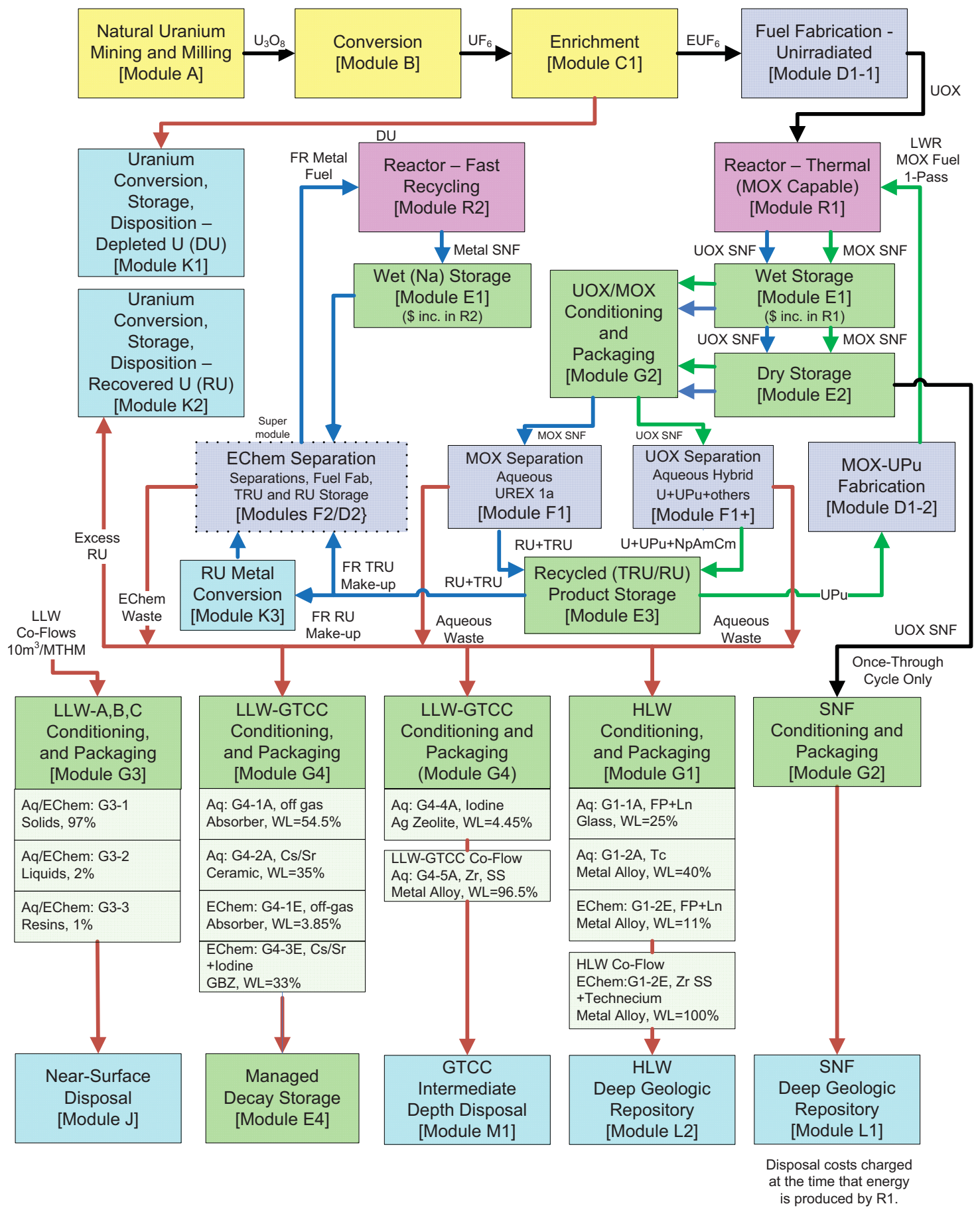

Figure 3. Schematic of the VISION Model flow control. 
VISION currently supports three types of reactors: light water thermal reactors that use only UOX, light water thermal reactors that can use UOX, MOX, or inert matrix fuels (IMF), and fast reactors. Fast reactors may operate in breeder or burner mode. Multiple thermal and fast reactor fuel recipes are available in VISION. The fuel recipes specify the initial fuel isotopic composition and the fuel compositions at the time the fuel is removed from the reactors. VISION provides long-term repository assessments for a given scenario such as long-term heat load, radiotoxicity, and dose.

VISION also has the flexibility to allow the user to run pre-defined scenarios or to develop additional scenarios. The user can examine the linkages, decision rules, and equations that manage the fuel flow. Data input/output can be provided through a spreadsheet, which allows maximum flexibility on modifying input parameters or customizing the output data for user-specific reports. This combination of transparency, simplicity, and flexibility is a key to the utility and power of VISION. The assumptions and calculations used in VISION are accessible through the model interface and through the user's guide currently under development.

VISION also has the capability within the software to perform system sensitivity analysis. This capability may be used to analyze the impacts on costs due to system uncertainty effects. An initial application of this capability on costs was prepared as an example sensitivity analysis for the "VISION Economic Submodel Description and Methodology" (Attachment H).

VISION is highly integrated with the economics submodel, VISION.ECON (Attachment H, Section 4.1). However, VISION is not dependent on VISION.ECON to run and produce module mass flow data as previously described. VISION can be integrated with the nuclear energy market assessment (main report-Section 1.1 and Attachment A), and the nuclear materials exchange (NME) supply/demand analysis (main report-Section 2.3 and Attachment D). Facility capacities and timing defined from the VISION analysis can be compared to the potential facility supplies in the NME database. Where there are future gaps, opportunity facilities can be identified. The waste volumes and forms of the waste can be tracked by VISION to help determine the potential physical protection and nonproliferation risks as described in the economic and nuclear security white paper (main report-Section 2.2 and Attachment C). VISION can assign deployment sequence numbers on reactor and fuel cycle facilities to account for learning (main report-Section 3.3 and Attachment G). Results from VISION can be compared to the static results from G4-ECONS (main report-Section 4.2 and Attachment I) as a check on mass balances, flows, and splits between modules.

Future versions of VISION could also include feedback loops between VISION and the VISION.ECON economic submodel. For instance, one would expect low and high-uranium demand scenarios modeled by VISION to be accompanied by varying uranium price trends (main report-Section 3.1 and Attachment E). Also, feedback from the economics submodel could allow cost projections to influence facility deployment.

Modeling improvements will be made in VISION based on the priority of the new functionality, cost to implement, and value of new capability to evaluate AFCI scenarios within the systems analysis option space. Future development areas for AFCI include:

1. Require new modules to be added to the model structure. For example, additional submodules and flows are needed to address differences in the separation module variations on the separation technologies.

2. Account for capacity utilization of fuel cycle facilities. Need to indicate by year what the actual capacity utilization is compared to the full operating capacity.

3. Add exogenous LWR fuel fabrication demand modules and used fuel supply modules to account for international fuel leasing and take back scenarios. 
4. Account for the deployment sequence of reactors and fuel cycle facilities so that cost learning curves can be applied in VISION.ECON.

Additional modeling activities are required for the economic submodel, as described in Section 4.1.

\subsection{Economic and Nuclear Security Tradeoffs}

The objective of the work described in Attachment C, "Achieving Non-proliferation Objectives in AFCI - Cost Considerations and Tradeoffs," is to take a proactive look at the factors that influence economics and nuclear security and consider the ramifications of nuclear strategies on these factors. The overarching mission is to support the global growth of nuclear energy, while reducing nuclear security risk (both legacy and future).

This study has produced an economics and nuclear security white paper in FY-07. The white paper has uncovered key insights to the tradeoffs between economics and nuclear security. The creation of the paper has also facilitated the linkage between economic activities under development by Department of Energy - Nuclear Energy (DOE-NE) and nuclear security activities supported by the National Nuclear Security Administration (DOE-NA).

Economics and nonproliferation are intricately linked, in that decisions made to reduce cost may have a significant impact on nonproliferation, and vice versa. Common drivers that have a significant impact on both cost and nonproliferation are used to compare the tradeoffs between these two crucial aspects of the nuclear fuel cycle. Each driver, or issue, is described in terms of the impact domestically and internationally, for both cost and nonproliferation. For example, the tradeoffs for transportation include: packaging materials for nonproliferation increases cost, while packaging for cost reduction increases the nonproliferation risk. These tradeoffs exist for many aspects of the nuclear fuel cycle.

In this paper, ten drivers were selected for assessments that are both important to economics and nuclear security. The drivers are associated with transportation, nuclear fuel supply markets, number and size of facilities, technological complexity, fuel composition, geographic placement of facilities, storage of materials, design standardization, fuel cycle backend closure, and grid appropriate reactors. In the course of studying these drivers, additional areas for examination were exposed. The additional candidates for evaluation may provide an even greater depth of understanding of the tradeoffs and mutual benefits. This document is a step toward identifying these tradeoffs and potential solutions for AFCI.

Understanding the ramifications on cost and nonproliferation of various fuel cycle choices is important to making selections that work optimally for both factors. The most desirable future strategies will be both sustainable economically and beneficial to nuclear security; it is a worthy endeavor to develop and cultivate such solutions. Multinational ownership of nuclear fuel cycle infrastructure, for example, appears to be a highly desirable and effective institutional approach that is good for both nuclear security and economics at the same time.

This activity can be integrated with the economic modeling in VISION (see Section 2.1) by tracking the waste volumes and waste forms, and determining the risk based on facility type, waste form, and waste quantity. VISION.ECON (main report-Section 4.1 and Attachment H) and G4-ECONS (main report-Section 4.2 and Attachment I) could be used to model the cost impacts associated with nonproliferation requirements, such as the added costs due to nonproliferation mandates forcing increased facility and process complexity. The nuclear materials exchange (main report-Section 2.3 and Attachment D) could be coupled to this activity to evaluate international exchanges of materials and risks from different types of international facilities. 
Subsequent work to the white paper will be performed jointly with the Pacific Northwest National Laboratory (PNNL) and NA-24. Future development areas (funded by NA-24) may include:

1. Selection and deployment issues associated with used fuel separation technology (UREX, PUREX, $\mathrm{COEX}^{\mathrm{TM}}$, and Pyroprocessing). This task will evaluate the tradeoffs associated with improved integration of reprocessing technologies and facilities within the fuel cycle. In summary, the study will address the trade-offs associated with integrated aqueous fuel separations processes that are located in a minimal number of facilities versus multiple facilities that are configured to execute discrete process functions (separations, solidification, packaging, storage, etc.), and integrated fuel processing with (mixed-oxide and TRU) fuel fabrication. The task will include the evaluation of the facility integration impacts on recycling costs and proliferation and security risks. Trade-offs between the economics and non-proliferation aspects of the reprocessing approaches will be identified and quantified as much as possible.

2. Spent fuel management, including interim storage, at reactors, or regional sites, and fuel "take back" (assured disposition), to also include the effects of transportation. This task will examine the use of insurance mechanisms as a reliable fuel service and supply option. This would serve to expand the framework developed for assessing fuel leasing to analyze the insurance requirements necessary to make a recipient country indifferent between building their own facilities to ensure available supply during either times of nuclear fuel supply interruption or the failure of supplier states to provide the necessary take-back arrangements for spent fuel. Also, this task will provide a scoping-level assessment of the economic tradeoffs of using grid-appropriate reactors versus upgrading the electrical grids of developing countries.

See Attachment C, "Economics and Nuclear Security White Paper Achieving Nonproliferation Objectives in AFCI- Cost Considerations and Tradeoffs," for more details.

\subsection{Nuclear Materials Exchange Database Description and Methodology}

The objective of the work described in Attachment D, "Nuclear Materials Exchange Database Description and Methodology," is to develop a capability that defines existing and new international nuclear resources and their linkages and relationships with current and future users within the international nuclear system.

In FY-07, this activity has developed a prototype relational database and populated the database with data sets including reactors and fuel cycle facilities located throughout the world with associated capacities and operational data.

Design for the NME database structure was leveraged off the design of an existing system developed by Bechtel (subsequently reorganized under NEXANT) called the Industrial Materials Exchange Planner (IMEP). The IMEP was created to evaluate opportunities in developing countries (Mexico, China) for conversion of petrochemical by-products into inputs for other industrial processes (industrial symbiosis). The IMEP provided the initial platform for development of the NME, which was focused on the interchange of materials within an international nuclear fuel cycle.

The NME can be used to support AFCI by identifying gaps in demand, calculated as the delta between supply (current capacities) and demand for a particular fuel cycle resource or service. These gaps could be filled by potential "opportunity" facilities/services. An opportunity facility could consist of a single large (multinational) facility or multiple smaller facilities distributed among several countries. A database query has been developed to quantify the current and future projected supply (or capacities) of materials or services over a selected period, by country or region. 
The NME could support AFCI through another novel application, by using industrial symbiosis for nuclear energy to evaluate the potential exchange of wastes-for-materials between user-supplier nations. This was the primary application when the development of the NME began late in FY-06, and also explains its full name: the "nuclear materials exchange." This would allow an NME user to answer questions such as: "With the availability of reprocessed materials from a new reactor, what new industries could be supported?" The NME could also be a planning tool for national, regional, and global planning scenarios that ask questions such as: "For a new reactor in a developing country, where will needed services, materials, and fuel be procured," or, "what are the needs and what is the potential for developing supporting industries in developed or developing countries to supply an expanding nuclear capacity?"

NME will be integrated with the VISION model (see Section 2.1) to evaluate the deltas between fuel cycle demands and (domestic and international) supply data contained in NME. VISION can produce module capacity demands for front and back-end fuel services based on a range of scenario growth rates (e.g., $1.5 \%-3.4 \% /$ year) or from the yearly market penetration rates produced through the nuclear energy market assessment (main report-Section 1.1 and Attachment A). International demands from user countries can also be input to VISION as an exogenous demand for fuel and as a source of used fuel for recycle and disposition. International nuclear energy demands can be produced by ETP through 2050 (Attachment A) that can also be compared to the global nuclear supply data in NME.

NME can integrate information from the uranium and secondary supply analysis (main reportSection 3.1 and Attachment E) to define potential supplies of uranium resources, RU, and DU. International fuel cycle costs and market structures developed in the enrichment and fuel fabrication market structure economic analysis (main report-Section 3.2 and Attachment F) could also be incorporated into the NME. Facility-related data that may be gleaned from NME data searches could be used in the "AFC Cost Basis" report (Shropshire, et al. 2007), and the VISION.ECON (main reportSection 4.1 and Attachment H) and G4-ECONS (main report-Section 4.2 and Attachment I) models.

NME could also be used in conjunction with the tradeoff analysis from the economic and nuclear security tradeoffs white paper (main report-Section 2.2 and Attachment C) to support a potential NA-24 task of "Mapping AFCI onto the World." This involves looking qualitatively at a range of AFCI scenarios including user/supplier relationships between countries, with an objective of developing structures that balance economics and non-proliferation concerns. NME may also use the results from the OECD study described in Section 2, to help define new suppliers of nuclear resources and relationships to potential users.

Future development areas for AFCI include:

1. Verifying and updating the data in the NME, and adding linkages to describe current user-supplier relationships and agreements, where information is readily available in the open literature.

2. Modifying the existing supply/demand query to allow analysis by fuel cycle module for comparison to module capacity demands generated by VISION.

3. Incorporating the capability to consider exogenous demands during VISION runs, running the selected AFCI scenario cases in VISION to determine the demand for selected fuel cycle modules, performing queries in NME to get supply capacities for selected fuel cycle modules, calculating the deltas between supply and demand for selected fuel cycle modules from 2010 to 2100, and finally, identifying opportunity facilities to satisfy the unmet demands.

See Attachment D, "Nuclear Materials Exchange Database Description and Methodology," for more details. 


\section{FAST REACTOR AND FUEL CYCLE ECONOMIC MEASURES AND MARKET STRUCTURES}

In the third functional level, targeted studies were developed to improve the AFCI estimating cost basis and rigor of analysis. This level includes several studies relating to understanding the market structures and resource supplies that influence fuel cycle costs for uranium, enrichment, and fuel fabrication. Methodologies were developed to model the learning effects from building and operating reactor and fuel cycle first-of-a-kind to nth-of-a-kind facilities. This level also provides a survey of the key economic questions/issues and data requirements for the AFCI facilities. The types of output created by this function will improve the cost information used in the "AFC Cost Basis" report and the modeling algorithms used to perform the AFCI economic analyses in FY-08 (Shropshire, et al. 2007).

Two key reports support this function. The first is the "AFC Cost Basis" report and the second is the "GenIV Cost Estimating Guidelines" (EMWG 2006) that were described in the Background section earlier in the report. These assessments provide targeted studies that will improve the AFCI estimating basis and rigor of analysis.

\subsection{Uranium and Secondary Supply Analysis}

The objective of the work described in Attachment E, "Uranium Resource Model," is to provide a cost basis for long-term supplies of uranium and analysis of secondary supplies from DU and RU.

In FY-07, econometric models were developed to generate a rigorous cost basis for uranium and a survey of DU and RU supplies.

The "AFC Cycle Cost Basis" report includes modules describing the expected unit costs of all fuel cycle steps that might arise under the AFCI scenarios (Shropshire, et al. 2007). These costs, rather than being present-day values, reflect an average of expected values over the next several decades. For many of the fuel cycle processes, bottom-up technology-based estimates exist in the literature. However, long-term price projection for the uranium resource does not lend itself to this approach. Therefore, the tools of resource economics were utilized to generate two forecasts of long-term uranium price trends. One of these forecasts postulated a functional dependence of the uranium price on a variety of historical uranium market indicator data. An econometric analysis solved for the values of the coefficients in this function. This regression analysis was conducted using statistical/econometric modeling software. Given that less than 40 years of historical uranium price and market data exists, it was believed necessary to confirm the results of this econometric model using a second, simpler model. This second approach creates an analogy between uranium price trends and that of several dozen other minerals for which 100 years or more of market data exists. The price evolution of each of these other minerals was obtained, and simple mathematical models describing their behavior were created. The modeling results for an "average" mineral commodity were then used to project the uranium price into the latter portion of this century. Agreement between the two approaches was good.

Presently, VISION and the other AFCI models do not include scenarios involving direct recycle of DU and RU. Given uncertainties surrounding the security and sustainability of uranium resource supply, it is desirable to ascertain the conditions under which DU and RU recycle might be economically advantageous. Therefore, a two-stage analysis of these resources was performed. First, the size and composition of the U.S. DU and RU inventories were obtained. For DU, this data could be obtained from public sources; however, calculations were required to obtain the isotopic composition of RU contained in current SF, as well as RU that might be generated in future used fuel. The size of the new uranium (NU)-equivalent supply reservoir represented by these materials proved to be considerable. It should be emphasized that the acronym RU, in this section and Attachment E, stands for reprocessable uranium. 
Therefore, it includes uranium that has already been separated but not re-irradiated, of which the U.S. holds only limited stocks, but also uranium that is presently contained in spent fuel that could, in the future, be separated.

Once inventories and future stocks were established, the options for DU and RU re-use and disposal were surveyed and tabulated. In each case, about six options were considered. For each of these, the fuel cycle mass flows (e.g., reactor charge and discharge compositions) and energy production rates were computed.

To ascertain when and if the options might become cost-competitive, elementary cost-benefit analyses were performed. These analyses serve two purposes: to rank order the options in terms of their desirability from an economic standpoint, and to indicate, to first order, the natural uranium price at which a similar strategy, pursued with NU, would break even with the DU or RU option being considered. A levelized cost approach was taken to conduct the study, and the unit fuel cycle costs associated with the options were obtained from the "AFC Cost Basis" report (Shropshire, et al. 2007).

The secondary uranium supply survey offers, in the absence of VISION recipes and other tools needed for a complete dynamic analysis, a method for analyzing scenarios involving the recycle in LWRs of uranium recovered from SF. Attachment E describes the tools needed to model a multi-isotope enrichment cascade and to generate simple recipes for fuel containing recycled uranium. The attachment also presents sample economic results on fuel cycle costs for a few scenarios. These examples are intended to aid in the selection of scenarios involving RU, if any, that may be worthwhile for detailed study using VISION.

This study integrates with several areas within the economics methodology. The uranium supply survey and market forecasts presented in this study were used to develop the cost estimate presented in Module A of the "AFC Cost Basis" report. This analysis could be coupled with the nuclear energy market assessment (main report-Section 1.1 and Attachment A) to produce shadow prices at market equilibrium for uranium. Forecasting methodologies developed in this task could be used to incorporate dynamic feedback in the VISION model (see Section 2.1). For instance, one would expect low and high-uranium demand scenarios modeled by VISION to be accompanied by varying uranium price trends. Such feedbacks can be addressed using the methods presented here. Uranium supply information from this study could be incorporated in the NME database (main report-Section 2.3 and Attachment D) and integrated with the enrichment and fuel fabrication market structure economic analysis (main reportSection 3.2 and Attachment F). This study could also integrate algorithms into VISION.ECON (main report-Section 4.1 and Attachment $\mathrm{H}$ ) and G4-ECONS (main report-Section 4.2 and Attachment I) to assess when to select new uranium versus DU and RU.

Future development areas for AFCI include:

1. Integrating the econometric models into VISION.ECON to determine uranium costs under various demand conditions.

2. Integrating assessment of RU into VISION.ECON to create decision algorithms that determine when uranium from used fuel should be recycled in fuel versus using fresh uranium.

3. Studying the cyclical nature of uranium costs to better understand the conditions when uranium costs escalate, peak, decline, and stabilize using data from the 1970s and the current price run-up and decline.

See Attachment E, "Uranium Resource Model," for more details. 


\subsection{Enrichment and Fuel Fabrication Market Structure Economics}

The objective of the work described in Attachment F, "Cost and Market Structure Economics of the International Nuclear Fuel Cycle" is to understand the nuclear market structures and implications on AFCI deployment.

In FY-07 this study has developed a methodology to evaluate international fuel cycle market structures and applied the methodology to enrichment and fuel fabrication markets.

This methodology for evaluating the economics of nuclear fuel cycle industries follows the Generation IV International Forum (GIF) EMWG, Cost Estimating Guidelines for Generation IV Nuclear Energy Systems (EMWG 2005), and is consistent with the economic modeling using G4-ECONS software (main report-Section 4.2 and Attachment I). This methodology identifies the cost structure, allowing construction of industry supply curves, and a determination of profitability. This methodology provides a foundation for understanding the economic incentives facing firms in fuel-cycle and non-fuelcycle states. The primary focus is on modeling levelized average cost as a function of the size of a fuel cycle facility. The resulting cost structure depends on (1) whether there are economies of scale in input usage, (2) the relative importance of fixed-to-variable costs, and (3) whether capacity is being added to an existing site or a new site. The methodology is applied to two sectors: uranium enrichment and LWR fuel fabrication, including low-enriched uranium (LEU) and MOX. An observation from the study is that due to high start up costs, the average costs are continuously declining in the uranium enrichment and the MOX LWR fuel fabrication industries.

Due to technological change from the energy intensive gaseous diffusion process to the more efficient gas centrifuge technology, the price of enrichment services could drop dramatically, leading to lower investment in new enrichment capacity. The current market structure of the LEU fuel fabrication industry is competitive and new entrants will find it difficult to compete, but market intervention is unlikely to be necessary to ensure sufficient capacity. MOX fuel fabrication, in contrast, is becoming more expensive and less profitable, leading to a possible decline in international MOX capacity. Some form of market intervention could be necessary if MOX becomes a preferred AFCI alternative.

This market structure economic analysis can be integrated with VISION.ECON (main reportSection 4.1 and Attachment H) and G4-ECONS (main report-Section 4.2 and Attachment I) to model and analyze future fuel cycle costs for enrichment and fuel fabrication services. This analysis could be coupled with the nuclear energy market assessment (main report-Section 1.1 and Attachment A) to define shadow prices at market equilibrium for enrichment and fuel fabrication. The international market structure relationships defined in this task could be incorporated into the NME (main report-Section 2.3 and Attachment D). The market structure analysis could also be applied to uranium markets (main reportand Attachment E). Information could help to further define facility-scaling relationships.

Future development areas for AFCI include:

1. Integrating cost algorithms for enrichment and fuel fabrication that are a function of the facility size into VISION.ECON (Attachment $\mathrm{H}$ ) to create future projections of fuel cycle costs.

2. Applying the methodology to other fuel cycle sectors with existing and future expanding capabilities, such as low-level waste disposal, used fuel storage facilities, and uranium markets.

See Attachment F, "Cost and Market Structure Economics of the International Nuclear Fuel Cycle," for more details. 


\subsection{AFCI Facility Deployment Analysis}

The objective of the work described in Attachment G, "The Cost Economics of Advanced Nuclear Power Technologies with an Application to Modular Sodium Fast Recycling Reactors," is to evaluate the learning effects from deploying first-of-a-kind (FOAK) to ${ }^{\text {th }}$-of-a-kind (NOAK) new technology systems. This methodology may be applied to project the future capital costs for reactors and fuel cycle facilities.

This study developed a learning curve methodology and prepared an initial application on fast reactor costs in FY-07. The study started with the General Electric's NOAK cost estimate of the Super-PRISM (Power Reactor Innovative Small Module). This is compared with an updated Argonne National Laboratory NOAK cost estimate for the PRISM Mod B, a burning fast reactor with a conversion ratio (CR) of $\mathrm{CR}=0.80$. The learning rates were set at $3.0 \%$ and $4.5 \%$ in the decline in cost from FOAK to NOAK with each doubling of reactor capacity, as well as plant capacity. From this assessment, a range of potential FOAK capital costs could be derived. The resulting learning from FOAK to NOAK represented a reduction of approximately $14 \%-24 \%$ in cost.

This methodology can also be extended to fuel cycle facilities when sufficient numbers of the facilities are built in a short enough time to experience learning effects. Such an application could be applicable to electrochemical separation and metal fuel fabrication facilities where multiple plants may be needed to support blocks of fast reactors. There is also potential application of this methodology to analyzing cost reductions in international nuclear energy markets.

This work could be integrated in VISION (see Section 2.1) and VISION.ECON (main reportSection 4.1 and Attachment H) by incorporating a cost algorithm that is a function of the facility deployment.

Future development areas for AFCI include:

1. Incorporating learning algorithms in VISION.ECON to be able to apply learning rates to fast reactor deployment and potentially some of the integrated fuel cycle facilities.

2. Comparing overall the electricity generation costs (including learning effects) for future nuclear technologies (GenIV, AFCI, and even Gen III) which could be provided to show there are wide ranges of costs for each of these concepts as well as for the clean-coal competition.

See Attachment G, "The Cost Economics of Advanced Nuclear Power Technologies with Application to Modular Sodium Fast Recycling Reactors," for more details. 


\section{SYSTEM LEVEL STATIC AND DYNAMIC ECONOMIC ANALYSIS UNDER CONDITIONS OF UNCERTAINTY}

Supported by the first three functional areas, the fourth functional level includes creation of static and dynamic models with uncertainty analysis to evaluate the economics of various fuel cycle and reactor scenarios. The G4-ECONS model provides a static analysis (or snapshot in time view) of the economics and mass flows for various reactor and fuel cycle scenarios. VISION.ECON provides dynamic analysis of fuel cycle and reactor scenarios, so the variations over time can be considered. Both of these models use data from the "AFC Cost Basis" report, which provides unit cost ranges for fuel cycle capabilities, and capital and operating cost ranges for thermal and fast reactors (Shropshire, et al. 2007). The types of output created by this function include fuel cycle and total electricity costs, either on a static "one point in time" basis or on a dynamic basis, showing costs by year from the present to 2100 . The output can show case-specific cost details or multiple case comparisons. Cost comparison outputs are shown as distribution curves over a range of costs to convey the uncertainty in the cost data and the range of potential costs.

Two key reports are associated with this function. The first is the "Advanced Fuel Cycle Economic Analysis of Symbiotic Light-Water Reactor and Fast Burner Reactor Systems," which was the primary AFCI economic document supporting systems analysis in FY-08 (Shropshire, et al. 2009). The report consisted of system cost comparisons between closed fuel cycles and the once-through fuel cycle. The report contains the economic modeling and case specific assumptions and economic results, including uncertainty analysis, for the cases analyzed using system dynamic modeling (with VISION and VISION.ECON) and static cost modeling (with G4-ECONS) to support verification of the costs. The following Sections 4.1 and 4.2 describe these models in additional detail.

The second report is the "AFCI Economic Tools, Algorithms, and Methodologies Report." This report provides a compilation of the studies, models, and methodologies developed by the AFCI Systems Analysis and a description of how they interrelate to provide economic analyses in support of the Secretary of Energy's AFCI decision in 2008. Further, these methodologies combine to create an economic toolbox that can be used to assist in the preparation of economic analysis of nuclear fuel cycles and reactors in the future. This report will be updated in FY-08 with up-to-date documentation on the methodologies and supporting studies being performed by the AFCI Systems Analysis.

These tools provide the capability to integrate the cost data, methodologies, and algorithms to produce the cost estimates and comparisons that will be used in the "AFCI Systems Analysis" report and summarized for the AFCI main decision document, as described in the earlier report section on the Structure of Economic Analysis for AFCI.

\subsection{VISION.ECON Modeling and Analysis}

The objective of the work described in Attachment H, "VISION Economic (VISION.ECON) Submodel Description and Methodology," is to document the architecture, modeling interfaces, graphical user interface, functionality, data input/outputs, algorithms, sensitivity analysis capabilities, and future development plans for the VISION.ECON economic submodel. This objective is closely coupled with the objective described for the VISION model discussed in Section 2.1.

The VISION.ECON submodel development was coupled to release 2.0 of VISION with documentation to the VISION user community in FY-07.

VISION (described in Section 2.1) calculates a wide variety of metrics to track the mass flow and ultimately the cost data associated with those flows. Annual flow data and total flow are tracked on a

yearly basis for each module in the fuel cycle. In addition, cost data is applied to the annual flow data for 
each module. Also, a summary of the total costs for fuel cycle costs and total cost of electricity generation is tracked yearly. At the end of the 100-year simulation, a Monte Carlo simulation of the total cost of each module is calculated as well as a summary of fuel cycle costs and total cost of electricity generation. All the results are output to Excel files for easy examination and post processing data analysis.

VISION.ECON was created as a submodel of VISION to provide economic analysis of nuclear fuel cycle cases. The submodel produces cost distributions for relative economic comparisons rather than absolute value cost estimates. VISION.ECON extends the modeling capability beyond static equilibrium analysis tools by providing insight to dynamic modeling impacts to cost over time. The tool currently includes the functionality to evaluate cost and system uncertainties. For each functional step or module in the fuel cycle, VISION.ECON retrieves the annual mass flows from VISION and calculates a cost distribution, based on the cost distribution for each module. The cost distribution data used in VISION.ECON are contained in the 2007 "AFC Cost Basis" report (Shropshire, et al. 2007). Model output showing the total cost uncertainties of a case are generated within VISION.ECON in a post processing mode using a modified Monte Carlo method. Cost and system uncertainties can be used to identify the variables within the model that have the largest impact on the cost for each case.

The economic capabilities provided by VISION.ECON are different from spreadsheet models performing static equilibrium analyses in several ways. First, it shows the dynamics of how nuclear fuel cycle costs change over time rather than an end-of-run single composite cost. Second, it shows the cost effects of facilities as they come online and retire. Third, the changes in facility costs, due to learning effects and economies of scale in going from a first-of-a-kind to nth-of-a-kind unit, can be included in the program. Fourth, the economic effects resulting from variable dynamic nuclear energy growth rates can be evaluated.

VISION.ECON is being developed to take advantage of the work supported by the AFCI Systems Analysis, such as input to other models (e.g., G4-ECONS) or as a recipient of cost data ("AFC Cost Basis" report), algorithms (learning curves), and exogenous input data generated by the other models and activities (e.g., nuclear energy growth data from market assessment). VISION.ECON is highly integrated with VISION (see Section 2.1) and is dependent on VISION to provide annual module mass flow data. VISION.ECON cannot be executed without input from VISION. VISION.ECON can be integrated with the learning methodology developed in the deployment of FOAK versus NOAK facilities (main reportSection 3.3 and Attachment G) and may include algorithms to assess when to cost new uranium versus DU and RU (main report-Section 3.1 and Attachment E). The market structure economic analysis (main report-Section 3.2 and Attachment F) could be integrated with VISION.ECON to model and analyze future fuel cycle costs for enrichment and fuel fabrication services. New facility data from the nuclear materials exchange (main report Section 2.3 and Attachment D) could result in changes to cost modules in VISION.ECON.

The model may also be used to evaluate "softer" areas, including measures of reduced global proliferation costs (main report-Section 2.2 and Attachment C), greater sustainability through preservation of natural resources (e.g., reduction in uranium use), value from weaning the U.S. from energy imports (e.g., measures of self-sufficiency), and minimization of future high level waste repositories world-wide.

Additionally, VISION modeling will be performed in parallel with cost modeling using G4-ECONS (main report-Section 4.2 and Attachment I) to help verify that the results being generated are reasonable and consistent.

The following gaps need to be filled in VISION.ECON to support the AFCI Economic Analysis in FY-08 (assuming funding is available to support continuation of these tasks). 
Additional gaps are required to be filled for the VISION model (see Section 2.1), that impact the ability to support additional economic capabilities. These include:

1. Requiring new AFCI cases to add new cost modules to the model structure.

2. Providing further cost discrimination in the modules. For example, in Module F1, additional details between UREX $+1,4$, and other separation options. Similarly in Module G, different waste form options may be required.

3. Converting storage costs to new units (e.g., $\$ /$ year/unit) to account for the annual storage capacity loading versus the mass flows into the storage modules. Algorithms may be needed to account for when additional wet or dry storage costs are needed beyond the costs included with the reactor.

4. Defining fuel cycle facilities costs as capital, O\&M, and D\&D (such as used for reactors).

5. Incorporating algorithms to account for economies of scale and production, and follow-on learning effects for reactors and potential fuel cycle facilities that are modular and are required in sufficient numbers.

6. Incorporating dynamic algorithms that vary module costs based on domestic and international demands. For example, adjust uranium costs based on world-wide nuclear growth demands.

7. Including changes to enhance the ability to perform system economic uncertainty analysis.

\subsection{G4-ECONS MODELING AND ANALYSIS}

The objective of the work described in Attachment I, "The Static Analysis and Uncertainty Analysis Toolbox for the Spreadsheet Evaluation of AFCI Reactor/Fuel Cycle Scenarios," is to provide an economic model for comparison of nuclear systems, including reactors and their fuel cycles.

In FY-07, this study has supported development of a spreadsheet "snapshot-in-time" reactor cost model and other fuel cycle cost tools in conjunction with the Generation IV EMWG.

Attachment I describes a "toolbox" of methodologies for estimating reactor and fuel cycle costs. These methodologies are applicable to the major facility and process elements of the scenarios projected to be of interest to the AFCI program. All of them are "static" in the temporal sense, (i.e., they can be used to represent the cost status of a scenario at a given point in time, in essence providing "snapshots" over the nearly one century duration of AFCI).

The static and uncertainty analysis "toolbox" has its origins in the GIF reactor systems program. Development of Cost Estimating Guidelines and a simplified spreadsheet model to calculate the levelized unit electricity cost (LUEC) for a nuclear power plant was one of the early tasks for the Generation IV

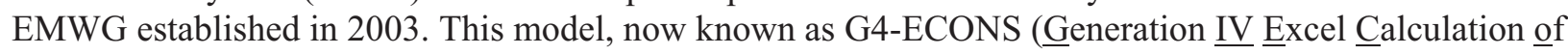
Nuclear Systems), has associated with it a fuel cycle model capable of modeling open, partially closed, and totally closed fuel cycles for reactors of a single type. In order to model the symbiotic fuel cycles (involving more than one reactor type), the model developer had to extract the fuel cycle spreadsheet model out of G4-ECONS and morph it into a "module-by-module" representation capable of handling more complex cycles where a fleet of LWRs can provide separated actinides to a fleet of advanced burner reactors. The "mills per kwh" fuel cycle component of the overall electricity generation cost for whole AFCI system is a major figure-of-merit.

The basic algorithms from G4-ECONS were also modified to create a fuel cycle facility (FCF) model (G4-ECONS-FCF) for which a unit cost of product or service from a fuel cycle facility can be calculated given the necessary cost-related inputs, such as facility capital and operating costs. 
The G4-ECONS-R was developed for Gen IV as reactor model applicable to any single reactor type. Attachment I includes a description of how the "module-by-module" spreadsheet approach can also be applied to complex AFCI scenarios. Uncertainty analysis can be used to augment the "deterministic" or single point cost estimates calculated by the spreadsheet models. Additional decision analysis software can be easily coupled to the spreadsheet model to produce cost uncertainties.

The G4-ECONS-related models described here relate most closely to the dynamic VISION model (see Section 2.1). Many of the economic algorithms described here have been incorporated into the VISION submodel, called VISION.ECON (main report-Section 4.1 and Attachment H). In 2008, the "snapshot-in-time" cases run with the G4-ECONS will have their inputs derived directly or at times indirectly from VISION. Care must be taken that the input data (i.e., mass balances) provide sufficient independence from the VISION calculations to achieve a reasonable comparison and verification of costs. VISION may be used to produce key data inputs (or derived through independent analysis), such as the material balance, facility capacity requirements, separation "recipes", and reactor "mixes" for any year over the span of AFCI (2010-2100). Modeling "snapshots" may be required over several time frames (e.g., 2025, 2050, 2075, and 2100) to capture periods relating to dynamic growth and equilibrium conditions. For each of these representative periods, a unit fuel cycle cost and unit cost of electricity can be calculated for the overall symbiotic AFCI system at that time. The series of cost data over time can be compared to the dynamic cost modeling results, and differences can be identified and analyzed.

Some of the assumptions used in G4-ECONS can flow from other models, such as the $\$ /$ kwe values required for competitive nuclear power. G4-ECONS could be used to crosscheck the costs of competing electric generation technologies from the nuclear energy market assessment (main report-Section 1.1 and Attachment A). Facility-related data can be gleaned from the nuclear materials exchange database (main report-Section 2.3 and Attachment D) and the enrichment and fuel fabrication market structure economics (main report-Section 3.2 and Attachment F) efforts. The uranium and secondary supply analysis (main report-Section 3.1 and Attachment E), the AFCI facility deployment analysis study (main report-Section 3.3 and Attachment G), and the market structure economic study (main report-Section 3.2 and Attachment F) will also influence the inputs to the G4-ECONS-based methodologies. This modeling system could help model the cost impacts associated with non-proliferation requirements (main reportSection 2.2 and Attachment C), such as the added costs due to nonproliferation mandates, which would force increased facility and process complexity and security.

The simplified G4-ECONS-type models exist for non-nuclear electrical production facilities, such as coal and natural gas plants. Information in Attachment B, "Comparison of Nuclear to Future New Electricity Generation Alternatives," could be used to generate TCOEs for such facilities.

G4-ECONS will support verification and validation of VISION.ECON by comparing costs when the VISION.ECON run is at equilibrium or "stopped" at certain times in the overall lifetime of AFCI (rest of $21^{\text {st }}$ century). Costs for each module, as well as total cost uncertainty curves, can be compared to the uncertainty curves generated from the G4-ECONS spreadsheet model when coupled to a decision analysis model.

Future development areas for AFCI include:

1. Developing a "higher fidelity" model for reprocessing plants that can differentiate costs between the various UREX options, COEX ${ }^{\mathrm{TM}}$, PUREX, and other aqueous concepts. A similar model for electrochemical processing is also desirable if data is available.

2. Needing additional modeling details to evaluate the cost impacts of storage and disposal of the waste streams generated by the separations processes.

3. Modifying G4-ECONS to provide a simple model for estimating international costs for small-medium reactor, also known as "grid-appropriate" reactors. 
See Attachment I, "The Static Analysis and Uncertainty Analysis Toolbox for the Spreadsheet Economic Evaluation of AFCI Reactor/Fuel Cycle Scenarios,” for more details. 


\section{CONCLUSION}

This report has described the economic analysis, modeling tools, and methodologies under development by the AFCI Systems Analysis. The work described in this report represents an ongoing effort to develop new economic analysis capabilities. Some example applications are provided in the following attachments to illustrate how the tools and methods may be used. The capabilities that have been developed for this report still require additional testing, validation, and some modification before being applied to the AFCI economic analysis. Ultimately, these economic analysis capabilities will be used by the AFCI to evaluate the economic ramifications of various fuel cycle scenarios both in domestic and international deployment, including which components have the largest uncertainty, and which components have the largest impact on overall cost. The results of this work can help to provide insight to the economic conditions needed to keep nuclear energy (including closed fuel cycles) economically competitive in the U.S. and globally. 


\section{REFERENCES}

Chandler, J. and Shropshire, D. E., "Financing Strategies for a Nuclear Fuel Cycle Facility," ICONE14 89255, 14th International Conference on Nuclear Engineering, July 17-20, 2006, Miami, Florida.

Energy Information Agency (EIA 2006a), Annual Energy Outlook 2006, www.eia.doe.gov/oiaf/archive/aeo06/pdf/trend_3.pdf, accessed February 19, 2007.

Generation IV Economic Modeling Working Group (EMWG), Cost Estimating Guidelines for Generation IV Nuclear Energy Systems, Rev. 4.1, September 2007.

Jacobson J. J., Yacout A. M., Matthern G. E., Piet S. J., Shropshire D. E., Laws C. T., "VISION: Verifiable Fuel Cycle Simulation Model," American Nuclear Society Conference, November 2006.

Shropshire, D. E. et al, 2008, “Advanced Fuel Cycle Cost Basis,” INL/EXT-07-12107, March 2008.

Shropshire, D. E. et al., “Advanced Fuel Cycle Economic Sensitivity Analysis,” INL/EXT-06-11947, December 2006.

Shropshire, D. E. et al, 2009, "Advanced Fuel Cycle Economic Analysis of Symbiotic Light-Water Reactor and Fast Burner Reactor Systems," INL/EXT-09-15254, January 2009.

Spurgeon, Dennis, "Nuclear Energy: Investing in Our Energy Security," Remarks by Dennis Spurgeon, Assistant Secretary for Nuclear Energy, U.S. Department of Energy, To the Conference on Opportunities in a Nuclear Renaissance, November 20, 2006, Washington, DC http://www.ne.doe.gov/pdfFiles/neSpeeches/spurgeonNatexisBleichroederSpeech112006.pdf, Web page accessed September 22, 2007.

Williams, K. A., 2007 Fuel Cycle Economic Analysis using an Excel Spreadsheet, American Nuclear Society Conference, June 2007. 
INL/EXT-09-15483 


\title{
Attachment A
}

\section{A Market-based Methodology to Project Future Deployment of AFCI Technologies in the U.S. and Nuclear Energy in the World}

\author{
Ann Reisman, John Lee and Vatsal Bhatt \\ Brookhaven National Laboratory \\ MPO No. 57165 \\ with Battelle Energy Alliance, LLC \\ Idaho Falls, Idaho
}


A-2

INL/EXT-09-15483 


\section{Preface}

The primary work for this attachment was completed in 2007. Since then, there have been some additions and expansions to the activities in this attachment. This information can be found in the following reference.

Bhatt, V., P. Friley, A. Reisman, and J. Lee, "A Methodology to Examine the Long-term Energy, Environmental and Economic Benefits of Advanced Nuclear Technologies," Proc. of the 4th International Conference on High Temperature Reactor Technology, Washington, DC, Sept 28 through Oct 1, 2008. 
A-4

INL/EXT-09-15483 


\begin{abstract}
The objective of the work described in Attachment A is to examine the growth of nuclear energy and the future deployment of Advanced Fuel Cycle Initiative (AFCI) technologies in the context of the overall energy market. The projected deployment of nuclear generating capacity results from market competition, and in some cases market intervention, to meet the future electricity demand. The methodology uses two separate modeling frameworks: the U.S. Market Allocation (MARKAL) model for domestic AFCI technology deployment and the Energy Technology Perspectives (ETP) MARKAL model for global penetration of advanced nuclear reactors. The data assumptions used are provided. Illustrative results of application of the MARKAL methodology are discussed. For the U.S. application, the impacts of alternative discount rates and carbon taxes on market competitiveness are explored. The global methodology examines the potential impact on the U.S. nuclear market of a hypothetical material supply to a large and a small global region and subsequent return of spent fuel to the U.S. The interaction of this work with work described in other attachments is outlined and potential future work is explored.
\end{abstract}


A-6

INL/EXT-09-15483 


\section{CONTENTS}

ABSTRACT

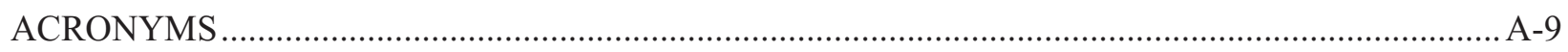

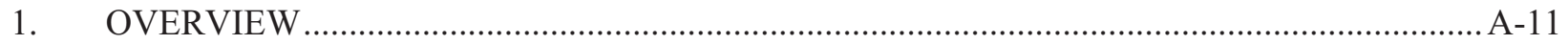

2. AFCI TECHNOLOGY DEPLOYMENT IN THE U.S........................................................

2.1 The U.S. MARKAL Model..................................................................................... A-11

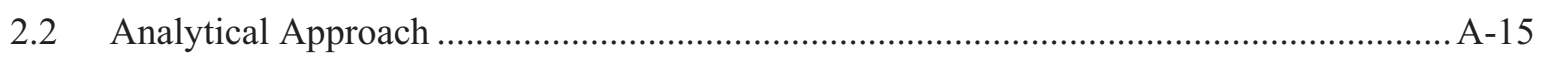

2.3 Economic and Energy Market Assumptions.................................................................... A-16

2.3.1 Economic and Demographic Assumptions ………………………………….... A-16

2.3.2 Assumptions on Energy Prices ……………………………………………...... A-16

2.4 Modeling the AFCI Technologies in the U.S. MARKAL ……………………………... A-17

2.5 Market Deployment and Barriers of Nuclear Technologies ………………………….... A-18

2.6 Case Studies on AFCI Market Deployment.................................................................... A-18

2.6.1 Market Deployment under the Sample AFCI Case............................................. A-18

2.6.2 Market Deployment under Climate Change Policy (e.g., Carbon Tax)..................A-21

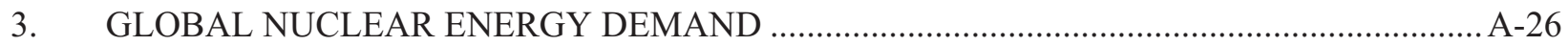

3.1 The ETP Global MARKAL Model............................................................................

3.2 Regional Electricity Markets for Nuclear Energy ……………………………………..... A-26

3.3 Global Deployment of Nuclear Technologies............................................................ A-28

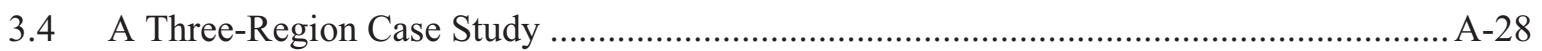

3.4.1 Projected Nuclear Capacity and Fuel Demand in Receiving Regions ....................A-28

3.4.2 Impact on U.S. Fresh Fuel Supply Market............................................................ A-29

3.4.3 Impact on U.S. Fast Reactor Technology Deployment........................................ A-30

4. UNCERTAINTIES: FACTORS AFFECTING THE MARKET DEPLOYMENT OF

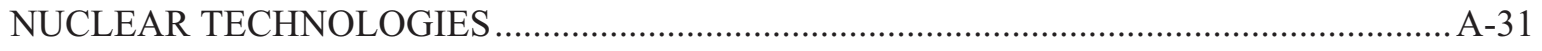

4.1 Per Capita Income and Electricity Demand ……………………………................. A-31

4.2 Relative Energy Prices .......................................................................................... A-31

4.3 Technological Innovation and Improvement ……………………………………...... A-32

4.4 Carbon Emission Constraints......................................................................................

4.5 Government Policy and Measures ........................................................................... A-32

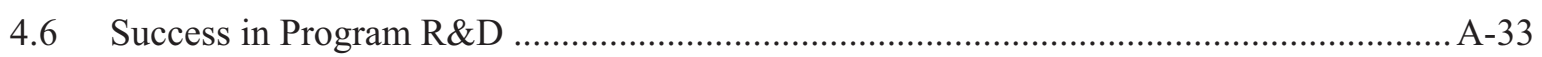

5. INTEGRATION AND INTERCONNECTION OF BNL WORK WITH OTHER ATTACHMENTS IN THE METHODOLOGY REPORT …………………………………….... A-33

6. OPPORTUNITIES AND CHALLENGES: SOME INSIGHTS FROM MARKAL

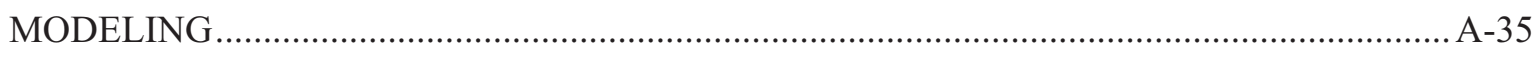

7. THE PATH FORWARD FOR MARKAL ANALYSIS ……………………………..............

7.1 Future U.S. MARKAL Analysis............................................................................ A-36

7.2 Future Global Analysis with ETP ................................................................................. A-36

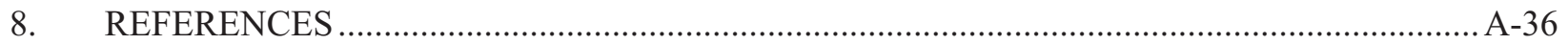




\section{FIGURES}

Figure 1. Reference energy system.

A-12

Figure 2. AFCI technology representation in U.S. MARKAL..............................................................

Figure 3. Overnight cost range of Fast Reactors (2005 \$/KW) ............................................................

Figure 4. Installed capacity versus overnight cost of fast reactors, 2050 (at 5\% discount rate)............A-20

Figure 5. Fast Reactor installed capacity at 4\% discount rate for Cost E. ...........................................20

Figure 6. Fast Reactor capacity in alternative carbon tax schedule..................................................22

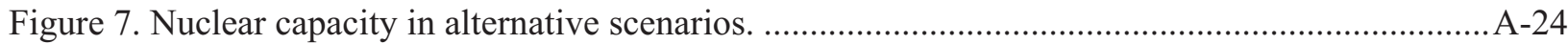

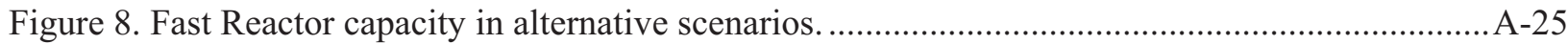

Figure 9. Nuclear reactor demand from two sample regions of the world..........................................29

Figure 10. Fresh fuel supplied to receiver nations from U.S. ............................................................29

Figure 11. Front-end fuel cycle capacity increment in U.S. .............................................................

Figure 12. U.S. Fast Reactor capacity increase due to the additional spent fuel received from two receiver nations.

A-30

\section{TABLES}

Table 1. Fuel cycle assumptions including reactor costs. Source: "AFC Cost Basis,” 2007.

A-13

Table 2. Comparison between AFCI and competing technologies. Source: "AFC Cost Basis" report (Shropshire, et al. 2007) for nuclear technologies and AEO-2006 (EIA 2006) for competing energy technologies.

Table 3. Reference macroeconomic and demographic assumptions....................................................

Table 4. MARKAL reference energy market prices (2005 \$) ...........................................................

Table 5. Levelized electricity costs for new plants in the base case, 2015 and 2030 (2005 mills/kWh)

Table 6. Electricity demand - average annual growth rates in alternative scenarios...........................A-23

Table 7. Average annual growth rates for nuclear technologies 2005-2050 ......................................23

Table 8. Average annual growth rates for Fast Reactors. .................................................................... 25

Table 9. Annual GDP growth rate by region-Energy Technology Perspectives Baseline. .................. A-26

Table 10. Annual population growth rate by region-Energy Technology Perspectives Baseline........A-27

Table 11. Projected world electricity demand-Energy Technology Perspectives Baseline (Billion $\mathrm{kW} \cdot \mathrm{hr})$. 


\section{ACRONYMS}

\begin{tabular}{|c|c|}
\hline AEO & Annual Energy Outlook \\
\hline $\mathrm{AFC}$ & Advanced Fuel Cycle \\
\hline $\mathrm{AFCI}$ & Advanced Fuel Cycle Initiative \\
\hline AGR & annual growth rate \\
\hline ALWR & Advanced Light Water Reactor \\
\hline bbl & Barrel of Oil \\
\hline BNL & Brookhaven National Laboratory \\
\hline Clad & Cladding \\
\hline $\mathrm{CO}_{2}$ & Carbon Dioxide \\
\hline DG & Distributed Generation \\
\hline DOE & U.S. Department of Energy \\
\hline EIA & Energy Information Administration \\
\hline ETP & Energy Technology Perspectives model \\
\hline FOAK & First of a Kind \\
\hline FP & Fission Product \\
\hline FR & Fast Reactor \\
\hline GDP & Gross Domestic Product \\
\hline GHG & greenhouse gas \\
\hline GPRA & Government Performance Results Act of 1993 \\
\hline GWe & Gigawatt Electric \\
\hline HLW & High-level Waste \\
\hline IEA & International Energy Agency \\
\hline INL & Idaho National Laboratory \\
\hline KW & Kilowatt \\
\hline LNG & liquefied natural gas \\
\hline LWR & Light Water Reactor \\
\hline MARKAL & Market Allocation model \\
\hline $\mathrm{MCF}$ & Million Cubic Feet \\
\hline MT/Mt & Metric Ton \\
\hline $\mathrm{NE}$ & Office of Nuclear Energy \\
\hline NOAK & Nth of a Kind \\
\hline $\mathrm{NO}_{\mathrm{x}}$ & Oxides of Nitrogen \\
\hline O\&M & Operation and Maintenance \\
\hline
\end{tabular}


OECD Organization for Economic Co-operation and Development

PV Photovoltaic

R\&D Research and Development

RES Reference Energy System

SFR Sodium Fast Reactor

SNF Spent Nuclear Fuel

$\mathrm{SO}_{\mathrm{x}}, \quad$ Sulfur Oxides

SWU Separative Work Units

TRU Transuranics

U3O8 Uranium Oxide

UREX Uranium Extraction Process 


\section{A Market-based Methodology to Project Future Deployment of AFCI Technologies in the U.S. and Nuclear Energy in the World}

\section{OVERVIEW}

This attachment provides a detailed description of the methodology used to project the future deployment of advanced nuclear technologies, including those proposed under the Advanced Fuel Cycle Initiative (AFCI) in the U.S., as well as in world energy markets. It first presents the underlying socioeconomic assumptions and sources of technical data used to characterize nuclear and other competing technologies represented in the analytical framework. The report then provides and discusses some illustrative results that can be obtained from application of the methodology. This is followed by a discussion of the linkages between this and the other attachments, some insights gained in the analysis, and a possible future path forward.

The projected deployment of nuclear generating capacity described in this attachment results from market competition, and in some cases market intervention, to meet the future electricity demand derived in the two separate modeling frameworks: the U.S. MARKAL model for domestic AFCI technology deployment and the ETP MARKAL model for global penetration of advanced nuclear reactors.

The generation of market deployment for nuclear technologies under the two modeling approaches is conceptually straightforward; the level of deployment is reached when the marginal cost (on a life-cycle basis) of electricity production by nuclear energy equals that of the competing technologies specified in the electrical system. However, this relatively simple concept is difficult and complex to implement. Numerous factors, including market barriers, waste storage constraints, and manufacturing capacities all can have significant impact on the deployment of nuclear technologies. A variety of parametric adjustments can be made in the models to implicitly capture these effects and their interactions. This attachment describes those adjustments made to frame the market conditions relating to AFCI technologies.

Section 2 of this attachment describes the modeling framework and analytical approach used to derive the future deployment of AFCI technologies in the U.S. It provides detailed assumptions in formulating the market scenarios and identifies issues relating to the uncertainties of the modeling results. Section 3 describes the ETP MARKAL model used to project the global demand for advanced nuclear reactors and their potential impact on U.S. AFCI technology development. It also highlights a three-region AFCI material exchange mechanism with the help of supplier nations and receiver nations. Section 4 addresses both internal and external factors that contribute uncertainty to the evaluation of nuclear power deployment by the MARKAL methodology. Section 5 discusses the linkages of this attachment with other attachments, Section 6 summarizes the lessons learned in terms of challenges and opportunities, and Section 7 presents a possible path forward.

\section{AFCI TECHNOLOGY DEPLOYMENT IN THE U.S.}

\subsection{The U.S. MARKAL Model}

The U.S. MARKAL model is a technology-driven linear optimization model of the U.S. energy system that runs in 5-year intervals over a 50-year projection period (Fishbone, et al. 1981 and Loulou, et al. 2004). MARKAL provides a framework to evaluate all resource and technology options within the context of the entire energy/materials system, and captures the market interaction among fuels to meet demands (e.g., competition between gas and coal for electric generation). The model explicitly tracks the 
vintage structure of all capital stock in the economy that produces, transports, transforms, or uses energy and the associated materials.

In MARKAL, the entire energy system is represented as a network, based on the reference energy system (RES) concept. The RES depicts all possible flows of energy from resource extraction, through energy transformation, distribution, and transportation, to end-use devices that satisfy the demands of useful energy services (e.g., ton in cooling, lumen-second in lighting). Figure 1 illustrates a simplified RES in graphical form. The U.S. MARKAL model has detailed technical representations of four end-use sectors (residential, commercial, industrial, and transportation), as well as fossil fuel and renewable resources, petroleum refining, power generation, hydrogen production, and other intermediate conversion sectors.

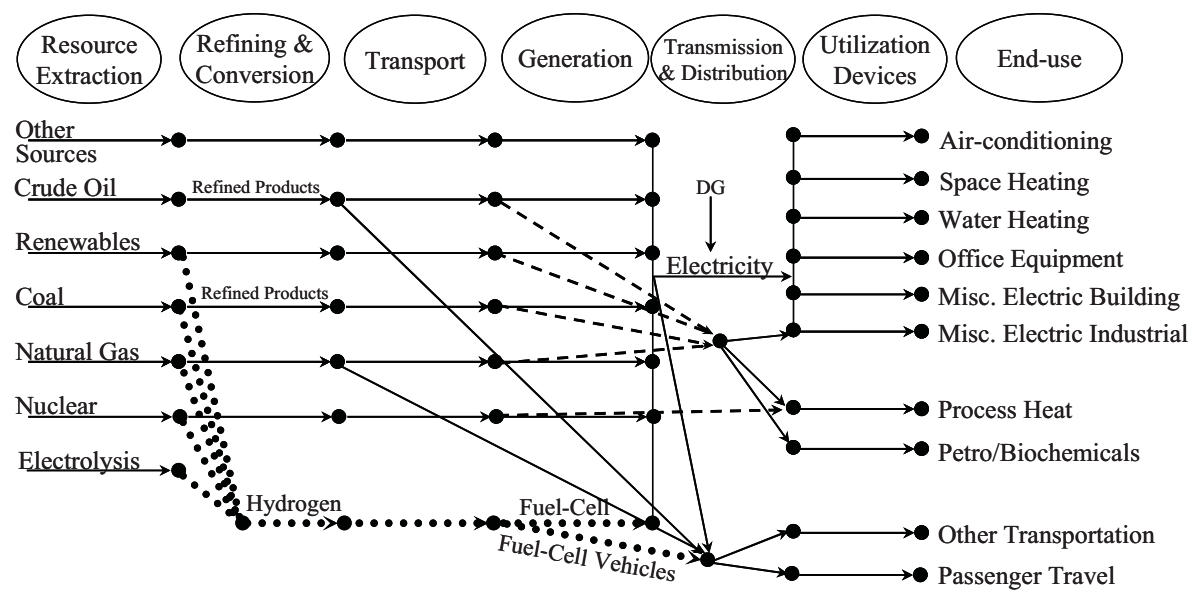

Figure 1. Reference energy system.

Technology choice in the MARKAL framework is based on the present value of the marginal costs of competing technologies in the same market sector. On the demand side, the marginal cost of demand devices is a function of levelized capital cost: Operation and Maintenance (O\&M) cost, efficiency, and the imputed price of the fuel used by these devices. For a specific energy-service demand and period, the sum of the energy-service output of competing technologies has to meet the projected demand in that period. The relative size of the energy-service output (market share) of these technologies depends not only on their individual characteristics (technical, economic, and environmental), but also on the availability and cost of the fuels (from the supply side) they use. The actual market size of a demand sector in the future depends on the growth rate of the demand services and the stock turnover rate of vintage capacities. MARKAL dynamically tracks these changes and defines future market potential. Another factor considered in MARKAL that affects the market penetration of a specific demand device, is the sustainability of the expansion in the implied manufacturing capacity to produce these devices.

On the supply side, the technology choices made in MARKAL are based on the imputed price of the energy products (e.g., uranium fuel) and the marginal cost of supply technologies (e.g., Advanced LightWater Reactor [ALWR]) to meet electricity demand (endogenously determined in MARKAL). The cost of resource input for production (exogenously projected in MARKAL) such as imported oil prices and cost of uranium ore, together with the characteristics of supply technologies (including electricity generation) determine the market share of a particular fuel type and the technology that uses it. The supply-demand balance achieved for all fuels under the least energy-system cost represents a partial equilibrium in the energy market. In particular, the intertemporal new investments in nuclear technologies under this equilibrium determine the market deployment of these technologies. Additionally, policies can be modeled that explicitly or implicitly provide economic incentives for less competitive technologies to accelerate their learning curves or market penetration. 
This project used various sources for energy technology and resources data. Section 2.3 provides an overview of U.S. MARKAL assumptions and Section 3.2 outlines the ETP assumptions. Idaho National Laboratory (INL) supplied nuclear fuel cycle data for the analysis. INL provided three cost curves (nominal, high and low) over time (for years 2005-2050) for each of the nuclear technologies considered for the project, including reactors and front-end and back-end fuel cycle technologies, based on the "Advanced Fuel Cycle (AFC) Cost Basis" report (Shropshire, et al. 2007). Table 1 shows alternative reactor technology costs.

Table 1. Fuel cycle assumptions including reactor costs.

Source: “AFC Cost Basis, ” 2007.

\begin{tabular}{|l|c|c|c|c|c|l|l|l|l|l|l|}
\hline \multicolumn{10}{|c|}{ Table 1a: Overnight nuclear reactor costs $(2005 \$ / \mathrm{KW})$} \\
\hline \multicolumn{1}{|c|}{ FR \& Generation IV Thermal } & \multicolumn{10}{c|}{ ALWR } \\
\hline Costs & 2030 & 2035 & 2040 & 2050 & & Costs & 2015 & 2020 & 2030 & 2040 & 2050 \\
\hline Nominal & 4,400 & 2,200 & 2,200 & 2,200 & & Nominal & 3,600 & 1,800 & 1,800 & 1,800 & 1,800 \\
\hline Low & 3,200 & 1,600 & 1,600 & 1,600 & & Low & 2,400 & 1,200 & 1,200 & 1,200 & 1,200 \\
\hline High & 12,000 & 6,000 & 6,000 & 6,000 & & High & 5,400 & 2,700 & 2,700 & 2,700 & 2,700 \\
\hline
\end{tabular}

\begin{tabular}{|l|c|c|c|}
\hline \multicolumn{4}{|c|}{ Table 1b: Front-end data $(2005 \$)}$. \\
\hline Available Natural Uranium Resources: & $\$ 50$ & $\$ 100$ & $\$ 150 / \mathrm{kg}$ \\
\hline Conversion Technology: & $\$ 5$ & $\$ 10$ & $\$ 15 / \mathrm{kg}$ \\
\hline Enrichment Technology: & $\$ 100$ & $\$ 115$ & $\$ 130 / \mathrm{SWU}$ \\
\hline ALWR Fabrication Technology: & $\$ 210$ & $\$ 220$ & $\$ 264 / \mathrm{kg}$ \\
\hline
\end{tabular}

Table 1c: Reprocessing technology (2005 \$).

\begin{tabular}{|c|c|c|c|c|c|}
\hline & $\begin{array}{l}\text { Time- } \\
\text { Independent } \\
\text { Data }\end{array}$ & 2020 & 2030 & 2040 & 2050 \\
\hline \multicolumn{6}{|c|}{ UREX+ Process for Light Water Reactor Spent Fuel (2,000 Mt/year plant) } \\
\hline $\begin{array}{ll}\text { Capital Cost }(\text { Million } \$)^{1} & \text { High } \\
\end{array}$ & & 8,000 & 8,000 & 7,000 & 7,000 \\
\hline Nominal & & 7,500 & 7,500 & 6,000 & 6,000 \\
\hline Low & & 7,000 & 7,000 & 5,000 & 5,000 \\
\hline Total O\&M Cost (Million \$/year) ${ }^{1}$ High & & 700 & 700 & 550 & 550 \\
\hline Nominal & & 625 & 625 & 450 & 450 \\
\hline Low & & 550 & 550 & 350 & 350 \\
\hline \multicolumn{6}{|l|}{ Capacity Factor (\%) } \\
\hline High & & 80 & 95 & 100 & 100 \\
\hline Nominal & & 77.5 & 87.5 & 97.5 & 97.5 \\
\hline Low & & 75 & 80 & 95 & 95 \\
\hline HLW, $\mathrm{m}^{3}$ per Mt SNF processed & & 0.12 & 0.09 & 0.09 & 0.05 \\
\hline TRU losses to HLW per Mt SNF processed & & $<0.1 \%$ & $<0.1 \%$ & $<0.1 \%$ & $<0.1 \%$ \\
\hline Secondary Wastes, $\mathrm{m}^{3}$ per Mt SNF processed & & 0.13 & 0.13 & 0.1 & 0.1 \\
\hline Commercial Availability Date (Year) & 2020 & & & & \\
\hline Plant Lifetime (Years) & 40 & & & & \\
\hline
\end{tabular}


Table 1c: Reprocessing technology (2005 \$).

\begin{tabular}{|c|c|c|c|c|c|}
\hline & $\begin{array}{l}\text { Time- } \\
\text { Independent } \\
\text { Data }\end{array}$ & 2020 & 2030 & 2040 & 2050 \\
\hline \multicolumn{6}{|c|}{ Pyrochemical Process for Fast Reactor Spent Fuel (collocated with reactor park, $5 \mathrm{Mt} / \mathrm{yr}$ plant) ${ }^{2,3}$} \\
\hline Capital Cost (Million $\$)^{1} \quad$ High & & & 700 & 700 & 700 \\
\hline Nominal & & & 525 & 525 & 525 \\
\hline Low & & & 350 & 350 & 350 \\
\hline Total O\&M Cost (Million \$/year) ${ }^{1}$ & & & 125 & 125 & 125 \\
\hline Nominal & & & 100 & 100 & 100 \\
\hline Low & & & 75 & 75 & 75 \\
\hline \multicolumn{6}{|l|}{ Capacity Factor (\%) } \\
\hline High & & & 60 & 70 & 75 \\
\hline Nominal & & & 65 & 75 & 80 \\
\hline Low & & & 70 & 80 & 85 \\
\hline HLW, $\mathrm{m}^{3}$ per Mt SNF processed & & & 0.67 & $\begin{array}{l}0.34- \\
0.67 \\
\end{array}$ & $\begin{array}{l}0.34- \\
0.67\end{array}$ \\
\hline TRU losses to HLW per Mt SNF processed & & & $<0.3 \%$ & $<0.3 \%$ & $<0.3 \%$ \\
\hline Secondary Wastes, $\mathrm{m}^{3}$ per Mt SNF processed & & & 0.25 & 0.25 & 0.25 \\
\hline Commercial Availability Date (Year) & 2035 & & & & \\
\hline Plant Lifetime (Years) & 40 & & & & \\
\hline \multicolumn{6}{|c|}{$\begin{array}{l}\text { Notes: } \\
\text { 1. Capital and operating cost estimates have a high uncertainty level } \\
\text { 2. The } 5 \mathrm{MT} / \mathrm{yr} \text { Pyrochemical plant is sized to support a } \sim 1.0 \mathrm{GWe} \text { Fast Reactor (FR) } \\
\text { 3. The } 5 \mathrm{MT} / \mathrm{yr} \text { Pyrochemical plant will produce } 2-2.5 \mathrm{MT} / \mathrm{yr} \text { of TRU product for recycle (depending on conversion ratio of } \\
\text { the FR) }\end{array}$} \\
\hline
\end{tabular}

Table 1d: Repository management.

\begin{tabular}{|c|c|c|}
\hline & $\begin{array}{l}\text { Repository Opening } \\
\text { (Yr) }\end{array}$ & $\begin{array}{l}\text { Total Life Cycle Cost } \\
\text { (Billion \$) }\end{array}$ \\
\hline Repository Costs-Low & $\begin{array}{l}2017 \text { (Estimated for } \\
\text { the First Repository) }\end{array}$ & 63 \\
\hline Repository Costs-Nominal & & 68.6 \\
\hline Repository Costs-High & & 103 \\
\hline
\end{tabular}

Table 2 depicts a numerical comparison of key cost components used by U.S. MARKAL to select among competing electricity generating technologies. 
Table 2. Comparison between AFCI and competing technologies.

Source: "AFC Cost Basis" report (Shropshire, et al. 2007) for nuclear technologies and AEO-2006 (EIA 2006) for competing energy technologies.

Overnight Cost (2005 $\$ / K W)$

\begin{tabular}{|c|c|c|c|c|c|c|c|c|c|}
\hline Type of Generator & 2010 & 2015 & 2020 & 2025 & 2030 & 2035 & 2040 & 2045 & 2050 \\
\hline FR Nominal & - & - & \begin{tabular}{|l}
- \\
\end{tabular} & - & 4400 & 2200 & 2200 & 2200 & 2200 \\
\hline ALWR Nominal & - & 3600 & 1800 & 1800 & 1800 & 1800 & 1800 & 1800 & 1800 \\
\hline Advanced Coal & 1469 & 1433 & 1386 & 1314 & 1237 & 1164 & 1095 & 1031 & 970 \\
\hline Adv. Combined Cycle & 585 & 574 & 550 & 534 & 520 & 506 & 492 & 479 & 466 \\
\hline Solar - PV & 4065 & 3833 & 3553 & 3188 & 2928 & 2842 & 2757 & 2676 & 2596 \\
\hline Wind & 1192 & 1191 & 1189 & 1188 & 1188 & 1170 & 1153 & 1136 & 1119 \\
\hline
\end{tabular}

\section{O\&M Cost}

\begin{tabular}{|l|r|c|}
\hline \multirow{2}{*}{ Technology } & \multicolumn{1}{|l|}{ Fixed } & Variable \\
\cline { 2 - 3 } & \$/KW/Yr & \$/MWh \\
\hline FR Nominal & $100^{\star}$ & NA \\
\hline ALWR Nominal & $100^{\#}$ & NA \\
\hline Advanced Coal & 36 & 7.64 \\
\hline Adv. Combined Cycle & 11 & 3.36 \\
\hline Solar - PV & 11 & 5.17 \\
\hline Wind & 29 & 6.78 \\
\hline * FOAK 2030 - \$200
\end{tabular}

\# FOAK 2015 - \$200

Technology Life (Years)
\begin{tabular}{|l|r|}
\hline Advanced & 30 \\
\hline Adv. Comb & 30 \\
\hline Solar - PV & 30 \\
\hline Wind & 30 \\
\hline FR & 60 \\
\hline ALWR & 60 \\
\hline
\end{tabular}

Capacity Factors
\begin{tabular}{|l|r|}
\hline FR - Nominal & $90 \%$ \\
\hline ALWR - Nominal & $82 \%$ \\
\hline Adv. Coal & $85 \%$ \\
\hline Adv. Combined Cycle & $85 \%$ \\
\hline Solar - PV & $24 \%$ \\
\hline Wind & $45 \%$ \\
\hline
\end{tabular}

Using MARKAL for prospective assessments requires the judicious application of constraints and parameter settings to avoid optimal solutions that do not reflect behavioral factors or real diversity in the attributes of energy services. Applications that are not directly reflected in the technology representations are a tougher challenge. In this regard, special attention was paid to the expansion path of manufacturing capacities that produce nuclear fuels and reactors, and store the high-level nuclear wastes.

\subsection{Analytical Approach}

The future deployment of AFCI technologies derived in this study was obtained from U.S. MARKAL model runs based on a reference energy market scenario defined in the 2006 Annual Energy Outlook (AEO) published by the Energy Information Agency (EIA 2006). Additional adjustments were made to this scenario for nuclear energy growth potential, and in particular for AFCI potential, based on the overall nuclear industry outlook identified in one of the sample AFCI Case targets (quoted here after as "the sample AFCI case") (McCarthy 2007). Several steps are involved in estimating the U.S. AFCI market deployment:

1. Develop the reference energy system market scenario for U.S. MARKAL based on 2006 AEO assumptions.

2. Modify the technological characteristics of ALWRs and the overall market potential (rate of build-up) for the nuclear industry, using information from DOE/NE.

3. Develop and incorporate fuel cycle and reactor technologies, based on the cost range (nominal, high, and low) from the "AFC Cost Basis" report into the detailed RES network of the MARKAL nuclear framework.

4. Perform MARKAL model runs and track the market deployment (or market barriers) of AFCI technologies.

5. Make parametric adjustments in MARKAL to remove market barriers of AFCI technologies so that the market deployments derived in the revised MARKAL run are consistent with the sample AFCI case. 
6. Run selected policy scenarios, such as various levels of carbon tax, to determine their impact on deployment of AFCI technologies.

\subsection{Economic and Energy Market Assumptions}

The reference energy system market scenario used to project AFCI technology deployment was benchmarked to AEO 2006 for the period of 2005-2030 and extended to 2050.

\subsubsection{Economic and Demographic Assumptions}

The U.S. MARKAL model uses the same input data and assumptions as were used to generate the AEO 2006 Reference Case to the extent possible. For example, the macroeconomic projections for Gross Domestic Product (GDP), housing stock, commercial square footage, industrial output, and vehicle miles traveled were taken from the AEO report. At the sector level, both supply-side and demand-side technologies were characterized to reflect the AEO assumptions. For the period after 2030 (not projected in the AEO), various sources were used to compile a set of economic and technical assumptions. For instance, the primary economic drivers of GDP and population were based on the real GDP growth rate from the Congressional Budget Office's Long-Term Budget Outlook (CBO 2005) and population growth rates from the Social Security Administration's (SSA) 2005 Annual Report to the Board of Trustees (SSA 2005). The reference market scenario macroeconomic assumptions are shown in Table 3. GDP is projected to increase at an average annual rate of $3.0 \%$ from 2005 to 2030, and then slow to an average annual rate of $2.4 \%$ from 2030 to 2050 . The population growth rate is projected to decline from an average annual rate of $0.8 \%$ between 2005 and 2030 to $0.5 \%$ from 2030 to 2050 .

Table 3. Reference macroeconomic and demographic assumptions.

\begin{tabular}{|c|c|c|c|c|c|c|c|c|c|c|c|c|c|}
\hline & & & & & & & & & & & \multicolumn{3}{|c|}{ Annual Growth Rates } \\
\hline & 2005 & 2010 & 2015 & 2020 & 2025 & 2030 & 2035 & 2040 & 2045 & 2050 & '05-'25 & $25-' 50$ & '05-'50 \\
\hline GDP (Bill. 2001\$) & $\$ 11,414$ & $\$ 13,356$ & $\$ 15,444$ & $\$ 17,962$ & $\$ 20,606$ & $\$ 23,666$ & $\$ 26,907$ & $\$ 30,295$ & $\$ 33,777$ & $\$ 37,220$ & $3.0 \%$ & $2.4 \%$ & $2.7 \%$ \\
\hline Population (Million) & 296.8 & 310.1 & 323.5 & 337.0 & 350.6 & 364.8 & 375.6 & 384.1 & 390.0 & 395.4 & $0.8 \%$ & $0.5 \%$ & $0.6 \%$ \\
\hline Total Households (Million) & 115.4 & 122.9 & 130.1 & 137.2 & 143.5 & 149.8 & 150.2 & 153.6 & 156.0 & 158.2 & $1.1 \%$ & $0.4 \%$ & $0.7 \%$ \\
\hline Commercial Floorspace (Bill. sq ft) & 76.2 & 82.3 & 88.9 & 96.0 & 103.7 & 112.0 & 119.7 & 127.3 & 134.7 & 141.6 & $1.6 \%$ & $1.3 \%$ & $1.4 \%$ \\
\hline Industrial Production $(2000=100)$ & 101 & 111 & 123 & 136 & 150 & 167 & 188 & 210 & 232 & 254 & $2.0 \%$ & $2.1 \%$ & $2.1 \%$ \\
\hline $\begin{array}{l}\text { Light Duty Vehicle Miles Traveled } \\
\text { (Bill. VMT) }\end{array}$ & 2,619 & 2,890 & 3,171 & 3,474 & 3,791 & 4,132 & 4,418 & 4,653 & 4,820 & 4,978 & $1.9 \%$ & $1.1 \%$ & $1.4 \%$ \\
\hline
\end{tabular}

Source: Derived from references EIA 2006, CBO 2005, and SSA 2005.

\subsubsection{Assumptions on Energy Prices}

Table 4 shows projected energy prices assumed for the MARKAL reference energy system market. Real natural gas prices are projected to drop between 2005 and 2015, and then increase at nearly $1.8 \%$ per year from 2015 to 2030 before increasing amounts of arctic gas and liquefied natural gas (LNG) imports limit the average annual increase to $0.8 \%$ from 2030 to 2050 . Real crude oil prices are also projected to drop between 2005 and 2015, increase at average annual rates of $1.4 \%$ between 2010 and 2030, and 1.0\% per year thereafter.

Average real mine mouth coal prices are projected to continue to decline by about $0.3 \%$ a year between 2005 and 2020, due to increasing productivity gains and a continued shift to less labor-intensive Western coal production. However, coal prices are projected to increase at an average rate of $1.2 \%$ per year after 2020, due to increased demands, gradually increasing mine depths and a saturation of labor productivity gains.

In comparison, this analysis used uranium resource costs, as mentioned in Table 1b, which ranges from $\$ 50 / \mathrm{kg}$ to $\$ 150 / \mathrm{kg}$. Analysis with Cost $\mathrm{E}$ includes uranium costs of $\$ 100 / \mathrm{kg}$. 
Table 4. MARKAL reference energy market prices (2005 \$).

\begin{tabular}{|l|r|r|r|r|r|}
\hline Energy Prices & \multicolumn{1}{|c|}{2005} & 2015 & 2025 & \multicolumn{1}{c|}{2035} & \multicolumn{1}{c|}{2050} \\
\hline World Oil Price (\$/bbl) & 51.95 & 43.77 & 50.21 & 55.83 & 61.30 \\
\hline Natural Gas Wellhead Price (\$/Mcf) & 8.46 & 4.42 & 5.27 & 6.35 & 7.07 \\
\hline Coal Mine Mouth Price (\$/short ton) & 21.95 & 20.96 & 21.44 & 24.72 & 30.27 \\
\hline
\end{tabular}

\subsection{Modeling the AFCI Technologies in the U.S. MARKAL}

As described earlier, the energy system in MARKAL is represented as an RES, depicting flows of energy carriers from extracting the resource through energy transformation, transmission, distribution, storage, and transport, to end-use devices. End-use devices deliver energy services to meet demand from various sectors. Each link in the RES is characterized by a set of technical coefficients (e.g., capacity, efficiency), environmental emission and materials flow coefficients (e.g., $\mathrm{CO}_{2}, \mathrm{SO}_{\mathrm{x}}, \mathrm{NO}_{\mathrm{x}}$, high-level waste), and economic coefficients (e.g., capital costs, date of commercialization).

The detailed nuclear energy system network and the associated flow of energy and waste modeled in the U.S. MARKAL are depicted in Figure 2. The brown boxes form the up-stream fresh fuel supply to the existing and new nuclear power plants. The blue boxes represent the existing Light-Water Reactors (LWRs) (with the Nuclear Regulatory Commission's projected schedule of decommissioning), new advanced LWRs, and non-AFCI reactors. The green boxes depict the AFCI technology and fuel cycle options that include FRs, UREX+, and pyrochemical process. A down-stream, comprehensive nuclear waste management system (grey boxes) was built into the model structure, including the Yucca Mountain Repository, for storing high-level waste. The nuclear system is linked to the rest of the RES by providing electricity to the grid. Note that the aggregated representation of the nuclear energy network in the U.S. MARKAL is to ensure that all major cost components and material flows in the nuclear system are accounted for, and that geological repository capacity imposes a realistic limit on high-level waste storage.

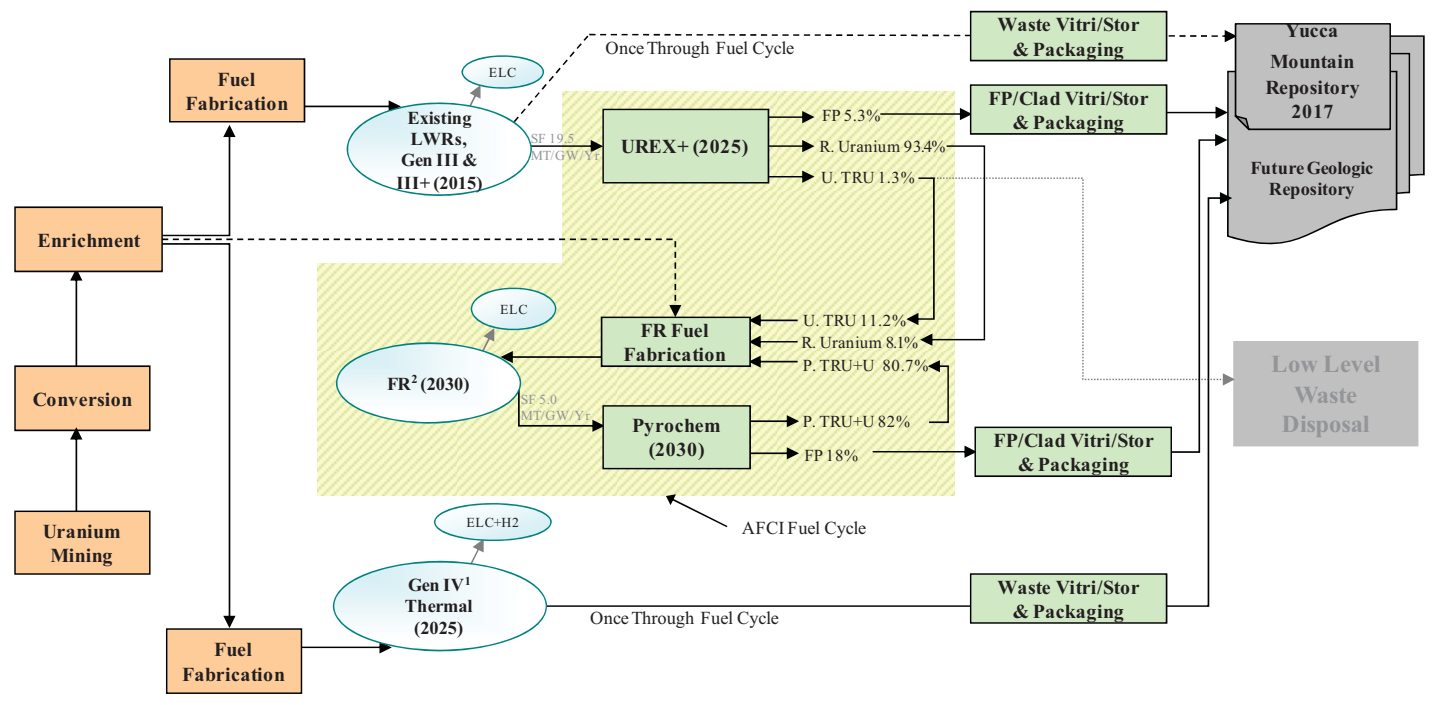

Notes: 1. Gen IV Thermal Technologies use VHTR as a surrogate, 2. FR Technology Covers: SFR for AFCI Analysis Abbreviations: SF: Spent Fuel, FP: Fission Product, H2: Hydrogen, ELC: Electricity, U. TRU: Transuranics from UREX+, P. TRU+U: Transuranics plus Uranium from Pyrochem, R. Uranium: Reprocessed Uranium

Reference: Shropshire, et al. 2006. Advanced Fuel Cycle Economic Sensitivity Analysis, INL/EXT-06-1 1947, December.

Figure 2. AFCI technology representation in U.S. MARKAL. 


\subsection{Market Deployment and Barriers of Nuclear Technologies}

At equilibrium, the shadow price of electricity determines the market deployment of a specific generating technology. The level of deployment tops out at the point at which the marginal cost of electricity generated from that technology equals the shadow price. A new technology with a marginal cost schedule consistently higher than the shadow price will not penetrate the market competitively in MARKAL. Some forms of economic incentives would have to be provided to that technology in order to remove its cost barriers to enter the market. There are many parametric instruments available to use in MARKAL to reflect various forms of economic incentives. These include varying the technology-specific discount rate on capital, or specifying a direct subsidy per unit of electricity generated.

The initial MARKAL runs, based strictly on market competition with the assumptions outlined above, returned no market penetration for AFCI technologies at the cost ranges provided in the "AFC Cost Basis" report. Cost and market comparison across MARKAL runs with various parametric adjustments, reflecting government economic incentives and more favorable market conditions to accelerate the market deployment of these technologies, are discussed in Section 2.6.

\subsection{Case Studies on AFCI Market Deployment}

Many factors influence the market deployment of a new technology in a MARKAL solution. For a AFCI reactor, factors such as its projected cost and learning pattern, upstream and downstream fuel cycle costs, the characteristics of the market segments in which it will compete (e.g., costs of advanced coal and gas power plants), varying coal and oil gas prices, government policies, and environmental externalities are all likely to impact the model's findings. In this section, a range of values were applied to some key model instruments in MARKAL and generated alternative market conditions that may affect the economics of AFCI technologies in order to quantify market barriers and opportunities, as well as to gain valuable insights on the successful adoption of AFCI technologies in the energy market.

\subsubsection{Market Deployment under the Sample AFCI Case}

When comparing the relative merits of technologies in the energy sector, a long time span is frequently required. Discounting of costs and benefits is usual in such analysis, and the choice of an appropriate discount rate can be vital. The available empirical evidence suggests that the appropriate real discount rate could vary widely depending on which concept it is based. For an example, Stocks (1984) suggests that for Australia, a value reflecting the social time preference rate could be as low as $2 \%$, while one based on the social opportunity cost of capital would be considerably higher, probably $7-10 \%$. In this multi-period U.S. MARKAL analysis evaluating AFCI deployment strategies, a 10\% discount rate has been used for all electricity-producing technologies.

To explore the sensitivity of AFCI's market competitiveness and growth against key cost components of the technologies it represents, a series of scenarios were ran based on a range of overnight costs for the advanced recycling reactors (FR) (Figure 3 ) at 10\% discount rate. The results indicate that capitalintensive technologies such as FR and associated front and back-end technologies are disadvantaged when using high discount rates. So, a range of discount rates was tested, $2 \%-10 \%$ for FRs and kept associated technologies at 5\% discount rate. The MARKAL results for FR's market penetration in 2050 corresponding to each of these overnight cost values at 5\% discount rate are shown in Figure 4. Lowering discount rates is one of the financial instruments to bring down technologies' hurdle rate. This cursory exercise suggests devising financial policies to provide incentives to AFCI technologies, which could be any kind of economic instruments such as government subsidy, loan guarantees, simplified facility siting requirements, license applications, or any other incentive. 
At the low end of the FR cost (Cost A), FRs reach their maximum potential sustainable in a closed fuel cycle where the overall growth rate of the nuclear industry (ALWRs and FRs combined) gradually increases over time and is capped at $10 \mathrm{GWe}$ per year by 2050. This refers to the industry potential (including allied supporting sectors that supply steel, cement, construction, etc.) for supporting new nuclear builds every year as the technology matures (e.g., by 2050). Similar growth was observed previously for the nuclear industry (maximum of $9.9 \mathrm{GWe}$ in 1974 and $9.1 \mathrm{GWe}$ in 1986) (EIA 2004). At the high end of the cost range (Cost F), AFCI technologies will not be competitive in the energy market even at a $2 \%$ discount rate.

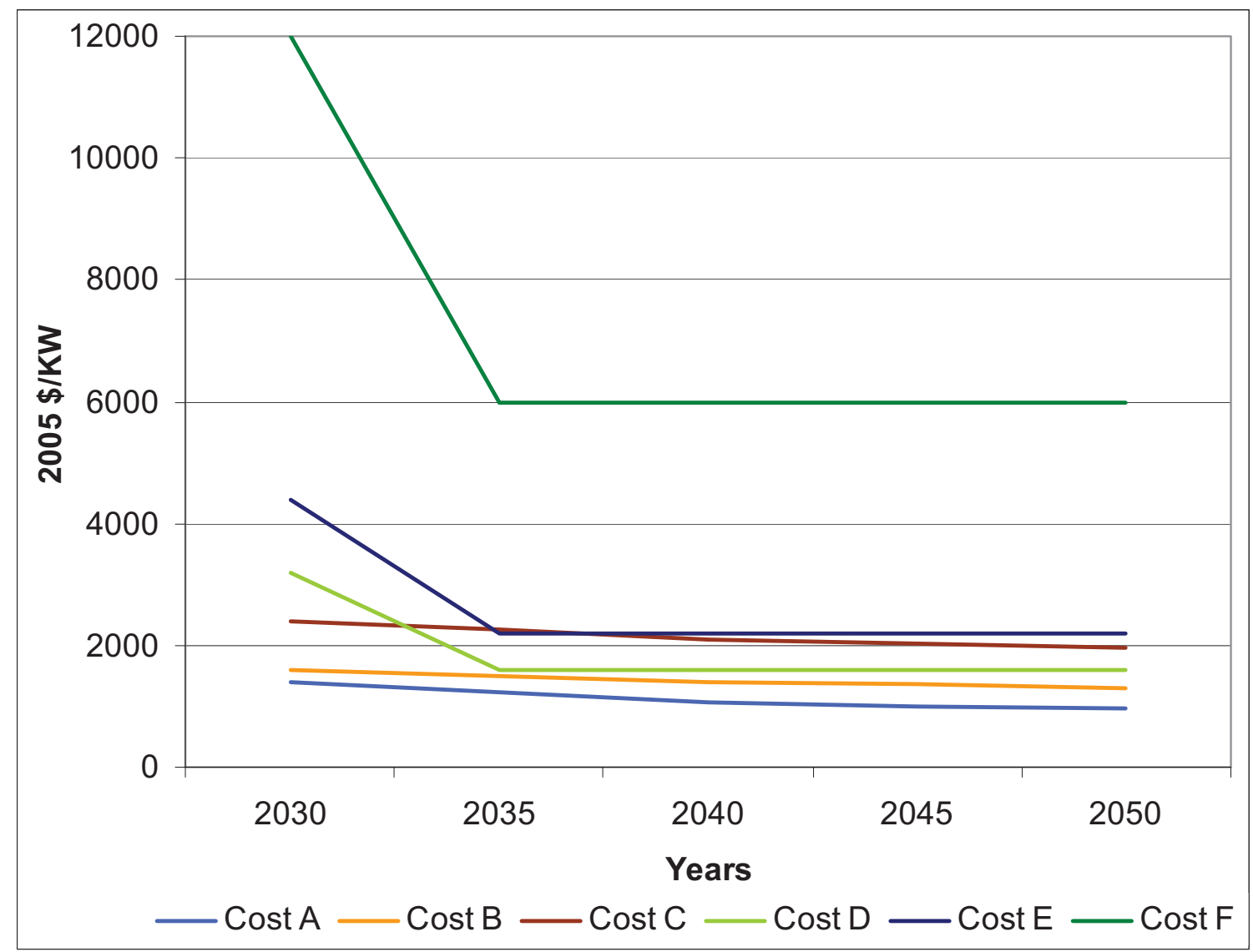

Figure 3. Overnight cost range of Fast Reactors (2005 \$/KW).

The sample AFCI case projects FR market penetration of 33 GWe by 2050. As shown in Figure 4, FRs cannot penetrate the market with Cost $\mathrm{E}$ at $5 \%$ discount rate. Achieving this target market penetration of FR technologies would require lowering their effective discount rate to $4 \%$ (through economic incentives such as government subsidy, simplified sitting requirements, and license applications). According to Figure 5, FRs penetrate the energy market at 4\% discount rate after 2040. For comparison, the discount rate used for the other competing, fossil-based, and renewable electricity generating plants is $10 \%$. 


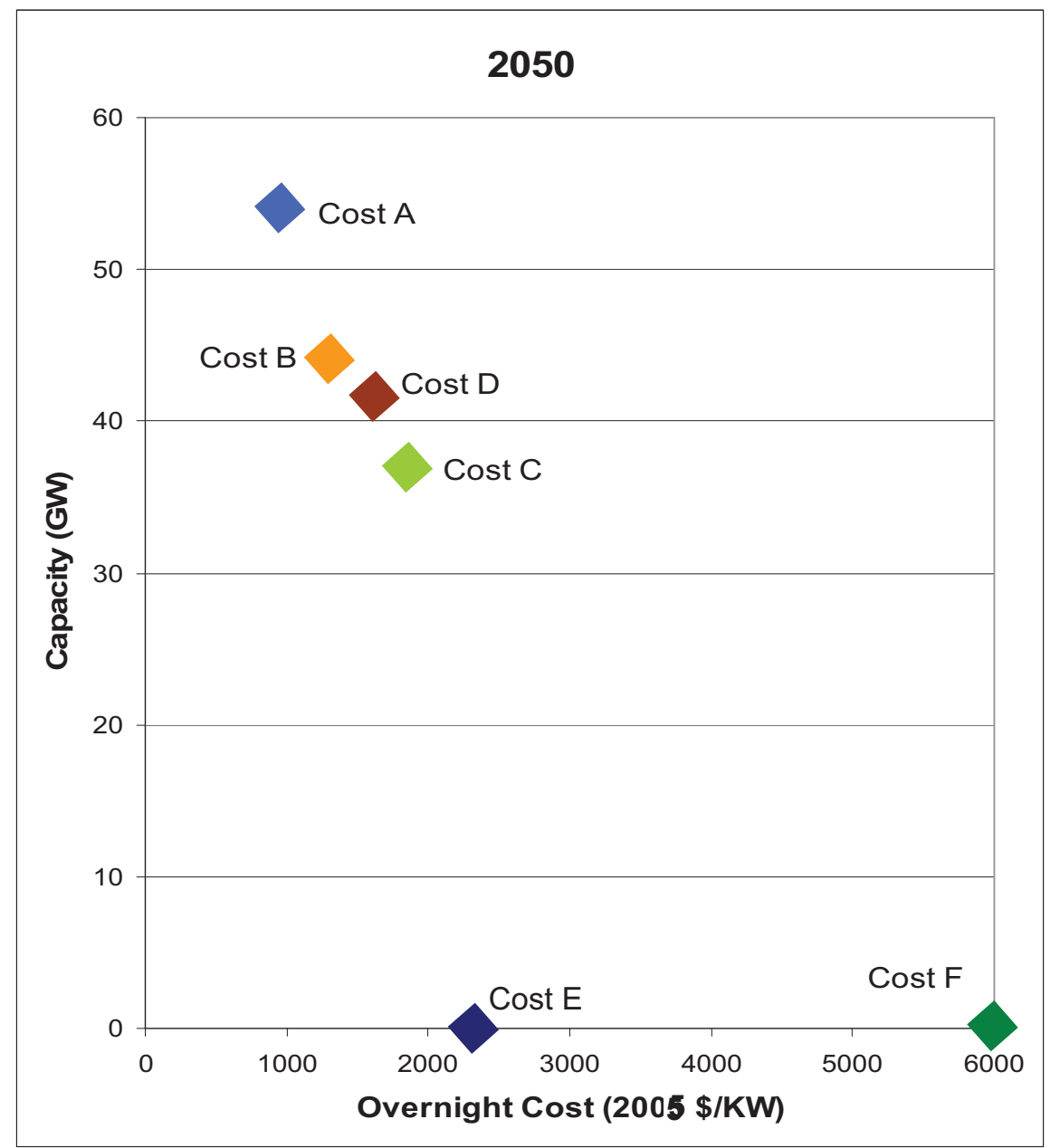

Figure 4. Installed capacity versus overnight cost of fast reactors, 2050 (at 5\% discount rate).

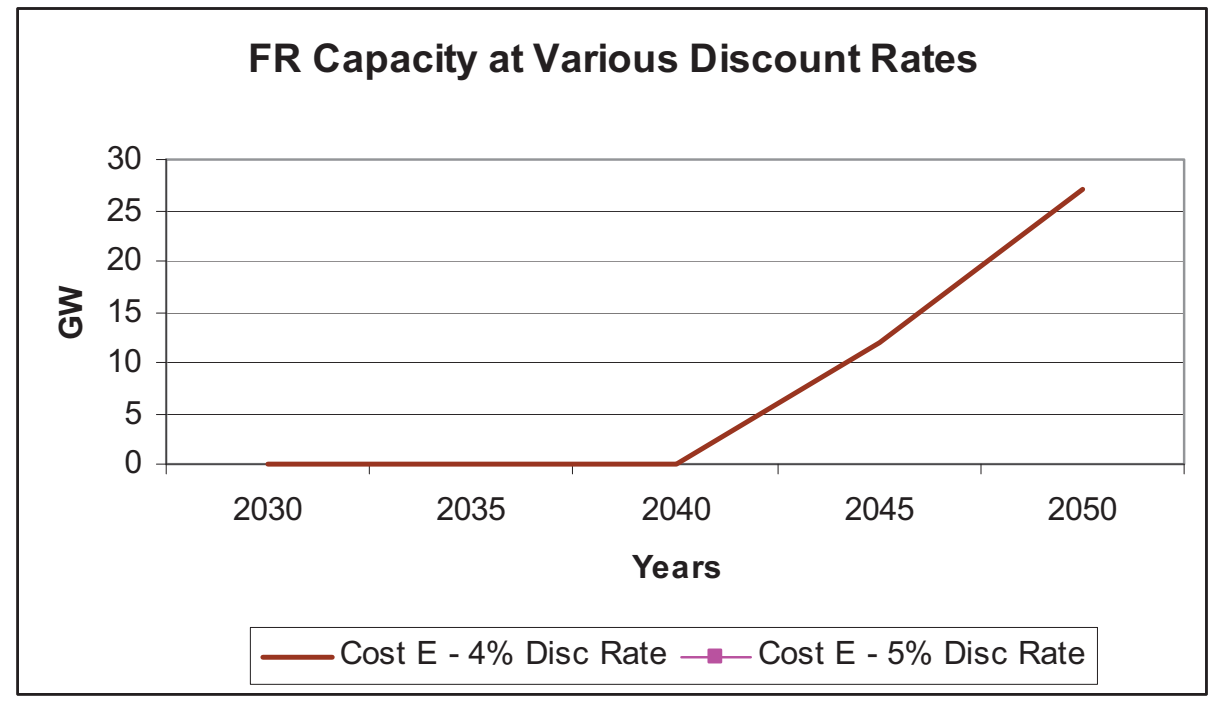

Figure 5. Fast Reactor installed capacity at 4\% discount rate for Cost E. 
Table 5 provides a comparison of the levelized electricity costs for new plants as depicted in the base scenario of the U.S. MARKAL, which is calibrated to the AEO (2006). The AEO (2006) referenced advanced nuclear technology costs were replaced by the cost curves detailed in Table 1 and Figure 3 to test sensitivity of FRs with the U.S. MARKAL in this exercise. Advanced nuclear technology overnight costs (as mentioned in Table 5) were assumed to be $\$ 2083 / \mathrm{GW}$ in 2005, $\$ 1978 / \mathrm{GW}$ in 2015 and $\$ 1792 / \mathrm{GW}$ in 2030 (adjusted to $2005 \$$ ).

Table 5. Levelized electricity costs for new plants in the base case, 2015 and 2030 (2005 mills/kWh).

\begin{tabular}{|l|c|r|r|r|c|}
\hline \multicolumn{7}{|c|}{ Technologies } & Capital & O\&M & Fuel & Transmission & Total \\
\hline $\mathbf{2 0 1 5}$ & 31.37 & 4.89 & 15.08 & 3.59 & $\mathbf{5 4 . 9 3}$ \\
\hline Coal & 11.72 & 1.45 & 38.23 & 2.98 & $\mathbf{5 4 . 3 7}$ \\
\hline Gas Combined Cycle & 42.05 & 8.59 & 0.00 & 7.00 & $\mathbf{5 7 . 6 5}$ \\
\hline Wind & 44.05 & 8.11 & 6.86 & 2.25 & $\mathbf{6 1 . 2 6}$ \\
\hline Adv. Nuclear & 28.72 & 4.89 & 16.36 & 3.52 & $\mathbf{5 3 . 4 9}$ \\
\hline $\mathbf{2 0 3 0}$ & 11.13 & 1.45 & 41.55 & 3.04 & $\mathbf{5 7 . 1 6}$ \\
\hline Coal & 45.48 & 8.76 & 0.00 & 7.27 & $\mathbf{6 1 . 5 0}$ \\
\hline Gas Combined Cycle & 42.80 & 8.11 & 6.88 & 2.94 & $\mathbf{6 0 . 7 2}$ \\
\hline Wind & & & \\
\hline Adv. Nuclear & \multicolumn{7}{|l|}{} \\
\hline Source: AEO 2006 &
\end{tabular}

\subsubsection{Market Deployment under Climate Change Policy (e.g., Carbon Tax)}

AFCI deployment under any climate change policy can be considered in the context of existing debates. In the real world, climate change is only one of many externalities - competition is not perfect, information and markets are not complete, and distorting taxes and transfers are widespread. These observations are important because many analyses of climate change policy assume that the externality of climate change is the only distortion that exists. The conclusions of such analyses may be misleading or incorrect.

Two different forms of economic incentives could achieve that goal: one would reduce emissions by setting a price on them, and the other would cap the overall level of emissions. However, given current information about the potential for near-term emissions to trigger abrupt and catastrophic damages, the price approach is more likely than a cap to maximize the difference between the policy's total benefits and total costs (further discussion of the topic can be found in Dinan and Shackleton 2005 and Nordhaus 2006). Under an emission tax system, sources that produce greenhouse gas (GHG) emissions must pay a tax per unit of emissions. ${ }^{\text {a }}$ To ensure that the cost of a given emission abatement is minimized; all emissions should be taxed at the same rate per unit of contribution to climate change.

A tax on the carbon content of fossil fuels - a carbon tax - is generally proposed in lieu of a tax on the $\mathrm{CO}_{2}$ emissions from fossil fuel use since it has a similar impact and is much simpler to administer. A $\mathrm{CO}_{2}$ emissions tax would require every source that uses fossil fuels to monitor its emissions and to pay the corresponding taxes. A carbon tax is a more efficient instrument for reducing energy-related $\mathrm{CO}_{2}$ emissions because a carbon tax changes relative costs, and so it provides incentives for fuel switching. In

a. Strictly speaking, the term "emission charge" or "fee" would be more appropriate, because this is a payment for a right to emit; however, the term "emission tax" is adopted because it is so widely used. 
other words, an imposition of a carbon tax on the energy system increases the competitiveness of noncarbon emitting technologies, such as nuclear.

Using this reasoning, supported also by IPCC (2007) and Clarke, et al. (2007), exploratory carbon tax schedules were ran from $\$ 75$ per ton of $\mathrm{CO}_{2}$ to $\$ 400$ per ton $\mathrm{CO}_{2}$, using the Cost $\mathrm{E}$ assumption with a discount rate of $10 \%$ (where, as discussed above, it does not penetrate the market). However, with a carbon tax on carbon-rich fuel, the MARKAL results show that FR market penetration increases as the carbon tax rate increases (Figure 6). The leveling off of FR capacity growth indicates that other electricity-producing technologies are more competitive in those years.

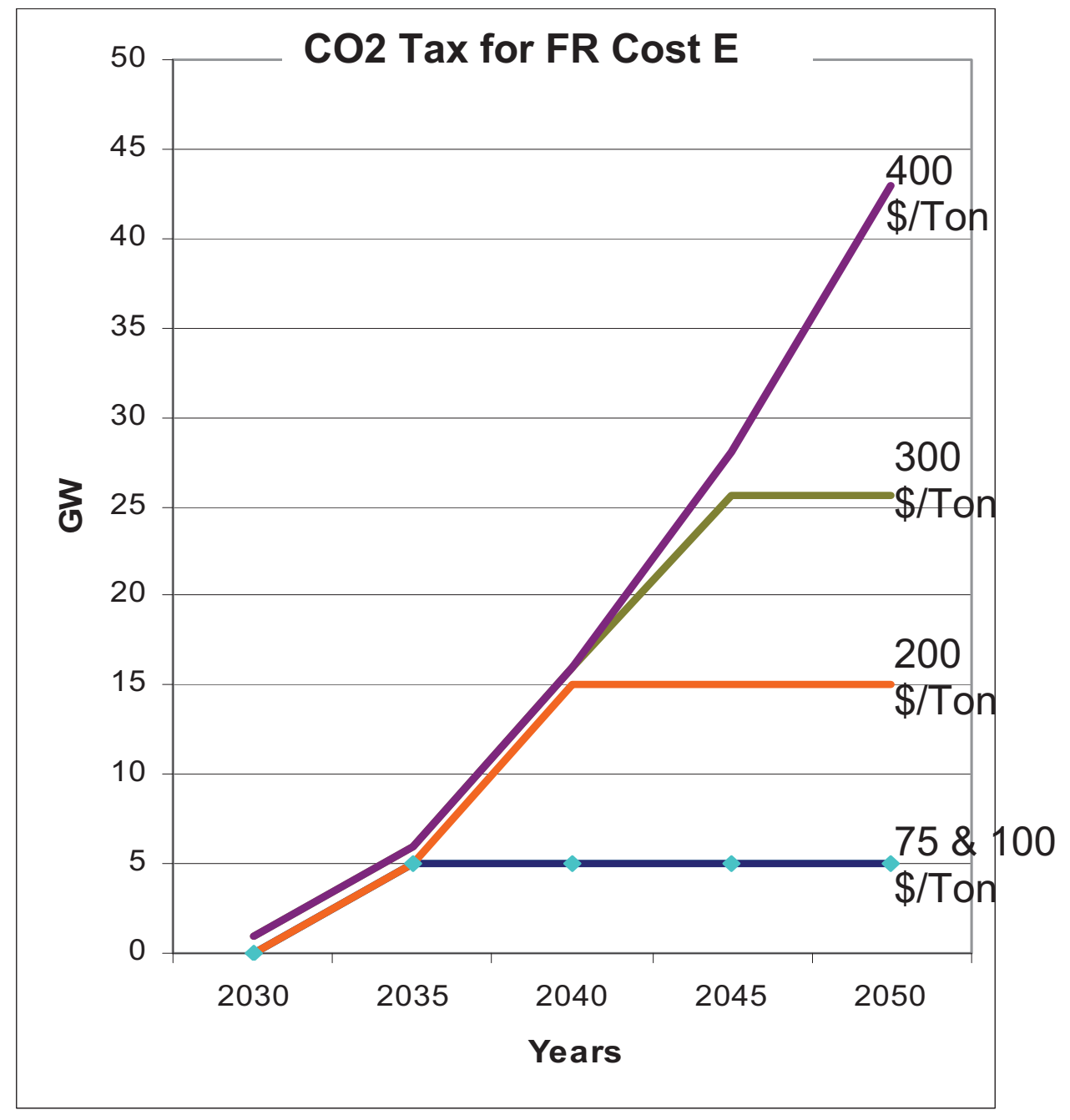

Figure 6. Fast Reactor capacity in alternative carbon tax schedule.

In Attachment H, "VISION Economic Sub-Model Description and Methodology," the authors postulate hypothetical growth rates for the nuclear industry of $0 \%, 1.8 \%$, and $3.4 \%$ per year. In a MARKAL analysis, the potential for nuclear technology growth, and in particular FR deployments, is based on the energy market competition with other electricity producing technologies. Table 6 highlights growth rates in overall electricity demand in each 5-year period. 
Table 6. Electricity demand - average annual growth rates in alternative scenarios.

\begin{tabular}{|c|c|c|c|c|c|c|c|c|c|c|}
\hline Scenarios & $\begin{array}{c}2005- \\
2010 \\
\end{array}$ & $\begin{array}{c}2010- \\
2015 \\
\end{array}$ & $\begin{array}{c}2015- \\
2020 \\
\end{array}$ & $\begin{array}{c}2020- \\
2025 \\
\end{array}$ & $\begin{array}{c}2025- \\
2030 \\
\end{array}$ & $\begin{array}{c}2030- \\
2035 \\
\end{array}$ & $\begin{array}{c}2035- \\
2040 \\
\end{array}$ & $\begin{array}{c}2040- \\
2045 \\
\end{array}$ & $\begin{array}{c}2045- \\
2050 \\
\end{array}$ & Overall $^{1}$ \\
\hline Base & $1.5 \%$ & $1.6 \%$ & $1.6 \%$ & $1.4 \%$ & $1.6 \%$ & $0.9 \%$ & $0.9 \%$ & $0.8 \%$ & $1.0 \%$ & $1.26 \%$ \\
\hline $\begin{array}{l}\text { Cost A - } 5 \% \\
\text { Disc Rate }\end{array}$ & $1.5 \%$ & $1.6 \%$ & $1.6 \%$ & $1.4 \%$ & $1.6 \%$ & $1.1 \%$ & $0.7 \%$ & $0.9 \%$ & $1.3 \%$ & $1.26 \%$ \\
\hline $\begin{array}{l}\text { Cost B - 5\% } \\
\text { Disc Rate }\end{array}$ & $1.5 \%$ & $1.6 \%$ & $1.6 \%$ & $1.4 \%$ & $1.6 \%$ & $1.0 \%$ & $0.8 \%$ & $0.9 \%$ & $1.1 \%$ & $1.24 \%$ \\
\hline $\begin{array}{l}\text { Cost C - 5\% } \\
\text { Disc Rate }\end{array}$ & $1.5 \%$ & $1.6 \%$ & $1.6 \%$ & $1.4 \%$ & $1.6 \%$ & $1.0 \%$ & $0.9 \%$ & $0.9 \%$ & $1.1 \%$ & $1.24 \%$ \\
\hline \multicolumn{11}{|c|}{ Alternative Scenarios for Cost E } \\
\hline $10 \%$ Disc Rate & $1.5 \%$ & $1.6 \%$ & $1.6 \%$ & $1.4 \%$ & $1.6 \%$ & $1.0 \%$ & $0.9 \%$ & $0.8 \%$ & $1.0 \%$ & $1.27 \%$ \\
\hline $5 \%$ Disc Rate & $1.5 \%$ & $1.6 \%$ & $1.6 \%$ & $1.4 \%$ & $1.6 \%$ & $1.0 \%$ & $0.8 \%$ & $0.9 \%$ & $1.0 \%$ & $1.29 \%$ \\
\hline 4\% Disc Rate & $1.5 \%$ & $1.6 \%$ & $1.6 \%$ & $1.4 \%$ & $1.6 \%$ & $1.0 \%$ & $0.9 \%$ & $0.9 \%$ & $1.1 \%$ & $1.31 \%$ \\
\hline CTax \$75/Ton & $1.4 \%$ & $1.6 \%$ & $1.6 \%$ & $1.2 \%$ & $1.5 \%$ & $0.9 \%$ & $0.9 \%$ & $0.9 \%$ & $1.1 \%$ & $1.30 \%$ \\
\hline CTax $\$ 100 /$ Ton & $1.4 \%$ & $1.6 \%$ & $1.6 \%$ & $1.2 \%$ & $1.5 \%$ & $0.9 \%$ & $1.0 \%$ & $1.0 \%$ & $1.1 \%$ & $1.27 \%$ \\
\hline CTax \$200/Ton & $1.4 \%$ & $1.6 \%$ & $1.7 \%$ & $1.3 \%$ & $1.5 \%$ & $0.9 \%$ & $1.0 \%$ & $1.0 \%$ & $1.1 \%$ & $1.27 \%$ \\
\hline CTax $\$ 300 /$ Ton & $1.4 \%$ & $1.6 \%$ & $1.6 \%$ & $1.3 \%$ & $1.5 \%$ & $1.0 \%$ & $1.0 \%$ & $1.0 \%$ & $1.1 \%$ & $1.27 \%$ \\
\hline CTax $\$ 400 /$ Ton & $1.4 \%$ & $1.6 \%$ & $1.7 \%$ & $1.3 \%$ & $1.5 \%$ & $0.9 \%$ & $1.1 \%$ & $1.1 \%$ & $1.2 \%$ & $1.27 \%$ \\
\hline
\end{tabular}

Annual nuclear technology growth rates determined in each scenario run are shown in Table 7. This covers all technologies, including existing, future ALWRs, and future FRs. Detailed nuclear technology growth is shown in Figure 7.

Table 7. Average annual growth rates for nuclear technologies 2005-2050.

\begin{tabular}{|l|c|}
\hline \multicolumn{1}{|c|}{ Scenario } & AGR \\
\hline Base & $-3.82 \%$ \\
\hline Cost $\mathrm{A}$ & $2.24 \%$ \\
\hline Cost B & $1.79 \%$ \\
\hline Cost C & $1.35 \%$ \\
\hline Cost E - 10\% Disc Rate & $-3.82 \%$ \\
\hline Cost E - 5\% Disc Rate & $0.82 \%$ \\
\hline Cost E - 4\% Disc Rate & $1.20 \%$ \\
\hline Cost E - CTax \$75/Ton & $0.89 \%$ \\
\hline Cost E - CTax \$100/Ton & $0.92 \%$ \\
\hline Cost E - CTax \$200/Ton & $1.06 \%$ \\
\hline Cost E - CTax \$300/Ton & $1.21 \%$ \\
\hline Cost E - CTax \$400/Ton & $1.42 \%$ \\
\hline
\end{tabular}

In the base (AEO 2006) scenario, existing nuclear reactors phase out on a schedule depending on the extended operation period, which also includes nearly $3 \mathrm{GW}$ of up rates. In addition, there are $11 \mathrm{GW}$ of advanced nuclear capacity builds for 2005-2050. For this base scenario, the average annual growth rate is negative in Table D7, also shown graphically in Figure 7. In Figure 7, the base scenario and Cost E at the $10 \%$ discount rate scenario are the same. 


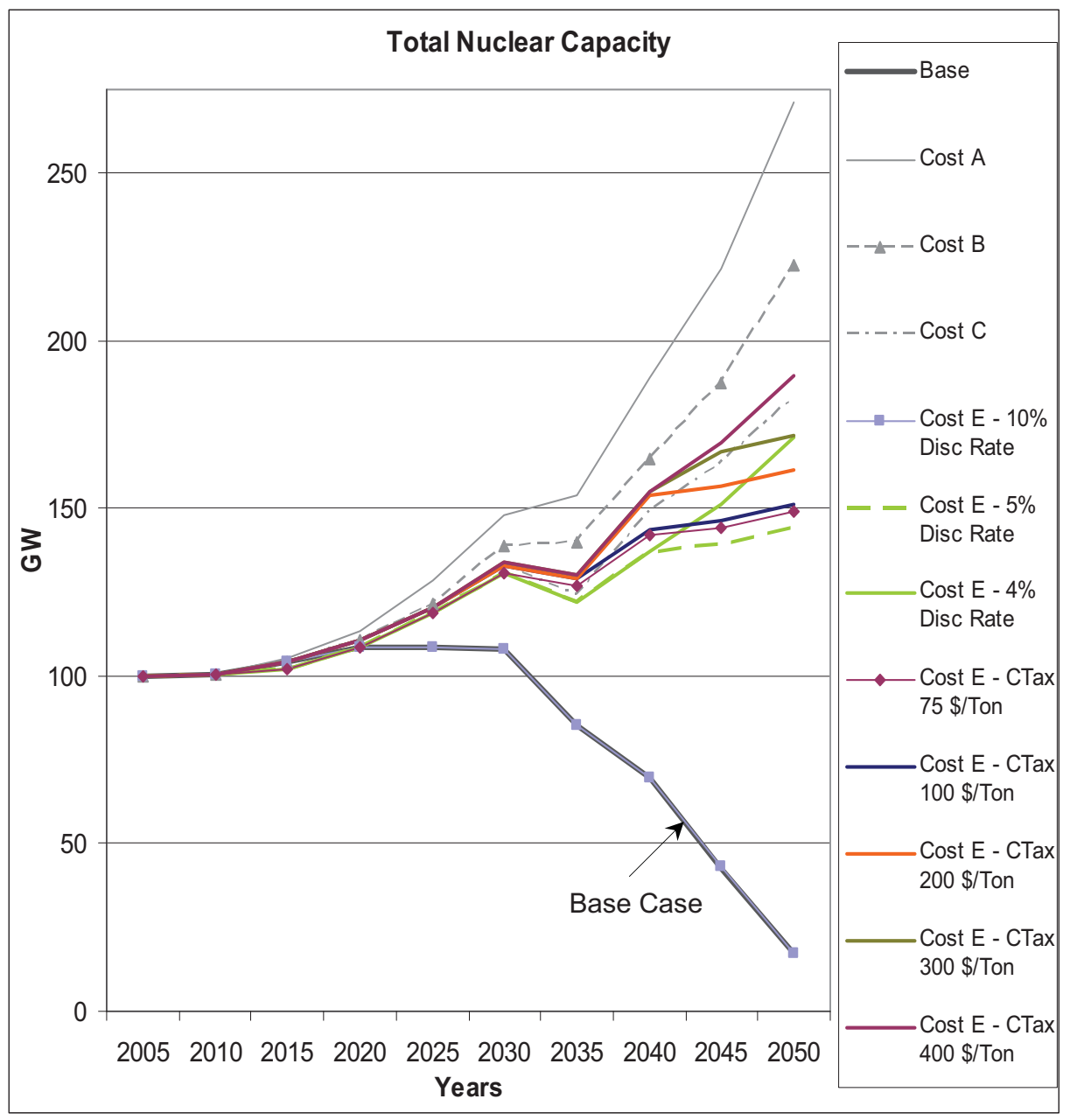

Figure 7. Nuclear capacity in alternative scenarios.

Scenarios graphed in Figure 7 show the sensitivity of overall nuclear penetration in the energy market place to selected market assumptions. Average annual nuclear growth rates, at a 5\% discount rate, for Costs A, B, and C are $1.35 \%, 1.79 \%$, and $2.24 \%$, respectively.

As discovered, FRs cannot be deployed with Cost $\mathrm{E}$ at either a $10 \%$ or $5 \%$ discount rate. So, $4 \%$ was tested (shown in Figure 5). The results are shown in Figure 7 for comparison with the other scenarios. Figure 8 depicts the penetration of FRs only under each set of scenario assumptions. The respective 2050 FR capacities range from $37 \mathrm{GW}$ to $54 \mathrm{GW}$, as can be seen in Figure 8.

Finally, the tables (7 and 8) and figures (7 and 8), respectively, also depict the penetration of nuclear technologies (including FRs) and FRs only under carbon tax as scenarios, as described earlier.

Thus in Figures 7 (all nuclear) and 8 (FRs only) all scenarios can be compared at once. These illustrations can provide insights as to what policies might be effective to encourage nuclear and FR penetration in the energy market. For an example, a trade-off analysis can be performed to offer economic incentives for AFCI technologies to effectively reduce the FR's discount rate from $10 \%$ to $4 \%$, or alternatively, to implement a comprehensive carbon tax across the entire energy sector. Further results from a MARKAL analysis could quantify the economic impacts of each scenario on the entire energy system or part thereof, to help determine whether to provide subsidies to the technologies of interest or impose taxes on competing carbon-rich fuel. 
Table 8. Average annual growth rates for Fast Reactors.

\begin{tabular}{|l|c|}
\hline \multicolumn{1}{|c|}{ Scenarios } & $\begin{array}{c}\text { AGR - Respective to the Initial } \\
\text { Penetration in the Market (Figure 8) }\end{array}$ \\
\hline Cost A - 5\% Disc Rate & $17.91 \%$ \\
\hline Cost B - 5\% Disc Rate & $20.69 \%$ \\
\hline Cost C - 5\% Disc Rate & $27.22 \%$ \\
\hline Cost E - 4\% Disc Rate & $39.04 \%$ \\
\hline Cost E - CTax \$75/Ton & $8.38 \%$ \\
\hline Cost E - CTax \$100/Ton & $8.38 \%$ \\
\hline Cost E - CTax \$200/Ton & $14.50 \%$ \\
\hline Cost E - CTax \$300/Ton & $17.62 \%$ \\
\hline Cost E - CTax \$400/Ton & $20.69 \%$ \\
\hline
\end{tabular}

Table 8 shows the average annual growth rate for FRs under each scenario where FR penetration occurs. The carbon tax scenarios all assume the $10 \%$ discount rate. It is calculated over the period from when the penetration first occurs to 2050, the time span of the present analysis. The comparable average annual growth rate under the sample AFCI case (McCarthy 2007) is 19.10\% from 2030 to 2050.

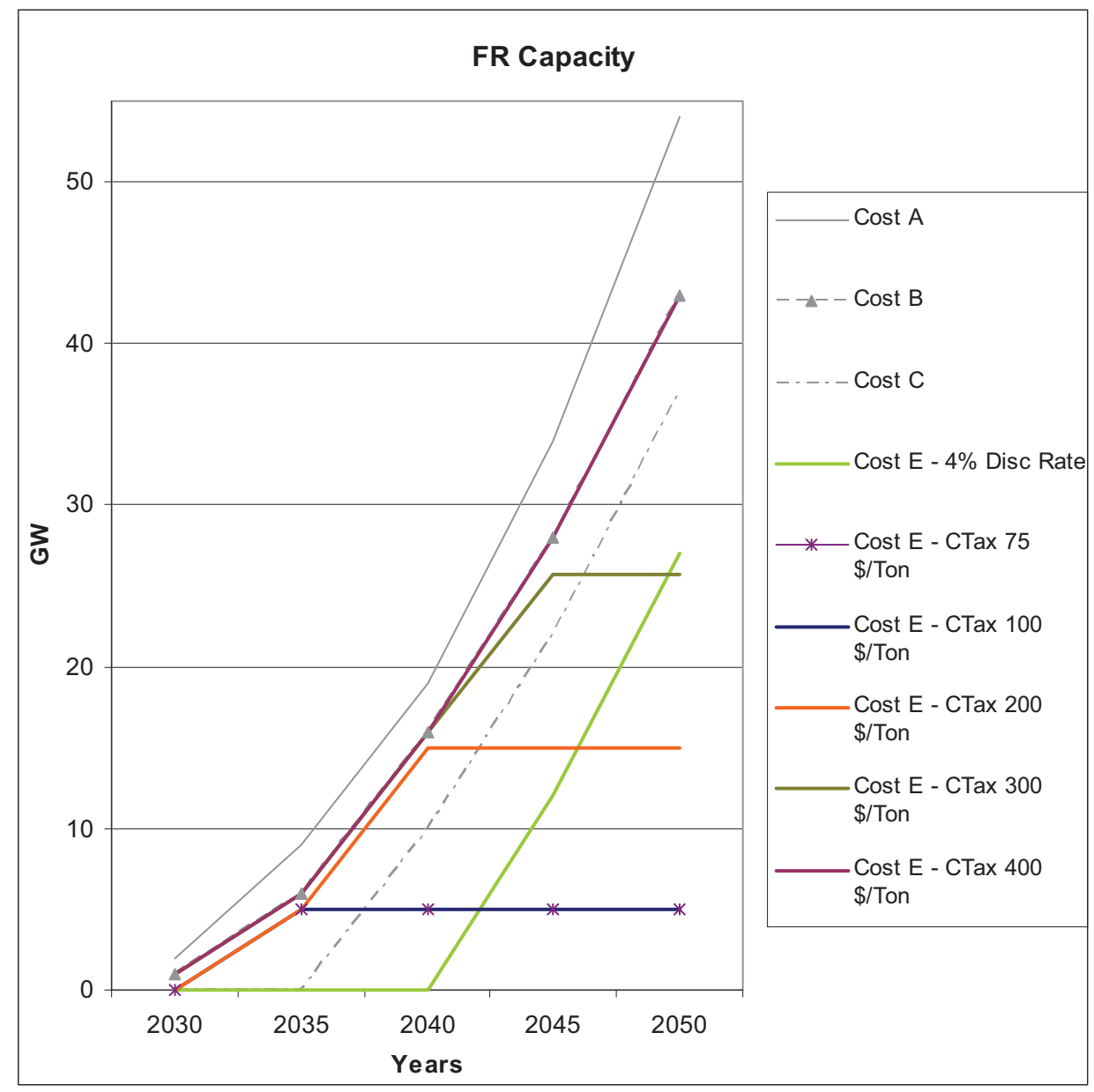

Figure 8. Fast Reactor capacity in alternative scenarios. 


\section{GLOBAL NUCLEAR ENERGY DEMAND}

\subsection{The ETP Global MARKAL Model}

The primary tool used to project the worldwide market deployment of nuclear technologies in this study is the IEA ETP model (IEA 2006). The model is a global 15-region version of the MARKAL modeling framework, developed specifically to assess the deployment of new energy technologies in the world market place. The 15 regions are: Africa, Australia/New Zealand, Canada, China, Rest of Asia, Eastern Europe, Former Soviet Union, India, Japan, Middle East, Mexico, Latin America, South Korea, United States, and Western Europe. These regions are linked via international markets for trade on energy products, materials, and carbon. The ETP Global Baseline Scenario used in this project was developed by extending the World Energy Outlook 2005 Reference Scenario from 2030 to 2050 (IEA 2005). The ETP Baseline Case includes the effects of technology developments and improvements in performance (e.g., efficiency and cost) that can be expected based on government policies already enacted. At this time, the ETP MARKAL model does not have specific markets for trade of nuclear materials (fuel and spent fuel), nor does it have the AFCI fuel cycle specified in its 15 regional reference energy systems.

\subsection{Regional Electricity Markets for Nuclear Energy}

Within each ETP region, the demand for nuclear reactors, among other competing technologies, is derived independently by the region's projected electricity demand. The key drivers for these regional electricity demands are GDP and population growth. Tables 9 and 10 depict these growth rates, which serve as the basis for developing growth rates for the 15 ETP regions.

Table 9. Annual GDP growth rate by region-Energy Technology Perspectives Baseline.

\begin{tabular}{|l|c|c|c|c|}
\hline & $1971-2003$ & $2003-2030$ & $2030-2060$ & $2003-2050$ \\
\hline OECD & 2.9 & 2.2 & 1.3 & 1.8 \\
\hline OECD North America & 3.1 & 2.4 & 1.8 & 2.1 \\
\hline OECD Europe & 2.4 & 2.1 & 0.7 & 1.5 \\
\hline OECD Pacific & 3.5 & 2.0 & 1.8 & 1.8 \\
\hline Transition Economies & 0.7 & 3.7 & 3.4 & 3.6 \\
\hline Developing Countries & 4.7 & 4.3 & 3.5 & 3.9 \\
\hline China & 8.4 & 5.0 & 3.8 & 4.5 \\
\hline India & 4.9 & 4.7 & 3.6 & 4.2 \\
\hline Other Asia & 5.2 & 4.1 & 3.1 & 3.7 \\
\hline Middle East & 2.9 & 3.0 & 2.9 & 3.0 \\
\hline Latin America & 2.9 & 3.2 & 2.8 & 3.0 \\
\hline Africa & 2.7 & 3.8 & 3.6 & 3.7 \\
\hline World & 3.3 & 3.2 & 2.6 & 2.9 \\
\hline Source: IEA 2006. & \multicolumn{3}{l}{} \\
\hline
\end{tabular}


Table 10. Annual population growth rate by region-Energy Technology Perspectives Baseline.

\begin{tabular}{|l|c|c|c|c|}
\hline & $1971-2003$ & $2003-2030$ & $2030-2060$ & $2003-2050$ \\
\hline OECD & 0.8 & 0.4 & -0.2 & 0.1 \\
\hline OECD North America & 1.3 & 0.9 & 0.5 & 0.7 \\
\hline OECD Europe & 0.5 & 0.1 & -0.9 & -0.3 \\
\hline OECD Pacific & 0.8 & 0.0 & -0.2 & -0.1 \\
\hline Transition Economies & 0.5 & -0.3 & -0.1 & -0.2 \\
\hline Developing Countries & 2.0 & 1.2 & 0.9 & 1.1 \\
\hline China & 1.4 & 0.4 & 0.1 & 0.3 \\
\hline India & 2.0 & 1.1 & 0.5 & 0.9 \\
\hline Other Asia & 2.1 & 1.3 & 0.9 & 1.1 \\
\hline Middle East & 3.1 & 1.9 & 2.0 & 1.9 \\
\hline Latin America & 1.9 & 1.0 & 0.7 & 0.9 \\
\hline Africa & 2.7 & 1.9 & 1.8 & 1.9 \\
\hline World & 1.6 & 1.0 & 0.7 & 0.9 \\
\hline Source: IEA 2006. & & & \\
\hline
\end{tabular}

The IEA used the above mentioned indicators along with other references to project the demand for energy services. These services (alternatively called service demands) drive the energy and electricity required for each region in ETP MARKAL. Table 11 depicts the projected electricity demand by region.

Table 11. Projected world electricity demand—Energy Technology Perspectives Baseline (Billion $\mathrm{kW} \cdot \mathrm{hr}$ ).

\begin{tabular}{|c|c|c|c|c|c|c|c|}
\hline Region & & & & & & & $2000-2050$ \\
\hline & 2000 & 2010 & 2020 & 2030 & 2040 & 2050 & AnnualGrowth \% \\
\hline Africa & 423 & 468 & 550 & 642 & 795 & 996 & 1.73 \\
\hline Australia \& New Zealand & 231 & 280 & 499 & 591 & 752 & 1233 & 3.40 \\
\hline Canada & 577 & 651 & 677 & 808 & 899 & 973 & 1.05 \\
\hline China & 1384 & 2199 & 3190 & 4026 & 5488 & 7517 & 3.44 \\
\hline Rest of Asia & 740 & 1011 & 1311 & 1823 & 2593 & 3769 & 3.31 \\
\hline Eastern Europe & 169 & 276 & 458 & 692 & 821 & 1006 & 3.63 \\
\hline FormalSoviet Union & 488 & 1225 & 1590 & 1349 & 1215 & 1400 & 2.13 \\
\hline India & 635 & 825 & 1326 & 1929 & 2789 & 4001 & 3.75 \\
\hline Japan & 1025 & 1088 & 1255 & 1472 & 1723 & 2082 & 1.43 \\
\hline Middle East & 442 & 496 & 678 & 782 & 927 & 1026 & 1.70 \\
\hline Mexico & 203 & 239 & 291 & 368 & 449 & 557 & 2.04 \\
\hline Latin America & 629 & 774 & 971 & 1203 & 1482 & 1763 & 2.08 \\
\hline South Korea & 252 & 352 & 494 & 659 & 751 & 819 & 2.39 \\
\hline United States & 3655 & 4363 & 5130 & 6206 & 6776 & 7678 & 1.50 \\
\hline Western Europe & 2634 & 3185 & 3620 & 4243 & 4598 & 4654 & 1.15 \\
\hline Total World & 13486 & 17430 & 22041 & 26793 & 32059 & 39474 & 2.17 \\
\hline
\end{tabular}




\subsection{Global Deployment of Nuclear Technologies}

With some updates to the ETP MARKAL database developed at IEA, the model produced the global deployment of advanced nuclear reactors for the period 2000-2050. The following updates to the ETP database were necessary to reflect recently completed or ongoing activities in nuclear power plant construction and redirected government policies:

1. The ETP model used 2000 as the base year to project energy activities for the period 2005-2050. As a result, the model's projection on the construction of nuclear power plants in its least-cost solution before 2015 does not reflect the actual projects, completed, ongoing, or on order between 2000-2010. This discrepancy was corrected by using the actual activities in nuclear power plant construction (worldwide) reported in the latest Nuclear News (ANS 2007) for this period, as exogenous input to ETP.

2. The projected nuclear energy activities in the ETP Base Case follow closely the trend assumed in the EIA 2005 Annual Energy Outlook: a gradually declining capacity to $90 \mathrm{GW}$ in 2050. To ensure ETP's solution for future nuclear market in the U.S. Region to be consistent with that of the U.S. MARKAL, critical input data based on Department of Energy (DOE), Office of Nuclear Energy (NE) Government Performance Results Act of 1993 (GPRA) analysis (Bhatt, et al. 2006) and the sample AFCI case (McCarthy 2007), were used to update the ETP Base Case.

\subsection{A Three-Region Case Study}

The three-region case study is a simplified example that illustrates how inter-regional arrangements under AFCI can affect the U.S. nuclear industry. The ETP MARKAL model was used for this study. The three regions selected consist of the U.S., and both a large and a small receiver region. The test arrangement assumes that the both the large and small regions will send their thermal spent fuel to the U.S. for reprocessing. In return, the U.S. will supply the estimated fresh fuel needed in those two regions. In ETP MARKAL, this arrangement can be modeled as a market for trading nuclear fresh and spent fuels for the three specific regions. For this case study, these transactions were "soft linked" by specifying the fresh fuel to the two regions as exports from U.S. MARKAL and the spent fuels from the selected large and small regions as imports to U.S. MARKAL. This test scenario quantified the increased availability of thermal spent fuel for the U.S. fuel cycle and the increased demand for U.S. fresh fuel as compared to the U.S.-only sample AFCI case. By comparing these results, the impact of the specified inter-regional fuel arrangement on the U.S nuclear economy was estimated.

\subsubsection{Projected Nuclear Capacity and Fuel Demand in Receiving Regions}

The combined demand for nuclear reactors projected in ETP MARKAL for the two receiving regions increases from below $2 \mathrm{GW}$ in 2015 to almost $20 \mathrm{GW}$ in 2050 (see Figure 9). This increment leads to an increase in fresh fuel demand from about 3 metric tons to 40 metric tons in the corresponding years (see Figure 10). 


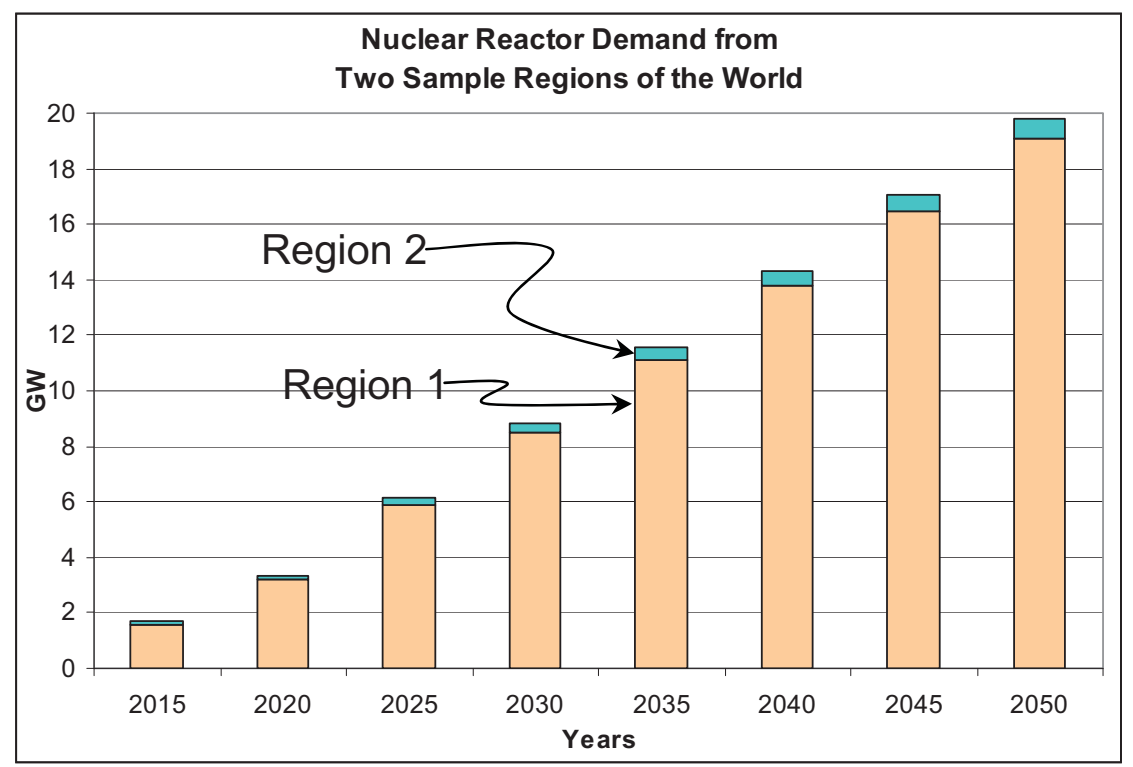

Figure 9. Nuclear reactor demand from two sample regions of the world.

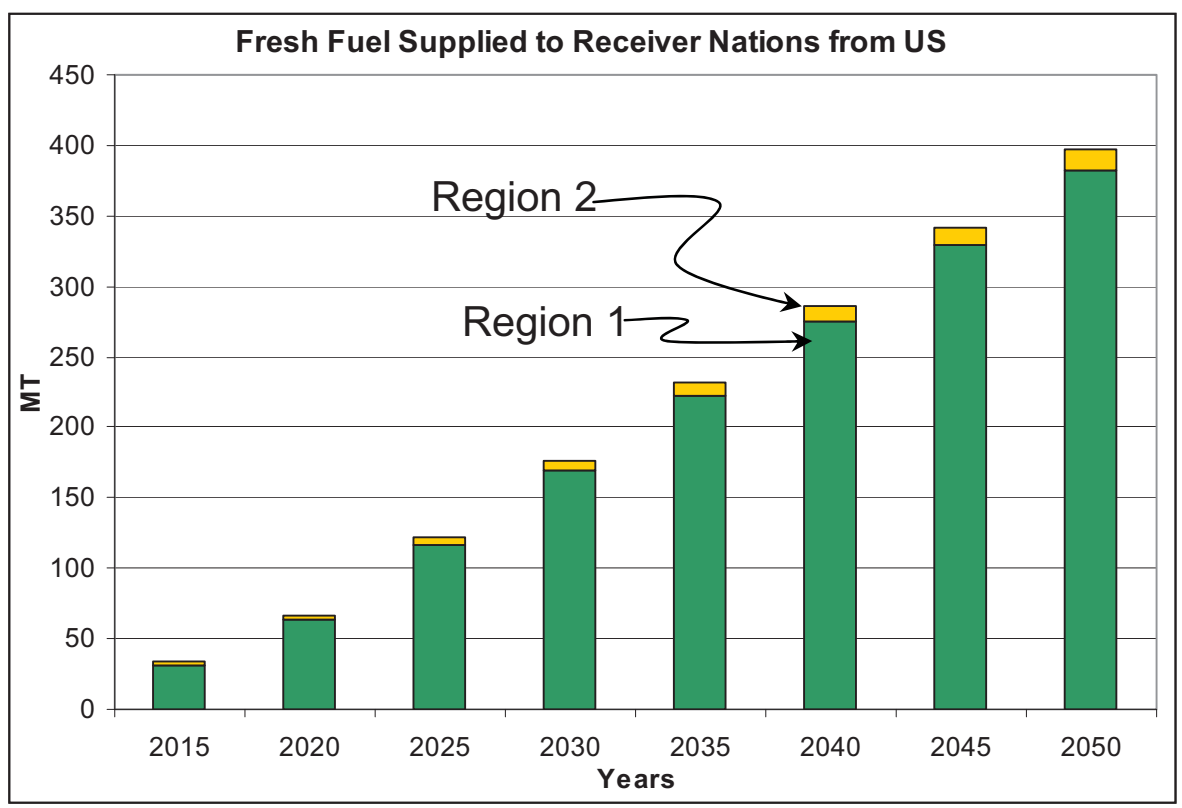

Figure 10. Fresh fuel supplied to receiver nations from U.S.

\subsubsection{Impact on U.S. Fresh Fuel Supply Market}

The shipment of fresh fuel from U.S. to the two receiving regions under the test arrangement requires the U.S. to increase its fresh fuel output (see Figure 11). This increase, however, is partially offset by the reduced domestic need in fresh fuel due to the increased activity in fuel recycling triggered by the spent fuel coming back from the receiving regions (not modeled here). 


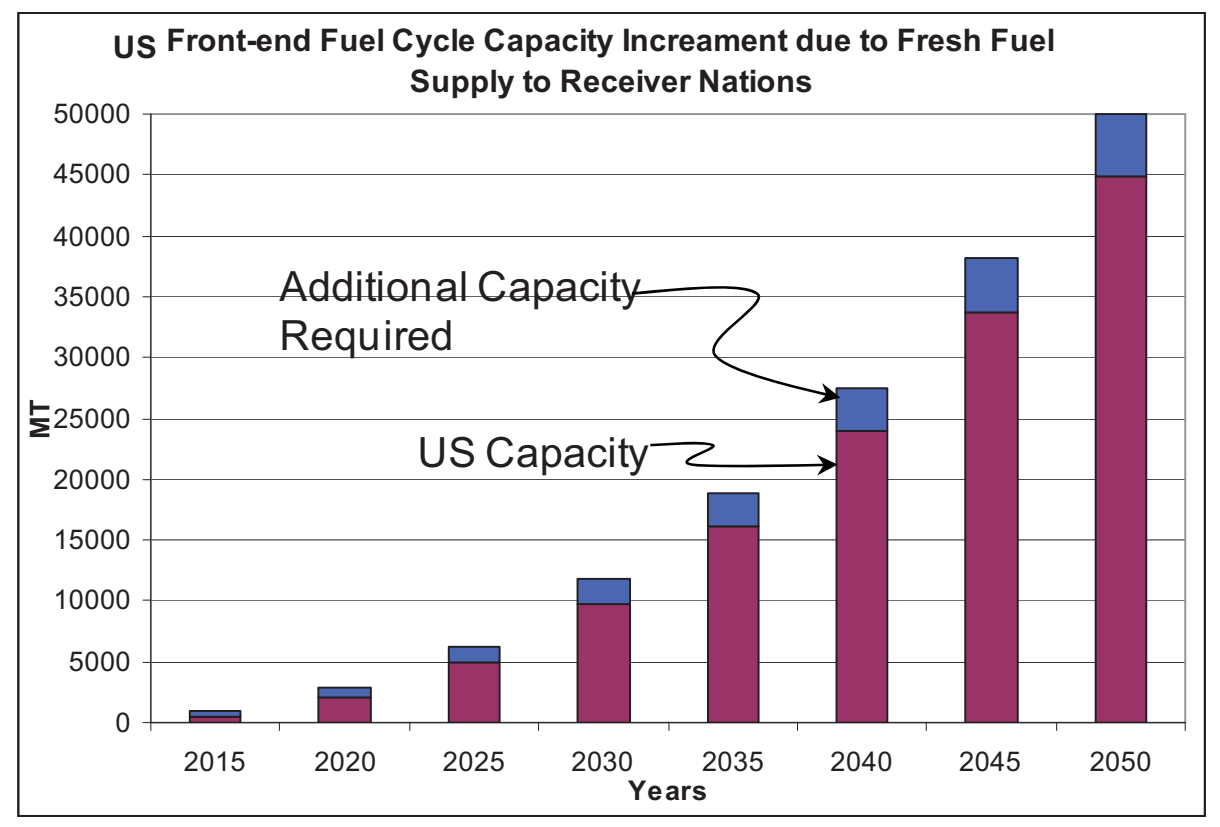

Figure 11. Front-end fuel cycle capacity increment in U.S.

\subsubsection{Impact on U.S. Fast Reactor Technology Deployment}

The spent fuel shipped back to the U.S. leads to an increase in U.S. fuel recycling capacity and the capacity of the FR to use the recycled fuel. The MARKAL model offers an option to store the spent fuel in a geological repository, which is evaluated to be economically inefficient compared to recycling. Figure 12 depicts the projected increased capacity of FRs in the U.S. under the three-region fuel arrangement as compared to the capacity in the sample AFCI case (McCarthy 2007) alone.

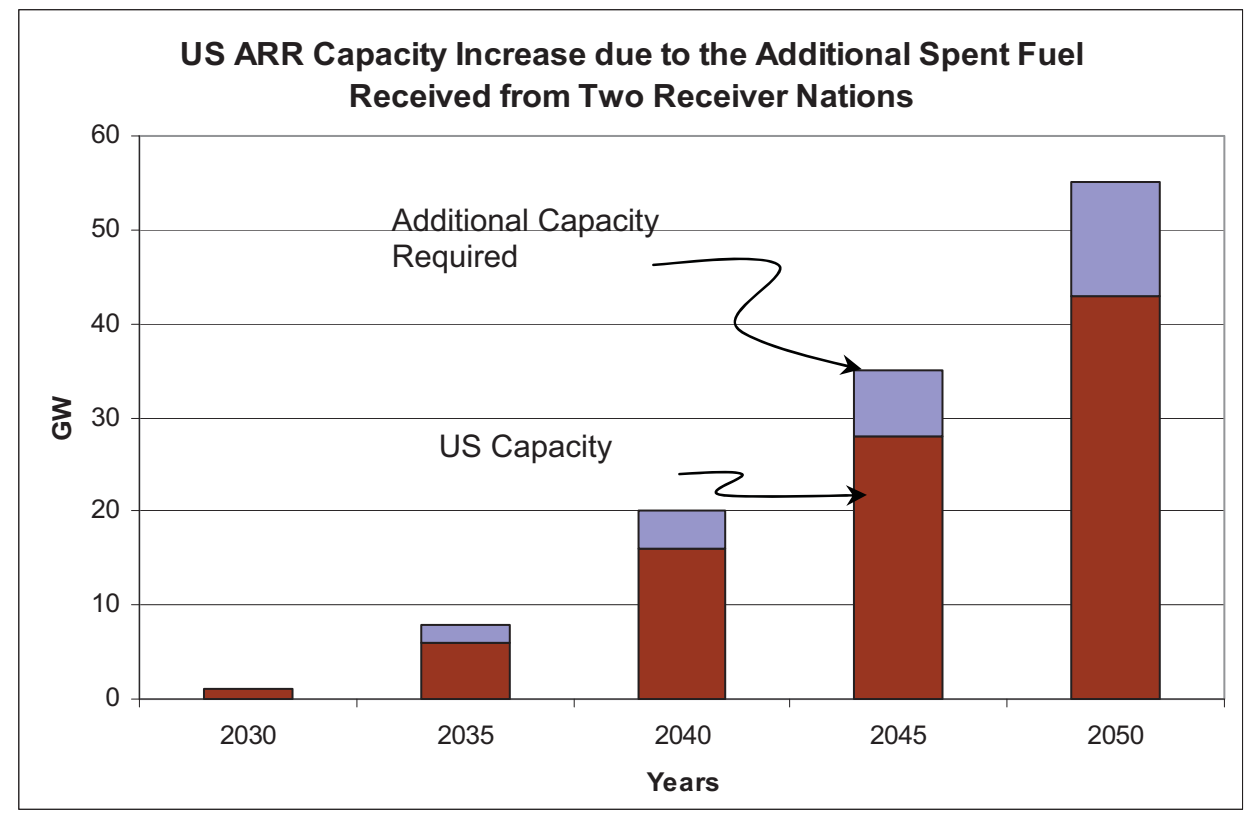

Figure 12. U.S. Fast Reactor capacity increase due to the additional spent fuel received from two receiver nations. 


\section{UNCERTAINTIES: FACTORS AFFECTING THE MARKET DEPLOYMENT OF NUCLEAR TECHNOLOGIES}

In any long-run scenario that sets assumptions for the market deployment of a new technology, there are inherent uncertainties associated with the underlying factors that could significantly affect the actual outcomes. The penetration of nuclear power in the electricity market is dependent on a number of such factors. Some are related to the competitiveness of nuclear technologies themselves, such as reactor capital, operating costs, and fuel-cycle costs. Others are market-driven, such as the overall demand for electricity, fuel prices, costs of competing generation technologies, and government policies. These factors may, and probably do, vary over time as well.

The following is a brief discussion of some of these factors, and how they impact the deployment of nuclear power in the MARKAL models.

\subsection{Per Capita Income and Electricity Demand}

In MARKAL, demand for energy is derived from demand for energy services. Energy services can be described as demands that require service output of end-use devices to satisfy, such as square feet of space to be heated, lumens of light per household or vehicle miles traveled. Service demands do not specify the quantity and specific fuel type required. The MARKAL model uses energy services as the drivers to determine the least-cost fuel mix and mix of technology choices over time.

The overall level of energy services is determined by a number of factors, such as economic activity (GDP), population growth and the resulting consumer demand. Consumer demand increases as per capita income (GDP/population) increases. Income elasticity (\% change in energy service / \%change in income) expresses how per capita income affects energy services. For energy services primarily dependent on electricity, their long-term income elasticities are very elastic, ranging from about 0.7 in developed countries to over 1.0 in many developing regions (Bose and Shukla 1999, von Hirschhausen and Andres 2000). Both GDP and population are the primary drivers to project energy service demands in the U.S.MARKAL (EIA 2006) and ETP-MARKAL (IEA 2006, IEA 2005). Alternative assumptions on these underlying parameters from the "business as usual" scenario ${ }^{\mathrm{b}}$ would significantly change the projected levels of energy services that are dependent on electricity. The higher the level of these service demands, the larger the size of the electricity demand market to satisfy them.

In MARKAL, the size of the projected electricity market over the period of interest is clearly an important determinant of the future deployment of nuclear power. The size of the electricity market and the nuclear share of that market are determined simultaneously in the model, based on cost minimization of the entire energy market, of which the electricity market is a subsector, to meet the exogenous energy service demands. Therefore, if the electricity demand increases, as a result, the nuclear supply of electricity will increase to meet partially that additional demand. For example, as shown in ETPMARKAL results (IEA 2006), a 14\% increase in total electricity demand in 2050 would lead to an increase of $9 \%$ for nuclear power capacity in the same year.

\subsection{Relative Energy Prices}

In the energy market, relative energy price changes lead to substitution of more expensive fuel by less expensive fuel to meet energy service demands.

\footnotetext{
b. The description of the growth in energy services and energy demand over time described in the documents above is based on the estimation of the respective authors of the documents that this is a most likely future, based on existing laws and regulations and expected improvements in technology. These are the reference "business as usual" scenarios used in U.S. MARKAL and ETP, against which the impacts of alternative future technology and economic assumptions are assessed.
} 
In both U.S. MARKAL and ETP-MARKAL, the demands for energy services (lighting, passenger travel, etc.) are exogenous input to the models, and therefore, are not affected by change in energy prices. Within the models, as relative energy supply costs change, the models will select the most cost-effective portfolio of technologies to meet specific energy or service demands (e.g. electricity generation technologies to meet electricity demands).

Nuclear power is used for base load electricity generation. This is reflected in the fact that in the U.S. MARKAL runs, it was observed that the market deployment rate of nuclear power is more sensitive to coal price changes than those of oil and gas. This is because for oil, the use of oil is insignificant and expensive in electricity generation, and therefore, its scope of substitution is very limited. For gas, the gas-fired generators (e.g., combined cycle) are more flexible, are used to meet peak power demands, and therefore, require less stand-by or reserve capacity. For coal on the other hand, coal price increases the generation costs of advanced coal technologies used for base load that compete directly with nuclear reactors.

\subsection{Technological Innovation and Improvement}

The pace of technological innovation and improvement associated with an electricity generation technology affects its cost in generating electricity, and hence, its market competitiveness. Projections of the technological mix in meeting future electricity demand are, therefore, very sensitive to assumptions on an individual technology's characteristics, which include capital and operating costs, efficiency, operating life, emissions and wastes generated, and the improvement in these characteristics over time. The characteristics of each competing technology relative to each other must be consistent for the market selection process to work properly as well.

In ETP-MARKAL, the "Technology Plus" Scenario (IEA 2006), where cost reduction in nuclear technologies is assumed relative to the baseline costs for competing technologies, shows a $130 \%$ increase in global electricity generation by nuclear power by 2050 as compared to the baseline generation.

\subsection{Carbon Emission Constraints}

The market deployment of nuclear technologies is very sensitive to the level of constraint on carbon emissions. A cap on carbon emissions implies a cost penalty on electricity-generating technologies that emit carbon, thus increasing the relative cost of these technologies relative to zero carbon-emitting technologies, such as nuclear generation. In U.S. MARKAL for DOE NE GPRA analysis, the nuclear market expands under a "Carbon Cap" scenario (Bhatt, et al. 2006).

\subsection{Government Policy and Measures}

Government policies and measures, such as taxes and subsidies, directly impact the deployment of nuclear technologies through increased R\&D support, and from financial incentives in the nuclear economy to accelerate the learning curve and to reduce the costs of construction and operation.

The MARKAL models can facilitate these types of analyses by converting government policies into technology cost penalties and/or benefits and then re-examining the market penetration of nuclear technology. By providing the results of such analyses in a quantitative, transparent, and well-documented format, governments can assist the nuclear industry to reduce public concerns about the costs and benefits of nuclear power, waste disposal options, and the risks of nuclear proliferation. 


\subsection{Success in Program R\&D}

The implication of uncertainty regarding the success of AFCI research and development (R\&D) efforts is an important factor affecting the actual outcome of the technologies' deployment. Even wellconceived R\&D programs are unlikely to have a $100 \%$ success rate. To address these inevitable failures or delays relating to specific AFCI R\&D targets would require the use of the stochastic version of MARKAL, a task not possible under the current project schedule and resources.

\section{INTEGRATION AND INTERCONNECTION OF BNL WORK WITH OTHER ATTACHMENTS IN THE METHODOLOGY REPORT}

The work described in this attachment provides an energy market perspective to examine nuclear and AFCI technologies. Due to the higher-level and integrated examination of the role of AFCI in the overall energy market over time, the BNL methodology and analysis can receive information from the more specific analyses described in the other attachments, as well as provide information to these studies. The following is a summary of the potential interconnections with the work described in the other attachments.

Attachment B: Comparison of Nuclear to Future New Electricity Generation Alternatives

The BNL analysis employs both a domestic and a global integrated energy, environmental, and economic model. The ultimate determination of penetration of nuclear technology in the marketplace over time requires the use of technical and cost information for the electricity generation technologies that compete with nuclear for market share. The data used in this analysis for competing technologies are provided in Table 2 of this attachment. As with any technology characterization, market penetration is impacted by numerous external and qualitative factors, some of which are described in Section 4 of this attachment. Attachment B provides additional discussion of some of these issues, mostly relating to the characterization of cost and technical data for competing technologies.

The BNL analyses can draw on these insights in the future to update the costs and technical parameters of competing technologies as new information is developed.

Attachment C: Achieving Non-Proliferation Objectives in AFCI-Cost Considerations and Trade-offs

At present, the non-proliferation work presented in Attachment $\mathrm{C}$ is concentrating on the economic cost impacts of some non-proliferation measures contemplated for individual new nuclear facilities.

In the future, the work described in this attachment could incorporate these costs and analyze relative proliferation indices in an overall energy market approach. An initial example of such an approach was presented at the International Energy Workshop organized at Stanford University in June 2007 (Reisman, et al. 2007).

Attachment D: Nuclear Materials Exchange (NME) Database Description and Methodology

The Nuclear Materials Exchange, a global database and analytical tool, provides information on existing and planned nuclear facilities, including information on nuclear materials.

In the future, the ETP model could iterate interactively with the NME by providing nuclear technology growth profiles and receiving technology/facility parameters for the global ETP analyses. 


\section{Attachment E: Uranium Resource Model}

In MARKAL the energy resources are represented by time-dependent supply curves. In the future, the BNL work can utilize information developed with the Uranium Resource model to describe more detailed uranium supply curves.

In addition, a MARKAL solution can provide a marginal price forecast of uranium under the specified market conditions. In the future, this capability could be used to crosscheck uranium resource forecasts from the Uranium Resource model.

Attachment G: The Cost Economics of Advanced Nuclear Power Technologies With Application to Modular Sodium Fast Recycling Reactors

First of a Kind-Nth of a Kind (FOAK-NOAK) costs are important when examining the potential market for new technologies. The MARKAL model assumes technology costs for each period over the timeframe of the analysis, based on best available information on the pattern of assumed technology costs over time.

In future work, technology learning factors derived from the FOAK-NOAK analysis can provide the basis for the development of detailed learning curves.

At present, the ETP global model contains nuclear technology information, including costs, for existing LWRs and advanced LWRs, for 15 global regions.

In future work, a more detailed nuclear fuel cycle could be added, including information from the analysis of international costs of certain nuclear facilities.

\section{Attachment H: VISION Economic (VISION.ECON) Sub-Model Description and Methodology}

VISION.ECON provides detailed analysis of deployment of nuclear and AFCI technologies and the resulting material flows over time. The MARKAL market deployment analysis in contrast provides the estimated demand growth for nuclear technologies over time under alternative market and policy assumptions. The methodology can provide the context of a broader setting in which to place the detailed descriptions provided by VISION for AFCI deployment. BNL work can also take nuclear growth profiles proposed by VISION.ECON as input to the MARKAL analyses and evaluate options for market deployment of nuclear and AFCI technologies. The BNL work can assess economic strategies and financial plans required to sustain desired market share of AFCI technologies. Economic uncertainties can be examined by defining and running alternative scenarios.

The BNL methodology can be used in future work to assess alternative nuclear futures, including but not limited to AFCI technologies, within the overall energy market. These analyses can examine the market penetration of nuclear technologies under many economic, environmental and policy assumptions, including taxes and subsidies, carbon constraints, different cost assumptions, etc. The resulting demand growth profiles can then be provided to VISION for more detailed analysis. The global MARKAL model, ETP, could be expanded to examine nuclear deployment and materials and equipment exchange under alternative economic and policy assumptions. The impacts of these scenarios on the deployment of nuclear technologies in the U.S. could then be examined by VISION.ECON.

Attachment I: The Static Analysis and Uncertainty Analysis Toolbox for the Spreadsheet Economic Evaluation of AFCI/AFCI Reactor/Fuel Cycle Scenarios

The G4 ECONS methodology examines in some detail the costs to build and operate an electric power generation facility. These costs are then annualized with a discount rate supplied by the analyst. 
The MARKAL costs are taken from referenced sources in DOE, and developed entirely separately. The two methodologies can be used to crosscheck the costs of competing electric generation technologies.

\section{OPPORTUNITIES AND CHALLENGES: SOME INSIGHTS FROM MARKAL MODELING}

The scenarios analyzed with the MARKAL model were intended to examine the effects of uncertainties in costs, and of energy policies such as a carbon tax, on the deployment of AFCI technologies in a future energy market. Based on the initial results obtained, it was observed that under the assumed baseline assumptions in the energy market described in Sections 2.3 and 2.4, further reduction in the overall cost of AFCI technologies is needed to bring them to the market on a competitive basis. Quantitatively, the level of reduction required is equivalent to a reduction in the discount rate from $10 \%$ to $4 \%$ for these technologies. How to achieve this reduction through various forms of government incentive programs, or what the cost reductions would need to be to be competitive under these assumptions, will require additional analysis.

One policy that favors deployment of AFCI technologies is to institute a cost penalty for carbon production. When a carbon tax is imposed on the energy system, the results from MARKAL runs show that AFCI technologies become more competitive as the carbon tax rate increases. A carbon tax increases the relative price of fossil fuels produced energy and hence, the cost of electricity generated from fossil fuel-based technologies. As future increase in AFCI's capacity is very sensitive to the market conditions created by an increase in the cost of using fossil fuel, a carbon tax can be expected to encourage increased AFCI deployment in the energy market.

To study the global impact of AFCI on inter-regional transfer of nuclear technologies and their associated materials flow requires the use of a multi-regional model representing the world's future nuclear energy market. The three-region case study using the ETP MARKAL model demonstrated MARKAL's capability to project the regional nuclear energy demand based on each region's economic and energy market characteristics. These characteristics drive the demand for nuclear fuel and the resulting generation of spent fuel for each region. "Soft-linking" the nuclear materials flow of these regions to the U.S. MARKAL model shows the impact under a specific fuel arrangement on the future U.S. nuclear industry in terms of increased AFCI capacity and fresh fuel fabrication. The future challenge here is to expand this three-region experience to cover the 15-region global market represented in the ETP MARKAL in order to capture AFCI's worldwide impact under various international agreements in the global energy marketplace.

The modeling effort and results obtained in this study represent a first yet necessary step in building a basis for evaluating the future market potential and significance of AFCI technologies. It also identifies some market conditions, impediments, government policies, and critical parameters that directly impact the market deployment path of AFCI-related technologies. To this end, the study has laid the foundation for future work in this area.

\section{THE PATH FORWARD FOR MARKAL ANALYSIS}

The work described in this attachment has laid the foundation for examining the role of nuclear energy and the nuclear fuel cycle, including AFCI technologies, in the overall energy marketplace. The analysis includes both the U.S. energy market using the MARKAL model, the global energy market using the MARKAL variant, and the ETP model. The path forward for MARKAL market analysis is described briefly below. 


\subsection{Future U.S. MARKAL Analysis}

- Assist the AFCI Systems Analysis to estimate and document demand for nuclear energy under alternative market conditions and energy policies. Examine nuclear generation and nuclear fuel cycle and long-term storage options, including the advanced fuel cycle (AFC), fast reactor (FR), AFCIrelated technologies, and nuclear hydrogen technologies.

- Evaluate scenarios to examine AFCI competitiveness under alternative polices for taxes, subsidies, and other government mechanisms. Estimate the net cost to the government under each alternative.

- Identify cost impediments to market deployment of selected AFCI, AFC and nuclear hydrogen technologies, and fuel cycles (e.g., IMF and MOX recycling, alternate burnup rates, conversion ratios, hydrogen production).

- Evaluate alternative scenarios, including cost ranges and carbon-constrained future, where a defined set of fuel-cycle technologies and reactors will penetrate the market. Employ AEO 2007 assumptions with updated fuel and technology parameters, including higher natural gas and oil prices.

- Integrate and iterate information developed under other AFCI Systems Analysis work packages, including VISION.ECON, G4ECONS, nuclear comparison studies, uranium resources, reactor technologies, and other fuel cycle activities.

\subsection{Future Global Analysis with ETP}

- Utilize ETP's capabilities of analyzing global energy market with inter-regional commodity trade to evaluate the potential of existing and advanced nuclear fuel cycle technologies in the global energy marketplace, including AFCI, other alternative fuel cycles, and nuclear hydrogen technologies.

- Define and incorporate a more detailed nuclear fuel cycle technology database for 15 world regions by modeling detailed fuel cycle technologies/facilities, commodities, market linkages, and constraints from the information provided by the Nuclear Materials Exchange database (NME), the IEA, the OECD, other information developed under AFCI Systems Analysis work packages, including VISION.ECON, G4ECONS, nuclear comparison studies, uranium resources, reactor technologies, and other fuel cycle activities.

- Examine the impact of selected global nuclear scenarios on the overall deployment of nuclear facilities in the world, supply and demand mechanisms of nuclear fuel (fresh and spent), and technologies in the world energy market, specifically in the U.S. nuclear market.

- Assess the potential of reducing greenhouse gas emissions by deploying nuclear technologies in the world energy market.

\section{REFERENCES}

ANS, 2007, "Nuclear News," 9th Annual Reference Issue, American Nuclear Society, March 2007.

Bhatt, V.; Friley, P.; Lee, J.; Reisman, A., 2006, "Prospective Benefits Analysis of the DOE Nuclear Energy Portfolio (GPRA 2008 Cycle): NE R\&D Program Data Assumptions, Approach, \& Results," a report submitted to the Office of Nuclear Energy, the Department of Energy, October 31, 2006.

Bose, R. K. and M. Shukla, 1999, "Elasticities of Electricity demand in India", Energy Policy, Volume 27, Issue 3, pp. 137-146, March 1999.

CBO, 2005, “The Long-Term Budget Outlook,” Congressional Budget Office, October 2005.

Clarke, L., J. Edmonds, H. Jacoby, H. Pitcher, J. Reilly, R. Richels, 2007, Scenarios of Greenhouse Gas Emissions and Atmospheric Concentrations, Sub-report 2.1A of Synthesis and Assessment Product 
2.1 by the U.S. Climate Change Science Program and the Subcommittee on Global Change Research, Department of Energy, Office of Biological \& Environmental Research, Washington, DC., USA, 2007.

Dinan, T. and Shackleton, R. 2005. Limiting Carbon Dioxide Emissions: Prices Versus Caps, Economic and Budget Issue Brief, A series of issue summaries from the Congressional Budget Office, March 15, 2005, http://www.cbo.gov/ftpdocs/61xx/doc6148/03-15-PriceVSQuantity.pdf, Web page accessed August 2007.

EIA, “Annual Energy Outlook-2006 (AEO),” Energy Information Administration, Department of Energy, February 2006.

Energy Information Administration, 2004, U.S. Nuclear Reactor List-Operational, http://www.eia.doe.gov/cneaf/nuclear/page/nuc reactors/operational.xls, Web page accessed June 2007.

Fishbone, L. and H. Abilock, 1981, “A Linear Programming Model for Energy Systems Analysis: Technical Description of the BNL Version," Energy Research, Volume 5, pp. 369-379, 1981.

IEA, 2005, “World Energy Outlook," International Energy Agency, OECD/IEA, Paris, France, 2005.

IEA, 2006, "Energy Technology Perspectives, 2006-Scenarios \& Strategies to 2050," International Energy Agency, OECD/IEA, Paris, France, 2006.

IPCC, 2007, Summary for Policymakers, In: Climate Change 2007: Mitigation. Contribution of Working Group III to the Fourth Assessment Report of the Intergovernmental Panel on Climate Change (B. Metz, O.R. Davidson, P.R. Bosch, R. Dave, L.A. Meyer [eds.]), Cambridge University Press, Cambridge, United Kingdom and New York, NY, USA, 2007.

Loulou, R., G. Goldstein, and K. Noble, 2004, "Documentation for the MARKAL Family of Models," Energy Technology Systems Analysis Program, International Energy Agency, October 2004.

McCarthy, K., 2007, "Systems Analysis Scenario Studies," the Systems Analysis Working Group meeting held March 14-15, Washington D.C, 2007.

Nordhaus, W., 2006. After Kyoto: Alternative Mechanisms to Control Global Warming, (Silver City, New Mexico and Washington, DC: Foreign Policy In Focus, March 27, 2006), http://www.fpif.org/fpiftxt/3167, Web page accessed August 2007.

Reisman, A.; Lee, J.; Bhatt, V.; Todosow, M., 2007, “An Integrated Framework to Evaluate Market Deployment and Potential for Proliferation Resistance," The International Energy Workshop 2007, Stanford, California, June 25-28, 2007.

Shropshire, D.; Williams, K.; Boore, W.; Smith, J.; Dixon, B.; Dunzik-Gougar, M.; Adams, R.; Gombert, D., 2007, Advanced Fuel Cycle Cost Basis, INL/EXT-07-12107, April 2007.

SSA, The 2005 Annual Report of the Board of Trustees of the Federal Old-Age and Survivors Insurance and Disability Insurance Trust Funds, Social Security Administration, p. 97, March 2005,

Stocks, K. J., 1984. "Discount Rate for Technology Assessment: An Application to the Energy Sector, Energy Economics," Volume 6, Issue 3, pp. 177-185, July 1984.

von Hirschhausen, C. and M. Andres, 2000, "Long-Term Electricity Demand-From Quantitative to Qualitative Growth?” Energy Policy, Volume 28, pp. 2313-241, 2000. 
A-38

INL/EXT-09-15483 


\section{Attachment B}

\section{Comparison of Nuclear to Future New Electricity Generation Alternatives}

Robert Cherry and David Shropshire

Idaho National Laboratory 
B-2

INL/EXT-09-15483 


\begin{abstract}
This attachment describes and compares the challenges of future non-nuclear electricity generation options in regards to development and commercialization, costs, and environmental compliance. The decision to build new nuclear power generation facilities will not be made solely on the pros and cons of nuclear technology itself, but also on how those factors compare among the alternatives to nuclear energy. A range of new fossil and renewable energy technologies are now being demonstrated and will likely be commercially feasible choices in the near future. Fossil energy, particularly coal, will be the major alternative to nuclear power. However, fossil energy has its own issues with demonstrating the next generations of advanced technology, high capital costs, price volatility, and $\mathrm{CO}_{2}$ emissions. The tradeoff between relative pros and cons of nuclear versus fossil power will be based on local circumstances. The likelihood of unforeseen changes in fuel costs, fuel supply, or required environmental performance appears to be greater for fossil-powered plants. Cogeneration and poly-generation of multiple forms of energy (electricity, heat, hydrogen, or shaft work) in one plant from multiple sources of energy may be useful in addressing some of nuclear and fossil energy's issues.
\end{abstract}


B-4

INL/EXT-09-15483 


\section{CONTENTS}

ABSTRACT

ACRONYMS

1. ALTERNATIVE FUEL SOURCES FOR NEAR TO INTERMEDIATE TERM

CAPACITY EXPANSION

2. FOSSIL-FUELED ELECTRICAL GENERATION TECHNOLOGIES.....

3. FOSSIL ENERGY DEVELOPMENT AND COMMERCIALIZATION ISSUES ....

B-11

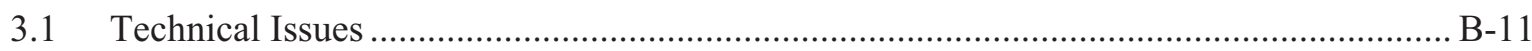

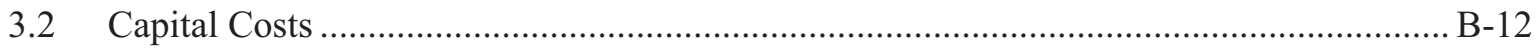

3.3 Future Fuel Costs and Availability ...................................................................... B-16

3.4 Carbon Dioxide and Other Emissions ........................................................................... B-17

4. INTEGRATION OF NEXT GENERATION NUCLEAR WITH OTHER ELECTRICITY

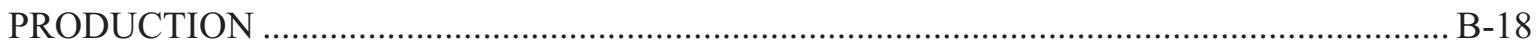

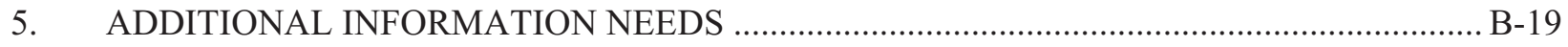

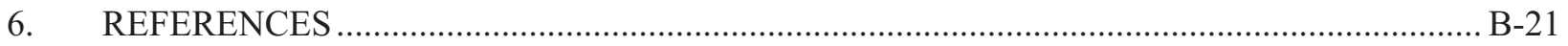

\section{FIGURES}

Figure 1. Fuel source for announced new electrical capacity to be built in 2006-2010

(EIA 2006a).

B-10

Figure 2. Projected electricity cost breakdown (year 2005 \$/MWh) from various sources (EIA 2006d)

B-13

Figure 3. Production and emission costs using various technologies (RAE 2004). At the time of the report the form of emissions allowances was not settled, so they were calculated as a notional cost of 30 pounds sterling/tonne on the total amount of $\mathrm{CO}_{2}$ emitted (i.e., no baseline or partial allowance).

\section{TABLES}

Table 1. Cost comparison of producing electricity in new plants of various technologies (2002 dollars) (Felder and Hajos 2006).

Table 2. Cost breakdown for various electricity production methods (EIA 2006a). B-14

Table 3. Comparison of issues for nuclear, fossil, and alternative energy sources. B-20 
B-6

INL/EXT-09-15483 


\section{ACRONYMS}

AFCI Advanced Fuel Cycle Initiative

BCF billion cubic feet

DOE Department of Energy

IGCC integrated gasification combined cycle

LNG liquefied natural gas

MSW municipal solid waste

USD United States dollars 
B-8

INL/EXT-09-15483 


\section{Comparison of Nuclear to Future New Electricity Generation Alternatives}

The decision to build new nuclear power generation facilities will not be made solely on the pros and cons of nuclear technology itself, but also on how those factors compare among the alternatives to nuclear energy. A range of new fossil and renewable energy technologies are now being demonstrated and will likely be commercially feasible choices in the near future. Fossil energy, particularly coal, will be the major alternative to nuclear power. However, fossil energy has its own issues with demonstrating the next generations of advanced technology, high capital costs, price volatility, and $\mathrm{CO}_{2}$ emissions. Co-generation and poly-generation of multiple forms of energy (electricity, heat, hydrogen, or shaft work) in one plant from multiple sources of energy may be useful in addressing some of nuclear and fossil energy's issues.

\section{ALTERNATIVE FUEL SOURCES FOR NEAR TO INTERMEDIATE TERM CAPACITY EXPANSION}

Because of their operating characteristics and consequent economic differences, the various options for electrical generating capacity are not all interchangeable. Baseload capacity provides the unvarying minimum level of demand needed 24 hours per day. Because this load does not change except on a seasonal basis, it is well suited to being provided by very large plants (nuclear and coal-fired plants) that operate best at steady conditions. In contrast, peaking generation capacity provides additional power needed for a few hours or days at a time, such as during normal afternoon load peaks, an extreme hot or cold spell, or an unexpected shutdown of a baseload plant. The operational flexibility that is required for this service justifies paying the higher fuel cost of the natural gas or fuel oil fired in such turbine-based plants, which are typically smaller than baseload plants.

This issue of flexibly providing power generation at the time it is needed - a concept known as dispatchability - is a major one for intermittent renewable sources, such as solar and wind. Because these sources may not be available at any given instant, assuring a supply of power means that readily dispatchable backup generating capacity must also be at hand. Fossil-fired, hydroelectric, nuclear, and renewable biomass-fired plants can provide this backup, but at the expense of sitting idle when the solar and wind facilities are operating. The economic penalty of building this backup capacity — or equivalently the expectation by customers that electrical power should be available whenever called for-is a major constraint on how much of a region's total electrical demand can be met by wind and solar sources. In part because of this, the total fraction from wind, geothermal, tidal, biomass, and new hydroelectric is not expected to be large in the near to intermediate future.

The intended fuel sources for new generation capacity announced as of 2005 for the period 20062010 are shown in Figure 1. Of the total 94,429 MW in 609 plants, 91\% is directly from fossil origin while the $2 \%$ from industrial gases represents purge streams from other chemical processing, and hence also a fossil origin (EIA 2006a). Because fossil-fueled technologies will remain predominant in new plants for several decades, the issues they face are compared in this attachment to the development and commercialization issues facing next generation nuclear power plants. Since the compilation of that data, it appears that rising prices will make new natural gas facilities less attractive, and that new nuclear facilities may be announced by 2010 , though their construction will be later. 


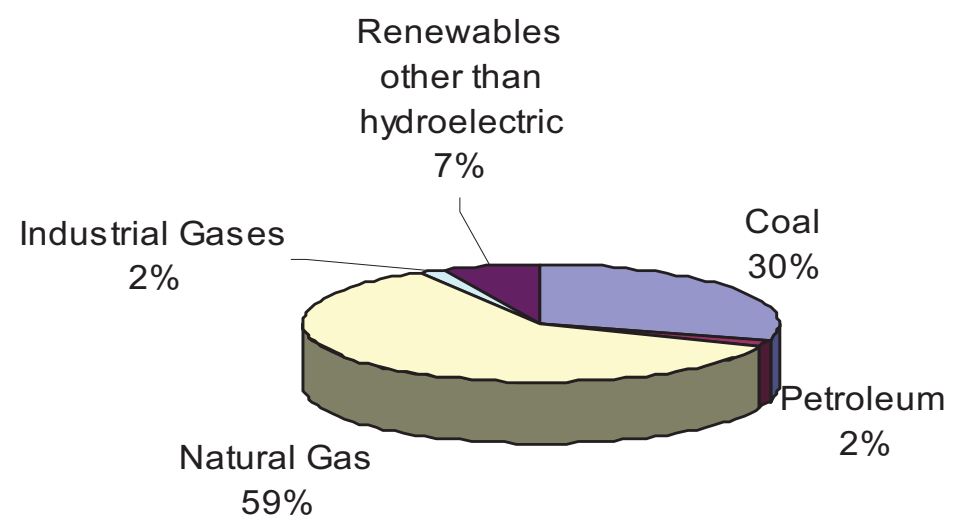

Figure 1. Fuel source for announced new electrical capacity to be built in 2006-2010 (EIA 2006a).

\section{FOSSIL-FUELED ELECTRICAL GENERATION TECHNOLOGIES}

There are several alternatives for advanced fossil-fueled production. Oil-fired plants are a small fraction of the current U.S. fleet (about $6.1 \%$, see EIA 2006a) and will become less common (1.7\% of planned additions during 2006-2010, see EIA 2006a) for obvious reasons of questionable security of fuel supply and uncertain fuel cost over a new plant's expected lifetime of perhaps 60 years. Natural gas and coal will be the primary fuel sources used, with several technologies for each (RAE 2004). Natural gas systems can be either simple gas turbines or combined cycle plants which offer greater efficiency at the penalty of greater equipment complexity and costs. Coal-using systems range from pulverized coal systems, similar to today's plants and progress through fluidized bed combustors, to integrated gasification combined cycle (IGCC). In all cases, the more sophisticated processes offer both greater thermal efficiency in converting fuel into electricity and the potential for reduced pollutant emissions. These benefits come at the cost of greater capital expenditure to build the plant and, at least now, greater technical risk because of a small or nonexistent base of commercial experience with the newer systems.

Current conventional plants use a single power cycle driven by combustion of the fuel. For natural gas-fired turbines, this is a Brayton cycle, while for coal-fired plants, a steam-based Rankine cycle is typical. Combined cycle plants using either fuel run a Brayton cycle to generate power from high-pressure combustion gases, and then use the residual thermal energy in those gases to generate steam and additional electricity in a Rankine cycle. Integrated gasification combined cycle plants elaborate on this two-stage process to reduce pollutant emissions. They first convert coal and nearly-pure oxygen into synthesis gas, a combustible mixture of hydrogen, carbon monoxide, and other gases. Before it is burned in a gas turbine, this mixture can be treated to remove contaminants, such as sulfur species, nitrogen oxides, and mercury, so they are ultimately not discharged to the atmosphere. Because the unburned synthesis gas is at a high pressure and does not contain a large amount of nitrogen from added combustion air, these separations are easier than they would be in the flue gas of a conventional power plant.

Of great potential future value, the synthesis gas in an IGCC plant can also be treated to largely eliminate carbon dioxide emissions. To do this, the water-gas shift reaction

$\mathrm{CO}+\mathrm{H}_{2} \mathrm{O} \rightarrow \mathrm{CO}_{2}+\mathrm{H}_{2}$

is used to transform essentially all the carbon monoxide into carbon dioxide. This reaction preserves almost all of the heating value of the $\mathrm{CO}$ in the additional hydrogen. After the $\mathrm{CO}_{2}$ is removed from this stream using conventional amine-based scrubbing techniques, the hydrogen can be burned in gas turbines to provide nearly the same amount of power as burning the synthesis gas. The $\mathrm{CO}_{2}$ can be recovered as an 
essentially pure stream suitable for sequestration. This $\mathrm{CO}_{2}$ recovery need not be built into the plant when it is first constructed; it can be designed in as a future option to be installed when regulations or economics justify the increased capital and operating expense.

Two IGCC plants were built at full scale in the 1990s to demonstrate the technology, the Wabash River project (www.globalenergyinc.com/920206.html) in Indiana and Tampa Electric Company's Polk Power Station (www.tecoenergy.com/news/powerstation/polk) in Florida (Rezaiyan and Cheremisinoff 2005). Both drove main turbines of 192 MWe capacity. The owner of the Wabash plant started construction on a larger 540 MW plant in 2006 (www.globalenergyinc.com/920207.html) with startup scheduled for 2009.

At the next stage of technology, the Department of Energy (DOE) FutureGen program has the goal of designing and testing a first-of-a-kind plant for IGCC power and hydrogen co-production with nearly complete $\mathrm{CO}_{2}$ capture and sequestration (DOE 2007). Co-production of hydrogen for use as a future vehicle fuel or for upgrading of alternative fossil fuels such as shale oil is a natural option since the IGCC process generates a concentrated hydrogen stream as the turbine fuel. As of mid-2007, this program is at the stage of selecting a demonstration site from a short list of four locations in Illinois and Texas.

The technology of carbon capture and sequestration is not nearly as mature as combustion technologies. The Department of Energy has funded seven regional consortia to study the range of capture and sequestration issues (www.netl.doe.gov/technologies/carbon_seq/index.html). Though plans for many tests of geologic sequestration have been announced, only two large-scale efforts are ongoing. One uses $\mathrm{CO}_{2}$ captured from Dakota Gasification Company's coal to methane process (www.dakotagas.com), which is sold to oilfields in Saskatchewan, Canada to enhance oil production. This end use, $\mathrm{CO}_{2}$ flooding, is a well established technique often used in the southwestern U.S. where $\mathrm{CO}_{2}$-rich gas streams are available from natural gas production. The significance of this effort is primarily the demonstration of carbon capture from a coal gasification process stream. The other project is in Norway's Sleipner Field where Statoil, the state oil and gas company, separates about 2,800 tonnes/day of $\mathrm{CO}_{2}$ from natural gas production and reinjects it 1,000 meters under the seafloor. This is done for sequestration purposes because of the country's tax on atmospheric emissions of the gas. In this case, the capture of the $\mathrm{CO}_{2}$ from natural gas is conventional technology, and the geologic and process aspects of the sequestration are of greater significance.

\section{FOSSIL ENERGY DEVELOPMENT AND COMMERCIALIZATION ISSUES}

The risks of using any of these advanced fossil-fueled technologies fall into one of four main categories: technical issues, capital costs, future fuel cost and availability, and carbon $\left(\mathrm{CO}_{2}\right)$ capture and sequestration costs. In addition to these risks that are amenable to engineering assessment, there are financial risks related to ability of the project to deliver a return to the investors. This category includes such things as exchange rate risks for overseas projects, regulatory changes, and unplanned delays, including wars and acts of God. Large capital-intensive projects like nuclear reactors and coal plants that require much spending to build the plant and years to construct before any income can be generated are at greater risk from such external factors. This section addresses the non-financial risks.

\subsection{Technical Issues}

The first technical risk concerns the problems inherent in early plants using a new technology at scales not previous tested. For natural-gas-fired plants, the technical risks are relatively small since the technologies are well understood and the process is straightforward. For coal-using plants, such as gasifiers in addition to advanced combustion furnaces, the feed itself introduces problems with solids 
handling (of the coal, the slag or ash, and fly ash in the product gases) and with the variety of products such as tars, pollutants, and corrosive species formed in the gasifier during both normal and upset conditions. Ever-tighter environmental regulations in the future will require higher levels of pollutant control from all types of processes. While these are not novel or insuperable difficulties, coal plants require more complex equipment and processes to handle these issues compared to gas-fired plants. Until they are demonstrated at full scale, there is a risk concerning whether these new processes and their modifications will work as expected. Some specific technical needs other than demonstration of integrated operation that have been identified for IGCC include:

- Gasifier components including improved refractories, heat recovery steam generators, and feeding and ash handling systems

- Gas turbine combustors and turbine designs to accommodate hydrogen-rich fuels

- Other component developments, such as less expensive air separation systems to supply nearly-pure oxygen to the gasifier

- Optimization studies on the various steps of the IGCC process, including the integration of $\mathrm{CO}_{2}$ capture

- Technical and economic studies on system design incorporating variations around the globe of the factors affecting project feasibility (Minchener 2005).

\subsection{Capital Costs}

Aggravating these technology risks is the large scale at which coal-fired power plants are built: on the order of 10,000 tons/day of feed, equivalent to 100 rail cars per day. Such equipment entails a large capital cost which would make potential investors sensitive to technical risks in any plants among the first of their kind. The projected capital costs for conventional coal plants are in the range of $\$ 500 \mathrm{M}$ to $\$ 1 \mathrm{~B}$ in 2003, with technologies such as IGCC being more expensive (NEA 2005). Capital cost estimates for 27 plants from a variety of countries found 2003 overnight construction costs in the range of $\$ 719$ to $\$ 2,347 / \mathrm{kWe}$ (South Korea and Japan respectively at those extremes) with the great majority in the narrower range $\$ 1,100$ to $\$ 1,400 / \mathrm{kWe}$. In contrast, gas-fired plants ranged from $\$ 364$ to $\$ 1,292 / \mathrm{kWe}$ (Italy and Netherlands, respectively) with most in the range $\$ 400$ to $\$ 800 / \mathrm{kWe}$, or about half the specific capital $(\$ / \mathrm{kWe})$ cost of a coal plant. Another study found similar results, but also included nuclear and pulverized coals plants, as shown in Table 1 (Felder and Hajos 2006). Nuclear energy has the greatest capital cost but the lowest fuel cost, both by a wide margin, with natural gas turbines being opposite in both dimensions. Coal is in the middle, with IGCC plants seeing a penalty for the additional equipment and energy (efficiency) costs of higher environmental performance compared to conventional pulverized coal systems.

Table 1. Cost comparison of producing electricity in new plants of various technologies (2002 dollars) (Felder and Hajos 2006).

\begin{tabular}{|l|c|c|c|}
\hline \multicolumn{1}{|c|}{ Technology } & $\begin{array}{c}\text { Overnight Capital Cost } \\
(\$ / \mathrm{kWe})\end{array}$ & $\begin{array}{c}\text { Fuel Cost } \\
(\$ / \mathrm{MWh})\end{array}$ & $\begin{array}{c}\text { Levelized Electricity } \\
\text { Cost }(\$ / \mathrm{MWh})\end{array}$ \\
\hline Nuclear & 2,000 & 0.89 & $67-80$ \\
\hline Combined cycle gas turbine & 500 & 41.60 & $55-64$ \\
\hline Pulverized coal & 1,300 & 10.80 & $40-44$ \\
\hline IGCC & 1,490 & 12.95 & $44-49$ \\
\hline
\end{tabular}


The Energy Information Agency has compiled from various sources a comprehensive analysis of the costs of many electricity production options (Table 2) (EIA 2006c). These also show the wide spread of capital costs per unit of generating capacity and the generally counterbalancing trend of lower operating and maintenance costs (which includes fuel in the variable O\&M category) for the more expensive capital costs. The specific capital costs in this table are based on the plant's maximum or peak electrical output; depending on the actual percentage of time and percentage of design capacity that these plants can operate, the cost per kilowatt-hour will increase. Despite the wide range of the breakdown numbers for various technologies, the resulting projected power costs for the major options are similar (Figure 2). Overall, natural gas-fired plants have the lowest risk associated with the capital cost, with significant increases in moving to coal-fired and again to nuclear systems.

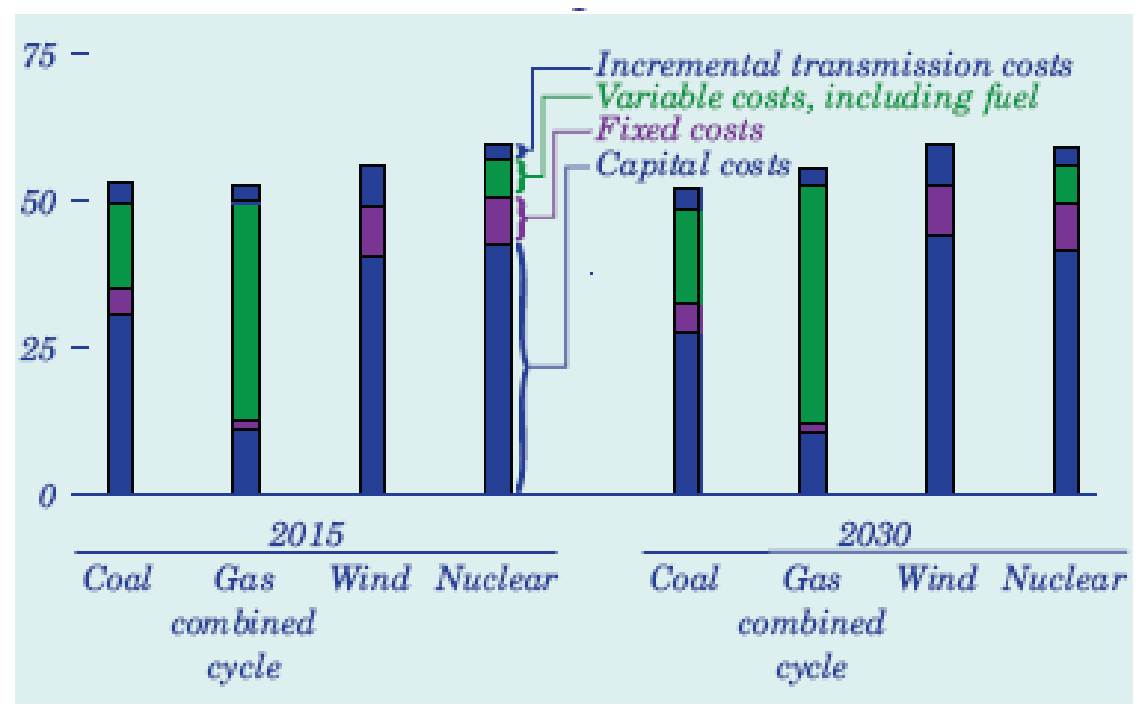

Figure 2. Projected electricity cost breakdown (year 2005 \$/MWh) from various sources (EIA 2006d). 


\section{Draft}

\begin{tabular}{|c|c|c|c|c|c|c|c|c|c|c|c|}
\hline & 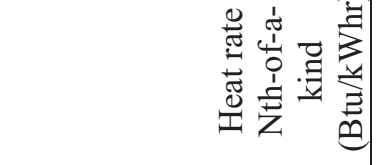 & 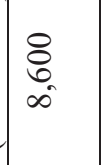 & ષ્ণ & ふ্ & 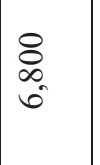 & గ్రై & 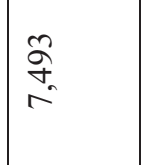 & 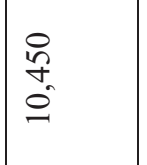 & $\begin{array}{l}\stackrel{0}{n} \\
n_{\infty} \\
\infty\end{array}$ & 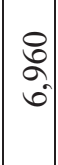 & \begin{tabular}{l}
8 \\
$\vdots$ \\
\hdashline \\
\hdashline
\end{tabular} \\
\hline & 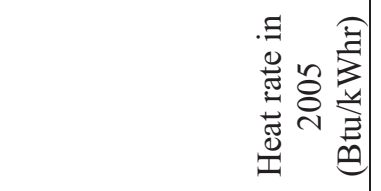 & 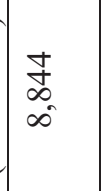 & 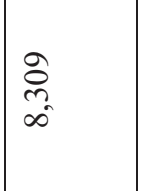 & $\stackrel{n}{\stackrel{2}{a}}$ & $\stackrel{\circ}{\stackrel{2}{\circ}}$ & $\begin{array}{l}\tilde{2} \\
\hat{6}\end{array}$ & $\begin{array}{l}m \\
\substack{0 \\
\infty}\end{array}$ & $\begin{array}{l}\text { I } \\
\infty \\
\stackrel{0}{0}\end{array}$ & $\begin{array}{l}\text { तิ } \\
\text {. }\end{array}$ & $\begin{array}{l}\stackrel{0}{2} \\
\\
\end{array}$ & \begin{tabular}{l}
8 \\
$q$ \\
\hdashline \\
0
\end{tabular} \\
\hline & 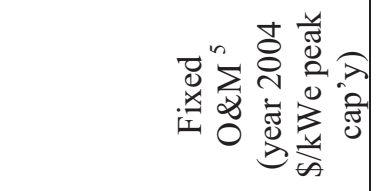 & à & $\begin{array}{l}\overrightarrow{\vec{v}} \\
\text { m }\end{array}$ & $\begin{array}{l}\underset{J}{J} \\
\vec{F}\end{array}$ & 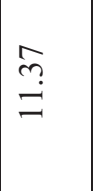 & 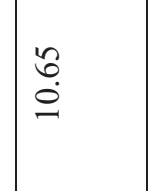 & 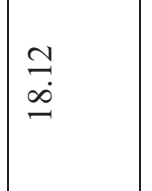 & $\stackrel{\wp}{\Xi}$ & aे & $\frac{n}{n}$ & 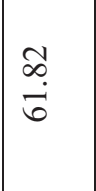 \\
\hline & 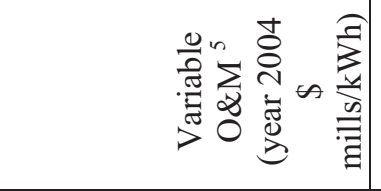 & $\stackrel{\infty}{\rightarrow}$ & $\begin{array}{l}n \\
\tilde{c}\end{array}$ & $\underset{+}{\stackrel{+}{+}}$ & $\begin{array}{l}\stackrel{\infty}{\infty} \\
\stackrel{\leftrightarrow}{-}\end{array}$ & $\stackrel{\infty}{\infty}$ & $\stackrel{\infty}{\stackrel{\infty}{\circ}}$ & 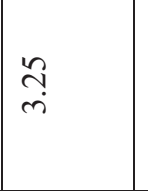 & 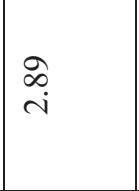 & $\begin{array}{l} \pm \\
\dot{q} \\
\dot{q}\end{array}$ & $\stackrel{n}{\stackrel{n}{0}}$ \\
\hline & 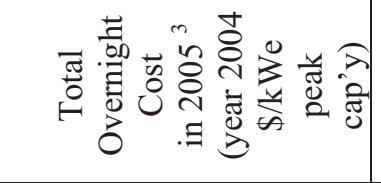 & $\stackrel{\stackrel{9}{+}}{-}$ & $\underset{f}{\mathcal{G}}$ & $\begin{array}{l}n \\
0 \\
i \\
i\end{array}$ & $\underset{i}{ \pm}$ & $\stackrel{n}{n}$ & $\stackrel{f}{=}$ & $\hat{q}$ & $\stackrel{\infty}{\infty}$ & $\begin{array}{c}+ \\
\text { ? } \\
+\end{array}$ & $\begin{array}{l}\vec{d} \\
\vec{i} \\
i\end{array}$ \\
\hline & 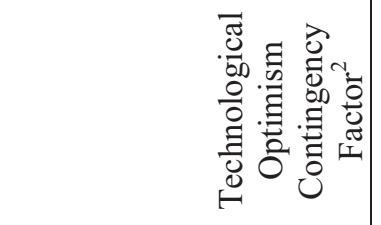 & $\stackrel{8}{-}$ & $\stackrel{8}{\stackrel{\leftrightarrow}{-}}$ & $\stackrel{\overbrace{}}{0}$ & $\underset{-}{\stackrel{8}{-}}$ & $\underset{-}{\stackrel{8}{-}}$ & $\underset{-}{\Delta}$ & $\stackrel{8}{\stackrel{\leftrightarrow}{*}}$ & $\underset{-}{\stackrel{i}{-}}$ & $\stackrel{\odot}{=}$ & $\stackrel{\leftrightarrow}{\stackrel{\leftrightarrow}{-}}$ \\
\hline & 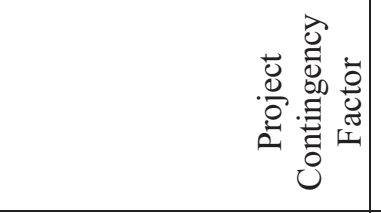 & $\stackrel{0}{-}$ & $\stackrel{\circ}{\rightarrow}$ & 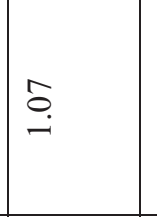 & $\stackrel{\leftrightarrow}{\circ}$ & $\stackrel{\infty}{\stackrel{\infty}{-}}$ & $\stackrel{\infty}{\rightarrow}$ & $\stackrel{\leftrightarrow}{\circ}$ & $\stackrel{n}{\circ}$ & $\stackrel{\leftrightarrow}{-}$ & $\stackrel{\varrho}{\leftrightarrows}$ \\
\hline & 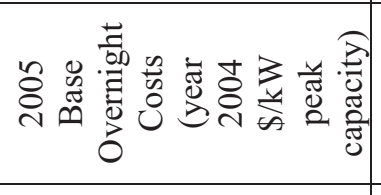 & $\stackrel{6}{=}$ & $\underset{\sim}{\stackrel{g}{*}}$ & 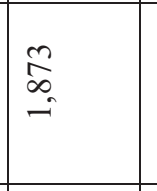 & in & $\tilde{n}$ & $\overrightarrow{\widehat{\sigma}}$ & $\begin{array}{l}\infty \\
\infty \\
m\end{array}$ & $\hat{\tilde{e}}$ & $\begin{array}{c}\hat{\infty} \\
\hat{\infty} \\
\end{array}$ & $\underset{⿱}{\stackrel{7}{二}}$ \\
\hline & 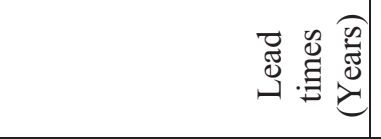 & + & $\sigma$ & $\nabla$ & $m$ & $m$ & $m$ & $\sim$ & $N$ & $m$ & 6 \\
\hline & 总璦 & 8 & in & 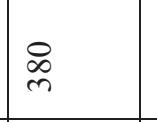 & मे & \&্ণ & ஓి & $\stackrel{8}{-}$ & ల్ల & 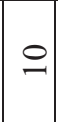 & $\stackrel{8}{\varrho}$ \\
\hline & 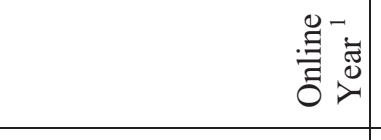 & ڤે̀ & ठ્ેે & $\stackrel{\circ}{\circ}$ & 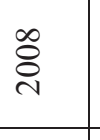 & 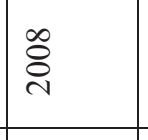 & $\stackrel{\circ}{\stackrel{i}{i}}$ & ڤे & ڤ్̀े & $\begin{array}{l}\infty \\
\stackrel{్}{\Lambda}\end{array}$ & $\stackrel{m}{\stackrel{N}{~}}$ \\
\hline & 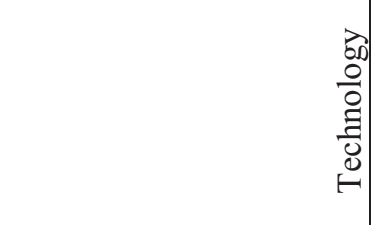 & 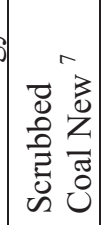 & 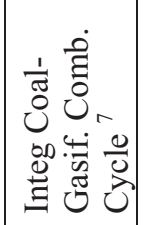 & 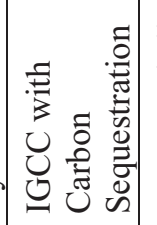 & $\begin{array}{ll}\overline{0} & 0 \\
0 & 0 \\
0 & 0 \\
0 & 0 \\
0 & 0 \\
0 & 0 \\
0 & 0 \\
0 & 0\end{array}$ & 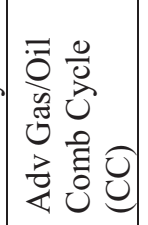 & 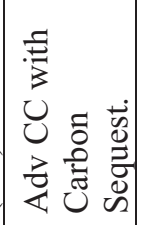 & 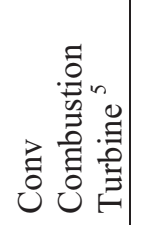 & 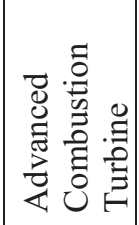 & 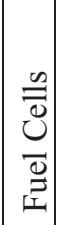 & 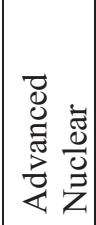 \\
\hline
\end{tabular}




\section{Draft}

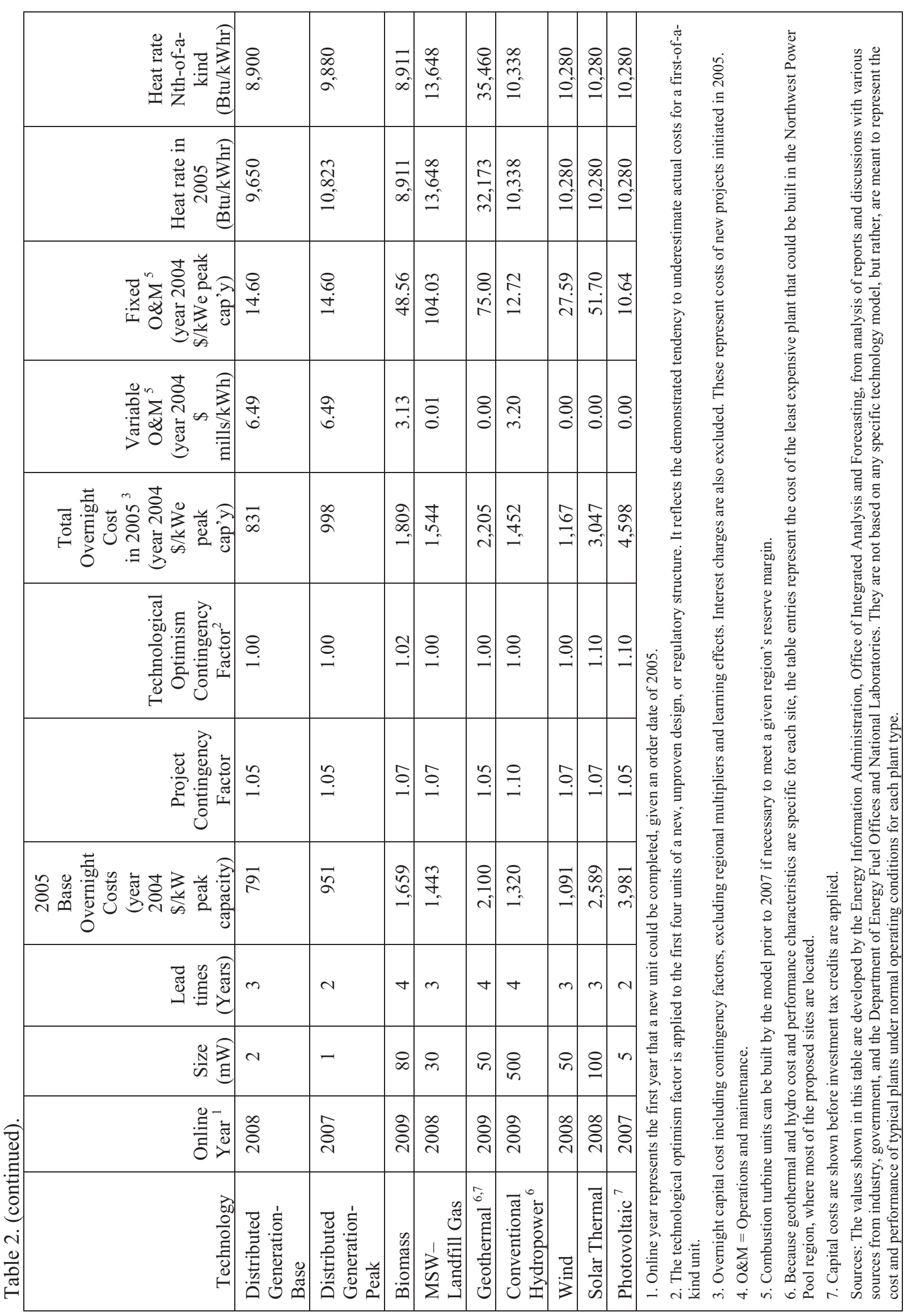

B-15

INL/EXT-09-15483 


\subsection{Future Fuel Costs and Availability}

Another major issue for any power production technology is the cost of fuel, or more specifically the risk of large price fluctuations or long-term moves to values not anticipated in the project's financial analyses. A comprehensive British report (RAE 2004) found that natural gas in 2003 averaged 2.05 pounds sterling per gigajoule energy (approximately $\$ 3.9$ per million BTU) while coal was 1.39 (\$2.5 per million BTU). However, the lower capital costs of natural gas systems meant that the cost of electricity from various baseload plants was similar, though not identical, as shown in the production cost portion of Figure 3. Similar results from another source are also reported as part of Table 1.

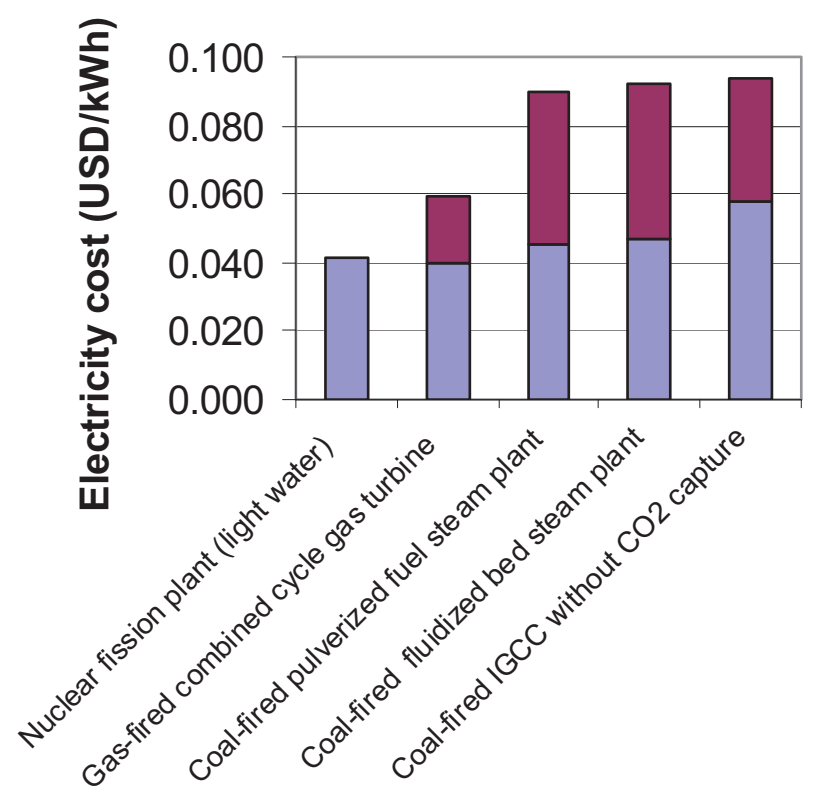

$\square$ CO2 costs@49 USD/ton

$\square$ Production cost

Figure 3. Production and emission costs using various technologies (RAE 2004). At the time of the report the form of emissions allowances was not settled, so they were calculated as a notional cost of 30 pounds sterling/tonne on the total amount of $\mathrm{CO}_{2}$ emitted (i.e., no baseline or partial allowance).

The economics of fossil fueled plants are strongly affected by fuel costs, as shown in Table 1. As history demonstrates, these costs are notoriously difficult to predict even over a few years, much less the decades that a new power plant will operate. Nonetheless, comparative studies on future electricity generation must make assumptions about fuel prices and there is risk associated with the accuracy of these estimates. At a minimum, these costs are affected by:

- Increases in demand by residential/commercial or industrial users (as happened with natural gas through the 1990s and early 2000s after years of softness) or by growing foreign markets such as China and India

- Changes in supply from the opening of major new reservoirs (such as oil fields offshore of western Africa) or supply routes (proposed gas pipelines from Alaska and northern Canada to the central United States, or proposed additional liquefied natural gas terminals)

- Changes in political circumstances, including war, in producer countries (contemporary Iraq).

A recent review (NEA 2005) of the literature from a number of countries on the future costs of electricity production showed 21 estimates of coal prices ranging from $\$ 1.14$ to $\$ 2.74$ /gigajoule (except South Africa \$0.10-\$0.15) in the year 2010. (One gigajoule [GJ] equals 0.948 million BTUs.) For the year 2050, about half the estimates remained the same as the 2010 price while the others increased 
between 10-33\% for an annual escalation rate well under $1 \%$. For a set of 15 cost studies from a similar set of countries, natural gas price projections were $\$ 3.72$ to $\$ 5.72 / \mathrm{GJ}$ in 2010 , then $\$ 4.42$ to $\$ 6.97 / \mathrm{GJ}$ in 2030 (all 15 studies), to in the nine studies with estimates for the year 2050 a range of $\$ 4.46$ to $\$ 8.35 / \mathrm{GJ}$. South Africa's natural gas costs were a constant $\$ 3.55 / \mathrm{GJ}$ and, as with their coal estimates, were excluded from these ranges as being held artificially low. As in the coal studies, about half of these studies assumed no cost escalation over this 40 -year period. Since publication of that report, natural gas prices have fluctuated dramatically to a peak near $\$ 15 / \mathrm{GJ}$, illustrating the risk of such projections.

With these cost projections and the assumption of a $5 \%$ discount rate on future costs, the typical fraction of the final levelized electricity cost attributable to fuel costs is $15-20 \%$ for nuclear, $40-60 \%$ for coal, and $65-85 \%$ for natural gas (NEA 2005). At a $10 \%$ discount rate, these ranges all drop by $5-10 \%$ because future fuel costs are more highly discounted compared to the upfront construction costs, but they remain in similar relative magnitude. The significance is that future unexpected fluctuations (of the same percentage magnitude) in the price of the fuels will have the greatest effect on the cost of electricity from natural gas systems and the least effect on nuclear supplies.

One of the key concerns around any energy resource is security of supply. This issue concerns whether the fuel will be available at all — regardless of price — with some causes for uncertainty being exhaustion of the locally available resource, political actions (including terrorism) that close some or all supply channels, and belated recognition of environmental or social problems (externalities) that make use of the fuel unacceptable. The focus here is on long-term supply disruption, but related issues exist on a shorter time scale for the physical transportation of fuels. Train wrecks or labor strikes could halt fuel delivery to an individual plant for up to several weeks. Coal and nuclear fuel are at opposite ends of that risk spectrum because of the quantities of each that must be delivered to a power plant.

In the case of coal, current U.S. reserves are estimated at 267 billion short tons as compared to domestic usage of 1.125 billion short tons in 2005, leading to a projected reserve lifetime of about 240 years (EIA 2006b). This number, however, does not include the effects of future growth in coal use either for electricity production or for conversion to synthetic vehicle fuels. Also, it assumes that these reserves are used in the United States and are not exported to any appreciable extent as either coal or synthetic fuel; the current level of exports is negligible. The conclusion is that under the current scenario coal will be readily available as an energy supply, though concerns about its emissions of carbon dioxide and other pollutants might introduce regulatory constraints on the extent of its use. The availability of domestic coal is a large factor favoring its use in the coming century for power production in the United States. The situation will be different in other countries.

Natural gas supplies are not as large. United States domestic reserves are 204,000 billion cubic feet (BCF) while consumption in 2005 was $23,488 \mathrm{BCF}$, implying an 8-9 year supply (EIA 2006e). Imports of 4,341 BCF made a significant contribution to meeting demand. Most of those imports came by pipeline from Canada and Mexico, but 15\% was as liquefied natural gas (LNG) from a variety of countries. LNG imports have almost tripled since 2000. Overall, the security of supply of natural gas, on the time-scale of power plant lifetimes, must be considered at least a moderate risk.

Uranium is currently primarily produced in the Canada, Russia, the United States, and Australia, the first through fourth largest producers. Civilian nuclear fuel purchases in 2005 were 17\% of U.S. origin (EIA 2005). Because Canada and Australia have long ties to the United States, the availability of the raw materials of nuclear fuels is not a major concern.

\subsection{Carbon Dioxide and Other Emissions}

The fourth major factor affecting selection of future power production technologies will be laws and regulations regarding carbon dioxide emissions. In the current environment, coal offers an attractive 
compromise between the cost and availability of fuel versus capital requirements to build a plant. However, it is the greatest producer of $\mathrm{CO}_{2}$ per unit of power generation, and consequently is at the most risk if $\mathrm{CO}_{2}$ emissions are eventually restricted or financially penalized in some way. Because these restrictions may be implemented differently in other countries or regions such as the European Union, the impact on coal-fired power generation will likely not be globally uniform. An estimate of the effect of $\mathrm{CO}_{2}$ emissions costs on power price (see RAE 2004), presented in Figure 3, shows that the cost of power from coal-fired plants might nearly double in one circumstance. Natural gas plants are less affected by these costs, and nuclear technologies are essentially unaffected because they emit no $\mathrm{CO}_{2}$ in operation.

Some analyses take into account the $\mathrm{CO}_{2}$ emissions related to construction of nuclear (and other) power plants. These include such contributors as transportation of materials, operation of construction machinery, and emissions during steel and cement manufacturing. These emissions exist, but are not included here because they would be small compared to the operational emissions of a fossil-fired plant.

Although $\mathrm{CO}_{2}$ is the largest emissions issue, coal is similarly at greater risk than other fuels if there is continued tightening of regulations concerning air emissions of SOx, NOx, mercury, or fine particulates (known as PM2.5 or PM10, particulate matter less than 2.5 or 10 microns in size). One study evaluating the environmental and health effects of all the emissions from various types of power plants found the total costs to be for coal $2.2-7.4$ cents $/ \mathrm{kWh}$, for gas $1.3-2.0$ cents $/ \mathrm{kWh}$, and for nuclear $0.26 \mathrm{cents} / \mathrm{kWh}$, converting currencies at $\$ 1.3$ /euro (Rabl and Spadara 2006). The major problem for selecting between the fuel options for a new power plant is not so much that coal emits pollutants in greater amounts than other fuels, but that the required levels of treatment, and therefore the costs for achieving them, cannot be reliably predicted for the lifetime of the plants. The magnitude of this risk is greatest for coal-fired plants, medium for natural gas-fired plants, and quite small for nuclear facilities.

\section{INTEGRATION OF NEXT GENERATION NUCLEAR WITH OTHER ELECTRICITY PRODUCTION}

Comparing next generation nuclear designs to advanced coal-based generation and the leading renewable alternatives shows there are many dimensions along which they can be measured with each technology having its own advantages and problems (Table 3). If one of the alternatives had an overwhelming preponderance of benefits that far outweighed the negatives, there would be no need for discussion about which to choose. For example, the issue of this study is about how to produce electricity; whether to produce it at all has an answer accepted without even posing the question. But when each option offers a different mix of characteristics both positive and negative, the selection among them comes down to a balancing of interests - for instance, economic criteria that vary with location or value judgments expressed by a society through its legislators - that will be different for each stakeholder group.

Such arguments are complex, and reaching consensus is difficult. Though the choice is among technical options, the debate is not primarily one about technical performance. At the risk of oversimplifying the discussion, the key questions are about the magnitude of the problems rather than of the benefits: How can society be confident that radioactive material will not escape its confinements during use and storage? How do we limit carbon dioxide emissions to minimize global warming and its consequences? How do we prevent biomass systems from affecting large parts of the environment or food supply system in ways that are not now apparent? Can wind and solar be relied on to produce more than a modest fraction of society's baseload energy demand?

In such a situation it is natural to look for counter-balancing synergies if two or more options are used together. Current nuclear, fossil-fired, and alternative energy sources generally have not been integrated in ways that might alleviate some of the shortcomings of each. (The major exception is development of coal-fired boilers that can also accept biomass as part of their feed.) Their relationships as options for a 
single power plant are as competing technologies, even though their capacities and relative costs for construction and operation do not make them equally suitable for all applications. Only at a systems level, such as a regional grid, are they complementary in broadly balancing various fuel-related risks such as cost, availability, and $\mathrm{CO}_{2}$ emissions. At least for power production, this situation does not seem likely to change in the foreseeable future.

These energy technologies could also potentially compete in the production of hydrogen if that gas eventually becomes established as a vehicle fuel. However, the relative status of each for hydrogen production is not greatly different from that in electricity production: coal or natural gas reforming to make hydrogen is established technology, but with the penalty of $\mathrm{CO}_{2}$ production; nuclear production using high-temperature reactors is still in the very early stages of development, but is potentially capable of large-scale production; and renewable methods appear to be economically impractical (biomass) or burdened with problems of intermittency and a lack of good storage technology (wind and solar). Synergies in hydrogen production are not apparent.

The one area of beneficial integration of these technologies may be the production of synthetic fuels, primarily liquid vehicle fuels, but possibly including synthetic natural gas from coal. The first step of an IGCC process - coal or natural gas gasification to make a mixture of hydrogen and carbon monoxidecan be the first step in synthesizing fuel molecules such as methanol, dimethyl ether, or diesel-type blends via Fischer-Tropsch chemistry. In this potential integration, the carbon in the fossil energy source is used only to construct the product fuel molecule and is not oxidized to provide process energy. The energy for both chemical bond formation and for purifying and processing the fuels can be obtained from a nuclear or renewable source. With this type of complementary process, $\mathrm{CO}_{2}$ emissions during the chemical processing are minimized and fuel production from the carbon source is maximized. In effect, the overall process allows the use of nuclear or renewable energy to power vehicles. And if the feed carbon came from biomass or was captured as $\mathrm{CO}_{2}$ from the atmosphere, there is no net release of that greenhouse gas even when the fuel is burned.

Further developing this idea, using nuclear, fossil, and renewable sources to co-generate synthetic fuel and electricity in varying ratios would allow full utilization of a plant's production capacity as the market need for each product changes on a daily to seasonal basis. Poly-generation of electricity with some combination of synthetic fuel, hydrogen, steam at various temperatures, or shaft work (to drive the extremely large compressors used in the processes to make ammonia, ethylene, or methanol) would open other possibilities. The key concept in this type of system has shifted from the source(s) of energy to its flexible conversion into one or several other forms needed to satisfy local market demands.

\section{ADDITIONAL INFORMATION NEEDS}

Future updates of this report can be enhanced with additional information. These might include:

- Trends in the development of power production technology, particularly co-generation of heat and power, whether nuclear-based or otherwise

- Developments in the use of nuclear reactors to supply process heat for chemical plants and the production of alternative fossil energy sources, such as oil sands and oil shale

- Economic, environmental, and political factors which might affect technology choices in major market areas, particularly foreign markets. 
Table 3. Comparison of issues for nuclear, fossil, and alternative energy sources.

\begin{tabular}{|c|c|c|c|}
\hline & $\begin{array}{l}\text { Next Generation } \\
\text { Nuclear Power }\end{array}$ & $\begin{array}{l}\text { FutureGen (coal gasification with } \\
\qquad \mathrm{CO}_{2} \text { sequestration) }\end{array}$ & $\begin{array}{l}\text { Renewables (wind, } \\
\text { biomass, and others) }\end{array}$ \\
\hline Energy source & $\begin{array}{l}\text { - Uranium is mined in } \\
\text { foreign (but friendly) } \\
\text { countries } \\
\text { - Fuel is a small part of } \\
\text { final power cost } \\
\text { - Enrichment and fuel } \\
\text { reprocessing require } \\
\text { proliferation controls }\end{array}$ & $\begin{array}{l}\text { - Coal is plentiful in the U.S. so } \\
\text { both availability and future } \\
\text { prices should be steady } \\
\text { - Coal mining industry has a high } \\
\text { accident and death rate }\end{array}$ & $\begin{array}{l}\text { - Wind and solar have zero } \\
\text { fuel supply costs } \\
\text { - Wind, solar are intermittent } \\
\text { - Not all locations are suitable } \\
\text { for wind or solar } \\
\text { - Biomass requires large } \\
\text { dedicated land area and } \\
\text { fertilizer inputs } \\
\end{array}$ \\
\hline $\begin{array}{l}\text { Facilities } \\
\text { issues }\end{array}$ & $\begin{array}{l}\text { - Very high capital costs } \\
\text { for large plants } \\
\text { - Permitting process is } \\
\text { long and contentious in } \\
\text { the U.S. }\end{array}$ & $\begin{array}{l}\text { - Very high capital costs for } \\
\text { large plants } \\
\text { - Need to demonstrate large scale } \\
\text { carbon capture and } \\
\text { sequestration } \\
\text { - Water usage may become } \\
\text { problematic for plants in the } \\
\text { arid West } \\
\text { - Permitting process becoming } \\
\text { more contentious }\end{array}$ & $\begin{array}{l}\text { - Low resource energy density } \\
\text { requires many small plants, } \\
\text { hence a large visual impact } \\
\text { and low economies of scale } \\
\text { - Anticipated more frequent } \\
\text { replacement of wind and } \\
\text { solar converters allows } \\
\text { updating of technology } \\
\text { - Land areas required can be } \\
\text { very large }\end{array}$ \\
\hline Transport & $\begin{array}{l}\text { - Fresh fuel is modest in } \\
\text { size and low hazard } \\
\text { - Used fuel requires high- } \\
\text { security shipping to } \\
\text { treatment site } \\
\text { - Large transmission needs } \\
\text { if not built near users }\end{array}$ & $\begin{array}{l}\text { - Large amount of coal train } \\
\text { traffic if plant is built near } \\
\text { consumers } \\
\text { - Need power transmission lines } \\
\text { to consumers if plant is at the } \\
\text { mine mouth } \\
\text { - Need a } \mathrm{CO}_{2} \text { pipeline to } \\
\text { sequestration site(s) if not at the } \\
\text { plant location }\end{array}$ & $\begin{array}{l}\text { - Distributed facilities have no } \\
\text { major transport needs if the } \\
\text { power is used locally } \\
\text { - Large remote facilities will } \\
\text { need transmission to users } \\
\text { - Biomass transport is only } \\
\text { feasible over a short distance } \\
\text { because of its low energy } \\
\text { density }\end{array}$ \\
\hline $\begin{array}{l}\text { Wastes } \\
\text { requiring } \\
\text { handling or } \\
\text { disposal }\end{array}$ & $\begin{array}{l}\text { - Used nuclear fuel to be } \\
\text { recycled (Advanced Fuel } \\
\text { Cycle Initiative [AFCI]) } \\
\text { or stored in deep } \\
\text { geologic depository(ies) } \\
\text { - No greenhouse gas } \\
\text { production }\end{array}$ & $\begin{array}{l}\text { - Large amount of } \mathrm{CO}_{2} \text { for } \\
\text { geologic sequestration with } \\
\text { unknown long term impacts } \\
\text { - Slag, ash, fly ash to landfill } \\
\text { (heavy metals, arsenic, etc.) } \\
\text { - Elemental sulfur for sale or } \\
\text { inventory (market saturation?) } \\
\text { - Mercury on activated carbon }\end{array}$ & $\begin{array}{l}\text { - No waste generation } \\
\text { (including } \mathrm{CO}_{2} \text { ) during wind } \\
\text { or solar operation } \\
\text { - Solar panels may contain } \\
\text { elements such as cadmium. } \\
\text { Manufacturing and ultimate } \\
\text { disposal may produce toxic } \\
\text { wastes. } \\
\text { - Ash from biomass com- } \\
\text { bustion goes to landfills or } \\
\text { agricultural fields }\end{array}$ \\
\hline $\begin{array}{l}\text { Synthetic } \\
\text { vehicle fuels } \\
\text { including } \mathrm{H}_{2} \\
\text { (all require } \\
\text { large-scale } \\
\text { demonstration) }\end{array}$ & $\begin{array}{l}\text { - } \mathrm{H}_{2} \text { from water by } \\
\text { electrolysis, high } \\
\text { temperature electrolysis, } \\
\text { thermochemical cycles } \\
\text { - Liquid fuels cannot be } \\
\text { made without a carbon } \\
\text { source to make into fuel }\end{array}$ & $\begin{array}{l}\text { - } \mathrm{H}_{2} \text { from water by electrolysis, } \\
\text { high-temperature electrolysis, } \\
\text { thermochemical cycles } \\
\text { - } \mathrm{H}_{2} \text { can be recovered from the } \\
\text { gasifier effluent syngas } \\
\text { - Fischer-Tropsch chemistry for } \\
\text { synthetic diesel from syngas is } \\
\text { already commercial }\end{array}$ & $\begin{array}{l}\text { - } \mathrm{H}_{2} \text { from water by electro- } \\
\text { lysis. Storage at small sites } \\
\text { will be a problem } \\
\text { - Ethanol or biodiesel from } \\
\text { biomass (without electricity } \\
\text { production) } \\
\text { - Possible synfuels from } \\
\text { biomass gasification }\end{array}$ \\
\hline
\end{tabular}




\section{REFERENCES}

1. Energy Information Agency (EIA 2006a), www.eia.doe.gov/cneaf/electricity/epa/epat2p2.html and www.eia.doe.gov/cneaf/electricity/epa/epat2p4.html, October 2006, Web page accessed February 5, 2007.

2. Royal Academy of Engineering (RAE 2004), The costs of generating electricity. London, March 2004.

3. Rezaiyan, J. and N. P. Cheremisinoff, Gasification Technologies - A Primer for Engineers and Scientists. Taylor and Francis: Boca Raton (2005).

4. Department of Energy (DOE 2007), www.fossil.energy.gov/programs/powersystems/futuregen/index.html, Web page accessed February 6, 2007.

5. Minchener, A. J., Coal gasification for advanced power generation. Fuel, 84, 2222-2235 (2005).

6. Nuclear Energy Agency (NEA 2005), International Energy Agency, Organization for Economic Cooperation and Development, Projected costs of generating electricity, 2005 update, 2005.

7. Felder, F. A. and A. Hajos, Using restructured electricity markets in the hydrogen transition: the PJM case, Proc. of the IEEE, 94, 1864-1879 (2006).

8. Energy Information Agency (EIA 2006c), Assumptions to the Annual Energy Outlook 2006, www.eia.doe.gov/oiaf/aeo/assumption/pdf/electricity.pdf, Web page accessed February 19, 2007.

9. Energy Information Agency (EIA 2006d), Annual Energy Outlook 2006, www.eia.doe.gov/oiaf/archive/aeo06/pdf/trend_3.pdf, Web page accessed February 19, 2007.

10. Energy Information Agency (EIA 2006b), www.eia.doe.gov/cneaf/coal/quarterly/html/t28p01p1.html and http://www.eia.doe.gov/pub/international/iea2004/table82.xls, dated December 2006, Web page accessed February 17, 2007.

11. Energy Information Agency (EIA 2006e), tonto.eia.doe.gov/dnav/ng/ng_sum_top.asp, Web page accessed February 21, 2007.

12. Energy Information Agency (EIA 2005), www.eia.doe.gov/cneaf/nuclear/umar/figure5.html, Web page accessed February 21, 2007.

13. Rabl, A. and J. V. Spadara, Environmental impacts and costs of energy, Ann. NY Acad. Sci., 1076, p. 516-526, 2006. 
B-22

INL/EXT-09-15483 


\title{
Attachment C
}

\section{Economics and Nuclear Security White Paper - Achieving Nonproliferation Objectives While Considering Cost Trade-offs}

\author{
David Shropshire and Trond Bjornard \\ Idaho National Laboratory \\ Tom Wood and Steven Short \\ Pacific Northwest National Laboratory
}


C-2

INL/EXT-09-15483 


\begin{abstract}
This attachment describes an evaluation of the factors that influence economics and nuclear security and that consider the ramifications of nuclear strategies on these factors. This study has uncovered key insights to the tradeoffs between economics and nuclear security. The primary focus is to show that economics and nonproliferation are intricately linked in that decisions made to reduce cost may have a significant impact on nonproliferation, and vice versa. Common drivers that have a significant impact on both cost and nonproliferation are used to compare the tradeoffs between these two crucial aspects of the nuclear fuel cycle. Each driver, or issue, is described in terms of the impact domestically and internationally, for both cost and nonproliferation. In this paper, 10 drivers were selected for assessment. The drivers are associated with transportation, nuclear fuel supply markets, number and size of facilities, technological complexity, fuel composition, and geographic placement of facilities, storage of materials, design standardization, fuel cycle backend closure, and grid appropriate reactors. In the course of studying these drivers, additional areas for examination were exposed. The additional candidates for evaluation may provide us with an even greater depth of understanding of the trade-offs and mutual benefits. This document is a step toward identifying these trade-offs and potential solutions.
\end{abstract}


C-4

INL/EXT-09-15483 


\section{CONTENTS}

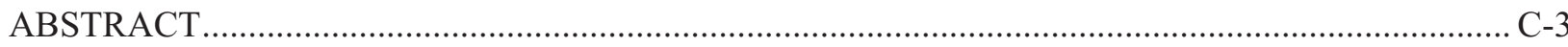

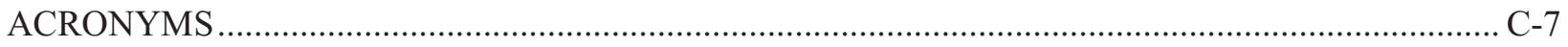

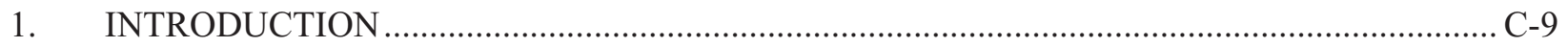

2. OVERVIEW—NUCLEAR SECURITY THREATS AND METRICS ..................................... C-9

3. THE INTERACTION OF ECONOMICS AND NUCLEAR SECURITY …........................... C-12

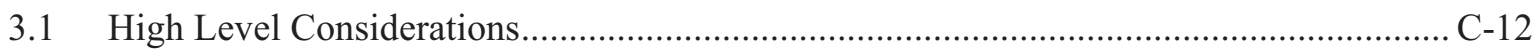

3.2 Examination of Specific Drivers and Features.............................................................. C-12

4. ANALYSIS AND INSIGHTS FROM PRELIMINARY EVALUATION ................................ C-13

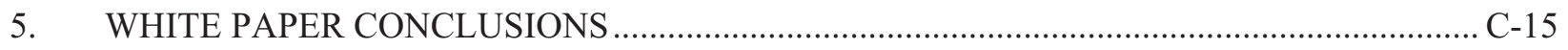

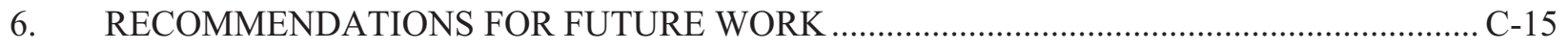

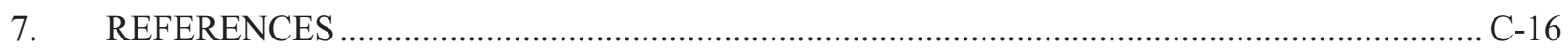

Appendix A-Relationship between Economic and Nuclear Security Issues/Drivers ......................... C-17

\section{FIGURES}

Figure 1. Example of economics and nuclear security trade-offs. C-11

\section{TABLES}

Table 1. Nuclear security threats and metrics. C-10 
C-6

INL/EXT-09-15483 


\section{ACRONYMS}

AFCI Advanced Fuel Cycle Initiative

CAT I Category 1

$\mathrm{CH} \quad$ contact handled

$\mathrm{COEX}^{\mathrm{TM}} \quad$ CO-EXtraction

DE Detection Resource Efficiency

DOE Department of Energy

DP Detection Probability

EU enriched uranium

FR fast reactor

FSU Former Soviet Union

GIF PRPP Generation IV International Forum Expert Group

HEU highly-enriched uranium

IAEA International Atomic Energy Agency

INFA International Nuclear Fuel Authority

MT Material Type

NNWS Non-Nuclear Weapons States

PAS Probability of Adversary Success

PC Proliferation Cost

PNNL Pacific Northwest National Laboratory

PP physical protection/security

PPR Physical Protection Resources

PR proliferation resistance

PRPP proliferation resistance and physical protection

PT Proliferation Time

PUREX Plutonium Uranium EXtraction

RH remotely handled

RU recycled uranium

SNF spent nuclear fuel

SST safe, secure transport

TD Technical Difficulty

TRU transuranic

UREX URanium EXtraction

WMD weapons of mass destruction 
C-8

INL/EXT-09-15483 


\section{Economics and Nuclear Security White Paper - Achieving Nonproliferation Objectives While Considering Cost Trade-offs}

\section{INTRODUCTION}

The overarching mission is to support the global growth of nuclear energy, while reducing nuclear security risk (both legacy and future). Economics is a factor that drives the global growth of nuclear energy (over other forms of energy). Choices made for the sake of economics can have implications for nonproliferation, while nuclear security strategies likely have economic implications. This document provides a first, high-level view of the mutual influence of economics and nuclear security in fuel cycle and policy strategies.

This effort was initiated in Fiscal Year 2007 by the Advanced Fuel Cycle Initiative (AFCI) Systems Analysis, together with representatives from Pacific Northwest National Laboratory (PNNL) and NA-24, to consider how economics and nonproliferation are interrelated, and the implications of this for future activities. A draft working paper was completed in May, and a number of group conference calls were conducted, resulting in progress in identifying the major economic features that ought to be considered.

Subsequently, it was determined that the most effective path forward would be to set aside the draft text and instead focus on developing the considerations in a tabular form, where the essence of sometimes complicated issues could be portrayed and juxtaposed in an efficiently condensed format. The table provided in Appendix A is the result of that activity, which includes the results of qualitative - and not quantitative - analysis. Economics are generally broadly understood, while on the other hand nonproliferation and physical security concepts are less well understood and deserve some definition and discussion. This is discussed in Section 2.

\section{OVERVIEW-NUCLEAR SECURITY THREATS AND METRICS}

In this document, the phrase "nuclear security" is used to include both nonproliferation (preventing the spread of nuclear weapons to a non-nuclear weapons state) and national safeguards and security (material accountancy and physical protection against subnational threats). The actors (both adversary and defender), the threat strategies (e.g., divert nuclear material at the state level for purposes of a national nuclear weapons program, as opposed to nuclear terrorism by a subnational actor), and the measures taken to mitigate those threats (e.g., international safeguards through the International Atomic Energy Agency [IAEA], as opposed to national safeguards and security by a national institution such as Department of Energy [DOE] or the Nuclear Regulatory Commission) are very different. Therefore, nuclear security considerations are appropriately divided into domestic (material accountancy and physical protection) and international (physical protection and nonproliferation) categories, as are the related economic considerations. This document follows this division.

Not only are the domestic and international threats different, but in some important ways, the specific fuel cycle needs of the U.S. are different from those of the international market. As a result, there are two distinct thrusts. "A domestic program to develop recycling and close the nuclear fuel cycle within the United States. It has an impact horizon beginning roughly mid-century. Much of the domestic work in the next couple of decades is focused on development of technology for recycling. The second thrust is aimed principally at supporting the international development of nuclear energy while reducing security risks. This has an immediate and urgent time horizon, and largely requires development of institutional arrangements (e.g., assured fuel supply). 
One of the primary objectives of new U.S. policy is to support the global growth of nuclear energy while reducing proliferation risk. Tactics are being developed to support this objective and include both technical and institutional measures. While technical measures are being pursued (e.g., improving safeguards technology), the biggest potential reductions in proliferation and security risk will result from controlling the architecture of the global nuclear enterprise (an institutional approach) in order to prevent access to weapons-usable technologies and fissile materials. From a nuclear security perspective, the immediate top priority should be preventing the spread of enrichment technology/capacity to new countries, especially Non-Nuclear Weapons States (NNWS), and removing both existing and future fissile materials from possible misuse.

Table 1 summarizes the basic threat categories and the metrics that can be used for assessing the relative proliferation resistance and physical protection (PRPP) robustness of alternative energy systems or facilities (PRPP 2006). This table contains the different threat strategies considered, as well as the relevant measures by which a system's resistance/robustness can be described. These concepts and criteria form the basis for the considerations and judgments in Appendix A.

Table 1. Nuclear security threats and metrics.

\begin{tabular}{|c|c|}
\hline \multicolumn{2}{|c|}{ Proliferation Resistance-Barriers to a country acquiring a nuclear weapon. } \\
\hline \multirow[t]{3}{*}{ High Level Threats } & Concealed acquisition of material from a declared facility \\
\hline & $\begin{array}{l}\text { Concealed production of material in a clandestine facility } \\
\text { (including by acquisition of sensitive technology through dual-use } \\
\text { channels) }\end{array}$ \\
\hline & Abrogation and overt misuse of declared materials and facilities \\
\hline \multirow{6}{*}{$\begin{array}{l}\text { Metrics (Measures) of } \\
\text { Proliferation Resistance (PR) }\end{array}$} & Proliferation Technical Difficulty (TD) \\
\hline & Proliferation Time $(\mathrm{PT})$ \\
\hline & Proliferation Cost (PC) \\
\hline & $\begin{array}{l}\text { Fissile Material Type (MT)-Resulting weapon material (e.g., highly- } \\
\text { enriched uranium [HEU] or WG-PU, RG-PU, etc.) }\end{array}$ \\
\hline & $\begin{array}{l}\text { Detection Probability (DP)-due to International Safeguards (or } \\
\text { Safeguardability) }\end{array}$ \\
\hline & Detection Resource Efficiency (DE)-(or Safeguardability) \\
\hline \multicolumn{2}{|c|}{ Physical Security-Barriers to theft or sabotage by a subnational. } \\
\hline \multirow[t]{2}{*}{ High Level Threats } & Theft of nuclear material, information or technology \\
\hline & Radiological sabotage of nuclear facilities or transport \\
\hline \multirow{3}{*}{$\begin{array}{l}\text { Metrics of Physical Protection } \\
\text { (PP) }\end{array}$} & Probability of Adversary Success (PAS) \\
\hline & Consequences \\
\hline & Physical Protection Resources (PPR) \\
\hline
\end{tabular}

A couple of examples are provided to illustrate the types of trade-offs between costs, physical protection, and proliferation risk.

Example 1. A simple example of a mutually beneficial option would be the use of institutional measures to reduce proliferation risk. This could be achieved through a bilateral agreement that obligates a country with a developing nuclear program to forgo entirely installing indigenous enrichment capability in exchange for fuel service guarantees. The country would avoid the investment costs of developing an enrichment capability in exchange for guarantees for economic fuel services. Nuclear security concerns would be reduced due to the avoidance of a potential proliferation capability. 
Example 2. A more complex example of a trade-off situation is provided in Figure 1. In this figure, a comparison is drawn between two facility design options requiring different concentrations of transuranic (TRU). Category I (also referred to as "CAT I") and other (lower security level) similarly designated facilities are DOE categories for U.S. national safeguards and security. ${ }^{\text {a }}$ These category designations are huge cost discriminators for facility capital and operating costs, so decision makers would typically want to avoid the added expense of a CAT I facility. On the other hand, such a choice can have a far-reaching impact on the fuel cycle. In this case, the higher TRU concentration would result in fabricating fewer transmutation fuel assemblies, less transportation, and needing fewer fast reactors (FRs) operating at conversion ratios less than $1.0 .^{\mathrm{b}}$ The other facility choice involves a CAT facility greater than 1 (CAT II, CAT III, etc.) using lower TRU concentrations. The higher CAT level facility would be less expensive to build and operate; however, the facility would incur much greater costs in the fuel cycle (i.e., requiring fabrication of many more fuel assemblies, more fuel transportation, etc.). Even more significantly from a cost of electricity standpoint, higher CAT levels would require a greater number of fast (burner) reactors to destroy the TRU. At the same time, however, neither option appears to have a significant impact on or advantage with respect to reducing proliferation risk.

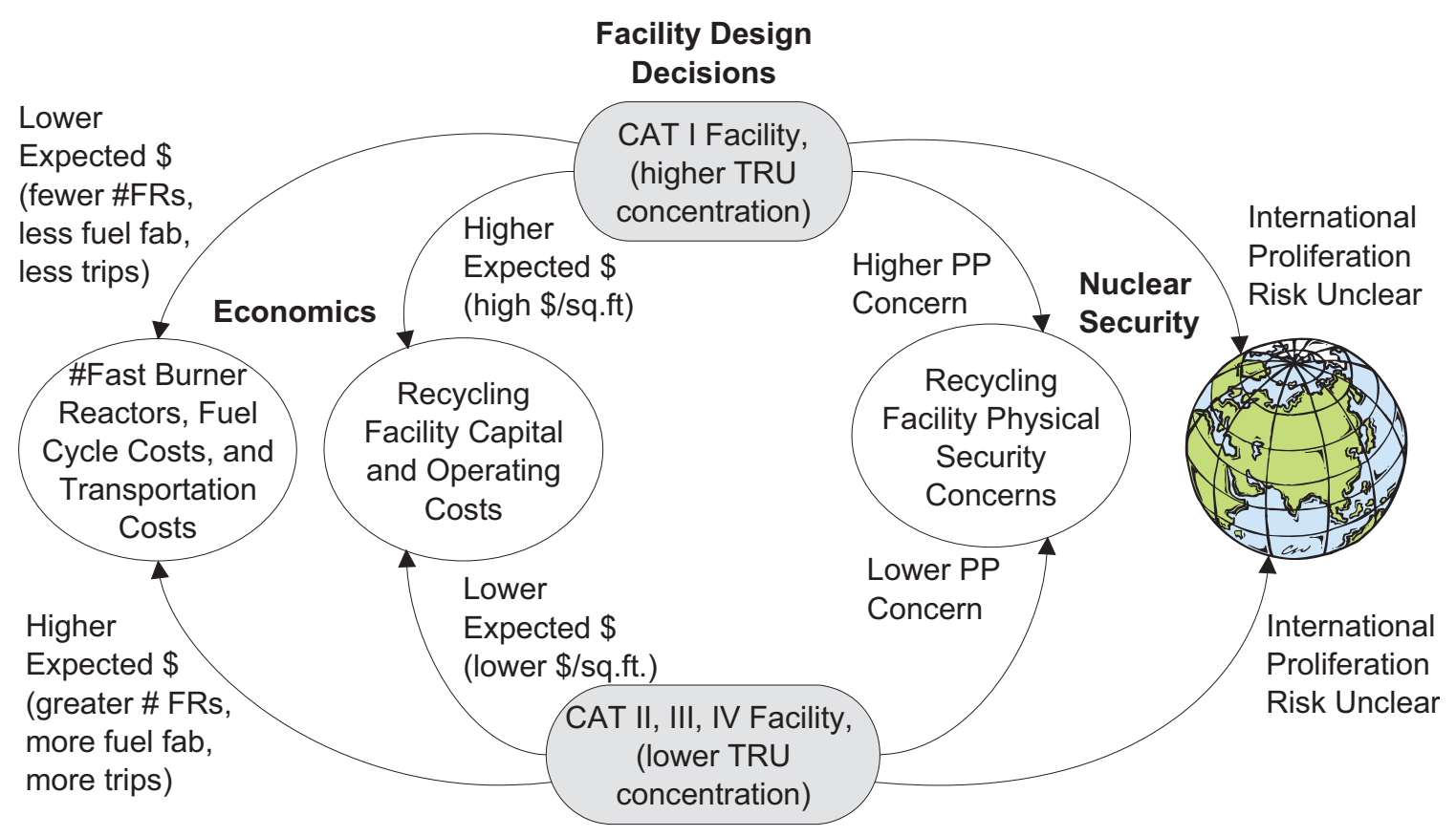

Figure 1. Example of economics and nuclear security trade-offs.

A statement of caution is in order. The analysis of the nonproliferation and physical security robustness of a system is not a simple matter, and conclusions drawn by deduction and judgmentwithout detailed analysis - can be deceptive. Further, the proliferation resistance and physical protection robustness of a system are often highly threat dependent, and consequently it is difficult to draw useful conclusions that are generally valid (threat independent). Thirdly, there is presently no widely-accepted, single figure of merit to describe security robustness - rather, it is a collection of measures that must be examined - and the individual metrics often move in contrary directions.

a. Category levels have nothing at all to do with foreign standards or international proliferation resistance issues. The levels represent a U.S. national physical protection matter.

b. The initial fast reactors are expected to have a price premium as compared to advanced light water reactors. 


\section{THE INTERACTION OF ECONOMICS AND NUCLEAR SECURITY}

\subsection{High Level Considerations}

The overarching mission is to support the global growth of nuclear energy while reducing nuclear security risk (legacy and future). Economics is one factor that drives the global growth of nuclear energy (over other forms of energy). Fuel cycle and nuclear enterprise architecture choices made for the sake of economics can impact nuclear security, while choices made for the sake of nuclear security usually have economic implications. These relationships must be understood and should inform the development process of both the fuel cycle architecture and nuclear energy policy.

The global nuclear enterprise will generally evolve along lines that are sustainably economic, unless it is somehow forced to evolve along different lines. Therefore, nonproliferation strategies that are inherently and sustainably economic are highly desirable. Sustainably economic strategies are more likely to be adopted and supported by industry, and will naturally reduce or even eliminate the burden to implement artificial and potentially expensive "special incentives or inducements" in order to affect a given course of action.

There are formal requirements to examine the connections between economics and nonproliferation. President George W. Bush outlined a seven-point agenda to strengthen the world's efforts to stop the spread of weapons of mass destruction (WMD) in a February 11, 2007 speech at the National Defense University (Bush 2007). President Bush stated that “...exporters should ensure that states have reliable access at reasonable cost to fuel for civilian reactors...." More recently, S.1138 was introduced by Senator Richard Lugar (R-IN) (GovTrack.us 2007). The legislation in S.1138 Nuclear Safeguards and Supply Act of 2007 is drafted "To enhance nuclear safeguards and to provide assurances of nuclear fuel supply." The bill specifically requires that economics must be taken into account while developing nonproliferation programs. This draft bill includes the requirements to consider "the economic rationale for a country or countries pursuing nuclear power..." and "the cost to the United States Government could be of establishing an INFA (International Nuclear Fuel Authority)." Additionally, in the DOE FY07 Congressional budget request, the budget provides $\$ 31.4 \mathrm{M}$ for the Gen IV initiative to expand research and development that could help achieve the desired goals of sustainability, economics, and proliferation resistance (DOE 2006).

Finally, note that nuclear security will be significantly enhanced by a strengthened role of the United States - and U.S. industry - in the global nuclear enterprise. Therefore, a renewed, reinvigorated, and dynamic role by United States industry in world nuclear markets should be strongly promoted and supported. This can be accomplished by such means as identifying and preferentially promoting strategies and tactics that improve the competitiveness of U.S. industry, both domestically and internationally. There is an urgent need for marketable solutions to problems that plague the U.S. and its nuclear industry. The lack of a viable domestic, marketable back end solution — either interim or final — is notable. The challenge to find solutions that will facilitate U.S. industry competing successfully is exacerbated by the fact that some of the significant foreign competitors are either partially or fully government owned or controlled industries (e.g., Russia and France).

\subsection{Examination of Specific Drivers and Features}

During the course of developing this white paper, the group chose a tabular approach to document the mutual exploration and evaluation of the drivers of mutual interest to economics and nuclear security. The comparison is provided in Appendix A, "Relationship between Economic and 'Nuclear Security' Issues/Drivers." For each driver, a number of specific factors were examined at a qualitative level. 
Specific points worthy of more detailed exploration are excellent candidates for quantitative treatment in the future as needs and resources permit.

In Appendix A, for each of the 10 drivers, national and international implications were considered for economics and nuclear security. The reader is encouraged to study this table. The row labeled "TradeOffs" seeks to capture, both for national and international scenarios, the interrelationship of economics and nuclear security. Those items found to have strong correlation are discussed further in Section 4.

\section{ANALYSIS AND INSIGHTS FROM PRELIMINARY EVALUATION}

Appendix A provides the details for 10 drivers that are important and applicable to economics and nuclear security. A number of these were chosen because they represent usual "norms" in economic analysis (e.g., standardization is generally regarded to be a cost-effective approach). These drivers considered include:

1. Transportation of new and used fuel, and separated fissile materials.

2. Diversity and organization of the nuclear supply market-providing enriched uranium (EU) or recycled uranium (RU).

3. Number and size of fuel cycle facilities.

4. Physical complexity (and technological sophistication) of fuel cycle facilities. Also relates to operational performance (capacity factors).

5. Reactor fuel composition (enrichment and radiotoxicity of fuel material).

6. Geographic distribution and location of fuel cycle facilities (centralized versus decentralized).

7. Buffer storage of fissile materials.

8. Standardization among fuel cycle facility designs.

9. Back-end closure of the fuel cycle through availability of long-term monitored retrievable storage and/or repositories for spent fuel.

10. Applications for grid-appropriate reactors.

The high-level evaluation of the tradeoffs between economics and nuclear security resulted in the observation that the issues/drivers generally fall into three categories of outcomes:

Outcome 1 can be stated, as "what's good for nuclear security is also good for economics" (and vice versa). This means that the best economic case is also at or near the best case from a PRPP perspective. Outcome 1 was the predominant result noted from this study, which is an important conclusion. Advanced fuel cycle scenarios with these characteristics could be sought to maximize these agreeable outcomes for economics and nuclear security. This outcome was supported by the evaluation of the following factors:

- Minimizing shipments of new and used fuel, and separated fissile materials (Driver 1)

- Minimizing the number (maximizing size) of fuel cycle facilities (Driver 3)

- Using low-enrichment, contact-handled fuels (Driver 5)

- Having only a few integrated and centralized fuel cycle facilities (Driver 6)

- $\quad$ Minimizing size of storage facilities for separated TRU (Driver 7)

- Using standardized fuel cycle facility designs (Driver 8)

- Minimizing onsite reactor storage and use of consolidated storage and disposal capabilities (Driver 9) 
- Using grid appropriate reactors where appropriate (Driver 10).

Outcome 2 is representative of a situation where there appears to be a conflicting trend between meeting economic and nuclear security goals. These are areas where additional analysis and study should be performed to quantify the costs and nuclear security risks for informed decision making. Conflicting trends between economics and nuclear security were evident in the following:

- Minimization of transportation to reduce costs (and physical security risk) versus build up of fissile material inventories in non-nuclear weapons states causing increases in proliferation risk (Driver 1)

- Creating high market diversity (competition) to minimize costs versus limiting the number of suppliers (e.g., using multinational facilities) to decrease the latent proliferation risk (Drivers 2, 3, and $6)$.

Outcome 3 is representative of a situation that requires further analysis. In the case of Driver 4, simple versus complex fuel cycle facilities, it was clear that economics will favor the simpler process. However, there is not a clear trend with either physical protection (material attractiveness predominates) or nonproliferation (simple may not be persuasively relevant). Further threat specific work is required to understand the tradeoffs.

In comparison of the implications from domestic versus international issues, the following perspectives were gained. On domestic issues, costs are tradeoff against the need for increased physical protection. The costs can be greatly increased to support physical protection/security (PP) requirements for transportation, fuel and TRU storage, recycling facility construction and operation, and for reactor facilities. The physical security risks that require additional protection (and hence more expense) will vary directly with the threat and the metrics of PP as described in Table 1.

For international issues, costs are traded against the requirements to support physical protection and provisions to minimize proliferation risk. These extra cost tradeoffs occur when taking steps to secure fuel at international facilities, paying higher costs due to using fewer trusted providers, paying additional transportation costs imposed by using more geographically dispersed (trusted) suppliers, incurring higher fuel cycle costs to support use of more intrinsically protected fuels, using less-than-economically sized storage and disposal facilities to minimize inventories, and imposing additional oversight costs to monitor facilities.

In addition to the 10 drivers evaluated in the white paper, other candidate concepts, factors, and drivers were identified for future investigation. These additional drivers include:

1. Selection of spent fuels separation technology (e.g., COEX ${ }^{\mathrm{TM}}$ versus UREX versus PUREX)

2. Collocated (e.g., pyroprocessing with fuel fabrication) versus separated facilities

3. Selection of aqueous separation products (e.g., group actinide separation versus separated $\mathrm{Pu}-\mathrm{Np}$ and Am-Cm, etc.)

4. Closing the fuel cycle via recycling and reprocessing, versus indeterminate interim storage of spent fuel

5. At reactor spent fuel storage versus consolidated storage at recycling facility

6. Assured fuel supply and take back arrangements versus continued "supply as usual"

7. Nuclear regulatory infrastructure for safety, security, safeguards, and training.

Also, it has been argued that nuclear safety should be considered as part of the bigger picture of nuclear risk, which has not been included in the present work where the focus is solely on nonproliferation and physical protection. 
If an assured fuel supply model is to be deployed to provide fuel services to other countries, certain inducements or considerations may be required, including potentially price subsidies, in order to discourage certain countries from developing indigenous capabilities. The additional cost of such arrangements would be incurred in order to reduce latent proliferation risk. What would be the costbenefit equation for this trade? Beginning such a tradeoff assessment could be an offspring from this white paper.

\section{WHITE PAPER CONCLUSIONS}

Development of future nuclear fuel cycle architecture, and policy, will benefit from a timely consideration of both economics and nonproliferation and physical security. The most desirable future strategies will be both sustainably economic and beneficial to nuclear security, and it is a worthy endeavor to develop and cultivate such solutions. Multinational ownership of nuclear fuel cycle infrastructure, for example, appears to be a highly desirable and effective institutional approach that is good for both nuclear security and economics, at the same time.

This white paper has uncovered some key insights to the trade-offs between economics and nuclear security. We have learned that for the predominance of issues/drivers, what is good for economics is also good from a nuclear security perspective (and vice versa). Guiding fuel cycle decisions toward these mutually beneficial scenarios is very desirable. This paper has also uncovered areas where the goals conflict, as can be particularly evident when a "global" perspective on the nuclear system is considered. We have examined the physical protection centered trade-offs for domestic deployment issues, and examined the shift toward proliferation risk concerns with international deployment.

In this paper, 10 drivers were selected for assessment. In the course of studying these drivers, additional areas for examination were exposed. These additional candidates for evaluation may provide us with an even greater depth of understanding of the trade-offs and mutual benefits. This paper is a step toward identifying these trade-offs and potential solutions.

As this investigation gains further clarity and quantitative understanding of the trade-offs, a range of potential solutions can be examined. For example, multinational ownership of nuclear fuel cycle infrastructure appears to be a highly desirable and effective institutional approach that has potential benefits for both nuclear security and economics. Further, nuclear security may be enhanced by strategies that strengthen the participation and competitiveness of U.S. industry in global nuclear markets. To this end, remedies for non-competitive aspects of U.S. industry could be sought (e.g., a competitively neutral spent fuel solution). The identification of a clear path forward that provides mutual benefits for economics and nuclear security is the projected outcome of this activity.

\section{RECOMMENDATIONS FOR FUTURE WORK}

The present work supports the importance of an assessment of economics and nonproliferation in the development of nuclear fuel cycle architecture and policy. A number of important issues urgently require further work:

1. Establish a business model for sustainably economic, secure, and reliable fuel services. A comprehensive study is needed that pulls together the work already completed in this area and which identifies and evaluates the economics of the most promising, proliferation-resistant options. This should also determine the cost to U.S. and international interests to establish such an endeavour (which might include establishing new cost-competitive suppliers and enhanced international regulatory oversight). 
2. Develop an effective international approach for spent fuel management that realistically considers the ability of U.S. business interests to compete internationally. This work should consider alternatives to spent fuel take-back, especially those that promote the competitiveness of U.S. interests. These alternatives should include, as a minimum, onsite dry storage with international regulatory oversight, and interim dry storage at a multinational interim storage facility. This should take full advantage of previous work to identify and evaluate the economics of the most promising and proliferationresistant options. Determine what it would cost the U.S. and the international community to establish such solutions.

3. Establish a viable business model for grid-appropriate reactors, including the development of innovative, economic, and secure approaches for supply to "lower-tier" locations (.e.g., multi-lateral ownership, extra-territorial siting, and so forth). This study would identify and assess the options for near and longer-term grid-appropriate proliferation-resistant reactors, the cost to establish suppliers of these reactors, and the cost to procure/construct. The study would select two or three countries for use as case studies to determine cost/challenges of implementation, including infrastructure development needs, and include an assessment of the security benefit associated with this approach. This work should coordinate closely with other efforts focused on the technology and security of grid appropriate reactors.

A number of other issues have been identified that warrant further consideration:

- When do we store materials versus transport to safer location?

- What is the optimal amount of product storage for future fuel fabrication?

- How do we determine the optimal number of suppliers?

- What is the optimal size of facilities?

- What is the optimal amount of reactor storage in NNWS?

- What are the optimal locations of facilities (storage, fuel cycle) to service the various markets?

- Identify situations where nuclear security overrides economics, and investigate effective solutions for engaging private industry to adopt these approaches (e.g., subsidies or other inducements).

\section{REFERENCES}

Bush, G. W., 2007, "President Announces New Measures to Counter the Threat of WMD," Remarks by the President on Weapons of Mass Destruction Proliferation, Fort Lesley J. McNair-National Defense University, Washington, D.C. (accessed September 10, 2007), http://www.whitehouse.gov/news/releases/2004/02/20040211-4.html, Web page accessed?

Dept. of Energy FY-2007 Congressional Budget Request, Budget Highlights, Office of Chief Financial Officer, February 2006, http://www.ne.doe.gov/budget/budgetpdfs/fy2007BudgetHighlights.pdf, Web page accessed Sept. 10, 2007.

GovTrack.us. S. 1138-110th Congress (2007): Nuclear Safeguards and Supply Act of 2007, GovTrack.us (database of federal legislation), http://www.govtrack.us/congress/bill.xpd?bill=s110-1138, Web page accessed Sept. 10, 2007.

PRPP, 2006, "Methodology for Assessment of Proliferation Resistance and Physical Protection of Generation IV Nuclear Energy Systems," Rev. 5. Generation IV Proliferation Resistance and Physical Protection (PRPP) Evaluation Methodology Group, 2006. 


\section{Appendix A}

\section{Relationship between Economic and Nuclear Security}

Issues/Drivers 
C-18

INL/EXT-09-15483 


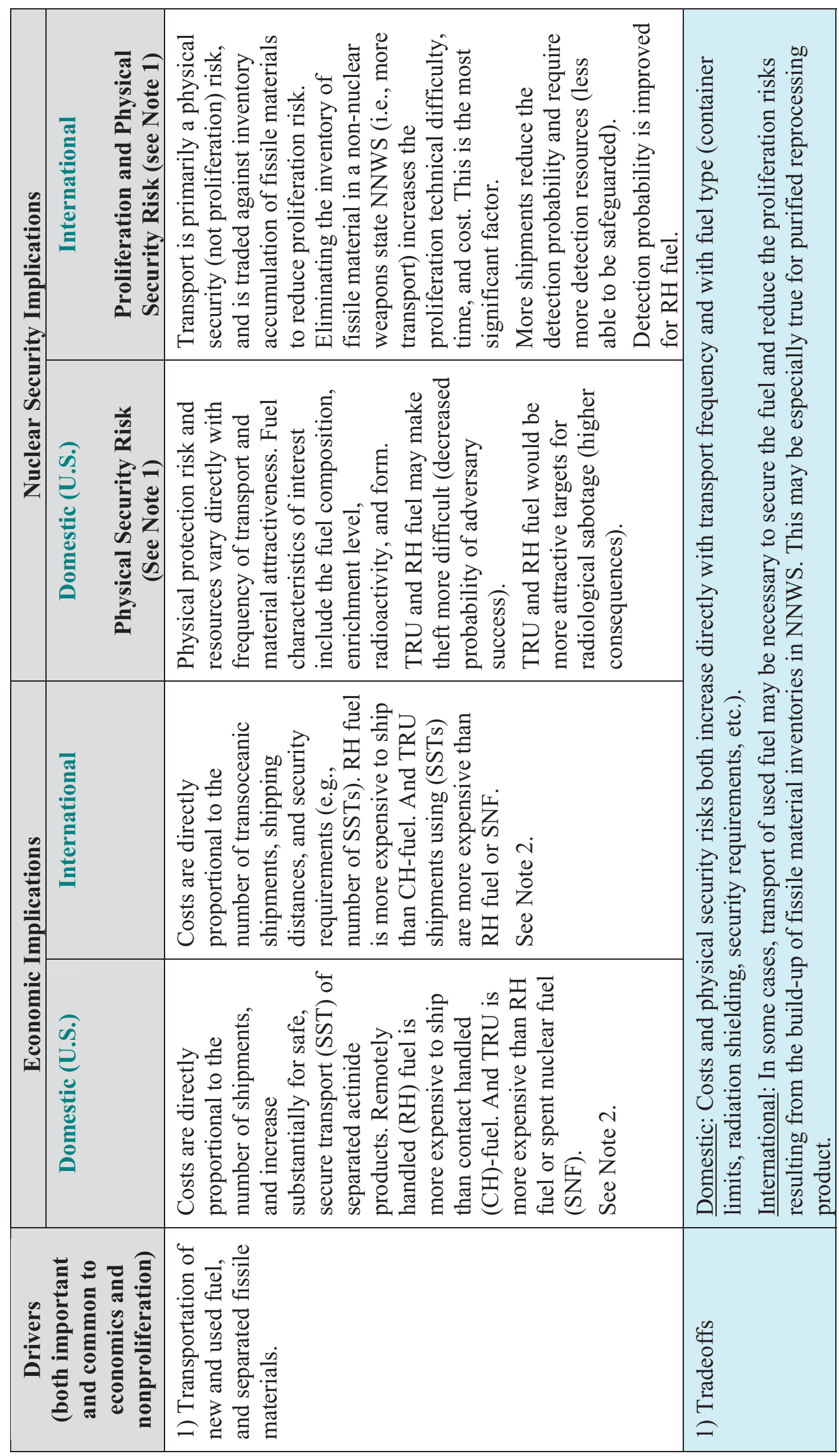




\begin{tabular}{|c|c|c|c|}
\hline \multirow{2}{*}{ 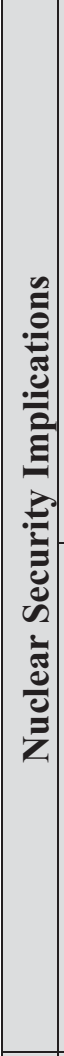 } & 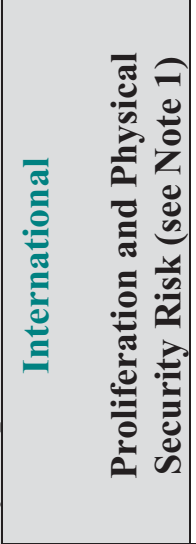 & 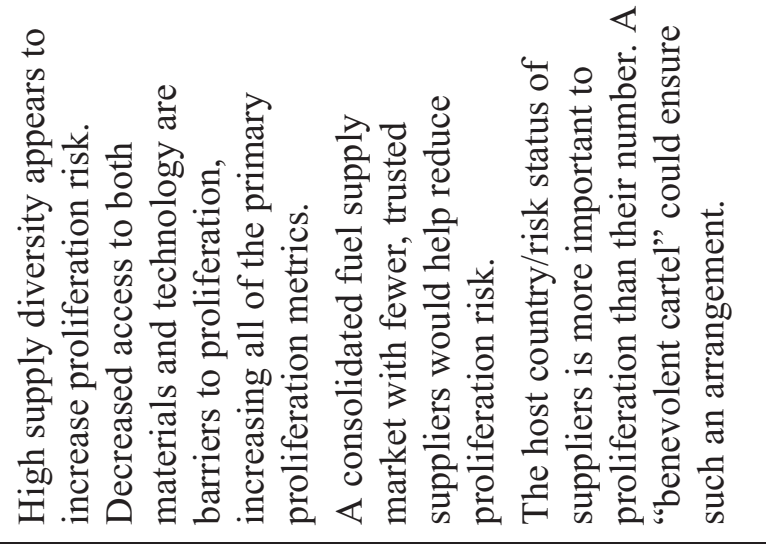 & \multirow{4}{*}{ 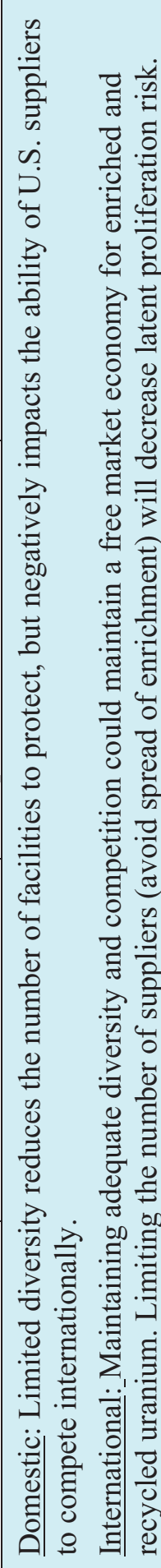 } \\
\hline & 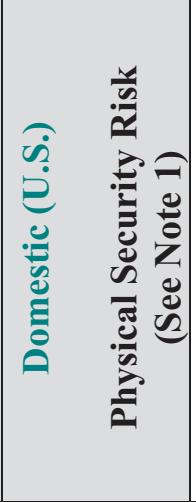 & 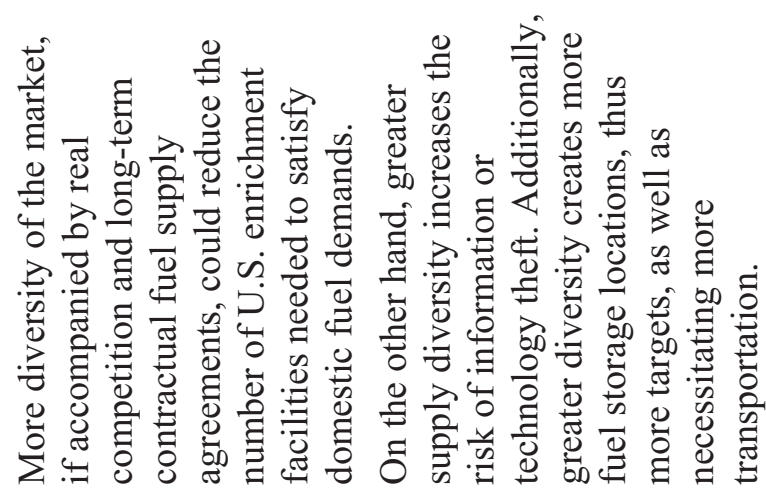 & \\
\hline \multirow{2}{*}{ 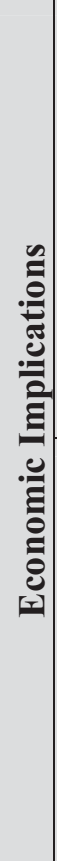 } & 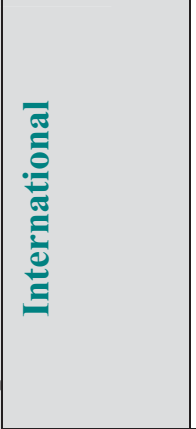 & 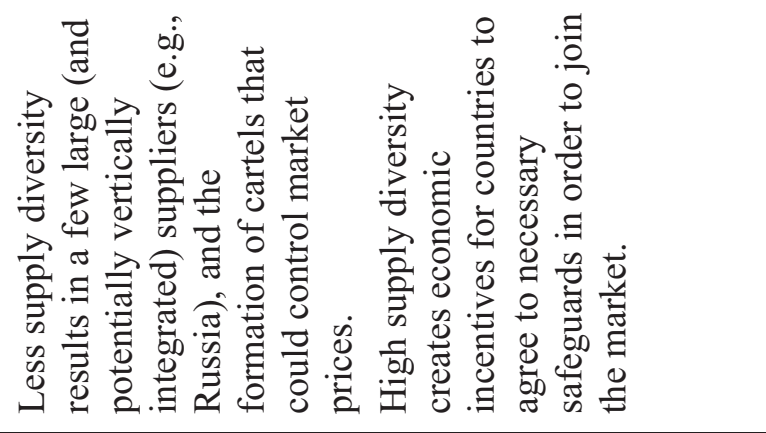 & \\
\hline & 苞 & 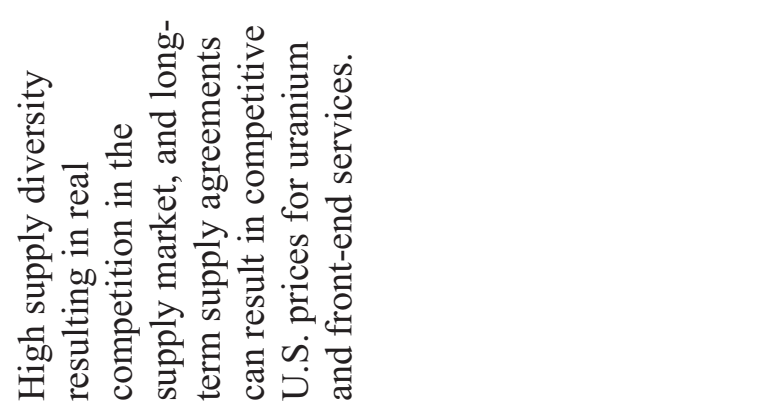 & \\
\hline \multicolumn{2}{|c|}{ 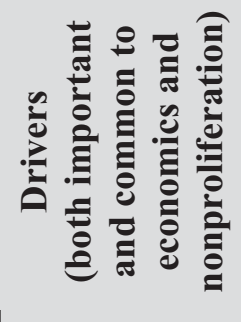 } & 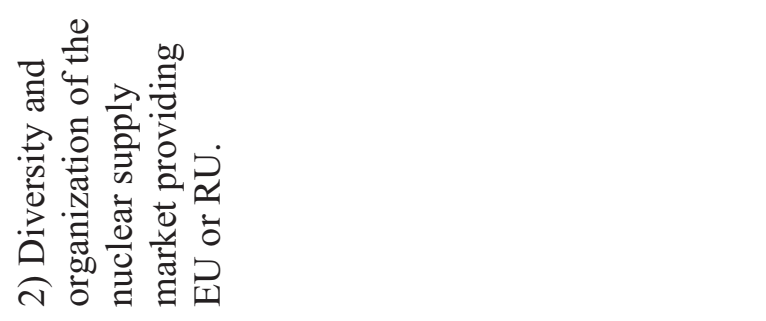 & 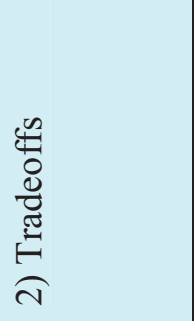 \\
\hline
\end{tabular}




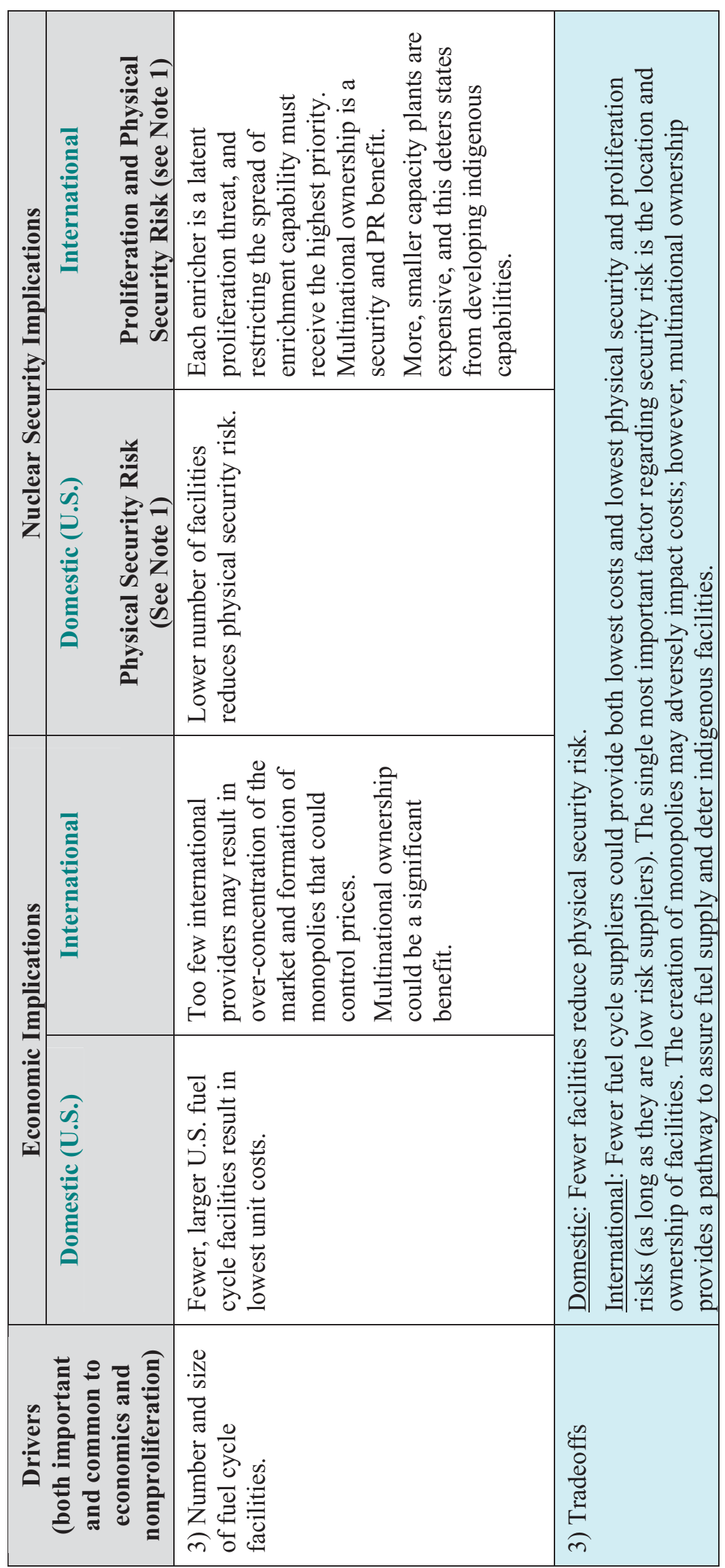

C-21

INL/EXT-09-15483 


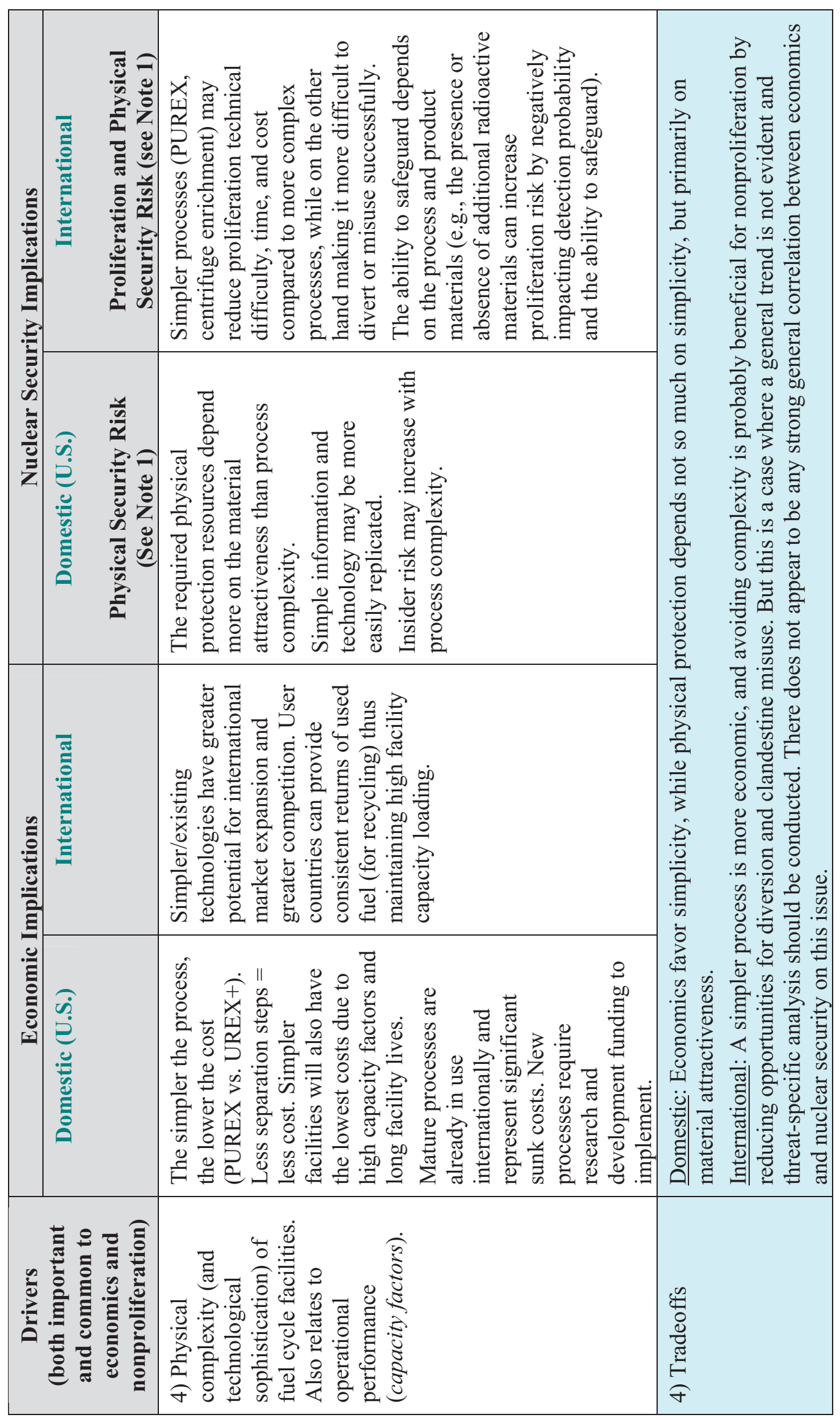




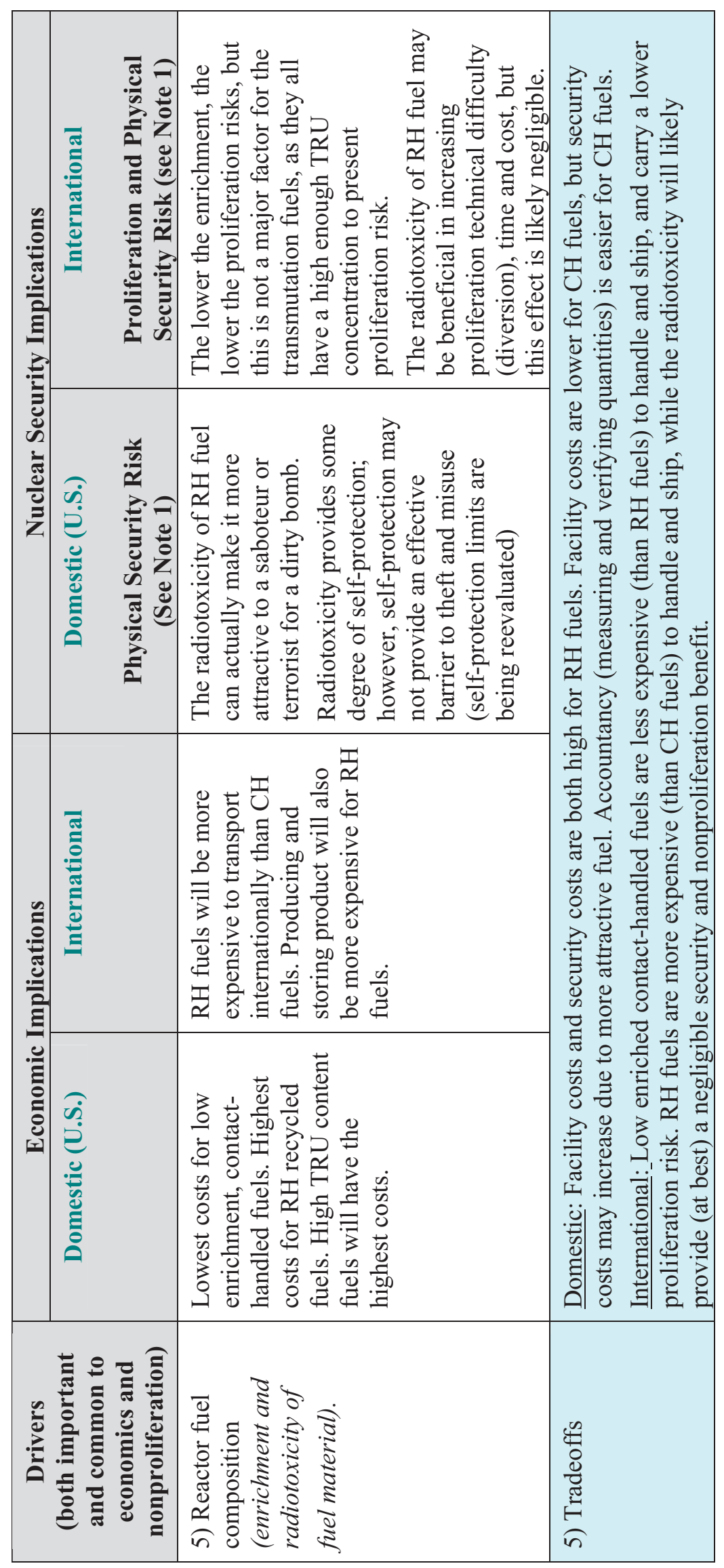

C-23

INL/EXT-09-15483 


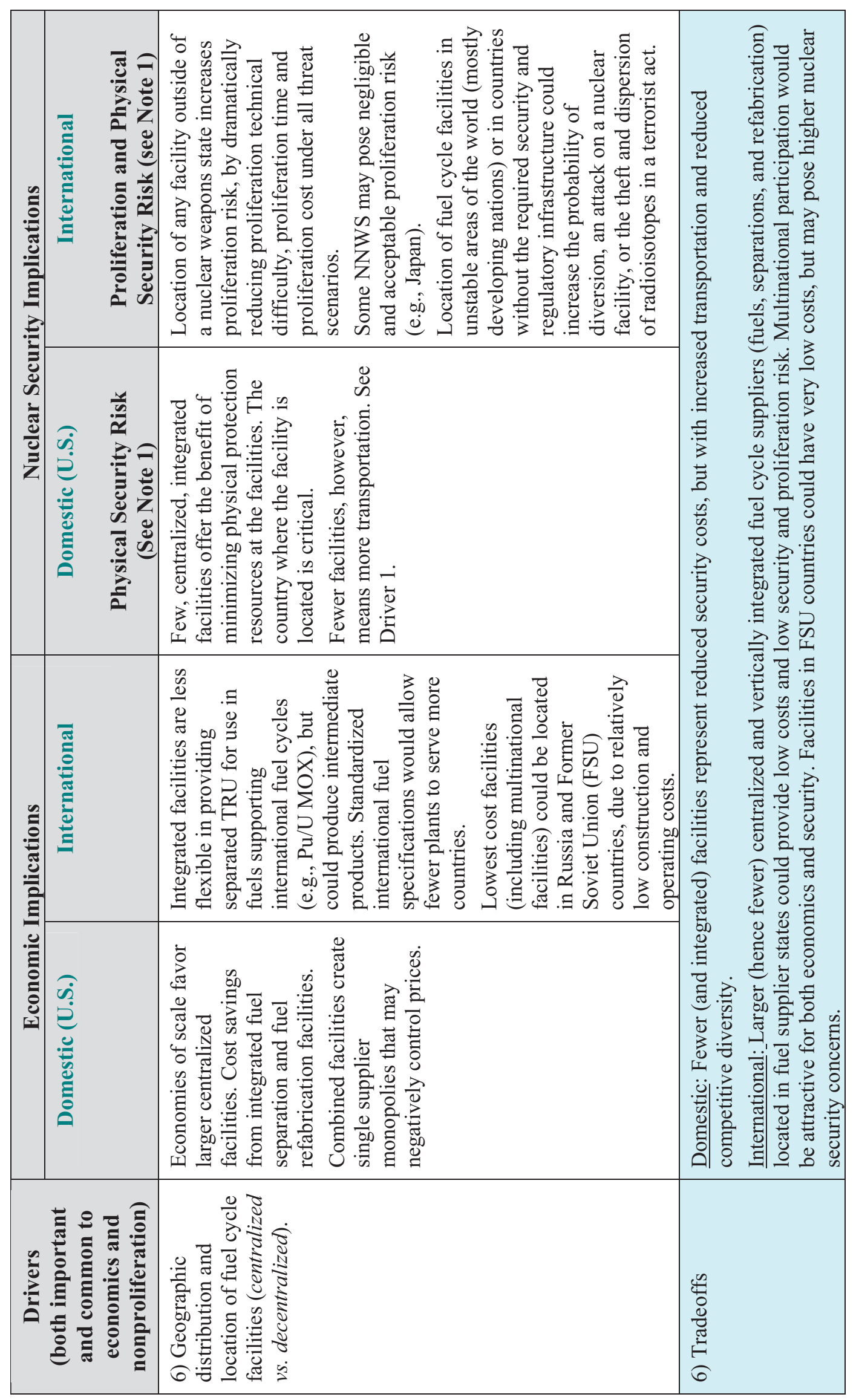




\begin{tabular}{|c|c|c|c|}
\hline \multirow{2}{*}{ 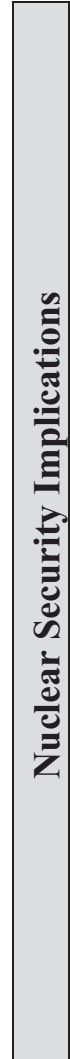 } & 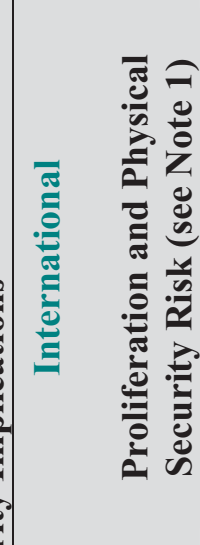 & 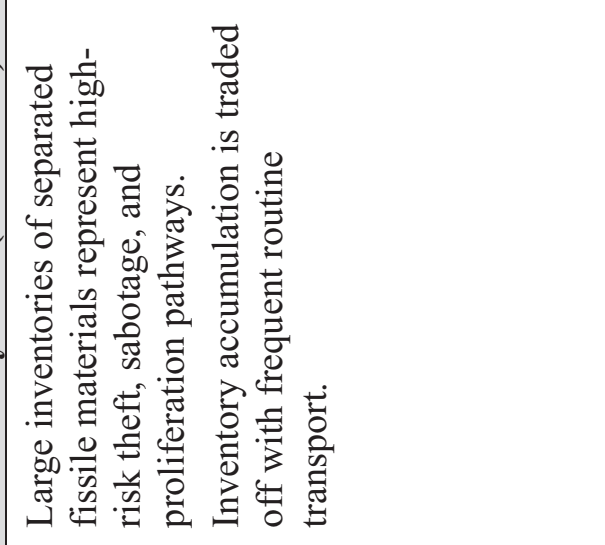 & \multirow{4}{*}{ 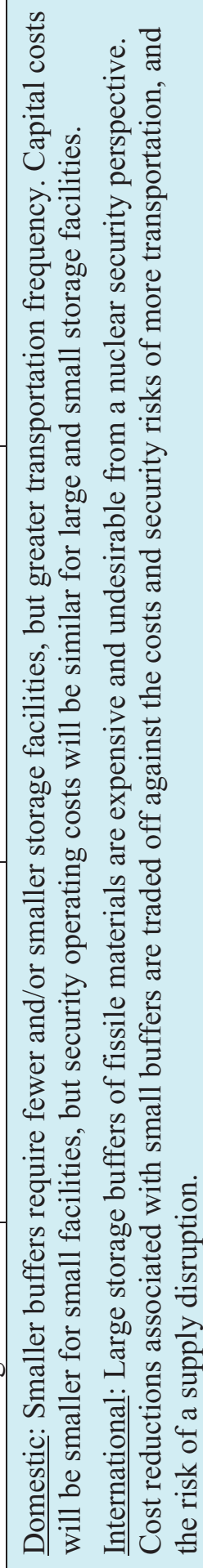 } \\
\hline & 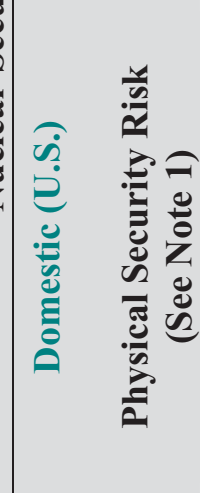 & 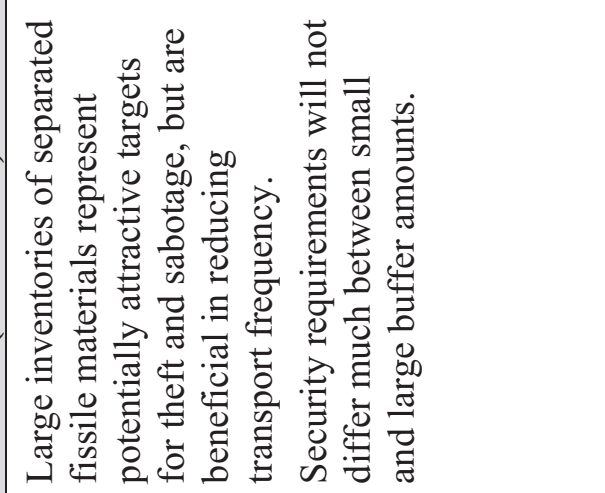 & \\
\hline & : & 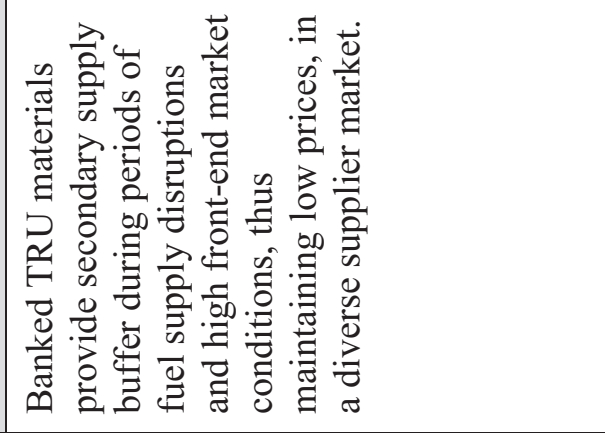 & \\
\hline 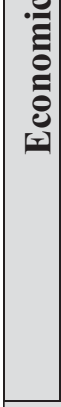 & 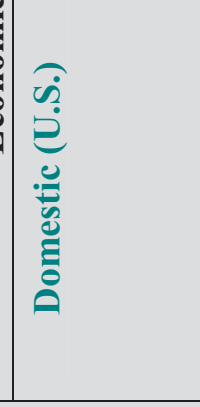 & 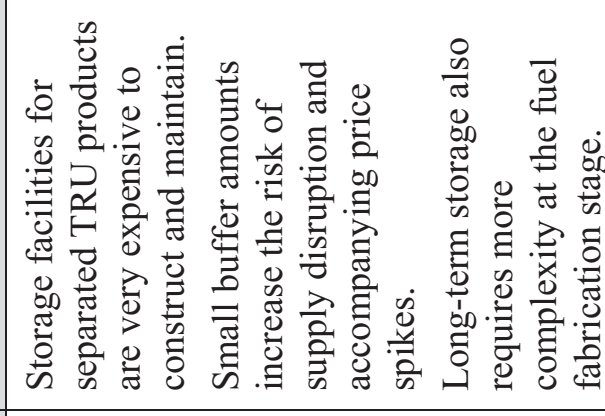 & \\
\hline & 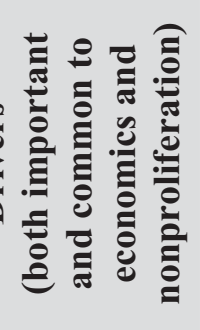 & 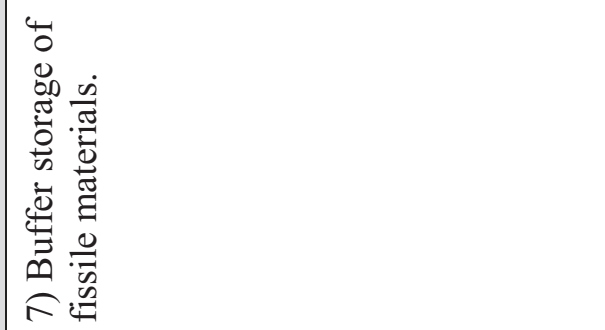 & 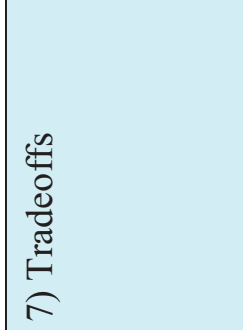 \\
\hline
\end{tabular}




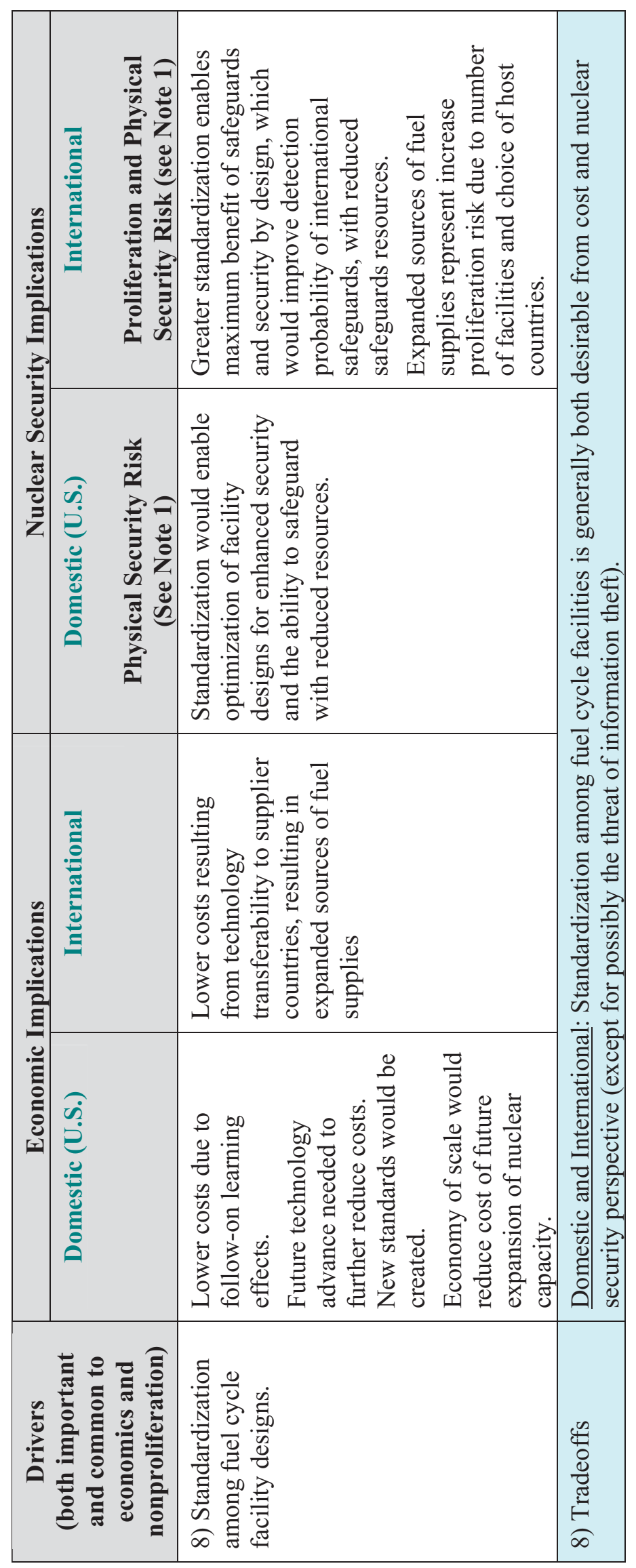

C-26

INL/EXT-09-15483 


\begin{tabular}{|c|c|c|c|}
\hline \multirow{2}{*}{ |ֶ: } & 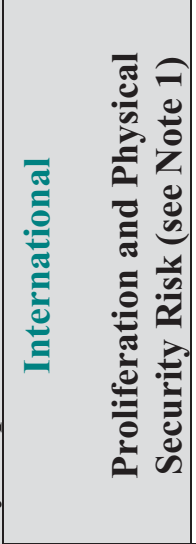 & 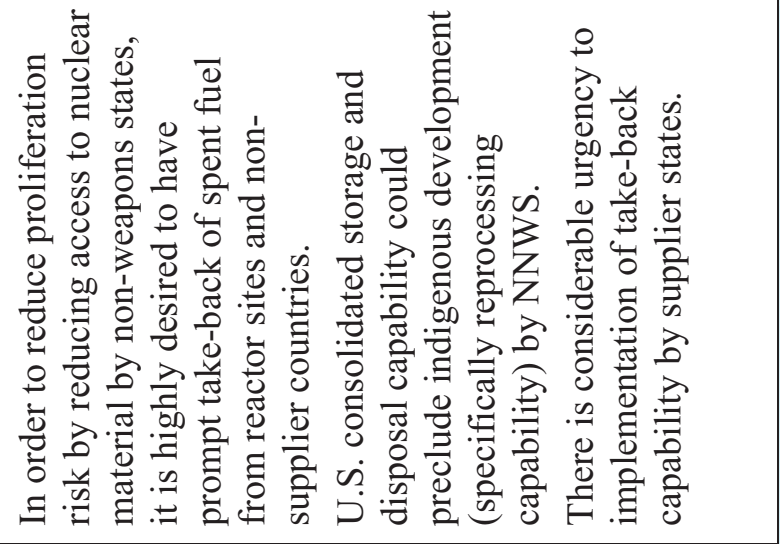 & \multirow{4}{*}{ 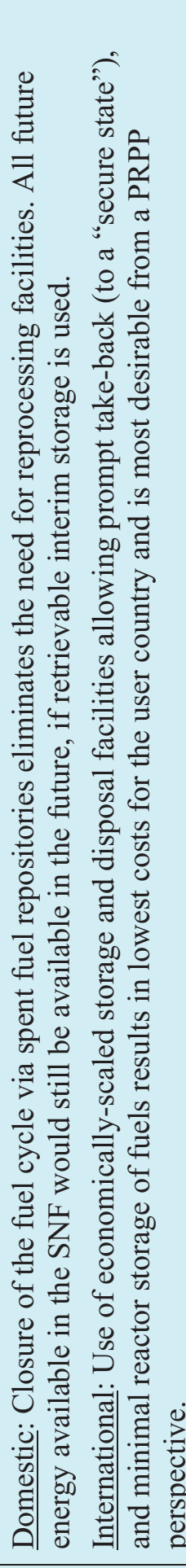 } \\
\hline & 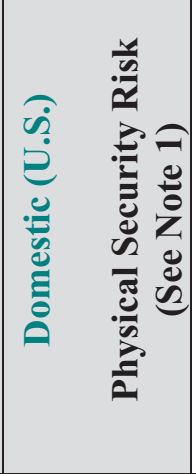 & 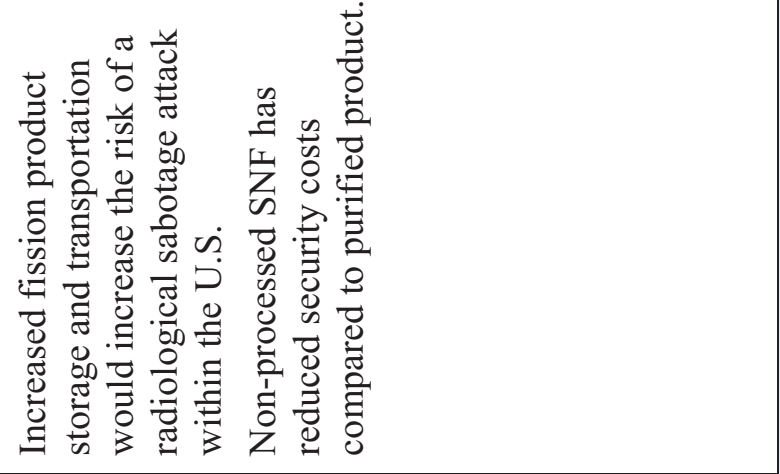 & \\
\hline \multirow{2}{*}{ 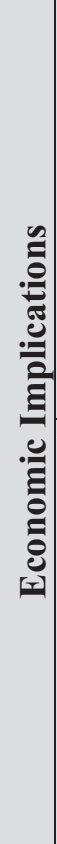 } & ) & 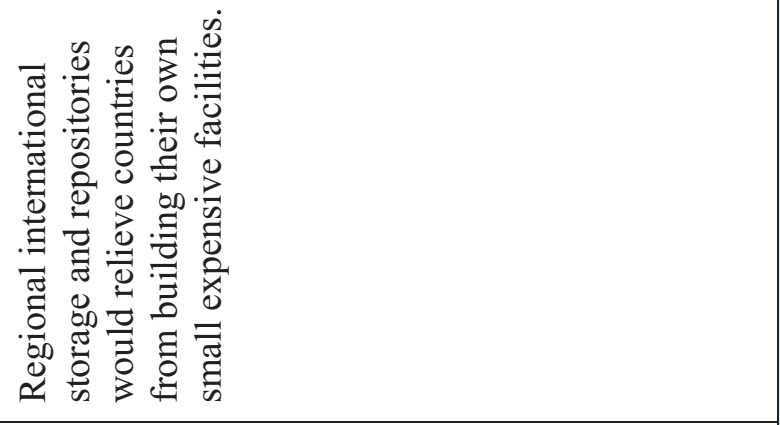 & \\
\hline & 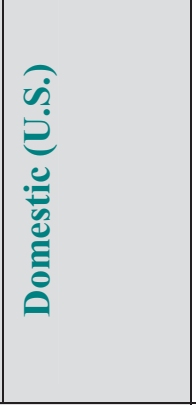 & 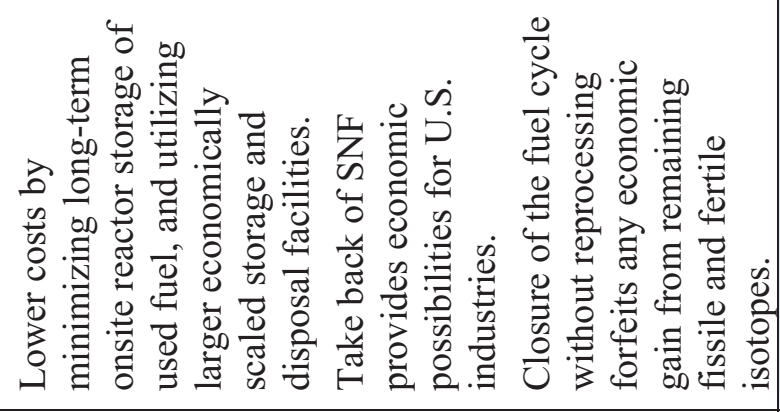 & \\
\hline & 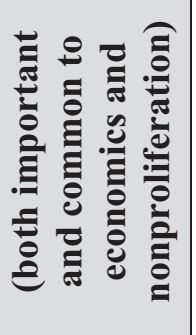 & 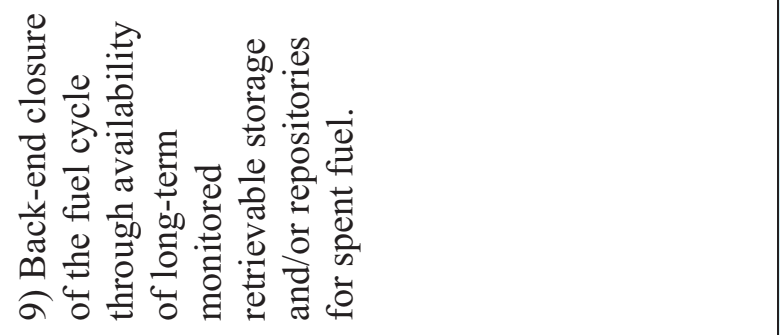 & 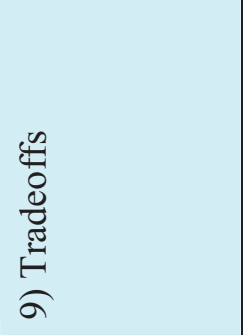 \\
\hline
\end{tabular}




\begin{tabular}{|c|c|c|c|}
\hline \multirow{2}{*}{ 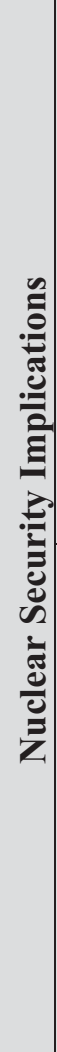 } & 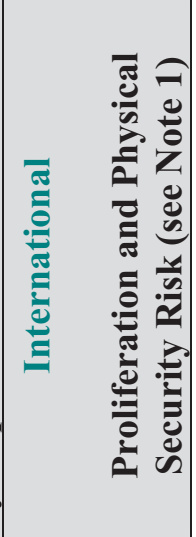 & 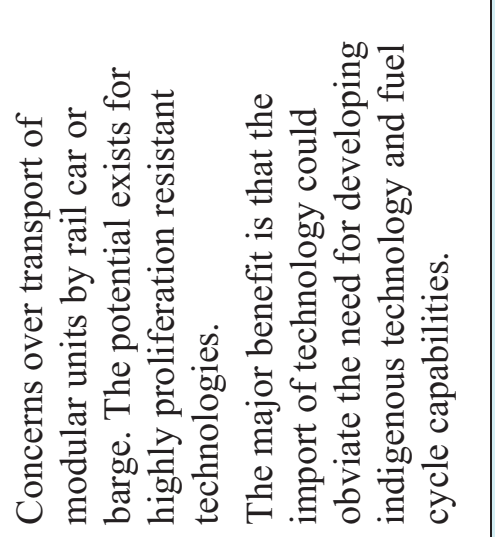 & \multirow{4}{*}{ 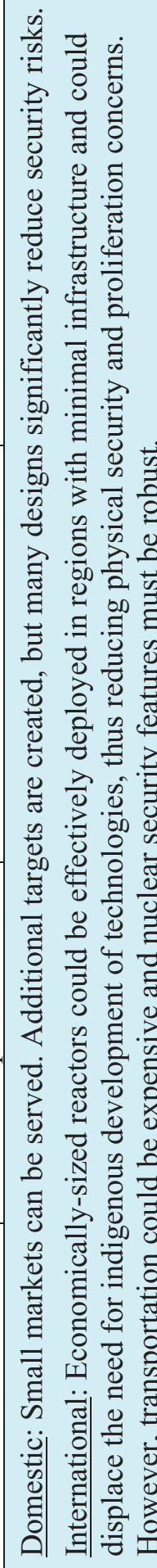 } \\
\hline & 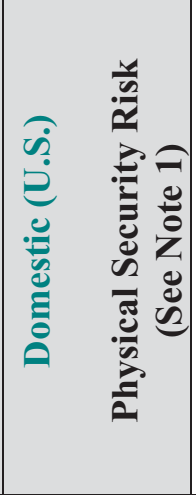 & 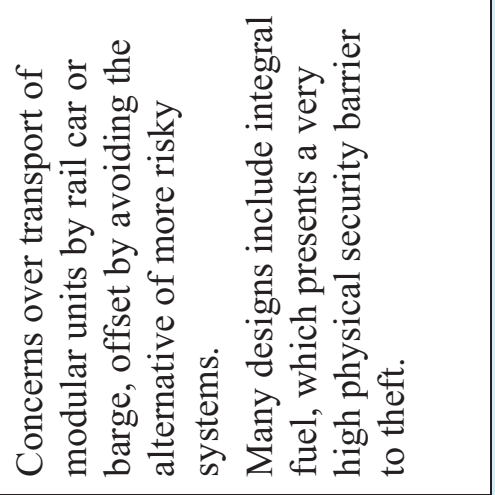 & \\
\hline \multirow{2}{*}{ 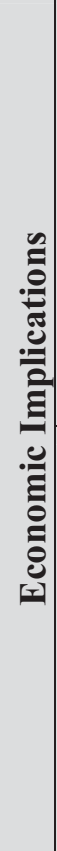 } & 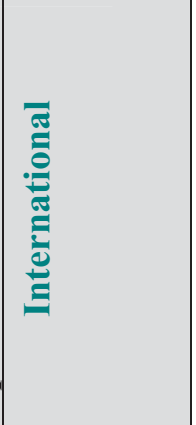 & 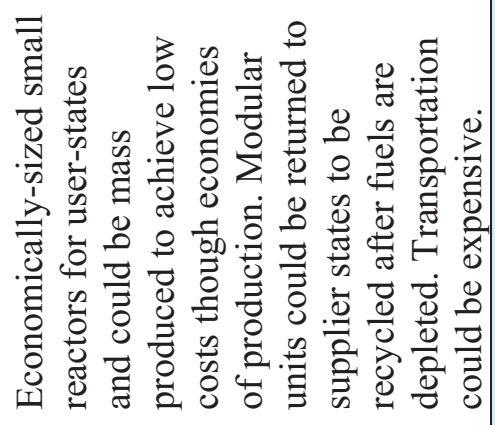 & \\
\hline & 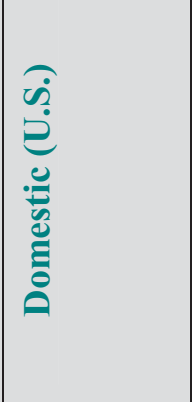 & 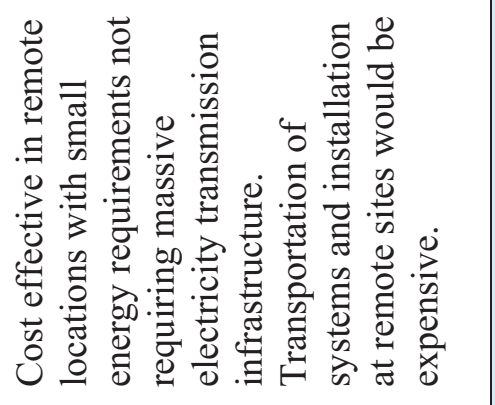 & \\
\hline \multicolumn{2}{|c|}{ 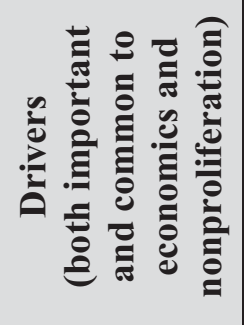 } & 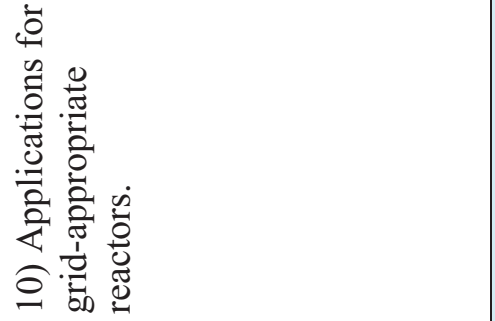 & 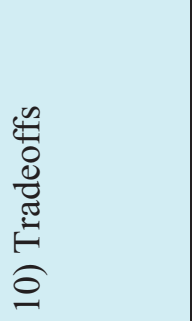 \\
\hline
\end{tabular}




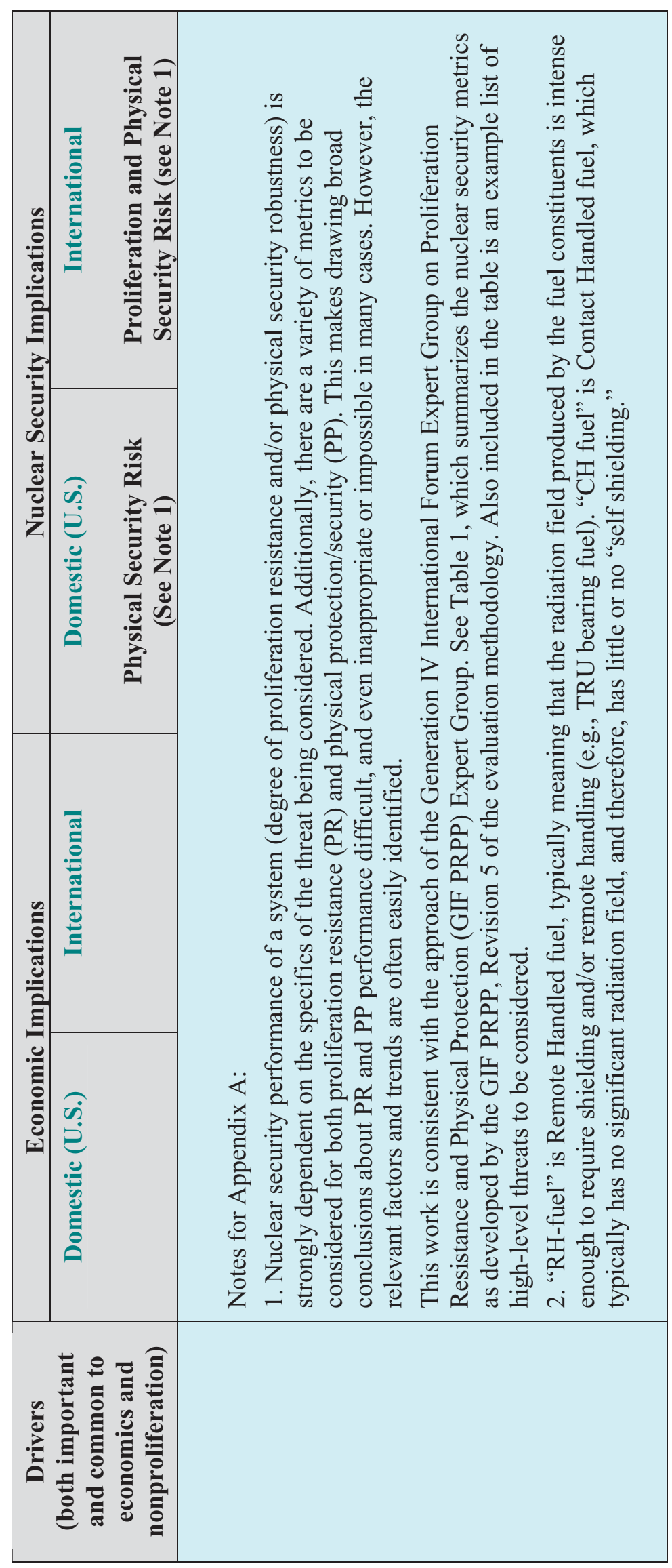

C-29

INL/EXT-09-15483 
C-30

INL/EXT-09-15483 


\title{
Attachment D
}

\section{Nuclear Materials Exchange Database Description and Methodology}

\author{
David Shropshire and Jennifer Morton \\ Idaho National Laboratory
}


D-2

INL/EXT-09-15483 


\begin{abstract}
The objective of the Nuclear Materials Exchange (NME) database has been to develop a capability that defines existing and new international nuclear resources and their linkages and relationships with current and future users within the international nuclear system. During FY-07, the NME has been developed as a prototype relational database and populated with data sets that describe the capacities and operational data for existing reactors and fuel cycle facilities located throughout the world. This report describes the NME and is intended to be a living document that will be expanded in lock step with the database development, so that there is a documented basis of the current capabilities, including the data sets, data structure, and available queries, as well as the next steps for its development.
\end{abstract}


D-4

INL/EXT-09-15483 


\section{CONTENTS}

ABSTRACT

ACRONYMS

1. DESCRIPTION

D-11

2. OBJECTIVE

D-11

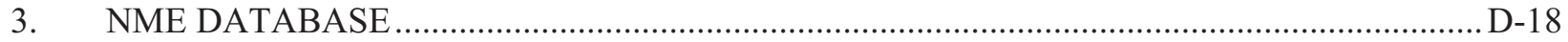

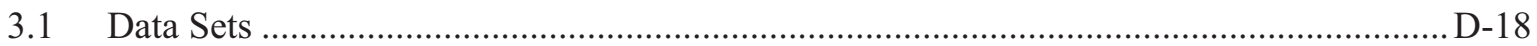

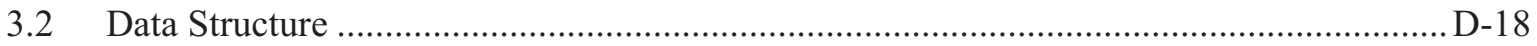

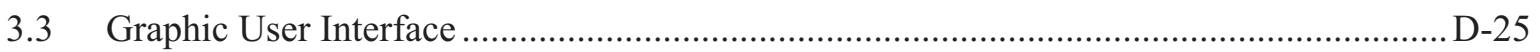

3.4 NME Integration with other Economic Tasks............................................................. D-26

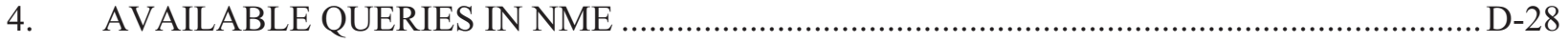

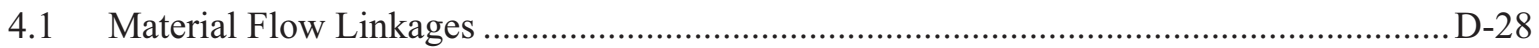

4.2 Identification of Fuel Cycle Facilities \& Reactors........................................................ D-30

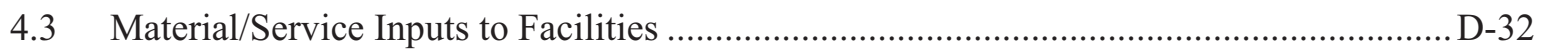

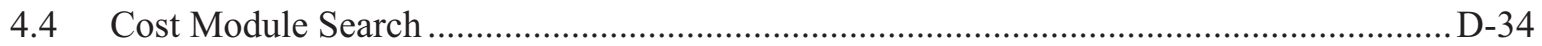

4.5 Summarizing Supply Capacity over Time …............................................................... D-37

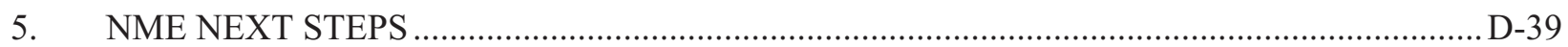

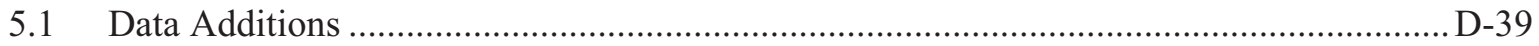

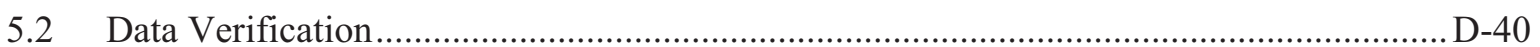

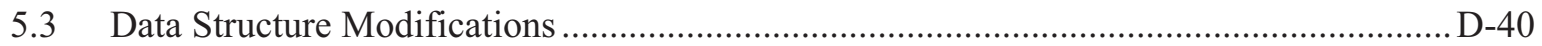

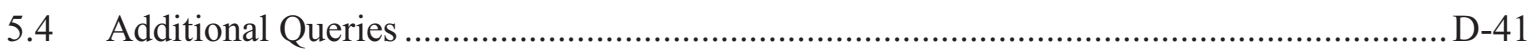

5.4.1 Human Resource Suppliers (Under Development) ............................................ D-41

5.4.2 Raw Resource Suppliers (Under Development) ............................................... D-42

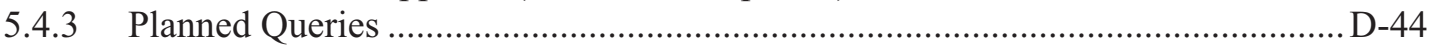

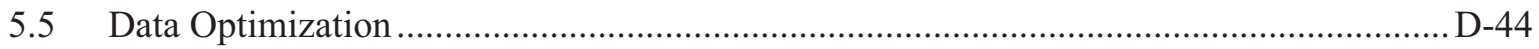

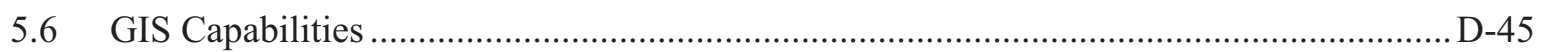

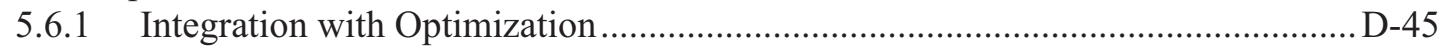

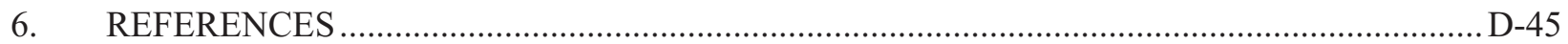

\section{FIGURES}

Figure 1. Application of industrial ecology and nuclear power: Potential Energy, Material \& Resource Flows with Nuclear Energy.

D-13

Figure 2. Comparison of fuel cycle modules in regions that are fuel suppliers versus fuel users, without a fuel bank.

D-14

Figure 3. Comparison of fuel cycle modules in regions that are fuel suppliers versus fuel users, with a fuel bank. 
Figure 4. Brainstorming which regions may be suppliers and users in 2050 in a world without advanced fuel cycles.

Figure 5. Brainstorming which regions may be suppliers and users in 2050 in a world with advanced fuel cycles.

Figure 6. Relationship diagram for the Nuclear Materials Exchange Database. .................................D-19

Figure 7. Screen shot of the Nuclear Materials Exchange main menu. ............................................... D-25

Figure 8. Screen shot of the "Operating Organization Profile" GUI. ................................................. D-26

Figure 9. Relationship between the Nuclear Materials Exchange and other Systems efforts................D-27

Figure 10. Screen shot of the "Material Flow Linkages" query. ........................................................ D-29

Figure 11. Selection from the resulting report for the "Material Flow Linkages" query example. ........D-30

Figure 12. Screen shot of the "Fuel Cycle Suppliers" query. ...........................................................

Figure 13. Selection from the resulting report for the "Fuel Cycle Suppliers" query example. ............. D-32

Figure 14. Screen shot of the "Material/Service Inputs to Facilities" query........................................ D-33

Figure 15. Selection from the resulting report for the "Material/Service Inputs to Facilities" query

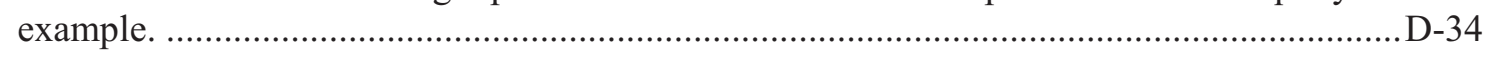

Figure 16. Screen shot of the cost module query............................................................................

Figure 17. Selection from the resulting report for the "Material/Service Inputs to Facilities" query

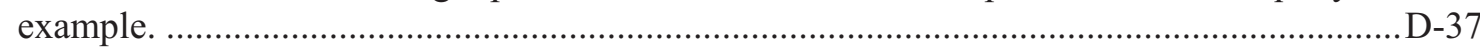

Figure 18. Screen shot of the "Supply Capacity over Time" query................................................... D-37

Figure 19. Selection from the resulting report for the "Supply Capacity over Time" query example, Part 1.

Figure 20. Selection from the resulting report for the "Supply Capacity over Time" query example, Part 2.

Figure 21. Screen shot of the current Human Resource Suppliers query. ……................................... D-41

Figure 22. Screen shot of the current raw resource suppliers query .................................................... D-43

\section{TABLES}

Table 1. "Country" table in the Nuclear Materials Exchange Database.............................................. D-20

Table 2. "Alliance" Table in the Nuclear Materials Exchange Database. ........................................... D-20

Table 3. "Alliance-Countries" Table in the Nuclear Materials Exchange Database..............................D-21

Table 4. "OperatingOrg” Table in the Nuclear Materials Exchange Database....................................D-2 1

Table 5. "Country-Orgs" Table in the Nuclear Materials Exchange Database.....................................D-21

Table 6. "Facility" Table in the Nuclear Materials Exchange Database................................................ D-22

Table 7. "OperatingOrg-Facilities" Table in the Nuclear Materials Exchange Database....................... D-22

Table 8. "Module" Table in the Nuclear Materials Exchange Database. ............................................. D-23

Table 9. "TransformFunction” Table in the Nuclear Materials Exchange Database.............................D-23

Table 10. "MaterialService" Table in the Nuclear Materials Exchange Database. ............................... D-23 
Table 11. "Units" Table in the Nuclear Materials Exchange Database. D-23

Table 12. "MaterialServiceUsage" Table in the Nuclear Materials Exchange Database. D-24

Table 13. "Quantity" Table in the Nuclear Materials Exchange Database. D-24

Table 14. Cost modules used in Nuclear Materials Exchange Database. D-35 
D-8

INL/EXT-09-15483 


\section{ACRONYMS}

AFC Advanced Fuel Cycle

AFCI Advanced Fuel Cycle Initiative

BNL Brookhaven National Laboratory

CANDU Canada Deuterium Uranium

ETP Energy Technology Perspectives

FBR fast breeder reactor

FR fast reactor

GIS Geographical Information Systems

GUI graphic user interface

HTGR high temperature gas reactors

HWR heavy water reactor

IAEA International Atomic Energy Agency

ID identification

IEA International Energy Agency

IMEP Industrial Materials Exchange Planner

LP linear optimization program

LWR light water reactor

MARKAL Market Allocation

MOX mixed uranium-plutonium oxide

NFCIS Nuclear Fuel Cycle Information System

NME Nuclear Materials Exchange

O\&M operation and maintenance

OECD Organization for Economic Cooperation and Development

OpOrg Operating Organization

PNNL Pacific Northwest National Laboratory

POC point of contact

PRIS Power Reactor Information System

PRPP Proliferation Resistance and Physical Protection

RU reprocessable uranium

SINEMA Simulation Institute for Nuclear Energy Modelling and Analyses

VB Visual Basic

VISION $\quad$ Verifiable Fuel Cycle $\underline{\text { Simulation }}$ 
D-10

INL/EXT-09-15483 


\section{Nuclear Materials Exchange Database Description and Methodology}

\section{DESCRIPTION}

The Nuclear Materials Exchange (NME) is a capability under development that intends to model the international fuel cycle. An NME prototype database has been developed. The initial data set includes the existing reactor and fuel cycle facilities located throughout the world. Additional information sets can be included such as: projected energy demands for each country; inputs and outputs of worldwide nuclear companies, as well as primary to tertiary supplier industries; company material balance profiles for region specific industrial symbiosis scenarios; historical, current, and projected quantity details for feedstocks, primary products, by-products, waste flows, and utilities; commodity prices and disposal costs; and generic profiles of manufacturing and recycling processes.

A current search of the open literature indicates that no nuclear materials exchange model of comparable features and capability as the NME exists. Design for the NME database structure was leveraged off the design of an existing system developed by Bechtel called the Industrial Materials Exchange Planner (IMEP) (Bechtel 2001). The IMEP was developed to look at how industrial symbiosis could be used to transition waste products from one industrial process into an input for another industrial process, thereby reducing the volume of waste and pollution, the costs of transportation and waste treatment, and the consumption of natural resources. This application of beneficially using nuclear byproducts as inputs to other industrial processes was the initial focus for developing the NME. During the past year, the interest in using it for other applications has expanded as described in Section 2. The database currently uses Microsoft ${ }^{\mathrm{a}}$ Access as its platform; this package was chosen because it is a common database package and easy to use.

This attachment is intended to be a living document that will be expanded in lock step with the database development, so that there is a documented basis of the current capabilities, including the data sets, data structure, and available queries, as well as the next steps for its development.

\section{OBJECTIVE}

The primary objective of the NME has been to develop a capability that models the international fuel cycle. To date, the NME has been designed with the following three applications in mind:

1. Support the concept of industrial symbiosis for nuclear energy to evaluate the potential exchange of wastes-for-materials between user-supplier nations. This was the primary application when the development of the NME began late in FY-06; it also explains its full name: the "nuclear materials exchange." This would allow an NME user to answer questions, such as: "With the availability of reprocessed materials from a new reactor, what new industries could be supported?" The NME could also be a planning tool for national, regional, and global planning scenarios that ask questions such as: "For a new reactor in a developing country, where will the necessary services, materials, and fuel be procured?" Or, "What are the needs and what is the potential for developing supporting industries in developed or developing countries to supply an expanding nuclear capacity?" Figure 1 is a diagram identifying what other co-located or nearby industries a nuclear reactor might be able to support through industrial symbiosis. This diagram is intended to apply to light water reactors (LWR), heavy water reactors (HWR), and fast reactors (FR) of all sizes. The dotted lines in the diagram are used to

\section{a. PRODUCT DISCLAIMER}

References herein to any specific commercial product, process, or service by trade name, trademark, manufacturer, or otherwise, does not necessarily constitute or imply its endorsement, recommendation, or favoring by the U.S. Government, any agency thereof, or any company affiliated with the Idaho National Laboratory. 
identify processes that are currently not using nuclear by-products because the technology is not available, it is not financially feasible, and/or clean traditional materials are plentiful. However, if the nuclear industry continues to grow, this may drive the market to consider alternatives to the traditionally used materials.

2. The second application to arise has been to assist with identifying gaps in demand as determined by calculating the delta between supply and demand for a particular fuel cycle material. These gaps could, in turn be filled by "opportunity facilities". A query has been developed to quantify the capacity of materials or services changing over a set period for a particular country or region. This is described in Section 4.5.

3. The third and most recent application to develop has been to support the Proliferation Resistance and Physical Protection (PRPP) concept of "Mapping Advanced Fuel Cycles onto the World." This will look qualitatively at scenarios without advanced fuel cycles and scenarios with advanced fuel cycles where economic and non-proliferation concerns are balanced. This can best be illustrated by Figures $2-5$. These figures show a preliminary effort to map which modules might exist in a supplier region versus a user region, as well as identify which regions (as defined by the International Energy Agency [IEA]) might fit into the supplier and user categories, and show how each region's capacities for enrichment, heavy water production, and separations (all of which are considered proliferation risks) might change if advanced fuel cycle concepts are introduced worldwide.

The first step in developing the NME has been to provide a comprehensive database of nuclear reactors and fuel cycle production facilities. The intent is to add primary supporting industries, including engineering and design, infrastructure, and components. The data has been aggregated by country, region, and alliance so that available national and regional capabilities can be identified. The NME could be used by U.S. and international users to:

- Locate fuel cycle suppliers (e.g., U supplies, conversion, enrichment, fuel fabrication)

- Locate raw resources (e.g., concrete, switches, rebar, and castings) needed to improve the electrical grid, construct and/or operate a particular nuclear fuel cycle facility or reactor

- Locate human resources (e.g., Architect-Engineering consultants, and safety analysts) needed during the following phases of nuclear power development: planning and licensing, construction, and operation and maintenance

- Identify linkage between a reactor and its supporting fuel cycle facilities.

Additional queries and data sets that may be added to the NME would allow it to:

- Show historical facility capacity information, current state, and future projections based on the expected operating life

- Show how regional blocks of countries could trade unique capabilities to build new nuclear generation capacity

- Show how recycled or un-recycled output streams could be used by secondary industries (e.g., medical isotopes)

- Show secondary industry expansion of country core infrastructures

- Show operational inputs and outputs to a global nuclear fuel bank

- Show economic tradeoffs and opportunities from sharing hard and soft capital resources, make/buy/trades, consuming new resources versus recycled resources, using or adapting technologies developed by other countries, and regional deployment of similar technologies. 


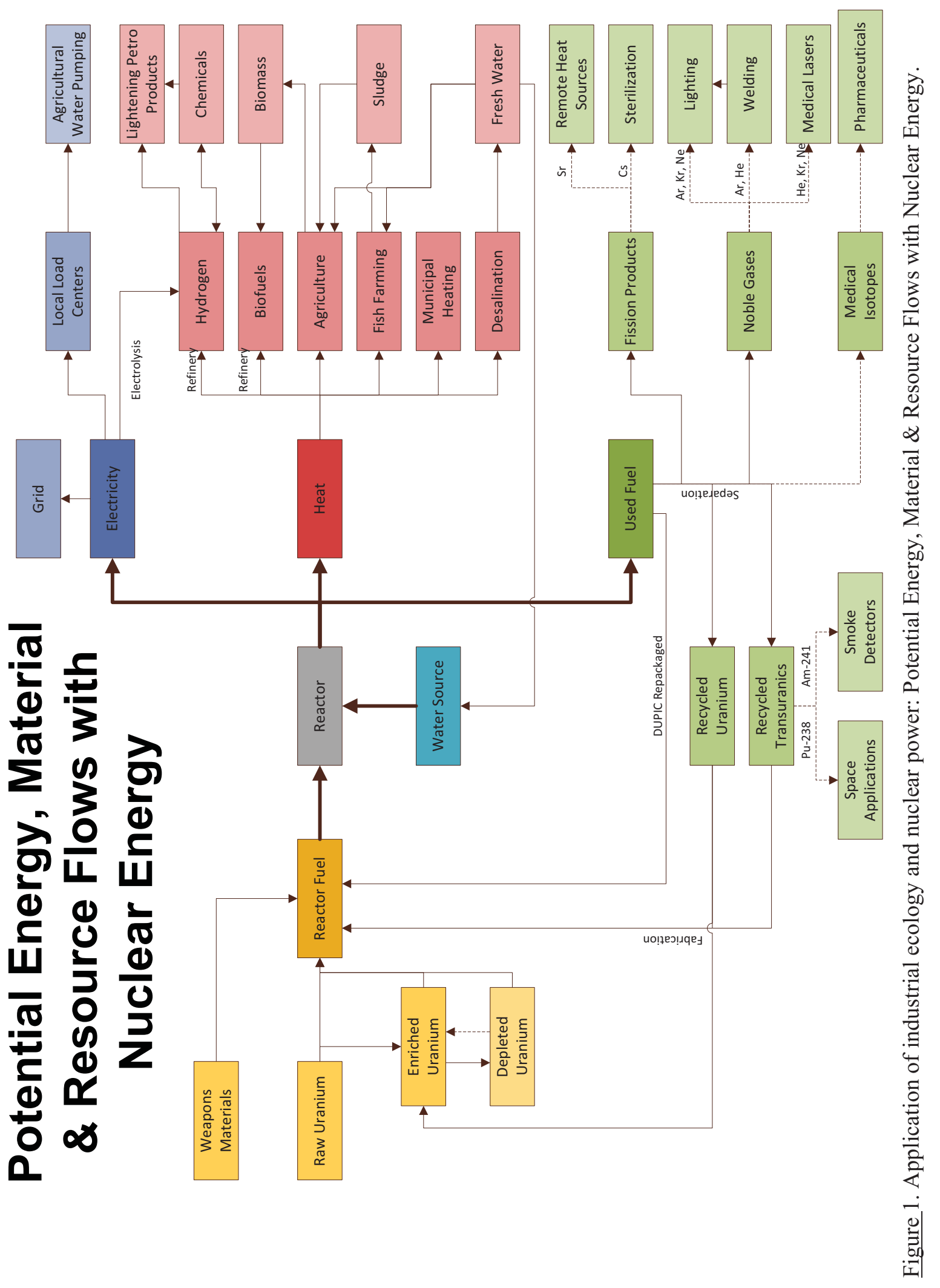


Draft

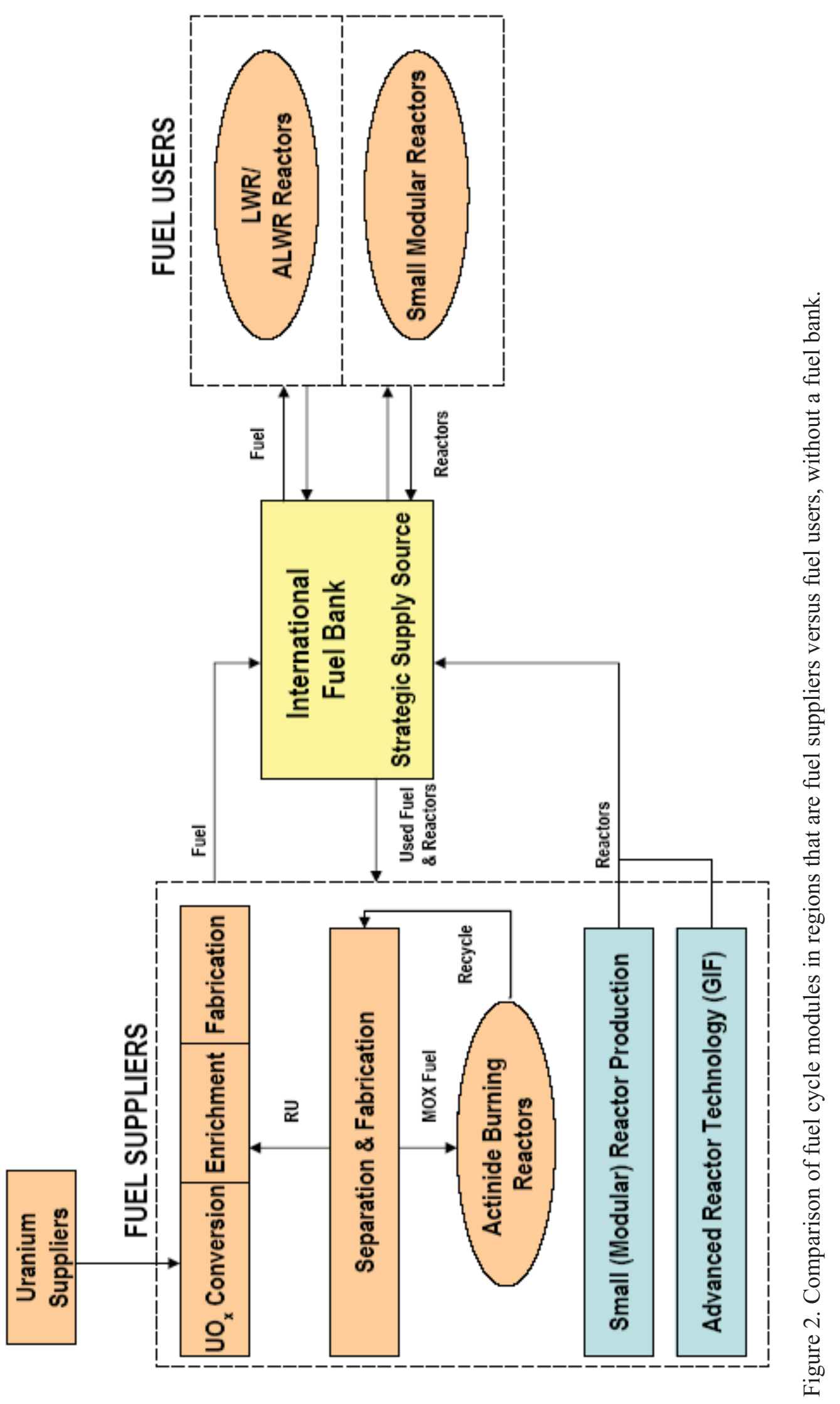

D-14

INL/EXT-09-15483 
Draft

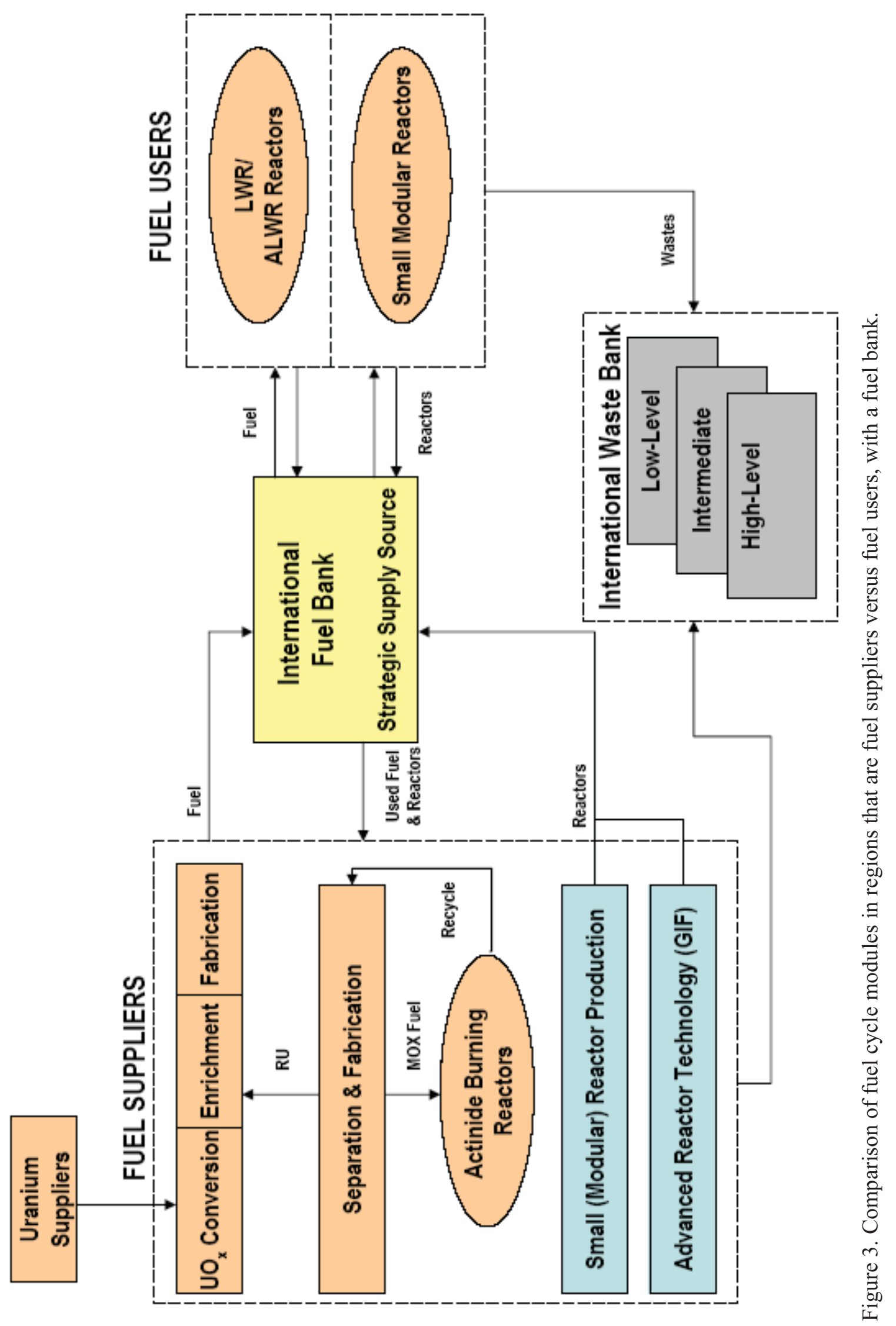

D-15

INL/EXT-09-15483 
Draft

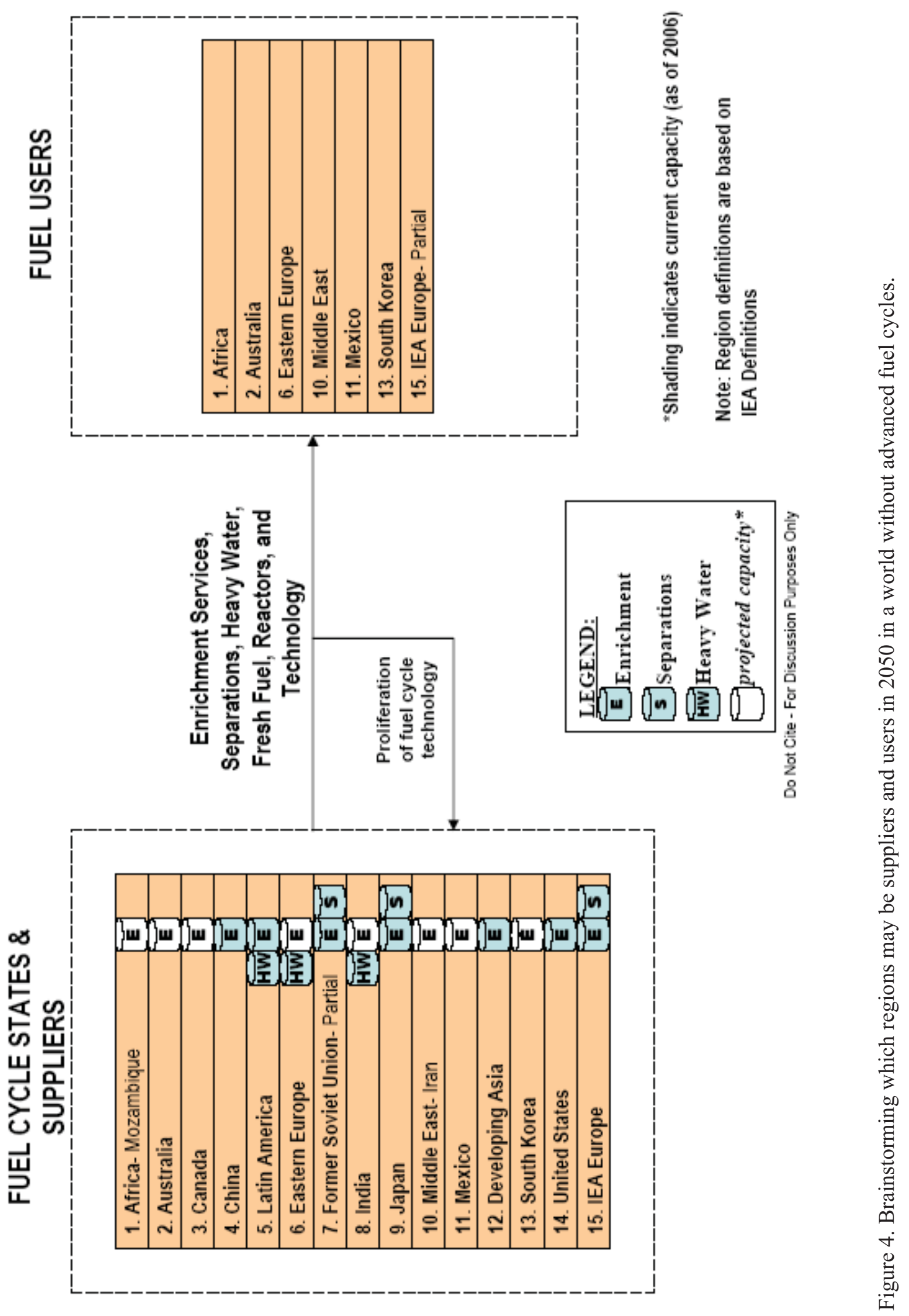


Draft

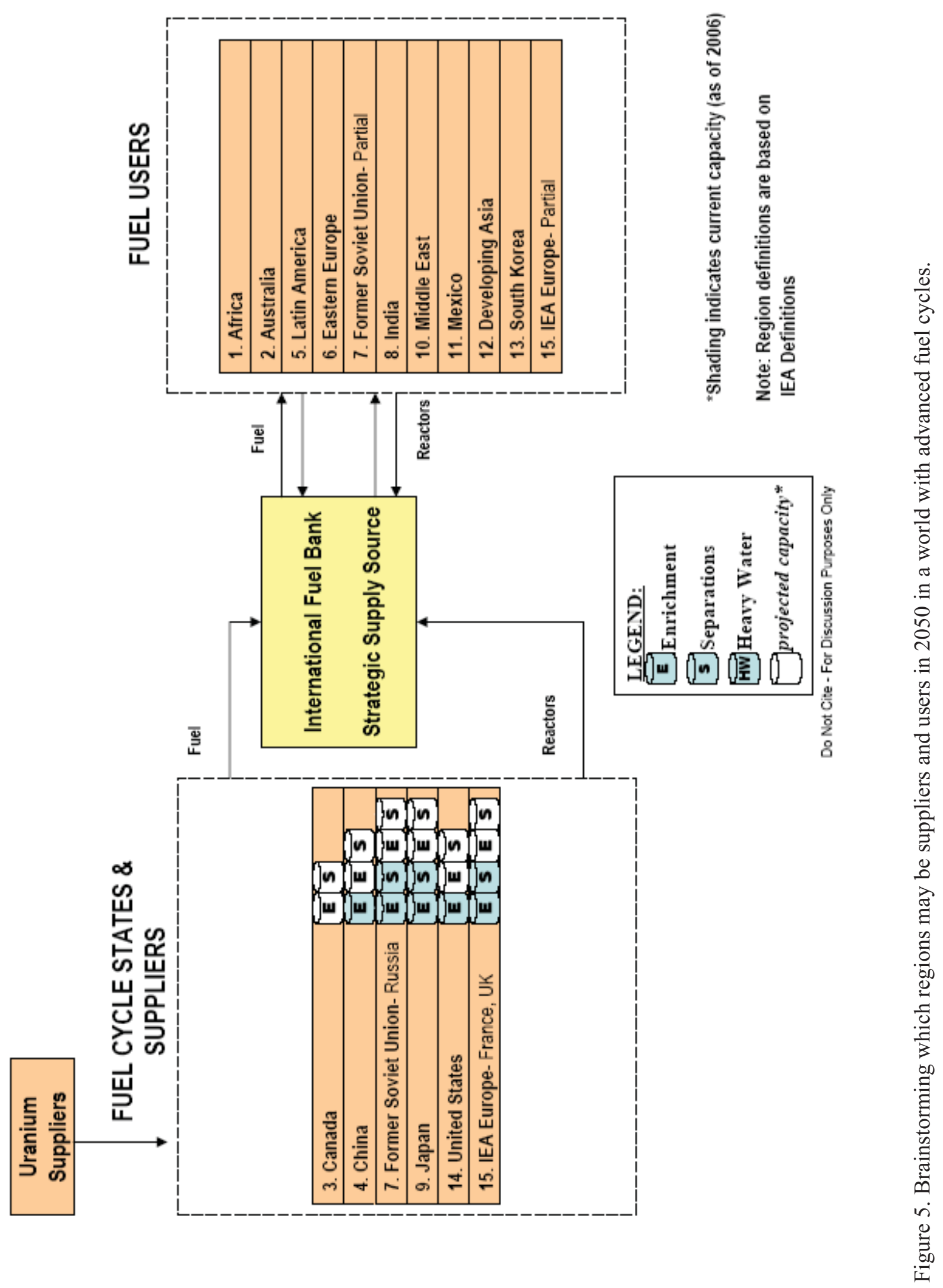




\section{NME DATABASE}

\subsection{Data Sets}

The initial data set includes existing reactor and fuel cycle facilities located throughout the world. Data has been mined from the following sources to date (type of data mined noted in parentheses):

- International Atomic Energy Agency (IAEA), Country Nuclear Fuel Cycle Profiles, Technical Report Series No. 425, $2^{\text {nd }}$ Edition, 2005. (Reactors and Fuel Cycle Facilities)

- IAEA, Nuclear Fuel Cycle Information System (NFCIS), www-nfcis.iaea.org/iNFCISMain.asp. (Fuel Cycle Facilities)

- World Nuclear Association Reactor Database, www.worldnuclear.org/wgs/decom/database/php/reactorsdb index.php. (Reactors)

- Nuke Database System, http://www.icjt.org/plants/index.html. (Latitude and Longitude coordinates for Reactors).

Database development for the NME model is a critically essential step. Without adequate data, the model will not be useful. However, the development is a time consuming process requiring a large effort. Much of the data is not readily available in the open literature. A systematic and a phased approach will be needed.

\subsection{Data Structure}

The prototype version of the NME was structured with an initial set of use cases or queries in mind, and the design of the IME as a reference. The design objective of the NME is to promote modularity in data and interfaces, so incremental enhancements are easily made, and fit within the overall design philosophy of the system. As new requirements are specified, the design will be adapted accordingly by adding new data structures.

The design philosophy of the NME has been to modularize data according to a hierarchical relationship among entities represented in the system. The data relationship diagram in Figure 6 shows the relationships between each of the tables and respective fields, also known as the "back-end" of the database. The links between each of the tables are shown with lines between the data fields that are specifically linked, and include an infinity $(\infty)$ or one (1) symbol. The infinity symbol identifies a "many" relationship and the one (1) identifies a unique relationship. For example, each facility has a unique listing with a unique identification number in the "Facility" table, but may be listed multiple times in the "OperatingOrg-Facilities" table where the relationship between the facility and its Operating Organization is defined. The same is true for an Operating Organization; it has only one unique listing in the "OperatingOrg" table, but may be listed many times in the "OperatingOrg-Facilities" table.

The highest-level entity in the NME is the Operating Organization (OpOrg). An operating organization is a specific Company or Organization. OpOrgs are associated with a Country, and made up of Facilities. Countries can be grouped into Alliances.

The next level in the hierarchy below the OpOrg is the Facility. Multiple Facilities can be associated with an OpOrg.

The final level is the TransformFunction. Multiple TransformFunctions can be associated with one Facility. TranformFunctions have inputs and outputs of materials and services. TransformFunctions are typically key process steps that produce one or more finished products or services. The TransformFunction keeps track of its material and service flows via a "Quantity" table. This table tracks 

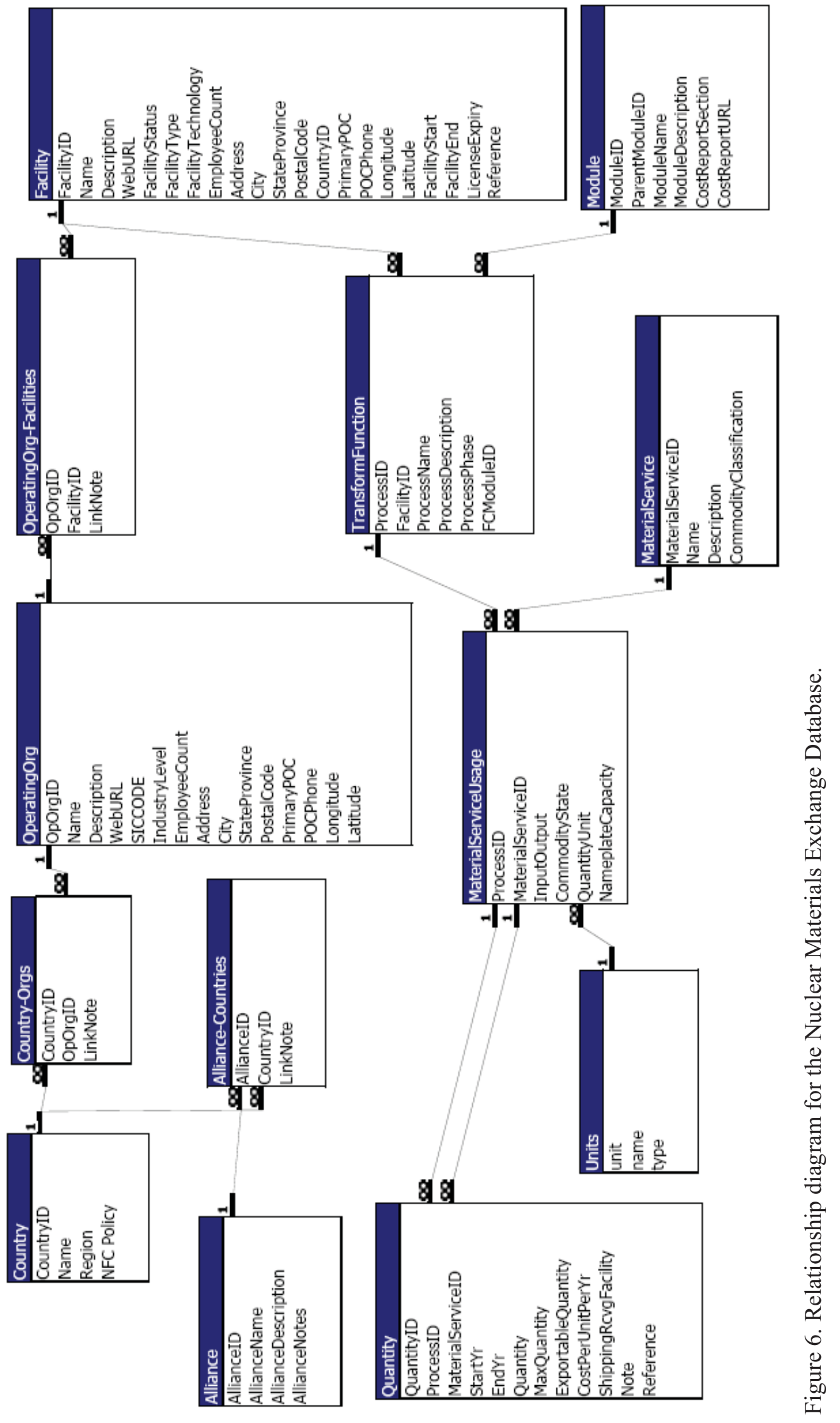

D-19

INL/EXT-09-15483 
the quantities of, and, if available, the source or destination of its inputs or outputs. The source/destination is intended to be identified at the Facility level.

This basic design is relatively simple and elegant, especially considering the large amount of data that may ultimately be collected. This design may need to evolve over time as additional functionality is needed in order to satisfy additional applications that may pose questions that could not be produced via a database query to the existing data structure. The "modularlized" design philosophy should be maintained when the data structure grows and/or is modified.

Descriptions of the fields in each of the tables shown in Figure 6 are shown in the tables below. The tables are shown in the order that the tables should be completed when populating the database from the "back-end" (much of the data can be added/altered from the front-end graphic user interface (GUI), as discussed in Section 3.3). It should be noted that while populating the NME with the initial data set, all of the data was entered from the back-end since this is the preferred method for loading large quantities of data. However, it is not the best method for making additions of single facilities or edits to existing fields since there is a great deal of bookkeeping required in order to avoid errors. The recommended method for making edits or small data editions is to use the GUI at the front-end of the database. This will be described further in Section 3.3.

Table 1, the "Country" Table in the NME Database, provides information on each country in the database.

Table 1. "Country" table in the Nuclear Materials Exchange Database.

\begin{tabular}{|l|l|}
\hline \multicolumn{1}{|c|}{ Field } & \multicolumn{1}{c|}{ Description } \\
\hline CountryID & $\begin{array}{l}\text { Identification (ID) number associated with the country (automatically } \\
\text { generated) }\end{array}$ \\
\hline Name & Name of the country \\
\hline Region & Geographical region of the world in which the country is located \\
\hline NFC Policy & $\begin{array}{l}\text { Nuclear Fuel Cycle Policy; Does the country have an open or closed fuel cycle } \\
\text { per the IAEA? }\end{array}$ \\
\hline
\end{tabular}

Table 2, the "Alliance" Table in the NME Database, provides information on each alliance in the database.

Table 2. "Alliance" Table in the Nuclear Materials Exchange Database.

\begin{tabular}{|l|l|}
\hline \multicolumn{1}{|c|}{ Field } & \multicolumn{1}{c|}{ Description } \\
\hline AllianceID & ID number associated with the alliance (automatically generated) \\
\hline AllianceName & Name of the alliance \\
\hline AllianceDescription & Description of the alliance \\
\hline AllianceNotes & Note(s) about the alliance \\
\hline
\end{tabular}

Table 3, the "Alliance-Countries" Table in the NME Database, defines the relationship between an alliance(s) and its associated countries. Note that a table name that includes a hyphen ("-") defines a relationship between two related information tables. In this case the table is defining the relationship between data fields in the Alliance and Country tables that have been previously populated. 
Table 3. "Alliance-Countries" Table in the Nuclear Materials Exchange Database.

\begin{tabular}{|l|l|}
\hline \multicolumn{1}{|c|}{ Field } & \multicolumn{1}{c|}{ Description } \\
\hline AllianceID & $\begin{array}{l}\text { ID number associated with the alliance which the country is participating } \\
\text { (defined previously in the Alliance Table) }\end{array}$ \\
\hline CountryID & $\begin{array}{l}\text { ID number associated with the country (defined previously in the Country } \\
\text { Table) }\end{array}$ \\
\hline LinkNote & Note about the link \\
\hline
\end{tabular}

Table 4, the "OperatingOrg" Table in the NME Database, provides information on each OpOrg in the database.

Table 4. "OperatingOrg" Table in the Nuclear Materials Exchange Database.

\begin{tabular}{|c|c|}
\hline Field & Description \\
\hline OpOrgID & ID number associated with the OpOrg (automatically generated) \\
\hline Name & Name of the OpOrg \\
\hline Description & Description of the OpOrg \\
\hline WebURL & Website address for the OpOrg \\
\hline SICCODE & $\begin{array}{l}\text { Industry code, this is a carryover from the Industrial Materials Exchange } \\
\text { Planner }\end{array}$ \\
\hline IndustryLevel & $\begin{array}{l}\text { Indicates whether the industry is a primary, secondary, or other industry } \\
\text { level }\end{array}$ \\
\hline EmployeeCount & Number of employees working for the OpOrg \\
\hline Address & Street address of the OpOrg \\
\hline City & City in which the OpOrg is located \\
\hline StateProvince & State or province in which the OpOrg is located \\
\hline PostalCode & Postal code in which the OpOrg is located \\
\hline PrimaryPOC & Name of the primary point of contact (POC) at the OpOrg \\
\hline POCPhone & Phone number for the POC at the OpOrg \\
\hline Longitude & $\begin{array}{l}\text { Longitude at which the OpOrg is located; intended for queries where } \\
\text { distances would be utilized }\end{array}$ \\
\hline Latitude & $\begin{array}{l}\text { Latitude at which the OpOrg is located; intended for queries where distances } \\
\text { would be utilized }\end{array}$ \\
\hline
\end{tabular}

Table 5, the "Country-Orgs" Table in the NME Database, defines the relationship between a country and its associated OpOrg.

Table 5. "Country-Orgs" Table in the Nuclear Materials Exchange Database.

\begin{tabular}{|l|l|}
\hline \multicolumn{1}{|c|}{ Field } & \multicolumn{1}{c|}{ Description } \\
\hline CountryID & $\begin{array}{l}\text { ID number associated with the country in which the OpOrg is located } \\
\text { (defined previously in the Country Table) }\end{array}$ \\
\hline OpOrgID & $\begin{array}{l}\text { ID number associated with the OpOrg (defined previously in the } \\
\text { OperatingOrg Table) }\end{array}$ \\
\hline LinkNote & Note about the link \\
\hline
\end{tabular}

Table 6, the "Facility" Table in the NME Database, provides information on each facility in the database. 
Table 6. "Facility" Table in the Nuclear Materials Exchange Database.

\begin{tabular}{|l|l|}
\hline \multicolumn{1}{|c|}{ Field } & \\
\hline FacilityID & ID number associated with the facility (automatically generated) \\
\hline Name & Name of the facility \\
\hline Description & Description of the facility \\
\hline WebURL & Website address for the facility \\
\hline FacilityStatus & $\begin{array}{l}\text { Status of the facility's operations from "planning" to "shutdown" and } \\
\text { everything in between }\end{array}$ \\
\hline FacilityType & $\begin{array}{l}\text { Identifies the type of operations being carried out at the facility (e.g., } \\
\text { Browns Ferry is a nuclear reactor) }\end{array}$ \\
\hline FacilityTechnology & $\begin{array}{l}\text { Identifies the particular technology being used (For a nuclear reactor, } \\
\text { identifies whether it is a LWR, HWR, etc.) }\end{array}$ \\
\hline EmployeeCount & Number of employees working for the facility \\
\hline Address & Street address of the facility \\
\hline City & City in which the facility is located \\
\hline StateProvince & State or province in which the facility is located \\
\hline PostalCode & Postal code in which the facility is located \\
\hline CountryID & $\begin{array}{l}\text { ID number associated with the country in which the facility is located } \\
\text { (defined previously in the Country Table) }\end{array}$ \\
\hline PrimaryPOC & Name of the POC at the facility \\
\hline POCPhone & Phone number for the POC at the facility \\
\hline Longitude & $\begin{array}{l}\text { Longitude at which the facility is located; intended for queries where } \\
\text { distances would be utilized }\end{array}$ \\
\hline Latitude & $\begin{array}{l}\text { Latitude at which the facility is located; intended for queries where } \\
\text { distances would be utilized }\end{array}$ \\
\hline FacilityStart & $\begin{array}{l}\text { Year that the facility started producing a material or service } \\
\text { commercially }\end{array}$ \\
\hline FacilityEnd & $\begin{array}{l}\text { Year that the facility stopped producing a material or service } \\
\text { commercially }\end{array}$ \\
\hline LicenseExpiry & Year that the operating license for the facility will expire \\
\hline Reference & Reference for where the data for the fields in the table was found \\
\hline & \\
\hline
\end{tabular}

Table 7, the "OperatingOrg-Facilities" Table in the NME Database, defines the relationship between an OpOrg and its associated facilities.

Table 7. "OperatingOrg-Facilities" Table in the Nuclear Materials Exchange Database.

\begin{tabular}{|l|l|}
\hline \multicolumn{1}{|c|}{ Field } & \multicolumn{1}{c|}{ Description } \\
\hline OpOrgID & $\begin{array}{l}\text { ID number associated with the OpOrg, which is responsible for the facility } \\
\text { (defined previously in the OperatingOrg Table) }\end{array}$ \\
\hline FacilityID & ID number associated with the facility (defined previously in the Facility Table) \\
\hline LinkNote & Note about the link \\
\hline
\end{tabular}

Table 8, the "Module" Table in the NME Database, provides information on each module in the database. 
Table 8. "Module" Table in the Nuclear Materials Exchange Database.

\begin{tabular}{|l|l|}
\hline \multicolumn{1}{|c|}{ Field } & \multicolumn{1}{c|}{ Description } \\
\hline ModuleID & $\begin{array}{l}\text { ID associated with the module as defined in the "Advanced Fuel Cycle (AFC) } \\
\text { Cost Basis" report (Shropshire, et al. 2007) (e.g., "A" for "Natural Uranium } \\
\text { Mining and Milling") }\end{array}$ \\
\hline ParentModuleID & $\begin{array}{l}\text { ID associated with the parent module as defined in the "AFC Cost Basis" report } \\
\text { (e.g., "D" is the parent module of Fuel Fabrication while Modules D1 and D2 } \\
\text { define the particular type of fuel fabrication) }\end{array}$ \\
\hline ModuleName & Name of the module \\
\hline ModuleDescription & Description of the module \\
\hline CostReportSection & $\begin{array}{l}\text { Section name/number of the "AFC Cost Basis" report where the module } \\
\text { information is located; this was included for future functionality and is not yet } \\
\text { utilized }\end{array}$ \\
\hline CostReportURL & $\begin{array}{l}\text { Web site address for the latest version of the "AFC Cost Basis" report. This is } \\
\text { where the NME database could be linked to the "AFC Cost Basis" report } \\
\text { database; however, it was included for future functionality and is not yet utilized. }\end{array}$ \\
\hline
\end{tabular}

Table 9, the "TransformFunction" Table in the NME Database, defines the relationship between a Facility and its associated Processes and Modules as shown below.

Table 9. "TransformFunction" Table in the Nuclear Materials Exchange Database.

\begin{tabular}{|l|l|}
\hline \multicolumn{1}{|c|}{ Field } & \multicolumn{1}{c|}{ Description } \\
\hline ProcessID & ID number associated with the process description for a facility \\
\hline FacilityID & $\begin{array}{l}\text { ID number associated with the facility that provides the particular service } \\
\text { (defined previously in the Facility Table) }\end{array}$ \\
\hline ProcessName & Name of the process \\
\hline ProcessDescription & Description of the process \\
\hline ProcessPhase & $\begin{array}{l}\text { Identifies the process phase, this is a carryover from the Industrial } \\
\text { Materials Exchange Planner }\end{array}$ \\
\hline FCModuleID & $\begin{array}{l}\text { ID associated with the module defined in the Cost Basis Report (defined } \\
\text { previously in the Module Table) }\end{array}$ \\
\hline
\end{tabular}

Table 10, the "MaterialService" Table in the NME Database, provides information on each material or service in the database.

Table 10. "MaterialService" Table in the Nuclear Materials Exchange Database.

\begin{tabular}{|l|l|}
\hline \multicolumn{1}{|c|}{ Field } & \multicolumn{1}{c|}{ Description } \\
\hline MaterialServiceID & ID number associated with the material or service that a facility provides \\
\hline Name & Name of the material or service \\
\hline Description & Description of the material or service \\
\hline CommodityClassification & Commodity classification of the material or service \\
\hline
\end{tabular}

Table 11, the "Units" Table in the NME Database, provides information on each set of units used in the database.

Table 11. "Units" Table in the Nuclear Materials Exchange Database.

\begin{tabular}{|l|l|}
\hline \multicolumn{1}{|c|}{ Field } & \multicolumn{1}{c|}{ Description } \\
\hline unit & Unit, abbreviated (e.g., t HM/a) \\
\hline name & $\begin{array}{l}\text { Name of unit, written out from abbreviation in previous field (e.g., tons of } \\
\text { heavy metal per annum) }\end{array}$ \\
\hline type & Type of unit (e.g., weight or production) \\
\hline
\end{tabular}


Table 12, the "Material Service Usage" Table in the NME Database, defines the relationship between a facility's process and the quantity and type of material or service that it inputs and/or outputs annually.

Table 12. "MaterialServiceUsage" Table in the Nuclear Materials Exchange Database.

\begin{tabular}{|l|l|}
\hline \multicolumn{1}{|c|}{ Field } & \multicolumn{1}{c|}{ Description } \\
\hline ProcessID & $\begin{array}{l}\text { ID number associated with the process description for a facility (defined } \\
\text { previously in the TransformFunction Table) }\end{array}$ \\
\hline MaterialServiceID & $\begin{array}{l}\text { ID number associated with the material or service that a facility provides } \\
\text { (defined previously in the MaterialService Table) }\end{array}$ \\
\hline InputOutput & $\begin{array}{l}\text { Identifies whether the Material or Service is an Input or Output to the } \\
\text { process; (e.g., For a nuclear reactor, fabricated fuel is an input, while } \\
\text { electricity and used fuel are outputs). }\end{array}$ \\
\hline CommodityState & $\begin{array}{l}\text { State of the commodity (material or service); this is a carryover from the } \\
\text { Industrial Materials Exchange Planner }\end{array}$ \\
\hline QuantityUnit & $\begin{array}{l}\text { Identifies the unit associated with the material (defined previously in the } \\
\text { Units Table) }\end{array}$ \\
\hline NameplateCapacity & Nameplate capacity of the material or service that a facility provides \\
\hline
\end{tabular}

Table 13, the "Quantity" Table in the NME Database, provides quantity flow information related to what facility is receiving or providing the material or service from/to the original facility, how long the facilities have been linked, and how much of the material or service is changing hands. Details are shown in the table below. It is significant to note that in Figure 6, the relationship diagram for NME, the link between the "FacilityID" field in the Facility Table and "ShippingRcvgFacility" field in the Quantity Table is not shown for simplicity of viewing, but it does in fact exist in the database.

Table 13. "Quantity" Table in the Nuclear Materials Exchange Database.

\begin{tabular}{|l|l|}
\hline \multicolumn{1}{|c|}{ Field } & \multicolumn{1}{c|}{ Description } \\
\hline QuantityID & $\begin{array}{l}\text { ID number associated with the quantity description for a process input or } \\
\text { output to a facility }\end{array}$ \\
\hline ProcessID & $\begin{array}{l}\text { ID number associated with the process description for a facility (defined } \\
\text { previously in TransformFunction Table) }\end{array}$ \\
\hline MaterialServiceID & $\begin{array}{l}\text { ID number associated with the material or service that a facility consumes } \\
\text { (inputs) or provides (outputs) (defined previously in MaterialService } \\
\text { Table) }\end{array}$ \\
\hline StartYr & $\begin{array}{l}\text { Year that the facility started consuming (input) or providing (output) the } \\
\text { material or service to the Shipping or Receiving Facility identified below }\end{array}$ \\
\hline EndYr & $\begin{array}{l}\text { Year that the facility ended (stopped) inputting or outputting the material } \\
\text { or service to the Shipping or Receiving Facility identified below }\end{array}$ \\
\hline Quantity & $\begin{array}{l}\text { Quantity of the material or service sent to or coming from the Shipping or } \\
\text { Receiving Facility, respectively, per annum }\end{array}$ \\
\hline MaxQuantity & $\begin{array}{l}\text { Maximum possible quantity of the material or service sent to or coming } \\
\text { from the Shipping or Receiving Facility, respectively, per annum }\end{array}$ \\
\hline ExportableQuantity & Quantity of the material or service that is available for export \\
\hline CostPerUnitPerYear & $\begin{array}{l}\text { Cost of the material or service on a per unit and per annum basis; the } \\
\text { intent is that this field will be used when the database is expanded and } \\
\text { queries are developed that incorporate economics }\end{array}$ \\
\hline ShippingRcvgFacility & $\begin{array}{l}\text { Facility ID for the Shipping (Input) or Receiving (Output) Facility for the } \\
\text { material or service described above }\end{array}$ \\
\hline Note & Note about the quantity information \\
\hline Reference & Reference for where the data for the fields in the table was found \\
\hline
\end{tabular}




\subsection{Graphic User Interface}

A GUI is available for users to maneuver through the front-end of the database with much greater ease than the back-end. Figure 7 shows the main menu that appears when opening the NME.

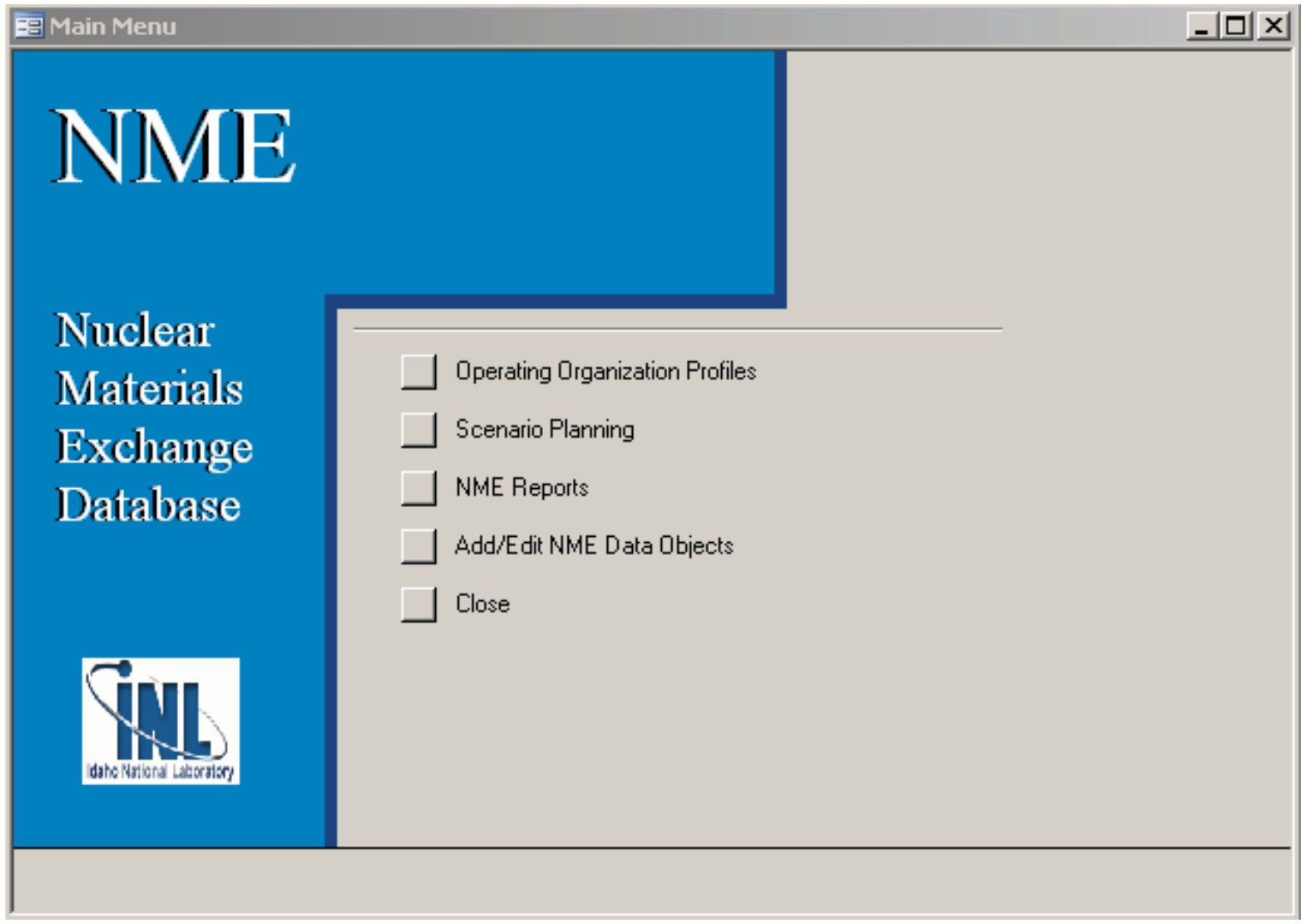

Figure 7. Screen shot of the Nuclear Materials Exchange main menu.

Clicking on the first option, Operating Organization Profiles, will bring the user to the window shown in Figure 8. Much of the information in the NME can be shown from this window. The profiles are organized alphabetically according to the name of the OpOrg. Moving through the tabs within this window will show the associated countries, country alliances, associated facilities, associated functions (of the facility), and the material or service inputs and outputs for the facility. A number of the database fields can be edited through this GUI; however, using the "Add/Edit NME Data Objects" option from the main menu (see Figure 7) offers a more complete opportunity for making edits and additions to the data. It should be noted that a handful of data fields have been recently added to the database and have not yet been incorporated into the "front-end" GUIs for the Operating Organization Profiles and "Add/Edit NME Data Objects." The only method to populate or edit these fields will be to use the back-end of the database and careful bookkeeping in order to avoid mistakes. 


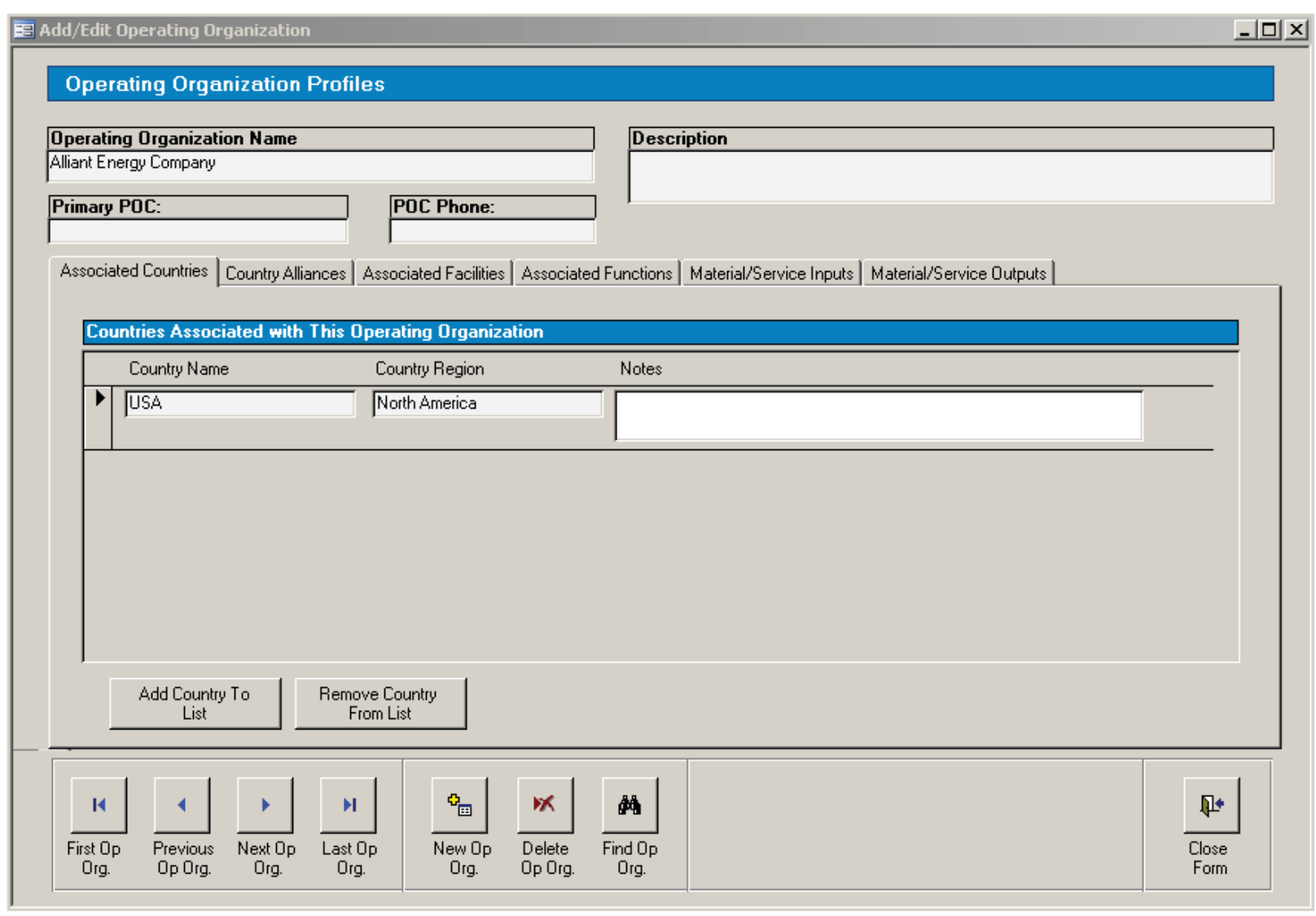

Figure 8. Screen shot of the "Operating Organization Profile" GUI.

\subsection{NME Integration with other Economic Tasks}

The Nuclear Materials Exchange database fits in with a number of other tasks being performed by the AFCI Systems Analysis, including Attachments A, F, G, and H of this "Advanced Fuel Cycle Economic Tools, Algorithms, and Methodologies" report. This integration is illustrated in Figure 9. 


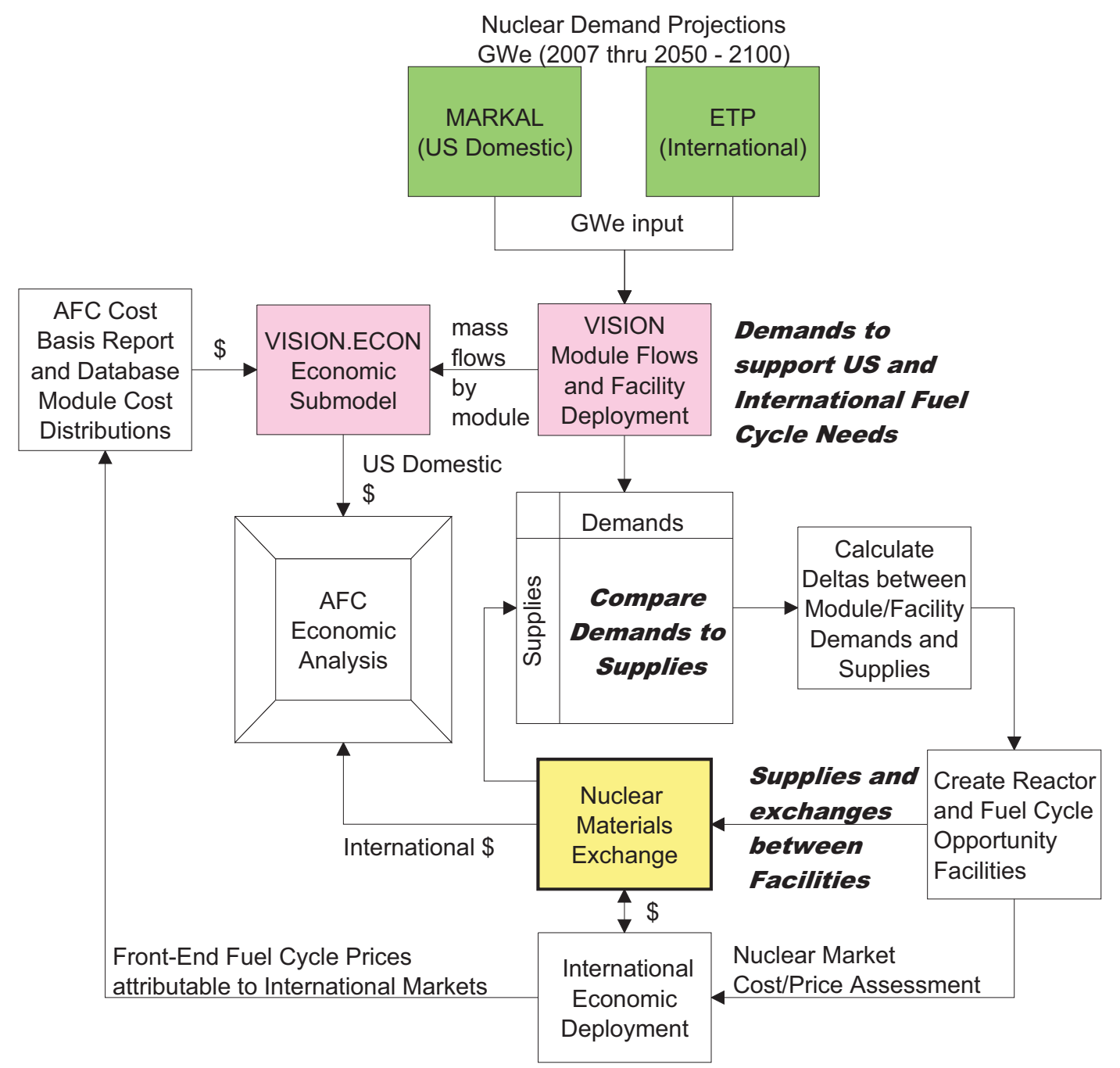

Figure 9. Relationship between the Nuclear Materials Exchange and other Systems efforts.

The following discussion walks the reader through Figure 9. Starting with the green boxes at the top, nuclear demand projections are made using Market Allocation (MARKAL) and Energy Technology Perspectives (ETP). These growth projections are thought to be more realistic than assuming linear growth rates for nuclear electricity, MARKAL and ETP results are based on looking at nuclear energy within the context of projections for the entire energy market. Of particular interest are the results from ETP that quantify nuclear growth internationally according to the IEA's 15 regions. For a "user" region or country, this growth can be interpreted as additional demand placed on a supplier country to provide front-end and back-end fuel cycle services. The work up to this point has been completed; the remaining discussion covers work to be completed.

Referring to the pink box on the right, VISION will produce the demands for each fuel cycle module (from 2010 to 2100) needed to meet the more realistic nuclear demand projections. The cases to be investigated will look the effects on the U.S.'s fuel cycle facilities to meet both domestic demands and the increased demands to supply a representative small and large user country. It should be noted that the nuclear demand projections are only through 2050 and have been extrapolated through 2100 for input into VISION that looks at a longer period. 
Continuing down the figure, the demands from VISION will be compared to the available supply for a fuel cycle module, as provided by the NME (yellow box). This latter step will be completed using the new query, "Summarizing Supply Capacity over Time" described in Section 4.5. The supply query considers reactors and fuel cycle facilities that are both existing and projected, and their respective license period or, in the case when the license expiration date is not known, a typical operating lifetime based on the facility type.

The delta between the supply and demand for a fuel cycle module will be calculated over time, specifically between 2010 and 2100 . This delta for each fuel cycle module will be used to identify "opportunity facilities," including both reactors and fuel cycle facilities that would need to be constructed in order to meet the projected nuclear demand.

The "opportunity facilities" will be modeled in the NME showing potential supplies and exchanges between these and the existing facilities to satisfy the necessary fuel cycle. This information will be considered for their potential affects on nuclear market prices.

Going back to the pink VISION box on the right and heading left instead of down, the VISION runs will be completed using the VISION.ECON submodel, to produce economic results.

\section{AVAILABLE QUERIES IN NME}

A preliminary set of queries to exemplify and demonstrate the basic features of the NME have been developed. The use cases identify several typical scenarios of expected queries by a user and are described in the following sections. For each query that is described, an example is included. It is important to note that the examples shown are not to be cited, they are for illustrative purposes only. A key example of this is that most of the currently operating facilities show end years that have been artificially set to 2100 as a default assumption.

\subsection{Material Flow Linkages}

The goals of this query is to show the linkage between a facility and its related fuel cycle facilities, and show facility capacity information based on the expected operating lives of the facilities. Figure 10 shows a screen shot of the query GUI. Links between a select group of countries have been completed. These links need to be completed at a more detailed facility-to-facility level, but unfortunately this will require a very detailed data mining search. Some of the links were completed based in the IAEA report (IAEA 2005), but since this only shows the links at a country or operating organization level at the NME data structure is set up for a facility level, much conservatism has been used. It has also been hypothesized that many of the links between fuel cycle facilities and reactors change frequently. The graphic within the query GUI shows a representative fuel cycle plot (taken from IAEA Report, TSR 425) displaying the type of links and facilities that may be available in the NME (IAEA 2005).

In the future, historical data as well as links for potential facilities could be included. 


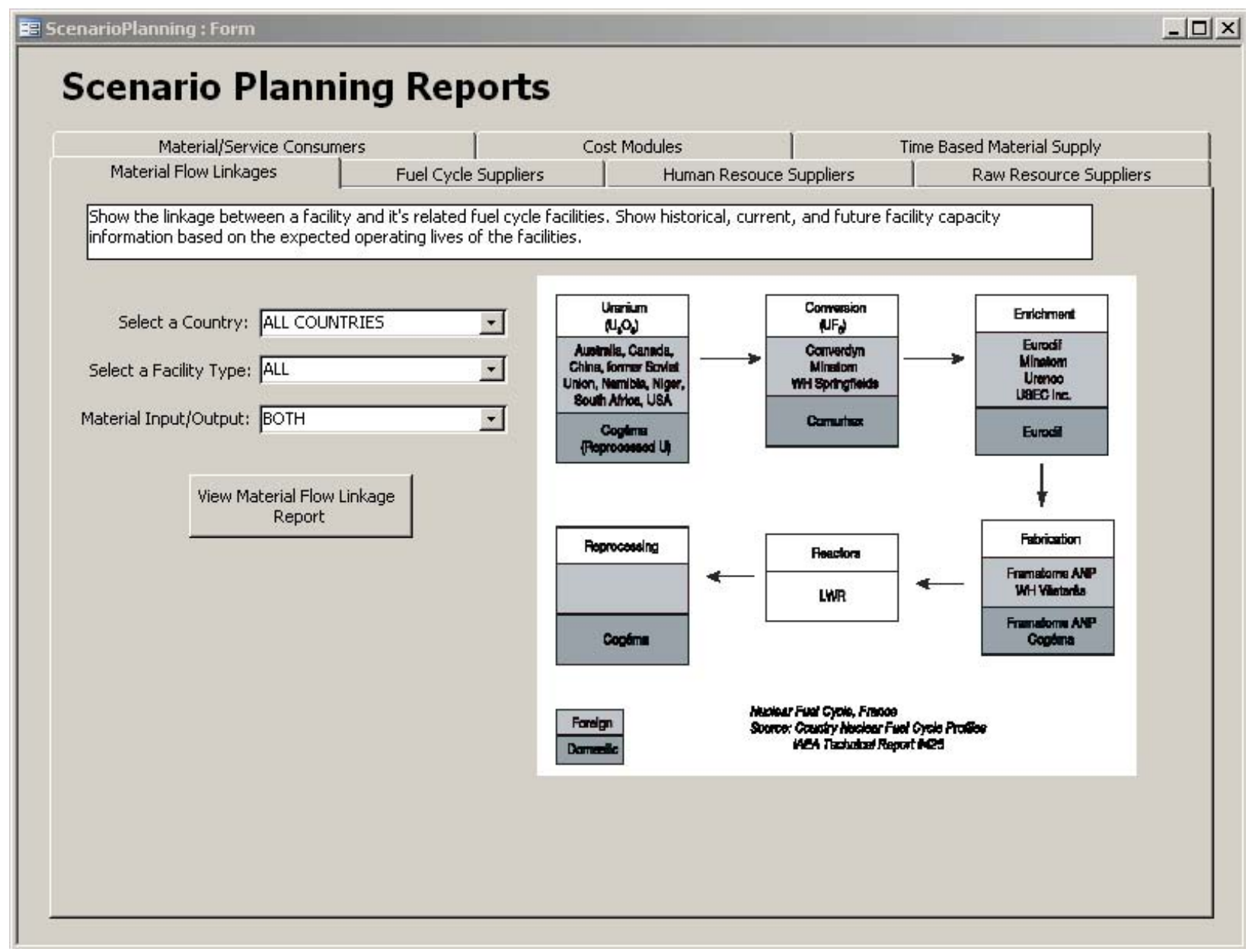

Figure 10. Screen shot of the "Material Flow Linkages" query.

\section{EXAMPLE OUTPUT DATA}

Scenario: Imagine you are interested in learning more about the inputs and outputs to nuclear reactors in France:

- Select "France" from the Country pull-down menu

- Select "Reactor" from the Facility Type pull-down menu

- Select "BOTH" from the Material Input/Output pull-down menu

- Click "View Material Flow Linkage Report."

A selection from the resulting report for this query is shown in Figure 11 below. 


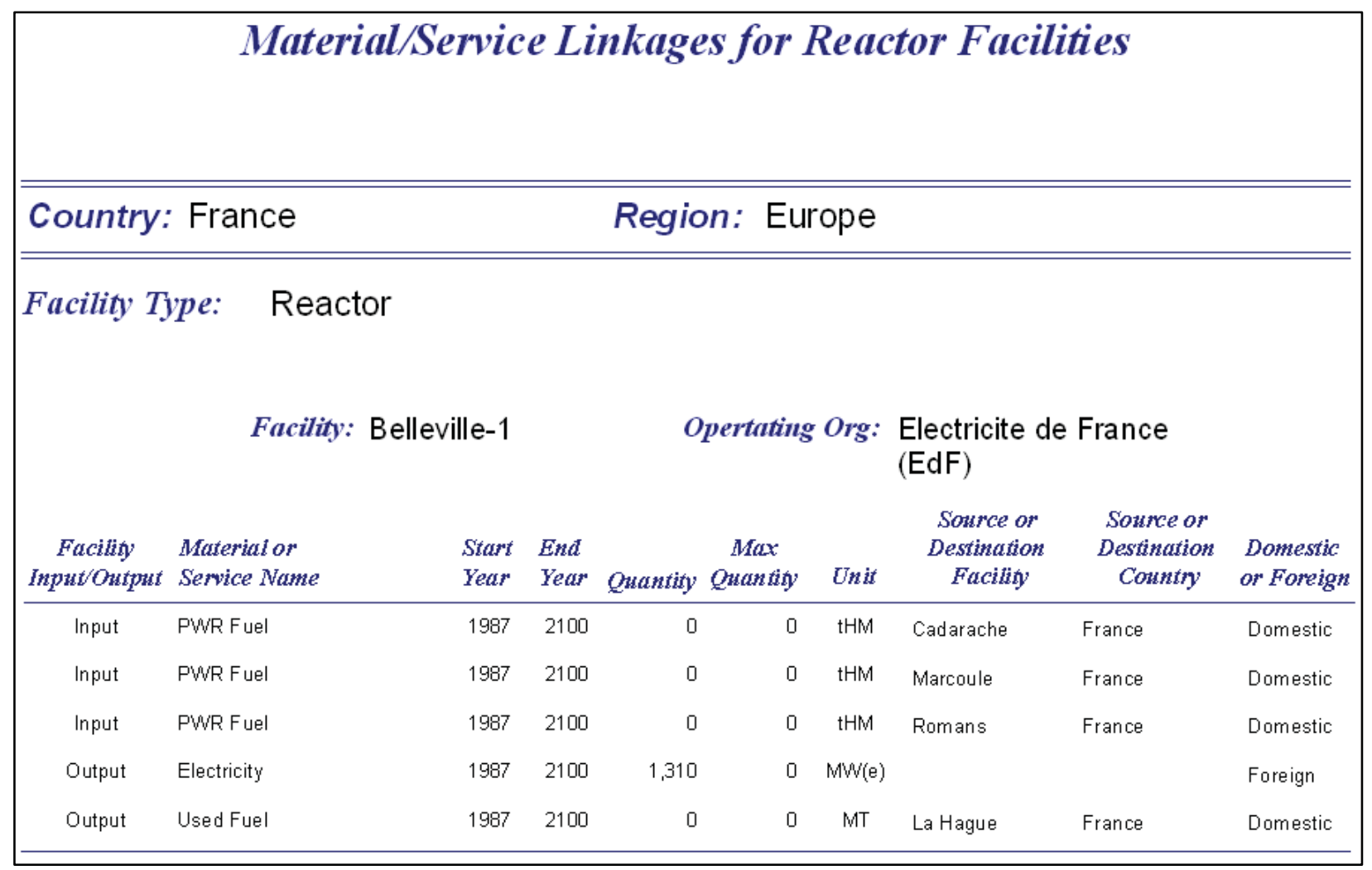

Figure 11. Selection from the resulting report for the "Material Flow Linkages" query example.

The results are sorted by facility name and show all inputs and outputs to the reactors in France. The links currently assume that all of the fabrication facilities in France service all of the French reactors and does not differ between whether one fuel fabricating facility in France only services specific reactors. The outputs for each of the reactors are shown as electrical power to the grid and used fuel.

\subsection{Identification of Fuel Cycle Facilities \& Reactors}

This query allows users to search for a particular fuel cycle facility or reactor in a specific geographical area (country, geographical region, or alliance) based on its output material or service. It can be used to show a country developing the capabilities to support nuclear reactors where they can locate fuel cycle suppliers (U suppliers, conversion, enrichment, fuel fabrication, etc.) both domestically and internationally. Figure 12 shows a screen shot of the query GUI. The graphic of the map shown on the query GUI is intended to show a capability that may be pursued in the future. Latitude and longitude information would be included for each of the facilities in NME and the user would be able to click on a particular location on the map where they were considering locating a nuclear reactor or fuel cycle facility and then drag out a certain distance to define the search radius. They could also graphically pick the regions or countries that they are interested in rather than using the pull-down menus. 


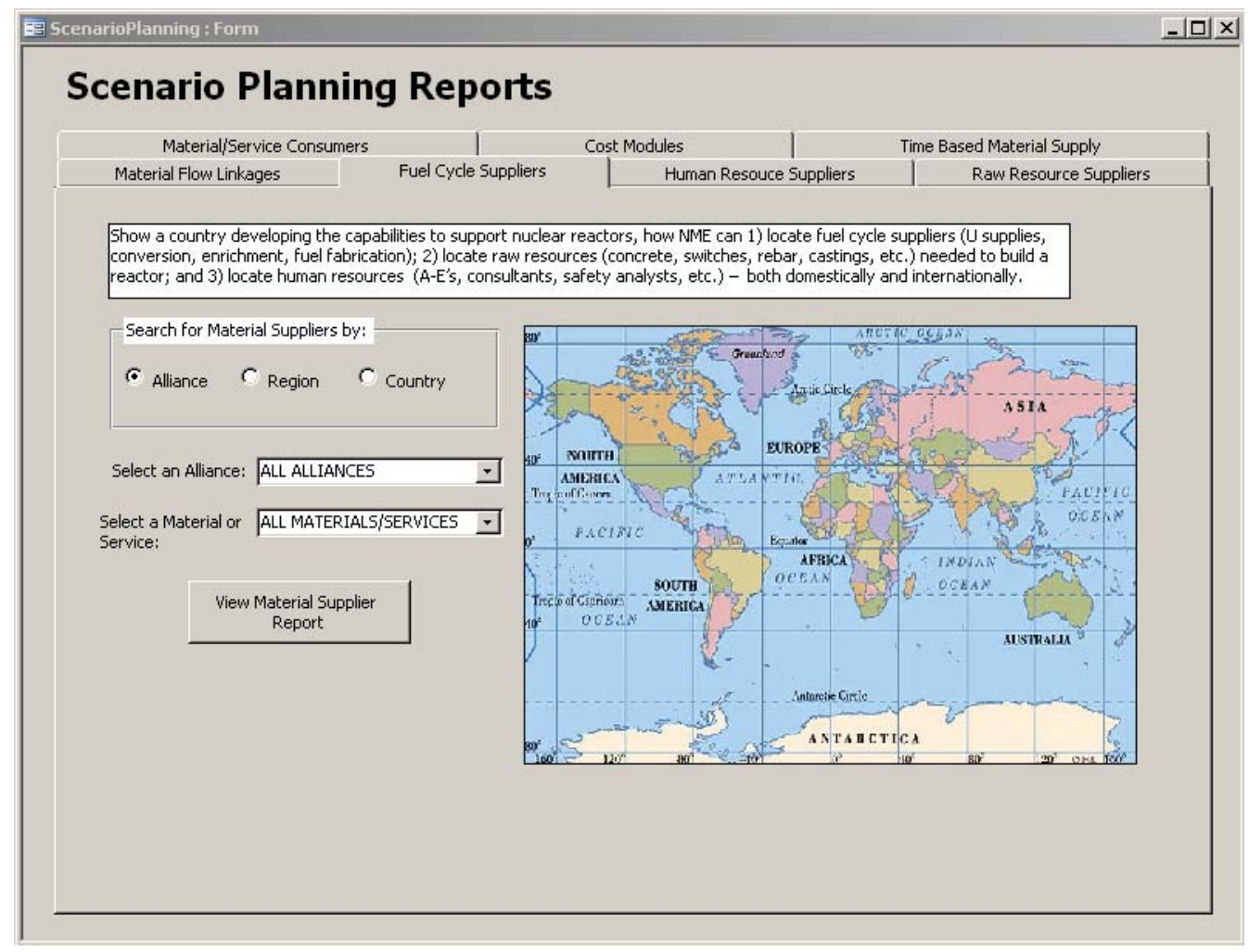

Figure 12. Screen shot of the "Fuel Cycle Suppliers" query.

\section{SAMPLE OUTPUT DATA}

Scenario: Imagine that you are in Argentina and you are interested in constructing a third reactor. You want to know what fuel cycle facilities are available in South America that could possibly provide materials for your new reactor:

- Click "Region"

- Select "South America" from the Region pull-down menu

- Select "ALL MATERIALS/SERVICES" from the Material/Service pull-down menu

- Click "View Material Supplier Report."

A selection from the resulting report for this query is shown in Figure 13. 


\section{Material/Service Suppliers}

\section{Region: South America}

Country: Argentina

Opertating Organization: CNEA

\begin{tabular}{llccccc} 
Facility & Material/Service Name & \multicolumn{2}{c}{ Start } & End & & Max \\
Year & Year & Quantity Quantity & Unit \\
\hline Sierra Pintada & Uranium Yellow Cake & 2006 & 2100 & 0 & 120 & t $\mathrm{HM}$ \\
\hline
\end{tabular}

Opertating Organization: Conuar S.A.

\begin{tabular}{llccccc} 
& & Start & End & & Max \\
Facility & Material Service Name & Year & Year & Quantity Quantity & Unit \\
\hline Ezeiza & CANDU 600 fuel bundles & 0 & 0 & 0 & 0 & tHM \\
Ezeiza & PHWR Fuel & 2006 & 2100 & 0 & 150 & $\mathrm{tHM}$ \\
\hline
\end{tabular}

Figure 13. Selection from the resulting report for the "Fuel Cycle Suppliers" query example.

The results are sorted by Country, Operating Organization, and then Facility. All outputs to the particular facilities are shown.

In the future, differentiation is desired between which materials are committed to existing facilities and which might be available to a new or expanding facility.

\subsection{Material/Service Inputs to Facilities}

This query can identify inputs that a particular facility may accept/consume. It can be used to support the concept of industrial symbiosis when a facility that produces excess of a particular by-product can identify facilities that may be able to beneficially use it as an input. Figure 14 shows a screen shot of the query GUI. 


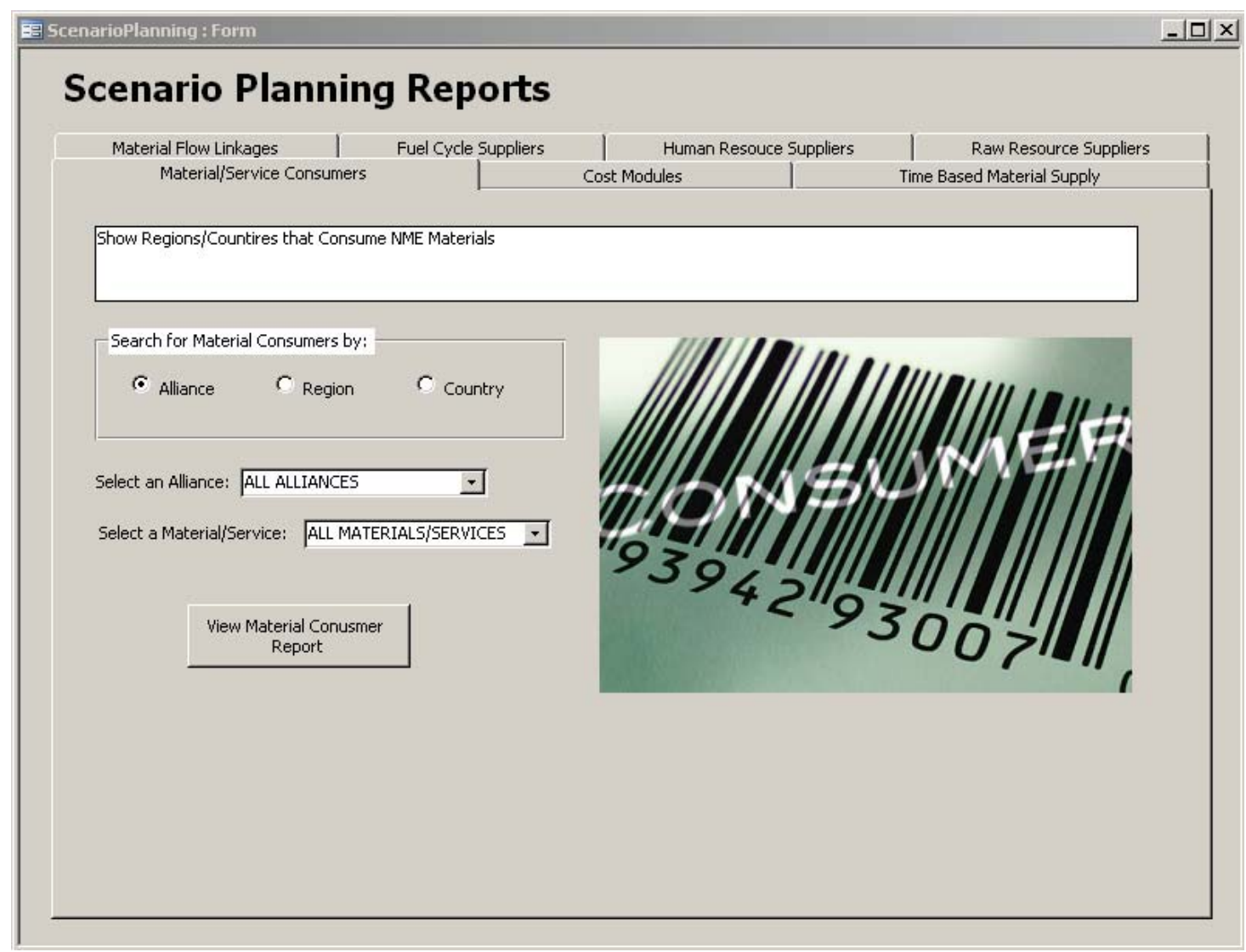

Figure 14. Screen shot of the "Material/Service Inputs to Facilities" query.

\section{EXAMPLE OUTPUT DATA}

Scenario: Imagine that you are a French reprocessing facility and you are interested in finding a facility somewhere else in the world that might accept your reprocessable uranium (RU):

- Click "Region"

- Select "ALL REGIONS" from the Region pull-down menu to search worldwide

- Select "RU" from the Material/Service pull-down menu

- Click "View Material Consumer Report."

A selection from the resulting report for this query is shown in Figure 15 below. 


\section{MaterialSupplier Consumers}

\section{Region: Nor th America}

Country: Canada

Opertating Organization: GE Canada

\begin{tabular}{|c|c|c|c|c|c|c|}
\hline Facility & Material/Service Name & $\begin{array}{l}\text { Start } \\
\text { Year }\end{array}$ & $\begin{array}{l}\text { End } \\
\text { Year }\end{array}$ & Quantity & $\begin{array}{c}\text { Max } \\
\text { Quantity }\end{array}$ & Unit \\
\hline Toronto GE Facility & RU & 2006 & 2100 & 0 & 0 & tu \\
\hline
\end{tabular}

Figure 15. Selection from the resulting report for the "Material/Service Inputs to Facilities" query example.

The report shows that a there is a facility in Canada that may hypothetically accept RU. Note that this example is not intended to be real since this facility's input materials was manipulated for this example.

This example is of interest because it shows how a material from a closed fuel cycle (RU from France) could hypothetically be used by a once-through fuel cycle in another country (Canada Deuterium Uranium [CANDU] cycle in Canada).

\subsection{Cost Module Search}

This query gives users the ability to search for facilities based on their associated module as defined in the "AFC Cost Basis" report (Shropshire, et al. 2007). The graphic in the GUI (Figure 16) shows the modules used in the "AFC Cost Basis" report.

The modules that are currently available to search by in the NME are identified in Table 14 below. There are some modules that are different from the latest version of the "AFC Cost Basis" report. These are identified as:

- Module A1, "Uranium from Phosphates" has been added to identify facilities called out in the NFCIS (IAEA) that do not fit in parent module A for Mining and Milling.

- F2/D2 appear individually as well as combined. Although these modules have been combined in the most recent "AFC Cost Basis" report, many currently operating facilities still operate as solely reprocessing, or recycled fuel fabrication facilities.

- Modules D, F, and R are considered the catch-all modules for facilities where the exact type is not known, or when the specific facility type is not called out in the "AFC Cost Basis" report (including HWR and their related fuel cycle facilities). 
Table 14. Cost modules used in Nuclear Materials Exchange Database.

\begin{tabular}{|l|l|}
\hline Cost Module Name & Cost Module \\
\hline Uranium Mining and Milling & A \\
\hline Uranium from Phosphates & A1 \\
\hline Conversion & B \\
\hline Enrichment & C1 \\
\hline HEU Blend-down & C2 \\
\hline Fuel Fabrication & D \\
\hline Fuel Fabrication - Unirradiated & D1 \\
\hline Fuel Fabrication - Recycled & D2 \\
\hline SNF Storage - Wet & E1 \\
\hline SNF Storage - Dry & E2 \\
\hline Recycled Product Storage & E3 \\
\hline Separation & F \\
\hline Separation - Aqueous & F1 \\
\hline Separation - Pyrolitic & F2 \\
\hline $\begin{array}{l}\text { Pyrochemical Reprocessing \& } \\
\text { Remote Fuel Fabrication }\end{array}$ & F2/D2 \\
\hline $\begin{array}{l}\text { Depleted Uranium Conversion } \\
\text { \& Disposition }\end{array}$ & K1 \\
\hline Reactors & R \\
\hline Thermal Reactors & R1 \\
\hline Fast Reactors & R2 \\
\hline
\end{tabular}

This query is also a way that the NME database could be linked to the Cost Basis database in the future, allowing the user to make decisions based on hard economic data. The user might also be able to look at economic tradeoffs between domestically available materials and those that could be provided by a regional alliance. 


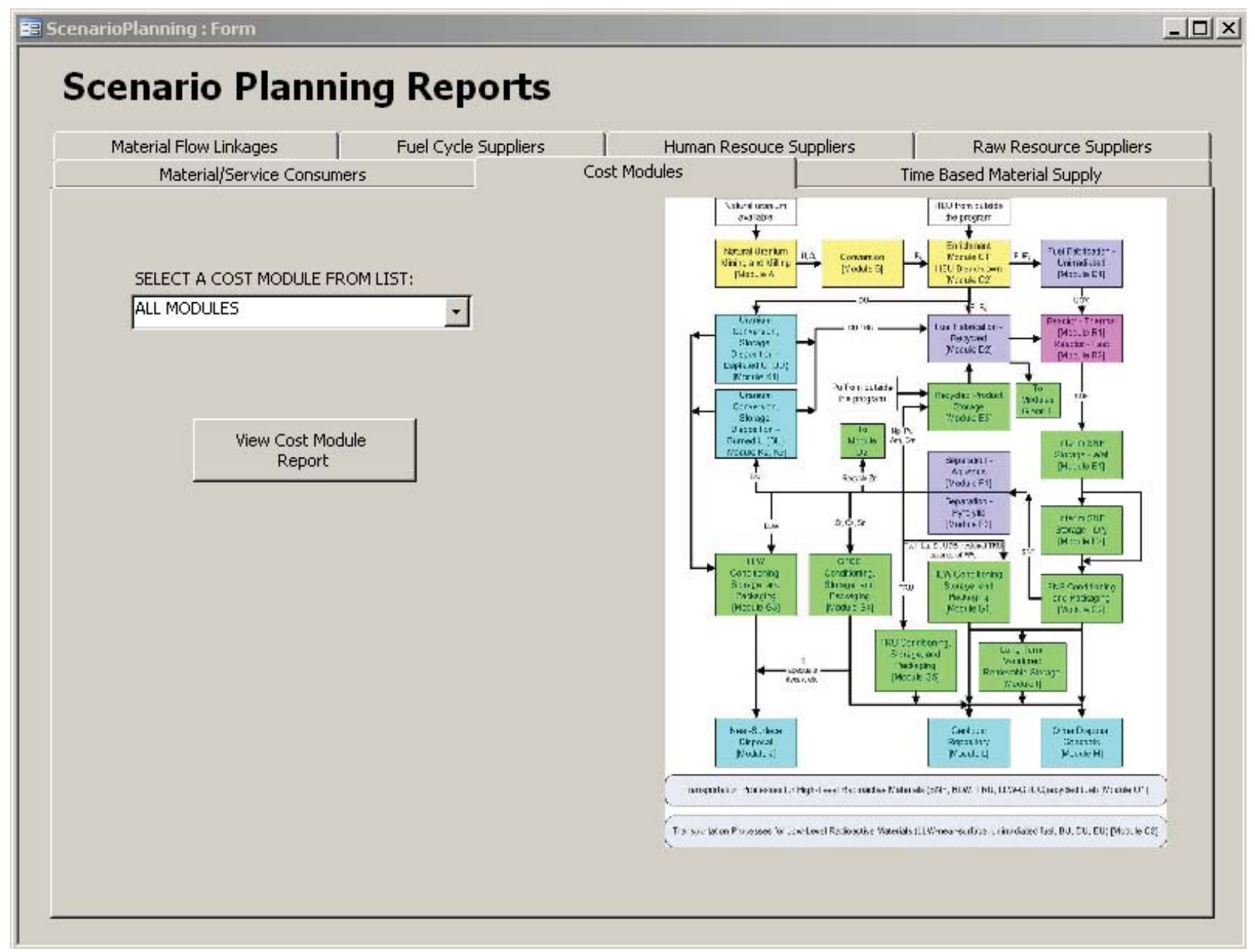

Figure 16. Screen shot of the cost module query.

\section{EXAMPLE OUTPUT DATA}

Scenario: Imagine you are interested in seeing a list of the "Natural Uranium Mining and Milling" Facilities listed in the NME:

- Select "Natural Uranium Mining and Milling" from the pull-down menu.

A selection from the resulting report for this query is shown in Figure 17. This is a selection from the resulting report showing the Natural Uranium Mining and Milling Facilities listed in the NME. 


\section{NME Facilities Grouped by Cost Module}

\section{ModuleName: Natural Uranium Mining and Milling}

\begin{tabular}{lll} 
Operaing Organization & Facility & Country \\
\hline CNEA & Sierra Pintada & Argentina \\
Caetite Operating Organization & Caetite & Brazil \\
Cogema CA & McClean Lake & Canada \\
COMINAK & Niger Facility 1 & Niger \\
SOMAÏR & Niger Facility 2 & Niger \\
\hline
\end{tabular}

Figure 17. Selection from the resulting report for the "Material/Service Inputs to Facilities" query example.

\subsection{Summarizing Supply Capacity over Time}

This query is the newest addition to the NME applications. It summarizes how the available supply for a particular material (as determined by the current and projected reactors and fuel cycle facilities) changes over a selected period. Figure 18 shows the current GUI.

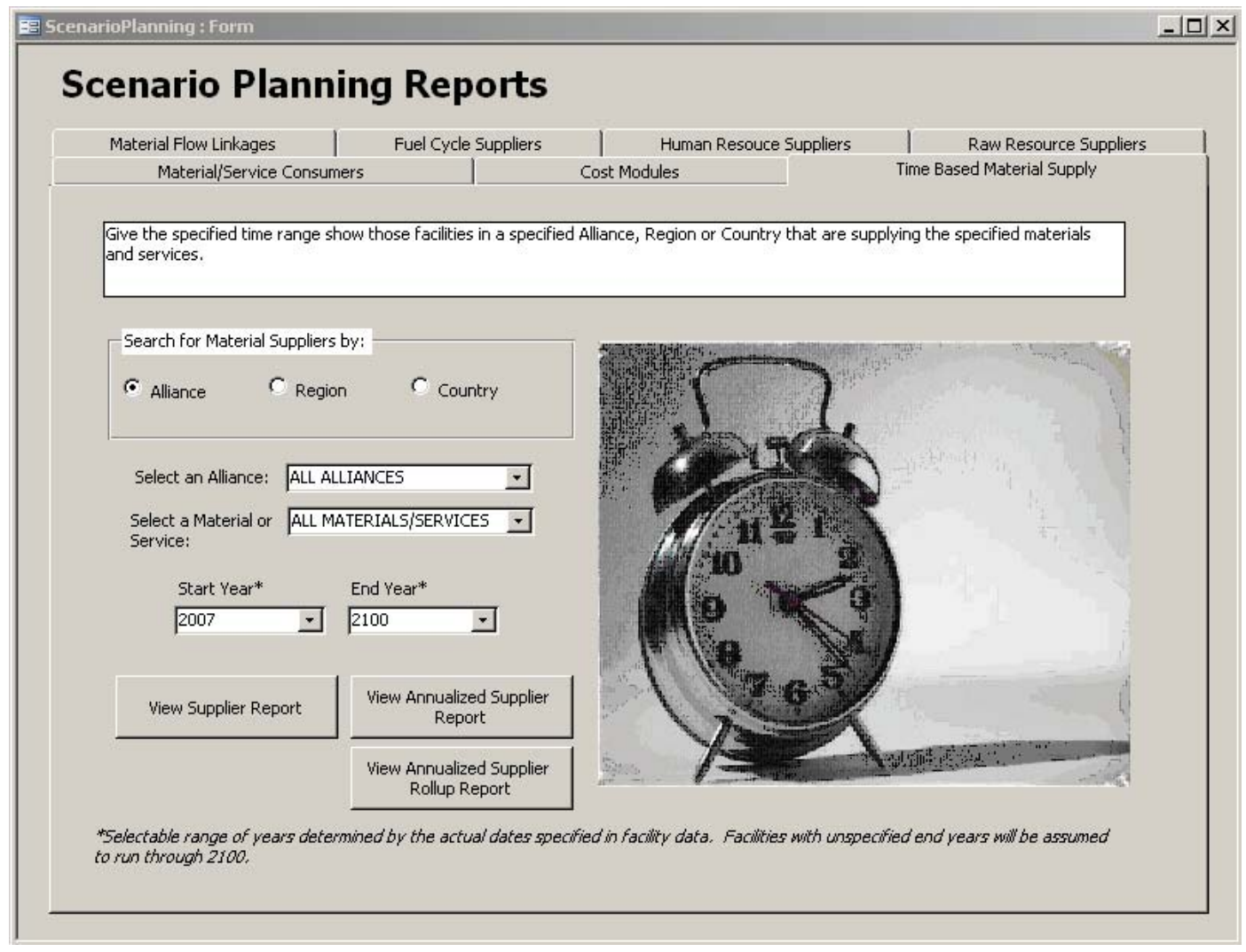

Figure 18. Screen shot of the "Supply Capacity over Time" query. 


\section{EXAMPLE OUTPUT DATA}

Scenario: Imagine you are interested in seeing how the currently planned U.S. reactor fleet will meet the projected demand for electricity from 2010 through 2050. This query in the NME will allow you to see all of the reactors that will be outputting electricity during the selected time (Part 1), as well as a table summarizing the annual electricity capacity for that same time (Part 2). The steps for Part 1 are:

- Click "Country"

- Select "USA" from the Country pull-down menu

- Select "Electricity" from the Material/Service pull-down menu

- Click "View Supplier Report."

\section{Material/Service Suppliers by Country \\ (With Availability for Any Year Within 2010-2050)}

\section{Material/Service Name: Electricity}

\begin{tabular}{|c|c|c|c|c|c|c|c|}
\hline Operating Org & Facility & Facility Status & Start $\mathrm{Yr}$ & End $Y r$ & $\begin{array}{c}\text { Nameplate } \\
\text { Capacity }\end{array}$ & $\begin{array}{c}\text { Annual } \\
\text { Production }\end{array}$ & Unit \\
\hline Entergy & Arkansas One-1 & In Operation & 1974 & $2100^{*}$ & 836 & 0 & $\mathrm{MW}(\mathrm{e})$ \\
\hline Entergy & Arkansas One-2 & In Operation & 1978 & $2100^{*}$ & 965 & 0 & $M W(e)$ \\
\hline FirstEnergy & Beaver Valley-1 & In Operation & 1976 & $2100^{*}$ & 810 & 0 & $M W(e)$ \\
\hline FirstEnergy & Beaver Valley-2 & In Operation & 1987 & $2100^{*}$ & 833 & 0 & $M W(e)$ \\
\hline Exelon & Braidwood-1 & In Operation & 1987 & $2100^{*}$ & 1,120 & 0 & $\mathrm{MW}(\mathrm{e})$ \\
\hline Exelon & Braidwood-2 & In Operation & 1988 & $2100^{*}$ & 1,120 & 0 & $M W(e)$ \\
\hline TVA & Browns Ferry-1 & In Operation & 1973 & $2100^{*}$ & 1,065 & 0 & $M W(e)$ \\
\hline TVA & Browns Ferry-2 & In Operation & 1974 & $2100^{*}$ & 1,118 & 0 & $\mathrm{MW}(\mathrm{e})$ \\
\hline
\end{tabular}

Figure 19. Selection from the resulting report for the "Supply Capacity over Time" query example, Part 1.

The selection from the report shown above (Figure 19) lists reactors in the U.S. that will be outputting electricity between 2010 and 2050 .

Stepping back to the query GUI, Part 2 of the example query can be completed as follows:

- Click "Country"

- Select "USA" from the Country pull-down menu

- Select "Electricity" from the Material/Service pull-down menu

- Click "View Annualized Supplier Report." 


\section{Annualized Material/Service Supplies}

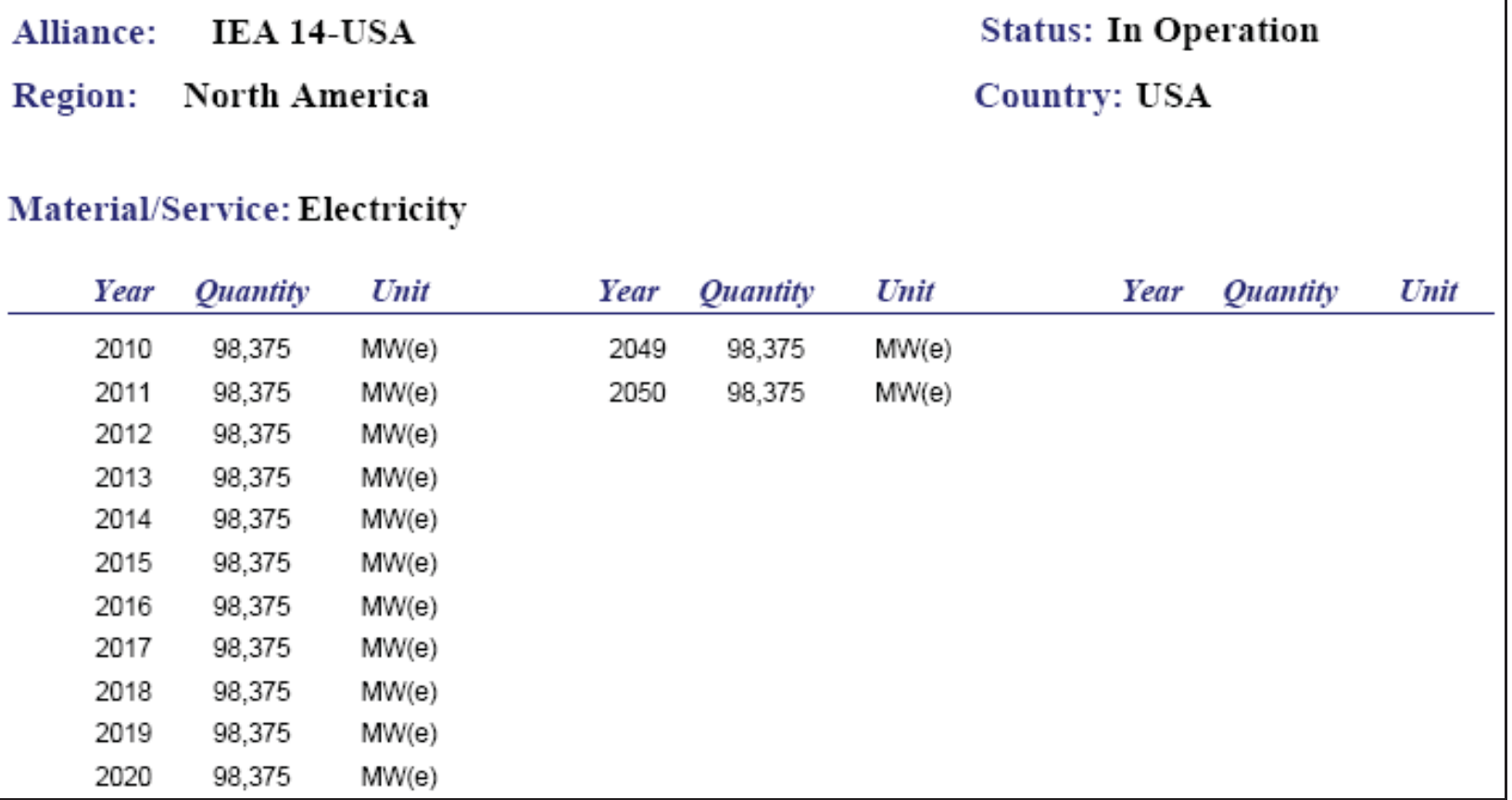

Figure 20. Selection from the resulting report for the "Supply Capacity over Time" query example, Part 2.

The selection from the report shown above (Figure 20) summarizes the electricity capacity in the U.S. for each of the years between 2010 and 2050, based on the data that is currently available in the NME.

This query will be revised in the near future to provide facility information according to the associated "AFC Cost Basis" report module rather than its output material. The intent is that this query can be used in parallel with VISION, which will be able to provide the demand quantities for each of the "AFC Cost Basis" report modules based on a selected scenario. Some of the first scenarios to be considered will be looking at the effects on the front-end and back-end fuel cycle modules of a supplier country like the United States supplying a small and large user country. By comparing the capacity data from the NME with the demand data from VISION, gaps will be identified in fuel cycle facility demand that need to be met. These gaps will be identified as opportunity facilities, or facilities that will need to be constructed to meet the currently projected demand.

\section{NME NEXT STEPS}

Next steps for the NME include data additions, data verification, and additional query development in addition to continued collaboration with groups such as IAEA, Organization for Economic Cooperation and Development (OECD), PRPP (NA-24), and Simulation Institute for Nuclear Energy Modelling and Analyses (SINEMA) Universities.

\subsection{Data Additions}

Data collection will continue to be done on a need basis as interest in the NME grows and its applications expand. Furthermore, data additions or modifications will be a constant effort as new facilities are added, facility statuses change (some facility have seen recent increases in capacity), and 
existing facilities come off-line. This could perhaps be optimized with a data-mining tool that sends alerts when facility changes occur.

Other possible data additions that may be incorporated into the NME are:

- Filling in the current data set. This will become pertinent as existing queries are expanded and new data queries are added.

- Including nuclear reactors that are in the planning, licensing, and/or construction phase. Although nuclear fuel cycle facilities in these phases are included, this has not yet been done for reactors.

- Adding historical data for a facility. The data gathering effort has been focused on "current" data for a facility.

- IAEA's Power Reactor Information System (PRIS) database offers historical performance information on reactors (IAEA 2007)

- Filling in facility-to-facility links to show which facility supplies another facility and vice versa.

- Incorporating data to support queries that are still being developed, such as the human resources and raw resources queries, that are described in Section 5.4 "Additional Queries."

- Identifying owners of facilities. This could begin by identifying whether a facility is owned privately or publicly and then identify the specific name and address of the owner(s), similar to the operating organization profile.

- Spreading into power generation, economics, country infrastructure, industry capability, effect on and development of secondary industries, human resource aspects, safety and radiation aspects (effects on human), proliferation aspects, future nuclear generation aspects, etc.

Additional information sets can be included, such as projected energy demands for each country; inputs and outputs of worldwide nuclear companies, as well as primary to tertiary supplier industries; company material balance profiles for region-specific industrial symbiosis scenarios; historical, current, and projected quantity details for feedstocks, primary products, by-products, waste flows, and utilities; commodity prices and disposal costs; and generic profiles of manufacturing and recycling processes.

\subsection{Data Verification}

Data verification will need to play a large role in the development of the NME and will need to include checks of data quality, validation, and consistency. Some of the sources that have been identified to use during the data validation are:

- IAEA, Power Reactor Information System (PRIS), www.iaea.or.at/programmes/a2

- $\quad$ Nuclear News, World List of Nuclear Power Plants, December 31, 2006.

\subsection{Data Structure Modifications}

The list of short-term changes to the data structure includes adding the following:

- “Operating Organization" Table: "E-mail for POC” field, "Reference" field

- "Facility" Table: "E-mail for POC" field

- “Transform Function" Table: "Reference" field

- "Material Service Usage" Table: "Reference" field. 
Longer-term data structure additions will likely be needed to support the newly developing applications of supply/demand and PRPP.

\subsection{Additional Queries}

There are a number of queries that are under development or planned. These are described below.

\subsubsection{Human Resource Suppliers (Under Development)}

This query is currently in development. The idea is that it would allow a country new to nuclear power that is considering constructing a reactor or fuel cycle facility to see what types of human resources are needed at each stage in the project, and also whether they may be able to find those resources locally or in a neighboring country. The list of possible human resources needed to start and operate a nuclear reactor or fuel cycle facility has been defined (based on discussions with Jerry Phillips, IAEA). A sample GUI has been developed (Figure 21), but there is only a pull-down menu of possible human resources; there is no data on specific human resource facilities in the NME to support a query. This data still needs to be collected.

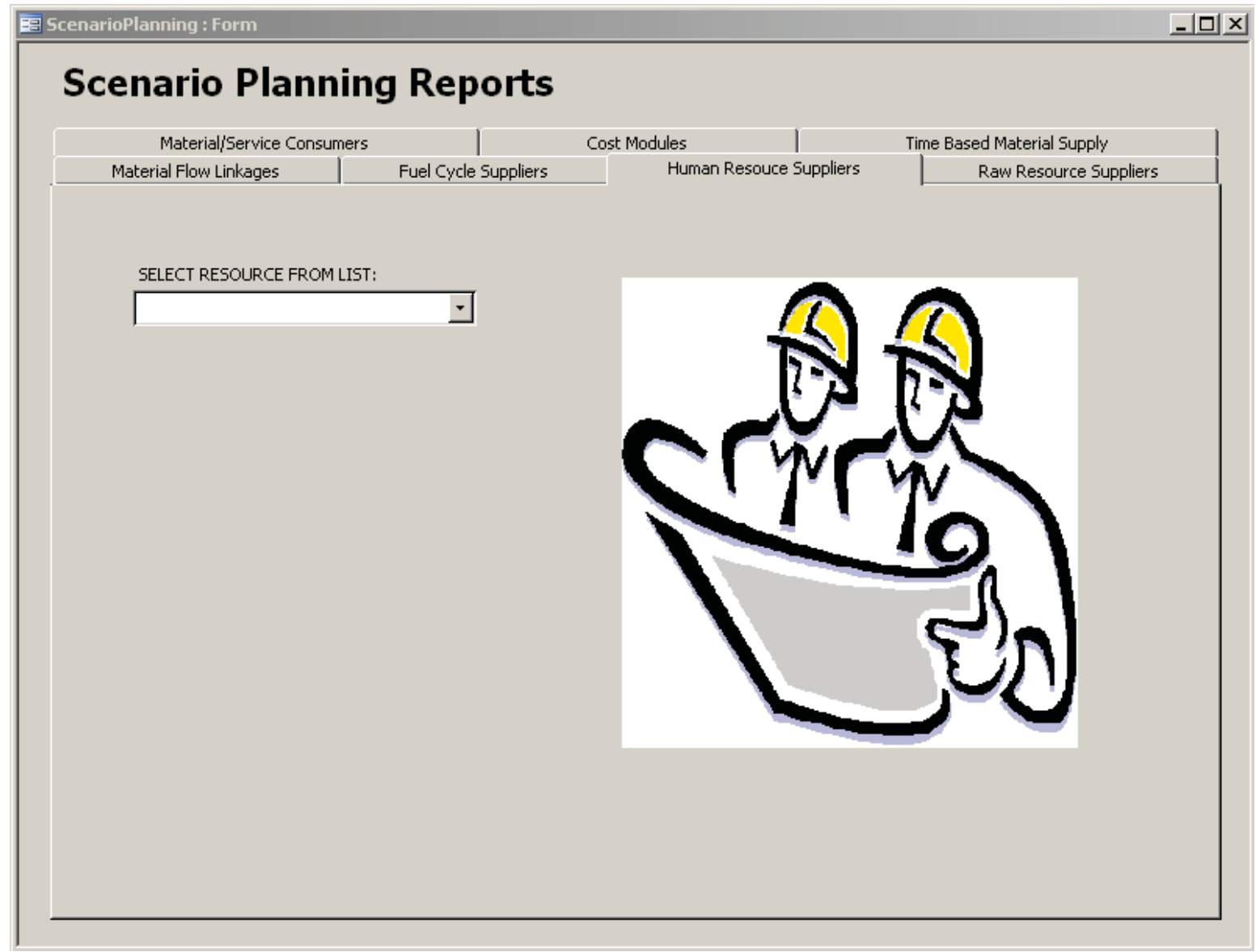

Figure 21. Screen shot of the current Human Resource Suppliers query. 
The list of human resource categories available in the query pull-down menu is as follows:

- Structural Engineers

- Nuclear Engineers

- Electrical Engineers

- Mechanical Engineers

- Metallurgical Engineers

- Installation Engineers

- Construction Engineers

- Electrical Technicians

- Laborers

- Testing Laboratory

- Safeguards \& Security Personnel

- Management Personnel

- Planners
- Operator Training Staff

- Simulator Facilities

- QA/QC Staff

- Staff to Write Procedures

- Staff to Start-up the Plant

- Operations Staff

- Risk Analysis Staff

- Educational Facilities to Train Engineers \& Technicians

- Food Service

- Transportation Services

- Energy Policy Experts

- Lawyers

In the future, the list of human resources could be personalized to be sorted by the facility type that one is interested in constructing, such as electrical grid improvements, nuclear power plants, or specific fuel cycle facilities. It could also be sorted by the phase that one is interested in: planning and licensing, construction, operation and maintenance $(\mathrm{O} \& \mathrm{M})$.

\subsubsection{Raw Resource Suppliers (Under Development)}

This query is currently in development. The intent is that it will show a country developing the capabilities to support nuclear reactors and how NME can locate raw resources (concrete, switches, rebar, castings, etc.) domestically and internationally. Similar to the human resource supplier query, the list of possible raw resources needed to construct a nuclear reactor or fuel cycle facility has been defined (based on discussions with Jerry Phillips, IAEA). A sample GUI has been developed (Figure 22), but there is only a pull-down menu of possible human resources; there is no data on specific human resource facilities in the NME to support a query. This data still needs to be collected. 


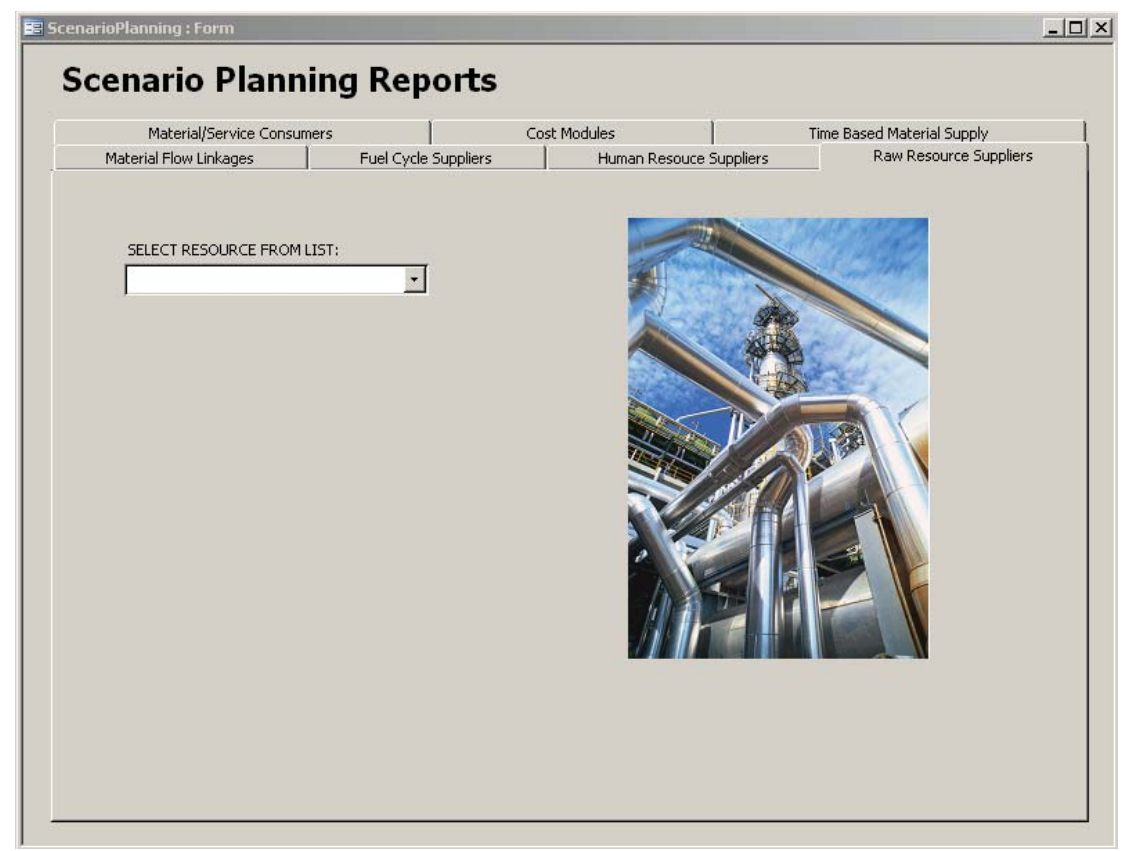

Figure 22. Screen shot of the current raw resource suppliers query.

The list of human resource categories available in the query pull-down menu is:

- Structural Steel

- Bolting Equipment

- Cabling and Wiring

- Transformers

- Substation Equipment

- Reactor Pressure Vessels

- Miscellaneous Vessels

- Piping Spool Pieces

- Piping

- Piping Supports

- Steam Turbine

- Wiring, Cabling

- Transformers

- Electrical Switchgear

- Motor Controllers

- Instrumentation

- Switches

- Sheet Metal Panels

- Seismic Anchors/Shock Absorbers

- Electrical Generators

- Sensors

- Test/Lab Equipment

- Valves

- Pumps

- Motors

- Relay Switches
- Computer Equipment

- Process Components for Plant

- Fans \& A/C Equipment

- Ducting

- Trailers for Temporary Office Space

- Metal Prefab Buildings

- Wood \& Metal Concrete Forms

- Concrete

- Coatings and Paints

- Chemicals \& Acids

- Fencing Materials

- Welding Equipment

- Weld Wire

- Earth Moving Equipment

- Scaffolding

- Spent Fuel Casks for Storage and Transportation

- Hot Cell Equipment

- Insulating Glass

- Remote Manipulators

- Specialized Materials for Chemical Tanks, Piping, Vessels, and Digesters

- HEPA Filters

- Sensors

- Dampers

- Dryers

- Casks for Storage and Transportation 
In the future, as with the human resource query, the user could sort this query by the facility type he/she is interested in constructing, such as electrical grid improvements, nuclear power plants, or specific fuel cycle facilities. It could also be sorted by the phase is the user is interested in: planning and licensing, construction, O\&M.

\subsubsection{Planned Queries}

A number of additional queries are planned. These include:

- Show how regional blocks of co-located countries could trade unique capabilities to build new nuclear generation capabilities. For example, during reactor construction, one country supplies electronic equipment, another construction labor and management, and another country have unique large metal fabrication capabilities.

- Show how recycled or un-recycled output streams could be used by secondary industries (e.g., production of medical isotopes, radiation therapy, thermal waste heat use, etc.). This use case involves identifying recycled or un-recycled reactor output streams that could be used by secondary industries. Reprocessed spent fuel is initially considered as an output steam for making isotopes for nuclear medicine application. A more in-depth data search will be needed to obtain quantitative information on the availability of isotopes, including both the major isotopes used in medical treatment and the major isotope vendors in the world.

- Secondary industry expansion of country core infrastructures (e.g., manufacturing, construction) to support nuclear power.

- Operational inputs/outputs of a nuclear fuel bank based on the projected scenario where supplier countries would input various fuels to the fuel bank, and user nations would make fuel withdrawals and then return the used fuel for supplier countries to separate and disposition accordingly.

- Symbiotic relationships across different reactors/fuel cycles.

- $\quad$ LWR RU (outputs) links to fuel (inputs) for HWR (CANDU).

- $\quad$ Fast breeder reactor (FBR) recycled ${ }^{233} \mathrm{U} / \mathrm{U}$, combined with thorium, linking to fuel (inputs) for small high-temperature gas reactors (HTGR) for use in developing countries (Study by Tokyo Institute of Technology).

- Show how we can link countries (i.e., France) using mixed uranium-plutonium oxide (MOX) recycled fuel to countries with UREX+ technology, to recycle the used MOX fuel in advanced burner reactors to destroy the transuranics.

- Economic tradeoffs and opportunities from the sharing of hard and soft capital resources, make/buy/trades, using new resources versus recycled resources, economies of scale from using or adapting technologies developed by other countries. Deployment ramifications on economics.

\subsection{Data Optimization}

So far in the NME and in the queries or use cases, the only question asked is, "Where are materials or services available?" and not, "How can the material and service demands of a particular facility be met in the most economic manner?" or "Can the demands of a facility be feasibly met by the available supply?" Production and transportation costs are two factors that determine economics. Available supply and given demands from other facilities can be used to determine the feasibility of meeting the demand from a new facility. In both cases, linear optimization programs (LPs) can address each of these questions.

In designing NME optimization capability, first, an appropriate optimization problem should be formulated. Second, an LP solver should be chosen, and Visual Basic (VB) code developed in the NME to output a text file as input to the solver, in a format specific to the solver. 
Formulations, such as the transportation and production problem, can be used to find optimal linkages, find infeasibilities, and determine requirements for additional capacity throughout the entire supply chain, from mining and milling to power generation, to fuel reprocessing and storage. In fact, it is only through an optimization approach, that basic questions of available supply and demand can be addressed. Otherwise, the NME would only be able to determine the availability of capabilities, and not the availability of particularly quantities of materials or services. In some cases, it will be sufficient to know only if a country or operating organization has a certain capability, such as the availability of engineering expertise in a particular domain, or the capability to reprocess a certain nuclear fuel. However, in other cases, knowing required or available supply quantities will be important.

\subsection{GIS Capabilities}

Graphical display and interactive graphics of NME scenarios can be a powerful and useful tool for analysis, presentations, and communication of results.

Another potentially useful application that was not implemented in IME is that of Geographical Information Systems (GIS) capabilities. GIS functionality can range from the generation of maps showing the locations of facilities and the flow of materials, to providing detailed information about the locations of facilities, including available infrastructure (highways, railways, water, etc.) and environmental information. GIS systems can also calculate distances between facilities and provide factors for calculating actual transportation distances via different modes of transportation, including highway, rail, inland water, ocean, air, and multi-modal transportation.

Simple mapping systems, such as MapMaker (www.mapmakker.com) or Google Maps (www.maps.google.com) could be used to locate facilities and generate maps. GIS software such as AGIS (www.agismap.com) has additional GIS capabilities and could be incorporated.

\subsubsection{Integration with Optimization}

If transportation costs and planning is an important consideration in NME planning, GIS systems can provide actual transportation distances and costs for material shipment. With latitude and longitude data for a given facility (which is part of the NME data structure), GIS systems can determine the costs and available transportation modes. However, for nuclear materials, additional data input may still be required to identify secure transportation and handling requirements for the materials.

Future NME design might include additional parameters for materials to indicate whether there are special transportation, handling, and security requirements.

\section{REFERENCES}

Bechtel, INEEL, and Nexant, Industrial Materials Exchange Planner, 2001.

IAEA, Country Nuclear Fuel Cycle Profiles, Technical Report Series No. 425 (TRS 425), $2^{\text {nd }}$ Edition, 2005.

IAEA, Nuclear Fuel Cycle Information System, www-nfcis.iaea.org/iNFCISMain.asp, Web page accessed March-August 2007.

IAEA, Power Reactor Information System (PRIS), www.iaea.or.at/programmes/a2, Web page accessed March-August 2007

Nexant, Development of the Nuclear Materials Exchange Planner, November 1, 2006.

Nuclear News, World List of Nuclear Power Plants, December 31, 2006. 
Nuke Database System, http://www.icjt.org/plants/index.html, Web page accessed January-March 2007.

Shropshire, D. E., et al., 2007 Advanced Fuel Cycle Cost Basis, INL/EXT-07-12107, July 2007.

World Nuclear Association Reactor Database, www.world-

nuclear.org/wgs/decom/database/php/reactorsdb index.php, Web page accessed November 2006August 2007. 


\title{
Attachment E
}

\section{Uranium Resource Model (U of TX-Austin)}

\author{
Erich Schneider and Anthony Scopatz \\ Department of Nuclear Engineering \\ University of Texas-Austin \\ Contract No. 00057910 \\ with Battelle Energy Alliance, LLC \\ Idaho Falls, Idaho
}


E-2

INL/EXT-09-15483 


\section{Preface}

The primary work for this attachment was completed in 2007. Since then, there have been some additions and expansions to the activities in this attachment. This information can be found in the following references.

Schneider, E. A., Deinert, M. R. and K. B. Cady, "Cost Analysis of the U.S. Spent Nuclear Fuel Reprocessing Facility," Energy Economics, in press 2009.

Scopatz, A. and E. A. Schneider, "A Parameterization of Uranium Recycle: Neutronics and Costs," Proc. PHYSOR 2008: Am. Nucl. Soc. Topical Meeting on Reactor Physics, Interlaken, Switzerland, September 2008.

Schneider, E. A. and W. C. Sailor, "Uranium Resource Depletion: a Comparative Analysis," Nucl. Tech., 162, 3, 379, June 2008.

Schneider, E. A. and N. Shah, "Near Term Deployment, Long Term Impact: Uranium Price Over the Lifetime of New Capacity," Proc. International Conference on Nuclear Engineering (ICONE) 16, Orlando, Florida, May 2008.

Schneider, E. A., "Uranium Price Trends for This Century: An Analogy to Historical Mineral Market data," Touch Briefings, January 2008.

Schneider, E. A., Deinert, M. R. and A. Scopatz, "Depleted and Recyclable Uranium: Inventories and Options," in Proc. GLOBAL 2007: Advanced Nuclear Fuel Cycles and Systems, Boise, Idaho, September 2007. 
E-4

INL/EXT-09-15483 


\section{ABSTRACT}

Long-Term Uranium Supply Modeling and Analysis

The "Advanced Fuel Cycle (AFC) Cost Basis" report includes modules describing the expected unit costs of all fuel cycle steps that might arise under the AFCI scenarios (Shropshire, et al. 2007). These costs, rather than being presentday values, reflect an average of expected values over the next several decades. For many of the fuel cycle processes, bottom-up technology-based estimates exist in the literature. However, long-term price projection for the uranium resource does not lend itself to this approach. Therefore, the tools of resource economics were utilized to generate two forecasts of long-term uranium price trends. One of these forecasts postulated a functional dependence of the uranium price on a variety of historical uranium market indicator data. An econometric analysis solved for the values of the coefficients in this function. This regression analysis used a dedicated statistical/econometric package, SAS. Given that less than 40 years of historical uranium price and market data exist, it was necessary to confirm the results of this econometric model using a second, simpler model. The second approach creates an analogy between uranium price trends and that of several dozen other minerals for which more than 100 years of market data exists. The price evolution of each of these minerals was obtained, and simple mathematical models describing their behavior were created. The modeling results for an "average" mineral commodity were then used to project the uranium price into the latter portion of this century. Both approaches predicted that a trend of gradually declining prices was likely.

Depleted and Reprocessable Uranium Supply Survey and Analysis

Presently, Verifiable Fuel Cycle Simulation (VISION) and the other AFCI models do not include scenarios involving direct recycling of depleted uranium (DU) and reprocessable uranium (RU). Given uncertainties surrounding the security and sustainability of uranium resource supply, it is desirable to ascertain the conditions under which DU and RU recycle might be economically advantageous. Therefore, a two-stage analysis of these resources was performed. First, the size and composition of the U.S. DU and reprocessable uranium inventories were obtained. For DU, this data could be obtained from public sources; however, calculations were required to obtain the isotopic composition of RU contained in current spent fuel (SF) as well as RU that might be generated in future SF. The size of the natural uranium (NU) equivalent supply reservoir represented by these materials proved to be considerable. Note that RU in this attachment stands for reprocessable uranium, which includes uranium that has already been separated, but not re-irradiated, of which the U.S. holds only limited stocks, but also uranium that is presently contained in SF and could be separated.

Once inventories and future activities were established, the options for DU and RU re-use and disposal were surveyed and tabulated. In each case, about six options were considered. For each of these, the fuel cycle mass flows (e.g., reactor charge and discharge compositions) and energy production rates were computed.

To ascertain when and if the options might become cost-competitive, elementary cost-benefit analyses were performed. These analyses serve two purposes: to rank the options in terms of their desirability from an economic 
standpoint, and to indicate, the natural uranium price at which a similar strategy, pursued with NU, would break even with the DU or RU option being considered. A leveled cost approach was taken to conduct the study and the unit fuel cycle costs associated with the options were obtained from the "AFC Cost Basis" report. 


\section{CONTENTS}

ABSTRACT E-5

ACRONYMS E-11

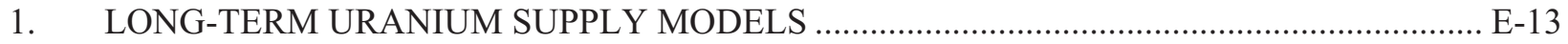

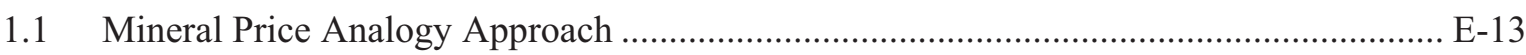

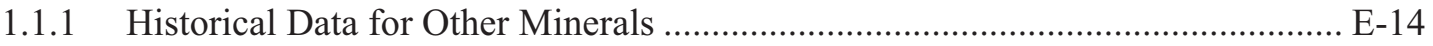

1.1.2 Correlation with Time for Other Minerals ..................................................... E-16

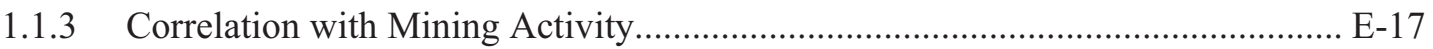

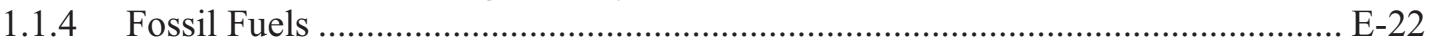

1.1.5 Conclusions and Application to Advanced Fuel Cycle Cost Basis....................... E-23

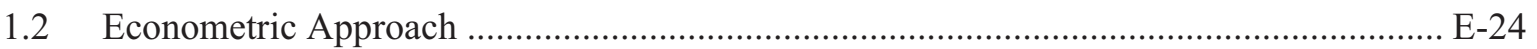

1.2.1 Model Formulation ...................................................................................... E-24

1.2.2 Sample Results and Conclusions .................................................................... E-28

2. DEPLETED AND REPROCESSABLE URANIUM ANALYSES......................................... E-32

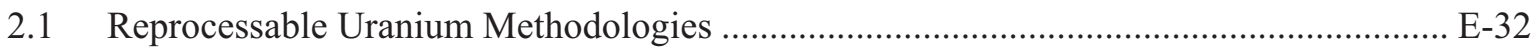

2.1.1 Uranium Composition of Spent LWR Fuel ……......................................... E-32

2.1.2 Multi-Component Enrichment ....................................................................... E-35

2.1.3 Discharge Burnup Achievable from RU Fuel .................................................... E-38

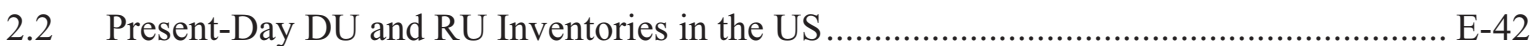

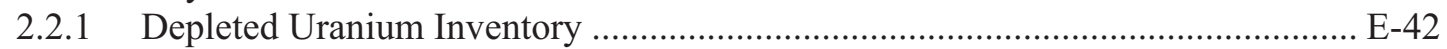

2.2.2 Reprocessable Uranium Inventory ....................................................... E-43

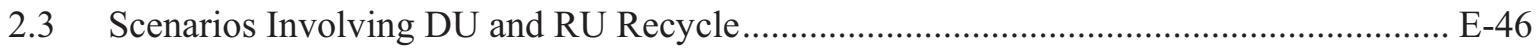

2.3.1 Probabilistic discount model for assessing the life cycle cost of nuclear fuel

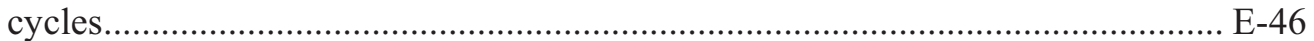

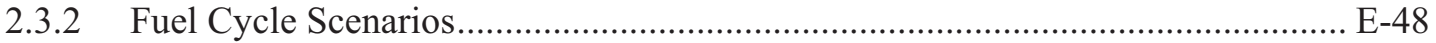

2.3.3 Sample Results and Conclusions ........................................................................ E-50

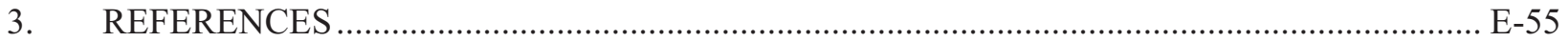

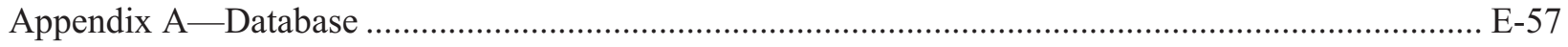

\section{FIGURES}

Figure 1. Mineral price variation for the years 1900-2000.

E-15

Figure 2. Price plotted against "s," cumulative world production scaled to the production rate in

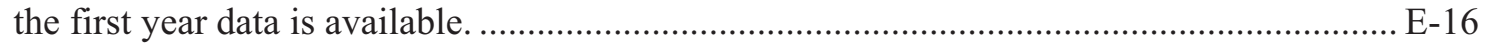

Figure 3. Exponential regressions and $M$-values for four minerals. ................................................ E-16

Figure 4. Price trends and M-coefficients for the three fossil fuels................................................... E-23

Figure 5. Unidentified system. Only one market-clearing point is defined. ....................................... E-26

Figure 6. Overidentified system. At least one of the supply and demand functions are defined parametrically as a function of multiple exogenous variables. 
Figure 7. Regression results. The abscissa is the year and the ordinate is the spot price in 2004 dollars. $\mathrm{R}^{2}=0.937$

Figure 8. Benchmark: model projections, 1995-2002, versus historical data. .................................... E-30

Figure 9. Supply curves, model versus external estimate. ................................................................ E-31

Figure 10. Uranium isotopic vectors. The $\mathrm{u}_{\mathrm{i}}$ are tabulated against initial enrichment and discharge

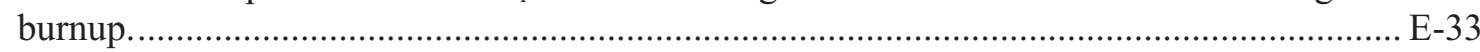

Figure 11. Diagram of looping pseudocode that calculates 3-tuple data. ........................................... E-34

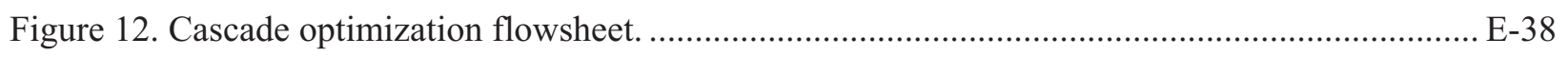

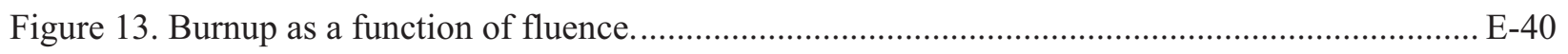

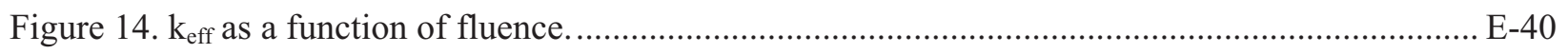

Figure 15. Maximum burnup achievable for various ${ }^{235} \mathrm{U}$ and ${ }^{236} \mathrm{U}$ enrichments for a three-batch

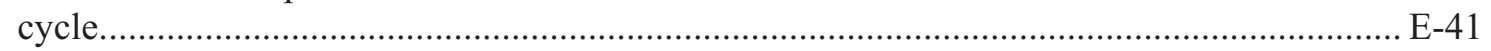

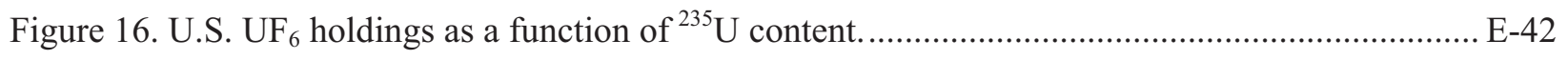

Figure 17. Estimated ${ }^{235} \mathrm{U}$ content of uranium contained in U.S. spent fuel....................................... E-44

Figure 18. Cumulative distribution function of estimated normalized ${ }^{236} \mathrm{U}$ content of RU with $0.55-0.65 \%{ }^{235} \mathrm{U}$. The ordinate shows the fraction of RU that has a ${ }^{236} \mathrm{U}$ content less than or equal to the value given on the abscissa................................................................. E-44

Figure 19. Cumulative distribution function of estimated normalized ${ }^{236} U$ content of RU with $0.85-0.95 \%{ }^{235} \mathrm{U}$. The ordinate shows the fraction of RU that has a ${ }^{236} \mathrm{U}$ content less than or equal to the value given on the abscissa..................................................................... E-45

Figure 20. Calculated assay distribution of U.S. recyclable uranium................................................ E-45

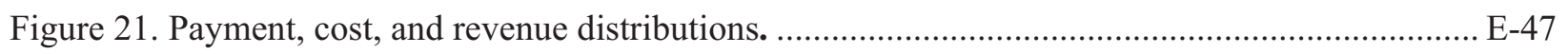

Figure 22. Energy equivalent options for comparison, 1: Direct RU enrichment. ............................... E-51

Figure 23. Material balance for Option 1: Enrichment of unblended RU........................................... E-52

Figure 24. Energy equivalent options for comparison, 2: RU+LEU blend. ....................................... E-53

Figure 25. Material balance for Option 2: Blending of RU with LEU. ............................................... E-54

\section{TABLES}

Table 1. Crustal abundance (grams/tonne) of selected elements..................................................... E-14

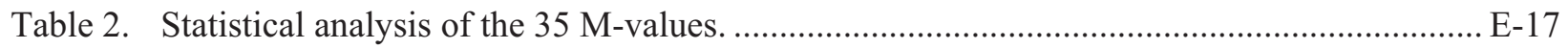

Table 3. Raw post-1947 USGS data for aluminum. (Note the discontinuity after 1952 where 47

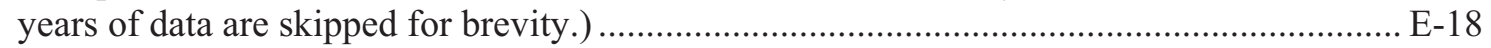

Table 4. Aluminum production normalized by 1947 mining rate. ................................................... E-19

Table 5. Cumulative aluminum production in units of 1947 mine years. .......................................... E-19

Table 6. $M$-values versus cumulative 1947 mine years for 27 minerals.......................................... E-20

Table 7. $M$-values versus cumulative 1974 mine years for 34 minerals.......................................... E-21

Table 8. $M$-values for minerals with relatively low and high mine year values, 1947 and 1974........ E-22 


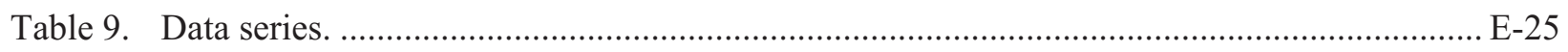

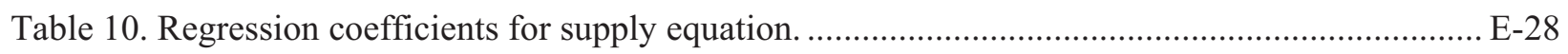

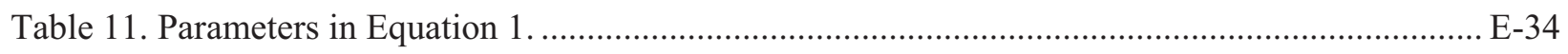

Table 12. Uranium composition [weight percent] of SF specified by VISION “Low Burnup

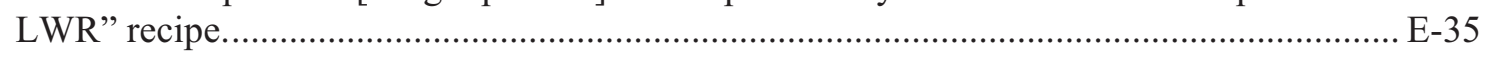

Table 13. Maximum burnup achievable for $4.3 \mathrm{wt} \%{ }^{235} \mathrm{U}$ and three batches. ..................................... E-41

Table 14. Isotopic composition (weight percent) of enriched RU feed, product, tails. ........................ E-52

Table 15. Isotopic composition (weight percent) of LEU feed, product, tails and blended LEU +

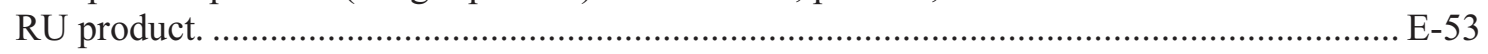

Table 16. Unit costs taken from Cost Basis Report modules. .......................................................... E-54

Table 17. Fuel cycle cost components for direct disposal versus two scenarios involving RU............ E-55

Table A-1. Data series used in regression analysis — Part I. ............................................................. E-64

Table A-1. Data series used in regression-Part II............................................................................ E-67 
E-10

INL/EXT-09-15483 


\section{ACRONYMS}

2SLS two-stage least squares

AFC Advanced Fuel Cycle

AFCI Advanced Fuel Cycle Initiative

ARIMA Autoregressive Integrated Moving-Average

BLS Bureau of Labor Statistics

BWR boiling water reactor

$\mathrm{CF} \quad$ capacity fraction

CPI consumer price index

DU depleted uranium

E\&C existing and committed

ECP\&P existing, committed, planned, and prospective

EIA U.S. Energy Information Administration

HEU highly-enriched uranium

LEU low-enriched uranium

LWR Light-Water Reactor

MOX mixed uranium-plutonium oxide

NU natural uranium

OECD Economic Co-operation and Development

ppm parts per million

PWR pressurized water reactor

RU reprocessable uranium

SF spent fuel

SWU separative work units

UOX uranium oxide fuel

USGS United States Geological Survey

VISION Verifiable Fuel Cycle Simulation 
E-12

INL/EXT-09-15483 


\section{Uranium Resource Model (U of TX-Austin)}

This document details the methods employed to conduct analyses supporting front-end economic and fuel cycle studies. Section 1 addresses long-term uranium supply modeling. This activity was motivated by the need to support the uranium price estimate presented in the "Advanced Fuel Cycle (AFC) Cost Basis" report (Shropshire 2007). Two approaches were taken. The first approach, presented in Section 1.1, draws upon an analogy to historical mineral prices. And, the second approach postulates a functional dependence of the price of uranium upon a number of explanatory variables related to market conditions. This econometric approach is described in Section 1.2.

Methods developed to support scenario analyses - spreadsheet-based and eventually in Verifiable Fuel Cycle Simulation (VISION) - where depleted uranium (DU) or reprocessable uranium (RU) are used in Light-Water Reactor (LWR) fuels, are described in Section 2. The presence of additional uranium isotopes of neutronic significance in RU requires that enrichment cascade and reactor physical calculations be performed to assess the performance of this material. Section 2.1 describes the methods developed to complete this task. Present-day DU and RU inventories, held by the U.S., are summarized in Section 2.2, with an emphasis on description of the methods used to obtain them. An AFCI scenario involving future DU and RU activities is employed in Section 2.3 to demonstrate the application of RU recycle to a limited number of test scenarios. The test cases are conducted in stand-alone fashion; if the results reveal that certain aspects of the DU and RU recycle scenarios are of interest, they can be studied in more detail with the aid of VISION.

\section{LONG-TERM URANIUM SUPPLY MODELS}

This section describes two independent models for predicting trends in the price of uranium over the next century. The models, whose forecast results are in general agreement, support the uranium price forecast given in the July 2007 version of the "AFC Cost Basis" report.

\subsection{Mineral Price Analogy Approach}

For most forecasts of future uranium price, the common practice is to base economic calculations on a growing scarcity of uranium in the future. Given that uranium is a relatively new mineral resource by historical standards, comparison of existing uranium supply estimates to the trends observed for minerals that have been extracted for many decades or centuries may offer a useful new perspective upon likely future uranium prices.

To this end, an analogy was drawn between uranium and 35 minerals for which the United States Geological Survey (USGS) maintains extensive records. The USGS mineral price data, which extends from 1900 to the present, was used to create a simple model describing long-term price evolution. Making the assumption that the price of uranium, a geologically unexceptional mineral, will evolve in a manner similar to that of the USGS minerals, the model was used to project its price trend for this century. Based upon the precedent set by the USGS data, there is an $80 \%$ likelihood that the price of uranium will decline. Moreover, the most likely scenario would see the equilibrium price of uranium decline by about $40 \%$ by mid-century.

Uranium is unexceptional in that, like other minerals, it is widely distributed throughout the crust of the earth. The ability to extract the uranium in a practical and cost-effective manner depends on the relative grade of the ore to be mined (i.e., the percentage of uranium in the ore body), the type of formation in which it resides, and the location. Uranium, on average, is more prevalent in the earth's crust than economically important metals such as silver and tungsten (Table 1); it is a constituent of most rocks and even found in the sea. 
Table 1. Crustal abundance (grams/tonne) of selected elements.

\begin{tabular}{|c|c|}
\hline Gold & 0.004 \\
\hline Silver & 0.07 \\
\hline Tungsten & 1.5 \\
\hline Molybdenum & 1.5 \\
\hline Uranium & 2.8 \\
\hline Thorium & 7 \\
\hline Lead & 13 \\
\hline Copper & 55 \\
\hline Zinc & 70 \\
\hline Iron & 50,000 \\
\hline
\end{tabular}

In addition, leaving in-situ leaching aside, the concentration factor at which uranium extraction is economically feasible is consistent with that of other minerals. The concentration factor is defined as the ore grade of an economically viable deposit divided by the average grade in the earth's crust. For uranium, taking $500 \mathrm{ppm}$ to be a viable concentration, the concentration factor is $(500 / 2.8)=180$. Other common minerals have concentration factor thresholds bracketing this value: gold, 2,500; iron, 10; mercury, 10,000; lead, 2,500; copper, 100 (Griffits 1973).

\subsubsection{Historical Data for Other Minerals}

The assumption of growing scarcity is valid over short time periods, but it neglects the effect of innovations in exploration and extraction. Such considerations do not act against short-term supply shocks, but they might be expected to hold prices down over generational timescales.

For many minerals, this effect is easily observable. There has been a historical trend in mineral commodity prices, downwards, when corrected for inflation. The USGS has a database of mineral prices and publications on their Web site describing this trend (USGS 2007.).

The values for over 30 minerals in this database were plotted together on the same 100-year time scale, and curve-fit using least squares. Those commodities that were omitted (e.g., peat, wood, helium and cement) were clearly not analogous to uranium and other minerals. Of those that are included, some (silver, 0.07 parts per million ( $\mathrm{ppm}$ ); tungsten and molybdenum, $1.5 \mathrm{ppm}$ ) have average crustal abundances lower than the $2.8 \mathrm{ppm}$ of uranium, while others are more abundant (lead, $13 \mathrm{ppm}$, copper, 55 ppm, zinc, $70 \mathrm{ppm}$ ). All prices are normalized to the value of the dollar in 2005, as defined by the consumer price index (CPI). In some cases, the data starts in the year 1900, sometimes after 1900. The price ratio (versus the first year of data) was plotted as a function of year number since the first available year of data. The results are shown in Figure 1. Each mineral was fitted to its own curve based on the relationship:

$\mathrm{P} / \mathrm{P}_{0}=\exp \left(M^{*} \mathrm{y}\right)$

where y is the year number. The majority of the commodities have a negative $M$ value, and two have $M$ values less than -0.04. More detailed results for specific minerals are addressed in Section 1.1.2. 


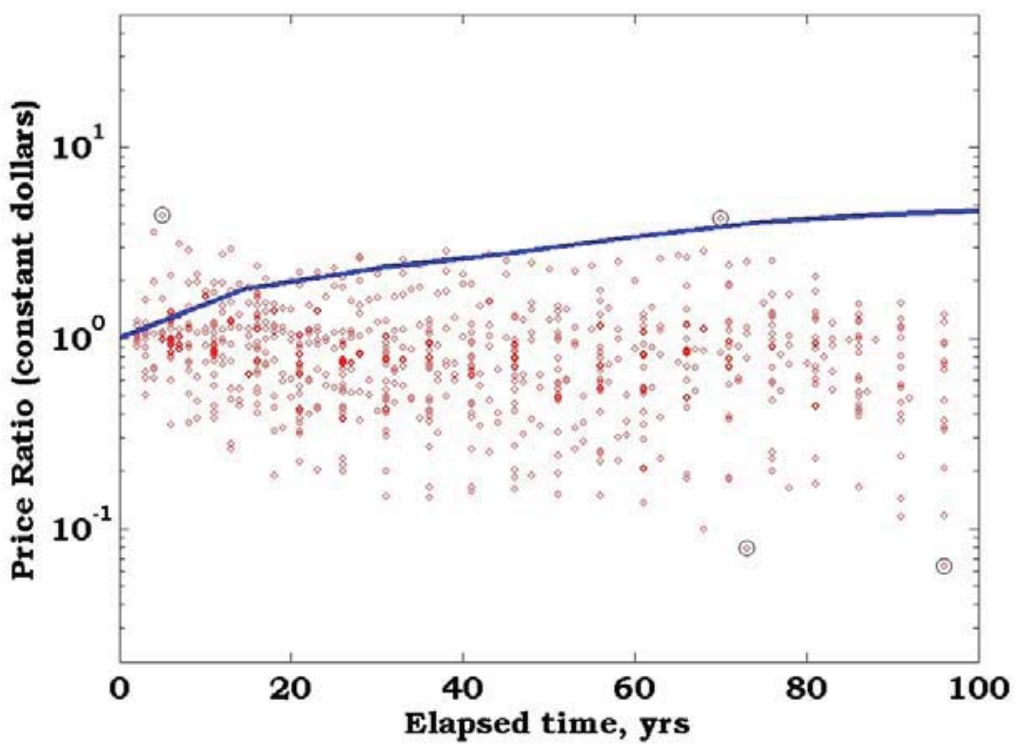

Figure 1. Mineral price variation for the years 1900-2000.

The solid blue curve in the figure is the projected uranium price ratio starting in the year 1995, following Scenario B from "Global Energy Perspectives" (Nakicenovic and Gruebler) for nuclear energy demand and the price/supply elasticity of the U.S. Department of Energy (DOE) Gen IV Fuel Cycle Crosscut Group (FCCCG) (DOE 2002). At 100 years under this scenario, $40 \mathrm{MtU}$ are consumed in the once-through nuclear fuel cycle. The projected curve for the uranium price appears to be significantly at variance with experience of the last 100 years.

The data were then plotted against another independent variable, which makes use of the availability of world production numbers for each material. In this variable, the number of mine-years "s" is taken as the cumulative world production of the mineral starting in the year the tabulation begins, and normalized to the production rate in that first year. Hence, "s" is the number of years of mining of that mineral if the world production was constant. Plotting prices against this variable should emphasize those materials, which have been heavily exploited (i.e., mined at an ever-increasing rate over many years).

If resource depletion were a real concern, an upward trend in prices would be observed with very high s-values. The plot that tests this hypothesis, Figure 2, shows that those minerals with high s-values tend to have prices that appear comparable to those with lower s-values. Hence, any effects of resource depletion over the years 1900-2000 for those materials have been outpaced by productivity increases even faster than the average mineral. The solid red line is the price expectation of the DOE Gen IV FCCCG.

The observed trend in the data supports a conjecture that accelerating production of a mineral stimulates lower production costs through a process of unit-based learning, which may occur in conjunction with time-based (or year-to-year) learning. 


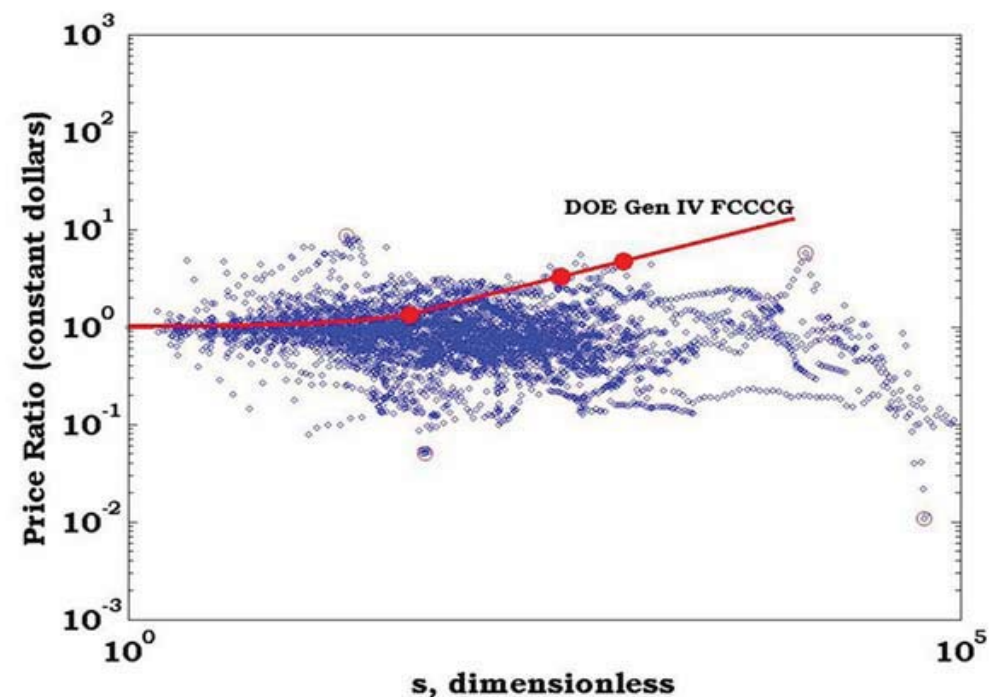

Figure 2. Price plotted against "s," cumulative world production scaled to the production rate in the first year data is available.

\subsubsection{Correlation with Time for Other Minerals}

The coefficient $M$ is interpreted as a price growth rate with respect to time. Minerals with negative $M$ values have experienced declining prices; for those with positive $M$-values, the price has increased over the past century. The data series and computed $M$-values for four minerals are depicted in Figure 3.
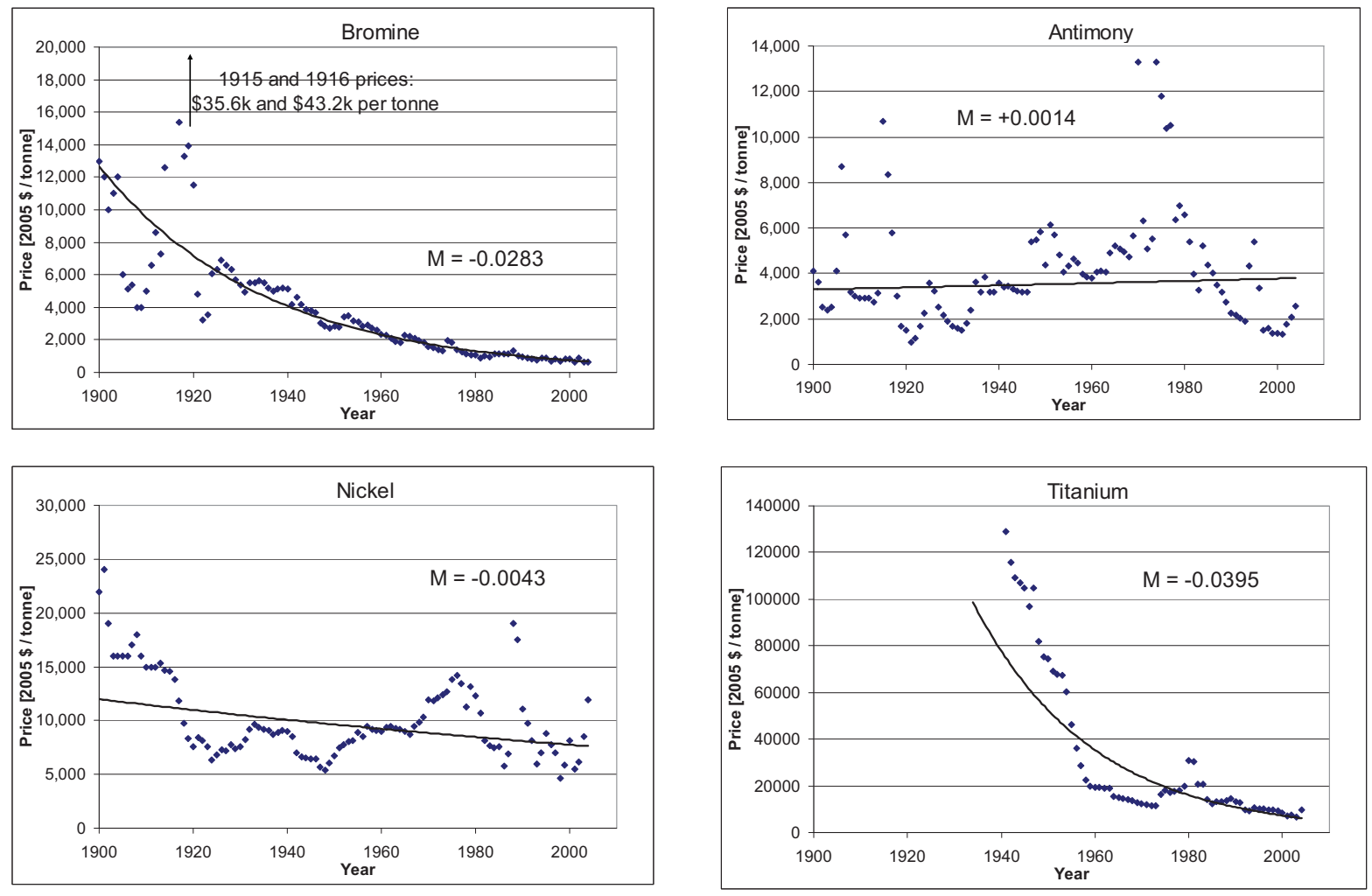

Figure 3. Exponential regressions and $M$-values for four minerals. 
The $M$-coefficients for six of the minerals were positive, while 29 were negative. The distribution of $M$-values might contain valuable information. For instance, it might show that the price trend for a "typical" mineral chosen at random from the sample is indeed likely to be downward. It can also be used to quantify the steepness of the descent in price for a typical mineral or the likelihood that a mineral might experience a rise in price.

To address these questions the $M$-value distribution was itself subjected to statistical analysis. It was assumed that the $M$-values adhere reasonably well to a normal or bell-shaped distribution. The mean and standard deviation of the distribution were calculated. Table 2 shows that the mean $M$-value was negative: -0.0118. This implies a decrease in average mineral prices with time. The standard deviation was computed to be 0.0136 , which implies about a $20 \%$ probability that the $M$-value for any given mineral will in fact be positive and its price will have risen over the century. The $95 \%$ confidence interval for $M-$ computed by calculating the interval falling within two standard deviations of the mean-is thus found to be $[-0.0390,+0.0153]$.

Table 2. Statistical analysis of the 35 M-values.

\begin{tabular}{|l|l|}
\hline Most Negative & Rhenium, -0.0499 \\
\hline Most Positive & Chromium, 0.0077 \\
\hline Mean & -0.0118 \\
\hline Standard Deviation & 0.0136 \\
\hline Two Standard Deviation Confidence Interval & {$[-0.0390,+0.0153]$} \\
\hline
\end{tabular}

If uranium is accepted to not be exceptional with respect to the surveyed minerals, then the mean $M$ value and its confidence interval can be used to make an approximate projection of uranium price evolution over this century. An extrapolation of this type requires an initial price point; since the price of uranium has varied by a factor of nearly ten over the past half-decade, selection of this price point is not trivial. The curve fits describe the long-term equilibrium situation in which shocks and boom-bust cycles are smoothed out. Therefore, the initial price point for uranium could be interpreted as the present-day equilibrium price level. This is the price that would be reached if the market reached a condition in which the price is governed only by the marginal cost of producing the most expensive to extract unit of uranium being sold. This data point is elusive. A recently published uranium production cost curve estimate is optimistic, predicting a near-term marginal production cost of about $\$ 50 / \mathrm{kgU}$ (UIF 2007). Another recent estimate (Nuclear Fuel Cycle Monitor 2007) predicts that prices will settle to about $\$ 60 / \mathrm{kgU}$ by the early part of the next decade.

The issue can be avoided entirely if it is discussed in relative terms only. For instance, if the price trend of a mineral obeys the mean $M$-value of -0.0118 , its equilibrium price would decline by $40 \%$ by mid-century. Likewise, if a mineral obeys an $M$-value of +0.0153 (i.e, lies at the top of the two standard deviation confidence interval), its price would double by mid-century. Further, given the $M$-value distribution shown in Table 2, there is an $80 \%$ likelihood that a given mineral would experience a decline in prices over the long term. Prices are no asserted to monotonically rise or decline; boom-bust cycles, shocks, and other factors that throw markets out of equilibrium will always exist. Nonetheless, long experience shows that, over the long term, prices for minerals, such as uranium, will likely to continue to decline.

\subsubsection{Correlation with Mining Activity}

Earlier it was observed that when price was compared to mining activity, as measured by the dimensionless variable "s," the price trends for minerals with rapidly accelerating rates of mining activity 
appeared similar to those for minerals extracted at more constant rates. This conjecture can be explored in more depth by again resorting to study of individual mineral price histories.

Therefore, the objective in this section is to quantify the effect of resource depletion upon mineral prices, specifically answering three questions. These questions are:

- Does a rapid increase in mining activity lead to a price increase?

- Do minerals with accelerating mining rates tend to rise in price when compared to minerals with stagnant or declining mining rates?

- Would the data support a concern that the resource base might not sustain a future of aggressive nuclear growth?

The USGS data is not as comprehensive for global mineral extraction volume as it is for price. Only a few data sets are complete (i.e., global mining data is tabulated as far back as 1900). Therefore, the definition is generalized of the cumulative number of mine years, "s," to the amount of a mineral mined in a given year, divided by the amount mined in a reference year.

Two reference dates were chosen, 1974 and 1947, as a number of data series commence in these years. The USGS has world primary production data extending back to 1974 for 34 minerals and to 1947 for 27 minerals. Therefore, defining a "1947 Mine Year" as the amount of a mineral extracted in 1947 and a "1974 Mine Year" as the amount mined in 1974, data series are constructed of mining activity versus price and time. Tables 3, 4, and 5 illustrate the construction of the data series normalized to 1947 for aluminum.

Table 3. Raw post-1947 USGS data for aluminum. (Note the discontinuity after 1952 where 47 years of data are skipped for brevity.)

\section{Aluminum}

Prices in Year 2005 \$ / tonne.

\begin{tabular}{|r|r|r|}
\hline Year & $\begin{array}{r}\text { Mining Rate } \\
\text { [tonnes/yr] }\end{array}$ & \multicolumn{1}{c|}{ Price } \\
\hline 1947 & $1,080,000$ & 2,420 \\
\hline 1948 & $1,270,000$ & 2,340 \\
\hline 1949 & $1,310,000$ & 2,570 \\
\hline 1950 & $1,490,000$ & 2,640 \\
\hline 1951 & $1,800,000$ & 2,640 \\
\hline 1952 & $2,060,000$ & 2,630 \\
\hline 2000 & $24,300,000$ & 1,550 \\
\hline 2001 & $24,300,000$ & 1,400 \\
\hline 2002 & $26,100,000$ & 1,300 \\
\hline 2003 & $27,900,000$ & 1,330 \\
\hline 2004 & $29,800,000$ & 1,600 \\
\hline
\end{tabular}


Table 4. Aluminum production normalized by 1947 mining rate.

Aluminum

\begin{tabular}{|r|r|r|}
\hline Year & $\begin{array}{c}\text { Mining Rate } \\
\text { [1947 Mine } \\
\text { Years / yr] }\end{array}$ & \multicolumn{1}{c|}{ Price } \\
\hline 1947 & 1.00 & 2,420 \\
\hline 1948 & 1.18 & 2,340 \\
\hline 1949 & 1.21 & 2,570 \\
\hline 1950 & 1.38 & 2,640 \\
\hline 1951 & 1.67 & 2,640 \\
\hline 1952 & 1.91 & 2,630 \\
\hline 2000 & 22.50 & 1,550 \\
\hline 2001 & 22.50 & 1,400 \\
\hline 2002 & 24.17 & 1,300 \\
\hline 2003 & 25.83 & 1,330 \\
\hline 2004 & 27.59 & 1,600 \\
\hline
\end{tabular}

Table 5. Cumulative aluminum production in units of 1947 mine years.

\section{Aluminum}

\begin{tabular}{|r|r|r|}
\hline & $\begin{array}{c}\text { Cumulative } \\
\text { Mining Rate [1947 } \\
\text { Mine Years] }\end{array}$ & \multicolumn{1}{c|}{ Price } \\
\hline 1947 & 1.00 & 2,420 \\
\hline 1948 & 2.18 & 2,340 \\
\hline 1949 & 3.39 & 2,570 \\
\hline 1950 & 4.77 & 2,640 \\
\hline 1951 & 6.44 & 2,640 \\
\hline 1952 & 8.34 & 2,630 \\
\hline 2000 & 561.99 & 1,550 \\
\hline 2001 & 584.49 & 1,400 \\
\hline 2002 & 608.66 & 1,300 \\
\hline 2003 & 634.49 & 1,330 \\
\hline 2004 & 662.08 & 1,600 \\
\hline
\end{tabular}

If a mineral was mined at a constant rate each year from 1947 to 2004, its cumulative mine-years value in 2004 would be 58 . Hence, it can be seen that aluminum production has accelerated significantly since 1947. Aluminum is not unique in this respect, although its mining rate has increased more quickly than that of most other minerals. The cumulative mining activity evinces variability from mineral to mineral, although only arsenic and mercury show a substantial deceleration in mining activity over part of the time.

For both the 1947 and 1974 starting points, the mineral prices were again fit to the function given by Equation 1. The period over which the regressions were carried out was limited to 1947 and 1974, respectively, so the $M$-values of individual materials are not the same between the two cases.

Tables 6 and 7 show the $M$-values of each mineral, sorted by cumulative mine years, for the 1947 and 1974 starting points, respectively. 
Table 6. $M$-values versus cumulative 1947 mine years for 27 minerals.

\begin{tabular}{|l|c|c|}
\hline Mineral & $\begin{array}{l}\text { Mine } \\
\text { Years }\end{array}$ & M-Value \\
\hline Arsenic & 48.8 & 0.001 \\
\hline Mercury & 64.6 & -0.041 \\
\hline Tin & 105.4 & -0.009 \\
\hline Antimony & 108.0 & -0.018 \\
\hline Silver & 123.2 & 0.002 \\
\hline Lead & 126.6 & -0.017 \\
\hline Bismuth & 126.7 & -0.034 \\
\hline Tungsten & 160.3 & -0.025 \\
\hline Cadmium & 177.7 & -0.067 \\
\hline Copper & 188.7 & -0.013 \\
\hline Zinc & 197.3 & -0.008 \\
\hline Iron Ore & 230.3 & -0.005 \\
\hline Gypsum & 235.2 & -0.012 \\
\hline Manganese & 239.8 & 0.008 \\
\hline Beryllium & 256.2 & -0.014 \\
\hline Chromium & 275.0 & 0.014 \\
\hline Nickel & 278.3 & 0.000 \\
\hline Molybdenum & 326.1 & -0.017 \\
\hline Magnesium & 436.9 & -0.002 \\
\hline Bromine & 445.8 & -0.029 \\
\hline Cobalt & 495.5 & 0.008 \\
\hline Platinum & 638.8 & 0.005 \\
\hline Bauxite & 642.0 & -0.014 \\
\hline Vanadium & 656.1 & -0.022 \\
\hline Aluminum & 662.1 & -0.013 \\
\hline Pumice & 664.1 & 0.001 \\
\hline Boron & 1258.8 & 0.005 \\
\hline
\end{tabular}


Table 7. $M$-values versus cumulative 1974 mine years for 34 minerals.

\begin{tabular}{|l|c|c|}
\hline Mineral & $\begin{array}{l}\text { Mine } \\
\text { Years }\end{array}$ & M-Value \\
\hline Mercury & 15.967 & -0.053 \\
\hline Bismuth & 24.260 & -0.056 \\
\hline Manganese & 27.875 & -0.004 \\
\hline Lead & 28.822 & -0.021 \\
\hline Pumice & 28.918 & 0.021 \\
\hline Tin & 29.433 & -0.059 \\
\hline Arsenic & 29.489 & -0.023 \\
\hline Germanium & 31.869 & -0.009 \\
\hline Iron Ore & 33.099 & -0.040 \\
\hline Cadmium & 33.879 & -0.126 \\
\hline Cobalt & 34.756 & -0.012 \\
\hline Antimony & 37.424 & -0.064 \\
\hline Tungsten & 37.513 & -0.061 \\
\hline Zinc & 37.915 & -0.029 \\
\hline Nickel & 38.684 & -0.021 \\
\hline Tantalum & 38.956 & -0.030 \\
\hline Lithium & 40.376 & -0.029 \\
\hline Bauxite & 40.745 & -0.048 \\
\hline Molybdenum & 41.064 & -0.054 \\
\hline Copper & 41.713 & -0.031 \\
\hline Bromine & 43.493 & -0.026 \\
\hline Aluminum & 43.712 & -0.027 \\
\hline lodine & 44.721 & -0.012 \\
\hline Gypsum & 46.248 & -0.023 \\
\hline Platinum & 46.385 & -0.009 \\
\hline Vanadium & 46.814 & -0.051 \\
\hline Silver & 47.627 & -0.056 \\
\hline Chromium & 49.054 & -0.018 \\
\hline Beryllium & 58.385 & -0.006 \\
\hline Gallium & 78.388 & -0.057 \\
\hline Indium & 78.389 & -0.039 \\
\hline Magnesium & 79.992 & -0.028 \\
\hline Rhenium & 107.659 & -0.034 \\
\hline Boron & 295.341 & -0.008 \\
\hline & & \\
\hline
\end{tabular}

For the 1947 data, the median number of mine years was 239.8. The median number of mine years for the minerals given in the 1974 data set was 40.5. The minerals are binned into two categories:

- Those showing a decrease or smaller-than-average increase in mining activity over the time period

- Those exhibiting a larger-than-average increase in mining activity over the time. 
Table 8 shows the mean $M$-values for the 1947 and 1974 data series if they are binned in this fashion. It reveals that, for both the 1947 and 1974 starting points, the prices of minerals that were extracted at strongly increasing rates did not fall as quickly as those of minerals whose mining rates are more constant.

Table 8. $M$-values for minerals with relatively low and high mine year values, 1947 and 1974.

\begin{tabular}{|c|c|c|c|}
\hline & $\begin{array}{c}\text { Mean } M \text {-value, } \\
\text { all minerals }\end{array}$ & $\begin{array}{c}\text { Mean } M \text {-value, } \\
\text { minerals with low } \\
\text { mine years }\end{array}$ & $\begin{array}{c}\text { Mean } M \text {-value, } \\
\text { minerals with high } \\
\text { mine years }\end{array}$ \\
\hline 1947 & -0.0115 & -0.0170 & -0.0061 \\
\hline 1974 & -0.0335 & -0.0362 & -0.0310 \\
\hline
\end{tabular}

Almost all minerals experienced accelerating mining rates over both periods, but a number of conclusions can be drawn from the differences between the entries reported in Tables 6, 7, and 8. Prices declined more quickly between 1974 and 2004, as evinced by more strongly negative $M$-values, than between 1947 and 1974. Mining rates, on the other hand, increased more quickly in relative terms between 1947 and 1974 than after 1974.

The results for individual periods reinforce this observation. When the minerals were binned according to mining rate, both the rapidly and slowly mined minerals declined in price, on average, over both periods. However, the prices of the more rapidly mined minerals did not, on average, decline as quickly. This difference is statistically significant in both cases, but more prominent for the longer (19472004) time series.

Therefore, price dependence upon mining rates can be inferred from the USGS data, with rapidly increasing mining rates leading, on average, to less quickly declining prices. Some minerals increased in price over one or both periods, and a price increase was more likely when the mining rate increased more quickly. It should be emphasized that the average price trend was still downward, although substitution and other mitigating effects have not been taken into account.

\subsubsection{Fossil Fuels}

The analogy between uranium and other minerals is imperfect in one major respect: demand for uranium is generally quite inelastic, and natural substitutes are very limited, especially in the short term. In this respect, uranium resembles the fossil fuels; therefore, it is instructive also to look at the price trends with time for coal, oil, and natural gas. At this point, the applicability of the fossil fuel analogy is uncertain, uranium is much more comparable to the minerals in all geologic respects.

Figure 4 shows EIA data for fossil fuel price trends from 1949 to the present. Note that the fossil fuel data are all given in dollars per million Btu of heat content, since this unit offers a convenient normalization for comparing fuels of different specific energy content (e.g., anthracite versus lignite coal). The price time series are regressed onto time, and the conclusions one might draw from this rather limited set are seen to be at odds to those seen with the minerals. The average price of one of the fossil fuels - coal - has been essentially flat while the other two have increased with time. Natural gas, in particular, has an M-coefficient whose value is several standard deviations above the mean obtained for the mineral data. 


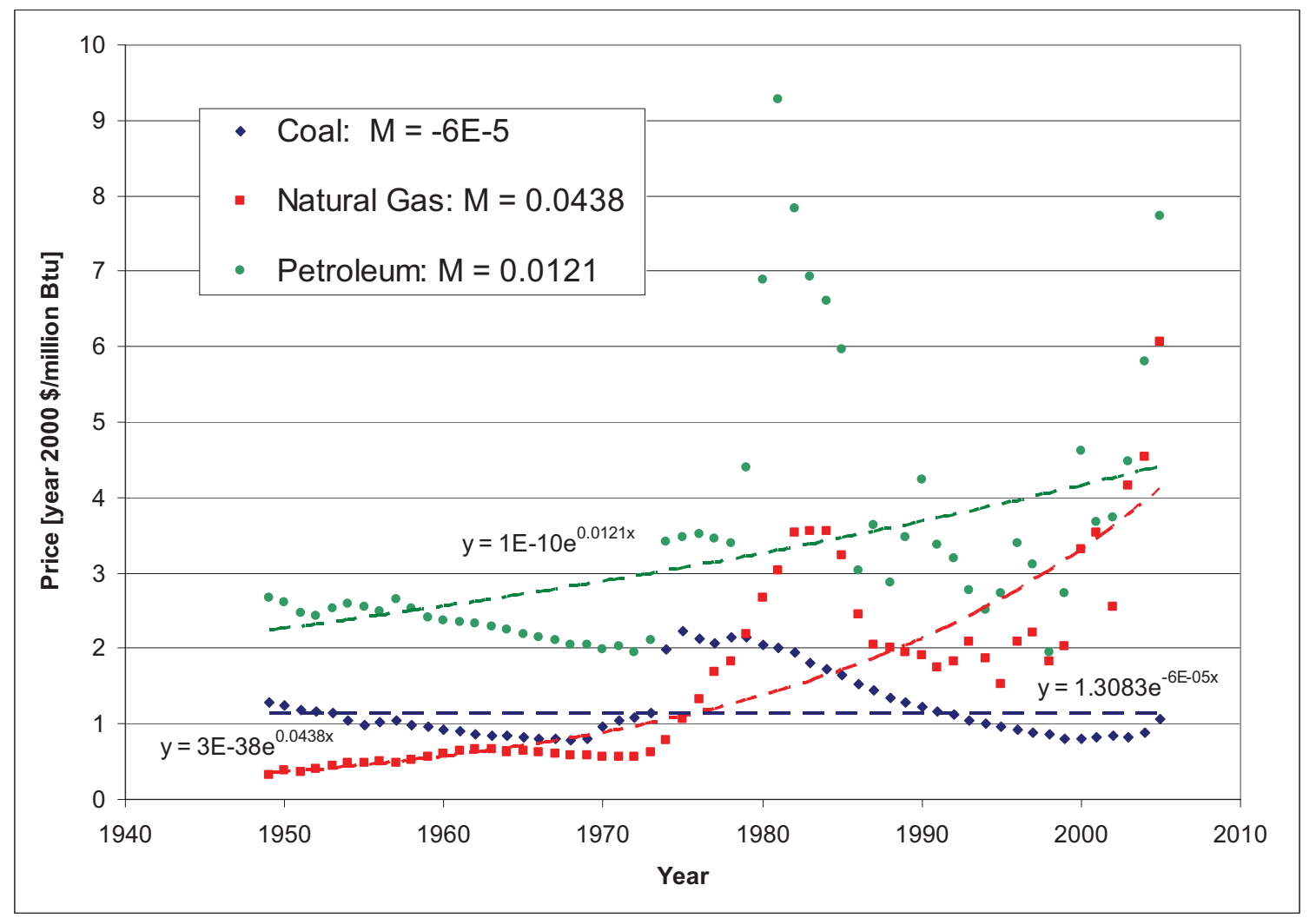

Figure 4. Price trends and M-coefficients for the three fossil fuels.

\subsubsection{Conclusions and Application to Advanced Fuel Cycle Cost Basis}

The survey of the relationship between price, quantity, and time for over 30 other minerals shows that prices for these other minerals have been falling, on average. This is true whether one employs time or quantity mined as the independent variable. Therefore, the effect of unit-based learning and technological evolution, which drives this behavior, should be explicitly included in any long-term uranium resource price model. Indeed, a simple extrapolation of past mineral price trends indicates that the long-term average price of mineral commodities is likely to decline by about $40 \%$ by mid-century. Although the analogy between uranium and other minerals is not perfect, it is reasonable to expect that uranium, an unexceptional material by geologic standards, would follow this trend.

Indeed, the trend of mineral price evolution versus time depicted by Equation 1 with the $M$-value range given in Table 2 was used to derive the uranium price forecast for the middle of this century given in the "AFC Cost Basis" report (Shropshire 2007). The most-likely $M$-value, -0.0118 , was employed to obtain the most-likely uranium price trend, and the plus/minus two standard deviation values for $M$ were utilized to develop upper and lower bounds on the price distribution. This procedure is described in detail in the "AFC Cost Basis" report, Module A (Shropshire 2007).

The price dependence upon mining activity, presented in Section 1.1.3 of this document, was not used to develop the price forecasts presented in the "AFC Cost Basis" report, although it could be added in the future. Presently, it was felt that adding this extra detail would be superfluous, as the other unit costs presented in the "AFC Cost Basis" report likewise do not yet depend on scale. 


\subsection{Econometric Approach}

\subsubsection{Model Formulation}

This model, like the mineral analogy described above, focuses upon the long-term trends where any quantitative analysis will be filled with uncertainty. It utilizes an econometric approach that has gained broad acceptance in the resource economics community.

An econometric model is a hypothesized correlation between an endogenous variable - in this case the uranium spot price - and a number of known, explanatory quantities. The model represents its creator's informed estimate of the functional nature of the input/output correlation, based on his/her understanding of the macroeconomic system. Given a functional form, correlation coefficients are obtained via regression analysis. A successful model must be explanatory, fitting past price behavior with small residuals. In addition, it can be predictive, a viable tool to forecast future price trends.

This model uses a functional form similar to that of U.S. Energy Information Administration in the Coal Market Supply Submodule of the National Energy Modeling System (EIA 2001). It is:

$$
P=K \prod_{i=1}^{N} e^{\beta_{i} X_{i}},
$$

where

$$
\begin{aligned}
& \mathrm{P}=\text { price of uranium }[\$ / \mathrm{kg}] \\
& \mathrm{K}=\text { normalization constant } \\
& \mathrm{X}_{\mathrm{i}}=\text { explanatory variables } \\
& \beta_{\mathrm{i}}=\text { regression coefficients. }
\end{aligned}
$$

Both $\mathrm{P}$ and the $\mathrm{X}_{\mathrm{i}}$ are time-series data. Note that the problem becomes one of linear regression if the natural logarithm of the above equation is taken. It should be noted that this equation originates from distinct supply and demand relationships, viz.:

$\mathrm{P}=f\left(\mathrm{Q}^{\mathrm{s}}\right.$, other explanatory variables) (Supply)

$\mathrm{P}=f\left(\mathrm{Q}^{\mathrm{d}}\right.$, other explanatory variables) (Demand)

where

$$
\begin{aligned}
& Q^{\mathrm{s}}=\text { quantity supplied } \\
& \mathrm{Q}^{\mathrm{d}}=\text { quantity demanded }
\end{aligned}
$$

$\mathrm{Q}^{\mathrm{s}}$ and $\mathrm{Q}^{\mathrm{d}}$ are equal for market-clearing conditions. Equations (3) and (4) can be combined to yield Equation (2); however, it is usually easier to write Equation (2) directly. Nonetheless, it will become necessary in this analysis to break the equation of form (2) into the form given by Equations (3) and (4).

Table 9 lists the explanatory variables chosen. The majority of the data were obtained from the Organization for Economic Co-operation and Development (OECD) Red Books (OECD 2006). Because the 1972 Red Book was the earliest to report most of these data series, the model only uses data from 1972 onward. The data is a dimensioned, given, and detailed attribution of each series provided (see Section 1.2.3). 
Table 9. Data series.

\begin{tabular}{|c|c|c|c|}
\hline Variable & Description & Variable & Description \\
\hline SP & $\begin{array}{l}\text { Average annual spot price of } \\
\text { uranium adjusted to constant } \\
\text { January } 2004 \text { U.S. dollars per } \\
\text { kilogram uranium }\end{array}$ & HEU & $\begin{array}{l}\text { Deliveries of down-blended } \\
\text { highly-enriched uranium (HEU) } \\
\text { from Russia to the U.S., } \\
\text { beginning in } 1995\end{array}$ \\
\hline $\mathrm{CP}$ & $\begin{array}{l}\text { Average annual contract price of } \\
\text { uranium adjusted to constant } \\
\text { January } 2004 \text { U.S. dollars per } \\
\text { kilogram uranium }\end{array}$ & PROD & $\begin{array}{l}\text { Mining industry productivity with } \\
\text { base-line value of } 1 \text { for } 1987\end{array}$ \\
\hline $\mathrm{T}$ & Time & PFEC & $\begin{array}{l}\text { Time } \mathrm{T} \text { forecast of production } \\
\text { capacity for existing and } \\
\text { committed sources in time }(\mathrm{T}+ \\
15)\end{array}$ \\
\hline DF & $\begin{array}{l}\text { Time } T \text { forecast of uranium } \\
\text { demand in time }(T+15)[\mathrm{yr}]\end{array}$ & EGEN & $\begin{array}{l}\text { Electricity produced by nuclear } \\
\text { reactors in year } \mathrm{T}\end{array}$ \\
\hline REQ & $\begin{array}{l}\text { Utility uranium requirements in } \\
\text { time T }\end{array}$ & ELEC & $\begin{array}{l}\text { Average annual electricity price } \\
\text { (total) adjusted to constant } \\
\text { January } 2004 \text { U.S. dollars per } \\
\text { kilowatt-hour }\end{array}$ \\
\hline $\mathrm{MC}$ & $\begin{array}{l}\text { Military consumption of uranium } \\
\text { in time } \mathrm{T}\end{array}$ & EXP & $\begin{array}{l}\text { Exploration expenditures, abroad } \\
\text { and domestic, in time (T - 15) } \\
\text { adjusted to constant January } 2004 \\
\text { U.S. dollars }\end{array}$ \\
\hline QM & $\begin{array}{l}\text { Primary uranium production in } \\
\text { time } \mathrm{T}\end{array}$ & GSF & $\begin{array}{l}\text { Scaling factor used to account for } \\
\text { gradual, but significant, shift in } \\
\text { market from } 1993 \text { to } 1997 \text { due to } \\
\text { the entrance of Eastern European } \\
\text { and former Soviet Union } \\
\text { countries }\end{array}$ \\
\hline QCUM & $\begin{array}{l}\text { Cumulative amount of uranium } \\
\text { produced by time } \mathrm{T}\end{array}$ & SI & $\begin{array}{l}\text { Inventory of secondary uranium } \\
\text { (NU or LEU) held by } \\
\text { governments and utilities }\end{array}$ \\
\hline PCAP & $\begin{array}{l}\text { Production capability from } \\
\text { existing and committed sources in } \\
\text { time T }\end{array}$ & UCENR & Unit cost of enrichment services \\
\hline XAVG & $\begin{array}{l}\text { Average fleet-wide enrichment of } \\
\text { uranium fuel }\end{array}$ & & \\
\hline
\end{tabular}

The numerical analyses were carried out using the SAS software package. However, a number of factors preclude application of a straightforward linear regression. To begin, the explanatory variables were tested for suitability in a time series regression. Autoregressive Integrated Moving-Average (ARIMA) analysis was employed to check for cyclic behavior and nonstationarity. This ARIMA analysis revealed that none of the variables showed statistically significant cyclical behavior.

Endogenous variables are determined within the system of regression equations. In the basic equation given above, the spot price would be an endogenous variable. Exogenous variables are determined 
completely outside the system; the data series given in the preceding table are exogenous variables. Finally, an instrument is an exogenous variable included in only one of the equations within the system.

The chief complication arising in the regression analysis lies in the relationship between the spot price, P [\$/kg], and the quantity supplied, Q [tonnes]. Clearly, Q must be one of the explanatory variables on the right-hand side of Equation (1). Evidently, however, the causal relationship between $\mathrm{P}$ and Q flows in both directions, so that an ordinary least-squares regression applied to Equation (1) would yield biased regression coefficients. The solution to this problem is to devise one or more instruments to predict Q independently. In other words, the issue of reverse causality can be circumvented by first estimating one of the correlated variables using ordinary least squares analysis.

The variable $\mathrm{Q}$ has been chosen to be predicted using available exogenous variables. For the case of uranium demanded by nuclear reactors, this is a natural choice. A relationship between exogenous variables and uranium consumption can be achieved by regressing the energy production of installed reactors, the prevailing fuel enrichment, and the SWU price onto the available data for the quantity demanded.

An additional complication arises because both the supply and demand equations must be identified. This concept is best illustrated graphically; Figures 5 and 6 define unidentified and overidentified systems of equations, respectively. In the examples below, $\mathrm{a}$ and $\mathrm{b}$ are regression coefficients, while $\mathrm{W}$ and $\mathrm{Y}$ are exogenous data series.

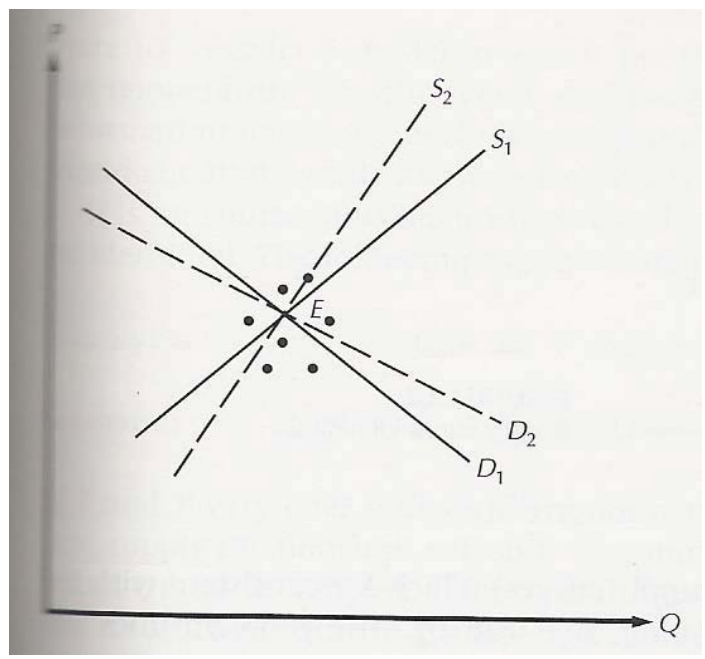

Figure 5. Unidentified system. Only one market-clearing point is defined.

Supply: $\mathrm{Q}=\mathrm{a} 1+\mathrm{a} 2 * \mathrm{P}$

Demand: $\mathrm{Q}=\mathrm{b} 1+\mathrm{b} 2 * \mathrm{P}$

Identified system. Supply and demand curves are fully defined.

Supply: $\mathrm{Q}=\mathrm{a} 1+\mathrm{a} 2 * \mathrm{P}+\mathrm{a} 3 * \mathrm{~W}$

Demand: $\mathrm{Q}=\mathrm{b} 1+\mathrm{b} 2 * \mathrm{P}+\mathrm{b} 3 * \mathrm{Y}$ 


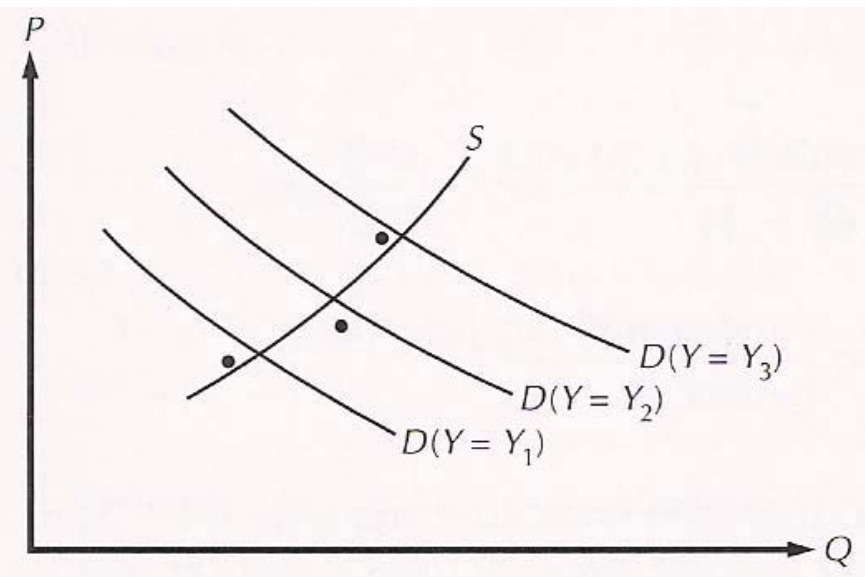

Figure 6. Overidentified system. At least one of the supply and demand functions is defined parametrically as a function of multiple exogenous variables.

Supply: Q $=\mathrm{a} 1+\mathrm{a} 2 * \mathrm{P}$

Demand: $\mathrm{Q}=\mathrm{b} 1+\mathrm{b} 2 * \mathrm{P}+\mathrm{b} 3 * \mathrm{Y}+\mathrm{b} 4 * \mathrm{~W}$

In most applications, both the supply and demand equations are overidentified, meaning that the supply and demand curves are not static, but rather shift as the exogenous variables evolve. These supply and demand equations are both over-identified:

$\mathrm{Q}^{\mathrm{d}}=f(\mathrm{P}, \mathrm{UCENR}, \mathrm{EGEN}, \mathrm{XAVG})$

$\mathrm{P}=f\left(\mathrm{Q}^{\mathrm{s}}, \mathrm{SI}, \triangle \mathrm{SI}, \mathrm{QCUM}, \mathrm{QM}, \mathrm{CAP}, \mathrm{DF}, \mathrm{PROD}, \mathrm{PFEC}, \mathrm{ELEC}, \mathrm{GSF}, \mathrm{MC}, \mathrm{HEU}, \mathrm{PCAP}\right)$

where

$$
\begin{aligned}
& \mathrm{Q}^{\mathrm{d}}=\mathrm{REQ} \\
& \mathrm{P}=\mathrm{SP}
\end{aligned}
$$

The endogenous variables are thus $\mathrm{Q}^{\mathrm{d}}, \mathrm{Q}^{\mathrm{s}}$, and $\mathrm{P}$. The regression then proceeds in two stages as follows.

1. Predict $Q^{d}$ by regressing the demand equation onto REQ. Replace Qs in the supply equation with the predicted $Q^{d}$.

2. Predict $\mathbf{P}$ by regressing the supply equation onto SP.

This two-step process is called two-stage least squares (2SLS) regression. It can be seen that 2SLS creates a single instrument that is a weighted average of the available instruments.

Standard tools of statistical analysis may be used to assess the goodness of fit and the explanatory power of the model. The coefficient of determination, notated $\mathrm{R}^{2}$, is unity for a perfect explanatory model and decreases to zero for a model that simply predicts all data points to take on the mean value of the series being modeled. The T-statistic can be used to gauge the likelihood that the null hypothesis is rejected for each of the candidate exogenous variables. In other words, regression coefficients associated with large T-statistics are likely to be other than zero, while those with small T-statistics may in fact be zero, meaning there is reasonable likelihood that they do not explain the behavior exhibited by the endogenous variable. 
A general model where the supply and demand equations have the form of Equations (4) and (5) was solved. Those exogenous variables whose regression coefficients did not pass the T-test were discarded as non-explanatory, and the regression was repeated. After several iterations, a result was obtained where all variables were significant with at least $90 \%$ confidence. This result is described in Section 1.2.2.

\subsubsection{Sample Results and Conclusions}

Following the procedure outlined in Section 1.2.1, the following model for the uranium spot price, SP, was obtained:

$$
\begin{aligned}
\ln (\mathrm{Q})= & \ln (\mathrm{K} 1)+\mathrm{a} 1 * \mathrm{UCENR}+\mathrm{a} 2 * \mathrm{EGEN}+\mathrm{a} 3 * \mathrm{XAVG}+\mathrm{e} 1 \\
\ln (\mathrm{SP}) & =\ln (\mathrm{K} 2)+\mathrm{b} 1 * \mathrm{Q}+[\mathrm{b} 2 * \ln (\mathrm{QCUM})]+[\mathrm{b} 3 * \ln (\mathrm{QM} / \mathrm{CAP})]+[\mathrm{b} 4 * \ln (\mathrm{DF})] \\
& +[\mathrm{b} 5 * \ln (\mathrm{PROD})]+[\mathrm{b} 6 * \ln (\mathrm{PFEC})]+[\mathrm{b} 7 * \ln (\mathrm{ELEC})]+\mathrm{b} 8 * \mathrm{GSF}+\mathrm{e} 2
\end{aligned}
$$

In these equations, $\mathrm{a}$ and $\mathrm{b}$ are regression coefficients whose units depend on what they multiply. The exogenous variables are defined in Table 10 and Section 2.1.3. The residual terms e1 and e 2 are timeseries data representing the error between the fit and the regressed variable. The regression coefficients for the supply Equation (7) take on the values given in Table 10. In this table, the expected dependence is the correlation that one would expect the variable to have with the price. The mine capacity utilization, for instance, should be positively correlated with the price of uranium - the price is determined by the marginal cost of producing the most expensive unit of uranium - and the idled capacity is assumedly that portion of total capacity, which is most expensive to operate. The estimates in this table are the values taken on by the regression coefficients, [i.e., the b in Equation (8)]. The significance is defined in a

\begin{tabular}{|c|c|c|c|c|}
\hline Parameter & $\begin{array}{c}\text { Expected } \\
\text { Dependence }\end{array}$ & Estimate & $\begin{array}{c}\text { Standard } \\
\text { Deviation }\end{array}$ & Significance \\
\hline Scaling constant & & 860 & 160 & $\star \star \star ~$ \\
\hline Reactor requirements & + & 6.3 & 0.8 & $\star \star \star$ \\
\hline Cumulative quantity mined & + & 0.20 & 0.08 & $\star \star$ \\
\hline Mine capacity utilization & + & 2.3 & 0.5 & $\star \star \star$ \\
\hline Demand forecast & + & 0.50 & 0.14 & $\star \star \star$ \\
\hline Productivity & - & -2.9 & 0.4 & $\star \star \star$ \\
\hline Mine capacity f'cst & $?$ & 1.2 & 0.1 & $\star \star \star ~$ \\
\hline Electricity price & + & 0.70 & 0.4 & $\star$ \\
\hline FSU scaling & $?$ & 0.20 & 0.15 & \\
\hline \multicolumn{5}{|c|}{$\begin{array}{ll}\text { According to T-statistic: } \\
\star \star \star: & \text { Significant at } 1 \% \text { level }(1 \% \text { probability that parameter does equal zero }) \\
\star \star: & \text { Significant at } 5 \% \text { level }(5 \% \text { probability that parameter does equal zero }) \\
\star: & \text { Significant at } 10 \% \text { level }(10 \% \text { probability that parameter does equal zero. })\end{array}$} \\
\hline
\end{tabular}
footnote in the table.

Table 10. Regression coefficients for supply equation.

The function defined by Equation (7) and the coefficient values are plotted (green line) versus the historical spot price data (red squares) in Figure 7. Note that the spot price data was available on a quarterly basis, while some of the exogenous variables were only available annually. Since utilizing the quarterly data improved the goodness of fit, those exogenous variables were interpolated to provide quarterly data points. 


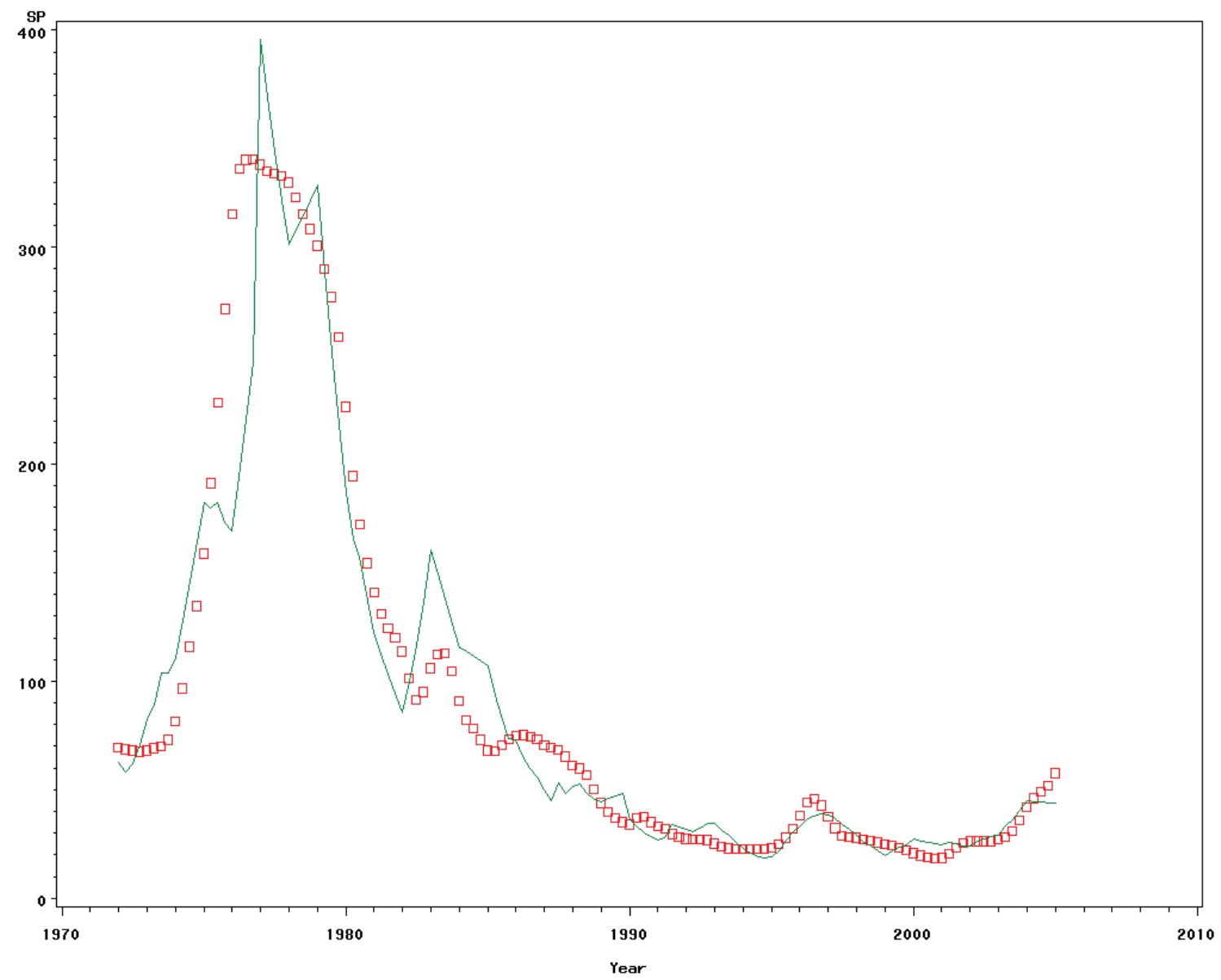

Figure 7. Regression results. The abscissa is the year and the ordinate is the spot price in 2004 dollars. $\mathrm{R}^{2}$ $=0.937$.

The model was benchmarked by regressing the model equations onto the pre-1992 and pre-1995 data. The projections obtained using these coefficients were compared to actual price data; the results are shown in Figure 8. In addition, error propagation, through the standard sum-of-squares formulation, has been included. Variances in regression coefficients and the residual, as well as covariances between the regression coefficients are propagated through model to the generate variance in spot price forecast. The two standard deviation error bars are also shown on Figure 8. Note that the model does not yet include uncertainties in independent variables used for forecast; the major obstacle to adding this feature is not the mathematics of propagating the uncertainties, but rather the manner in which they would be chosen. In addition, the model benefits from a weighted regression in that its goodness of fit is improved. Since complete data sets only exist through 2005, the recent upturn in price is not well reproduced in short-term projections. 


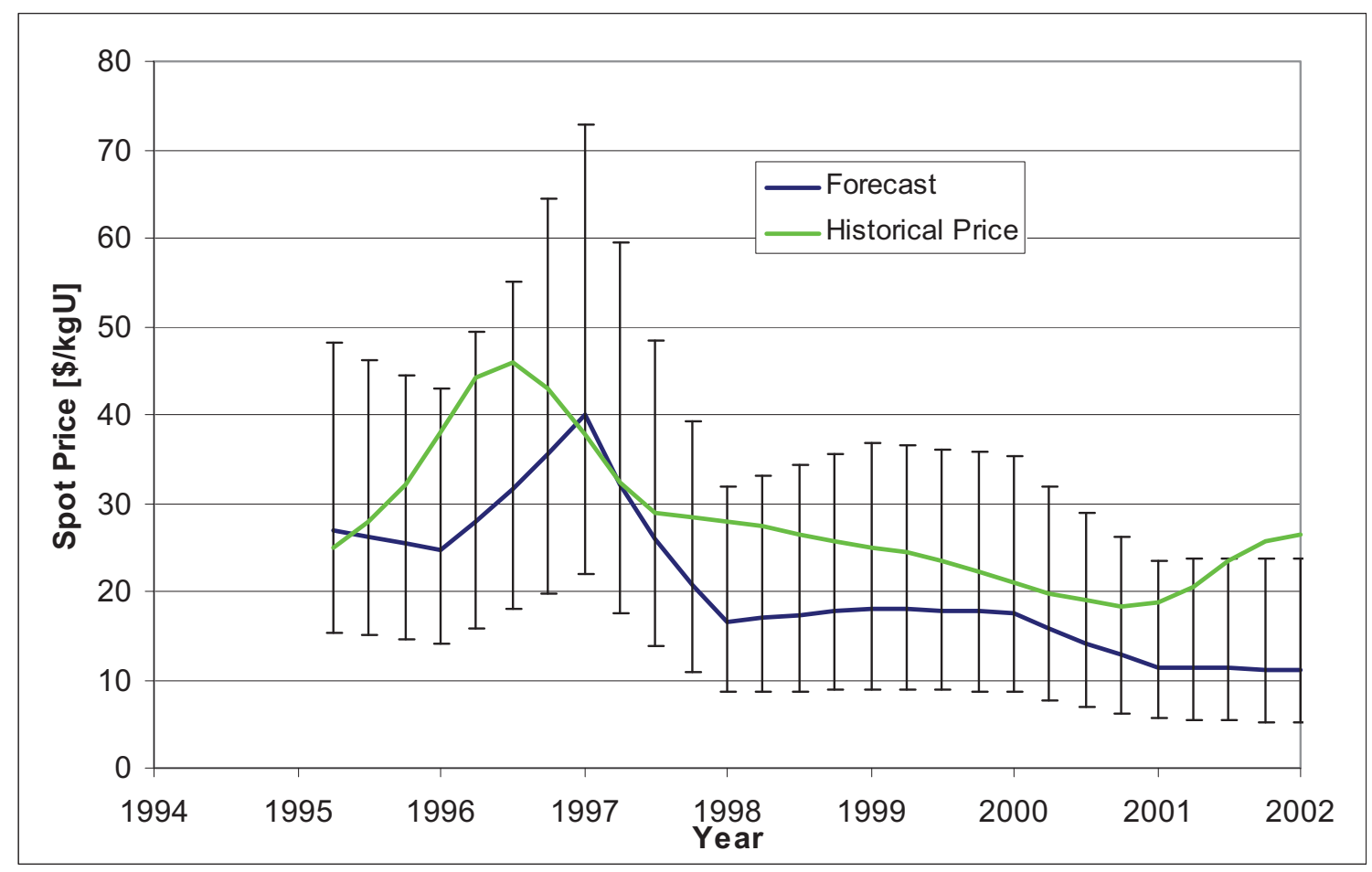

Figure 8. Benchmark: model projections, 1995-2002, versus historical data.

Two brief points of commentary offer insight into the physical significance of the regression coefficients. Note that if all factors other than the cumulative quantity mined, $\mathrm{Q}_{\text {cum }}$, were held constant, the price would vary as:

$\mathrm{P} \sim \mathrm{Q}_{\text {cum }}{ }^{0.20}$

This implies that $\mathrm{Q}_{\text {cum }} \sim \mathrm{P}^{5}$, which is more bullish than other forecasts where the exponent ranges from 2 to 3.5. These previous forecasts estimated this relationship based on crustal concentration estimates. In this regression, the $\mathrm{Q}_{\text {cum }}$ term explains both resource depletion effects and unit-based learning. Therefore, the regression coefficient is expected to be smaller than was the case for estimates based on geology alone. However, given that the standard deviation of the regression coefficient is 0.08 , the model does not rule out the validity of the other forecasts.

In a given year, the price is driven most strongly by the ratio of mine production to mine production capacity (call it the capacity fraction $[\mathrm{CF}]$ ). Holding everything else fixed, the model predicts a price dependence of:

$\mathrm{P} \sim \mathrm{CF}^{2.3}$

Say the $\mathrm{CF}$ in a given year is 0.6. Imagine that a major mine floods during the next year, so that the remaining mines must be operated nearer to full capacity (say, $\mathrm{CF}=0.9$ ) to meet demand. Under this scenario, the model predicts that the price would increase by a factor of $(0.9 / 0.6) 2.3=2.5$.

Figure 9 is a projection of production capability versus production cost by International Nuclear, Inc. The overlay shows projections using the exponent predicted by the current version of the model (2.3) and the exponent predicted by the model if the 2002-2005 data is weighted less heavily (1.3). The model projections assume a fixed capacity, so capacity utilization is varied to obtain the curves. Hence, the two plots are not perfectly analogous. 


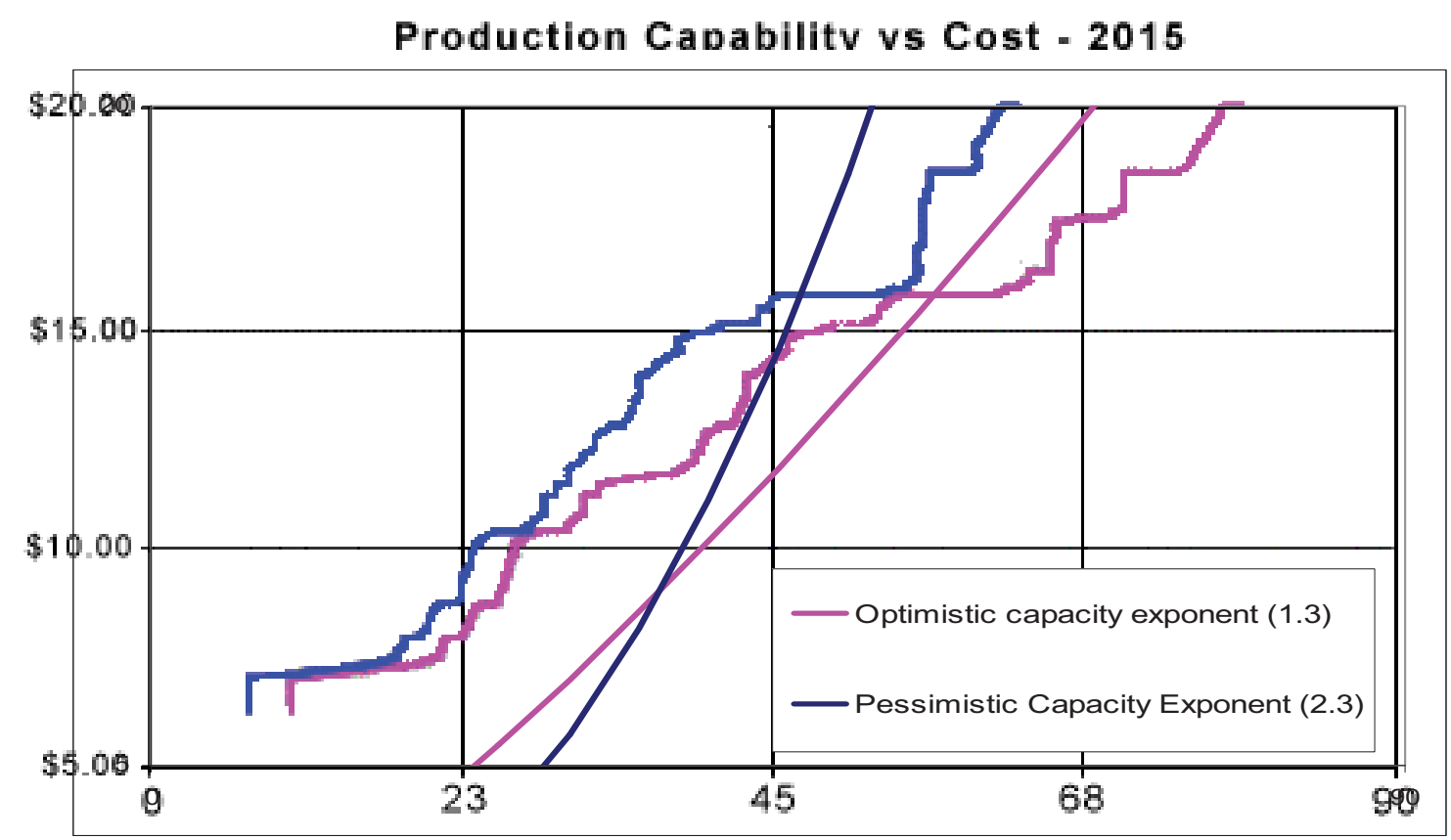

Thousand tonnes $\mathrm{U}_{3} \mathrm{O}_{8}$ per year

\section{- Optimistic Production Scenario Pessimistic Production Scenario}

Figure 9. Supply curves, model versus external estimate.

To conclude, an econometric model of the uranium market was postulated. The model assumes that the price of uranium is explained by a few basic indicators: mining rate and mine capacity, resource depletion, productivity gains, and others. When 2SLS regression was employed, the model showed good ability to explain historical uranium prices. Two-stage least squares is necessary because the correlation between the amount of uranium mined in a given year and the price goes in both directions.

Some of the individual regression coefficients have been verified against bottom-up estimates. One significant issue remains to be resolved. Presently, the spot price of uranium is utilized as the independent variable. However, only one-tenth of uranium purchases are made in the spot market. Most planned deliveries are made under long-term contracts, which have an average lag time of 4 years. Unfortunately, the use of contract price data is hindered by the secretive nature of contract information. To accurately implement contract prices into the model, more detailed information is being obtained on exact delivery times and price adjustments.

A complete tabular listing of the database of independent, explanatory variables can be found in Appendix A. The table is preceded by an itemization of the sources for each data series. 


\section{DEPLETED AND REPROCESSABLE URANIUM ANALYSES}

\subsection{Reprocessable Uranium Methodologies}

The worth of any quantity of nuclear fuel is measured in terms of how much energy is extractable from it. This is as true for spent fuel as it is for fresh fuel. Therefore, the value of a mass of reprocessable uranium is still given by how much energy can be recovered from it. The amount of energy retrievable from a fuel source is given in terms of its discharge burnup [MWd/kg]. The discharge burnup is a function of the amount of ${ }^{235} \mathrm{U}$ as well as that of other uranium isotopes that are present. The situation for RU is complicated because, as is not the case with natural uranium (NU) or DU, multiple uranium isotopes are present in neutronically significant amounts. To further complicate the matter, fuel management strategies come into play, as the discharge burnup is also a function of the number of batches into which the core loading is divided.

The purpose of this study is to compute the cost of extracting a given amount of energy from RU and DU, under various strategies for blending and re-enriching these materials. This result will be compared to the cost of purchasing and enriching NU with the objective of determining the breakeven price of NU for which recycle of DU or RU becomes beneficial. In carrying out this analysis, it is desirable to consider both legacy SF as well as used nuclear fuel to be generated in the future. This will entail a characterization of the current RU inventory in the United States as well as a study of RU with composition given by the recipes currently in use by VISION.

Since typical RU only has ${ }^{235} \mathrm{U}$ content of about $0.85 \mathrm{w} / \mathrm{o}$, considerable enrichment would be required to make the RU into a usable fuel. This multicomponent enrichment cascade cannot be characterized by the simple mass balances and separative work expressions found in textbooks. Therefore, this document will also include a discussion of multi-component enrichment analysis. Finally, since a number of isotopes, especially ${ }^{236} \mathrm{U}$, alter the neutron balance of low-enriched uranium (LEU) created from RU as compared to NU, its discharge burnup cannot be drawn from existing recipes and will need to be calculated. This methodology is also addressed in Sections 2.1.2 and 2.1.3.

\subsubsection{Uranium Composition of Spent LWR Fuel}

Although the U.S. holds about six times more DU, by mass, than reprocessable uranium contained in $\mathrm{SF}$, these uranium reservoirs contain roughly equal quantities of ${ }^{235} \mathrm{U}$. Historical DU inventories are already characterized by isotopic content, and future DU inventories and assay will be computed by VISION. However, additional analysis is needed to obtain the equivalent data for RU. RU isotopics are most strongly dependent on the initial enrichment of the fuel and its subsequent discharge burnup. This section presents a generalized methodology for estimating the uranium isotopics of burned LWR fuel. Section 2.2.2 demonstrates the application of this methodology to estimate the uranium isotopic content of present U.S. SF holdings. This U.S. result was computed using data on SF discharge dates, burnup and reactor prevalence (pressurized water reactor [PWR] versus boiling water reactor [BWR]) from the EIA Nuclear Fuel Data Survey (Croff 1980).

The mass distribution of the legacy SF inventory, in terms of each of its component isotopes, fully characterizes the legacy fuel. It is a challenging task to determine this distribution in a general fashion because the initial enrichments and burnup histories of the legacy SF assemblies are quite diverse. ORIGEN2.2 burnup calculations offer a simple, medium-fidelity route toward characterizing the SF compositions (von Halle 1987). To specify the irradiation times and power densities required to carry out an ORIGEN2.2 burnup calculation, a general model of typical irradiation cycles was developed. 
Pressurized water reactors and boiling water reactors have sufficiently distinct neutron spectra to warrant separate treatment even to meet the relatively low-fidelity needs of this application. For BWRs, only one cross section library was used in performing burnup calculations. This library, calculated assuming a discharge burnup of $33 \mathrm{MWd} / \mathrm{kg}$, was used for the entire range of burnups for BWRs of 15$50 \mathrm{MWd} / \mathrm{kg}$. For PWR fuel, which constitutes the bulk of U.S. SF, characteristic cross section libraries existed or were prepared for 33, 50, and $60 \mathrm{MWd} / \mathrm{kg}$ discharge burnups. When a burnup fell between two of the values for which libraries existed, interpolation was used to form a new library specific to that burnup. If the burnup was higher or lower than any of the relevant libraries, the highest or lowest cross section library was used, respectively. For PWRs the burnups ran from $15-70 \mathrm{MWd} / \mathrm{kg}$. For both types of reactors, the enrichment varied from $2 \%$ to $6 \%$.

By varying both the initial enrichment and burnup for fuel each reactor type, spent fuel isotopic compositions can be calculated for each assembly with ORIGEN2.2. However given the large number of assemblies and the relatively small set of parameters needed to describe the burnup history of an assembly, an algorithm for creating a look up table of SF compositions was developed.

Given that typical reactor power densities, batchwise fuel management schemes, and load factors are assumed (e.g., a three batch cycle with 38 days of downtime at 18 month intervals), only enrichment and discharge burnup remain as variables distinguishing the composition of the spent fuel assemblies (postirradiation decay is handled separately and is discussed below). For a given burnup and reactor type, the enrichment was determined in steps of size $0.1 \%$ for the range from $2 \%$ to $6 \%$. For each of these enrichments and burnups, the discharge composition of the respective SF was found. This was then repeated for all burnups in their range (15-55 MWd/kg for BWR, 15-70 MWd/kg for PWR) using a step size of $2 \mathrm{MWd} / \mathrm{kg}$. The lookup table thus constructed is depicted schematically in Figure 10.

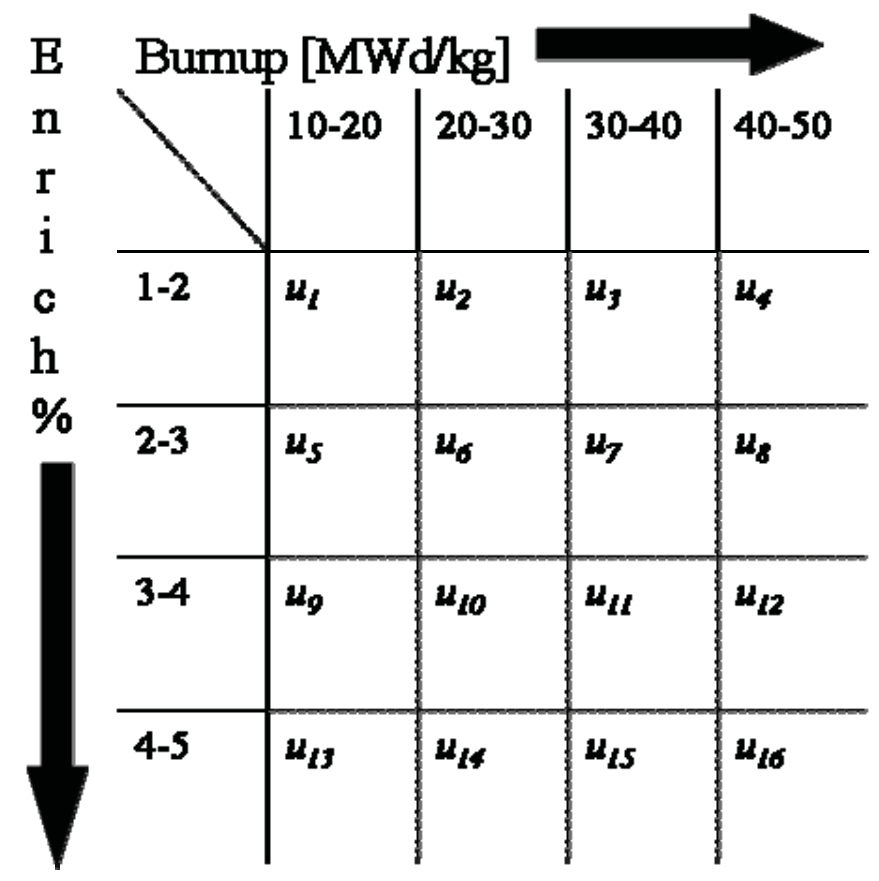

Figure 10. Uranium isotopic vectors. The $\mathrm{u}_{\mathrm{i}}$ are tabulated against initial enrichment and discharge burnup.

In a more algorithmic sense, this process contains three nested loops, as shown in Figure 11. The top loop is the reactor type, the middle loop is the burnup, and the bottom loop is the enrichment of ${ }^{235} \mathrm{U}$. All of this serves to create a set of 3-tuple data sets for each reactor type. The first coordinate is the burnup, the second is the enrichment, and the third is a vector of the isotopic composition of SF. 


\section{For PWRs and BWRs:}

For Burnups 15 to $55 \mathrm{MWd} / \mathrm{kg}$ :

For Enrichments 2 to $4.4 \% \mathrm{U}-235$ :

\section{Run ORIGEN \\ Analyze ORIGEN for Discharge Composition \\ Data $=($ Burnup, Enrichment, Discharge Composition) \\ Write Data to Lookup Table}

Figure 11. Diagram of looping pseudocode that calculates 3-tuple data.

The above method was used with ORIGEN2.2 to populate lookup tables, and the results were used in combination with the U.S. Energy Information Administration (EIA) data to generate data on the uranium compositions of the current U.S. SF stockpile. The complete data set for each fuel assembly type was fitted to the equation:

$\mathrm{xi}(\mathrm{BU}, \mathrm{eo})=\mathrm{k} * \operatorname{Exp}[-(\mathrm{A} * \mathrm{BU}+\mathrm{B} * \mathrm{eo})]$

Here $\mathrm{x}_{\mathrm{i}}$ is the weight percent of heavy metal of a given isotope at discharge with $\mathrm{A}, \mathrm{B}$, and $\mathrm{k}$ being fitting parameters. A has units of $\mathrm{kg} / \mathrm{MWd}, \mathrm{B}$ of (weight percent of initial heavy metal at charge $)^{-1}$, and $\mathrm{k}$ of weight percent or initial heavy metal at discharge. The variables BU and e represent the burnup and enrichment respectively. Once the specific parameters A, B, and $\mathrm{k}$ have been found, the data from the EIA database can be used in conjunction with Equation 1 to find the uranium composition for all fuel assemblies.

Equation 1 and Table 11 depict the method used to determine the uranium isotopic concentrations in $\mathrm{SF}$. Although each uranium isotope was subjected to this analysis, as were isotopes like ${ }^{238} \mathrm{Pu}$ that are decay parents of uranium isotopes, only the results for ${ }^{235} \mathrm{U}$ and ${ }^{236} \mathrm{U}$ will be presented here.

Table 11. Parameters in Equation 1.

\begin{tabular}{|c|c|c|c|c|}
\hline & $\mathrm{BWR}^{235} \mathrm{U}$ & $\mathrm{PWR}^{235} \mathrm{U}$ & $\mathrm{BWR}^{236} \mathrm{U}$ & $\mathrm{PWR}^{236} \mathrm{U}$ \\
\hline $\mathrm{K}$ & 0.670 & 0.640 & 0.106 & 0.105 \\
\hline $\mathrm{A}$ & 0.0448 & 0.0392 & -0.0124 & -0.0129 \\
\hline $\mathrm{B}$ & -0.509 & -0.497 & -0.264 & -0.259 \\
\hline
\end{tabular}

For the U.S. legacy fuel, the EIA database gives the mass of each fuel assembly, so the uranium isotopic vectors can easily be combined with the assembly masses to compute their total uranium content by isotope. These results reflect fuel compositions at the time of discharge. ${ }^{232} \mathrm{U}$ and ${ }^{238} \mathrm{Pu}$, both with roughly 80-year half-lives are the only isotopes whose decay strongly affects the composition of RU over the few-decade timescales that are of interest. These decay channels are being taken into account by a simple post-processing routine that evolves SF compositions as a function of time post-discharge.

While the composition of legacy fuel is of interest for historical and benchmarking purposes, future applications of this methodology are likely to be perturbations from VISION LWR fuel recipes. The VISION recipe for "Low Burnup LWR SF," which reflects PWR irradiation of $4.3 \%$ enriched uranium fuel to a burnup of $51 \mathrm{MWd} / \mathrm{kg}$, is shown in Table 12. At the burnup corresponding to this recipe, there are $0.934 \mathrm{~kg} \mathrm{U}$ in each $\mathrm{kg}$ of SF. It will be used as the reference RU composition for analyses described in subsequent portions of this appendix. Given the reprocessed uranium of known composition, the tasks of modeling its enrichment and reactor recycle remain. 
Table 12. Uranium composition [weight percent] of SF specified by VISION "Low Burnup LWR" recipe.

\begin{tabular}{|l|l|}
\hline $\mathrm{U}-232$ & $1.11 \mathrm{E}-07$ \\
\hline $\mathrm{U}-233$ & $2.37 \mathrm{E}-07$ \\
\hline $\mathrm{U}-234$ & 0.018 \\
\hline $\mathrm{U}-235$ & 0.819 \\
\hline $\mathrm{U}-236$ & 0.611 \\
\hline $\mathrm{U}-238$ & 98.55 \\
\hline
\end{tabular}

\subsubsection{Multi-Component Enrichment}

Given an isotopic definition for reprocessed uranium, it is next necessary to concentrate the ${ }^{235} \mathrm{U}$ in an abundance that would make a worthwhile fuel. This would involve preferentially separating the ${ }^{235} \mathrm{U}$ from the other isotopes present. The enrichment that occurs would likely take place using a gaseous centrifuge process. However, this centrifuge process is not as trivial a process as it is for only the two canonical uranium isotopes.

A centrifuge works by stochastically separating lighter particles from heavier ones. First, the uranium must become a fluid. Uranium hexafluoride $\left(\mathrm{UF}_{6}\right)$ happens to be a gas at temperatures and pressures not that different from normal conditions. Lighter isotopes of uranium in the $\mathrm{UF}_{6}$ are sent towards the middle while the heavier ones are transported towards the outer walls. Thus, for NU the ${ }^{235} \mathrm{U}$ moves towards the middle and the ${ }^{238} \mathrm{U}$ finds itself more against the outer walls. However, the RU contains everything from ${ }^{232} \mathrm{U}$ to ${ }^{238} \mathrm{U}$. Therefore, the enrichment process will take all of the lightest elements, preferentially in its heads stream. The lighter the isotope, the more it will appear in the fuel.

The ${ }^{235} \mathrm{U}$ is the isotope that is desired, while ${ }^{236} \mathrm{U}$ is a poison and is not wanted. Thus, generally the isotopes ${ }^{236} \mathrm{U}$ and heavier are what is wanted separated from the isotopes ${ }^{235} \mathrm{U}$ and lighter. Of course, ${ }^{234} \mathrm{U}$ and especially ${ }^{232} \mathrm{U}$ are undesirable members of the product stream. Methods for mitigating their concentration in the product will be discussed below.

The problem of multi-component enrichment has been considered since the early days of nuclear energy when the natural uranium supply picture was less certain than today. Andrew de la Garza addressed this issue in the 1960s for gaseous diffusion (de la Garza, et al. 1961). More recently, E. von Halle reformulated these results for centrifuge cascades in the late 1980s; von Halle generalized de la Garza's result, which assumed small stage separation factors, so that it was also applicable to centrifuge machines, which have a much larger separation factor (von Halle 1987).

Simple mass balance equations are sufficient to determine cascade output in a two-component mixture. However, when more than two isotopes are introduced, the system of mass balance equations becomes underdetermined. In other words, additional information must be supplied to compute product isotopic enrichments given those of the feed. While the system is naturally constrained by mass in any cascade, this does not imply anything about the isotopic distribution as the mass flows through the cascade. Thus, de la Garza presented the idea of the matched abundance ratio cascade. This is a generalization of the familiar two-isotope ideal cascade where for each isotope, the same relative amount independent of stage number is present when a heads stream from the N-1th stage meets the tails from the $\mathrm{N}+1$ th stage and is fed as input to the Nth stage. In other words, $\mathrm{x}_{\mathrm{i}, \mathrm{N}-1} / \mathrm{x}_{\mathrm{i}, \mathrm{N}+1}$ is constant for all isotopes for all stage numbers, where $\mathrm{x}_{\mathrm{i}}$ is an isotopic abundance in weight percent. Essentially, another constraint is put on the system such that the uranium composition of all meeting streams in the same.

The above is accomplished using an overall stage separation factor, $\alpha_{0}$. Rather than needing to find a separation factor for a centrifuge for each isotope from stage to stage, $\alpha_{0}$ is what all of these separation 
factors have in common. This is a physical quantity derived from the machine itself. While the maximum theoretical separation factor for centrifuge machines may be greater than 1.1, to better reflect currentlyachievable values, this factor for centrifuges used for uranium enrichment is taken in this study to be 1.05. From the overall stage separation factor, isotopic separation factors for the ith isotope may be calculated using Equation 12.

$\alpha_{\mathrm{i}}^{*}=\alpha_{0}^{\wedge}\left(\mathrm{M}^{*}-\mathrm{M}_{\mathrm{i}}\right)$

where

$$
\begin{aligned}
& \mathrm{M}_{\mathrm{i}}=\text { molecular weight is of the ith isotope and } \\
& \mathrm{M}^{*}=\text { average molecular weight of the two key components. }
\end{aligned}
$$

The key components are chosen such that the enrichment is done as efficiently as possible. Since $\mathrm{M}^{*}$ is an average, it follows that it may take any real value. Additionally, because molecular weights are positive, then $\mathrm{M}^{*}$ must also be positive. Also, it is worthy of note that components with a molecular weight less than $M^{*}$ are enriched, while those with molecular weights greater than $M^{*}$ are depleted in the product stream. The situation is reversed in the tails stream.

For this purpose, what is initially known about the system is only the overall stage separation factor $\alpha_{0}$, the feed composition $\mathrm{x}_{\mathrm{F}}$, and the heads and tails weight percent desired for a single, important isotope. Here this isotope is ${ }^{235} \mathrm{U}$. Normally a cascade is set up such that it produces specified ${ }^{235} \mathrm{U}$ enrichments in both the product and waste streams, so it seems realistic to specify these numbers for a multicomponent stream as well. Similarly, the feed composition will always be known-either taken from a VISION recipe or calculated as described in the previous section. As stated before, the overall stage separation factor is a physical quantity that is based on the design of the actual centrifuge cylinders.

The ${ }^{235} \mathrm{U}$ enrichment in the product stream will only be specified to the extent that the fabricated enriched fuel must achieve some desired burnup. However, the neutronic behavior of the enriched fuel will also depend on the prevalence of ${ }^{236} \mathrm{U}$ and other isotopes. Therefore, the process of performing the enrichment calculations then assessing the achievable burnup with the resultant fuel is iterative. This will be discussed further in Section 2.1.3.

Even given a known or guessed value for the ${ }^{235} \mathrm{U}$ content of the product, two new variables that are not known and must be solved for in a multicomponent calculation, are the number of enriching stages in the cascade $(\mathrm{N})$ and the number of stripping stages $(\mathrm{M})$. Once these are known, the full composition of the product stream $\mathrm{x}_{\mathrm{P}}$, the full composition of the waste stream $\mathrm{x}_{\mathrm{W}}$, and $\mathrm{M}^{*}$ can be obtained.

This methodology solves first for the number of enriching and stripping stages. Equation 74 from von Halle's paper and the analogous equation for the waste stream are given here as Equations 13 and 14 (von Halle 1987).

$\mathrm{x}_{\mathrm{i}, \mathrm{P}}=\mathrm{x}_{\mathrm{i}, \mathrm{F}}\left(\alpha_{\mathrm{i}}{ }^{*} \wedge(\mathrm{M}+1)-1\right) /\left(\alpha_{\mathrm{i}}{ }^{*} \wedge(\mathrm{M}+1)-\alpha_{\mathrm{i}}{ }^{*} \wedge(-\mathrm{N})\right) /(\mathrm{P} / \mathrm{F})$

$\mathrm{x}_{\mathrm{i}, \mathrm{W}}=\mathrm{x}_{\mathrm{i}, \mathrm{F}}\left(1-\alpha_{\mathrm{i}}{ }^{*} \wedge(-\mathrm{N})\right) /\left(\alpha_{\mathrm{i}}{ }^{*} \wedge(\mathrm{M}+1)-\alpha_{\mathrm{i}}{ }^{*} \wedge(-\mathrm{N})\right) /(\mathrm{W} / \mathrm{F})$

where

$\mathrm{P}, \mathrm{F}$, and $\mathrm{W}=$ flow rates $[\mathrm{kg} / \mathrm{s}]$ for the product, feed, and waste streams respectively

$\mathrm{x}_{\mathrm{i}}=$ the weight percent of the $\mathrm{i}^{\text {th }}$ isotope for either the product, feed, or waste stream.

The product and tails flow rates can still be expressed in terms of the mass balance: 
$\mathrm{P} / \mathrm{F}=\left(\mathrm{x}_{\mathrm{i}, \mathrm{F}}-\mathrm{x}_{\mathrm{i}, \mathrm{W}}\right) /\left(\mathrm{x}_{\mathrm{i}, \mathrm{P}}-\mathrm{x}_{\mathrm{i}, \mathrm{W}}\right)$

$\mathrm{W} / \mathrm{F}=\left(\mathrm{x}_{\mathrm{i}, \mathrm{F}}-\mathrm{x}_{\mathrm{i}, \mathrm{P}}\right) /\left(\mathrm{x}_{\mathrm{i}, \mathrm{W}}-\mathrm{x}_{\mathrm{i}, \mathrm{P}}\right)$

Since Equations 13-16 are true for any isotope that is a component of the mixture, they certainly must be true for the isotope that the product and waste weight percents are set for, ie ${ }^{235} \mathrm{U}$. Thus, $\mathrm{P} / \mathrm{F}$ and W/F are known quantities. To simplify the situation at hand, call ${ }^{235} \mathrm{U}$ the $\mathrm{j}^{\text {th }}$ component, it is one of the two key components. Therefore, Equations 15 and 16 are solved for the $\mathrm{j}^{\text {th }}$ component as a preliminary to solving Equations 13 and 14.

Now, unfortunately to calculate Equations 13 and $14, \mathrm{M}^{*}$ is needed. However, it was already stated that $\mathrm{M}^{*}$ is an unknown quantity. Thus, at this point in the optimization of the cascade, an educated guess for $\mathrm{M}^{*}$ is used. Also, since the product and waste weight percent is only known for the $\mathrm{j}^{\text {th }}$ component $\left({ }^{235} \mathrm{U}\right)$, Equations 13 and 14 can only be solved for the $\mathrm{j}^{\text {th }}$ component. To solve for the number of enriching and stripping stages, $\mathrm{N}$ and $\mathrm{M}$, root finding must be employed. While Equations 13 and 14 govern $\mathrm{N}$ and $\mathrm{M}$, a version of each equation can be written for each isotope present in the feed stream. Therefore, for the typical RU enrichment problem with five initial isotopes, 10 equations can be written from the prototype Equations 13 and 14. These, combined with the overall cascade mass and isotopic balances, may be solved simultaneously. By inspection, it is easy to tell that Equations 13 and 14 are nonanalytic with respect to $\mathrm{N}$ and $\mathrm{M}$. Hence, an iterative process is employed, with the initial guesses for $\mathrm{N}$ and $\mathrm{M}$ being updated until convergence is achieved.

Therefore, passable values for $\mathrm{N}$ and $\mathrm{M}$ are obtained simultaneously with the mass fractions of the other isotopes present, thereby generating the product and waste stream compositions $\mathrm{x}_{\mathrm{P}}$ and $\mathrm{x}_{\mathrm{W}}$. However, the initial choice for $\mathrm{M}^{*}$ may not have been the best. By this it is meant that $\mathrm{M}^{*}$ might not give the cascade setup that most efficiently enriches in terms of the separative work units (SWU) that is used, or more generally it might not minimize the flow rates through the system. Since a SWU is expensive, it is important to optimize around this. However, to do this, another equation is needed since $\mathrm{M}^{*}$ becomes yet another parameter. To find this equation, results developed in Houston G. Wood's (et al.) research are utilized (Wood, et al. 1999). Equation 28 in this reference is presented here as Equation 17. Take L as the total cascade flow rate $[\mathrm{kg} / \mathrm{s}]$ and the subindex $\mathrm{k}$ to denote the other key component, which is ${ }^{238} \mathrm{U}$ here.

$\mathrm{L} / \mathrm{F}=\sum_{*}\left((\mathrm{P} / \mathrm{F}) \mathrm{x}_{\mathrm{i}, \mathrm{P}} \log \left(\mathrm{x}_{\mathrm{j}, \mathrm{P}} / \mathrm{x}_{\mathrm{k}, \mathrm{P}}\right)+(\mathrm{W} / \mathrm{F}) \mathrm{x}_{\mathrm{i}, \mathrm{W}} \log \left(\mathrm{x}_{\mathrm{j}, \mathrm{W}} / \mathrm{x}_{\mathrm{k}, \mathrm{W}}\right)-\mathrm{x}_{\mathrm{i}, \mathrm{F}} \log \left(\mathrm{x}_{\mathrm{j}, \mathrm{F}} / \mathrm{x}_{\mathrm{k}, \mathrm{F}}\right)\right) /$ $\left(\log \left(\alpha_{j}^{*}\right)\left(\alpha_{i}^{*}-1\right) /\left(\alpha_{i}^{*}+1\right)\right)$

Thus L/F is the unitless quantity, which is minimized. This is minimized in the same way in that values of $\mathrm{M}^{*}$ are now looped over until some smallest value is found. What the actual value of $\mathrm{L} / \mathrm{F}$ is in the end does not much matter. It serves only as a metric by which to find the optimum value of $\mathrm{M}^{*}$. Figure 12 represents the flow of all of the operations that have just been listed in order to find the optimum parameters of the cascade. 


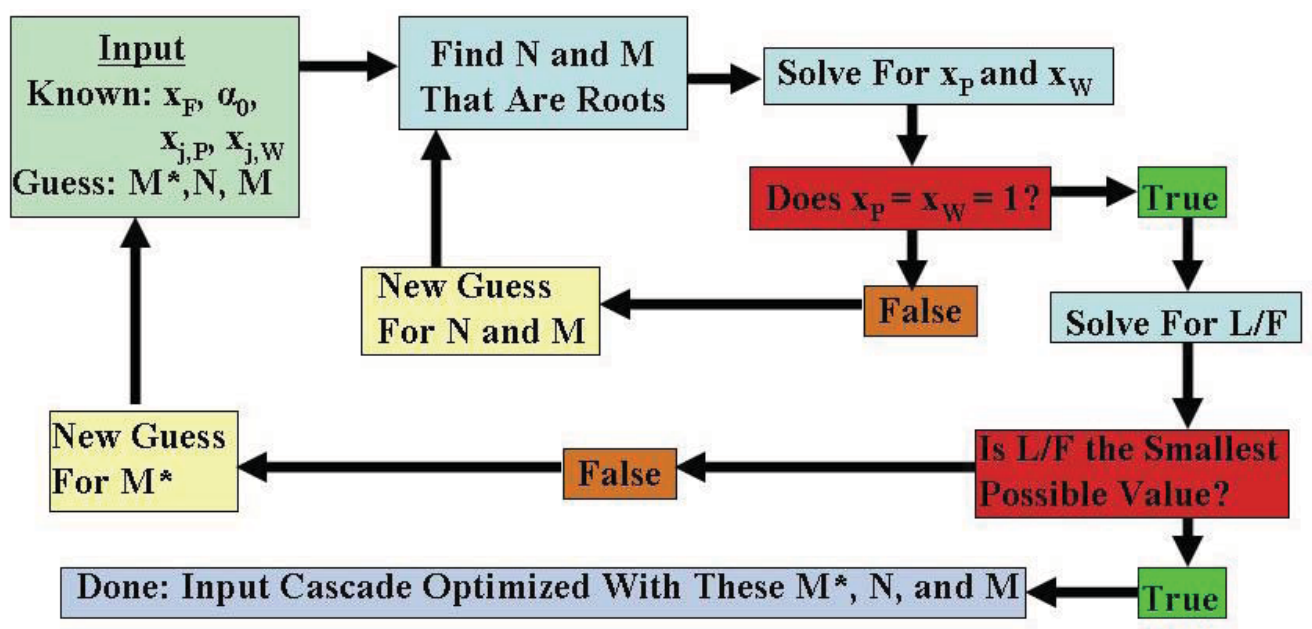

Figure 12. Cascade optimization flowsheet.

At this point all relevant values of the enrichment cascade are known. The number of enrichment and stripping stages, the product and waste stream compositions, and $\mathrm{M}^{*}$ have all been calculated. However, for the purposes of determining the value of the spent fuel after it has been enriched, only the product stream composition $\mathrm{x}_{\mathrm{P}}$ is important.

\subsubsection{Discharge Burnup Achievable from RU Fuel}

Once a composition vector for enriched reprocessed uranium is known, it is necessary to compute the burnup, which fuel could achieve in a reactor. Most burnup dependent compositional effects are only weakly dependent on irradiation time. Therefore, it is desirable to reduce the number of unknowns in the analysis by calculating the fuel burnup in a time independent manner. This is done by using the quantity of fluence, which is the time integral of the neutron flux $\phi\left[\mathrm{n} / \mathrm{cm}^{2} / \mathrm{s}\right]$. Symbolically,

$\mathrm{F}=\int \varphi \mathrm{dt}$

Irradiation calculations for each isotope that is an initial constituent of nuclear fuel can be accomplished using the constant flux irradiation feature of ORIGEN. When the flux is held constant, the fluence is simply the flux multiplied by the exposure time. This approach gives quite reasonable fuel burnup results as long as the flux level chosen for the irradiation is typical of LWRs. For this study, the irradiation calculations were performed using a flux of $4 \times 10^{14}\left[\mathrm{n} / \mathrm{cm}^{2} / \mathrm{s}\right]$. ORIGEN, in addition to outputting the fuel composition as a function of fluence, also disseminates three key values as a function of fluence: burnup, the neutron production rate, and the neutron destruction rate.

Now, since the ultimate goal is to find the achievable discharge burnup, the burnup as a function of fluence for each initial constituent of the fuel is calculated by integrating the number of fissions resulting from the constituent. This approach succeeds since, as long as the correct neutron energy spectrum is used in the irradiation calculation for each isotope, the fuel composition can be computed as a linear combination of that of the individual isotopes. Therefore, the burnup as a function of fluence can then be tabulated for the fuel by linearly combining the results for each constituent isotope, as can the neutron production and destruction rates. This requires ORIGEN to calculate only the data for the isotopically pure samples. This transforms the problem of burnup calculations into one of lookup table query.

Once the burnup as a function of fluence is known, the discharge burnup can be computed as that value of burnup for which the core ceases to be critical. The fluence-dependent neutron production and destruction rates for each constituent are used here to compute the effective multiplication factor, $\mathrm{k}_{\text {eff }}$. 
When $\mathrm{k}_{\text {eff }}$ drops below unity, a reactor full of fuel of this type would no longer be able to sustain a chain reaction. $\mathrm{k}_{\text {eff }}$ is approximated by calculating the neutron production rate $[\mathrm{n} / \mathrm{s} / \mathrm{kg}]$ for the whole core, divided by the neutron destruction rate $[\mathrm{n} / \mathrm{s} / \mathrm{kg}]$ for the whole core, multiplied by a nonleakage probability $\mathrm{P}_{\mathrm{NL}}$. Namely,

$\mathrm{k}_{\mathrm{eff}}=\mathrm{p}_{\mathrm{C}}(\mathrm{F}) / \mathrm{d}_{\mathrm{C}}(\mathrm{F}) \mathrm{P}_{\mathrm{NL}}$

Since these rates $\left(\mathrm{p}_{\mathrm{C}}\right.$ and $\mathrm{d}_{\mathrm{C}}$ ) are given by ORIGEN as well, $\mathrm{k}_{\text {eff }}$ may then be calculated as a function of fluence by the linear combination of the rates for each initially present isotope. $\mathrm{k}_{\text {eff }}$ may thus be set equal to 1 and then this equation solved for the fluence. This fluence can then be reinserted into to equations garnered for the burnup, and the burnup of the fuel composition is attained.

Additional factors complicate the calculation of the neutron production and destruction rates. As it happens, the rates calculated by ORIGEN are for the fuel alone. Since the reactor is not entirely made of fuel, the rates garnered from ORIGEN must be modified to include non-fuel components. This amounts to the moderator outside of fuel regions and the oxygen portion of UOX inside of fuel regions for the destruction rate for the entire core. Disadvantage factors that affect the flux suppression in fuel regions need to be counted as well. As far as altering the production rate, the only thing that produces neutrons in the core is the fuel, so non-fuel elements do not need to be added.

What has just been shown is how to find the burnup achievable with a given fuel composition for one batch. However, for multiple batches of fuel, the process is less straight forward as the production and destruction rates are averaged over their end of cycle values for each batch. The general idea is to perform these operations in reverse and then iterate over them. In other words, one picks a burnup and then solves for $\mathrm{k}_{\mathrm{eff}}$. Then one picks another burnup that will yield a $\mathrm{k}_{\text {eff }}$ closer to 1 and resolves for $\mathrm{k}_{\mathrm{eff}}$. This process continues ad infinitum or until a $\mathrm{k}_{\text {eff }}$ is found that is acceptably close to 1 . The secant method, rather than Newton's, is used to pick successively closer values of $\mathrm{k}_{\mathrm{eff}}$.

A walkthrough of the details of this process for multiple batches follows. First, a maximum discharge burnup, BUd, is guessed with some impunity. Say without loss of generality that the system at hand is concerned with a three batch refueling cycle. Then the fluence must be found for three burnups: namely $\mathrm{BUd}, 2 / 3 \mathrm{BUd}$, and 1/3 BUd. Lines drawn on this graph from the burnup axis to the curve and then down from the curve to the fluence axis will give the fluence at the three points required. This process is illustrated in Figure 13. After the fluence for each of the burnups has been calculated, the effective multiplication factor of the system needs to be known. 


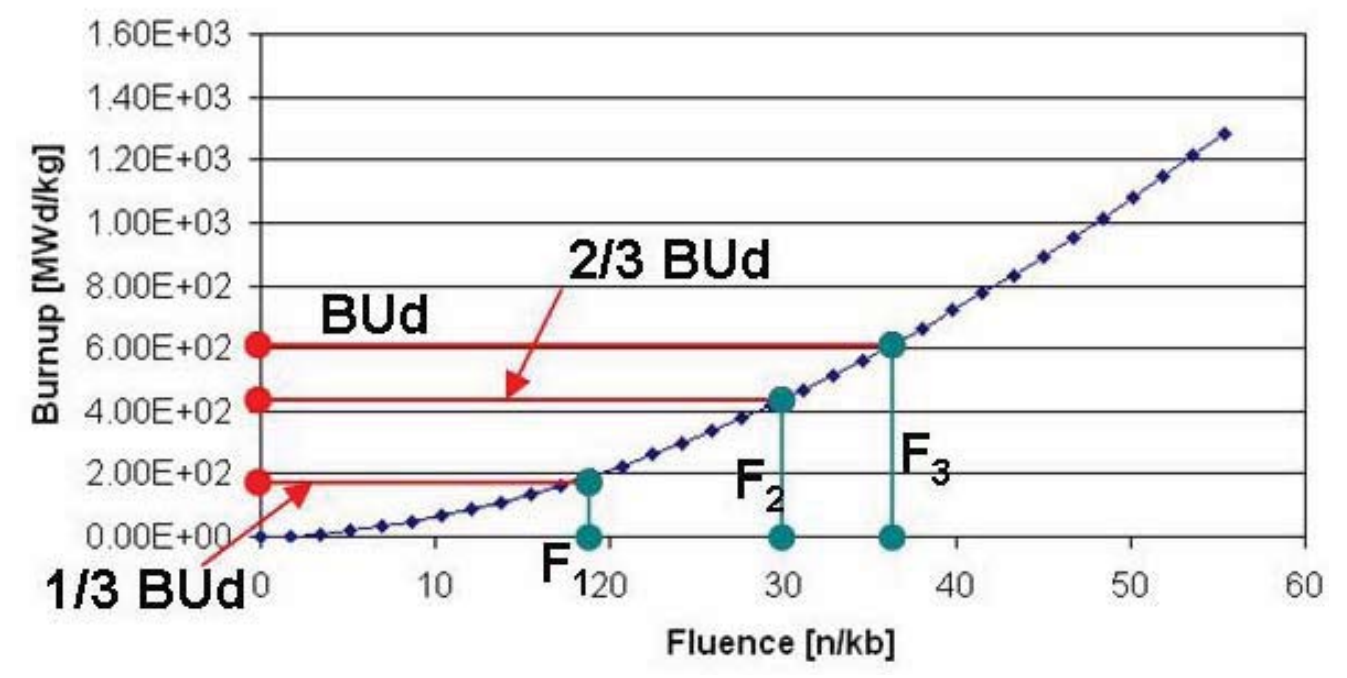

Figure 13. Burnup as a function of fluence.

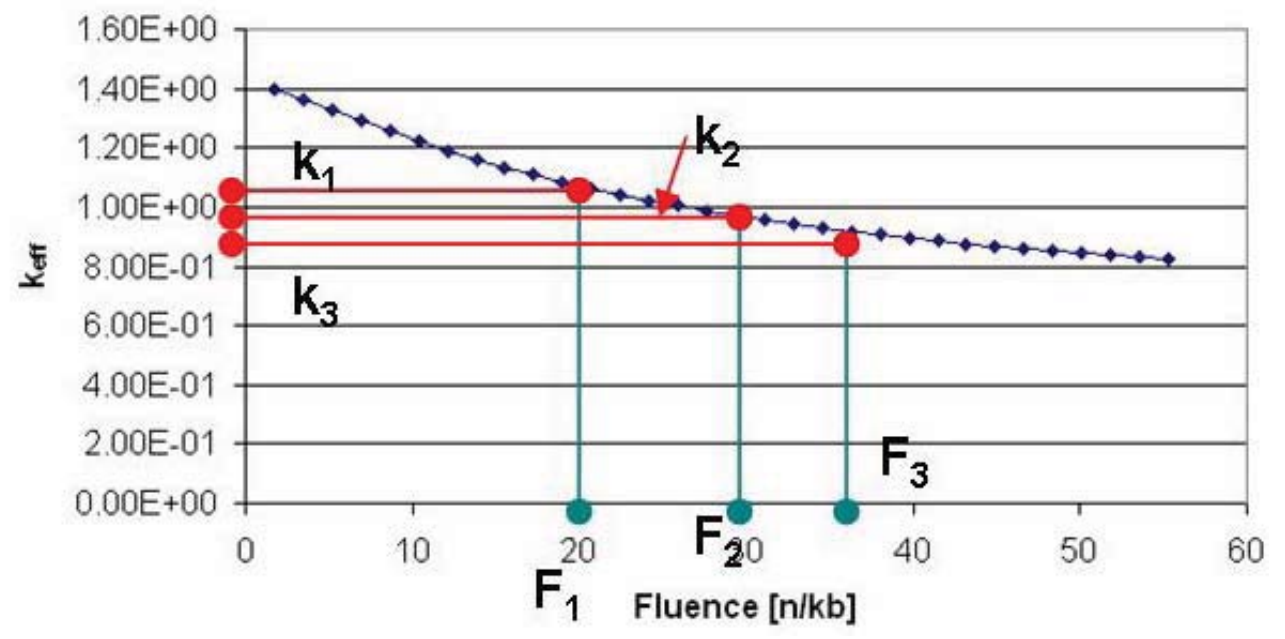

Figure 14. $\mathrm{k}_{\mathrm{eff}}$ as a function of fluence.

However, the production rate, divided by the destruction rate, is no longer the $\mathrm{k}_{\text {eff }}$ of the system. Instead, the weighted average of the production, divided by destruction rates with the flux as a weight, gives the $\mathrm{k}_{\mathrm{eff}}$ for $\mathrm{q}$ number of batches.

$\mathrm{k}_{\mathrm{eff}}=\sum\left(\mathrm{p}_{\mathrm{i}} / \mathrm{d}_{\mathrm{i}}\right) \varphi_{\mathrm{i}} / \sum \varphi_{\mathrm{i}}$

The process for determining $\mathrm{k}_{\mathrm{eff}}$ is shown graphically in Figure 14. Now that a $\mathrm{k}_{\mathrm{eff}}$ has been found, its value is compared to that of unity via the secant method. Another value of the maximum discharge burnup is then chosen and this process is repeated until a max BUd is found that yields a $\mathrm{k}_{\mathrm{eff}}=1$. Figures 15 and 16 represent the process of finding an effective multiplication factor for a sample threebatch system.

Looking at the whole picture, what has just been found was one discharge burnup for a specific fuel composition for a given number of batches. Clearly, the number of batches and the fuel composition can be varied to create a vast array of values of maximum burnup achievable. These values can then be 
plotted against each other and otherwise manipulated. Finally, fitting all of these data points to some function will yield an equation that gives the maximum discharge burnup based on the fuel composition and the number of batches of the fuel that will reside in the core. Figure 15 shows the maximum burnup achievable for fuel that is composed of various enrichments of ${ }^{235} \mathrm{U}$ and ${ }^{236} \mathrm{U}$. This particular example is for a three-batch cycle as well. The data is parameterized and stored in tabular form for use in fuel cycle analyses involving RU. All points on the same line share the same ${ }^{236} \mathrm{U}$ enrichment.

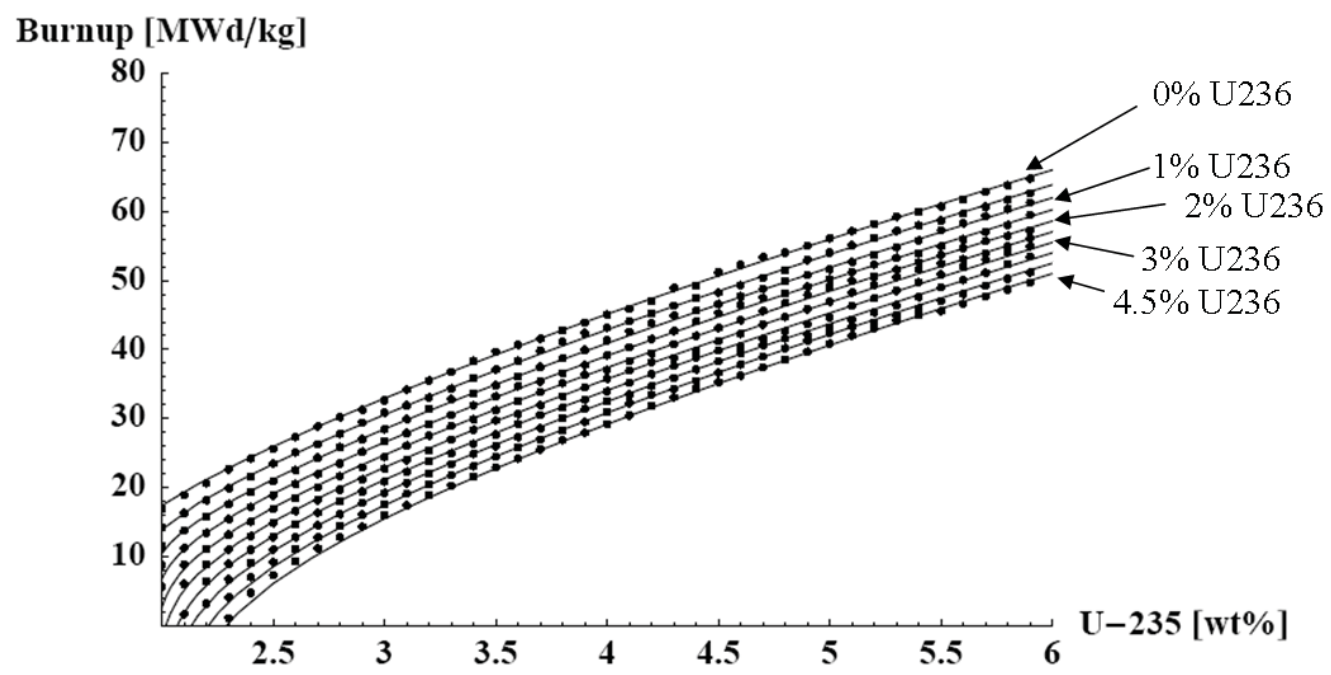

Figure 15. Maximum burnup achievable for various ${ }^{235} \mathrm{U}$ and ${ }^{236} \mathrm{U}$ enrichments for a three-batch cycle.

This information can be communicated in tabular form as well. Table 13 contains a slice of the data that is presented in Figure 15. All of the data in Table 13 is for ${ }^{235} \mathrm{U}$ enriched to $4.3 \mathrm{wt} \%$ burned up with three batches. What varies then is the ${ }^{236} \mathrm{U}$ enrichment and the dependent parameter - the burnup.

Table 13. Maximum burnup achievable for $4.3 \mathrm{wt} \%{ }^{235} \mathrm{U}$ and three batches.

\begin{tabular}{|c|c|}
\hline $\begin{array}{c}{ }^{236} \mathrm{U} \\
{[\mathrm{wt} \%]}\end{array}$ & $\begin{array}{c}\text { Burnup } \\
{[\mathrm{MWd} / \mathrm{kg}]}\end{array}$ \\
\hline 0.0 & 48.9 \\
\hline 0.5 & 46.4 \\
\hline 1.0 & 44.9 \\
\hline 1.5 & 42.7 \\
\hline 2.0 & 40.8 \\
\hline 2.5 & 38.8 \\
\hline 3.0 & 37.6 \\
\hline 3.5 & 35.9 \\
\hline 4.0 & 34.2 \\
\hline 4.5 & 33.0 \\
\hline
\end{tabular}

Conclusion:

Fuel cycle material balances involving enrichment and recycle of uranium from LWR spent fuel can be modeled using the technique presented here. First, the composition of the fuel itself can be predicted based on known characteristics of its assembly. If this fuel were to be enriched, as some scenarios call for it to be, the product of this enrichment process can be found. Since this product has different neutronic 
characteristics than enriched natural uranium, to accurately determine its value its maximum discharge burnup can be determined by inserting its composition into Figure 15.

\subsection{Present-Day DU and RU Inventories in the US}

\subsubsection{Depleted Uranium Inventory}

Figure 16 shows the amount of depleted uranium in $\mathrm{UF}_{6}$ form in the U.S. as a function of ${ }^{235} \mathrm{U}$ assay. The $\mathrm{UF}_{6}$ is stored in 58,890 cylinders at Paducah and Portsmouth. In total, as of the end of 2006, there are 708,189 million tonnes of $\mathrm{UF}_{6}$ in the U.S. Data are from the DOE UF 6 Cylinder Information Database, December 2006 update (Bechtel Jacobs 1998).

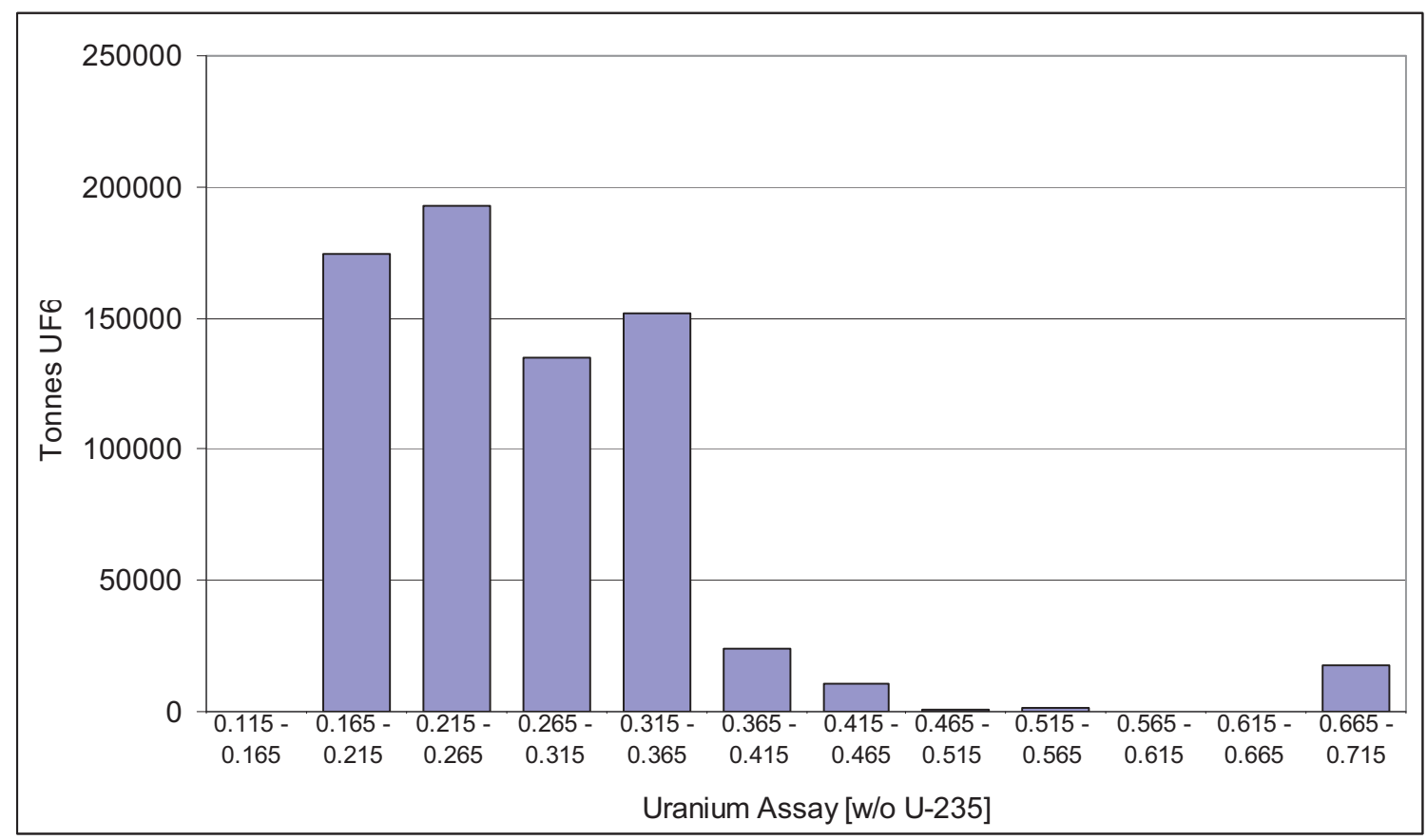

Figure 16. U.S. $\mathrm{UF}_{6}$ holdings as a function of ${ }^{235} \mathrm{U}$ content.

The total inventory of uranium-declared surplus by DOE- 59.2 million $\mathrm{kg}$ of natural $\mathrm{U}_{3} \mathrm{O}_{8}$ equivalent as of May 2006-includes HEU and NU, as well as DU (USGS 2007). Of this excess uranium, 24.5 million $\mathrm{kg}$ is HEU to be blended to LEU; most of the rest is $\mathrm{NUF}_{6}$ or DUF 6 "of economic value." To avoid distorting effects that would accompany large-scale dumping, DOE proposes to place on the market no more than $10 \%$ of the annual fuel requirements of the domestic reactor fleet, or about 5 million tonnes natural uranium equivalent per year.

The DU depicted in Figure 16 contains the same number of ${ }^{235} \mathrm{U}$ atoms as 180,000 tonnes of natural uranium. Simple mass balance calculations show that if all of this DU were enriched to $4.2 \%$ with tails assay of $0.1 \%$, over 26,000 tonnes of reactor fuel - about 12 years' supply at current consumption ratescould be produced. To enrich all U.S.-held DU to $4.2 \%$, though, would require about 500 million SWU, or 44 years worth of full-time deployment of the current U.S. enrichment capacity of 11.3 million SWU/year. Therefore, it is likely that the pace of DU re-enrichment will be set by the amount of excess SWU capacity available at any given time, its price and that of NU. This will be discussed in further detail in Section 2.3.2. 
Adjustment of DU tails assay is the sole short-term method of introducing demand elasticity available to utilities. Prior to 2000, the prevailing DU tails assay in the United States was $0.3 \mathrm{w} / \mathrm{o}{ }^{235} \mathrm{U}$. As the price of uranium has increased, the front-end cost-minimizing tails assay has decreased to less than $0.2 \mathrm{w} / \mathrm{o}$

${ }^{235} \mathrm{U}$, although even as NU prices have risen, the multi-year nature of many separative work contracts has caused actual tails assays to lag the cost-minimizing value for utilities. To place this in context, when producing $4.2 \%$ enriched fuel a reduction of tails assay from 0.3 to $0.2 \mathrm{w} / \mathrm{o}$ will decrease natural uranium requirements by $18 \%$. Hence, market forces can lead to considerable economies of primary uranium consumption.

DU will of course continue to accumulate, although it is difficult to project the average assay of future holdings. For purposes of illustration, assume an average future assay of $0.25 \%$, reflecting assays that had been prevalent in Europe for decades. The U.S. Department of Energy currently plans to deconvert the majority of stockpiled $\mathrm{UF}_{6}$ to $\mathrm{U}_{3} \mathrm{O}_{8}$ for stable storage until final disposal. In Section 2.3.2, the relative merits of immobilization versus storage in hexafluoride form-preserving the option to reenrich - are discussed in the context of both current DU holdings and future accumulations.

\subsubsection{Reprocessable Uranium Inventory}

Historical data concerning the U.S. SF inventory was obtained from the EIA. The EIA maintains records on all fuel assemblies in the U.S. and includes data on every fuel assembly's mass, burnup, initial enrichment, and the reactor in which it was irradiated. Currently, the EIA has data on 29,454 spent nuclear fuel assemblies, which is current through 2002 (EIA 2002). The methodology outlined in Section 2.1.1 was applied to the U.S. SF inventory.

The calculated cumulative distribution of uranium in U.S. legacy SF by its ${ }^{235} U$ content is shown in Figure 17. It can be seen from the figure that the median ${ }^{235} \mathrm{U}$ enrichment of RU is about $0.85 \%$. It is important to note that each residual ${ }^{235} \mathrm{U}$ enrichment level is associated with some spread of ${ }^{236} \mathrm{U}$ assay, which is shown in Figures 18 and 19. Figure 18 shows the normalized cumulative distribution of ${ }^{236} U$ in uranium that contains $0.55-0.65 \%{ }^{235} \mathrm{U}$ when it comes out of the reactor. Figure 19 shows the same normalized distribution for RU containing $0.85-0.95 \%{ }^{235} \mathrm{U}$. Figures 18 and 19 are normalized for convenience of comparison; in fact, there is a great deal more uranium in the $0.85-0.95 \%{ }^{235} \mathrm{U}$ bin than in the $0.55-0.65 \%$ bin. 


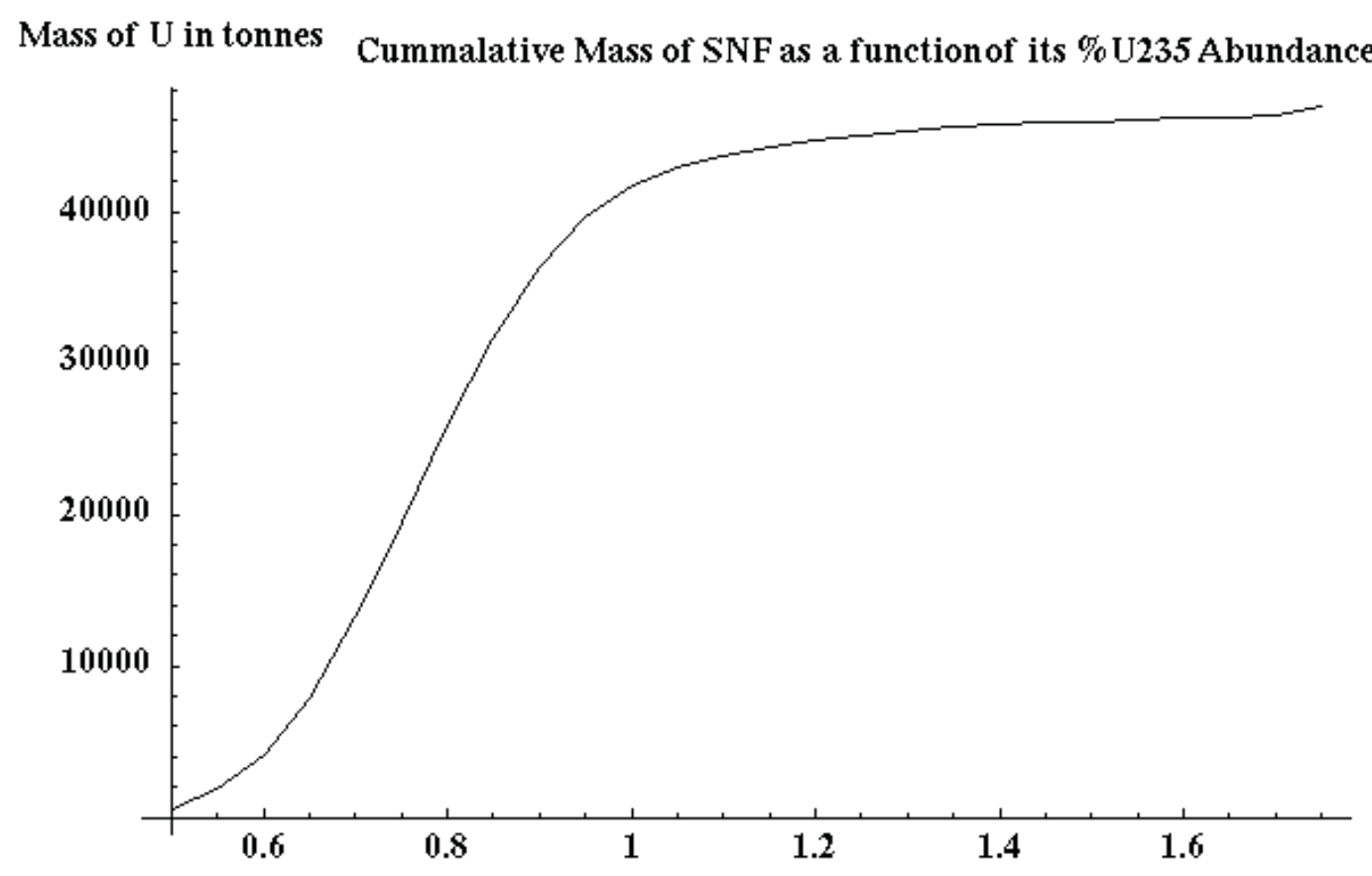

Figure 17. Estimated ${ }^{235} \mathrm{U}$ content of uranium contained in U.S. spent fuel.

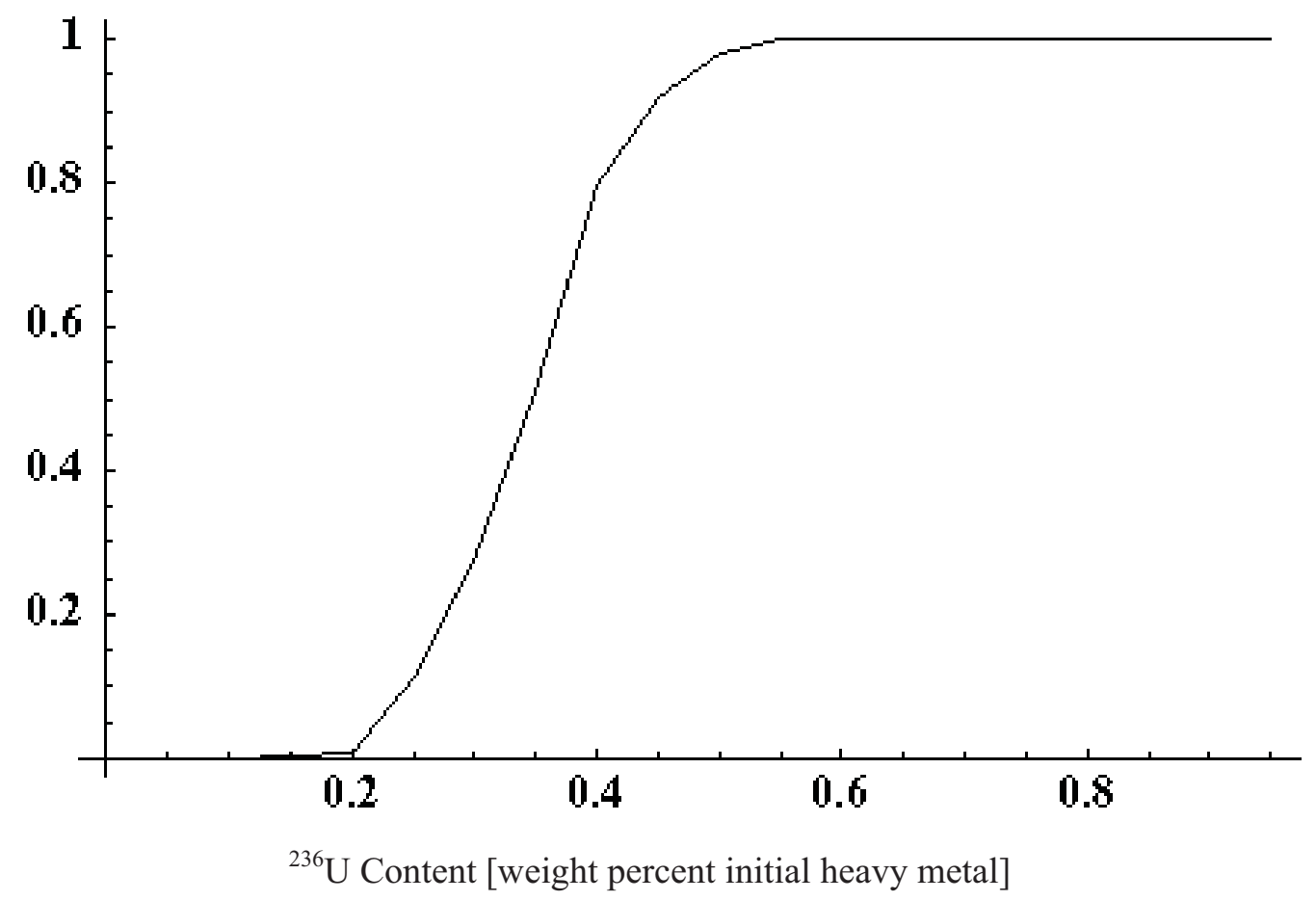

Figure 18. Cumulative distribution function of estimated normalized ${ }^{236} U$ content of RU with $0.55-0.65 \%$ ${ }^{235} \mathrm{U}$. The ordinate shows the fraction of RU that has a ${ }^{236} \mathrm{U}$ content less than or equal to the value given on the abscissa. 


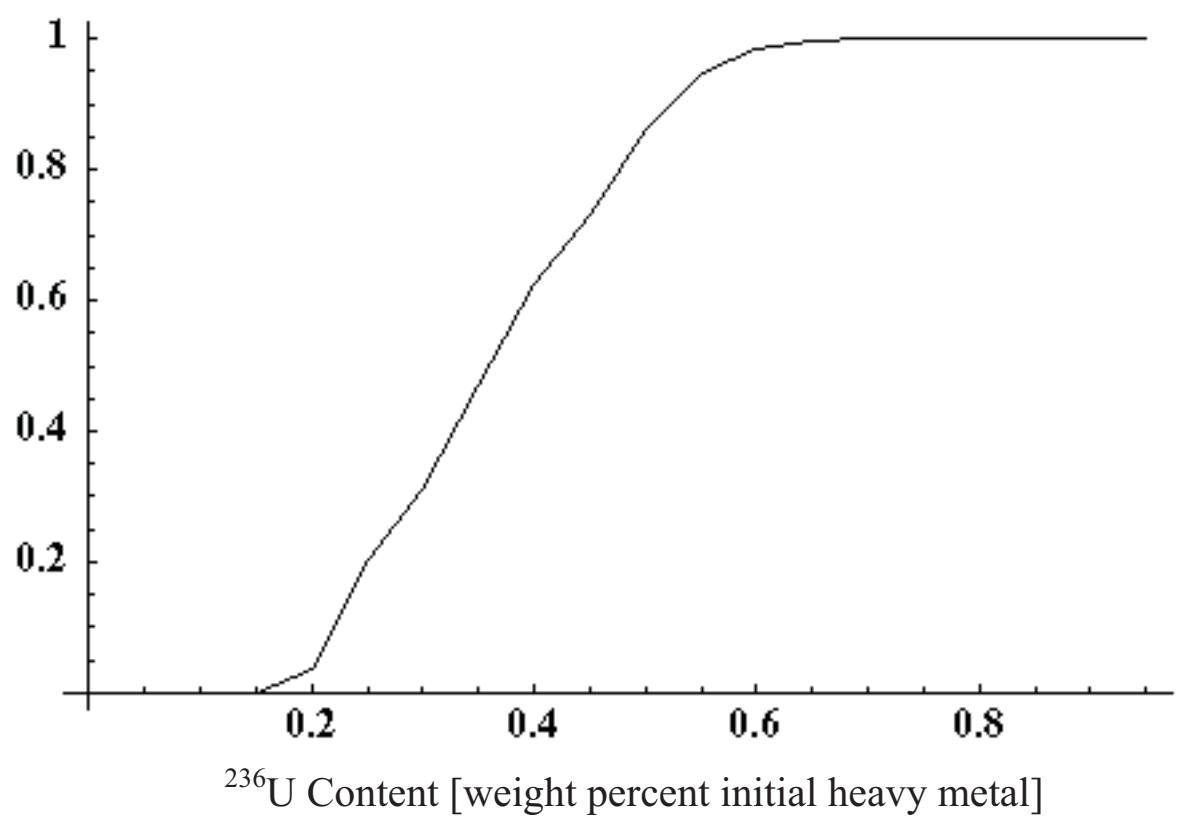

Figure 19. Cumulative distribution function of estimated normalized ${ }^{236} U$ content of RU with $0.85-0.95 \%$ ${ }^{235} \mathrm{U}$. The ordinate shows the fraction of RU that has a ${ }^{236} \mathrm{U}$ content less than or equal to the value given on the abscissa.

Figure 20 gives the percentage of the 46,999 tonnes of uranium contained, as of December 31, 2002, in U.S. SF as a function of ${ }^{235} \mathrm{U}$ assay. Complete actinide isotopics have been compiled for each SF assembly, though Figure 20 only shows ${ }^{235} \mathrm{U}$ composition.

The above discussion generally pertains to legacy SF specifically and any irradiated fuel that is not covered by the VISION recipes.

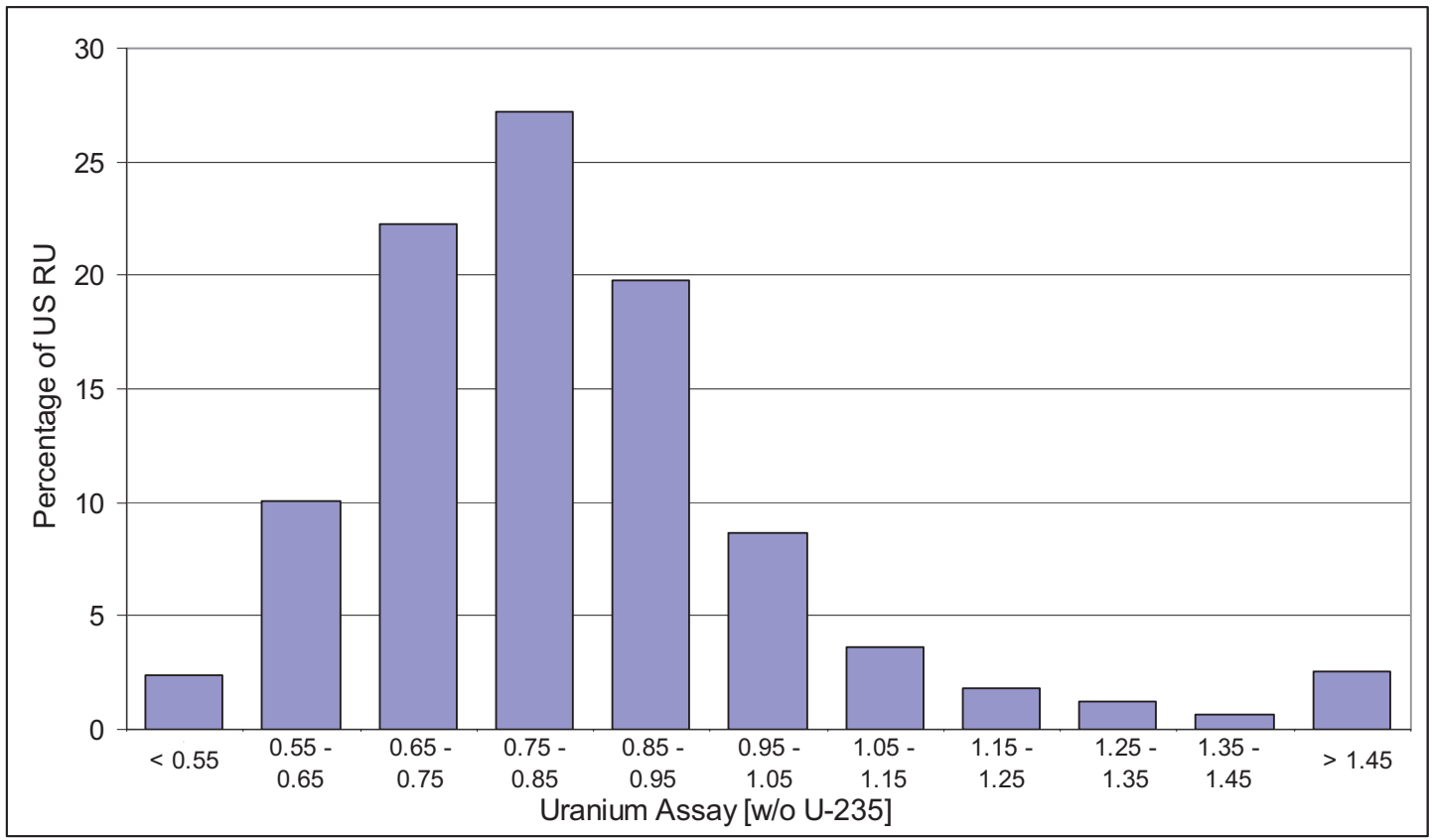

Figure 20. Calculated assay distribution of U.S. recyclable uranium. 


\subsection{Scenarios Involving DU and RU Recycle}

\subsubsection{Probabilistic discount model for assessing the life cycle cost of nuclear fuel cycles}

The U.S. Department of Energy currently plans to deconvert depleted $\mathrm{UF}_{6}$ to $\mathrm{U}_{3} \mathrm{O}_{8}$ for stable storage until final disposal, the form of which is still open to debate. This path is favored in part because only a limited number of uses for DU and RU exist beyond re-enrichment, which has been more expensive historically than mining fresh uranium. Nonetheless, given the sharp rise in primary uranium prices, it has become important to identify scenarios in which DU and RU could act (for a period) as cost-effective partial alternatives to further uranium mining. Future economic analysis, for example to compare the current DOE strategy with domestic re-enrichment of depleted $\mathrm{UF}_{6}$, as well as re-enrichment done abroad (Diehl 2004) and the conversion of depleted $\mathrm{UF}_{6}$ to uranium metal for use in making SF storage casks (Michaels and Welch 1993), will involve costs spanning many years or decades. Therefore, if these costs are not appropriately discounted, distorted results, leading to erroneous conclusions, may be obtained.

The simplest way to track costs in a given fuel cycle is to follow material from its initial state as ore to the final burial of its progeny. A probabilistic model for the total cost is then easily formulated in terms of data for the fuel cycle unit costs. The associated standard deviations can be determined if the variances in unit costs are known and the assumption is made, the unit costs are normally distributed. Continuous discounting can be used within the framework of the 1994 OECD/NEA study to level all front and backend costs, as well as the revenue from electricity production, to the date at which fresh uranium oxide fuel (UOX) is loaded into a reactor (OECD/NEA 1994). The result is mathematically simpler than discrete discounting and it introduces negligible error relative to the large variances for unit cost predications.

With this approach, levelized costs are easily obtained using:

$\mathrm{PV}=\int \mathrm{p}(\mathrm{t}) \mathrm{e}^{-\rho \mathrm{t}} \mathrm{dt}$

where

$$
\begin{aligned}
& \mathrm{PV}[\$]=\text { present value of a cash outflow, } \mathrm{p}(\mathrm{t})[\$ / \mathrm{yr}] \\
& \rho=\text { respective discount rate }[1 / \mathrm{yr}] \\
& \mathrm{t}=\text { time }[\mathrm{yr}] .
\end{aligned}
$$

Figure 21 lists various distributions for $\mathrm{p}(\mathrm{t})$ that are of relevance, as well as equations for their associated PV. The total cost of the fuel cycle is given by the sum over the respective front and back-end costs:

$$
\mathrm{E}_{\mathrm{c}}=\sum_{\mathrm{i}} \mathrm{PV}_{\mathrm{i}}
$$

Equation (21) has the convenient feature of being linear with respect to the total cost of each fuel cycle component. As a result, $\mathrm{E}_{\mathrm{c}}$ can be scaled to account for changes in unit cost, provided that time points for the integral in Equation (20) remain fixed. The fuel cycle costs in $\$ / \mathrm{kWh}(\mathrm{e})$ is calculated by dividing $\mathrm{E}_{\mathrm{c}}$ by the total $\mathrm{kWh}(\mathrm{e}) \mathrm{s}$ of electricity produced. Electricity production is also discounted to reflect the temporal distribution of the revenue stream. To make the conversion, the electricity e produced by the reactor fleet $\{\mathrm{kWh}(\mathrm{e})\}$ was computed during the interval $\left[\mathrm{T}_{1}, \mathrm{~T}_{2}\right]$ and discounted at the same rate $\mathrm{r}$ as was applied to the unit costs: 


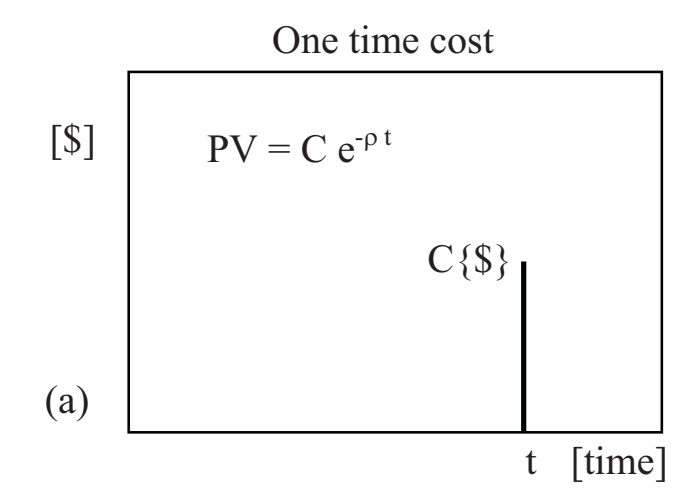

Distributed cost, one time payment

(c)

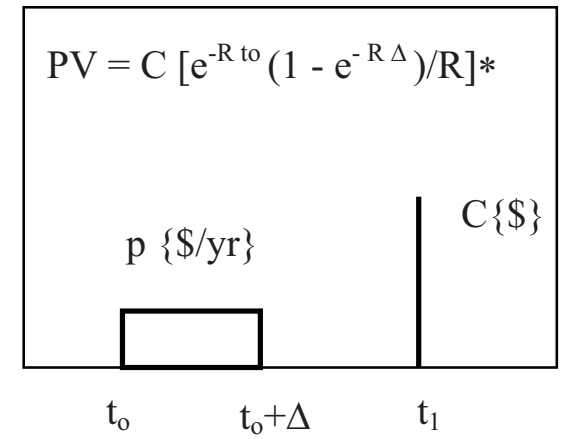

Escalating cost

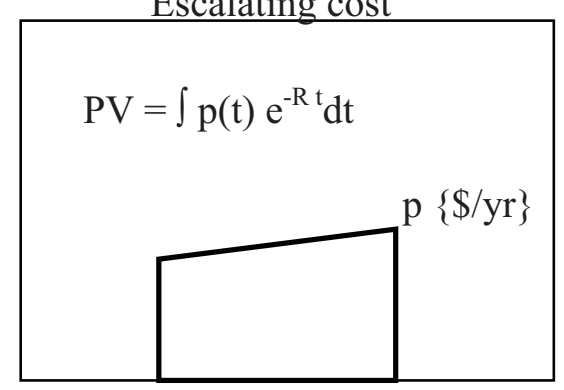

(b)

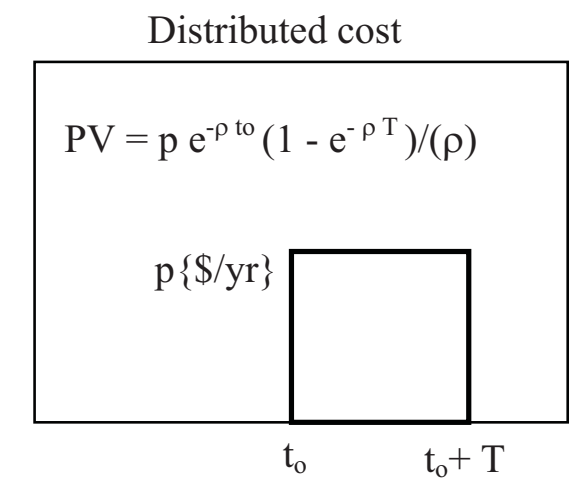

Distributed cost, distributed payment

(d)

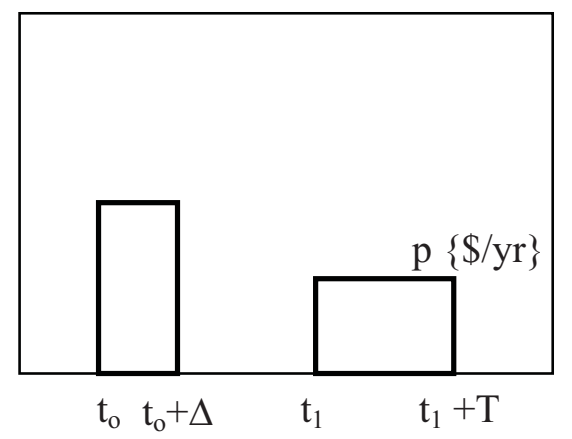

Arbitrary distribution

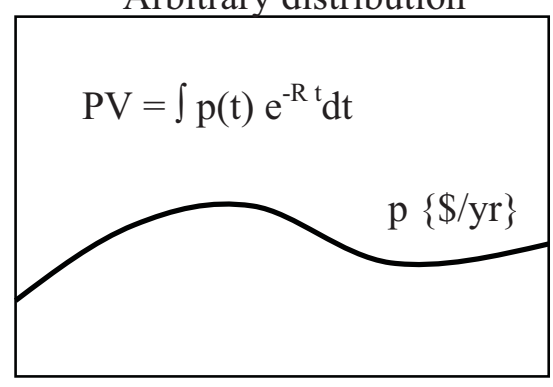

Figure 21. Payment, cost, and revenue distributions.

$$
\mathrm{E}=\alpha \mathrm{P}_{0} \int_{\mathrm{T}_{1}}^{\mathrm{T}} \mathrm{e}^{(\mathrm{g}-\mathrm{-r}) \mathrm{t}} \mathrm{dt}
$$

where

$$
\begin{aligned}
& \mathrm{P}_{0}=\text { reactor fleet's thermal output }\{\mathrm{MW}\} \\
& \alpha=\text { its capacity factor } \\
& \mathrm{g}=\text { nuclear power growth rate. }
\end{aligned}
$$

Uncertainty in unit costs causes a corresponding uncertainty in the prediction of $\mathrm{E}_{\mathrm{c}}$. These effects are accounted for by using the well known formula for error propagation where the variance of $\mathrm{E}_{\mathrm{c}}\left(\mathrm{x}_{\mathrm{i}}\right)$ is given by: 
$\operatorname{var}\left(\mathrm{E}_{\mathrm{c}}\right)=\sum_{\mathrm{i}}\left(\frac{\partial \mathrm{E}_{\mathrm{c}}}{\partial \mathrm{x}_{\mathrm{i}}}\right)^{2} \operatorname{var}\left(\mathrm{x}_{\mathrm{i}}\right)+2 \sum_{\mathrm{i}} \sum_{\mathrm{j} \neq \mathrm{i}}\left(\frac{\partial \mathrm{E}_{\mathrm{c}}}{\partial \mathrm{x}_{\mathrm{i}}}\right)\left(\frac{\partial \mathrm{E}_{\mathrm{c}}}{\partial \mathrm{x}_{\mathrm{j}}}\right) \sqrt{\operatorname{var}\left(\mathrm{x}_{\mathrm{i}}\right)} \sqrt{\operatorname{var}\left(\mathrm{x}_{\mathrm{j}}\right)} \mathrm{r}\left(\mathrm{x}_{\mathrm{i}}, \mathrm{x}_{\mathrm{j}}\right)$

Here the inputs, $\mathrm{x}_{\mathrm{i}}$, represent the $\mathrm{PV}_{\mathrm{i}}$ in Equation (1) with respective variances $\operatorname{var}\left(\mathrm{x}_{\mathrm{i}}\right)$. The term $\mathrm{r}\left(\mathrm{x}_{\mathrm{i}}, \mathrm{x}_{\mathrm{j}}\right)$ is the correlation coefficient: 1 for fully correlated, -1 for anticorrelated, and 0 for uncorrelated. The maximum and minimum variances are given by assuming that $r=1,-1$ receptively with uncorrelated, $\mathrm{r}=0$, falling into the midrange. The electricity cost is assumed to have a Gaussian distribution which can be justified by the Central Limit Theorem, with the standard deviation of $\mathrm{E}_{\mathrm{c}}$ being the square root of the variance. An appropriate discount rate for what utilities could expect to receive in the short term is $7 \%$ above inflation (Tolley and Jones 2004), but for projects that run on a multi-decadal or intergenerational lifecycle 2\% would be more appropriate (Arrow 1999).

Distributions for $\mathrm{p}(\mathrm{t})$ applicable to Equation (20) are shown in Figure 21. In the figure, $\mathrm{C}$ stands for one time cost, and $\mathrm{p}$ for distributed payment. The rate of return on the sinking fund is denoted by $\mathrm{r}$, and $\mathrm{R}$ is the rate of return that a utility could expect from investment of free cash. In all cases, the present values are discounted back to time $\mathrm{t}=0$. In (c) and (d) the payment distributions are shown between $\mathrm{t}_{\mathrm{o}}$ and $\mathrm{t}_{\mathrm{o}}+\Delta$. In $(a, b, e, f)$ the payments are assumed to be one time events which occur at time $t=0$.

\subsubsection{Fuel Cycle Scenarios}

Within the context of the AFCI, only a handful of uses for DU exist beyond re-enrichment. Depleted uranium can realistically be used as a matrix for down blending HEU from dismantled nuclear weapons, in energy storage flywheels, or for use as fast reactor blanket material. However, only its use in shielding applications for spent fuel storage casks appears capable of absorbing the amount of material that is currently stockpiled. This disparity is likely to grow with time, especially if demand for nuclear power increases.

The U.S. Department of Energy currently plans to deconvert the $\mathrm{UF}_{6}$ to $\mathrm{U}_{3} \mathrm{O}_{8}$ for stable storage until final disposal, the form of which is still open to debate. This path is favored in part because only a limited number of uses for DU and RU exist beyond re-enrichment, which has been more expensive historically than mining fresh uranium. Nonetheless, given the sharp rise in primary uranium prices, it has become important to identify scenarios in which DU and RU could act (for a period) as cost-effective partial alternatives to further uranium mining. The options to be considered for DU are listed below; letters are assigned to them so that they may be referenced in subsequent text.

Current DOE strategy envisions conversion of $\mathrm{UF}_{6}$ to $\mathrm{U}_{3} \mathrm{O}_{8}$ with subsequent disposal. Alternate strategies include (A) domestic re-enrichment of $\mathrm{UF}_{6}$. In this strategy, the DU might be enriched to $0.71 \%$ or $1 \%$, using excess separative work capacity, followed by storage as $\mathrm{UF}_{6}$. Alternatively, it may continue to be stored as $\mathrm{DUF}_{6}$ until re-enrichment is called for. Shipment of $\mathrm{UF}_{6}$ abroad, re-enrichment, and return to the U.S. (B) affords the same enrichment options as (A); however, considerable additional excess capacity exists abroad particularly in Russia. There is a precedent: Germany, France and, very recently, Japan have pursued an arrangement of this type with Russia. A significant technical obstacle to realize this strategy exists: the transport of $\mathrm{UF}_{6}$ casks is subject to complex regulations; many casks could not be transported abroad and others would require overpacks.

Conversion of $\mathrm{UF}_{6}$ to $\mathrm{U}$ metal for use in spent fuel disposal casks (C) would streamline the disposal process. The cask cost has been estimated to be $\$ 22.80 / \mathrm{kg} \mathrm{UF}_{6}$ in 1994 dollars (Hertzler and Nishimoto 1994). This strategy would immobilize nearly all current DU holdings. However, the fate of DU produced in the future would still be open to question. 
Conversion of $\mathrm{UF}_{6}$ to UOX or metal for use as matrix in mixed uranium-plutonium oxide (MOX), fast burner reactor fuel, or for downblending HEU (D) affords an attractive recycle option. However, even under aggressive MOX fuel or burner reactor deployment plans, system studies have shown that only a few percent of DU produced each year could be recycled in this way (OECD/NEA 2002). Owing to the limited stocks of HEU anticipated to be released by DOE, the same constraints are active if DU is used to dilute HEU.

Non-nuclear military applications include the use of DU metal (via reduction of Uranium hexafloride to a uranium metal) in ballistics and armor, and DU has also been considered in energy storage flywheels or counterweights (Diehl 2004, Hertzler and Nishimoto 1994). However, the amount of material required to supply these applications is small compared to the current supply of DU. Non-nuclear military applications include the use in ballistics and armor. The use of DU in energy storage flywheels or counterweights has also been explored (Diehl 2004, Hertzler and Nishimoto 1994). However, the amount of material required to meet these applications is small compared to the current supply.

Options for RU beyond re-enrichment are even more proscribed. Moreover, disposal of RU is filled with greater political concerns and constraints than is the case for DU. Since re-enrichment of RU will still require the disposal of radioactive tails, the use of $\mathrm{RU}$ in fast reactor blankets could be an attractive option. Once again, though, unless a breeding fuel cycle comes to fruition, RU recycle, as a matrix material in MOX or fast reactors, would be insufficient to immobilize more than a few percent of the RU produced annually by the LWR fleet.

Although commercial RU enrichment is not presently occuring (subject to change in the near term in view of Russian-Japanese negotiations), the U.S., Russia, and France have enriched RU in significant quantities in the past. The most recent major study of RU enrichment in the U.S. took place in 1993 (Michaels and Welch 1993). Although this study must now be considered outdated, it is certain that the most substantial additional expenses that adhere to RU enrichment are purification and tails disposal. Both of these issues are complicated by the presence of the isotope ${ }^{232} U$. Although ${ }^{232} U\left(T_{1 / 2}=68.9 \mathrm{yr}\right)$ is present in RU at levels of a few parts per $10^{7}$ atoms, ${ }^{228} \mathrm{Th}$ and other daughters in its chain that undergo particularly energetic decays lead this parent isotope to be the dominant contributor to the RU dose field. Given that these daughters are removed from the uranium stream at the time of separation, it is advantageous to enrich RU as quickly as possible to avoid a costly secondary purification step. Indeed, the dose rate from RU immediately following its separation is very nearly the same as that of NU. One year after separation, the RU dose rate increases to almost ten times that of NU and its decay power exhibits an even more substantial increase; the radiation field from RU peaks about 10 years after separation. Therefore, it seems essential to enrich the RU within a few months of its separation.

If quick re-enrichment is not possible, or if the original separation process does not sufficiently extract certain fission products and actinides, additional "polishing" of the RU would be required. A number of polishing processes have been proposed. While PUREX or a similar aqueous process could be employed, given the low contaminant concentrations, other methods offering considerably less complexity and expense can be pursued. One of these is fluoride volatility purification - high-purity separation of uranium fluorides from fluorides of many fission products and actinides. Uranium fluorides become volatile at significantly lower temperatures than other fluoride compounds; none of the noble metal fluorides become gaseous at a temperature within $30 \mathrm{~K}$ of the $\mathrm{UF}_{6}$ boiling point. Indeed, this purification process is already employed at the Metropolis Works and other U fluorination facilities, and the cost of purifying RU in this fashion would be similar to the cost of conversion.

To ensure that the tails from the RU enrichment process can be stored and disposed in the same manner as DU, it is advantageous to consider three additional options for RU, in addition to those given above for DU. The first of these entails blending RU feedstock with NU to decrease ${ }^{232} U$ and ${ }^{236} U$ 
concentrations (F). This strategy offers the further advantage of reducing the level of over-enrichment required to compensate for the negative effect of ${ }^{236} \mathrm{U}$ on the neutron economy of a reactor.

Two other options mitigate concerns arising from the concentration of undesirable isotopes in an enrichment product stream. The first option is employment of a secondary cascade to produce a second tails stream that is highly concentrated in ${ }^{232} U(G)$. The small amount of secondary product material would require some decades of storage before becoming disposable in the same fashion as traditional DU. Blending of RU with over-enriched NU $(\mathrm{H})$ is another option. Under this option, RU would not pass through an enrichment plant at all. However, sustainability benefits-reductions in NU and SWU requirements per unit energy produced - are minimal to nonexistent. An important and attractive variant of this option would arise if already-existing HEU were made available for blending.

Documenting DU and RU inventories and laying out the space of options connected to the disposal or re-use of these materials is a first step. Future work will include levelized cost-benefit analyses of the options. These analyses will seek to identify the NU and SWU prices at which the various options become competitive with a baseline strategy of immobilization followed by disposal. It is expected that some of the re-use options may serve as valuable hedges against periods of elevated primary uranium prices. An initial analysis is presented in the following section; more detailed discussion of utilization options can be found in Schneider's (et al.) 2007 document.

\subsubsection{Sample Results and Conclusions}

In this section, two of the options for RU recycle are explored in detail using the methodologies outlined above. Using SF from the VISION $51 \mathrm{MWd} / \mathrm{kg}$ LWR recipe as a starting point, this demonstration explores material balance impacts and costs associated with RU recycle. This is a sample calculation and should not be considered a result derived from AFCI modeling activities.

Therefore, the enrichment is modeled using the multi-isotope cascade model presented in Section 2.1.2. The reactor physics associated with RU of diverse isotopics is handled via the one group cross section criticality estimates described in Section 2.1.3. Unit costs are taken from Modules A, B, C1, D, K1, and K2 of the "AFC Cost Basis" report (Shropshire 2007) and the simplest features of the levelized life cycle cost methodology presented in Section 2.3.1 are employed to calculate fuel cycle costs.

The steps required to prepare RU for recycle, outlined in Modules K1 and K2, are somewhat complex and bear review. RU comes out of the reprocessing plant in nitrate form. The concentration of uranyl nitrate hexahydrate concentration and conversion to a stable form $\left(\mathrm{U}_{3} \mathrm{O}_{8}\right)$ may be considered the reference option for RU disposal. Module K2 gives its cost range (low/most likely/high) as $\$ 6 / \$ 7 / \$ 12$ per $\mathrm{kg} \mathrm{RU}$ ) if polishing (aqueous ${ }^{232} \mathrm{U}$ daughter removal) is not necessary. If polishing is necessary, $\mathrm{K} 2$ specifies the cost as $\$ 20 / \$ 30 / \$ 41$ per $\mathrm{kg}$ RU. For the remainder of this section, prompt re-use of the RU following recycle is assumed, so that polishing is not needed.

There are two subsequent processes involved in the disposal of this $\mathrm{U}_{3} \mathrm{O}_{8}$. They are long-term $(\sim 40 \mathrm{yr})$ storage $(\$ 6 / \$ 12 / \$ 30$ per kg RU) followed by repository disposal $(\$ 61 / \$ 72 / \$ 93$ per $\mathrm{kg} \mathrm{RU})$.

Two RU recycle options will be contrasted to the disposal strategy:

1 Direct RU enrichment

2 Blending of RU with NU enriched to greater than 5\%.

For the first option, enrichment of the RU is assumed to take place immediately following its discharge from the separation facility. RU costs, for enrichment just as for pre-disposal handling, depend on the age of the RU. Material older than approximately one year must be aqueously polished to remove 
high-activity ${ }^{232} U$ daughters. A schematic of the material flows for this process are shown in Figure 22. In this figure, the blue arrows indicate the flow of RU. In the disposal option, the RU is converted to $\mathrm{U}_{3} \mathrm{O}_{8}$, stored, and disposed. But for this option to generate the same amount of energy as the enrichment option, a quantity of NU must be enriched and fabricated. Therefore, the processes enclosed in the red box produce the same amount of electricity as the enrichment processes within the green box.

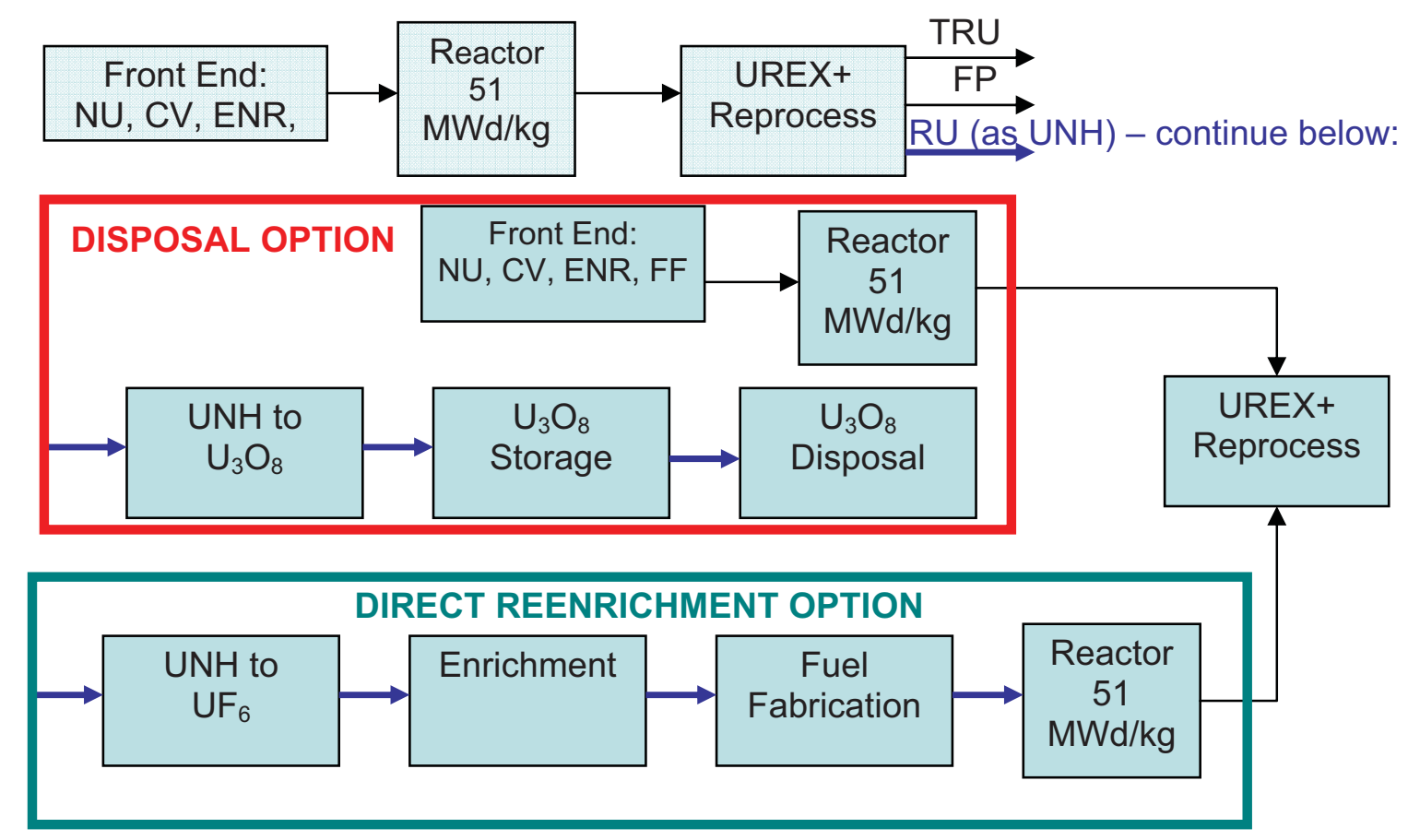

Figure 22. Energy equivalent options for comparison, 1: Direct RU enrichment.

Several details of the enrichment process are neglected in this simple analysis. There will be an extra cost per SWU to reflect enrichment plant contamination (higher decommissioning costs). In the past, DOE has added a $10 \%$ charge to all SWUs performed on RU. Instead, SWU was computed according to the method outlined in de la Garza's (et al.) report, which should approximately reflect this surcharge (de la Garza, et al. 1961). However, it is questionable whether such a minimal surcharge would apply in the future. Also, neutronic considerations (e.g., ${ }^{236} \mathrm{U}$ buildup) limit this option to no more than two passes at the very most, so this quasi-equilibrium approach presents only an incomplete picture of the situation. Likewise, the resource sustainability benefit is limited: single recycle of RU reduces NU consumption by $\sim 1 / 7$. Any effect this might have on uranium and other prices is neglected. The surcharge recommended in Module D1-1 of the "AFC Cost Basis" report for fabricating fuel containing RU is included in this analysis (Shropshire 2007). This higher unit cost is used for both the RU blending and enrichment scenarios.

To move from the schematic depicted above to a material balance suitable for calculations, mass flows must be obtained. The multicomponent enrichment cascade methodology described in Section 2.1.2 coupled with the fuel discharge burnup estimation technique presented in Section 2.1.3 are used for this purpose. To obtain from RU fresh fuel that is burnable to $51 \mathrm{MWd} / \mathrm{kg}$, given spent fuel that comes from the VISION recipe for $51 \mathrm{MWd} / \mathrm{kg}$ LEU fuel, the cascade depicted in Table 14 must be set up. 
Table 14. Optimized Cascade Parameters for RU Enrichment Case.

$\mathrm{N}$, enrichment stage number:

27.4

$\mathrm{M}$, stripping stage number:

15.1

M*, Cascade key weight

236.5

$\mathrm{L} / \mathrm{F}$, total flow rate over feed flow rate (minimized):

328.4

SWU per $1 \mathrm{~kg}$ Feed:

0.851

SWU per $1 \mathrm{~kg}$ Product:

Solving the cascade gives the following compositions for product, feed, and waste. Figure 23 presents a quantitative flowchart for the enrichment option, and Table 15 shows the isotopic distributions of the product, feed, and waste from the enrichment cascade.

Table 15. Isotopic composition (weight percent) of enriched RU feed, product, tails.

\begin{tabular}{|l|l|l|l|l|}
\hline & $\mathrm{U}-234$ & $\mathrm{U}-235$ & $\mathrm{U}-236$ & $\mathrm{U}-238$ \\
\hline Product & 0.147 & 5.503 & 2.84 & 91.50 \\
\hline Feed & 0.0183 & 0.818 & 0.610 & 98.55 \\
\hline Waste & $2.747 \times 10^{-5}$ & 0.250 & 0.339 & 99.40 \\
\hline
\end{tabular}

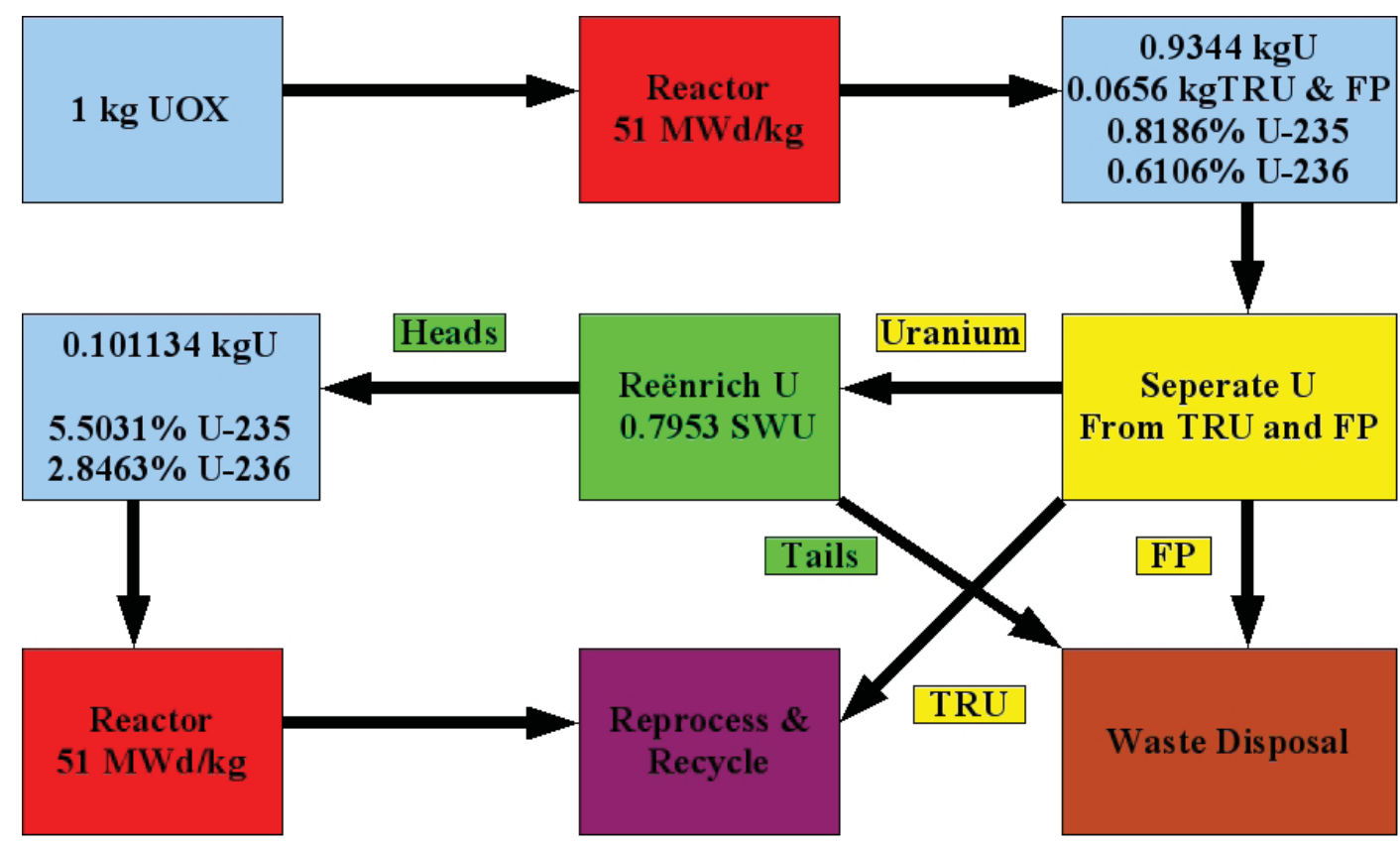

Figure 23. Material balance for Option 1: Enrichment of unblended RU.

As described in Section 3.2, perturbations to direct recycle mitigate some of its drawbacks. Only one perturbation will be considered in detail for the present, namely blending of RU and LEU of higher enrichment. Since future enrichment plants may be licensed to produce $8 \%$ enriched product, this figure will be chosen as a nominal value for the LEU to be blended. Under this option, RU would not pass through an enrichment plant at all. Sustainability benefits - marginal reductions in NU and SWU requirements per unit energy produced - are minimal, and economic benefits, if any, will depend on the cost of RU disposal. However, this strategy does offer the possibility of sustained recycle of most or all of 
the RU produced by the LWR fleet. It could become more attractive if considerable quantities of HEU were to become available for downblending with RU.

Material flows for this process are shown schematically in Figure 24. Once again, the blue arrows indicate the flow of RU. The processes enclosed in the red box produce the same amount of electricity as those within the dark blue box.

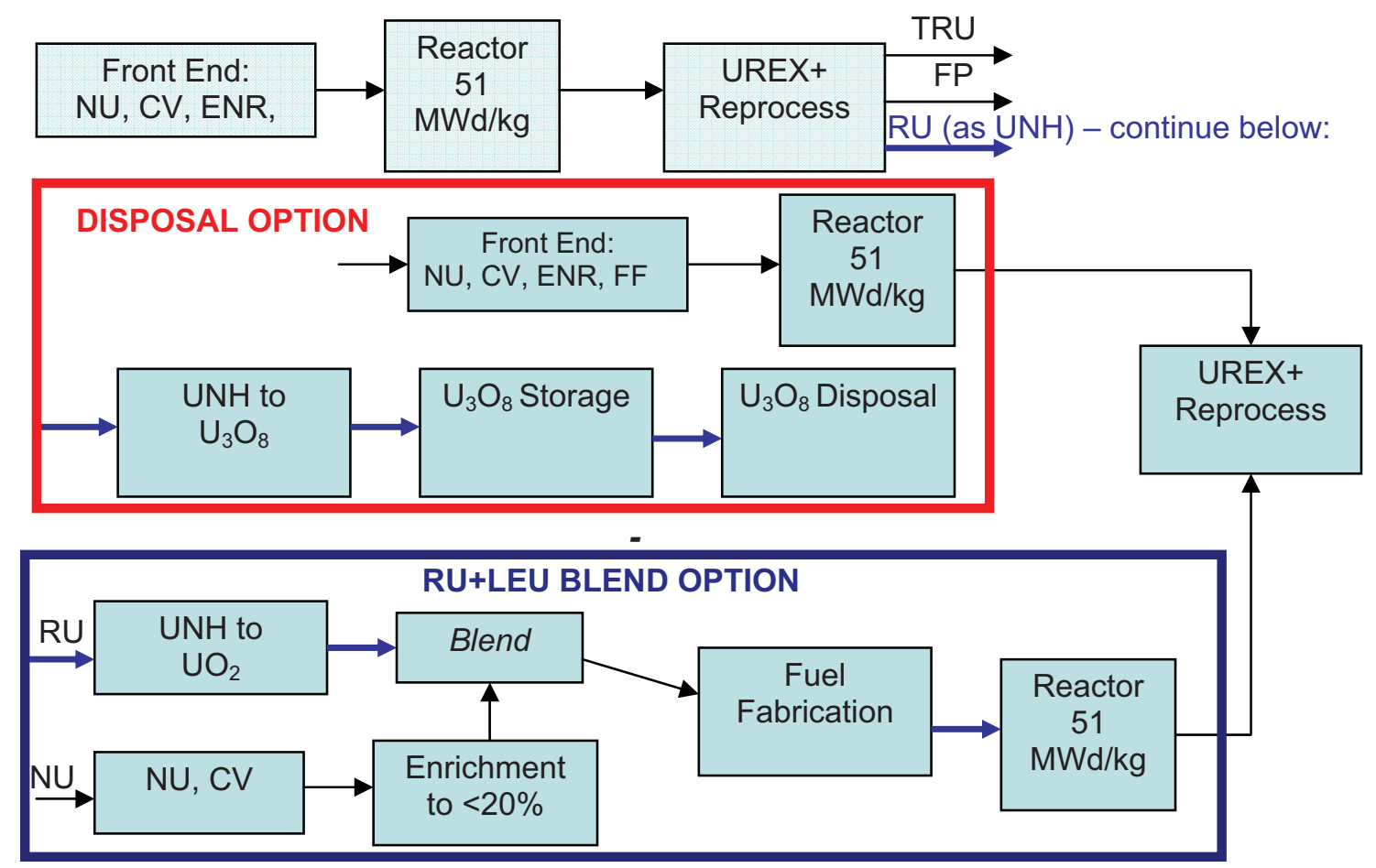

Figure 24. Energy equivalent options for comparison, 2: RU+LEU blend.

Once again, mass flows are computed with the aid of techniques presented in Section 2.1.3. To obtain fuel that is burnable to $51 \mathrm{MWd} / \mathrm{kg}$ from fuel that comes from the blending of NU enriched to $8 \%$, given spent fuel that comes from the VISION recipe for $51 \mathrm{MWd} / \mathrm{kg} \mathrm{LEU} \mathrm{fuel,} \mathrm{the} \mathrm{following} \mathrm{NU} \mathrm{product,} \mathrm{feed,}$ and waste streams, as well as blended product stream will be required. The mass flows are shown diagrammatically in Figure 25. Table 16 shows the isotopic distribution of the enrichment plant streams and the blended product.

Table 16. Isotopic composition (weight percent) of LEU feed, product, tails and blended LEU + RU product.

\begin{tabular}{|l|l|l|l|l|}
\hline & $\mathrm{U}-234$ & $\mathrm{U}-235$ & $\mathrm{U}-236$ & $\mathrm{U}-238$ \\
\hline Blended Product & 0.0490 & 4.650 & 0.285 & 95.02 \\
\hline Product & 0.0755 & 8.010 & 0 & 91.922 \\
\hline Feed & 0.0055 & 0.72 & 0 & 99.2745 \\
\hline Waste & $9.86 \times 10-6$ & 0.250 & 0 & 99.748 \\
\hline
\end{tabular}




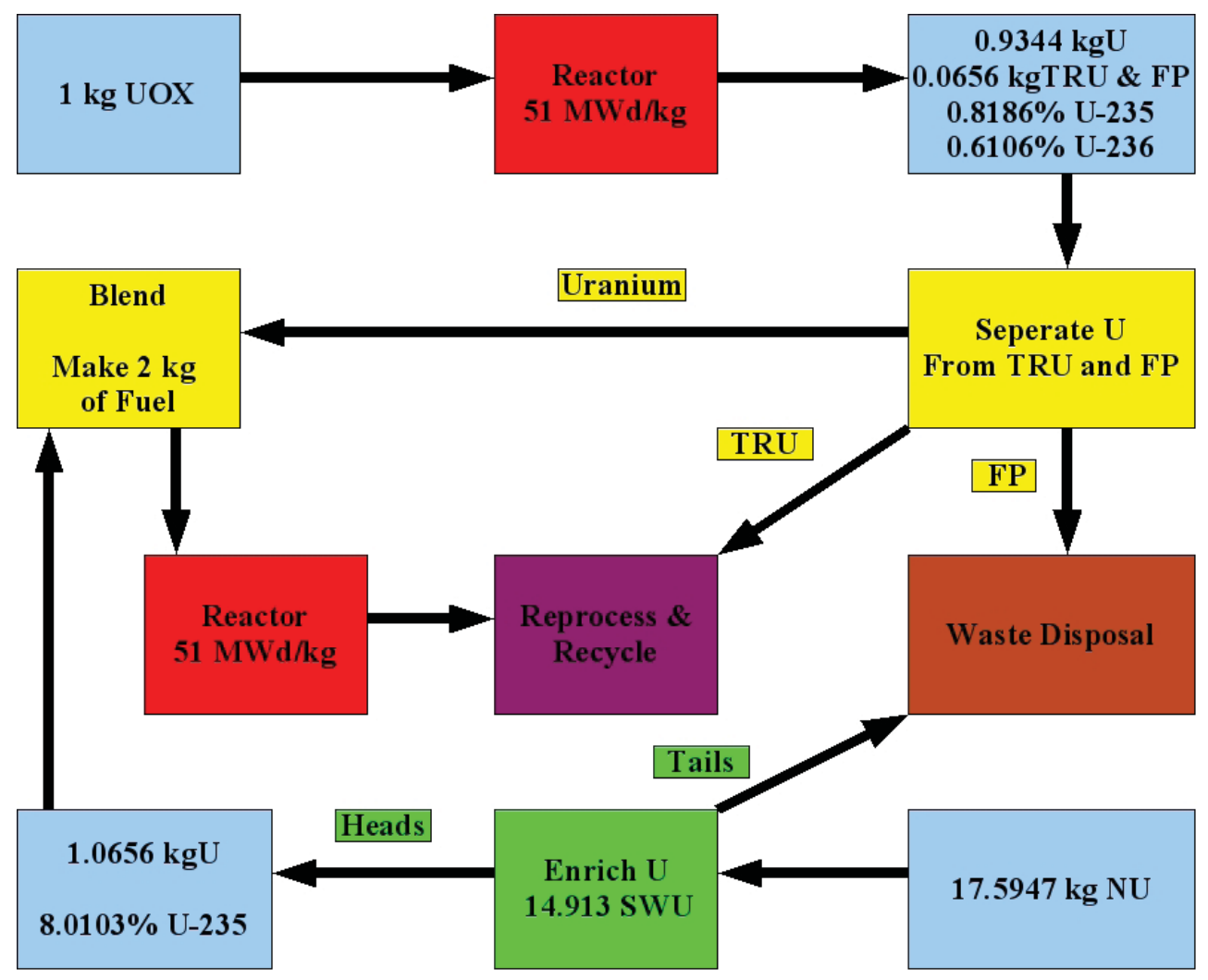

Figure 25. Material balance for Option 2: Blending of RU with LEU.

The material balances, presented in the above figures and tables, specify the fuel cycle mass flows, so that comparisons of the disposal, enrichment, and blending options may be carried out. Table 17 summarizes the unit costs, taken from the "AFC Cost Basis" report, used in this analysis (Shropshire 2007). Only the nominal or most likely values are used here.

Table 17. Unit costs taken from "Advanced Fuel Cycle Cost Basis" report modules.

\begin{tabular}{|c|c|c|c|c|c|}
\hline & LO & $\begin{array}{c}\text { Most } \\
\text { Likely }\end{array}$ & $\mathrm{HI}$ & UNIT & Module \\
\hline U Mining, Milling & 25 & $108^{\mathrm{a}}$ & 240 & $\$ / \mathrm{kgU}$ & A \\
\hline $\mathrm{U}_{3} \mathrm{O}_{8}$ to $\mathrm{UF}_{6}$ Conversion & 5 & 10 & 15 & $\$ / \mathrm{kgU}$ & $\mathrm{B}$ \\
\hline Enrichment & 80 & 105 & 130 & \$/SWU & $\mathrm{C} 1$ \\
\hline UOX Fabrication & 220 & 220 & 264 & $\$ / \mathrm{kgHM}$ & $\mathrm{D}$ \\
\hline UOX Fabrication from Reprocessed U & 290 & 290 & 350 & $\$ / \mathrm{kgHM}$ & D1-1 \\
\hline DU Disposal & 5 & 10 & 50 & $\$ / \mathrm{kgU}$ & K1 \\
\hline Reprocessed UNH to $\mathrm{UF}_{6}$ Conversion & 6 & 7 & 12 & $\$ / \mathrm{kgU}$ & $\mathrm{K} 2$ \\
\hline Reprocessed UNH to $\mathrm{U}_{3} \mathrm{O}_{8}$ Conversion & 4 & 5 & 10 & $\$ / \mathrm{kgU}$ & $\mathrm{K} 2$ \\
\hline Reprocessed UNH to $\mathrm{UO}_{2}$ Conversion & & 41 & & $\$ / \mathrm{kgU}$ & $\mathrm{K} 2$ \\
\hline $\mathrm{RU}_{3} \mathrm{O}_{8}$ Storage $(40 \mathrm{yr})$ & 6 & 12 & 30 & $\$ / \mathrm{kgU}$ & $\mathrm{K} 2$ \\
\hline $\mathrm{RU}_{3} \mathrm{O}_{8}$ Disposal & 61 & 72 & 93 & $\$ / \mathrm{kgU}$ & $\mathrm{K} 2$ \\
\hline
\end{tabular}


The cost calculation is a simple one, a summation of (Unit costs $\times$ mass flows) $/ \mathrm{kWh}(\mathrm{e})$, as detailed in Section 2.3.1. A thermal to electric conversion efficiency of $33 \%$ was assumed. Since most of the costs and revenues would be incurred within 2 years of one another, no discounting is employed for the most part. The exception is $\mathrm{RU}_{3} \mathrm{O}_{8}$ repository disposal, which follows 40 years of storage. This cost component was discounted at 5\% p.a. The results of the cost analysis are shown in Table 18.

Table 18. Fuel cycle cost components for direct disposal versus two scenarios involving RU.

\begin{tabular}{|c|c|c|c|}
\hline Units: mills/kWh(e) & DISPOSE & ENRICH & BLEND \\
\hline U Mining, Milling & 2.24 & 0 & 2.28 \\
\hline $\mathrm{U}_{3} \mathrm{O}_{8}$ to $\mathrm{UF}_{6}$ Conversion & 0.21 & 0 & 0.21 \\
\hline Enrichment & 1.61 & 2.05 & 1.77 \\
\hline UOX Fabrication & 0.53 & 0.70 & 0.70 \\
\hline DU Disposal & 0.18 & 0.20 & 0.20 \\
\hline Rep UNH to $\mathrm{UF}_{6}$ Conversion & 0 & 0.16 & 0 \\
\hline Rep UNH to $\mathrm{U}_{3} \mathrm{O}_{8}$ Conversion & 0.011 & 0 & 0 \\
\hline Rep UNH to $\mathrm{UO}_{2}$ Conversion & 0 & 0 & 0.05 \\
\hline $\mathrm{RU}_{3} \mathrm{O}_{8}$ Storage $(40 \mathrm{yr})$ & 0.027 & 0 & 0 \\
\hline $\mathrm{RU}_{3} \mathrm{O}_{8}$ Disposal & 0.023 & 0 & 0 \\
\hline Total & 4.82 & 3.10 & 5.20 \\
\hline
\end{tabular}

If one follows the unit costs given in the "AFC Cost Basis" report, it appears that RU enrichment is cost effective (Shropshire 2007). The simple reason for this is that a separated uranium stream is obtained from the UREX+ process at no extra cost. Therefore, since this uranium is only slightly less valuable from a neutronic standpoint than NU, it is advantageous to extract that value.

The blending option does not conserve the uranium resource or reduce $\mathrm{SWU} / \mathrm{kWh}(\mathrm{e})$, nor is it cheaper than simple disposal of RU, if one accepts the nominal values from the "AFC Cost Basis" report. However, if the "high" cost values for RU disposal given in the "AFC Cost Basis" report were chosen, this option would be advantageous as compared to disposal. The most noteworthy feature of this strategy is that it is the only sustainable pathway, short of breeding, to reducing the waste component of SF from about $0.9 \mathrm{~kg}$ per $\mathrm{kg}$ of used fuel to zero, so it may bear consideration. Nonetheless, RU disposal costs appear small when compared to fuel cycle costs, even if the pessimistic estimates are chosen.

\section{REFERENCES}

Arrow, K., "Discounting, Morality, and Gaming," Stanford University Working Paper 97004, 1996.

Bechtel Jacobs, Inc., (1998), "Functional System Design Document DOE UF 6 Cylinder Information Database (CID)," Technical Report, 1998.

Croff, A. G., "A User's Manual for the ORIGEN2 Computer Code," Oak Ridge National Laboratory Technical Report ORNL/TM-7175, 1980.

de la Garza, A, G. A. Garrett, and J. E. Murphy. "Multicomponent Isotope Separation in Cascades."

Chemical Engineering Science (England) 15, p. 188-209, 1961.

Diehl P., "Re-enrichment of West European depleted uranium tails in Russia," WISE Uranium Project, 2004.

Griffits, W. R., U.S. Geological Survey Professional Paper 820, 1973. 
Hertzler, T. J. and D. D. Nishimoto, "Depleted urnaium management alternatives," Idaho National Engineering and Environmental Laboratory, Idaho Falls, Idaho, EGG-MS-11416, 1994.

Michaels, G. and T. Welch, "Evaluation of Disposition Options for Reprocessed Uranium," Oak Ridge National Laboratory Report ORNL/TM-12326, 1993.

Nakicenovic, N. and A. Gruebler, "Global Energy Perspectives," Cambridge University Press, Cambridge, 1998.

Nuclear Fuel Cycle Monitor, "Investment Firm Predicts Peak in Uranium Prices in 2009," p. 8, June 18, 2007.

OECD Nuclear Energy Agency (OECD 2006), "Forty Years of Uranium Resources, Production and Demand in Perspective: 'The Red Book Retrospective'," NEA-06096, 2006.

OECD Nuclear Energy Agency (OECD/NEA), “Accelerator Driven Systems and Fast Reactors in Advanced Nuclear Fuel Cycles,” Technical Report NEA-3109/ADS, OECD Paris, 2002.

OECD Nuclear Energy Agency, "Burnup Credit Criticality Benchmark Phase IV-B: Results and Analysis of MOX Fuel Depletion Calculations," NEA Technical Report NEA/NSC/DOC(2003)4, OECD/NEA Paris, 2003.

OECD Nuclear Energy Agency, “The Economics of the Nuclear Fuel Cycle,” Technical Report, OECD Paris, 1994.

Schneider, E. A., Bathke, C. G. and M. R. James, "NFCSim: A Dynamic Fuel Burnup and Fuel Cycle Simulation Tool," Nuclear Technology 151, p. 35-50, 2005.

Schneider, E. A., Deinert, M. R., and A. Scopatz, "Depleted and Reprocessable Uranium in the United States: Inventories and Options," Proc. GLOBAL 2007, Boise, Idaho, September 2007.

Shropshire, D. E., et al., Advanced Fuel Cycle Cost Basis, INEEL/EXT-07-12107, July 2007.

Tolley, G. S., D. W. Jones. "The economic future of nuclear power," Technical Report, The University of Chicago, Chicago IL, 2004.

U.S. Department of Energy, "Generation-IV Roadmap: Report of the Fuel Cycle Crosscut Group," Technical Report, March 2002.

U.S. Energy Information Administration (EIA 2001), "Model Documentation of the Coal Market Module of the National Energy Modeling System," DOE/EIA-M060, 2001.

United States Department of Energy, "Proposed Long-Term Uranium Sales Strategy," DOE Offices of Nuclear Energy, Environmental Management, and Defense Nuclear Nonproliferation, http://www.ne.doe.gov/pdfFiles/proposedDoeLtUraniumSalesStrategyIndustryPresentationAug\%204t h2006.pdf, August 4, 2006, Web page accessed May 15, 2007.

United States Energy Information Administration, "Form RW-859-The Nuclear Fuel Data Survey," 2002 .

United States Geological Survey, http://minerals.usgs.gov/minerals/pubs, Web page accessed September 2007.

Uranium Information Centre Ltd (UIF), “Uranium Markets,” Nuclear Issues Briefing Paper 36, March 2007, http://www.uic.com.au/nip36.htm, Web page accessed May 15, 2007.

von Halle, E., "Multicomponent Isotope Separation in Matched Abundance Ratio Cascades Composed of Stages with Large Separation Factors," Proc. 1st Workshop on Separation Phenomena in Liquids and Gases, Darmstadt, Germany, July 20-27, 1987, p. 325.

Wood, Houston G., V. D. Borisevich, and G. A. Sulaberidze. "On a Criterion Efficiency for Multi-Isotope Mixtures Separation.” Separation Science and Technology, 34, p. 343-357, 1999. 


\section{Appendix A}

\section{Database}

E-57

INL/EXT-09-15483 
E-58

INL/EXT-09-15483 


\section{Appendix A}

\section{Database}

The following outlines the sources for each data series and, if relevant, the steps taken to prepare this series. A full listing of all collected data can be found at the conclusion of the section.

\section{Contract Prices (1972-2004)}

Thomas L. Neff, "Insights into the Future: Uranium Prices and Price Formation 1947-2004"

- Estimated from U.S. Average Delivered Price data line on Figure 6 of Neff, "U.S. Average Delivered and Euraton Multi-Annual Prices" (p.10)

- Kept constant 2004 value for later dates

- Not currently used in regression.

\section{Spot Prices (1972-2005)}

Trade Tech Uranium Monthly Spot, http://www.uranium.info/prices/monthly.html

- Must cite Web site when used

- January 1972-May 1972: monthly data

- June 1972-December 2005: 6 month average (month and previous five)

- Adjusted to constant January 2004 U.S.\$ using CPI conversion

- Quarterly data used in regression: 3-month averages.

\section{SWU Prices (1986-2005)}

Trade Tech Enrichment Spot, http://www.uranium.info/prices/enr_spot.html

- Must cite Web site when used

- January 1986-December 2005: monthly data

- Quarterly data used in regression: 3-month averages

- January 1972-December 1985. Same trend as electricity price

- $\quad$ Scaled using 10-year (1986-1996) average of SWU/electricity price ratio.

\section{Electricity Price (1972-2005)}

Energy Information Agency, http://www.eia.doe.gov/aer/txt/ptb0810.html

- Table 8.10 Average Retail Prices of Electricity, 1960-2005

Exploration Expenditures (1972-2005)

Red Books-Nuclear Energy Agency

- For years in which Red Books are not published (and for quarterly values), linear interpolation was used to determine value

- Not currently used in regression. 


\section{Demand Forecasts (1972-2005)}

Red Books-Nuclear Energy Agency

- When appropriate year was not reported, linear interpolation was used to determine value

- For years in which Red Books are not published (and for quarterly values), linear interpolation was used to determine value.

\section{Production Capacity (E\&C)}

(1972-2003)

Red Book Retrospective-Nuclear Energy Agency

(2004-2005)

2005 Red Book-Nuclear Energy Agency.

Production Capacity, Existing, Committed, Planned, and Prospective (ECP\&P) (1992-2005)

Red Books-Nuclear Energy Agency

- For years in which Red Books are not published (and for quarterly values), linear interpolation was used to determine value

- Currently not used in regression.

Production Capacity Forecast, Existing, and Committed (E\&C) (1977-2005)

Red Books-Nuclear Energy Agency

- When appropriate year was not reported, linear interpolation was used to determine value

- For years in which Red Books are not published (and for quarterly values), linear interpolation was used to determine value

- 1972-1977: constant - five year average from 1977-1982.

\section{Production Capacity Forecast (ECP\&P) (1983-2005)}

Red Books-Nuclear Energy Agency

- When appropriate year was not reported, linear interpolation was used to determine value

- For years in which Red Books are not published (and for quarterly values), linear interpolation was used to determine value

- Currently not used in regression.

\section{Reactor Requirements (1972-2005)}

Red Books-Nuclear Energy Agency

- For years in which Red Books are not published (and for quarterly values), linear interpolation was used to determine value.

Quantity Mined (1972-2005)

Red Books-Nuclear Energy Agency

- For years in which Red Books are not published, linear interpolation was used to determine value. 
Inventories (Utilities, Government, and Producers) (1975-2005)

Red Books-Nuclear Energy Agency

- Breakdown between each group was gathered from individual country reports

- List of countries reporting inventories for a given year and inventory policies for individual countries are detailed in the Red Book Retrospective

- For years in which Red Books are not published, linear interpolation was used to determine value

- Currently not used in regression.

HEU Deliveries (1995-2005)

USEC Megatons to Megawatts, http://www.usec.com/v2001_02/HTML/megatons Milestones.asp

Program Results: Yearly shipment data

- Currently not used in regression.

\section{Military Use (1972-2005)}

- Provided by Trade Tech from calculation based on data from DOE

- Adjusted from $10^{\wedge} 6 \mathrm{lbs}$ to $10^{\wedge} 3 \mathrm{lbs}$ (values unreasonable before adjustment).

\section{Productivity-Raw data}

(2001-2004)

Bureau of Labor Statistics

- Series ID: IPUBN2122_L000

- Sector: Mining

- Industry: Metal ore mining

(1972-2000)

Bureau of Labor Statistics

- Standard Industrial Classification (SIC) data

U.S. Census Bureau, http://www.census.gov/epcd/ec97sic/E97SUS.HTM. Used to translate to total mining industry from separate mineral mining.

Regression: $\mathrm{PROD}=\mathrm{K}^{*} \exp (\mathrm{b} 1 * \mathrm{~T})$ where $\mathrm{T}=$ dimensionless time

\begin{tabular}{lcccc}
\multicolumn{2}{c}{ Approx } & \multicolumn{2}{c}{ Approx } \\
Parameter & Estimate & Std Err & t Value & Pr $>t \mid$ \\
& & & \\
K & 0.404717 & 0.00992 & 40.79 & $<.0001$ \\
b1 & 1.697906 & 0.0318 & 53.36 & $<.0001$
\end{tabular}




\section{Electricity Generated}

(1972-2004)

Energy Balances of Non-OECD Countries-International Energy Agency (2005)

World Nuclear Association, http://www.world-nuclear.org/info/reactors.html

- World Nuclear Power Reactors 2005-2007 and Uranium Requirements.

\section{Burn-up (1972-2002)}

Energy Information Administration, http://www.eia.doe.gov/cneaf/nuclear/spent fuel/ussnftab3.html

- Table 3. Annual Spent Fuel Discharges and Burnup, 1968-2002

- 1972-2002: Weighted average between BWR (1/3) and PWR (2/3)

- 2002-2005: Linear trend from 1999-2002

\section{Average Enrichment-Raw data}

World Nuclear Association, "Uranium Markets," March 2007

- Graph from article

- Source: Uranium Institute 1992

- 1972-2005: Linear fit to raw data

Bureau of Labor Statistics (BLS) supplied individual SIC industries

- Iron ores-reported 1972-2000 (SIC 101)

- Copper ores-reported 1972-2000 (SIC 102)

- Lead and zinc ores - reported 1987-2000 (SIC 103)

- Gold ores-reported 1987-2000 (SIC 1041)

- Silver ores - reported 1987-2000 (SIC 1044).

The baseline year is 1987 , which means that it has a value of 1.0 no matter which data series is referenced.

1972-1986

- Used weighted average of Iron ores and Copper ores

Weights were determined using U.S. Census Bureau data

\begin{tabular}{|l|c|c|}
\hline \multicolumn{1}{|c|}{ Industry Title } & Weight & Raw Data \\
\hline Iron Ores & 0.325367677 & $1,937,749$ \\
\hline Copper Ores & 0.674632323 & $4,017,818$ \\
\hline
\end{tabular}

1987-2000

- Used weighted average of all industries 
Weights were determined using U.S. Census Bureau data

\begin{tabular}{|l|l|r|}
\hline \multicolumn{1}{|c|}{ Industry Title } & \multicolumn{1}{c|}{ Weight } & Raw Data \\
\hline Iron Ores & 0.1834955 & $1,937,749$ \\
\hline Copper Ores & 0.38046802 & $4,017,818$ \\
\hline Lead and Zinc Ores & 0.050317896 & 531,367 \\
\hline Gold Ores & 0.374211698 & $3,951,750$ \\
\hline Silver Ores & 0.011506885 & 121,515 \\
\hline
\end{tabular}

$2001-2004$

- Used BLS metal ore mining productivity data

- Divided the BLS data for a given year by the 1987 BLS data, so that it had a baseline value of 1.0 in 1987, and to piece the two sets together.

The numerical data described in the above listing is provided in Table A-1. 
Table A-1. Data series used in regression analysis-Part I.

\begin{tabular}{|c|c|c|c|c|c|c|c|c|c|}
\hline Year & Spot Price & $\begin{array}{c}\text { Contract } \\
\text { Delivery } \\
\text { Price } \\
\end{array}$ & SWU Price & $\begin{array}{l}\text { Demand } \\
\text { Forecast }\end{array}$ & $\begin{array}{l}\text { PCAP } \\
(\mathrm{E} \& C)\end{array}$ & $\begin{array}{l}\text { PCAPF } \\
(\text { E\&C) }\end{array}$ & $\begin{array}{c}\text { Reactor } \\
\text { Requirements }\end{array}$ & $\begin{array}{c}\text { Primary } \\
\text { Production }\end{array}$ & $\begin{array}{l}\text { Cumulative } \\
\text { Production }\end{array}$ \\
\hline & $\begin{array}{c}\text { Year } 2004 \\
\$ / \mathrm{kgU}\end{array}$ & $\begin{array}{c}\text { Year } 2004 \\
\$ / \mathrm{kgU}\end{array}$ & $\begin{array}{c}\text { Year } 2004 \\
\$ / \text { SWU }\end{array}$ & $\begin{array}{l}\mathrm{tU} \text { in Year } \\
+15\end{array}$ & $\mathrm{tU}$ & $\begin{array}{l}\mathrm{tU} \text { in Year } \\
+15\end{array}$ & $\mathrm{tU}$ & $\mathrm{tU}$ & $\mathrm{tU}$ \\
\hline 1972 & 69.42 & 67.59 & 88.12 & 125925.00 & 36437.00 & 93506.21 & 16245.00 & 20110.00 & 20110.00 \\
\hline 1972.25 & 68.83 & 66.62 & 86.58 & 128818.75 & 36420.75 & 93506.21 & 16612.75 & 20083.25 & 40193.25 \\
\hline 1972.5 & 68.21 & 65.64 & 86.35 & 131712.50 & 36404.50 & 93506.21 & 16980.50 & 20056.50 & 60249.75 \\
\hline 1972.75 & 67.68 & 64.67 & 87.11 & 134606.25 & 36388.25 & 93506.21 & 17348.25 & 20029.75 & 80279.50 \\
\hline 1973 & 68.10 & 63.70 & 88.56 & 137500.00 & 36372.00 & 93506.21 & 17716.00 & 20003.00 & 100282.50 \\
\hline 1973.25 & 69.31 & 64.02 & 90.45 & 139625.00 & 35372.50 & 93506.21 & 17911.75 & 19677.25 & 119959.75 \\
\hline 1973.5 & 70.03 & 64.35 & 92.60 & 141750.00 & 34373.00 & 93506.21 & 18107.50 & 19351.50 & 139311.25 \\
\hline 1973.75 & 73.08 & 64.67 & 94.83 & 143875.00 & 33373.50 & 93506.21 & 18303.25 & 19025.75 & 158337.00 \\
\hline 1974 & 81.60 & 65.00 & 97.03 & 146000.00 & 32374.00 & 93506.21 & 18499.00 & 18700.00 & 177037.00 \\
\hline 1974.25 & 96.74 & 68.24 & 99.10 & 148125.00 & 33299.00 & 93506.21 & 18860.25 & 18862.00 & 195899.00 \\
\hline 1974.5 & 116.12 & 71.49 & 100.97 & 150250.00 & 34224.00 & 93506.21 & 19221.50 & 19024.00 & 214923.00 \\
\hline 1974.75 & 134.69 & 74.74 & 102.60 & 152375.00 & 35149.00 & 93506.21 & 19582.75 & 19186.00 & 234109.00 \\
\hline 1975 & 158.82 & 77.99 & 103.96 & 154500.00 & 36074.00 & 93506.21 & 19944.00 & 19348.00 & 253457.00 \\
\hline 1975.25 & 191.40 & 87.09 & 105.06 & 154062.50 & 37690.50 & 93506.21 & 20742.25 & 20303.50 & 273760.50 \\
\hline 1975.5 & 228.36 & 96.19 & 105.89 & 153625.00 & 39307.00 & 93506.21 & 21540.50 & 21259.00 & 295019.50 \\
\hline 1975.75 & 271.61 & 105.29 & 106.48 & 153187.50 & 40923.50 & 93506.21 & 22338.75 & 22214.50 & 317234.00 \\
\hline 1976 & 315.26 & 114.39 & 106.86 & 152750.00 & 42540.00 & 93506.21 & 23137.00 & 23170.00 & 340404.00 \\
\hline 1976.25 & 336.17 & 118.94 & 107.06 & 152312.50 & 43250.00 & 93506.21 & 23665.50 & 24521.75 & 364925.75 \\
\hline 1976.5 & 340.48 & 123.49 & 107.13 & 151875.00 & 43960.00 & 93506.21 & 24194.00 & 25873.50 & 390799.25 \\
\hline 1976.75 & 340.52 & 128.04 & 107.10 & 151437.50 & 44670.00 & 93506.21 & 24722.50 & 27225.25 & 418024.50 \\
\hline 1977 & 338.10 & 132.59 & 107.02 & 151000.00 & 45380.00 & 116277.00 & 25251.00 & 28577.00 & 446601.50 \\
\hline 1977.25 & 335.10 & 133.24 & 106.92 & 146275.00 & 47690.25 & 116224.00 & 25717.50 & 29963.00 & 476564.50 \\
\hline 1977.5 & 334.02 & 133.89 & 106.85 & 141550.00 & 50000.50 & 116171.00 & 26184.00 & 31349.00 & 507913.50 \\
\hline 1977.75 & 333.01 & 134.54 & 106.85 & 136825.00 & 52310.75 & 116118.00 & 26650.50 & 32735.00 & 540648.50 \\
\hline 1978 & 329.87 & 135.19 & 106.94 & 132100.00 & 54621.00 & 116065.00 & 27117.00 & 34121.00 & 574769.50 \\
\hline 1978.25 & 323.11 & 135.51 & 107.14 & 127375.00 & 54055.50 & 116011.75 & 27663.00 & 35175.50 & 609945.00 \\
\hline 1978.5 & 315.40 & 135.84 & 107.49 & 122650.00 & 53490.00 & 115958.50 & 28209.00 & 36230.00 & 646175.00 \\
\hline 1978.75 & 308.45 & 136.16 & 107.98 & 117925.00 & 52924.50 & 115905.25 & 28755.00 & 37284.50 & 683459.50 \\
\hline 1979 & 300.80 & 136.49 & 108.62 & 113200.00 & 52359.00 & 115852.00 & 29301.00 & 38339.00 & 721798.50 \\
\hline 1979.25 & 290.17 & 139.09 & 109.41 & 109050.00 & 53752.50 & 109087.50 & 28986.75 & 39815.00 & 761613.50 \\
\hline 1979.5 & 277.13 & 141.69 & 110.33 & 104900.00 & 55146.00 & 102323.00 & 28672.50 & 41291.00 & 802904.50 \\
\hline 1979.75 & 258.60 & 144.29 & 111.38 & 100750.00 & 56539.50 & 95558.50 & 28358.25 & 42767.00 & 845671.50 \\
\hline 1980 & 226.57 & 146.89 & 112.52 & 96600.00 & 57933.00 & 88794.00 & 28044.00 & 44243.00 & 889914.50 \\
\hline 1980.25 & 194.70 & 151.44 & 113.73 & 92450.00 & 57876.50 & 82029.50 & 28483.00 & 44236.00 & 934150.50 \\
\hline 1980.5 & 172.41 & 155.99 & 114.97 & 88300.00 & 57820.00 & 75265.00 & 28922.00 & 44229.00 & 978379.50 \\
\hline 1980.75 & 154.63 & 160.54 & 116.20 & 84150.00 & 57763.50 & 68500.50 & 29361.00 & 44222.00 & 1022601.50 \\
\hline 1981 & 141.07 & 165.09 & 117.38 & 80000.00 & 57707.00 & 61736.00 & 29800.00 & 44215.00 & 1066816.50 \\
\hline 1981.25 & 131.02 & 168.66 & 118.46 & 78454.38 & 58637.50 & 60617.00 & 30318.00 & 43525.25 & 1110341.75 \\
\hline 1981.5 & 124.65 & 172.24 & 119.42 & 76908.75 & 59568.00 & 59498.00 & 30836.00 & 42835.50 & 1153177.25 \\
\hline 1981.75 & 120.04 & 175.81 & 120.19 & 75363.13 & 60498.50 & 58379.00 & 31354.00 & 42145.75 & 1195323.00 \\
\hline 1982 & 113.74 & 179.39 & 120.75 & 73817.50 & 61429.00 & 57260.00 & 31872.00 & 41456.00 & 1236779.00 \\
\hline 1982.25 & 101.36 & 175.49 & 121.06 & 72271.88 & 58190.25 & 56141.25 & 32581.75 & 40340.50 & 1277119.50 \\
\hline 1982.5 & 91.52 & 171.59 & 121.11 & 70726.25 & 54951.50 & 55022.50 & 33291.50 & 39225.00 & 1316344.50 \\
\hline 1982.75 & 95.12 & 167.69 & 120.88 & 69180.63 & 51712.75 & 53903.75 & 34001.25 & 38109.50 & 1354454.00 \\
\hline 1983 & 106.13 & 163.79 & 120.37 & 67635.00 & 48474.00 & 52785.00 & 34711.00 & 36994.00 & 1391448.00 \\
\hline 1983.25 & 112.59 & 156.64 & 119.60 & 66641.75 & 49374.00 & 51539.50 & 36600.25 & 37458.25 & 1428906.25 \\
\hline 1983.5 & 113.09 & 149.49 & 118.61 & 65648.50 & 50274.00 & 50294.00 & 38489.50 & 37922.50 & 1466828.75 \\
\hline 1983.75 & 104.59 & 142.34 & 117.47 & 64655.25 & 51174.00 & 49048.50 & 40378.75 & 38386.75 & 1505215.50 \\
\hline 1984 & 91.04 & 135.19 & 116.25 & 63662.00 & 52074.00 & 47803.00 & 42268.00 & 38851.00 & 1544066.50 \\
\hline 1984.25 & 82.17 & 133.56 & 115.08 & 62668.75 & 52408.00 & 46557.50 & 42436.50 & 38966.25 & 1583032.75 \\
\hline 1984.5 & 78.49 & 131.94 & 114.11 & 61675.50 & 52742.00 & 45312.00 & 42605.00 & 39081.50 & 1622114.25 \\
\hline
\end{tabular}


Table A-1 Part I. (continued).

\begin{tabular}{|c|c|c|c|c|c|c|c|c|c|}
\hline Year & Spot Price & $\begin{array}{c}\text { Contract } \\
\text { Delivery } \\
\text { Price }\end{array}$ & SWU Price & $\begin{array}{l}\text { Demand } \\
\text { Forecast }\end{array}$ & $\begin{array}{l}\text { PCAP } \\
(\mathrm{E} \& C)\end{array}$ & $\begin{array}{l}\text { PCAPF } \\
(\mathrm{E} \& \mathrm{C})\end{array}$ & $\begin{array}{c}\text { Reactor } \\
\text { Requirements }\end{array}$ & $\begin{array}{c}\text { Primary } \\
\text { Production }\end{array}$ & $\begin{array}{l}\text { Cumulative } \\
\text { Production }\end{array}$ \\
\hline & $\begin{array}{c}\text { Year } 2004 \\
\$ / \mathrm{kgU}\end{array}$ & $\begin{array}{c}\text { Year } 2004 \\
\$ / k g U\end{array}$ & $\begin{array}{l}\text { Year } 2004 \\
\$ / S W U\end{array}$ & $\begin{array}{l}\text { tU in Year } \\
\quad+15\end{array}$ & $\mathrm{tU}$ & $\begin{array}{l}\mathrm{tU} \text { in Year } \\
\quad+15\end{array}$ & $\mathrm{tU}$ & $\mathrm{tU}$ & $\mathrm{tU}$ \\
\hline 1984.75 & 73.04 & 130.31 & 113.53 & 60682.25 & 53076.00 & 44066.50 & 42773.50 & 39196.75 & 1661311.00 \\
\hline 1985 & 68.18 & 128.69 & 113.57 & 59689.00 & 53410.00 & 42821.00 & 42942.00 & 39312.00 & 1700623.00 \\
\hline 1985.25 & 68.05 & 126.42 & 114.51 & 58670.20 & 53952.25 & 41160.25 & 43356.25 & 39835.75 & 1740458.75 \\
\hline 1985.5 & 70.51 & 124.14 & 116.69 & 57651.40 & 54494.50 & 39499.50 & 43770.50 & 40359.50 & 1780818.25 \\
\hline 1985.75 & 73.45 & 121.87 & 120.49 & 56632.60 & 55036.75 & 37838.75 & 44184.75 & 40883.25 & 1821701.50 \\
\hline 1986 & 75.14 & 119.59 & 135.64 & 55613.80 & 55579.00 & 36178.00 & 44599.00 & 41407.00 & 1863108.50 \\
\hline 1986.25 & 75.26 & 115.69 & 131.97 & 54595.00 & 55377.75 & 34517.25 & 45152.50 & 41237.00 & 1904345.50 \\
\hline 1986.5 & 74.46 & 111.79 & 131.56 & 53576.20 & 55176.50 & 32856.50 & 45706.00 & 41067.00 & 1945412.50 \\
\hline 1986.75 & 73.40 & 107.89 & 133.08 & 52557.40 & 54975.25 & 31195.75 & 46259.50 & 40897.00 & 1986309.50 \\
\hline 1987 & 70.77 & 103.99 & 131.07 & 51538.60 & 54774.00 & 29535.00 & 46813.00 & 40727.00 & 2027036.50 \\
\hline 1987.25 & 69.42 & 102.04 & 113.23 & 51462.53 & 54535.50 & 30220.00 & 47586.25 & 40718.50 & 2067755.00 \\
\hline 1987.5 & 68.42 & 100.09 & 120.34 & 51386.45 & 54297.00 & 30905.00 & 48359.50 & 40710.00 & 2108465.00 \\
\hline 1987.75 & 65.51 & 98.14 & 104.99 & 51310.38 & 54058.50 & 31590.00 & 49132.75 & 40701.50 & 2149166.50 \\
\hline 1988 & 61.30 & 96.19 & 103.75 & 51234.30 & 53820.00 & 32275.00 & 49906.00 & 40693.00 & 2189859.50 \\
\hline 1988.25 & 59.90 & 90.02 & 107.15 & 51158.23 & 53695.00 & 32960.00 & 50512.25 & 39969.00 & 2229828.50 \\
\hline 1988.5 & 57.06 & 83.84 & 102.64 & 51082.15 & 53570.00 & 33645.00 & 51118.50 & 39245.00 & 2269073.50 \\
\hline 1988.75 & 50.40 & 77.67 & 100.04 & 51006.08 & 53445.00 & 34330.00 & 51724.75 & 38521.00 & 2307594.50 \\
\hline 1989 & 44.02 & 71.49 & 100.97 & 50930.00 & 53320.00 & 35015.00 & 52331.00 & 37797.00 & 2345391.50 \\
\hline 1989.25 & 39.74 & 57.85 & 99.34 & 51316.62 & 51993.75 & 34471.75 & 51735.75 & 36407.00 & 2381798.50 \\
\hline 1989.5 & 37.16 & 62.40 & 97.11 & 51703.24 & 50667.50 & 33928.50 & 51140.50 & 35017.00 & 2416815.50 \\
\hline 1989.75 & 35.21 & 57.85 & 95.64 & 52089.85 & 49341.25 & 33385.25 & 50545.25 & 33627.00 & 2450442.50 \\
\hline 1990 & 34.16 & 53.30 & 74.26 & 52476.47 & 48015.00 & 32842.00 & 49950.00 & 32237.00 & 2482679.50 \\
\hline 1990.25 & 37.08 & 51.02 & 71.60 & 52527.89 & 48367.50 & 32298.75 & 51317.50 & 31151.25 & 2513830.75 \\
\hline 1990.5 & 37.70 & 48.75 & 70.39 & 52579.31 & 48720.00 & 31755.50 & 52685.00 & 30065.50 & 2543896.25 \\
\hline 1990.75 & 35.07 & 46.47 & 70.64 & 52630.73 & 49072.50 & 31212.25 & 54052.50 & 28979.75 & 2572876.00 \\
\hline 1991 & 33.28 & 44.20 & 70.07 & 52682.14 & 49425.00 & 30669.00 & 55420.00 & 27894.00 & 2600770.00 \\
\hline 1991.25 & 32.05 & 43.87 & 75.11 & 53584.85 & 50244.25 & 30125.50 & 55883.00 & 29929.25 & 2630699.25 \\
\hline 1991.5 & 29.71 & 43.55 & 90.34 & 54487.55 & 51063.50 & 29582.00 & 56346.00 & 31964.50 & 2662663.75 \\
\hline 1991.75 & 28.20 & 43.22 & 92.35 & 55390.26 & 51882.75 & 29038.50 & 56809.00 & 33999.75 & 2696663.50 \\
\hline 1992 & 27.50 & 42.90 & 93.50 & 56292.96 & 52702.00 & 28495.00 & 57272.00 & 36035.00 & 2732698.50 \\
\hline 1992.25 & 27.12 & 41.92 & 86.99 & 60412.27 & 52197.75 & 28076.75 & 57585.75 & 35335.50 & 2768034.00 \\
\hline 1992.5 & 27.30 & 40.95 & 87.63 & 64531.58 & 51693.50 & 27658.50 & 57899.50 & 34636.00 & 2802670.00 \\
\hline 1992.75 & 26.97 & 39.97 & 88.75 & 68650.89 & 51189.25 & 27240.25 & 58213.25 & 33936.50 & 2836606.50 \\
\hline 1993 & 25.32 & 39.00 & 85.85 & 72770.20 & 50685.00 & 26822.00 & 58527.00 & 33237.00 & 2869843.50 \\
\hline 1993.25 & 23.91 & 37.05 & 85.62 & 72661.55 & 51032.50 & 25946.00 & 58147.50 & 32830.50 & 2902674.00 \\
\hline 1993.5 & 23.09 & 35.10 & 86.99 & 72552.90 & 51380.00 & 25070.00 & 57768.00 & 32424.00 & 2935098.00 \\
\hline 1993.75 & 22.94 & 33.15 & 86.40 & 72444.25 & 51727.50 & 24194.00 & 57388.50 & 32017.50 & 2967115.50 \\
\hline 1994 & 22.95 & 31.20 & 85.43 & 72335.60 & 52075.00 & 23318.00 & 57009.00 & 31611.00 & 2998726.50 \\
\hline 1994.25 & 22.94 & 31.52 & 84.05 & 72226.95 & 51543.75 & 22442.00 & 58101.00 & 31496.75 & 3030223.25 \\
\hline 1994.5 & 22.87 & 31.85 & 83.32 & 72118.30 & 51012.50 & 21566.00 & 59193.00 & 31382.50 & 3061605.75 \\
\hline 1994.75 & 22.95 & 32.17 & 84.99 & 72009.65 & 50481.25 & 20690.00 & 60285.00 & 31268.25 & 3092874.00 \\
\hline 1995 & 23.35 & 32.50 & 92.47 & 71901.00 & 49950.00 & 19814.00 & 61377.00 & 31154.00 & 3124028.00 \\
\hline 1995.25 & 24.91 & 36.77 & 95.32 & 72102.29 & 50153.75 & 21417.75 & 61154.75 & 32402.75 & 3156430.75 \\
\hline 1995.5 & 27.94 & 41.05 & 102.57 & 72303.58 & 50357.50 & 23021.50 & 60932.50 & 33651.50 & 3190082.25 \\
\hline 1995.75 & 32.20 & 45.33 & 107.31 & 72504.86 & 50561.25 & 24625.25 & 60710.25 & 34900.25 & 3224982.50 \\
\hline 1996 & 38.09 & 39.00 & 107.54 & 72706.15 & 50765.00 & 26229.00 & 60488.00 & 36149.00 & 3261131.50 \\
\hline 1996.25 & 44.16 & 38.35 & 111.21 & 72907.44 & 50741.25 & 27832.50 & 61305.25 & 36292.75 & 3297424.25 \\
\hline 1996.5 & 45.83 & 37.70 & 110.23 & 73108.73 & 50717.50 & 29436.00 & 62122.50 & 36436.50 & 3333860.75 \\
\hline 1996.75 & 42.99 & 37.05 & 108.67 & 73310.01 & 50693.75 & 31039.50 & 62939.75 & 36580.25 & 3370441.00 \\
\hline 1997 & 37.80 & 36.40 & 104.46 & 73511.30 & 50670.00 & 32643.00 & 63757.00 & 36724.00 & 3407165.00 \\
\hline 1997.25 & 32.36 & 35.75 & 104.04 & 72625.64 & 51217.50 & 32807.00 & 62705.50 & 36264.50 & 3443429.50 \\
\hline 1997.5 & 29.01 & 35.10 & 101.33 & 71739.98 & 51765.00 & 32971.00 & 61654.00 & 35805.00 & 3479234.50 \\
\hline
\end{tabular}


Table A-1 Part I. (continued).

\begin{tabular}{|c|c|c|c|c|c|c|c|c|c|}
\hline Year & Spot Price & $\begin{array}{c}\text { Contract } \\
\text { Delivery } \\
\text { Price }\end{array}$ & SWU Price & $\begin{array}{l}\text { Demand } \\
\text { Forecast }\end{array}$ & $\begin{array}{l}\text { PCAP } \\
(\mathrm{E} \& C)\end{array}$ & $\begin{array}{r}\text { PCAPF } \\
(\mathrm{E \& C})\end{array}$ & $\begin{array}{c}\text { Reactor } \\
\text { Requirements }\end{array}$ & $\begin{array}{c}\text { Primary } \\
\text { Production }\end{array}$ & $\begin{array}{l}\text { Cumulative } \\
\text { Production }\end{array}$ \\
\hline & $\begin{array}{c}\text { Year } 2004 \\
\$ / k g U\end{array}$ & $\begin{array}{c}\text { Year } 2004 \\
\$ / \mathrm{kgU} \\
\end{array}$ & $\begin{array}{c}\text { Year } 2004 \\
\text { \$/SWU }\end{array}$ & $\begin{array}{l}\mathrm{tU} \text { in Year } \\
\quad+15 \\
\end{array}$ & $\mathrm{tU}$ & $\begin{array}{l}\mathrm{tU} \text { in Year } \\
\quad+15 \\
\end{array}$ & $\mathrm{tU}$ & $\mathrm{tU}$ & $\mathrm{tU}$ \\
\hline 1997.75 & 28.31 & 34.45 & 98.64 & 70854.31 & 52312.50 & 33135.00 & 60602.50 & 35345.50 & 3514580.00 \\
\hline 1998 & 28.01 & 33.80 & 95.33 & 69968.65 & 52860.00 & 33299.00 & 59551.00 & 34886.00 & 3549466.00 \\
\hline 1998.25 & 27.30 & 33.47 & 94.06 & 69082.99 & 53566.25 & 33462.75 & 60060.50 & 34209.25 & 3583675.25 \\
\hline 1998.5 & 26.54 & 33.15 & 95.21 & 68197.33 & 54272.50 & 33626.50 & 60570.00 & 33532.50 & 3617207.75 \\
\hline 1998.75 & 25.78 & 32.82 & 94.88 & 67311.66 & 54978.75 & 33790.25 & 61079.50 & 32855.75 & 3650063.50 \\
\hline 1999 & 25.02 & 32.50 & 94.51 & 66426.00 & 55685.00 & 33954.00 & 61589.00 & 32179.00 & 3682242.50 \\
\hline 1999.25 & 24.37 & 32.17 & 92.86 & 66379.79 & 54487.50 & 34997.75 & 62195.25 & 33137.00 & 3715379.50 \\
\hline 1999.5 & 23.37 & 31.85 & 90.45 & 66333.58 & 53290.00 & 36041.50 & 62801.50 & 34095.00 & 3749474.50 \\
\hline 1999.75 & 22.27 & 31.52 & 86.95 & 66287.36 & 52092.50 & 37085.25 & 63407.75 & 35053.00 & 3784527.50 \\
\hline 2000 & 20.94 & 31.20 & 86.10 & 66241.15 & 50895.00 & 38129.00 & 64014.00 & 36011.00 & 3820538.50 \\
\hline 2000.25 & 19.86 & 29.90 & 85.20 & 66194.94 & 51636.75 & 39172.50 & 64092.75 & 36263.25 & 3856801.75 \\
\hline 2000.5 & 18.89 & 28.60 & 84.52 & 66148.73 & 52378.50 & 40216.00 & 64171.50 & 36515.50 & 3893317.25 \\
\hline 2000.75 & 18.26 & 27.30 & 84.07 & 66102.51 & 53120.25 & 41259.50 & 64250.25 & 36767.75 & 3930085.00 \\
\hline 2001 & 18.67 & 26.00 & 83.97 & 66056.30 & 53862.00 & 42303.00 & 64329.00 & 37020.00 & 3967105.00 \\
\hline 2001.25 & 20.53 & 26.00 & 88.67 & 67810.83 & 54007.50 & 42396.00 & 64950.50 & 36775.50 & 4003880.50 \\
\hline 2001.5 & 23.35 & 26.00 & 88.55 & 69565.35 & 54153.00 & 42489.00 & 65572.00 & 36531.00 & 4040411.50 \\
\hline 2001.75 & 25.69 & 26.00 & 88.80 & 71319.88 & 54298.50 & 42582.00 & 66193.50 & 36286.50 & 4076698.00 \\
\hline 2002 & 26.32 & 26.00 & 90.22 & 73074.40 & 54444.00 & 42675.00 & 66815.00 & 36042.00 & 4112740.00 \\
\hline 2002.25 & 26.43 & 28.82 & 92.69 & 74828.93 & 53318.00 & 42768.25 & 67220.00 & 35904.50 & 4148644.50 \\
\hline 2002.5 & 26.33 & 31.65 & 92.29 & 76583.45 & 52192.00 & 42861.50 & 67625.00 & 35767.00 & 4184411.50 \\
\hline 2002.75 & 26.44 & 34.47 & 92.00 & 78337.98 & 51066.00 & 42954.75 & 68030.00 & 35629.50 & 4220041.00 \\
\hline 2003 & 27.21 & 37.30 & 91.08 & 80092.50 & 49940.00 & 43048.00 & 68435.00 & 35492.00 & 4255533.00 \\
\hline 2003.25 & 28.37 & 34.47 & 91.42 & 80020.63 & 49430.00 & 45751.25 & 65976.25 & 36684.75 & 4292217.75 \\
\hline 2003.5 & 31.06 & 31.65 & 88.30 & 79948.75 & 48920.00 & 48454.50 & 63517.50 & 37877.50 & 4330095.25 \\
\hline 2003.75 & 36.07 & 28.82 & 88.29 & 79876.88 & 48410.00 & 51157.75 & 61058.75 & 39070.25 & 4369165.50 \\
\hline 2004 & 41.90 & 26.00 & 87.50 & 79805.00 & 47900.00 & 53861.00 & 58600.00 & 40263.00 & 4409428.50 \\
\hline 2004.25 & 46.21 & 26.00 & 86.28 & 79733.13 & 48145.00 & 56564.50 & 58053.75 & 40509.75 & 4449938.25 \\
\hline 2004.5 & 49.07 & 26.00 & 85.96 & 79661.25 & 48390.00 & 59268.00 & 57507.50 & 40756.50 & 4490694.75 \\
\hline 2004.75 & 51.92 & 26.00 & 85.45 & 79589.38 & 48635.00 & 61971.50 & 56961.25 & 41003.25 & 4531698.00 \\
\hline 2005 & 57.69 & 26.00 & 84.92 & 79517.50 & 48880.00 & 64675.00 & 56415.00 & 41250.00 & 4572948.00 \\
\hline 2005.25 & 77.41 & & 84.43 & & & & 58943.50 & 40346.00 & 4613294.00 \\
\hline 2005.5 & 86.50 & & 84.67 & & & & 61472.00 & 39442.00 & 4652736.00 \\
\hline 2005.75 & 96.98 & & 84.24 & & & & 64000.50 & 38538.00 & 4691274.00 \\
\hline 2006 & 112.73 & & 93.08 & & & & 66529.00 & 37634.00 & 4728908.00 \\
\hline 2006.25 & & & 97.34 & & & & & & \\
\hline 2006.5 & & & 103.78 & & & & & & \\
\hline 2006.75 & & & 113.24 & & & & & & \\
\hline
\end{tabular}


Table A-1. Data series used in regression-Part II.

\begin{tabular}{|c|c|c|c|c|c|c|c|c|}
\hline Year & $\begin{array}{c}\text { Military } \\
\text { Consumption }\end{array}$ & $\begin{array}{l}\text { Electricity } \\
\text { Price }\end{array}$ & Productivity & $\begin{array}{l}\text { Inventory of } \\
\text { Secondary } \\
\text { Supply }\end{array}$ & $\begin{array}{l}\text { HEU } \\
\text { Supply }\end{array}$ & $\mathrm{BU}$ & xavg & $\begin{array}{c}\text { Soviet } \\
\text { Bloc Flag }\end{array}$ \\
\hline & $\mathrm{tU}$ & $\begin{array}{l}\text { Year } 2004 \\
\text { cents / } \\
\text { kWh(e) }\end{array}$ & See Text & $\begin{array}{c}\text { tNU } \\
\text { Equivalent }\end{array}$ & $\begin{array}{c}\text { tNU } \\
\text { Equivalent }\end{array}$ & $\begin{array}{c}\mathrm{MWd}(\mathrm{t}) / \\
\mathrm{kgIHM}\end{array}$ & $\begin{array}{c}\% \text { U- } \\
235 \\
\end{array}$ & - \\
\hline 1972 & 15475.61 & 0.08 & 0.41 & & & 17.10 & 2.65 & 1 \\
\hline 1972.25 & 15582.26 & 0.08 & 0.41 & & & 17.96 & 2.66 & 1 \\
\hline 1972.5 & 15688.90 & 0.08 & 0.42 & & & 18.82 & 2.67 & 1 \\
\hline 1972.75 & 15795.54 & 0.08 & 0.43 & & & 19.68 & 2.68 & 1 \\
\hline 1973 & 15902.18 & 0.08 & 0.43 & & & 20.53 & 2.69 & 1 \\
\hline 1973.25 & 15903.29 & 0.09 & 0.44 & & & 19.56 & 2.70 & 1 \\
\hline 1973.5 & 15904.40 & 0.09 & 0.44 & & & 18.58 & 2.71 & 1 \\
\hline 1973.75 & 15905.50 & 0.09 & 0.45 & & & 17.61 & 2.72 & 1 \\
\hline 1974 & 15906.61 & 0.09 & 0.45 & & & 16.63 & 2.73 & 1 \\
\hline 1974.25 & 16004.98 & 0.10 & 0.46 & & & 16.93 & 2.74 & 1 \\
\hline 1974.5 & 16103.35 & 0.10 & 0.46 & & & 17.23 & 2.75 & 1 \\
\hline 1974.75 & 16201.73 & 0.10 & 0.47 & & & 17.53 & 2.76 & 1 \\
\hline 1975 & 16300.10 & 0.10 & 0.48 & 82795.00 & & 17.83 & 2.77 & 1 \\
\hline 1975.25 & 16417.03 & 0.10 & 0.48 & 85278.63 & & 18.24 & 2.77 & 1 \\
\hline 1975.5 & 16533.96 & 0.10 & 0.49 & 87762.25 & & 18.65 & 2.78 & 1 \\
\hline 1975.75 & 16650.90 & 0.10 & 0.49 & 90245.88 & & 19.06 & 2.79 & 1 \\
\hline 1976 & 16767.83 & 0.10 & 0.50 & 92729.50 & & 19.47 & 2.80 & 1 \\
\hline 1976.25 & 16646.63 & 0.10 & 0.51 & 95213.13 & & 20.22 & 2.81 & 1 \\
\hline 1976.5 & 16525.43 & 0.10 & 0.51 & 97696.75 & & 20.97 & 2.82 & 1 \\
\hline 1976.75 & 16404.22 & 0.10 & 0.52 & 100180.38 & & 21.72 & 2.83 & 1 \\
\hline 1977 & 16283.02 & 0.10 & 0.53 & 102664.00 & & 22.47 & 2.84 & 1 \\
\hline 1977.25 & 16416.59 & 0.10 & 0.53 & 103258.20 & & 22.90 & 2.85 & 1 \\
\hline 1977.5 & 16550.16 & 0.10 & 0.54 & 103852.40 & & 23.33 & 2.86 & 1 \\
\hline 1977.75 & 16683.73 & 0.10 & 0.54 & 104446.60 & & 23.77 & 2.87 & 1 \\
\hline 1978 & 16817.29 & 0.11 & 0.55 & 105040.80 & & 24.20 & 2.88 & 1 \\
\hline 1978.25 & 16432.38 & 0.10 & 0.56 & 105635.00 & & 24.56 & 2.89 & 1 \\
\hline 1978.5 & 16047.47 & 0.10 & 0.57 & 106229.20 & & 24.92 & 2.89 & 1 \\
\hline 1978.75 & 15662.55 & 0.10 & 0.57 & 106823.40 & & 25.28 & 2.90 & 1 \\
\hline 1979 & 15277.64 & 0.10 & 0.58 & 107417.60 & & 25.63 & 2.91 & 1 \\
\hline 1979.25 & 14840.34 & 0.10 & 0.59 & 119408.03 & & 26.07 & 2.92 & 1 \\
\hline 1979.5 & 14403.05 & 0.10 & 0.59 & 131398.45 & & 26.50 & 2.93 & 1 \\
\hline 1979.75 & 13965.76 & 0.10 & 0.60 & 143388.88 & & 26.93 & 2.94 & 1 \\
\hline 1980 & 13528.46 & 0.11 & 0.61 & 155379.30 & & 27.37 & 2.95 & 1 \\
\hline 1980.25 & 13409.30 & 0.11 & 0.62 & 167369.73 & & 27.58 & 2.96 & 1 \\
\hline 1980.5 & 13290.14 & 0.11 & 0.62 & 179360.15 & & 27.78 & 2.97 & 1 \\
\hline 1980.75 & 13170.97 & 0.11 & 0.63 & 191350.58 & & 27.99 & 2.98 & 1 \\
\hline 1981 & 13051.81 & 0.11 & 0.64 & 203341.00 & & 28.20 & 2.99 & 1 \\
\hline 1981.25 & 13084.15 & 0.11 & 0.65 & 196044.75 & & 28.21 & 3.00 & 1 \\
\hline 1981.5 & 13116.49 & 0.11 & 0.66 & 188748.50 & & 28.22 & 3.01 & 1 \\
\hline 1981.75 & 13148.83 & 0.12 & 0.66 & 181452.25 & & 28.23 & 3.01 & 1 \\
\hline 1982 & 13181.17 & 0.12 & 0.67 & 174156.00 & & 28.23 & 3.02 & 1 \\
\hline
\end{tabular}


Table A-1 Part II. (continued).

\begin{tabular}{|c|c|c|c|c|c|c|c|c|}
\hline Year & $\begin{array}{c}\text { Military } \\
\text { Consumption }\end{array}$ & $\begin{array}{l}\text { Electricity } \\
\text { Price }\end{array}$ & Productivity & $\begin{array}{c}\text { Inventory of } \\
\text { Secondary } \\
\text { Supply }\end{array}$ & $\begin{array}{l}\text { HEU } \\
\text { Supply }\end{array}$ & $\mathrm{BU}$ & xavg & $\begin{array}{c}\text { Soviet } \\
\text { Bloc Flag }\end{array}$ \\
\hline & $\mathrm{tU}$ & $\begin{array}{l}\text { Year } 2004 \\
\text { cents / } \\
\mathrm{kWh}(\mathrm{e})\end{array}$ & See Text & $\begin{array}{c}\text { tNU } \\
\text { Equivalent }\end{array}$ & $\begin{array}{c}\text { tNU } \\
\text { Equivalent }\end{array}$ & $\begin{array}{c}\mathrm{MWd}(\mathrm{t}) / \\
\mathrm{kgIHM}\end{array}$ & $\begin{array}{c}\% \text { U- } \\
235\end{array}$ & - \\
\hline 1982.25 & 12958.30 & 0.12 & 0.68 & 166859.75 & & 28.47 & 3.03 & 1 \\
\hline 1982.5 & 12735.44 & 0.12 & 0.69 & 159563.50 & & 28.70 & 3.04 & 1 \\
\hline 1982.75 & 12512.58 & 0.12 & 0.70 & 152267.25 & & 28.93 & 3.05 & 1 \\
\hline 1983 & 12289.71 & 0.12 & 0.71 & 144971.00 & & 29.17 & 3.06 & 1 \\
\hline 1983.25 & 11969.31 & 0.12 & 0.72 & 145960.50 & & 28.95 & 3.07 & 1 \\
\hline 1983.5 & 11648.90 & 0.11 & 0.72 & 146950.00 & & 28.73 & 3.08 & 1 \\
\hline 1983.75 & 11328.49 & 0.11 & 0.73 & 147939.50 & & 28.52 & 3.09 & 1 \\
\hline 1984 & 11008.08 & 0.11 & 0.74 & 148929.00 & & 28.30 & 3.10 & 1 \\
\hline 1984.25 & 10488.17 & 0.11 & 0.75 & 149918.50 & & 28.53 & 3.11 & 1 \\
\hline 1984.5 & 9968.27 & 0.11 & 0.76 & 150908.00 & & 28.75 & 3.12 & 1 \\
\hline 1984.75 & 9448.36 & 0.11 & 0.77 & 151897.50 & & 28.98 & 3.13 & 1 \\
\hline 1985 & 8928.46 & 0.11 & 0.78 & 152887.00 & & 29.20 & 3.13 & 1 \\
\hline 1985.25 & 8377.56 & 0.11 & 0.79 & 151090.38 & & 28.80 & 3.14 & 1 \\
\hline 1985.5 & 7826.66 & 0.11 & 0.80 & 149293.75 & & 28.40 & 3.15 & 1 \\
\hline 1985.75 & 7275.76 & 0.11 & 0.81 & 147497.13 & & 28.00 & 3.16 & 1 \\
\hline 1986 & 6724.86 & 0.11 & 0.82 & 145700.50 & & 27.60 & 3.17 & 1 \\
\hline 1986.25 & 6316.78 & 0.11 & 0.83 & 143903.88 & & 27.85 & 3.18 & 1 \\
\hline 1986.5 & 5908.70 & 0.10 & 0.84 & 142107.25 & & 28.10 & 3.19 & 1 \\
\hline 1986.75 & 5500.63 & 0.10 & 0.85 & 140310.63 & & 28.35 & 3.20 & 1 \\
\hline 1987 & 5092.55 & 0.10 & 0.86 & 138514.00 & & 28.60 & 3.21 & 1 \\
\hline 1987.25 & 4062.91 & 0.10 & 0.87 & 135882.88 & & 29.12 & 3.22 & 1 \\
\hline 1987.5 & 3033.27 & 0.10 & 0.88 & 133251.75 & & 29.63 & 3.23 & 1 \\
\hline 1987.75 & 2003.63 & 0.10 & 0.89 & 130620.63 & & 30.15 & 3.24 & 1 \\
\hline 1988 & 974.00 & 0.10 & 0.91 & 127989.50 & & 30.67 & 3.25 & 1 \\
\hline 1988.25 & 864.35 & 0.10 & 0.92 & 125358.38 & & 30.33 & 3.26 & 1 \\
\hline 1988.5 & 754.71 & 0.10 & 0.93 & 122727.25 & & 30.00 & 3.26 & 1 \\
\hline 1988.75 & 645.07 & 0.10 & 0.94 & 120096.13 & & 29.67 & 3.27 & 1 \\
\hline 1989 & 535.43 & 0.10 & 0.95 & 117465.00 & & 29.33 & 3.28 & 1 \\
\hline 1989.25 & 535.43 & 0.10 & 0.96 & 115192.66 & & 29.87 & 3.29 & 1 \\
\hline 1989.5 & 535.43 & 0.09 & 0.98 & 112920.31 & & 30.40 & 3.30 & 1 \\
\hline 1989.75 & 535.43 & 0.09 & 0.99 & 110647.97 & & 30.93 & 3.31 & 1 \\
\hline 1990 & 535.43 & 0.09 & 1.00 & 108375.63 & & 31.47 & 3.32 & 1 \\
\hline 1990.25 & 535.43 & 0.09 & 1.01 & 106103.28 & & 31.87 & 3.33 & 1 \\
\hline 1990.5 & 535.43 & 0.09 & 1.03 & 103830.94 & & 32.27 & 3.34 & 1 \\
\hline 1990.75 & 535.43 & 0.09 & 1.04 & 101558.59 & & 32.67 & 3.35 & 1 \\
\hline 1991 & 535.43 & 0.09 & 1.05 & 99286.25 & & 33.07 & 3.36 & 1 \\
\hline 1991.25 & 535.43 & 0.09 & 1.06 & 97013.91 & & 33.37 & 3.37 & 1 \\
\hline 1991.5 & 535.43 & 0.09 & 1.08 & 94741.56 & & 33.67 & 3.38 & 1 \\
\hline 1991.75 & 535.43 & 0.09 & 1.09 & 92469.22 & & 33.97 & 3.38 & 1 \\
\hline 1992 & 535.43 & 0.09 & 1.10 & 90196.88 & & 34.27 & 3.39 & 0.95 \\
\hline 1992.25 & 535.43 & 0.09 & 1.12 & 87924.53 & & 34.78 & 3.40 & 0.90 \\
\hline 1992.5 & 535.43 & 0.09 & 1.13 & 85652.19 & & 35.30 & 3.41 & 0.86 \\
\hline
\end{tabular}


Table A-1 Part II. (continued).

\begin{tabular}{|c|c|c|c|c|c|c|c|c|}
\hline Year & $\begin{array}{c}\text { Military } \\
\text { Consumption }\end{array}$ & $\begin{array}{l}\text { Electricity } \\
\text { Price }\end{array}$ & Productivity & $\begin{array}{c}\text { Inventory of } \\
\text { Secondary } \\
\text { Supply }\end{array}$ & $\begin{array}{c}\text { HEU } \\
\text { Supply }\end{array}$ & $\mathrm{BU}$ & xavg & $\begin{array}{c}\text { Soviet } \\
\text { Bloc Flag }\end{array}$ \\
\hline & $\mathrm{tU}$ & $\begin{array}{c}\text { Year } 2004 \\
\text { cents / } \\
\mathrm{kWh}(\mathrm{e})\end{array}$ & See Text & $\begin{array}{c}\text { tNU } \\
\text { Equivalent }\end{array}$ & $\begin{array}{c}\text { tNU } \\
\text { Equivalent }\end{array}$ & $\begin{array}{c}\operatorname{MWd}(\mathrm{t}) / \\
\operatorname{kgIHM}\end{array}$ & $\begin{array}{c}\% \text { U- } \\
235\end{array}$ & - \\
\hline 1992.75 & 535.43 & 0.09 & 1.15 & 83379.84 & & 35.82 & 3.42 & 0.81 \\
\hline 1993 & 535.43 & 0.09 & 1.16 & 81107.50 & & 36.33 & 3.43 & 0.76 \\
\hline 1993.25 & 535.43 & 0.09 & 1.18 & 81065.69 & & 36.75 & 3.44 & 0.71 \\
\hline 1993.5 & 535.43 & 0.09 & 1.19 & 81023.88 & & 37.17 & 3.45 & 0.67 \\
\hline 1993.75 & 535.43 & 0.09 & 1.20 & 80982.06 & & 37.58 & 3.46 & 0.62 \\
\hline 1994 & 535.43 & 0.09 & 1.22 & 80940.25 & & 38.00 & 3.47 & 0.57 \\
\hline 1994.25 & 535.43 & 0.09 & 1.23 & 80898.44 & & 38.08 & 3.48 & 0.52 \\
\hline 1994.5 & 535.43 & 0.09 & 1.25 & 80856.63 & & 38.15 & 3.49 & 0.48 \\
\hline 1994.75 & 535.43 & 0.08 & 1.27 & 80814.81 & 1152.68 & 38.23 & 3.50 & 0.43 \\
\hline 1995 & 535.43 & 0.08 & 1.28 & 80773.00 & 1439.30 & 38.30 & 3.51 & 0.38 \\
\hline 1995.25 & 535.43 & 0.08 & 1.30 & 81417.38 & 1725.92 & 38.19 & 3.51 & 0.33 \\
\hline 1995.5 & 535.43 & 0.08 & 1.31 & 82061.75 & 2012.54 & 38.08 & 3.52 & 0.29 \\
\hline 1995.75 & 535.43 & 0.08 & 1.33 & 82706.13 & 2299.15 & 37.98 & 3.53 & 0.24 \\
\hline 1996 & 535.43 & 0.08 & 1.35 & 83350.50 & 2468.03 & 37.87 & 3.54 & 0.19 \\
\hline 1996.25 & 535.43 & 0.08 & 1.36 & 83994.88 & 2636.90 & 38.10 & 3.55 & 0.14 \\
\hline 1996.5 & 535.43 & 0.08 & 1.38 & 84639.25 & 2805.77 & 38.33 & 3.56 & 0.10 \\
\hline 1996.75 & 535.43 & 0.08 & 1.40 & 85283.63 & 2974.65 & 38.57 & 3.57 & 0.05 \\
\hline 1997 & 535.43 & 0.08 & 1.42 & 85928.00 & 2928.17 & 38.80 & 3.58 & 0 \\
\hline 1997.25 & 535.43 & 0.08 & 1.43 & 83442.25 & 2881.69 & 39.47 & 3.59 & 0 \\
\hline 1997.5 & 535.43 & 0.08 & 1.45 & 80956.50 & 2835.21 & 40.13 & 3.60 & 0 \\
\hline 1997.75 & 535.43 & 0.08 & 1.47 & 78470.75 & 2788.73 & 40.80 & 3.61 & 0 \\
\hline 1998 & 535.43 & 0.08 & 1.49 & 75985.00 & 3058.31 & 41.47 & 3.62 & 0 \\
\hline 1998.25 & 535.43 & 0.08 & 1.51 & 73499.25 & 3327.89 & 41.43 & 3.63 & 0 \\
\hline 1998.5 & 535.43 & 0.08 & 1.52 & 71013.50 & 3597.46 & 41.40 & 3.63 & 0 \\
\hline 1998.75 & 535.43 & 0.07 & 1.54 & 68527.75 & 3867.04 & 41.37 & 3.64 & 0 \\
\hline 1999 & 535.43 & 0.07 & 1.56 & 66042.00 & 4229.58 & 41.33 & 3.65 & 0 \\
\hline 1999.25 & 535.43 & 0.07 & 1.58 & 66441.35 & 4592.11 & 41.65 & 3.66 & 0 \\
\hline 1999.5 & 535.43 & 0.07 & 1.60 & 66840.70 & 4954.65 & 41.97 & 3.67 & 0 \\
\hline 1999.75 & 535.43 & 0.07 & 1.62 & 67240.05 & 5317.18 & 42.28 & 3.68 & 0 \\
\hline 2000 & 535.43 & 0.07 & 1.64 & 67639.40 & 5388.45 & 42.60 & 3.69 & 0 \\
\hline 2000.25 & 535.43 & 0.07 & 1.66 & 68038.75 & 5459.72 & 42.74 & 3.70 & 0 \\
\hline 2000.5 & 535.43 & 0.07 & 1.68 & 68438.10 & 5530.99 & 42.88 & 3.71 & 0 \\
\hline 2000.75 & 535.43 & 0.08 & 1.70 & 68837.45 & 5602.25 & 43.03 & 3.72 & 0 \\
\hline 2001 & 535.43 & 0.08 & 1.73 & 69236.80 & 5563.52 & 43.17 & 3.73 & 0 \\
\hline 2001.25 & 535.43 & 0.08 & 1.75 & 68766.81 & 5524.79 & 43.33 & 3.74 & 0 \\
\hline 2001.5 & 535.43 & 0.08 & 1.77 & 68296.83 & 5486.06 & 43.48 & 3.75 & 0 \\
\hline 2001.75 & 535.43 & 0.07 & 1.79 & 67826.84 & 5447.32 & 43.64 & 3.75 & 0 \\
\hline 2002 & 535.43 & 0.07 & 1.81 & 67356.85 & 5489.15 & 43.80 & 3.76 & 0 \\
\hline 2002.25 & 535.43 & 0.07 & 1.84 & 66886.86 & 5530.99 & 44.15 & 3.77 & 0 \\
\hline 2002.5 & 535.43 & 0.07 & 1.86 & 66416.88 & 5572.82 & 44.34 & 3.78 & 0 \\
\hline 2002.75 & 535.43 & 0.07 & 1.88 & 65946.89 & 5614.65 & 44.54 & 3.79 & 0 \\
\hline 2003 & 535.43 & 0.07 & 1.91 & 65476.90 & 5591.41 & 44.73 & 3.80 & 0 \\
\hline
\end{tabular}


Table A-1 Part II. (continued).

\begin{tabular}{|c|c|c|c|c|c|c|c|c|}
\hline Year & $\begin{array}{c}\text { Military } \\
\text { Consumption }\end{array}$ & $\begin{array}{l}\text { Electricity } \\
\text { Price }\end{array}$ & Productivity & $\begin{array}{c}\text { Inventory of } \\
\text { Secondary } \\
\text { Supply }\end{array}$ & $\begin{array}{c}\text { HEU } \\
\text { Supply }\end{array}$ & BU & xavg & $\begin{array}{c}\text { Soviet } \\
\text { Bloc Flag }\end{array}$ \\
\hline & $\mathrm{tU}$ & $\begin{array}{c}\text { Year } 2004 \\
\text { cents / } \\
\mathrm{kWh}(\mathrm{e})\end{array}$ & See Text & $\begin{array}{c}\text { tNU } \\
\text { Equivalent }\end{array}$ & $\begin{array}{c}\text { tNU } \\
\text { Equivalent }\end{array}$ & $\begin{array}{c}\mathrm{MWd}(\mathrm{t}) / \\
\mathrm{kgIHM}\end{array}$ & $\begin{array}{c}\% \text { U- } \\
235\end{array}$ & - \\
\hline 2003.25 & 535.43 & 0.07 & 1.93 & 65262.53 & 5568.17 & 44.93 & 3.81 & 0 \\
\hline 2003.5 & 535.43 & 0.07 & 1.95 & 65048.15 & 5544.93 & 45.12 & 3.82 & 0 \\
\hline 2003.75 & 535.43 & 0.07 & 1.98 & 64833.78 & 5521.69 & 45.31 & 3.83 & 0 \\
\hline 2004 & 535.43 & 0.07 & 2.00 & 64619.40 & 5451.97 & 45.51 & 3.84 & 0 \\
\hline 2004.25 & 535.43 & 0.08 & 2.03 & 64405.03 & 5382.25 & 45.70 & 3.85 & 0 \\
\hline 2004.5 & 535.43 & 0.08 & 2.05 & 64190.65 & 5312.54 & 45.90 & 3.86 & 0 \\
\hline 2004.75 & 535.43 & 0.08 & 2.08 & 63976.28 & 5242.82 & 46.09 & 3.87 & 0 \\
\hline 2005 & 535.43 & 0.08 & 2.10 & 63761.90 & 5280.00 & 46.29 & 3.88 & 0 \\
\hline 2005.25 & 535.43 & & 2.13 & & 5317.18 & & 3.88 & \\
\hline 2005.5 & 535.43 & & 2.16 & & 5354.37 & & 3.89 & \\
\hline 2005.75 & 535.43 & & 2.18 & & 5391.55 & & 3.90 & \\
\hline 2006 & 535.43 & & 2.21 & & & & 3.91 & \\
\hline \multicolumn{9}{|l|}{2006.25} \\
\hline \multicolumn{9}{|l|}{2006.5} \\
\hline 2006.75 & & & & & & & & \\
\hline
\end{tabular}




\title{
Attachment F
}

\section{Cost and Market Structure Economics of the International Nuclear Fuel Cycle}

\author{
Geoffrey Rothwell \\ Department of Economics \\ Stanford University, Stanford, California \\ Contract No. 00058512 \\ with Battelle Energy Alliance, LLC \\ Idaho Falls, Idaho
}


F-2

INL/EXT-09-15483 


\section{PREFACE}

The primary work for this attachment was completed in 2007. Since then, there have been some additions and expansions to the activities in this attachment. This information can be found in the following references.

Rothwell, Geoffrey, "International Nuclear Fuel Fabrication Supply: Are Fabrication Services Assured?," Energy Economics, 2009.

Rothwell, Geoffrey, "Monopoly Power in Uranium Enrichment," Science \& Global Security, 2009.

Rothwell, Geoffrey, "Forecasting Nuclear Fuel Reprocessing Costs: Why have they been increasing 4.5\% per year for 40 years?," Global 2009 The Nuclear Fuel Cycle, Paris, France (September 2009). 
F-4

INL/EXT-09-15483 


\begin{abstract}
This attachment describes a methodology for evaluating the economics of nuclear fuel cycle sector industries. This methodology identifies the cost structure - allowing construction of industry supply curves - and a determination of profitability. It also provides a foundation for understanding the economic incentives facing firms in fuel-cycle and non-fuel-cycle states. The primary focus is on modeling levelized average cost as a function of the size of a fuel cycle facility. The resulting cost structure allows calculation of the economies of scale, which depend on (1) whether there are economies of scale in input usage, (2) the relative importance of fixed to variable costs, and (3) whether capacity is being added to an existing site or a new site. The methodology is applied to two sectors: uranium enrichment and Light Water Reactor (LWR) fuel fabrication, including low-enriched uranium (LEU) and mixed uranium-plutonium oxide (MOX). Due to high startup costs, average costs are continuously declining in the uranium enrichment and the MOX LWR fuel fabrication industries. Due to technological change, the price of enrichment services could drop dramatically, leading to lower investment in new capacity. Therefore, it might be optimal to limit the number of producers in these sectors, introduce rate regulation, and reduce access to these technologies. On the other hand, LWR LEU fuel fabrication appears to exhibit few economies of scale for incumbent producers. The industry continues to be profitable. The current market structure of the LEU industry is competitive and new entrants will find it difficult to compete, but market intervention is unlikely to be necessary to insure sufficient capacity.
\end{abstract}


F-6

INL/EXT-09-15483 


\section{ACKNOWLEDGEMENTS}

This paper was written with partial funding from Standard Research Subcontract No. 00058512 with Battelle Energy Alliance, LLC, Idaho Falls, Idaho, through the Stanford Institute for Economic Research (SIEPR), and with partial funding from Department of Energy, U.S. DOE 03ID14448. Thanks to J.-P. Bariteau, E. Bertel, C. Braun, M. Crozat, D. Korn, B. Rasin, E. Schneider, D. Shropshire, R. Versluis, K. Williams, and members of the Advanced Fuel Cycle Initiative (AFCI) and the Economic Modeling Working Group (EMWG) of the Generation IV International Forum (GIF) for their encouragement, references, data, and comments. This paper reflects the views and conclusions of the author and not those of the employers, sponsors, publishers, SIEPR, AFCI, EMWG, GIF, or U.S. DOE. 
F-8

INL/EXT-09-15483 


\section{CONTENTS}

PREFACE

ABSTRACT F-5

ACKNOWLEDGEMENTS

ACRONYMS

F-11

1. COST STRUCTURE AND MARKET ANALYSIS OF SECTORS OF THE NUCLEAR FUEL CYCLE

2. ECONOMICS OF THE NUCLEAR FUEL CYCLE: COST AND MARKET STRUCTURE.

3. COST AND MARKET STRUCTURE OF THE URANIUM ENRICHMENT INDUSTRY ......F-17

4. COST AND MARKET STRUCTURE OF LIGHT WATER REACTOR LEU FUEL FABRICATION

5. COST AND MARKET STRUCTURE OF LIGHT WATER REACTOR MOX FUEL FABRICATION F-26

6. SUMMARY AND FUTURE RESEARCH …........................................................................

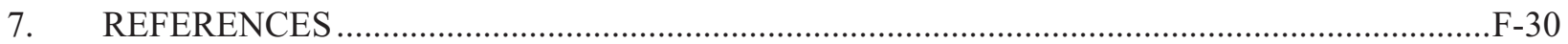

\section{FIGURES}

Figure 1. Closed fuel cycle management system.............................................................................

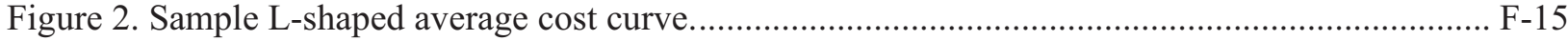

Figure 3. Estimated capital cost for centrifuge enrichment technology ……...................................... F-18

Figure 4. Estimated investment cost, centrifuge technology. …......................................................... F-19

Figure 5. Supply of uranium enrichment services, 2005 .............................................................. F-21

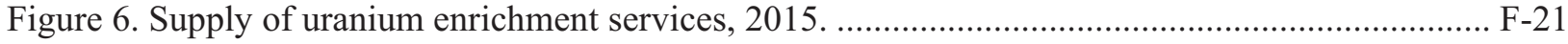

Figure 7. Number of employees as a function of size in MTU/year............................................... F-23

Figure 8. New entrants and incumbents fuel fabrication cost curves............................................ F-25

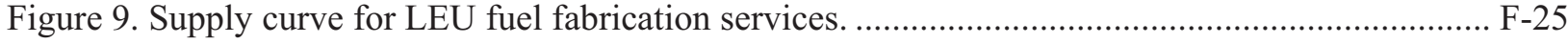

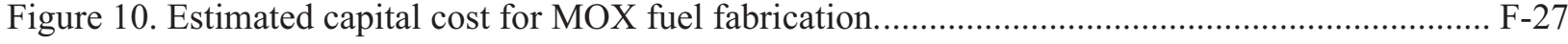

Figure 11. New entrants and incumbents estimated fuel fabrication cost curves. ............................... F-29

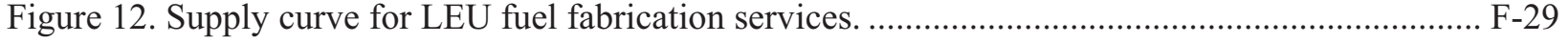




\section{TABLES}

Table 1. Estimation of scale economies for enrichment capital........................................................ F-18

Table 2. Estimation of scale economies for fuel fabrication labor. ..................................................... F-23

Table 3. Estimation of scale economies for capital in MOX fuel fabrication....................................... F-27 


\section{ACRONYMS}

AC average cost

ACP American Centrifuge Plant

AFCI Advanced Fuel Cycle Initiative

AVC average variable cost

BWR Boiling Water Reactor

D\&D decommissioned and decontaminated

DOE Department of Energy

EMWG Economic Modeling Working Group

FC fixed cost

GIF Generation IV International Forum

LES Louisiana Enrichment Services

LEU low-enriched uranium

LWR Light Water Reactor

MC marginal cost

MES Minimum Efficient Scale

MOX mixed uranium-plutonium oxide

MTHM Metric Tons of Heavy Metal

MTU metric tonnes of uranium

OLS ordinary least squares

PWR Pressurized Water Reactor

SIEPR Stanford Institute for Economic Research

SMP Sellafield MOX Plant

SRS Savannah River Site

SWU Separative Work Units

TC total annual cost

TCIC total capital investment cost

TR total annual revenue

USEC U.S. Enrichment Corporation

VC variable costs 
F-12

INL/EXT-09-15483 


\section{Cost and Market Structure Economics of the International Nuclear Fuel Cycle}

\section{COST STRUCTURE AND MARKET ANALYSIS OF SECTORS OF THE NUCLEAR FUEL CYCLE}

This paper provides a cost structure and market analysis methodology for modeling each sector of the nuclear fuel cycle: uranium mining and milling, uranium enrichment, fuel fabrication, light water reactor (LWR) spent nuclear fuel separation, transmutation fuel separation, and transmutation fuel fabrication. The methodology is a microeconomics extension of G4-ECONS developed through the Economic Modeling Working Group of the Generation IV International Forum (see EMWG 2005). The paper applies the methodology to uranium enrichment and LWR fuel fabrication (low-enriched uranium [LEU] and mixed uranium-plutonium oxide [MOX] fuels).

Figure 1 describes a closed nuclear fuel cycle. This methodology was developed with cost information from the left-hand-side of Figure 1 (not including uranium mining and milling, see Schneider and Rankin 2007). Future research will apply the methodology to the middle columns of Figure 1. Section 2 develops a general economics model applicable to any industrial sector of the nuclear fuel cycle. Section 3 applies the methodology to uranium enrichment. Sections 4 and 5 apply the methodology to LEU fuel fabrication and to LWR MOX fuel fabrication. Section 6 summarizes the methodology.

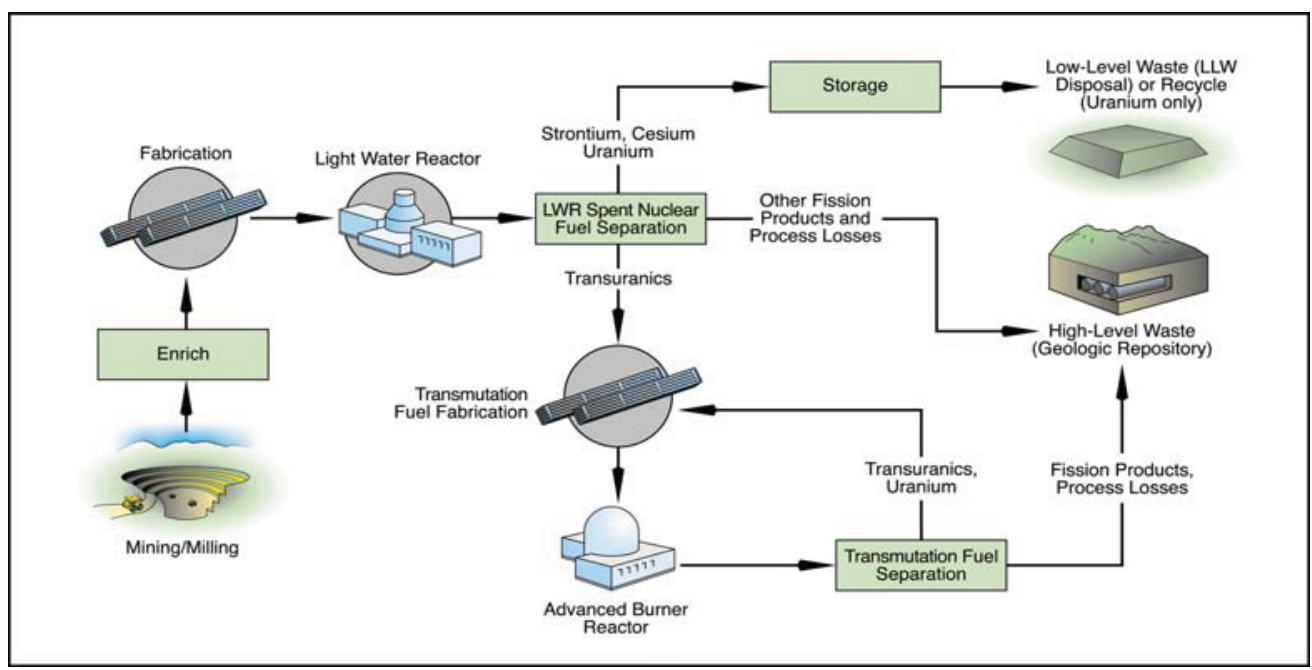

Figure 1. Closed fuel cycle management system.

\section{ECONOMICS OF THE NUCLEAR FUEL CYCLE: COST AND MARKET STRUCTURE}

Each sector of the nuclear fuel cycle can be characterized by the production function:

$Q=\mathrm{f}(K, L, E, M)$,

where

$Q=$ measured in annual (metric) tons of product or units of service (e.g., Separative Work Units [SWU]) 
$K=$ total capital investment cost (TCIC, defined in EMWG 2005) measured in millions, M, of 2005 dollars

$L=$ number of employees at the facility

$E=$ energy required to produce $Q$

$M=$ other materials that might be used in the process (e.g., fuel fabrication hardware or chemicals).

The total annual cost, $T C$, of producing $Q$ is:

$T C=p_{K} K+p_{L} L+p_{E} E+p_{M} M$,

where

$$
\begin{aligned}
p_{K}= & \begin{array}{l}
\text { capital recovery factor (plus other charges associated with the size of the investment [the cost } \\
\text { of decommissioning, equipment replacement, etc.]) }
\end{array} \\
p_{L}= & \text { annual salary (and burden) of an average employee in } 2005 \text { dollars } \\
p_{E}= & \text { the price of energy (e.g., } 2005 \text { dollars per megawatt-hour [MWh]) } \\
p_{M}= & \text { price of materials. }
\end{aligned}
$$

The total annual revenue, $T R$, is equal to the market price of the product or service, $p_{Q}$, times $Q$. Total economic profit is $T R$ minus $T C$, or:

PROFIT $=p_{Q} Q-\left(p_{K} K+p_{L} L+p_{E} E+p_{M} M\right)$

(Economic profit is the residual after payments to debt and a risk-adjusted rate of return on equity; accounting profit is the residual after payments to debt [Rothwell and Gomez, 2003, p. 25]) The discounted total system life-cycle cost, TSLCC, of producing total quantity, $\Sigma Q_{t}$, is:

$T S L C C=\sum\left(p_{K \mathrm{t}} K_{\mathrm{t}}+p_{L \mathrm{t}} L_{\mathrm{t}}+p_{E \mathrm{t}} E_{\mathrm{t}}+p_{M \mathrm{t}} M_{\mathrm{t}}\right)(1+r)^{-\mathrm{t}}$,

where the summation is over the commercial life of the facility, all construction costs are discounted to the year of commercial operation, and $r$ is the discount rate.

The Levelized Unit Cost, or Long-Run Average Cost, $A C$, is:

$A C=T S L C C /\left[\Sigma Q_{t}(1+r)^{-t}\right]$

If $T C$ and $Q$ do not change over time, Equation (5) reduces to $A C=T C / Q$.

To determine the economic incentives of adding capacity to an existing facility or constructing a new facility, one needs to know the relationship between $A C$ and $Q$, as well as the capital-at-risk, $K$. Implicitly, many levelized cost estimates assume a constant relationship between $A C$ and $Q$. However, with high fixed costs (costs that are sunk with the development of the facility and cannot be recovered through the sale of assets), $A C$ is likely to decline with $Q$ until some constraint (such as a health and safety limit) causes the average cost to increase.

The textbook $A C$ curve has a $\mathrm{U}$-shape and is derived from a quadratic (or higher order) total cost curve (this is a reduced form, not a cost function or summation, as above):

$T C=\mathrm{a}_{0}+\mathrm{a}_{1} Q+\mathrm{a}_{2} Q^{2}$ 
$A C=(T C / Q)$ marginal cost $(M C)=(\mathrm{d} T C / \mathrm{d} Q)$

$A C=\left(\mathrm{a}_{0} / Q\right)+\mathrm{a}_{1}+\mathrm{a}_{2} Q$

$M C=\mathrm{a}_{1}+2 \mathrm{a}_{2} Q$

Further, in Equation (6) $\mathrm{a}_{0}$ represents fixed cost ( $F C$, costs that do not vary with output) and $\left(\mathrm{a}_{1} Q+\mathrm{a}_{2} Q^{2}\right)$ represents variable costs $(V C$, costs that vary with output $)$. Also, average fixed costs is $\left(\mathrm{a}_{0} /\right.$ $Q)$ and average variable cost $(A V C)$ is $\left(\mathrm{a}_{1}+\mathrm{a}_{2} Q\right)$.

With simulated cost data for different sized facilities, the implicit relationship between $A C$ and size can be identified. If parameter $\mathrm{a}_{2}$ is insignificant, the forecasting equation reduces to a reciprocal model where $\left(\mathrm{a}_{0} / Q\right)$ (= average fixed costs) declines to zero as size increases, and $\mathrm{a}_{1}$ is the expected asymptotic cost. The graph of this equation is not U-shaped, but L-shaped.

According to Intriligator (1978, p. 282), "For a wide variety of industries, including manufacturing, mining, distribution, transportation, and trade, it has been found that the long-run average cost curves are L-shaped, rather than U-shaped." Figure 2 shows this. Further, "average cost at first falls sharply (based, in part, on spreading fixed costs over more output) but then reaches, or asymptotically approaches, a certain minimum level $A C_{0}$ at a critical level of output," $Q_{0}$, and remains flat at this level; the critical level of output $Q_{0}$ is the Minimum Efficient Scale (MES). Also, Intriligator (1978, p. 283) stated, "Local economies of scale hold if and only if the average cost curve is decreasing, while increasing average cost is equivalent to local diseconomies of scale." In Figure 2, there are economies of scale up to $Q_{0}$, and constant returns to scale beyond $Q_{0}$. (On scale economies, see Rothwell and Gomez, 2003, p. 37-40.)

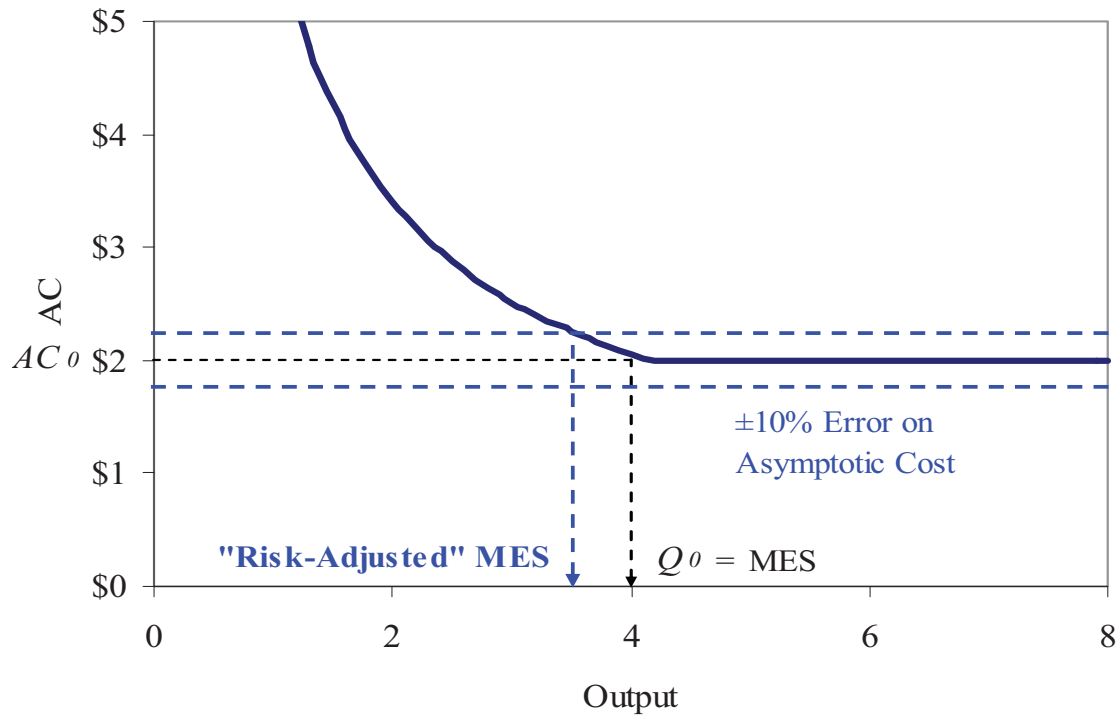

Figure 2. Sample L-shaped average cost curve.

While it is easy to see a "kink" in the average cost curve in Figure 2, the $A C$ curve is more likely to be estimated as a reciprocal equation with a slower approach to the asymptote than in the figure (see Figure 4). Further, because these are cost estimates, there is a probability distribution associated with them that arises from modeling and measurement error. Therefore, let MES be that size where the minimum estimated cost is statistically indistinguishable from the asymptotic cost. If the standard error of the cost estimate is equal to the contingency rate (Rothwell 2005), then let the MES occur where cost is 
within $10 \%$ of the estimated asymptotic cost (i.e., where $A C$ intersects the dashed upper error band in Figure 2).

In addition to spreading fixed costs over more output, economies of scale also arise from declines in the use of inputs as the size of the facility increases. Although there could be economics of scale in energy and materials, these are usually negligible in the nuclear fuel cycle. More important are the economies of scale in capital and labor; positive economies of scale imply a less than proportional increase in the use of an input (e.g., a 10\% increase in plant size could require less than a 10\% increase in either capital or labor or both). Economies of scale are measured as the elasticity of capital or labor with respect to size: $(\mathrm{d} \ln K / \mathrm{d} \ln Q)$ and $(\mathrm{d} \ln L / \mathrm{d} \ln Q)$.

To understand the underlying economies of scale, three relationships can be estimated: (1) Total Capital Investment Cost, $K$, as a function of facility size, $K=f_{K}(Q) ;(2)$ the number of employees, $L$, as a function of facility size, $L=f_{L}(Q)$; and (3) the average cost, $A C$, as a function of facility size, $A C=f_{A C}(Q)$. The production function becomes:

$Q=\mathrm{f}(K(Q), L(Q), E, M)$.

This emphasizes the simultaneous nature of the determination of the size of the facility and the level of inputs in the production function. To test whether there are positive economies of scale in capital or labor, the following equations can be estimated:

$\ln K=\mathrm{b}_{01}+\mathrm{b}_{1} \ln Q$ and

$\ln L=\mathrm{b}_{02}+\mathrm{b}_{2} \ln Q$.

If $b_{i}$ is not significantly different than 1 , there are constant returns to scale. If $b_{i}$ is significantly less than 1 , there are positive economies of scale. This would be the case if, as often assumed from the relationship between volume and surface area, $b_{i}=0.67$. This would imply that a $10 \%$ increase in size would require only a $6.7 \%$ increase in capital investment. Unfortunately, data is not always available on both capital and labor inputs for each industry. When one set of data is unavailable, this analysis assumes $b_{1}=b_{2}$ (i.e., there is a single "economy of scale" for the production system).

If constant returns to scale are found (i.e., $b_{1}$ and/or $b_{2}=1$ ), then Equations (10) and (11) reduce to $K=\exp \left(\mathrm{b}_{01}\right) Q$ and $L=\exp \left(\mathrm{b}_{02}\right) Q$. For forecasting purposes, these are estimated as linear forms:

$K=\mathrm{c}_{01}+\mathrm{c}_{1} Q$

$L=\mathrm{c}_{02}+\mathrm{c}_{2} Q$

where $\mathrm{c}_{01}$ and $\mathrm{c}_{02}$ are not expected to be significantly different from zero. If $\mathrm{c}_{01}=\mathrm{c}_{02}=0$, then these equations reduce to $K=\mathrm{c}_{1} Q$ and $L=\mathrm{c}_{2} Q$, or $\mathrm{c}_{1}=K / Q$ and $\mathrm{c}_{2}=L / Q$, where $\mathrm{c}_{1}$ and $\mathrm{c}_{2}$ can be interpreted as the "technical coefficients" in a fixed-proportions production function. On estimating these technical coefficients, Intriligator (1978, p. 273) points out, "The estimation is typically based on a single observation, so regression techniques are not used." Here, with three or more observations, ordinary least squares (OLS) will be used to estimate $c_{1}$ and $c_{2}$.

Finally, average costs for plants of different sizes are calculated using Equations (10) or (12) for capital, Equations (11) or (13) for labor, and constants for energy and materials levels and prices. These values enter Equation (5) for different costs of capital (e.g., 5\% and 10\%, following the EMWG 2005). From these calculations, the implicit relationship between $A C$ and size can be examined by estimating Equation (7).

Also, assuming that facilities are willing to sell their products or services at (long-run) average cost (including a reasonable return to capital), international supply curves can be traced using the hypothesized 
cost structures. Hypothetical profits can be calculated for each facility by subtracting total cost from total revenue, given by the annual production rate (size times the capacity factor) and the observable market price.

In summary, four cost inputs can be estimated for each sector of the nuclear fuel cycle. From these estimates, the MES can be calculated. This depends on economies of scale in capital and labor, and the importance of fixed cost relative to variable cost. To understand whether a non-fuel cycle state has an economic incentive to enter an industrial sector of the nuclear fuel cycle as its anticipated nuclear industry grows, the MES can be compared with the new entrant's facility size. If the MES for a new entrant is large (due to the high fixed costs of designing, licensing, and testing a facility), the new entrant is unlikely to be profitable and might not enter the market. If the sector is unprofitable, profit-oriented firms will not invest in new capacity, even if there is an increase in nuclear fuel cycle service demand. Of course, if the product or service supplier has non-profit motives, entry could occur anyway, either by a fuel-cycle or non-fuel cycle state subsidizing the industry.

\section{COST AND MARKET STRUCTURE OF THE URANIUM ENRICHMENT INDUSTRY}

This section models total and average costs for enrichment service, measured in millions of Separative Work Units ( $S W U=Q$ in this section). The cost data for four uranium enrichment plants allows an estimate of total capital investment cost, $K$, as a function of facility size, $S W U$. These announced centrifuge enrichment plants (see Rothwell and Braun, 2007, for sources) are:

1. The Brazil government is building an enrichment plant at its Resende nuclear fuel cycle site to supply 203,000 SWU by 2015 for its Angra 1 and 2 nuclear power plants at an estimated cost of 550M Brazilian Real. See Cabrera-Palmer and Rothwell (2007).

2. The Louisiana Enrichment Services (LES) plant, being built in New Mexico, is based on Urenco technology (TC-12 machines) capable of approximately $50 \mathrm{SWU} /$ centrifuge/ year. The plant is expected to cost $\$ 1,500 \mathrm{M}$ and produce 3 million SWU/year.

3. The American Centrifuge Plant (ACP) is being built in Ohio by the U.S. Enrichment Corporation (USEC), employing U.S. DOE developed, large-sized, 320 SWU/year centrifuge. USEC is building the ACP in two steps of 3.5 million SWU/year each. The first step has been estimated to cost $\$ 1,700 \underline{\mathrm{M}}$.

4. The George Besse II enrichment plant being built near Tricastain, France, is based on Urenco's TC12 centrifuges. This plant is being built by Eurodif of the French Areva group. The plant is expected to cost 3,000M Euro and produce 7.5 million SWU/year.

The Total Capital Investment Cost, $K$, for each plant is translated into 2005 dollars at $\$ 1.25=1$ Euro and $\$ 0.46=1$ Brazilian Real to estimate economies of scale, based on Equation (10). The OLS estimates of Equation (14) are presented in Table 1.

$\ln K_{\mathrm{SWU}}=\mathrm{b}_{01}{ }^{\mathrm{SWU}}+\mathrm{b}_{1}{ }^{\mathrm{SWU}} \ln S W U$ 
Table 1. Estimation of scale economies for enrichment capital.

\begin{tabular}{|l|l|l|l|}
\hline \multicolumn{4}{|c|}{ OLS Regression Statistics for $\ln (\mathrm{K})$ on $\ln (\mathrm{Q})$} \\
\hline R Squared & 0.990 & Std Error & 0.145 \\
\hline & SS & MS & F \\
\hline Regression & 3.96 & 3.96 & 189.46 \\
\hline Residual & 0.04 & 0.02 & \\
\hline & Value & SError & t Stat \\
\hline $\ln ($ constant $)$ & 1.580 & 0.409 & 3.864 \\
\hline $\ln ($ SWU) & $\mathbf{0 . 7 2 9}$ & $\mathbf{0 . 0 5 3}$ & $\mathbf{1 3 . 7 6 4}$ \\
\hline
\end{tabular}

Results imply that Equation (14) is well estimated, that there are strong economies of scale in size, and this function can be represented in exponential form as:

$K=\exp (1.58) \cdot S W U^{0.73}=4.86 \cdot S W U^{0.73}$

This function is graphed in Figure 3, which shows observations for the four plants.

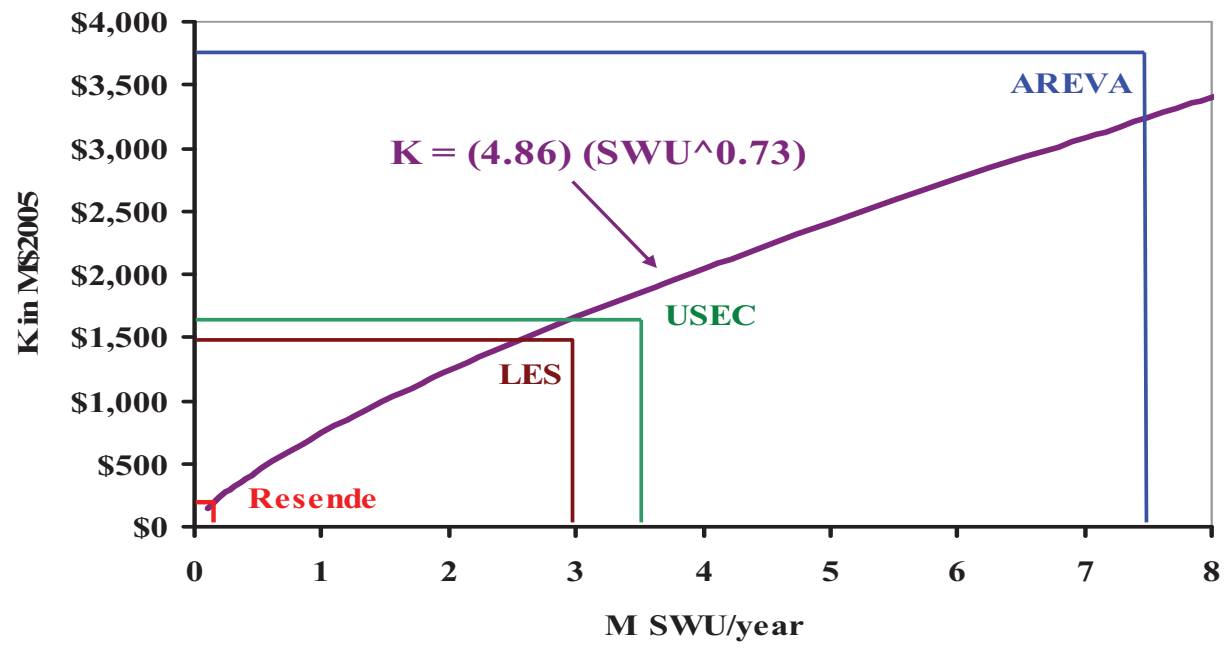

Figure 3. Estimated capital cost for centrifuge enrichment technology.

Next, consider costs for labor $(L)$, materials (here, machine replacement, $M$ ), and energy (electricity, $E$ ). Regarding staff sizes, the announced number of employees at the ACP plant is 500. If staff sizes at enrichment plants scale with the staff size at the ACP, then:

$L_{i}=500\left(3.5 / S W U_{i}\right)^{\mathrm{b} 2}$,

where $L_{i}$ is the staff size at plant $i, 3.5$ is the size of the first module of the ACP now under construction in millions of SWU per year, $S W U_{i}$ is the size of plant $i$, and $b_{2}$ is a "scaling factor" from Equation (11). Let $\mathrm{b}_{2}=0.73$ from Equation (15). Assume a "fully burdened" average annual salary is $\$ 60,000$ (including all overheads) in France and the U.S., and \$30,000 in Brazil (see Cabrera-Palmer and Rothwell 2007).

Also, assume the annual enrichment equipment replacement rate (here, $M$ ) is $1 \%$ of the total investment $(=0.01 \mathrm{~K})$. To determine energy costs, the electricity consumption is assumed to be 50 $\mathrm{kWh} / \mathrm{SWU}$ for all facilities with an electricity price of $\$ 50 / \mathrm{MWh}(=\$ 0.05 / \mathrm{kWh})$. 
Following the EMWG's Guidelines, total cost calculations are made with two costs of capital, 5\% and $10 \%$. This analysis assumes (1) the plant is immediately decommissioned and decontaminated (D\&D) after 30 years of economic life, and (2) the cost of D\&D is 33\% of the total investment in real 2005 dollars. With this information, $A C$ per SWU is calculated at $5 \%$ and $10 \%$ costs of capital. To understand the relationship between $A C$ and $Q$, a function based on Equation (7) is estimated:

$A C=\mathrm{a}_{1} \mathrm{SWU}+\left(\mathrm{a}_{0} \mathrm{SWU} / S W U\right)$.

(In models where $S W U$ was included with $1 / S W U$, as in Equation 2.7, $S W U$ was not significant, so Equation (17) reduces to $\mathrm{a}_{1}+\mathrm{a}_{0} / S W U$.) Rothwell and Braun (2007) provide estimates of the following equations:

$\mathrm{AC}_{5 \%}=\$ 52.86+\$ 12.19(1 / S W U)$

$\mathrm{AC}_{10 \%}=\$ 71.64+\$ 18.39(1 / S W U)$

For example, if a plant had a capacity of 1 million SWU per year, the levelized average cost would be approximately $\$ 71.64+\$ 18.93=\$ 90.57 / \mathrm{SWU}$ with $r=10 \%$. Figure 4 graphs these equations. The MES for each cost of capital is identified on Figure 4. The MES is about 2.5 million SWU/year (capable of supplying $20 \mathrm{GW}$ LWRs) (i.e., 12 times the size of the Brazilian facility).

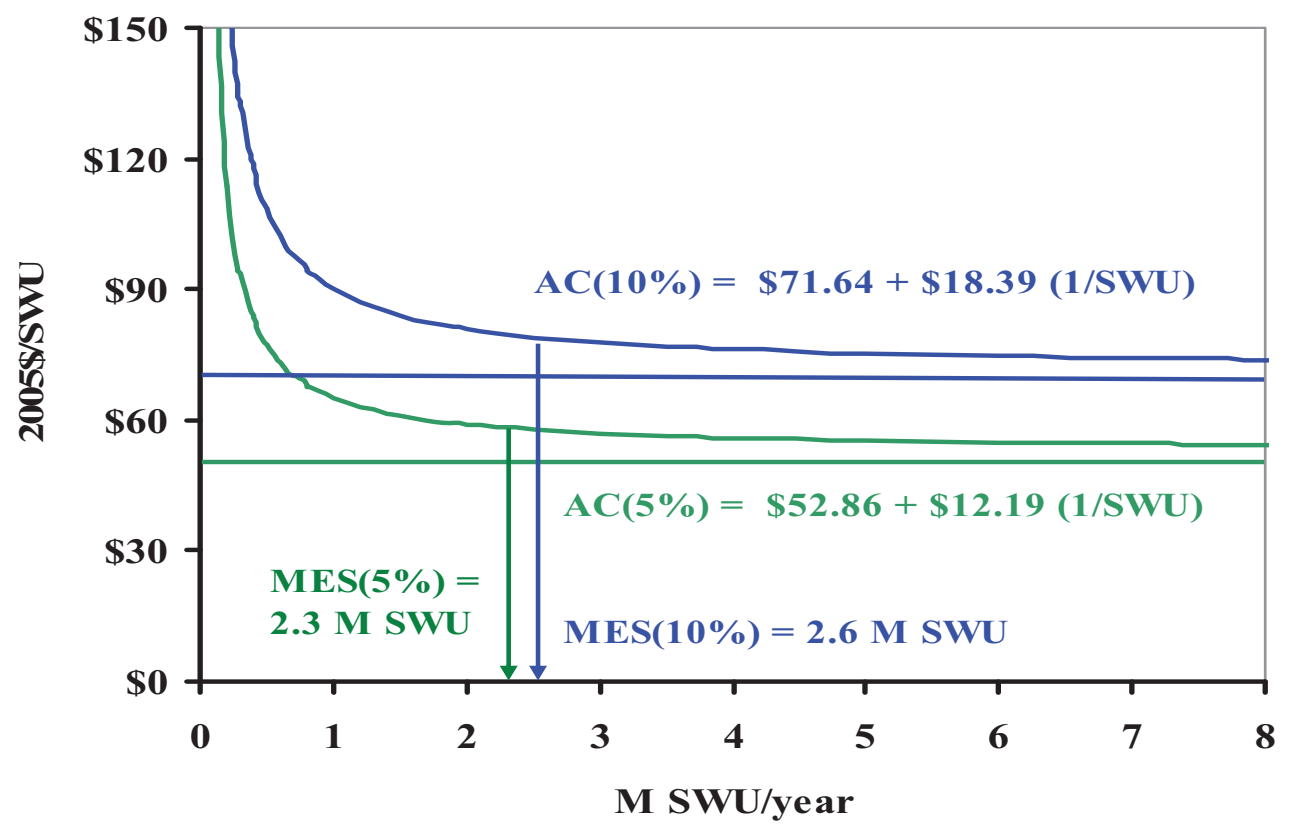

Figure 4. Estimated investment cost, centrifuge technology.

In the rest of this section, this cost structure is used to construct reasonable cost estimates of existing commercial enrichment plants, for example, those owned by Urenco and Tenex (the Russian enrichment production and export corporation). See Table 7 in Rothwell and Braun (2007). Urenco had a capacity of 7.4 million SWU at the end of 2004. This is modeled as five 1.5 million SWU plants, following the approximate sizes of its plants in Germany, the Netherlands, and the U.K. Using Equation (15), the replacement value of each of the 1.5 million SWU plants is $\$ 940 \mathrm{M}$. Given the similarity of the centrifuge technologies, cost estimates of the Urenco plants follow the cost assumptions for EURODIF's George Besse II plant and the LES plant in New Mexico. Due to the smaller size of each of the Urenco plants, 
unit costs are higher than for those projected for the George Besse II plant. (Urenco cost estimates are used to project average cost of the Japanese 1 million SWU/year enrichment plant at Rokkasho.)

A similar analysis is applied to estimate the costs at Tenex's centrifuge-based plants in Ekaterinberg (9 million SWU/year), Krasnoyarsk (5 million SWU/year), Tomsk (3 million SWU/year), and Angarsk (2 M SWU/year). While the replacement values of the plants can be modeled with Equation (15), due to the age of the Russian facilities (they were built by the Soviet Union), the cost of capital is assumed to be 1\% per year applied to the replacement value. Further, assume the same cost of labor as in Brazil. The projected average cost for the Russian plants is between $\$ 22$ and \$35 per SWU, much lower than any competitor.

Finally, the cost structure is stretched to approximate the cost of the existing commercial diffusion plants owned by USEC and EURODIF. See Table 8 in Rothwell and Braun (2007). Using the same technique for projecting investment costs as above, Rothwell and Braun find that the current investment costs (replacement value) for each plant is about $\$ 4,000 \mathrm{M}$. Assume a $1 \%$ cost of capital per year to determine the annual capital charge for these legacy plants. All other costs follow from Tables 2, 3, and 7 in Rothwell and Braun (2007). Further, assume that EURODIF's newer diffusion plant (completed in 1982) operates at 2,200 kWh/SWU, whereas the older USEC plant (Paducah, Kentucky, completed in 1954) operates at $2,500 \mathrm{kWh} / \mathrm{SWU}$. To match enrichment market prices, the price of electricity is set at $\$ 45 / \mathrm{MWh}$ for the two diffusion plants. Due to the huge electricity bill associated with the diffusion plants, all other costs are secondary.

These results can be used to approximate the supply curve for the existing international market in commercial uranium enrichment services. See Figures 5 (2005) and 6 (2015). Figure 5 assumes that Russian production is limited, such that the Ekaterinberg plant (with 9 million SWU/year) is not competing in the international market. In Figure 5, about one quarter of the international enrichment market is low cost (less than $\$ 50 / \mathrm{SWU}$ ), one quarter is moderate cost (between $\$ 50$ and $\$ 100 / \mathrm{SWU}$ ), and one half of the market is high cost (more than $\$ 100 / \mathrm{SWU}$ ). With requirements at 40 million SWU (approximately 120,000 SWU/LWR-GW/year), the market price is determine by the highest cost producer (USEC) at approximately $\$ 133 /$ SWU. With a price of $\$ 133 /$ SWU and quantity of 40 million SWU, total industry annual revenues at Fourth-Quarter-2006 prices were about \$5,300M.

With the retirement of the world's gaseous diffusion enrichment capacity and assuming no constraints on Russian participation in the market, the supply curve for enrichment services will shift between now and 2015 to a situation more similar to that in Figure 6 (which includes the Brazilian capacity). At 2005 quantities (40 million SWU), world requirements could be satisfied by all enrichers, and total revenues would be approximately $\$ 3,000 \mathrm{M}$. If enrichment requirements do not increase between 2005 and 2015, then the LES capacity could hypothetically set the competitive market price at approximately \$76/SWU: A huge price drop and big savings to consumers of nuclear-generated electricity. 


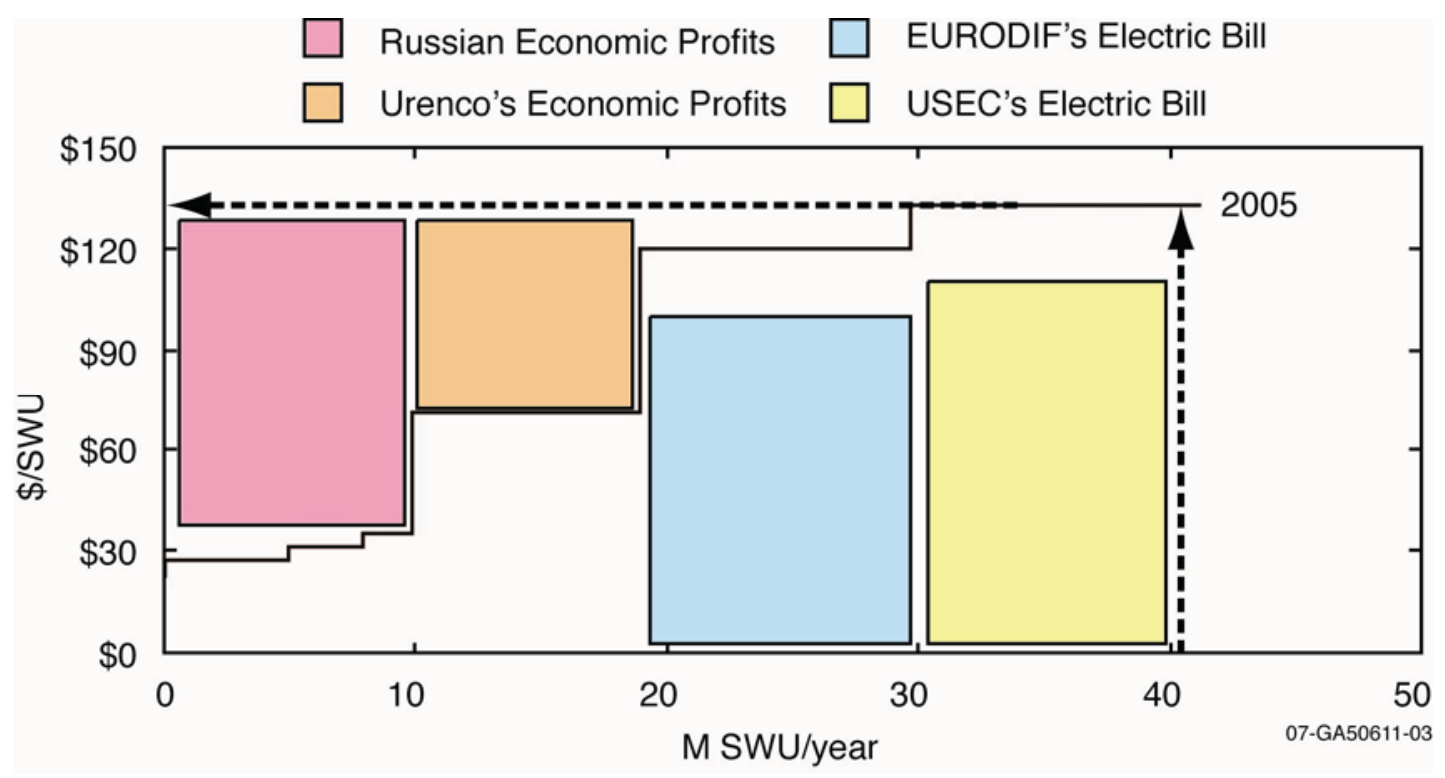

Figure 5. Supply of uranium enrichment services, 2005.

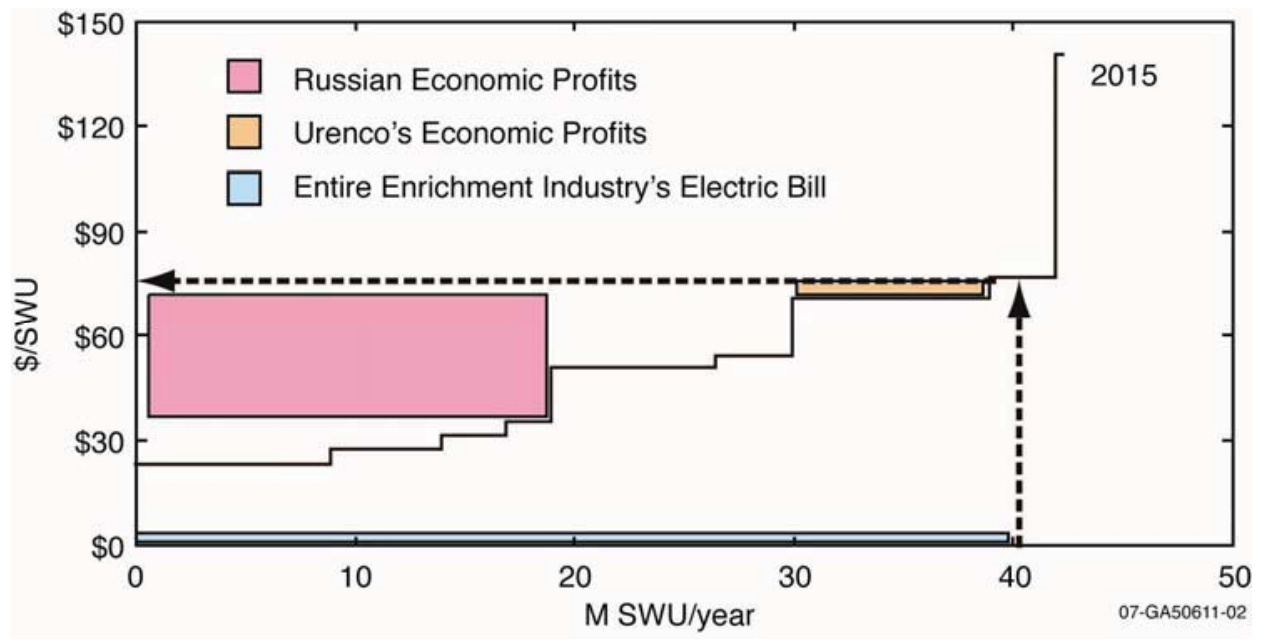

Figure 6. Supply of uranium enrichment services, 2015.

To understand the implications of these changes, consider economic profits in 2005 versus 2015. In Figure 5, the pink box represents Russian economic profits, equal to $\$ 980 \mathrm{M}$ (not including profits from the lower cost plants). In Figure 5, the orange box represents Urenco's economic profits, equal to $\$ 470 \mathrm{M}$. (Also, the blue box represents EURODIF's electricity bill of $\$ 1,100 \mathrm{M}$ and the yellow box represents USEC's electricity bill of $\$ 1,300 \mathrm{M}$.)

In 2015, the profit situation changes: In Figure 6 the pink box represents Russian profits, which are equal to $\$ 790 \mathrm{M}$ (not including profits from the lower cost plants). This is based on an assumed increase in the Russian enrichment capacity dedicated to the international market (i.e., capacity not required for the Russian enrichment market). The orange box in Figure 6 represents Urenco's economic profits, equal to $\$ 44 \mathrm{M}$. The blue box at the lower part of Figure 6 represents the electricity bill for the entire enrichment industry in 2015. 
Therefore, as uneconomic diffusion enrichment capacity is retired and most Russian capacity (not required for domestic supply) enters the international market, Russian economic profits decline by almost $20 \%$ (despite an increase in exports). Urenco's profits could decline by almost $90 \%$ if international enrichment prices are reduced to the level of the average production cost of centrifuge plants. Due to their ultimately larger size, EURODIF's George Besse II and USEC's APC enrichment plants should earn economic profits, but the LES plant, as the highest cost producer, might not be economically profitable. This situation could make private financing for private enrichers difficult to obtain at costs of capital that will allow them to be competitive. Some market intervention might be necessary to assure that sufficient investment will be made to meet future demand.

\section{COST AND MARKET STRUCTURE OF LIGHT WATER REACTOR LEU FUEL FABRICATION}

In modeling LWR fuel fabrication there are three relevant costs: total capital investment costs, $K$, labor costs, $L$, and materials ( $M$, hardware) costs. According to Judkins and Olsen (1979, p. 16), energy costs are only $1 \%$ of total annual operating costs, and therefore are ignored in this analysis. These costs are levelized over discounted lifetime output, equal to the nominal capacity (metric tonnes of uranium [MTU] per year) times the capacity factor - a percentage. It is difficult to know the capacity factors of these plants. This analysis assumes a capacity factor of $80 \%$ (unless capacity factor information is available for a particular plant). Average Costs are expressed in 2005 dollars per kilogram of uranium $(\$ / \mathrm{kgU})$.

To evaluate $A C$, first approximate the cost of materials, $p_{\mathrm{M}} \cdot M$, as a function of the weight of the hardware associated with Pressurized Water Reactor (PWR) and Boiling Water Reactor (BWR) fuel assemblies. Rothwell (2007) shows that if PWR fuel sells for $\$ 220 / \mathrm{kgU}$ and BWR fuel sells for $\$ 270 / \mathrm{kgU}$, a reasonable cost for PWR hardware is $\$ 22.52 / \mathrm{kgU}$ and a reasonable cost for BWR hardware is $\$ 72.52 / \mathrm{kgU}$. So, the price of a kilogram of "generic" LEU fuel is $\$ 197.48 / \mathrm{kgU}(\approx \$ 200 / \mathrm{kgU})$ under these assumptions.

The next step is to estimate the annual average labor bill, $p_{\mathrm{t}} \cdot L$. This is done by examining the number of employees working at nuclear fuel fabrication facilities. Of the 20 currently operating plants, employee data could only be found for 10 of them. Figure 7 is a plot of these data (with International Atomic Energy Agency country abbreviations). 


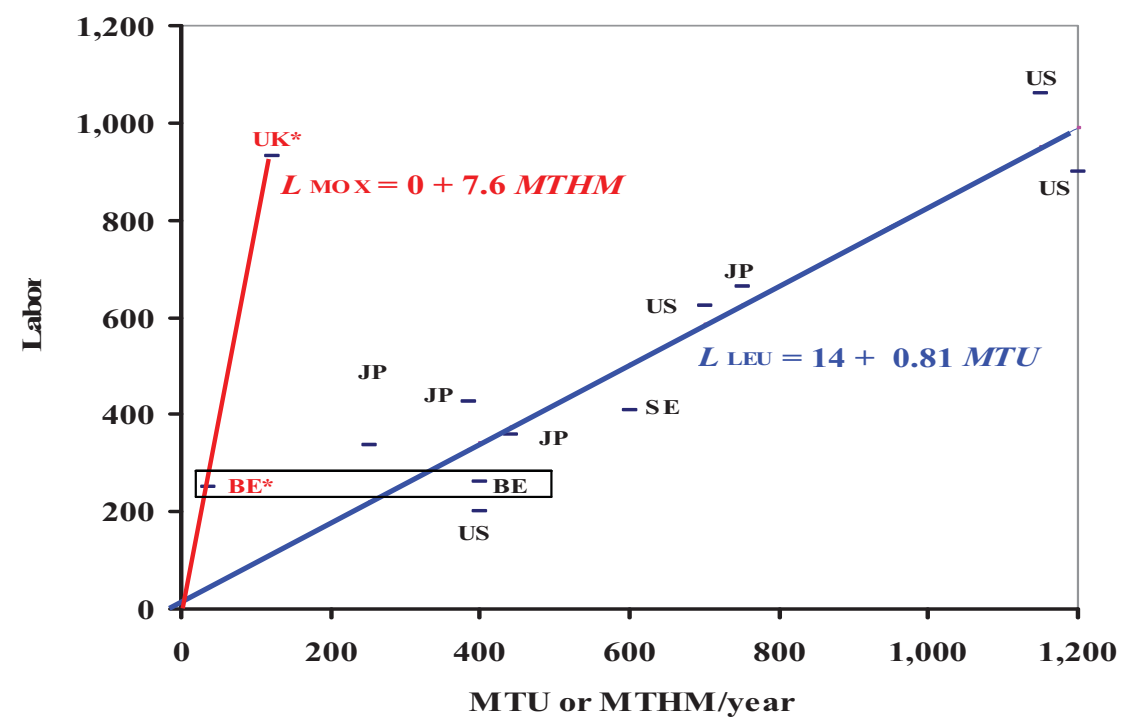

Source: Tables 2 and 7 in Rothwell (2007). * = MOX Plant. Belgian (BE) data from Bergmans and Van Steenberge (2006, p. A-31)

Figure 7. Number of employees as a function of size in MTU/year.

Table 2 explores whether there are economies of scale in labor at LEU fuel fabrication facilities, following Equation (11). Given that the estimated elasticity coefficient on $\ln (\mathbf{M T U})$ is not statistically different from 1.0, this technology exhibits constant returns to labor. Nuclear fuel fabrication lines (operated in batch mode) appear to be able to be added in parallel and each line requires a similar number of employees.

Table 2. Estimation of scale economies for fuel fabrication labor.

\begin{tabular}{|l|l|l|l|}
\hline \multicolumn{4}{|c|}{ OLS Regression Statistics for $\ln (\mathrm{L})$ on $\ln (\mathrm{Q})$} \\
\hline R Squared & 0.735 & Std Error & 0.292 \\
\hline & SS & MS & F \\
\hline Regression & 1.89 & 1.89 & 22.16 \\
\hline Residual & 0.68 & 0.09 & \\
\hline & Estimate & Std Error & t Stat \\
\hline $\ln$ (constant) & 0.420 & 1.217 & 0.346 \\
\hline $\ln$ (MTU) & $\mathbf{0 . 9 0 3}$ & $\mathbf{0 . 1 9 2}$ & $\mathbf{4 . 7 0 8}$ \\
\hline
\end{tabular}

Given constant returns to labor, to estimate the number of employees, Rothwell (2007) presents the OLS estimates following Equation (13):

$L_{\mathrm{LEU}}=14.111+0.812 \cdot M T U$

The model is well estimated, although the standard error on the constant term is such that one cannot reject the hypothesis that the constant is zero (the constant can be interpreted as the number of nonproduction employees, such as administrative and security personnel). Equation (20) can be used to estimate the number of employees at a typical LEU fuel fabrication facility. The labor cost per $\mathrm{kgU}$ of LEU fuel can be calculated by assuming (1) the fully-burdened annual salary is $\$ 60,000,(2)$ the plant capacity is $1,000 \mathrm{MTU} / y e a r$, and (3) the capacity factor is $80 \%$. Under these assumptions, the total labor bill is $\$ 49.56 \mathrm{M}$ and cost of labor is $\$ 61.95 / \mathrm{kgU}$. 
Before determining capital costs for LEU fuel fabrication, other variable costs must be identified and subtracted. Following Judkins and Olsen (1979), these costs include:

- General and administrative expenses, equal to $\$ 10.06 / \mathrm{kgU}(2005 \$)$

- $\quad$ Direct and indirect materials and supplies, updated to $\$ 7.23 / \mathrm{kgU}(2005 \$)$

- Property taxes and property insurance, equal to $3 \%$ of $K$ per year

- Equipment replacement charge, equal to $1 \%$ of $K$ per year.

(Because taxes, insurance, and equipment replacement are proportions of $K$, these are added to the capital cost per $\mathrm{kgU}$.) Therefore, the levelized capital cost (including property taxes, insurance, and equipment replacement) is approximately $\$ 118.24 / \mathrm{kgU}(=\$ 197.48 / \mathrm{kgU}-\$ 61.95 / \mathrm{kgU}-\$ 10.06 / \mathrm{kgU}-\$ 7.23 / \mathrm{kgU})$.

Capital charges of $\$ 118.24 / \mathrm{kgU}$ include return on investment, $K$, an annual contribution to the decommissioning of the plant, and property taxes, insurance, and equipment replacement. Following EMWG (2005), if (1) decommissioning is one-third of $K$; (2) the return on the decommissioning trust fund is $5 \%$ real; (3) the weighted cost of capital (return on fuel fabrication investment) is $15 \%$ real (as assumed in Judkins and Olsen, 1979, p. 17); and (4) the plant has a 15-year life (see Judkins and Olsen, 1979 , p. 17), then the approximate cost of a 1,000 MTU is $\$ 400 \mathrm{M}\left(=K_{\mathrm{LEU}}\right)$. This yields an annual capital recovery charge of $\$ 85.58 / \mathrm{kgU}$ (adjusting for the capacity factor).

If $\$ 400 \mathrm{M}$ is the approximate cost of a 1,000 MTU plant, what might be the cost of a 500 MTU plant or a 1,500 MTU plant? INL (2007, p. D1-13) states, "It is likely that if new U.S. production capacity is needed, it will be added by reopening existing lines, constructing additional process lines, or going to additional shift operations at existing facilities. An educated guess is that a new fabrication line of 200$300 \mathrm{MTU} / \mathrm{yr}$ capacity would cost over $\$ 100 \mathrm{M}$ in an existing building." Following this, assume the cost for an additional capacity of 300 MTU per year is $\$ 100 \mathrm{M}$, or $\$ 333,000 / \mathrm{MTU}$ at an existing facility (i.e., one where the set-up costs of opening a facility of any size would have been amortized). If the implicit fixed costs of licensing, designing, and preparing a new site were $\$ 67 \mathrm{M}$, then, following Equation (12):

$K_{\mathrm{LEU}}=\$ 67,000,000+\$ 333,000 \cdot M T U$

With these cost equations, Figure 8 plots the estimated levelized average costs for various capacities. It is apparent from Figure 8, that there are increasing returns to scale, as indicated by the steady decline in average costs for the entire capacity range. Increasing returns to scale arise from the high set-up costs (e.g., licensing the plant and its fuel, and testing its equipment) that must be levelized over lifetime output. Due to these high set-up costs, the MES at a new LEU fuel fabrication facility is 1,130 MTU/year, larger than all but two operating plants. 


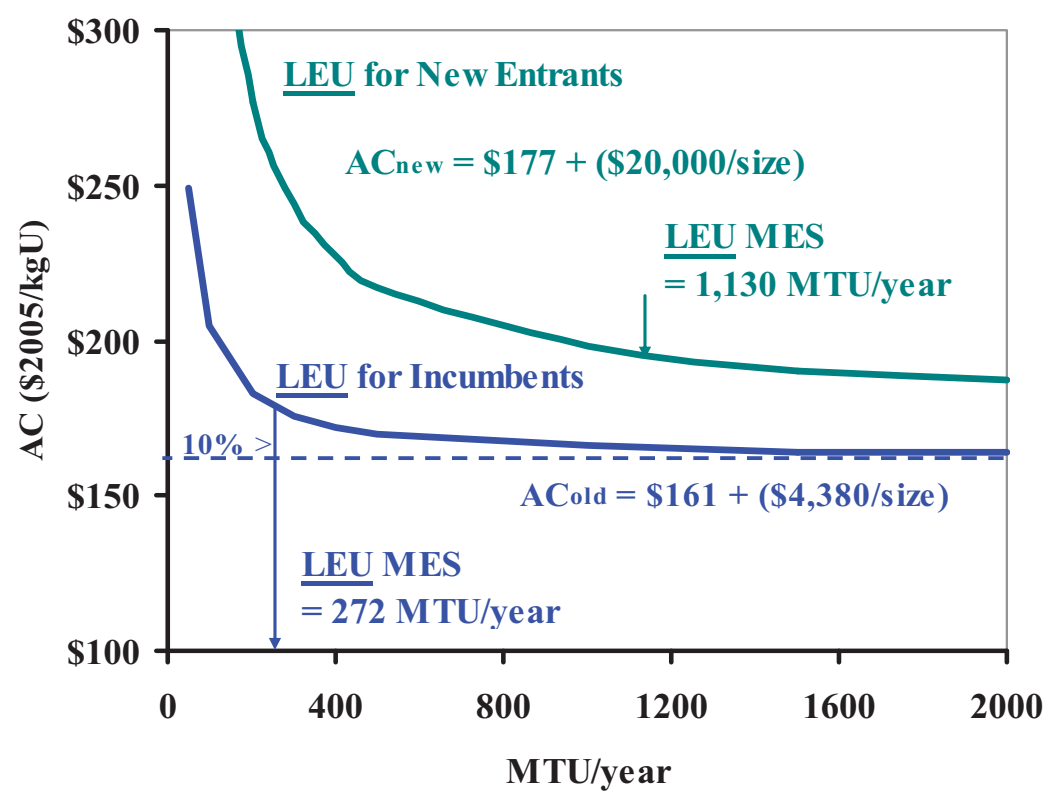

Figure 8. New entrants and incumbents fuel fabrication cost curves.

In addition, the cost structure of an incumbent supplier can be modeled by assuming that the licensing costs have been amortized. This leads to alternative values for incumbent producers and allows tracing the incumbent's cost structure, as shown in Figure 8. MES for additions to existing plants is 272 MTU/year.

With this cost model, long-run marginal costs, proxied by $A C$ can be approximated for each international LEU fuel fabricator under the following assumptions: any plant over 15 years old faces incumbent capital costs, and labor costs in Brazil, China, India, and Russia are half as much as in Europe, Japan, and the U.S. The costs associated with each increment of capacity trace out a supply curve (see Figure 9) for generic LEU fuel fabrication services. The supply curve has four segments:

1. Suppliers in countries with low labor costs and/or depreciated plant (i.e., Brazil and Russia [Novosibirsk] with 1,250 MTU/year)

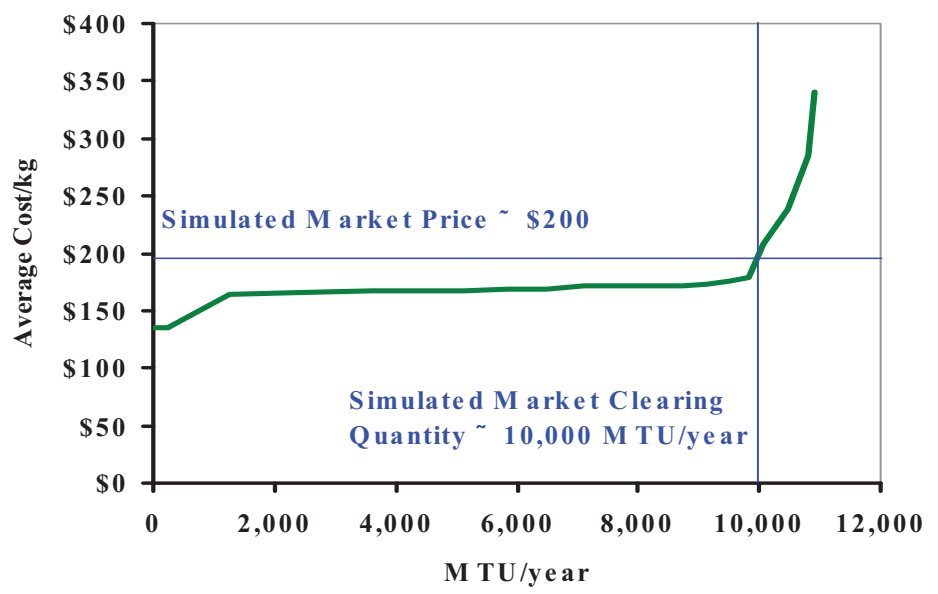

Figure 9. Supply curve for LEU fuel fabrication services. 
2. Large suppliers in Europe, Japan, and the U.S. that have similar costs, and a capacity of 8,800 MTU/year

3. Small suppliers in Europe and the U.S. with higher costs and a combined capacity of 750 MTU/year

4. Suppliers that do not enjoy any economies of scale (i.e., China and India, with $125 \mathrm{MTU} / \mathrm{year}$ ) where the central government directly or indirectly subsidizes production costs for industry development or energy security goals.

Assuming a market clearing price of about $\$ 200 / \mathrm{kgU}$ (without hardware), the market clearing quantity is about 10,000 MTU/year (not considering separate markets for BWR, PWR, or VVER fuel). This implies that plants in the two highest cost segments (about $900 \mathrm{MTU} /$ year) might be operating at a low rate of return (i.e., as long as the market price is above $A V C$, a firm continues to produce, although at a lower rate of return on equity; if the market price is below $A V C$, it is in a firm's interest to shut down to minimize losses). At this price and quantity, total industry revenues are approximately $\$ 2,000 \mathrm{M}$ (without hardware). Total industry costs are about $\$ 1,700 \mathrm{M}$. Therefore, the industry could be earning economic profits of approximately $\$ 300 \mathrm{M}$. This industry is profitable, and costs appear to be as assumed in Bunn et al. (2003, p. 56), (i.e., "below $\$ 200 / \mathrm{kgHM").} \mathrm{The} \mathrm{industry} \mathrm{is} \mathrm{unlikely} \mathrm{to} \mathrm{require} \mathrm{non-market} \mathrm{intervention}$ under a nuclear renaissance.

\section{COST AND MARKET STRUCTURE OF LIGHT WATER REACTOR MOX FUEL FABRICATION}

The fabrication of MOX fuel for LWRs is similar to the fabrication of LEU fuel for LWRs. According to INL (2007, p. D1-22), "The steps involved in the fabrication of MOX fuel are basically the same as those for LEU fuel assembly production except that most of the front and middle steps must be enclosed in glove boxes to protect the workers and public from exposure to radiotoxic plutonium compounds." This simplifies the economic modeling, because the cost structure of MOX fuel fabrication can be based on the cost structure of LEU fuel fabrication. This section builds on the economic model developed for LEU fuel in Section 4 (e.g., it assumes the costs of the hardware for PWR and BWR). MOX fuel are identical to the costs of PWR and BWR hardware for LEU fuel.

There is some publicly available information on international commercial MOX plants concerning employees, capacity factors, and construction costs. Unlike LEU fuel fabrication facilities, most of the MOX plant owners are subject to some form of government review.

First, total capital investment cost, $K$, is estimated as a function of facility size measured in Metric Tons of Heavy Metal (MTHM) using Equations (10) and (12) with the following information: (1) the Japanese Rokkasho plant was estimated to cost $\$ 1,160 \mathrm{M}$, (2) the BNFL Sellafield MOX Plant (SMP) was built for \$750M, and (3) the U.S. DOE plant at the Savannah River Site (SRS) was projected to cost $\$ 550 \mathrm{M}$. (Costs have increased substantially since 2002, and adjustments are made below). Figure 10 presents these data with diamonds (where capacity has been adjusted by the anticipated capacity factor). 


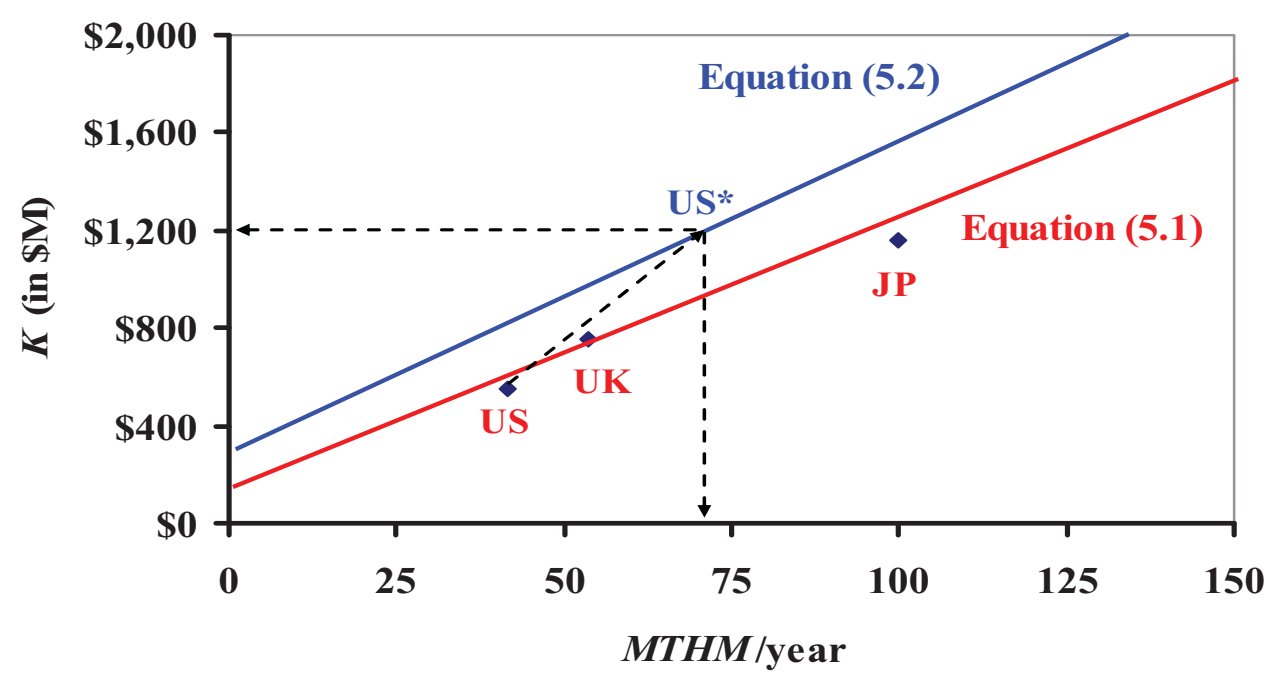

Figure 10. Estimated capital cost for MOX fuel fabrication.

Table 3 shows that the estimate of scale economies (with $10 \%$ confidence) is $0.816 \pm 2.9 \cdot(0.108)$ (i.e., constant scale economies cannot be rejected). So, a linear function of plant capacity, adjusted by anticipated capacity factor $(\underline{M T H M})$ was estimated:

$K_{\mathrm{MOX}}=\$ 173,000,000+\$ 9,960,000 \cdot \underline{M T H M}$

Table 3. Estimation of scale economies for capital in MOX fuel fabrication.

\begin{tabular}{|l|l|l|l|}
\hline \multicolumn{2}{|l|}{ OLS Regression Statistics for $\ln (\mathrm{K})$ on $\ln (\mathrm{Q})$} & \\
\hline R Squared & 0.98 & Std Error & 0.07 \\
\hline & SS & MS & F \\
\hline Regression & 0.276 & 0.276 & 57.18 \\
\hline Residual & 0.005 & 0.005 & \\
\hline & Estimate & Std Error & t Stat \\
\hline Intercept & 3.313 & 0.445 & 7.449 \\
\hline $\ln ($ MTHM x CF) & $\mathbf{0 . 8 1 6}$ & $\mathbf{0 . 1 0 8}$ & $\mathbf{7 . 5 6 2}$ \\
\hline
\end{tabular}

However, investment costs at Savannah River have increased to at least $\$ 1,200 \mathrm{M}$ since 2002 (see INL, 2007, p. D1-26). Without updated information on the cost of Rokkasho, it is not possible to determine appropriate updated values for both parameters in Equation (22). Therefore, this analysis assumes (1) the constant in Equation (22) has doubled to \$350M (i.e., plant licensing costs have doubled since 2002) and MTHM is not adjusted by the capacity factor (i.e., unit capital costs have increased). Solving for the slope coefficient so that the $K_{\mathrm{MOX}}$ of Savannah River equals $\$ 1,200 \mathrm{M}$ :

$K_{\mathrm{MOX}}=\$ 350,000,000+\$ 12,140,000 \cdot M T H$

Figure 10 graphs Equation (23). If Equation (23) holds, generally, the Rokkasho plant could cost at least \$2,000M (about 200,000M 2005 yen) when completed in 2012 .

Next, there are two observations on the number of employees, $L_{\mathrm{MOX}}$, and capacity, MTHM: (1) 250 employees at the Belgium Dessel plant of a nominal $35 \mathrm{MTHM} / \mathrm{year}$ (Bergmans and Van 
Steenberge, 2006, p. A-31, which is the same source for the number of employees at the LEU fuel fabrication facility in Belgium) and (2) approximately 930 employees at the U.K.'s Sellafield plant of a nominal $120 \mathrm{MTHM} /$ year. The nominal labor-to-capacity ratio at the two plants is identical at one significant digit (i.e., $[250 / 35=7.14]$ and $[930 / 120=7.75]$ ). Therefore, a labor forecasting equation based on Equation (13) is:

$L_{\mathrm{MOX}}=0.0+7.6 \cdot M T H M$

Comparing equations (20) and (24), the coefficient on SIZE is almost an order of magnitude larger for MOX plants than for LEU plants. This is likely due to increases in health physics and safety technicians, specialized equipment maintenance technicians, and security personnel. (At the two side-by-side Belgian facilities, the LEU plant has 1.5 MTU/employee and the MOX plant has 0.14 MTHM/employee.) MOX production appears to exhibit a constant labor-to-capacity ratio between 35 and 120 MTHM. Assuming the same wage rate, labor costs are much higher for MOX fuel fabrication facilities than for LEU facilities. Figure 7, above, graphs Equation (24) with Equation (20).

To calculate average cost for MOX fuel fabrication, using Equations (23) and (24) to forecast capital and labor, the following modifications of the LEU cost structure are made: (1) the capacity factor is set at $100 \%$ (but changed to $80 \%$ in the sensitivity analysis, below) and (2) the cost of capital is set at $9.43 \%$ (but changed to $15 \%$ in the sensitivity analysis, below). (The value of $9.43 \%$ was selected so that average cost would match the cost estimate in INL, 2007.) Incumbent capital costs follow Equation (22) with the constant set equal to zero (i.e., design, licensing, and testing costs) are assumed to be amortized.

Under these assumptions, Rothwell (2007) shows that at an annual capacity of $120 \mathrm{MTHM} / \mathrm{year}$, generic MOX costs are \$3,200/kgHM, which matches the estimate in INL (2007, p. D1-28). Figure 11 presents the entrant and incumbent's postulated average cost curves. The incumbent's costs are nearly $50 \%$ lower than the new entrant's costs. New entrants face high entry costs and increasing returns to scale with a MES of $240 \mathrm{MTHM} / \mathrm{year}$ (i.e., larger than any existing or planned facility). The MES for incumbents is $67 \mathrm{MTHM} / \mathrm{year}$. It is the cost of designing, licensing, and testing that increases the MES size of new MOX plants.

To test the sensitivity of the MOX fuel fabrication cost estimate, this analysis assumes the capacity factor falls to $80 \%$ and the cost of capital rises to $15 \%$. This increases average cost by $50 \%$. At 120 MTHM/year the entrant's costs could be more than $\$ 4,800 / \mathrm{kgHM}$. These estimates are much higher than assumed in earlier publications (e.g., in Bunn et al. [2003, p. 19]). Therefore, it is unlikely that new MOX fuel fabricators can be competitive with LEU fuel at risk-adjusted costs of capital.

Figure 12 traces MOX fuel fabrication supply assuming a 5\% real cost of capital (which would be appropriate for government financing) in 2007 (not including Indian capacity) and 2017. By 2017, Rokkasho and SRS are scheduled to open, and SMP is scheduled to close. If the market price is less than $\$ 2,500$, then only one firm is making economic (competitive) profits in this industry: MELOX. Sellafield, due to its low capacity factor, could be operating at a loss. In 2017, the new entrants, Rokkasho and SRS are likely to be producing at a cost much higher than MELOX. Therefore, this market could be drifting into a de facto natural monopoly, but one where the price of MOX is effectively regulated by the competing price of LEU fuel. Thus, no market intervention is necessary, unless proliferation concerns are important. On the other hand, if governments, such as those in Japan and the U.S., want MOX fuel fabrication facilities, they will likely be required to subsidize them. 


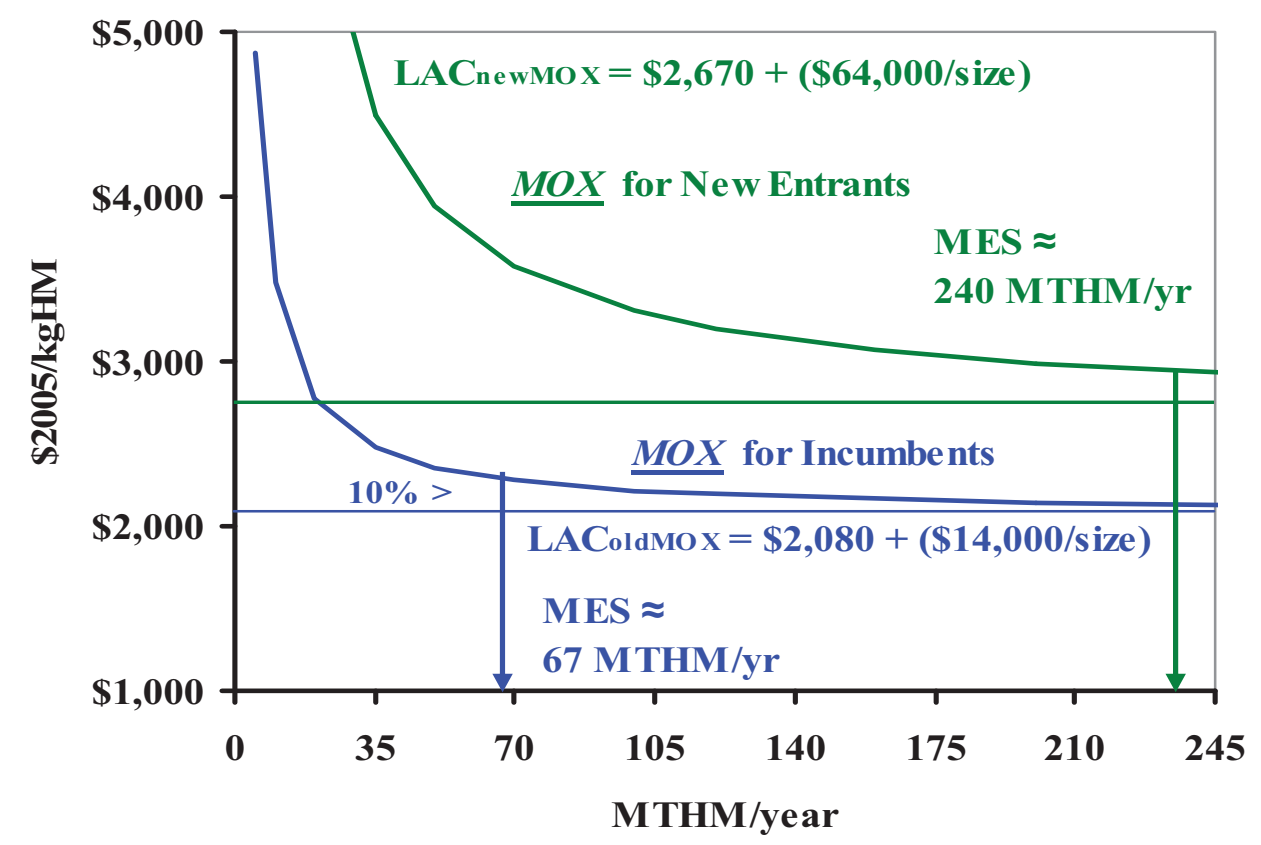

Figure 11. New entrants and incumbents estimated fuel fabrication cost curves.

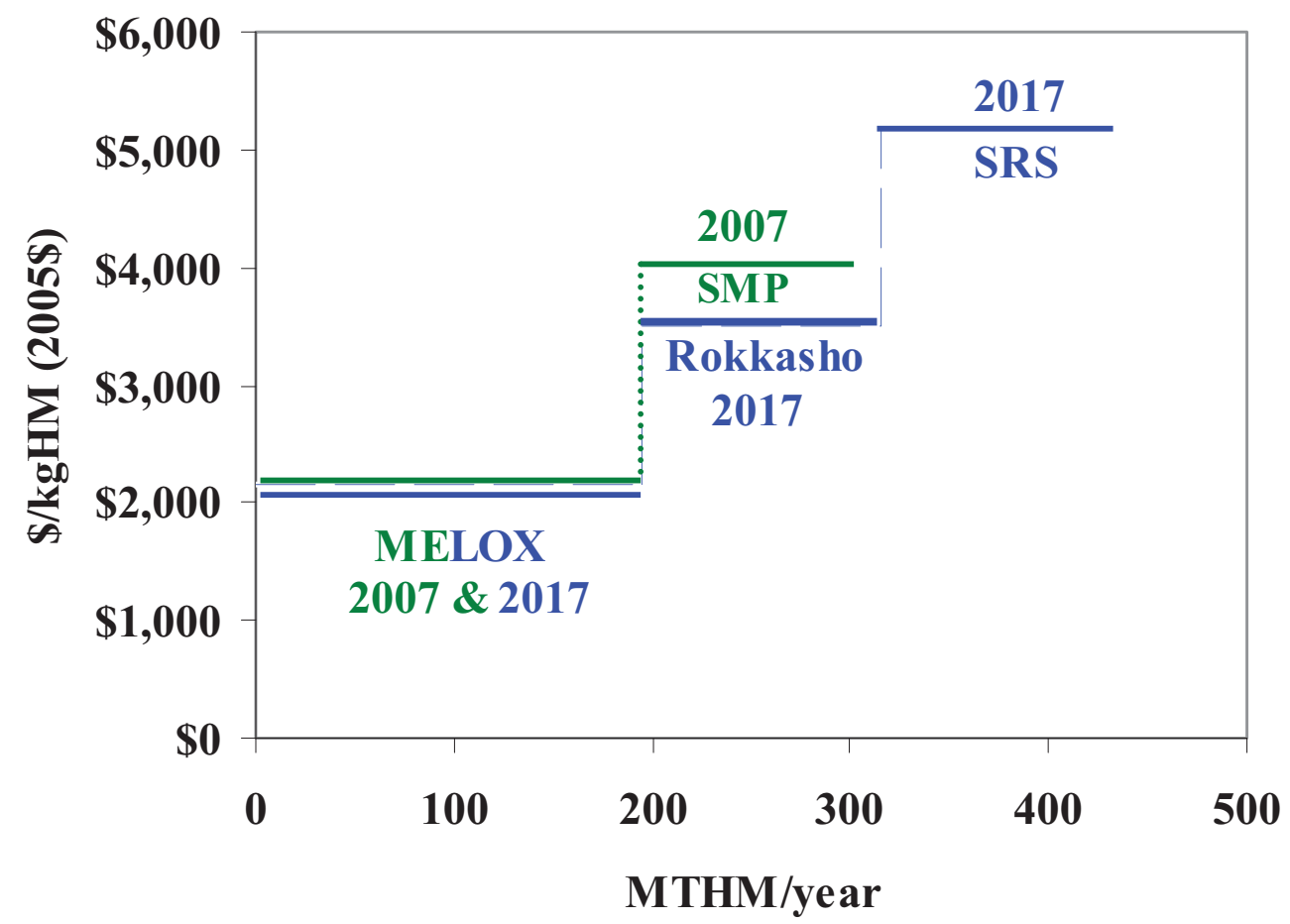

Figure 12. Supply curve for LEU fuel fabrication services. 


\section{SUMMARY AND FUTURE RESEARCH}

To apply this methodology to the remaining sectors of the closed fuel cycle (to understand the economic incentives of fuel and non-fuel cycle states as the size of anticipated national nuclear industries grow):

- Gather international data on existing and proposed facilities in the sector (see INL, 2007)

- Use data to estimate economies of scale in capital and labor (compare with literature)

- Determine reasonable fixed and variable costs to forecast capital and labor requirements

- Determine cost differences between incumbents and new entrants

- Set parameters such that cost structure mimics other cost study conclusions

- Calculate levelized average costs under various costs of capital; perform sensitivity analyses

- Estimate minimum efficient scale at each cost of capital for incumbents and entrants

- Trace the international supply curve and calculate hypothetical profits

- Compare profitability analysis with available financial analyses of the sector (this step is not presented in this attachment, see Rothwell, 2007, and Rothwell and Braun, 2007, for examples)

- Determine whether market intervention might be necessary for economic reasons.

This analysis found that due to high start up costs, average costs are continuously declining in the uranium enrichment industry and in the MOX LWR fuel fabrication industry. There is no guarantee that these markets will not "fail" in the near future (in the economic sense that price will not equal cost, or that firms will exit the industry). Therefore, it might be optimal to introduce a regulatory regime to limit the number of producers in these two sectors, and reduce access to these two technologies. (This is also true for proliferation reasons.)

Alternatively, LWR LEU fuel fabrication appears to exhibit constant economies of scale for incumbent firms. Economics of scale arise from the high cost of designing, testing, and licensing, but these costs have been amortized by incumbent facilities. There is no compelling economic reason to regulate this industry. The current market structure of the LEU industry is profitable, but competitive and new entrants will find it difficult to compete with incumbents. (Also, there appears to be little proliferation concern associated with fuel fabrication technology itself.)

Because of the lack of information on these sectors, the current methodology will be extended to incorporate learning and changes in MES as costs decline from First-of-a-Kind levels to Nth-of-a-Kind levels. This involves the incorporation of methodologies described in Rothwell and Williams (2007).

\section{REFERENCES}

Bergmans, A. and Van Steenberge, A., "CARL Country Report - Belgium: Appendices," Department of Sociology, University of Antwerp, Belgium, 2006.

Bunn, M, Fetter, S., Holdren, J.P., and van der Zwaan, Bob, The Economics of Reprocessing vs. Direct Disposal of Spent Nuclear Fuel, Project on Managing the Atom, Belfer Center for Science and International Affairs, John F. Kennedy School of Government, Harvard University, Cambridge, MA, 2003.

Cabrera-Palmer, B. and G.S. Rothwell, "Why Is Brazil Enriching Uranium?: To Assure its Nuclear Fuel Cycle," Stanford Institute for Economic Policy Research, Stanford University, 2007. 
Economic Modeling Working Group (EMWG), Cost Estimating Guidelines for Generation IV Nuclear Energy Systems. EMWG of the Generation IV International Forum (GIF), 2005, http://nuclear.inl.gov/deliverables/docs/emwgguidelines_rev2.pdf, Web page accessed Sept 30, 2005.

Idaho National Laboratory (INL), Advanced Fuel Cycle Cost Basis, INL, Idaho Falls, ID, INL-EXT-0712107 (April), 2007.

Intriligator, M.D., Econometric Models, Techniques, \& Applications, Prentice-Hall, 1978.

Judkins, R.R. and A.R. Olsen, "Estimation of Costs for Fabrication of Pressurized-Water Reactor Fuel," Oak Ridge National Laboratory, ORNL/TM-6501, 1979.

Rothwell, G.S., "Cost Contingency as the Standard Deviation of the Cost Estimate," Cost Engineering 47, 7, 2005.

Rothwell, G.S., "Cost Structure and Market Sustainability of the International Light Water Reactor Fuel Fabrication Industry," Stanford Institute for Economic Policy Research, Stanford University, 2007.

Rothwell, G.S. and C. Braun., "International Uranium Enrichment Supply," Stanford Institute for Economic Policy Research (March), 2007.

Rothwell, G.S. and K. Williams, "The Costs of Developing and Commercializing the Advanced Burner Reactor," presented at the American Nuclear Society 2007 Annual Meeting, Boston, MA (June 27), 2007.

Rothwell, G.S. and T. Gomez, Electricity Economics: Regulation and Deregulation (IEEE Press/John Wiley), 2003.

Schneider, E. and K. Rankin, "An Econometric Model of the Uranium Market," presented at the American Nuclear Society 2007 Annual Meeting, Boston, MA (June 26), 2007. 
F-32

INL/EXT-09-15483 


\title{
Attachment G
}

\section{The Cost Economics of Advanced Nuclear Power Technologies with Application to Modular Sodium Fast Recycling Reactors}

\author{
Geoffrey Rothwell \\ Department of Economics \\ Stanford University, Stanford, California \\ Contract No. 00058512 \\ with Battelle Energy Alliance, LLC \\ Idaho Falls, Idaho
}


G-2

INL/EXT-09-15483 


\begin{abstract}
This attachment estimates the Levelized Unit Electricity Cost (equal to LongRun Average Cost) for the Advanced Recycling Reactor following the Generation IV International Forum (GIF) Economic Modeling Working Group (EMWG), Cost Estimating Guidelines for Generation IV Nuclear Energy Systems (2005). The cost economics methodology involves specifying input levels and prices, a discussion of block versus plant economies of scale, the definition of types of fixed costs in nuclear facility construction, and a continuous (rather than discrete) decline of First-of-a-Kind (FOAK) to $\mathrm{N}^{\text {th }}$-of-aKind (NOAK) capital and average costs. The methodology is applied to General Electric's NOAK cost estimate of the Super-PRISM (Power Reactor Innovative Small Module) with 1,520 MWe (net). This is compared with updated estimates of Argonne National Laboratory's NOAK cost estimate for the PRISM Mod B, a "burning" fast reactor with a conversion ratio of 0.80 . Based on the University of Chicago report, two learning rates are assumed (3-4.5\%) in the decline in cost from FOAK to NOAK with each doubling of capacity. With the "S-PRISM Mod B" four-reactor configuration, FOAK capital costs range from about $\$ 3,100 / \mathrm{kWe}$ with a cost of capital of $5 \%$ and a learning rate of $3 \%$, to about $\$ 3,700 / \mathrm{kWe}$ with a cost of capital of $10 \%$ and a learning rate of $4.5 \%$. Average (levelized) cost ranges from about $\$ 50 / \mathrm{kWh}$ to about $\$ 78 / \mathrm{kWh}$ for FOAK cost estimates.
\end{abstract}


G-4

INL/EXT-09-15483 


\section{ACKNOWLEDGEMENTS}

This attachment was written with funding from Standard Research Subcontract No. 00058143 with Battelle Energy Alliance, Idaho Falls, Idaho. Thanks to E. Bertel, C. Braun, M. Crozat, D. Korn, B. Rasin, D. Shropshire, R. Versluis, K. Williams, and members of the Advanced Fuel Cycle Initiative (AFCI) and the Economic Modeling Working Group (EMWG) of the Generation IV International Forum (GIF) for their encouragement, references, data, and comments. This attachment reflects the views and conclusions of the author and not those of the employers, sponsors, publishers, AFCI, EMWG, GIF, or U.S. Department of Energy. 
G-6

INL/EXT-09-15483 


\section{CONTENTS}

ABSTRACT G-3

ACKNOWLEDGEMENTS G-5

ACRONYMS G-9

1. COST STRUCTURE AND MARKET ANALYSIS OF THE FAST REACTOR INDUSTRY G-11

2. ECONOMICS OF NUCLEAR FACILITIES: COST STRUCTURES....................................... G-11

2.1 Nuclear Industry Production Functions and Total Cost .................................................... G-11

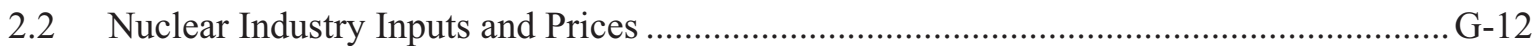

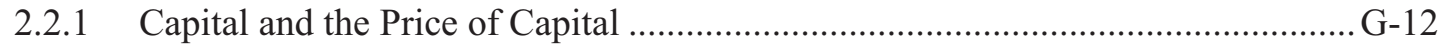

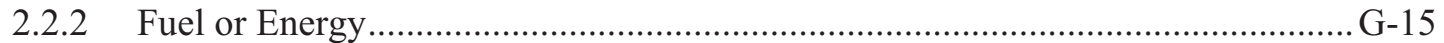

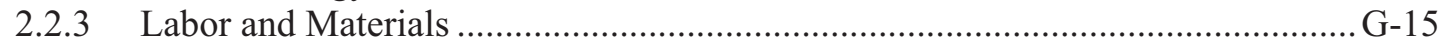

2.3 Nuclear Industry Average Cost and its Relationship to Output ........................................ G-16

2.4 Scale Economies in Capital and Labor and Modeling Fixed and Variable Costs.............. G-18

2.5 Transforming Nth-of-a-Kind Costs into First-of-a-Kind Costs ........................................ G-18

2.6 Nuclear Industry Average Cost, Output, Profit, and Supply.......................................... G-20

3. APPLICATION OF THE COST ECONOMICS METHODOLOGY TO SODIUM FAST

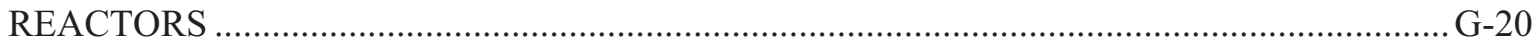

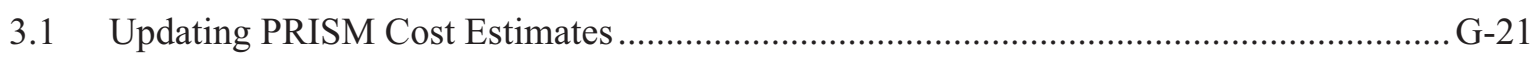

3.1.1 Updating Super-PRISM Capital and Average Costs .............................................

3.1.2 Updating PRISM Mod B Capital and Average Costs ............................................ G-23

3.2 Cost Reductions from First-of-a-Kind to Nth-of-a-Kind for the PRISM Mod B .............. G-26

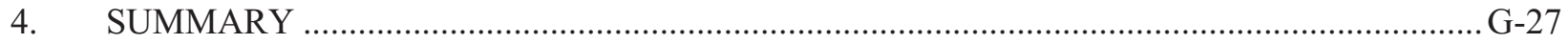

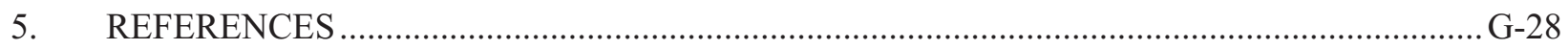

\section{FIGURES}

Figure 1. Example of a production block in a nuclear power plant. .....................................................

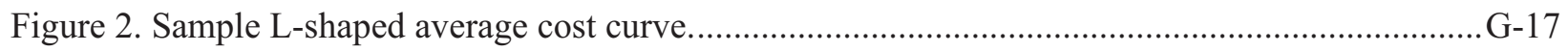

Figure 3. Block Configurations for S-PRISM and PRISM Mod B...................................................

\section{TABLES}

Table 1. Updating GE (2000) to EMWG (2005) and 2005 \$: TCIC and K/kWe. G-22

Table 2. Updating GE (2000) to EMWG (2005) and 2005 \$: Average Cost. G-23

Table 3. Updating ANL (2004) to EMWG (2005) and 2005 \$: Capital Cost. G-24

Table 4. Updating ANL (2004) to EMWG (2005) and 2005 \$: Average Cost. G-25

Table 5. FOAK Costs for the "S-PRISM Mod B." .G-27 
G-8

INL/EXT-09-15483 


\section{ACRONYMS}

AFCI Advanced Fuel Cycle Initiative

ANL Argonne National Laboratory

AVC average variable cost

CEA Council of Economic Advisers

CRF capital recovery factor

DDC decommissioning and decontamination of cost

ECG Economics Crosscut Group

EMWG Economic Modeling Working Group

FOAK First-of-a-Kind

G4-ECONS Generation IV Economic Costs of Nuclear Systems (software)

GDP Gross Domestic Product

GE General Electric

GIF Generation IV International Forum

IAEA International Atomic Energy Agency

IDC interest during construction

MES Minimum Efficient Scale

MWh Megawatt-hour

NOAK Nth-of-a-Kind

O\&M Operation and Maintenance

OLS Ordinary Least Squares

PRISM Power Reactor Innovative Small Module

PRISM Mod B Power Reactor Innovative Small Module modified for burning actinides

SFR Sodium Fast Reactor

S-PRISM Super-Power Reactor Innovative Small Module

TCIC total capital investment cost

TSLCC total system life-cycle cost

$\mathrm{vc}$

variable costs 
G-10

INL/EXT-09-15483 


\section{The Cost Economics of Advanced Nuclear Power Technologies with Application to Modular Sodium Fast Recycling Reactors}

\section{COST STRUCTURE AND MARKET ANALYSIS OF THE FAST REACTOR INDUSTRY}

The purpose of this analysis is to create an economic model to forecast the costs of a First-of-a-Kind (FOAK) and Nth-of-a-Kind (NOAK) advanced, recycling fast reactor. The model is a synthesis of previous cost engineering and econometric studies. This attachment presents a general model of nuclear facility costs and applies it to a fast reactor energy system. The fuel cycle cost estimates from references are taken as given (after updating them for inflation). Parallel work is being done on cost structures and markets for thermal and fast fuel cycles, see Attachment F and Williams (2007).

\section{ECONOMICS OF NUCLEAR FACILITIES: COST STRUCTURES}

\subsection{Nuclear Industry Production Functions and Total Cost}

Each nuclear facility can be characterized by a production function:

$Q=Q(K, F, L, M)$,

where

$Q=$ annual output measured in units of service (e.g., megawatt-hours, MWh) or kilograms of product (e.g., kg of Uranium, $\mathrm{kgU}$ )

$K=$ total capital investment cost (TCIC) (defined in EMWG 2005) measured in millions, M, of 2005 dollars

$F=$ fuel or energy input (measured by energy content [MWh] or weight $[\mathrm{kgU}]$ ) required to produce $Q$

$L=$ number of employees at the facility

$M=$ other materials that might be used in the process (e.g., chemicals, measured by weight).

Unless otherwise specified, these are Nth-of-a-Kind, NOAK, input levels. (Section 5 discusses FOAK costs and the relationship between FOAK and NOAK inputs and costs.)

Following Rothwell (1990),

$C F=Q /(N \cdot h)$ or $Q=C F \cdot N \cdot h$

where

$$
\begin{aligned}
& C F=\text { annual capacity factor } \\
& N=\text { nominal (net) capacity of the plant (e.g., MWh) } \\
& h=\text { a constant that translates } N \text { into annual quantities. }
\end{aligned}
$$


If size is measured in megawatt-hours of capacity, then $h=8,766$ hours (on average). If both output and size are measured in millions of tons per year, then $h=1$.

The total annual cost, $T C$, of producing $Q$ is:

$T C_{\mathrm{t}}=p_{K} K_{\mathrm{t}}+p_{F} F_{\mathrm{t}}+p_{L} L_{\mathrm{t}}+p_{M} M_{\mathrm{t}}$

where

$$
\begin{aligned}
& p_{K}=\text { annual capital charge rate } \\
& p_{F}=\text { price of fuel or energy, (e.g., } 2005 \text { dollars per megawatt-hour [MWh]) } \\
& p_{L}=\text { annual (burdened) salary of an employee in } 2005 \text { dollars } \\
& p_{M}=\text { price of materials. }
\end{aligned}
$$

(Real prices remain unchanged; only levels of inputs change over time.) An analysis of a stochastic version of Equation (3) can be found in Rothwell (2006).

The total annual revenue, $T R_{\mathrm{t}}$ is equal to the market price of the product or service, $p_{Q}$, times $Q_{\mathrm{t}}$. Total economic profit is $T R_{\mathrm{t}}$ minus $T C_{\mathrm{t}}$, or

PROFIT $_{t}=p_{Q} Q_{t}-\left(p_{K} K_{t}+p_{F} F_{t}+p_{L} L_{t}+p_{M} M_{t}\right)$

(Economic profit is the residual after payments to debt and a risk-adjusted rate of return on equity; accounting profit is the residual after payments to debt [Rothwell and Gomez 2003, p. 25.]) The discounted total system life-cycle cost, TSLCC, of producing total quantity, $\Sigma Q_{t}$, is:

$T S L C C=\Sigma\left(p_{K} K_{\mathrm{t}}+p_{F} F_{\mathrm{t}}+p_{L} L_{\mathrm{t}}+p_{M} M_{\mathrm{t}}\right)(1+r)^{-\mathrm{t}}$

where the summation is over the commercial life of the facility, all construction costs are discounted to the quarter of commercial operation, and $r$ is the appropriate discount rate. The Levelized Unit Cost, or Long-Run Average Cost, $A C$, is:

$A C=T S L C C /\left[\Sigma Q_{t}(1+r)^{-\mathrm{t}}\right]$

If inputs and outputs are constant over time, then $A C=T C / Q$. Following neo-classical economic theory, the nuclear facility owner/operator is assumed to maximize profit subject to the production function. On the other hand, substituting Equation (2) into Equation (1), the facility owner could be attempting to maximize profit by maximizing the capacity factor subject to exogenous prices. For more on this approach, see Rothwell (1996).

\subsection{Nuclear Industry Inputs and Prices}

This section discusses the inputs $\left(\underline{x}=\left[\begin{array}{llll}K & F & L & M\end{array}\right]\right)$ and prices $\left(\underline{\underline{p}}=\left[\begin{array}{ll}p_{K} & p_{F} \\ p_{L} & p_{M}\end{array}\right]\right)$. Section 2.3 will use these, with information on output, to calculate total and average cost.

\subsubsection{Capital and the Price of Capital}

First, consider $K(=\mathrm{TCIC})$ and $p_{K}$, the price of capital, where $p_{K} \cdot K$ is the annual capital charge. TCIC includes the direct, DIRECT, and indirect costs of plant construction, owner's costs, and contingency (which is equal to zero when construction is complete), and interest during construction, IDC (EMWG 2005, p. 31): 
"In the Generation IV International Forum (GIF) TCIC account system, preconstruction costs are allocated to Accounts 10, direct costs to Accounts 20, capitalized indirect services to Accounts 30 and the totals of these Accounts 10 thru 30 representing base construction costs of the plant. Capitalized owner costs are allocated to Accounts 40, and supplementary costs to Accounts 50. The subtotal at this level (Accounts 10 thru 50) represents the plant overnight construction costs. Remaining capitalized costs for financing are allocated to Accounts 60 for a Total Capital Investment Cost (TCIC)."

Direct costs (including site preparation costs) can be found in Accounts 10 and 20 in the GIF Codeof-Accounts. Indirect, owner's, and supplemental costs can be expressed as percentage mark-ups on direct cost: $\mathrm{C}_{\text {indirect }}$ (Account 30), $\mathrm{C}_{\text {owners }}$ (Account 40), and $\mathrm{C}_{\text {other }}$ (Account 50). So BASE cost is

BASE $=\left(1+\mathrm{C}_{\text {indirect }}+\mathrm{C}_{\text {owners }}+\mathrm{C}_{\text {other }}\right)$ DIRECT $=k_{1} \cdot$ DIRECT

where $k_{1}=\left(1+\mathrm{C}_{\text {indirect }}+\mathrm{C}_{\text {owners }}+\mathrm{C}_{\text {other }}\right)$ is a multiplier that translates direct costs into base costs. $\mathrm{C}_{\text {indirect }}$, $\mathrm{C}_{\text {owners, }}$, and $\mathrm{C}_{\text {other }}$ can be estimated from the bottom-up (with bid information) or from the top-down as a percentage of direct costs at similar facilities. For example, if DIRECT were $\$ 1,000 \mathrm{M}_{2} \mathrm{C}_{\text {indirect }}=20 \%$, and $\mathrm{C}_{\text {owners }}=\mathrm{C}_{\text {other }}=5 \%$, then $k_{1}=1.3$ and $B A S E=\$ 1,300 \mathrm{M}$.

Also, contingency can be expressed as a percentage $\left(\mathrm{C}_{\text {contingency }}\right)$ mark-up on $B A S E$, where the rate depends on the error associated with the cost estimate (Rothwell 2005). BASE plus contingency is equal to overnight cost, $O C$ :

$O C=\left(1+\mathrm{C}_{\text {contingency }}\right) k_{1} \operatorname{DIRECT}=k_{2} \cdot \operatorname{DIRECT}$

where $k_{2}=\left(1+\mathrm{C}_{\text {contingency }}\right) k_{1}$ is a multiplier that translates direct costs into overnight costs. For example, if the contingency rate is $10 \%$, then $k_{2}=1.43$. Total Capital Investment Cost, $K$, is equal to overnight costs plus financing charges (i.e., IDC). IDC can be expressed as a multiplier, $\mathrm{C}_{\mathrm{IDC}}$ :

$K=\left(1+\mathrm{C}_{\mathrm{IDC}}\right) k_{2} \cdot \operatorname{DIRECT}=k^{\prime} \cdot \operatorname{DIRECT}$

where $k^{\prime}=\left[1+\mathrm{C}_{\mathrm{IDC}}(\mathrm{r}, L T, \mathrm{D})\right] k_{2}$ is a multiplier that translates direct costs into total capital investment costs, (e.g., if $k_{2}=1.43$ and $\mathrm{C}_{\mathrm{IDC}}=20 \%$ ), then $k^{\prime}=1.716$, or, if $O C$ equals $\$ 1,430 \mathrm{M}$ and the IDC factor is $20 \%$, then $K$ is $\$ 1,716 \mathrm{M}$. Let $K^{\prime}=K / k^{\prime}=D I R E C T$.

IDC is estimated by calculating cash flows in all periods of construction and discounting them to commercial operation. Therefore, IDC is a function of the discount rate (equal to the cost of capital, r), the length of construction (lead time, $L T$, from first concrete to commercial operation [IAEA 2006]), and the distribution of spending during construction (D). So, $\mathrm{C}_{\mathrm{IDC}}=\mathrm{C}_{\mathrm{IDC}}(\mathrm{r}, L T$, D) in Equation (9). Therefore, $K$ is a function of (1) a parameter that translates direct costs into overnight costs, (2) the cost of capital during construction, (3) the length of construction, (4) the spending distribution, and (5) direct costs.

DIRECT costs can be allocated between fixed costs, $F C$, and variable costs, $V C$. Fixed costs include (1) costs associated with the development of the site (e.g., site licensing fees and site preparation expenses [capitalized pre-construction costs]), and (2) "first-unit" costs (i.e., costs that would be required if the plant could only produce one unit of output). These include all "common costs" (e.g., costs shared by more than one production unit). (The costs of single unit and first-unit LWRs, built in the U.S. between 1970 and 1980, were higher than follow-on reactors at the same site [Rothwell 1986].) Variable costs, $V C$, vary with the size, $N$. So:

$K^{\prime}=D I R E C T=F C+V C(N)$ 
For example, the fixed cost component is $F C=\$ 200 \mathrm{M}$. The equation for the variable cost is $V C=$ avc $(\$ / \mathrm{kW}) \times N(\mathrm{~kW})$, which is a linear multiple of the capacity of the facility. The VC for an $\$ 800 / \mathrm{kW}$ plant would be $\$ 800 / \mathrm{kW} \times 1,000,000(\mathrm{~kW})=\$ 800 \mathrm{M}$. So using both $\mathrm{FC}$ and VC cost terms, the DIRECT $=$ $\$ 200 \mathrm{M}+\$ 800 \mathrm{M}=\$ 1,000 \mathrm{M}$. With $k^{\prime}=1.716$, total capital investment costs would be $\$ 1,716 \mathrm{M}$, or $\$ 1,716 / \mathrm{kW}$.

The size of the facility is equal to the size, $n$, of the standardized production block (e.g., one nuclear reactor plus one turbine-generator) times the number of blocks, $B$, (i.e., $N=n B$ ). See Figure 1. For example, at a Sodium Fast Reactor (SFR), $n_{\mathrm{SFR}}$ could be $333 \mathrm{MWe}$ and $B_{\mathrm{SFR}}$ could be 6 , so $N_{\mathrm{SFR}}$ would be 2,000 MWe. Section 2.4 will address the question of whether variable cost is a linear function (or some other function) of the size of the standardized production block, the number of production blocks, and/or the total facility size.

$$
\begin{aligned}
& 1 \text { block = } \\
& \begin{array}{c}
\begin{array}{c}
\text { NUCLEAR } \\
\text { REACTOR }
\end{array} \\
\text { e.g., } 1000 \mathrm{MW} \text { (th) }
\end{array}+\underset{\begin{array}{c}
\text { TURBINE } \\
\text { GENERATOR }
\end{array}}{\text { e.g., } 333 \mathrm{MW}(\mathrm{e})} \\
& \text { There are } B \text { standard blocks at } 1 \text { plant, } \\
& \text { each with } n \text { units of capacity: } \\
& \text { Plant size, } N=n \times B
\end{aligned}
$$

Figure 1. Example of a production block in a nuclear power plant.

Next, consider the price of capital, $p_{K}$. The primary component of the price of capital is the capital recovery factor $(\mathrm{CRF})$. However, there are several charges associated with the total capital investment cost, such as decommissioning, capital replacement expenses, local property taxes, and property insurance. Because these are functions of $K$, and are usually expressed as percentages of $K$, they are included in $p_{K}$ (although some of these expenses are allocated to Operation and Maintenance [O\&M], accounts in the GIF Code-of-Accounts).

The Capital Recovery Factor (CRF) yields an annual annuity rate as a function of the cost of capital, $\mathrm{r}$, and the economic life time, $\mathrm{T}$, of the facility:

$\mathrm{CRF}=\left[\mathrm{r}(1+\mathrm{r})^{\mathrm{T}}\right] /\left[(1+\mathrm{r})^{\mathrm{T}}-1\right]$

For example, with a cost of capital of $10 \%$ and an economic life of 15 years, CRF equals $13.1 \%$. On the other hand, with a cost of capital of $10 \%$ and an economic life of 40 years, CRF equals $10.2 \%$. As T increases, CRF approaches $r$. Therefore, for reasonable costs of capital and long discounting, the CRF can be set to the cost of capital. With a cost of capital of $10 \%$ and an economic life of 40 years, the difference between CRF and $r$ is less than $3 \%$.

Decommissioning is treated here as a sinking fund, earning a rate of return, $\underline{r}$, during the economic life of the facility. The future value of the fund should be equal to the decommissioning and decontamination cost $(D D C)$ of the facility (Rothwell 1991). Following EMWG (2005), DDC is one-third of the direct costs. So, the annual contribution is:

$D D C=(\underline{\mathrm{r}} / 3) /\left[(1+\underline{\mathrm{r}})^{\mathrm{T}}-1\right] \cdot \operatorname{DIRECT}$

Because DIRECT $=K / k^{\prime}$

$D D C=\left(\underline{\mathrm{r}} / 3 k^{\prime}\right) /\left[(1+\underline{\mathrm{r}})^{\mathrm{T}}-1\right] \cdot K=\mathrm{D} \& \mathrm{D}\left(\underline{\mathrm{r}}, k^{\prime}, \mathrm{T}\right) \cdot K$ 
Because of the restrictions placed on Nuclear Decommissioning Trust Funds, the rate of return on these funds, $\underline{r}$, is lower than the facility owner's cost of capital, r. For simplicity, let $\underline{r}=r / 2$ (i.e., if the cost of capital is $10 \%$ ) then the rate of return on the trust fund would be $5 \%$. This does not follow EMWG (2005). On the other hand, some of the IAEA's economic models assume $\underline{r}=0 \%$, increasing the levelized cost of decommissioning above the levelized cost of fuel. The methodology here balances these two assumptions.

Finally, capital replacement expenses and spare parts (Accounts 75 and 77) are modeled as a constant percentage, $\mathrm{C}_{\text {parts }}$, of $K$, for example, $\mathrm{C}_{\text {parts }}=1 \%$. Similarly, property insurance is a constant percentage, $\mathrm{C}_{\text {insure }}$, of $K$, for example, $\mathrm{C}_{\text {insure }}=1 \%$, and property taxes are a constant percentage, $\mathrm{C}_{\text {taxes }}$, of $K$, for example, $\mathrm{C}_{\text {taxes }}=3 \%$ (Account 78 includes both taxes and insurance).

To summarize:

$p_{K}=\mathrm{CRF}(\mathrm{r}, \mathrm{T})+\mathrm{D} \& \mathrm{D}\left(\mathrm{r}, k^{\prime}, \mathrm{T}\right)+\mathrm{C}_{\text {parts }}+\mathrm{C}_{\text {insure }}+\mathrm{C}_{\text {taxes }}$

For example, if $\mathrm{r}=10 \%$ per year, $\mathrm{T}=40$ years, $k^{\prime}=1.716$, and $\mathrm{C}_{\text {parts }}+\mathrm{C}_{\text {insure }}+\mathrm{C}_{\text {taxes }}=5 \%$, then $p_{K}=$ $15.37 \%$ and $p_{K} \cdot K=\$ 264 \mathrm{M}$ per year with a TCIC of $\$ 1,716 \mathrm{M}$. (This includes some costs usually allocated O\&M accounts.) If $p_{K}$ is simplified to $15 \%$, the annual charge is $\$ 257 \mathrm{M}$ (i.e., an error of less than $3 \%$ ).

\subsubsection{Fuel or Energy}

Second, consider $F$, the fuel or energy input, and $p_{F}$, the price of fuel or energy, where $p_{F} \cdot F$ is the annual fuel or energy bill. The price and quantity of fuel depend on the nuclear facility being considered. For example, for centrifuge enrichment facilities, $F$ equals $50 \mathrm{kWh} / \mathrm{SWU}$ times the nominal size of the facility, N, (e.g., $1 \mathrm{M} \mathrm{SWU}$, or 50,000 MWh per year). On the other hand, for diffusion enrichment facilities, $F$ equals $2,500 \mathrm{kWh} / \mathrm{SWU}$ times N, or 20,000,000 MWh per year for an $8 \mathrm{M} \mathrm{SWU} /$ year plant. The price of energy, $p_{F}$, depends on the form of energy (e.g., industrial electricity sells for about $\$ 50 / \mathrm{MWh}$ ). The total annual energy bill for an enrichment plant varies from $\$ 2.5 \mathrm{M}$ for a centrifuge plant of $1 \mathrm{M} \mathrm{SWU}$ and $\$ 1,000 \mathrm{M}$ for a diffusion plant of $8 \mathrm{M} \mathrm{SWU}$.

On the other hand, nuclear power plants produce energy (e.g., MWh) using nuclear fuel, $F$, measured in kilograms of uranium $(\mathrm{kgU})$ per year at a price of $p_{F}$, expressed in $\$ / \mathrm{kgU}$. The annual fuel bill equals $p_{F}$ $F$ (plus contributions to the Nuclear Waste Trust Fund, or a similar waste management and disposal charge).

Also, $p_{E} \cdot E$ can be added to Equation (3) to represent energy used by joint-production facilities (e.g., heat with a desalination facility). The transfer price for the energy enters as a negative value in Equation (3), reducing the total costs of generating electricity. On nuclear co-generation, see Rothwell (2007a).

\subsubsection{Labor and Materials}

Labor and materials, $L$ and $M$, costs are often grouped together in nuclear facility costs as $O \& M$ where

$O \& M=p_{L} \cdot L+p_{M} \cdot M$

Annualized O\&M costs are described in EWMG (2005): "The O\&M costs include all non-fuel costs, such as costs of plant staffing, consumable operating materials (worn parts) and equipment, repair and interim replacements, purchased services, and nuclear insurance. They also include taxes and fees. .." The GIF O\&M accounts can be allocated as 


\begin{tabular}{|c|c|c|}
\hline Account & Account Title & Allocation \\
\hline 71 & Operations and Maintenance Staff & included in $p_{L} \cdot L$ \\
\hline 72 & Management Staff & included in $p_{L} \cdot L$ \\
\hline 73 & Salary Related Costs & included in $p_{L} \cdot L$ \\
\hline 74 & Operations Chemicals and Lubricants & included in $p_{M} \cdot M$ \\
\hline 75 & Spare Parts & included in $p_{k} \cdot K$ \\
\hline 76 & Utilities, Supplies, and Consumables & included in $p_{F} \cdot F$ \\
\hline 77 & Capital Plant Upgrades & included in $p_{k} \cdot K$ \\
\hline 78 & Taxes and Insurance & included in $p_{k} \cdot K$ \\
\hline
\end{tabular}

Of course, Accounts 75,77, and 78 could be included in O\&M, although they are calculated as percentages of $K$. In this analysis of cost structures and scale economies, $p_{L} \cdot L$ includes Accounts 71, 72, and $73 ; p_{M} \cdot M$ includes Accounts 74 and 76 (where energy utilities should be included in $p_{F} \cdot F$ ); and $p_{K}$. $K$ includes Accounts 75,77 , and 78. This allows the analysis of scale economies in capital and labor.

An estimate of $p_{L}$, the annual salary plus all benefits and overheads (burdens) should be similar to salaries in similar industries, such as the chemical industry. In this analysis, the average (burdened) labor year is assumed to cost $\$ 60,000$ (a constant, $\boldsymbol{p}_{L}$ ) in Europe, Japan, and the U.S., and half this in transitional and developing countries $\left(\boldsymbol{p}_{L} / 2\right)$. (This can be changed parametrically with a multiplier, $\mathrm{C}_{\mathrm{L}}$ [i.e., substitute $\mathrm{C}_{\mathrm{L}} \cdot \boldsymbol{p}_{\boldsymbol{L}}$ for $\boldsymbol{p}_{\boldsymbol{L}}$.) If the annual labor bill is known or can be estimated, then the number of employees, $L$, can be estimated and used in an analysis of scale economies.

Finally, $p_{M} \cdot M$ is the annual materials bill. If quantities of materials are known, the annual materials bill can be estimated directly. For example, if the weight of hardware for nuclear fuel can be estimated and price information is available, then $p_{M} \cdot M$ can be calculated from these estimates. Generally, the materials bill is estimated as a residual (i.e., total O\&M is given), Accounts 71, 72, 73, 75, 77, and 78 are calculated and subtracted from total O\&M, yielding the annual materials bill, $p_{M} \cdot M$. Under this procedure, there are no separate estimates for $p_{M}$ and $M$.

With information on inputs and prices, total cost (Equation [3]) can be calculated. With information on output, the average cost (Equation [6]) can be calculated for different levels of output, $Q$, and facility sizes, $N$.

\subsection{Nuclear Industry Average Cost and its Relationship to Output}

To determine the economic incentives of investing in an existing facility or a new facility, one needs to know the relationship between $A C$ and $Q$ (as well as the capital-at-risk, $K$, if there are capital market constraints). Although many levelized cost estimates assume a constant relationship between $A C$ and $Q$, with high fixed costs (e.g., costs of developing a facility), $A C$ is likely to decline with $Q$ until some constraint, such as a health and safety limit, causes the average cost to increase.

The textbook $A C$ curve has a U-shape and is derived from a quadratic (or higher order) total cost curve (this is a reduced form, not a cost function or cost summation, as above):

$T C=\mathrm{a}_{0}+\mathrm{a}_{1} Q+\mathrm{a}_{2} Q^{2}$

$A C=T C / Q$, and marginal cost, $M C=\mathrm{d} T C / \mathrm{d} Q$.

So, following Equation (16):

$A C=\left(\mathrm{a}_{0} / Q\right)+\mathrm{a}_{1}+\mathrm{a}_{2} Q$ 
$M C=\mathrm{a}_{1}+2 \mathrm{a}_{2} Q$.

Further, in Equation (16) $\mathrm{a}_{0}$ represents fixed cost $(F C$, costs that do not vary with output) and $\left(\mathrm{a}_{1} Q+\mathrm{a}_{2} Q^{2}\right)$ represents variable costs $(V C)$. Also, average fixed costs is $\left(\mathrm{a}_{0} / Q\right)$ and average variable cost $(A V C)$ is $\left(\mathrm{a}_{1}+\mathrm{a}_{2} Q\right)$.

With (simulated) cost data for different sized facilities, the implicit relationship between $A C$ and output can be identified. If parameter $\mathrm{a}_{2}$ is insignificant, the forecasting equation reduces to a reciprocal model where $\left(\mathrm{a}_{0} / Q\right)(=$ average fixed costs $)$ declines to zero as size increases, and $\mathrm{a}_{1}$ is the expected asymptotic cost. The graph of this equation is not $\mathrm{U}$-shaped, but L-shaped.

According to Intriligator (1978, p. 282), "For a wide variety of industries, including manufacturing, mining, distribution, transportation, and trade, it has been found that the long-run average cost curves are L-shaped, rather than U-shaped." Figure 2 shows this. Further, "average cost at first falls sharply (based, in part, on spreading fixed costs over more output) but then reaches, or asymptotically approaches, a certain minimum level $A C_{0}$ at a critical level of output," $Q_{0}$. It also remains flat at this level; the critical level of output $Q_{0}$ is the Minimum Efficient Scale (MES). Also, Intriligator (1978, p. 283) states, "Local economies of scale hold if and only if the average cost curve is decreasing, while increasing average cost is equivalent to local diseconomies of scale." In Figure 2 there are economies of scale up to $Q_{0}$, and constant returns to scale beyond $Q_{0}$. (See Rothwell and Gomez, 2003, p. 37-40 for information on scale economies.)

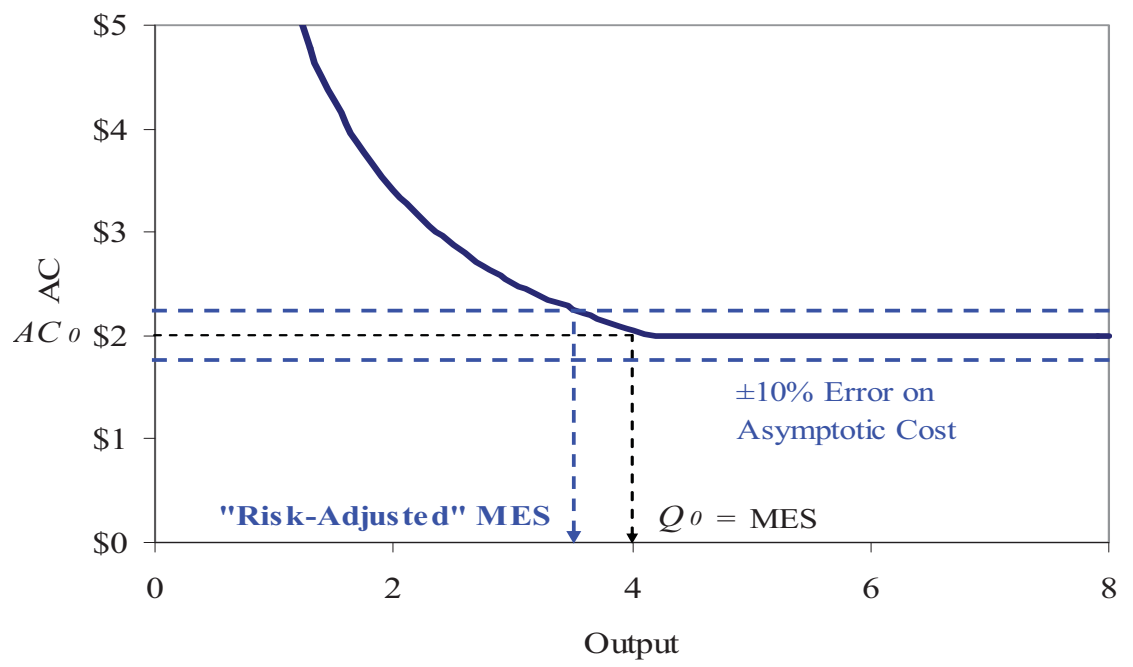

Figure 2. Sample L-shaped average cost curve.

While it is easy to see a "kink" in the average cost curve in Figure 2, the $A C$ curve is more likely to be estimated as a reciprocal equation with a slower approach to the asymptote than in the figure. Further, because these are cost estimates, there is a probability distribution associated with them that arises from modeling and measurement error. Therefore, let MES be that size where the minimum estimated cost is statistically indistinguishable from the asymptotic cost. If the standard error of the cost estimate is equal to the contingency rate (Rothwell 2005), then let the MES occur where cost is within $10 \%$ of the estimated asymptotic cost (i.e., where $A C$ intersects the dashed upper error band in Figure 2). 


\subsection{Scale Economies in Capital and Labor and Modeling Fixed and Variable Costs}

In addition to spreading fixed costs over more output, economies of scale also arise from declines in the use of inputs as the size of the facility increases. Although there could be scale economies in fuel and materials, this analysis assumes fuel and materials exhibit constant returns to scale. The focus here is on economies of scale in capital and labor: positive economies of scale imply a less than proportional increase in the use of an input (e.g., a 10\% increase in plant size could require less than a $10 \%$ increase in either capital or labor, or both). Economies of scale are measured as the elasticity of capital or labor with respect to size: $(\mathrm{d} \ln K / \mathrm{d} \ln N)$ and $(\mathrm{d} \ln L / \mathrm{d} \ln N)$.

To understand the underlying economies of scale, two relationships can be investigated: (1) Total Capital Investment Cost, $K$, as a function of facility size, $K=f_{K}(N)$, and (2) the number of employees, $L$, as a function of facility size, $L=f_{L}(N)$. To test whether there are positive scale economies in capital or labor, the following equations can be estimated:

$\ln K=\mathrm{b}_{01}+\mathrm{b}_{1} \ln N$

$\ln L=\mathrm{b}_{02}+\mathrm{b}_{2} \ln N$.

If $b_{i}$ is not significantly different from 1.0 , there are constant returns to scale. If $b_{i}$ is significantly less than one, there are positive economies of scale. This would be the case if, as often assumed from the relationship between volume and surface area, $b_{i}=0.67$. This would imply a $10 \%$ increase in size would require only a $6.7 \%$ increase in capital investment. Unfortunately, data is not always available on both capital and labor inputs for each industry. When one set of data is unavailable, this analysis assumes $\mathrm{b}_{1}=\mathrm{b}_{2}$, i.e., then there is a single "economy of scale" for the production system.

If constant returns to scale are found (i.e., $b_{1}$ and/or $b_{2}=1$ ), then Equations (19) and (20) reduce to $K$ $=\exp \left(\mathrm{b}_{01}\right) N$ and $L=\exp \left(\mathrm{b}_{02}\right) N$. For forecasting purposes these are estimated as linear forms:

$K=\mathrm{c}_{01}+\mathrm{c}_{1} N$

$L=\mathrm{c}_{02}+\mathrm{c}_{2} N$

where $\mathrm{c}_{01}$ and $\mathrm{c}_{02}$ are not expected to be significantly different from zero. If $\mathrm{c}_{01}=\mathrm{c}_{02}=0$, then these equations reduce to $K=\mathrm{c}_{1} N$ and $L=\mathrm{c}_{2} N$, or $\mathrm{c}_{1}=K / N$ and $\mathrm{c}_{2}=L / N$, where $\mathrm{c}_{1}$ and $\mathrm{c}_{2}$ can be interpreted as the "technical coefficients" in a fixed-proportions production function. On estimating these technical coefficients, Intriligator (1978, p. 273) points out, "The estimation is typically based on a single observation, so regression techniques are not used."

\subsection{Transforming Nth-of-a-Kind Costs into First-of-a-Kind Costs}

Rewriting Equation (10) allows easy comparison with Equation (21):

$K=k^{\prime} \cdot[F C+\underline{a v c} \cdot N]$

Specifically, Equation (23) is equivalent to Equation (21) if $\mathrm{c}_{01}=\left(k^{\prime} \cdot F C\right)$ and $\mathrm{c}_{1}=\left(k^{\prime} \cdot \underline{a v c}\right)$.

Generalizing $F C$ in Equation (23), define two types of fixed cost. $F C_{0}$ are "true First-of-a-Kind costs," according to EMWG $(2005$, p. 48, 80), associated with the development and commercialization of the technology; these decline to zero when NOAK costs are achieved (by definition). And, $\underline{F C}$ are the costs specific to a particular site, including site-specific design, licensing, and preparation; these costs are assumed to not decline with plant size or the cumulative capacity of a particular technology (e.g., they are assumed to be $\$ 100 \mathrm{M}$ in Section 3.1). Also, if a particular plant is considering the addition of new blocks 
to an existing site, and if the site fixed costs have already been completely amortized, then the incumbent's capital cost for additional capacity would only be the variable costs, $\underline{\operatorname{avc}} N$

Further, generalizing $v c$ in Equation (23), define two types of variable cost: (1) $v c$ are costs associated with the production block (e.g., the reactor and turbine-generator), and (2) $\underline{v c}$ are a balance of plant costs. Substituting into Equation (23):

$K=k^{\prime} \cdot\left[F C_{0}+\underline{F C}+(v c+\underline{v c}) N\right]$

Finally, assume that variable costs associated with the production block decline with the cumulative number of blocks produced due to learning in block manufacture, and that variable costs associated with the balance of a plant decline with the cumulative number of plants:

$K_{i}=k^{\prime} \cdot\left[F C_{0}+\underline{F C}+v c\left(B_{\mathrm{j}}\right) \cdot N+\underline{v c}\left(N_{\mathrm{i}}\right) \cdot N\right]$

$K_{i} / N=k^{\prime} \cdot\left[\left(F C_{0} / N\right)+(\underline{F C} / N)+v c\left(B_{\mathrm{j}}\right)+\underline{v c}\left(N_{\mathrm{i}}\right)\right]$

where plants are indexed in sequence by $\mathrm{i}$ and blocks are indexed in sequence by $\mathrm{j}$.

Given that costs estimates have been for the NOAK plant (as presented in most cost studies), FOAK costs must be determined. Let:

$v c_{\mathrm{j}}=v c \cdot\left(1+\mathrm{C}_{\text {LEARN } 1}\right)^{\left[\left(\ln \mathrm{X}_{\mathrm{B}} / \ln 2\right)-(\ln \mathrm{j} / \ln 2)\right]}$

$\underline{v \mathcal{C}} \underline{\mathrm{i}}=\underline{v \mathcal{C}} \cdot\left(1+\mathrm{C}_{\mathrm{LEARN} 2}\right)^{\left[\left(\ln \mathrm{X}_{\mathrm{N}} / \ln 2\right)-(\ln \mathrm{i} / \ln 2)\right]}$

where $\mathrm{j}$ indexes the sequence order of the production block (e.g., nuclear reactor $\mathrm{j}$ ), $\mathrm{i}$ indexes the sequence order of the facility (e.g., nuclear power plant $\mathrm{i}$ ), $\mathrm{C}_{\mathrm{LEARN} 1}$ is the learning rate at the block level, $\mathrm{C}_{\mathrm{LEARN} 2}$ is the learning rate at the plant level, $\mathrm{X}_{\mathrm{N}}$ is the sequence number of the plant where costs are equal to NOAK cost, and $\mathrm{X}_{\mathrm{B}}$ is the sequence number of the block where costs are equal to NOAK cost. See application in Section 3.2.

In EMWG (2005) $\mathrm{X}_{\mathrm{N}}=\mathrm{X}_{\mathrm{B}}=8,000 \mathrm{MW}$. Here, on the other hand (for mathematical tractability), learning continues beyond the first $8,000 \mathrm{MW}$ of capacity (or the appropriate NOAK size for other nuclear facilities). For example, with nuclear power plants of $1,000 \mathrm{MW}$, a learning rate of 5\%, and assuming NOAK costs are achieved with the 8th plant, then:

$v c_{13}=v c \cdot(1.05)^{[3-(\ln 13 / \ln 2)]}=v c \cdot(1.05)^{-0.7}=v c \cdot(1.05)^{-0.7}=v c \cdot 0.97$

(i.e., $3 \%$ less than NOAK costs). So, costs fall continuously from the first plant or block to the last plant or block, and they are equal to NOAK cost of the "NOAK" plant or block.

The question remains what learning rates, $\mathrm{C}_{\text {LEARN1 }}$ and $\mathrm{C}_{\text {LEARN2}}$, to use. EMWG (2005, p. 49) recommends different learning rates for capital (equipment) and (construction) labor:

"Each system development team (Proponent) will perform the estimates for the standard FOAK plant based on current construction experience for similar facilities. Learning experience can be included for NOAK plant based on learning factors to be developed by each team. Guideline factors for each doubling of construction experience are 0.94 for equipment costs, 0.90 for construction labor and a $10 \%$ reduction in material costs for multi plant orders."

Unfortunately, it is difficult to determine labor in the construction of a facility in a top-down model (unlike estimating production labor at a facility), and it is difficult to model multiplant orders. Therefore, consider the University of Chicago report (2004, p. 4-1): 
"A plausible range for future learning rates in the U.S. nuclear construction industry is between 3 and 10 percent. Three percent is consistent with a scenario involving low capacity growth, reactor orders of a variety of designs spaced widely enough apart in time that engineering and construction personnel cannot maintain continuity, some construction delays, and a construction industry that can retain internally a considerable proportion of learning benefits. A medium learning rate of 5 percent is appropriate for a scenario with more or less continuous construction, with occasional, but not frequent, cases of sequential units built at a single facility, a narrower range of reactor designs built by a more competitive construction industry, with delays uncommon. A 10 percent learning rate is aggressive. It would necessitate a continuous stream of orders that keep engineering teams and construction crews intact, a highly competitive construction industry, and streamlined regulation largely eliminating construction delays."

The specifics of deployment relevant to each nuclear sector will be considered in determining the appropriate learning rates in the application of this methodology.

\subsection{Nuclear Industry Average Cost, Output, Profit, and Supply}

Average costs for plants of different sizes are calculated using either Equation (19) or (25) for capital and either Equation (20) or Equation (22) for labor (assuming the simplest forecasting equations to minimize error), and constants for energy and materials, and their prices. These values enter Equation (6) for different costs of capital (e.g., 5\% and 10\% real, following the EMWG [2005], and 15\% as an upper bound on the cost of capital to merchant owners of nuclear facilities). From these calculations, the implicit relationship between $A C$ and output can be examined by estimating Equation (17) for each cost of capital.

Assuming facilities are willing to sell their products or services at average cost (which is equal to long-run marginal cost and includes a reasonable return to capital), supply curves can be traced using the hypothesized cost structures. Hypothetical profits can be calculated for each facility by subtracting total cost from total revenue, given by the annual production rate (size multiplied by the capacity factor) and the observable market price.

In sum, four cost inputs and a single output can be estimated for each nuclear facility. From these estimates, the MES can be calculated. This depends on economies of scale in capital and labor, and the importance of fixed cost relative to variable cost. To understand whether a non-fuel cycle state has an economic incentive to enter an industrial sector of the nuclear fuel cycle as its anticipated number of nuclear power plants grows, the MES can be compared with the new entrant's facility size. If the MES for a new entrant is large (due to the high fixed costs of designing, licensing, and testing a facility), the new entrant is unlikely to be profitable and might not enter the market. If the sector is unprofitable, profitoriented firms will not invest in new capacity, even if there is an increase in nuclear fuel cycle services or reactor demand. Of course, if the product or service supplier has non-profit motives, entry could occur anyway, either by a fuel-cycle or non-fuel cycle state subsidizing the industry.

\section{APPLICATION OF THE COST ECONOMICS METHODOLOGY TO SODIUM FAST REACTORS}

While this cost economics methodology is applicable to Light Water Reactors (see Rothwell [2006]), and to High-Temperature Gas Reactors (see Rothwell and Williams [2006]), this attachment applies the methodology to Sodium Fast Reactors. In particular, the analysis focuses on General Electric's (GE) 
PRISM fast reactor. Section 3.1 updates NOAK estimates of the TCIC $(=K)$ and Levelized Unit Electricity Cost $(=A C)$ for the S-PRISM and PRISM Mod B. One update is to set pre-construction costs to $\$ 100 \mathrm{M}$ for each plant site reflecting anticipated site licensing costs. Section 3.2 discusses FOAK costs.

In the PRISM discussion, the term "block" is used to describe a production unit where one, two, or three reactors are connected to a single turbine-generator (see Figure 3). On the left side are blocks in Boardman, Hui, Carroll, Dubberley (2000), hereafter referred to as GE (2000). On the right side are blocks in Hoffman, Hill, and Finck (2004), hereafter referred to as ANL (2004). However, in the discussion of the change in cost from FOAK to NOAK, the term block will refer only to a single nuclear reactor with a single turbine-generator (as in Section 2.2).
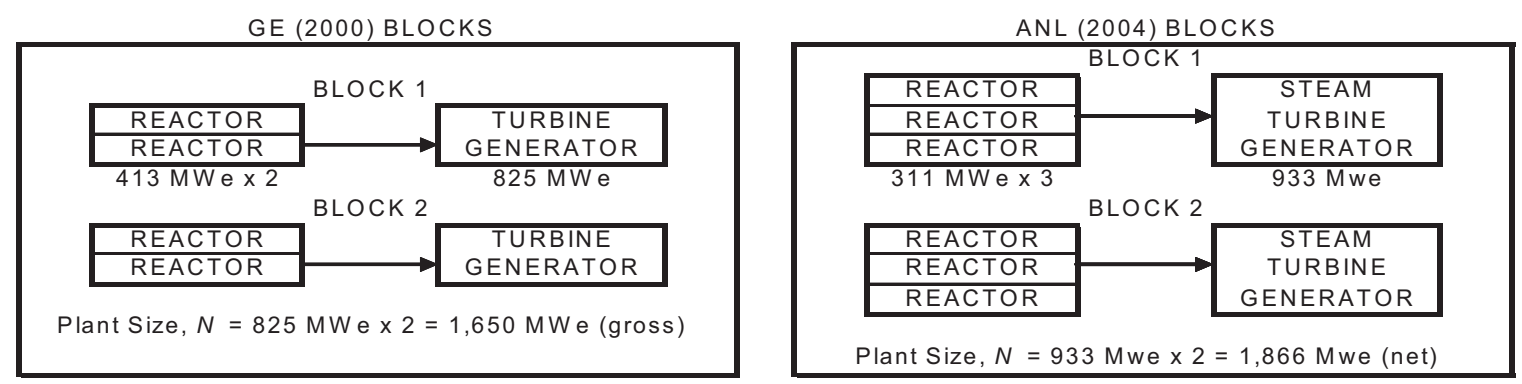

Figure 3. Block Configurations for S-PRISM and PRISM Mod B.

\subsection{Updating PRISM Cost Estimates}

\subsubsection{Updating Super-PRISM Capital and Average Costs}

"Table 1, S-PRISM Cost Summary" in GE (2000) is reproduced in Table 1. TCIC $(=K)$ is $\$ 2,200 \mathrm{M}$ (1996 dollars, including IDC of \$31M and no contingency) for a 2-block power plant (see Figure 3) of 1,651 MWe (gross; 1,520 MWe net). These are NOAK cost estimates. The specific TCIC (i.e., \$ $/ \mathrm{kWe}$ ) is $\$ 1,334 / \mathrm{kWe}$ (gross). The levelized TCIC is $\$ 16.80 / \mathrm{MWh}$. The (net) levelized unit electricity cost $(=A C)$ is $\$ 29.02 / \mathrm{MWh}$, see Table 2 . 
Table 1. Updating GE (2000) to EMWG (2005) and 2005 \$: TCIC and K/kWe.

\begin{tabular}{|c|c|c|c|c|}
\hline $\begin{array}{l}\text { S-PRISM from GE (2000) } \\
\text { all costs in \$M }\end{array}$ & $\begin{array}{l}\text { GE (2000) } \\
\text { Estimate }\end{array}$ & $\begin{array}{l}\text { GE (2000) } \\
\text { Estimate }\end{array}$ & $\begin{array}{l}\text { Updated } \\
\text { Estimate }\end{array}$ & $\begin{array}{l}\text { Updated } \\
\text { Estimate }\end{array}$ \\
\hline Description (for Total Cost accounts) & $\begin{array}{l}\text { Total Cost } \\
(\$ \mathrm{M})\end{array}$ & $\begin{array}{l}\text { Specific Cost } \\
\text { in } \$ / \mathrm{kWe}\end{array}$ & $\begin{array}{c}\text { Specific } \\
\text { Cost at } 5 \%\end{array}$ & $\begin{array}{c}\text { Specific } \\
\text { Cost at } 10 \%\end{array}$ \\
\hline Plant Size in MWe, $N=1,651$ (gross) and 1,520 (net) & 1,651 & 1,651 & 1,520 & $\mathbf{1 , 5 2 0}$ \\
\hline $\begin{array}{l}\text { Pre-Construction Costs (Account 10) } \\
\text { Capitalized Direct Costs (Accounts in the } 20 \text { series) } \\
\text { Buildings, Structures, \& Improvements on Site } \\
\text { Reactor Plant equipment } \\
\text { Turbine/Generator Plant equipment } \\
\text { Electrical equipment } \\
\text { Water intake and heat rejection plant } \\
\text { Miscellaneous plant equipment } \\
\text { Special materials } \\
\text { Capitalized Direct Costs (Account 20) } \\
\text { DIRECT = (Account } \mathbf{1 0 + A c c o u n t ~ 2 0 )}\end{array}$ & $\begin{array}{r}\$ 0 \\
\$ 232 \\
\$ 900 \\
\$ 275 \\
\$ 128 \\
\$ 0 \\
\$ 39 \\
\$ 20 \\
\mathbf{\$ 1 , 5 9 4} \\
\mathbf{\$ 1 , 5 9 4}\end{array}$ & $\begin{array}{r}\$ 141 \\
\$ 545 \\
\$ 167 \\
\$ 78 \\
\$ 0 \\
\$ 24 \\
\$ 12 \\
\mathbf{\$ 9 6 5} \\
\mathbf{\$ 9 6 5}\end{array}$ & $\begin{array}{r}\$ 66 \\
\$ 199 \\
\$ 773 \\
\$ 236 \\
\$ 110 \\
\$ 0 \\
\$ 33 \\
\$ 17 \\
\$ \mathbf{\$ 1 , 3 6 8} \\
\mathbf{\$ 1 , 4 3 4}\end{array}$ & $\begin{array}{r}\$ 66 \\
\$ 199 \\
\$ 773 \\
\$ 236 \\
\$ 110 \\
\$ 0 \\
\$ 33 \\
\$ 17 \\
\mathbf{\$ 1 , 3 6 8} \\
\mathbf{\$ 1 , 4 3 4}\end{array}$ \\
\hline $\begin{array}{l}\text { Indirect Multiplier (Account 30) } \\
\text { Owner's Cost Multiplier (Account 40) } \\
\text { Supplementary Cost Multiplier (Account 50) } \\
D I R E C T \text { to BASE Multiplier (k1) } \\
\text { BASE } \\
\text { Contingency Multiplier } \\
\text { Overnight Cost, OC } \\
\text { Interest During Construction (IDC) Multiplier } \\
\text { Total Capitalized Investment Cost and } \boldsymbol{K} / \mathbf{k W e} \\
\text { Levelized TCIC (T=40 years) }\end{array}$ & \begin{tabular}{r|}
1.179 \\
1.182 \\
1.000 \\
1.361 \\
$\$ \mathbf{2}, 170$ \\
1.000 \\
$\$ \mathbf{\$ 2 , 1 7 0}$ \\
1.015 \\
$\mathbf{\$ 2 , 2 0 0}$ \\
$\mathbf{\$ 1 6 . 8 0}$
\end{tabular} & $\begin{array}{r}1.179 \\
1.182 \\
1.000 \\
1.361 \\
\$ \mathbf{\$ 1 , 3 1 4} \\
1.000 \\
\mathbf{\$ 1 , 3 1 4} \\
1.015 \\
\mathbf{\$ 1 , 3 3 4} \\
\mathbf{\$ 1 6 . 8 0} \\
\end{array}$ & $\begin{array}{r}1.179 \\
1.182 \\
1.000 \\
1.361 \\
\$ \mathbf{\$ 1 , 9 5 2} \\
1.200 \\
\mathbf{\$ 2 , 3 4 3} \\
1.137 \\
\mathbf{\$ 2 , 6 6 4} \\
\mathbf{\$ 2 0 . 6 0}\end{array}$ & $\begin{array}{r}1.179 \\
1.182 \\
1.000 \\
1.361 \\
\mathbf{\$ 1 , 9 5 2} \\
1.200 \\
\mathbf{\$ 2 , 3 4 3} \\
1.300 \\
\mathbf{\$ 3 , 0 4 6} \\
\mathbf{\$ 4 1 . 3 3} \\
\end{array}$ \\
\hline
\end{tabular}

The following changes are made to these estimates (see Table 2) to conform to (1) EMWG (2005), (2) the spreadsheet accompanying EMWG (2005), Generation IV Economic Costs of Nuclear Systems (G4-ECONS), and (3) assumptions in Argonne National Laboratory (ANL) (2004).

1. Changing fuel cycle assumptions to follow G4-ECONS software and changing refueling period changed to 1.33 years following Hoffman et al. (2004) doubles back-end fuel cycle cost from $\$ 3.17$ to $\$ 6.55$.

2. When dollars are updated from 1996 to 2005 using the U.S. Gross Domestic Product (GDP) deflator, see CEA (2007), levelized cost increases from $\$ 32.41$ to $\$ 38.30$. (Fuel cycle costs in G4-ECONS are in 2001 dollars, so they were converted to 2005 dollars.)

3. With the following changes levelized cost increases from $\$ 38.30$ to $\$ 49.07$ : (a) capacity factor is decreased from $93 \%$ to $86 \%$, to account for more frequent refuelings in recycle mode; (b) cost of capital is changed from $9.16 \%$ to $10 \%$ following EMWG (2005), (c) the construction period (first pour to commercial operation) is lengthen to 5 years, increasing IDC from $\$ 21 / \mathrm{kWe}$ to $\$ 618 / \mathrm{kWe}$, and (d) decommissioning is changed to EMWG (2005) standards, decreasing D\&D sinking fund contributions.

4. When contingency is increased from $0 \%$ to $20 \%$ following ANL (2004, p. 14), and pre-construction costs are set to $\$ 100 \mathrm{M}$, levelized cost increases from $\$ 49.07$ to $\$ 60.12$.

5. When the cost of capital is decreased from 10\% to 5\%, following EMWG (2005), levelized cost decreases from $\$ 60.12$ to $\$ 39.39$. (EMWG, 2005, suggests discounting costs at $5 \%$ and $10 \%$ ). 
Table 2. Updating GE (2000) to EMWG (2005) and 2005 \$: Average Cost.

\begin{tabular}{|c|c|c|c|c|c|c|c|}
\hline & & (1) & (2) & (3) & (4) & (5) & \\
\hline $\begin{array}{l}\text { Updating Boardman et al (2000) to } 2005 \text { dollars, } \\
\text { GIF Guidelines, and G4ECONS software }\end{array}$ & Original & $\begin{array}{l}\text { Fuel } \\
\text { Cycle }\end{array}$ & $\begin{array}{c}2005 \\
\text { dollars }\end{array}$ & $\begin{array}{c}\text { Capital } \\
\& \text { IDC \& DD }\end{array}$ & $\begin{array}{c}\text { Contingency } \\
20 \%\end{array}$ & $\begin{array}{c}\text { Capital } \\
\text { Cost }=5 \%\end{array}$ & Units \\
\hline $\begin{array}{l}\text { Site size } \\
\text { Reactor Net Electrical Capacity } \\
\text { Reactor Average Capacity factor over life } \\
\text { Annual Electricity Production (calculated) } \\
\text { Thermodynamic efficiency } \\
\text { Fuel cycle length } \\
\text { Plant economic and operational life } \\
\text { Years to construct (implicit to match IDC) } \\
\text { Spending profile during construction }\end{array}$ & $\begin{array}{c}\mathrm{n} / \mathrm{a} \\
1520 \\
93.00 \% \\
1.238 \mathrm{E}+10 \\
37.90 \% \\
1.33 \\
40 \\
0.285 \\
\text { S-curve }\end{array}$ & $\begin{array}{c}\mathrm{n} / \mathrm{a} \\
1520 \\
93.00 \% \\
1.238 \mathrm{E}+10 \\
37.90 \% \\
1.33 \\
40 \\
0.285 \\
\text { S-curve }\end{array}$ & $\begin{array}{c}\mathrm{n} / \mathrm{a} \\
1520 \\
93.00 \% \\
1.238 \mathrm{E}+10 \\
37.90 \% \\
1.33 \\
40 \\
0.285 \\
\text { S-curve }\end{array}$ & $\begin{array}{c}\mathrm{n} / \mathrm{a} \\
1520 \\
86.00 \% \\
1.145 \mathrm{E}+10 \\
37.90 \% \\
1.33 \\
40 \\
5.000 \\
\text { S-curve }\end{array}$ & $\begin{array}{c}\mathrm{n} / \mathrm{a} \\
1520 \\
86.00 \% \\
1.145 \mathrm{E}+10 \\
37.90 \% \\
1.33 \\
40 \\
5.000 \\
\text { S-curve }\end{array}$ & $\begin{array}{c}\mathrm{n} / \mathrm{a} \\
1520 \\
86.00 \% \\
1.145 \mathrm{E}+10 \\
37.90 \% \\
1.33 \\
40 \\
5.000 \\
\text { S-curve }\end{array}$ & $\begin{array}{c}\text { acres } \\
\text { MWe } \\
\% \\
\text { kwh/yr } \\
\% \\
\text { Years } \\
\text { Years } \\
\text { Years } \\
\text { form }\end{array}$ \\
\hline $\begin{array}{l}\text { EMWG Non-fuel Data for Reactor } \\
\text { Real discount rate for IDC \& amortization } \\
\text { Estimated D\&D cost for reactor at end-of-life }\end{array}$ & $\begin{array}{l}9.16 \% \\
\$ 531\end{array}$ & $\begin{array}{l}9.16 \% \\
\$ 531\end{array}$ & $\begin{array}{l}9.16 \% \\
\$ 638\end{array}$ & $\begin{array}{c}10.00 \% \\
\$ 638\end{array}$ & $\begin{array}{c}10.00 \% \\
\$ 638\end{array}$ & $\begin{array}{l}5.00 \% \\
\$ 638\end{array}$ & $\begin{array}{c}\% / \text { year } \\
\$ M\end{array}$ \\
\hline $\begin{array}{l}\text { Non-Fuel Operational Annual Costs } \\
\text { On-site Staffing Cost } \\
\text { Pensions and Benefits } \\
\text { Consumables } \\
\text { Purchased services \& subcontracts } \\
\text { Insurance premiums \& taxes } \\
\text { Regulatory fees } \\
\text { Radioactive waste management } \\
\text { Other General and Administrative (G\&A) }\end{array}$ & $\begin{array}{l}\$ 29.571 \\
\$ 7.021 \\
\$ 18.336 \\
\$ 0.326 \\
\$ 6.910 \\
\$ 4.600 \\
\$ 3.448 \\
\$ 7.392\end{array}$ & $\begin{array}{l}\$ 29.571 \\
\$ 7.021 \\
\$ 18.336 \\
\$ 0.326 \\
\$ 6.910 \\
\$ 4.600 \\
\$ 3.448 \\
\$ 7.392\end{array}$ & $\begin{array}{l}\$ 35.521 \\
\$ 8.434 \\
\$ 22.025 \\
\$ 0.392 \\
\$ 8.300 \\
\$ 5.526 \\
\$ 4.142 \\
\$ 8.879\end{array}$ & $\begin{array}{l}\$ 35.521 \\
\$ 8.434 \\
\$ 22.025 \\
\$ 0.392 \\
\$ 8.300 \\
\$ 5.526 \\
\$ 4.142 \\
\$ 8.879\end{array}$ & $\begin{array}{l}\$ 35.521 \\
\$ 8.434 \\
\$ 22.025 \\
\$ 0.392 \\
\$ 8.300 \\
\$ 5.526 \\
\$ 4.142 \\
\$ 8.879\end{array}$ & $\begin{array}{l}\$ 35.521 \\
\$ 8.434 \\
\$ 22.025 \\
\$ 0.392 \\
\$ 8.300 \\
\$ 5.526 \\
\$ 4.142 \\
\$ 8.879\end{array}$ & $\begin{array}{l}\text { \$M/Year } \\
\$ M / \text { Year } \\
\$ M / \text { Year } \\
\$ M / \text { Year } \\
\$ M / \text { Year } \\
\text { \$M/Year } \\
\$ M / \text { Year } \\
\text { \$M/Year }\end{array}$ \\
\hline $\begin{array}{r}\text { Capital (Including Financing) } \\
\text { Operation } \\
\text { Fuel Cycle - Front End } \\
\text { Fuel Cycle - Back End } \\
\text { D\&D Sinking Fund } \\
\text { LUEC }=\mathbf{A C}\end{array}$ & $\begin{array}{c}16.80 \\
6.27 \\
1.81 \\
3.17 \\
0.97 \\
\mathbf{2 9 . 0 2}\end{array}$ & $\begin{array}{c}16.80 \\
6.27 \\
1.81 \\
6.55 \\
0.97 \\
\mathbf{3 2 . 4 1}\end{array}$ & $\begin{array}{c}20.18 \\
7.53 \\
2.05 \\
7.38 \\
1.17 \\
\mathbf{3 8 . 3 0}\end{array}$ & $\begin{array}{c}30.27 \\
8.14 \\
2.21 \\
7.98 \\
0.46 \\
\mathbf{4 9 . 0 7}\end{array}$ & $\begin{array}{c}41.33 \\
8.14 \\
2.21 \\
7.98 \\
0.46 \\
\mathbf{6 0 . 1 2}\end{array}$ & $\begin{array}{c}20.60 \\
8.14 \\
2.21 \\
7.98 \\
0.46 \\
\mathbf{3 9 . 3 9}\end{array}$ & $\begin{array}{l}\$ / \mathrm{MWh} \\
\$ / \mathrm{MWh} \\
\$ / \mathrm{MWh} \\
\$ / \mathrm{MWh} \\
\$ / \mathrm{MWh} \\
\$ / \mathrm{MWh}\end{array}$ \\
\hline
\end{tabular}

The last two columns of Table 1 show construction cost estimates associated with the (4th) and (5th) columns of Table 2. Therefore, if the range of financing varies from $5 \%$ to $10 \%$ (real), the cost per $\mathrm{kWe}$ of an S-PRISM in 2005 dollars could be between $\$ 2,664 / \mathrm{kWe}$ and $\$ 3,046 / \mathrm{kWe}$ with a levelized cost between $\$ 39.39 / \mathrm{MWh}$ and $\$ 60.12 / \mathrm{MWh}$ based on GE (2000).

\subsubsection{Updating PRISM Mod B Capital and Average Costs}

An extended cost assessment of the PRISM Mod B (conversion ratio of 0.80) is ANL (2004). Its "Table 6, NOAK, 3 Power Block PRISM Mod B Capital Cost Breakdown" is reproduced in Table 3. TCIC is $\$ 2,899 \mathrm{M}$ (1994 dollars, including IDC of $\$ 362 \mathrm{M}$ and $16.7 \%$ contingency) for a 2-block power plant of 1,866 MWe (net). (These are NOAK cost estimates.) The specific TCIC (i.e., \$K/kWe) is $\$ 1,554 / \mathrm{kWe}$ (net). The levelized TCIC is $\$ 20.00 / \mathrm{MWh}$. And the levelized unit cost of electricity (LUEC $=A C$ ) is $\$ 40.54 / \mathrm{MWh}$ (see Table 4). 
Table 3. Updating ANL (2004) to EMWG (2005) and 2005 \$: Capital Cost.

\begin{tabular}{|c|c|c|c|c|}
\hline $\begin{array}{l}\text { PRISM Mod B from ANL (2004) } \\
\text { all costs in \$M }\end{array}$ & $\begin{array}{l}\text { ANL (2004) } \\
\text { Estimate }\end{array}$ & $\begin{array}{l}\text { ANL (2004) } \\
\text { Estimate }\end{array}$ & $\begin{array}{l}\text { Updated } \\
\text { Estimate }\end{array}$ & $\begin{array}{l}\text { Updated } \\
\text { Estimate }\end{array}$ \\
\hline Description (for Total Cost accounts) & $\begin{array}{l}\text { Total Cost } \\
\text { (\$M) }\end{array}$ & $\begin{array}{l}\text { Specific Cost } \\
\text { in } \$ / k W e\end{array}$ & $\begin{array}{c}\text { Specific } \\
\text { Cost at } 5 \%\end{array}$ & $\begin{array}{l}\text { Specific } \\
\text { Cost at } 10 \%\end{array}$ \\
\hline Plant Size in MWe, $N=1,866$ (net) & 1,866 & 1,866 & 1,866 & 1,866 \\
\hline $\begin{array}{l}\text { Pre-Construction Costs (Account 10) } \\
\text { Capitalized Direct Costs (Accounts in the } 20 \text { series) }\end{array}$ & $\$ 11$ & $\$ 6$ & $\$ 54$ & $\$ 54$ \\
\hline Buildings, Structures, \& Improvements on Site & $\$ 297$ & $\$ 159$ & $\$ 199$ & $\$ 199$ \\
\hline Reactor Plant equipment & $\$ 817$ & $\$ 438$ & $\$ 547$ & $\$ 547$ \\
\hline Turbine/Generator Plant equipment & $\$ 277$ & $\$ 148$ & $\$ 185$ & $\$ 185$ \\
\hline Electrical equipment & $\$ 101$ & $\$ 54$ & $\$ 67$ & $\$ 67$ \\
\hline Water intake and heat rejection plant & $\$ 40$ & $\$ 21$ & $\$ 27$ & $\$ 27$ \\
\hline Miscellaneous plant equipment & $\$ 36$ & $\$ 19$ & $\$ 24$ & $\$ 24$ \\
\hline Special materials & $\$ 0$ & $\$ 0$ & $\$ 0$ & $\$ 0$ \\
\hline Capitalized Direct Costs (Account 20) & $\$ 1,568$ & $\$ 840$ & $\$ 1,049$ & $\$ 1,049$ \\
\hline DIRECT $=($ Account 10+Account 20 $)$ & $\$ 1,579$ & $\$ 846$ & $\$ 1,103$ & $\$ 1,103$ \\
\hline Indirect Multiplier (Account 30) & 1.186 & 1.186 & 1.186 & 1.186 \\
\hline Owner's Cost Multiplier (Account 40) & 1.193 & 1.193 & 1.193 & 1.193 \\
\hline Supplementary Cost Multiplier (Account 50) & 1.000 & 1.000 & 1.000 & 1.000 \\
\hline DIRECT to BASE Multiplier (k1) & 1.378 & 1.378 & 1.378 & 1.378 \\
\hline$B A S E$ & $\$ 2,176$ & $\$ 1,166$ & $\$ 1,519$ & $\$ 1,519$ \\
\hline Contingency Multiplier & 1.167 & 1.167 & 1.200 & 1.200 \\
\hline Overnight Cost, $O C$ & $\$ 2,539$ & $\$ 1,361$ & $\$ 1,823$ & $\$ 1,823$ \\
\hline Interest During Construction (IDC) Multiplier & 1.143 & 1.143 & 1.137 & 1.300 \\
\hline Total Capitalized Investment Cost and $K / \mathrm{kWe}$ & $\$ 2,899$ & $\$ 1,554$ & $\$ 2,073$ & $\$ 2,371$ \\
\hline Levelized TCIC $(\mathrm{T}=40$ years, $\mathrm{CF}=86 \%)$ & $\$ 20.00$ & $\$ 20.00$ & $\$ 16.03$ & $\$ 32.17$ \\
\hline
\end{tabular}

The following changes are made to ANL (2004) (see Table 4):

1. When dollars are updated from 1994 to 2005 using the U.S. GDP deflator, levelized cost increases from $\$ 40.54$ to $\$ 49.11$;

2. With the following changes levelized, cost increases from $\$ 49.11$ to $\$ 53.34$ : (a) capacity factor is already set to $86 \%$; (b) cost of capital is changed from implicitly $9.44 \%$ to $10 \%$ following EMWG (2005), (c) the implicit building period is lengthen to 5 years, increasing IDC from $\$ 362 / \mathrm{kWe}$ to $\$ 524 / \mathrm{kWe}$, and (d) decommissioning is changed to EMWG (2005) standards, decreasing D\&D sinking fund contributions.

3. Levelized cost increases from $\$ 53.34$ to $\$ 55.53$ when pre-construction costs are increased from $\$ 11 \mathrm{M}$ to $\$ 100 \mathrm{M}_{2}$ and contingency is increased from $16.7 \%$ to $20 \%$ following EMWG (2005) and ANL (2004, p.14).

4. When the cost of capital is decreased from $10 \%$ to $5 \%$, levelized cost decreases from $\$ 55.53$ to $\$ 39.39$ (EMWG, 2005, suggests discounting costs at 5\% and 10\%). 
Table 4. Updating ANL (2004) to EMWG (2005) and 2005 \$: Average Cost.

\begin{tabular}{|c|c|c|c|c|c|c|c|}
\hline & & (1) & (2) & (3) & (4) & (5) & \\
\hline $\begin{array}{l}\text { Updating Hoffman et al (2004) to } 2005 \text { dollars, } \\
\text { GIF Guidelines, and G4ECONS software }\end{array}$ & Original & $\begin{array}{l}\text { Fuel } \\
\text { Cycle }\end{array}$ & $\begin{array}{c}2005 \\
\text { dollars }\end{array}$ & $\begin{array}{c}\text { Capital } \\
\& \text { IDC \& DD }\end{array}$ & $\begin{array}{c}\text { Contingency } \\
20 \%\end{array}$ & $\begin{array}{c}\text { Capital } \\
\text { Cost }=5 \%\end{array}$ & Units \\
\hline $\begin{array}{l}\text { Site size } \\
\text { Reactor Net Electrical Capacity } \\
\text { Reactor Average Capacity factor over life } \\
\text { Annual Electricity Production (calculated) } \\
\text { Thermodynamic efficiency } \\
\text { Fuel cycle length } \\
\text { Plant economic and operational life } \\
\text { Years to construct (implicit to match IDC) }\end{array}$ & $\begin{array}{c}\mathrm{n} / \mathrm{a} \\
1866 \\
86 \% \\
1.406 \mathrm{E}+10 \\
37.00 \% \\
1.33 \\
40 \\
2.725\end{array}$ & $\begin{array}{c}\mathrm{n} / \mathrm{a} \\
1866 \\
86 \% \\
1.406 \mathrm{E}+10 \\
37.00 \% \\
1.33 \\
40 \\
2.725\end{array}$ & $\begin{array}{c}\mathrm{n} / \mathrm{a} \\
1866 \\
86 \% \\
1.406 \mathrm{E}+10 \\
37.00 \% \\
1.33 \\
40 \\
2.725\end{array}$ & $\begin{array}{c}\mathrm{n} / \mathrm{a} \\
1866 \\
86 \% \\
1.406 \mathrm{E}+10 \\
37.00 \% \\
1.33 \\
40 \\
5.000\end{array}$ & $\begin{array}{c}\mathrm{n} / \mathrm{a} \\
1866 \\
86 \% \\
1.406 \mathrm{E}+10 \\
37.00 \% \\
1.33 \\
40 \\
5.000\end{array}$ & $\begin{array}{c}\mathrm{n} / \mathrm{a} \\
1866 \\
86 \% \\
1.406 \mathrm{E}+10 \\
37.00 \% \\
1.33 \\
40 \\
5.000\end{array}$ & $\begin{array}{c}\text { acres } \\
\text { MWe } \\
\% \\
\mathrm{kwh} / \mathrm{yr} \\
\% \\
\text { Years } \\
\text { Years } \\
\text { Years }\end{array}$ \\
\hline $\begin{array}{l}\text { Non-fuel Data for Reactor } \\
\text { Real discount rate for IDC \& amortization } \\
\text { Estimated D\&D cost for reactor at end-of-life }\end{array}$ & $\begin{array}{l}9.44 \% \\
\$ 526\end{array}$ & $\begin{array}{l}9.44 \% \\
\$ 526\end{array}$ & $\begin{array}{l}9.44 \% \\
\$ 657\end{array}$ & $\begin{array}{c}10.00 \% \\
\$ 657\end{array}$ & $\begin{array}{c}10.00 \% \\
\$ 657\end{array}$ & $\begin{array}{l}5.00 \% \\
\$ 657\end{array}$ & $\begin{array}{c}\% \text { year } \\
\$ M\end{array}$ \\
\hline $\begin{array}{l}\text { Non-Fuel Operational Annual Costs } \\
\text { On-site Staffing Cost } \\
\text { Pensions and Benefits } \\
\text { Consumables } \\
\text { Purchased services \& subcontracts } \\
\text { Insurance premiums \& taxes } \\
\text { Regulatory fees } \\
\text { Radioactive waste management } \\
\text { Other General and Administrative (G\&A) }\end{array}$ & $\begin{array}{l}\$ 29.539 \\
\$ 8.800 \\
\$ 28.100 \\
\$ 9.100 \\
\$ 8.200 \\
\$ 4.600 \\
\$ 0.000 \\
\$ 10.000\end{array}$ & $\begin{array}{c}\$ 29.539 \\
\$ 8.800 \\
\$ 28.100 \\
\$ 9.100 \\
\$ 8.200 \\
\$ 4.600 \\
\$ 0.000 \\
\$ 10.000\end{array}$ & $\begin{array}{l}\$ 36.894 \\
\$ 10.991 \\
\$ 35.097 \\
\$ 11.366 \\
\$ 10.242 \\
\$ 5.745 \\
\$ 0.000 \\
\$ 12.490\end{array}$ & $\begin{array}{c}\$ 36.894 \\
\$ 10.991 \\
\$ 35.097 \\
\$ 11.366 \\
\$ 10.242 \\
\$ 5.745 \\
\$ 0.000 \\
\$ 12.490\end{array}$ & $\begin{array}{l}\$ 36.894 \\
\$ 10.991 \\
\$ 35.097 \\
\$ 11.366 \\
\$ 10.242 \\
\$ 5.745 \\
\$ 0.000 \\
\$ 12.490\end{array}$ & $\begin{array}{l}\$ 36.894 \\
\$ 10.991 \\
\$ 35.097 \\
\$ 11.366 \\
\$ 10.242 \\
\$ 5.745 \\
\$ 0.000 \\
\$ 12.490\end{array}$ & $\begin{array}{l}\text { \$M/Year } \\
\text { \$M/Year } \\
\text { \$M/Year } \\
\text { \$M/Year } \\
\text { \$M/Year } \\
\text { \$M/Year } \\
\text { \$M/Year } \\
\text { \$M/Year }\end{array}$ \\
\hline $\begin{array}{r}\text { Capital (Including Financing) } \\
\text { Operation } \\
\text { Fuel Cycle - Front End } \\
\text { Fuel Cycle - Back End } \\
\text { D\&D Sinking Fund } \\
\text { TOTAL LUEC }\end{array}$ & $\begin{array}{c}20.00 \\
7.13 \\
2.47 \\
10.02 \\
0.92 \\
\mathbf{4 0 . 5 4}\end{array}$ & $\begin{array}{c}20.00 \\
7.13 \\
2.47 \\
10.02 \\
0.92 \\
\mathbf{4 0 . 5 4}\end{array}$ & $\begin{array}{c}24.98 \\
8.90 \\
2.78 \\
11.28 \\
1.16 \\
\mathbf{4 9 . 1 1}\end{array}$ & $\begin{array}{c}29.98 \\
8.90 \\
2.78 \\
11.28 \\
0.39 \\
\mathbf{5 3 . 3 4}\end{array}$ & $\begin{array}{c}32.17 \\
8.90 \\
2.78 \\
11.28 \\
0.39 \\
\mathbf{5 5 . 5 3}\end{array}$ & $\begin{array}{c}16.03 \\
8.90 \\
2.78 \\
11.28 \\
0.39 \\
\mathbf{3 9 . 3 9}\end{array}$ & $\begin{array}{l}\text { \$/MWh } \\
\text { \$/MWh } \\
\text { \$/MWh } \\
\text { \$/MWh } \\
\text { \$/MWh } \\
\text { \$/MWh }\end{array}$ \\
\hline
\end{tabular}

The last two columns of Table 3 show construction cost estimates associated with the (4th) and (5th) columns of Table 4. Due to the modifications of the PRISM to achieve a 0.80 conversion ratio, the cost of the fast recycling reactor in 2005 dollars is between $\$ 2,073 / \mathrm{kWe}$ and $\$ 2,371 / \mathrm{kWe}$ with a levelized cost between $\$ 39.39 / \mathrm{MWh}$ and $\$ 55.53 / \mathrm{MWh}$. This is similar to the updated levelized cost estimates in GE (2000). However, one reason for the difference between these two cost estimates is that the reactor and turbine generator is estimated to cost $\$ 928 / \mathrm{kWe}$ for the S-PRISM in GE (2000) and only $\$ 732 / \mathrm{kWe}$ for the PRISM Mod B in ANL (2004). In fact, the total cost of the reactors and turbine-generators for the updated S-PRISM is $\$ 1,175 \mathrm{M}$ (Table 1) and only $\$ 1,094 \mathrm{M}$ (Table 2), even though the S-PRISM is a smaller plant.

Given the similarity of these updated estimates, a simplifying (and conservative) assumption is made that the cost per kilowatt for the "Super PRISM Mod B" (S-PRISM-B) is equal to the S-PRISM in the updated GE (2000) estimate, from Table 2. On the other hand, the operating and fuel costs from ANL (2004) in Table 4 are more appropriate for the costs in "burning" mode. Therefore, the average capital costs for an S-PRISM-B are about $\$ 21 / \mathrm{kWe}$ at a $5 \%$ cost of capital and about $\$ 41 / \mathrm{kWe}$ at a $10 \%$ cost of capital. Average operating, fuel, and D\&D costs are about \$23/MWh. So, reasonable levelized NOAK unit costs are between about $\$ 44 / \mathrm{MWh}$ at a $5 \%$ cost of capital and $\$ 64 / \mathrm{MWh}$ at a $10 \%$ cost of capital. The next section translates NOAK to FOAK cost estimates. 


\subsection{Cost Reductions from First-of-a-Kind to Nth-of-a-Kind for the PRISM Mod B}

To determine FOAK costs from NOAK cost estimates, calculate Equation (26). First, given that GE (2000) and ANL (2004) estimated NOAK costs, "true" FOAK costs $\left(\mathrm{FC}_{0}\right)$ were not considered. Assuming that these costs are evenly distributed over the first $8 \mathrm{GW}$ of capacity (following EMWG, 2005) and that these costs are on the order of \$272M for FOAK engineering and design certification (see ECG 2002, p. 23 ), then $\left(F C_{0} / N\right)=\$ 34 / \mathrm{kWe}$, which can be added to the other pre-construction costs in Table 1 (i.e., FOAK pre-construction costs are $\$ 100 / \mathrm{kWe})$. This increases levelized TCIC to $\$ 21.09$ at a $5 \%$ discount rate and $\$ 42.31$ at a $10 \%$ discount rate.

Second, $v c$ (variable costs for the reactor-turbine-generators) and $\underline{v c}$ (variable costs for the balance of plant, not including the pre-construction costs) can be taken from Table 1: $v c=\$ 1,009 / \mathrm{kWe}$ and $\underline{v c}=$ $\$ 359 / \mathrm{kWe}$.

Third, to calculate Equations (27) and (28), $\mathrm{X}_{\mathrm{B}}$ and $\mathrm{X}_{\mathrm{N}}$ must be determined. If a S-PRISM Mod B reactor is $413 \mathrm{MWe}$, then $8 \mathrm{GW}$ is achieved with the 20th reactor, so $\mathrm{X}_{\mathrm{B}}=20$. If a S-PRISM Mod B plant is $1,650 \mathrm{MWe}$, then $8 \mathrm{GW}$ is achieved with the 5 th plant, so $\mathrm{X}_{\mathrm{N}}=5$.

Fourth, the learning rates must be determined. ANL (2004, Table 1) proposes a decline in cost of $15.6 \%$ in NOAK to FOAK costs for multiple reactor plants. Implicitly assuming 3.5 doublings, the learning rate ANL (2004, Table 1 ) on cumulative capacity is $4.55 \%$. Is this a reasonable rate for $\mathrm{C}_{\text {LEARN1 }}$ and/or $\mathrm{C}_{\text {LEARN2}}$ ? Consider the following five characteristics of a fast reactor deployment of at least $8 \mathrm{GW}$ with a commercial fleet size of $32 \mathrm{GW}$ (as assumed in EMWG, 2005, for fuel-cycle-facility planning):

1. The FOAK deployment of advanced recycle reactors (e.g., a PRISM-like reactor) would involve more or less continuous construction of two reactors per power block with 8 power blocks (i.e., 16 to 24 modular reactors, with an equilibrium production of two reactors per year from 8 to 12 years), thus capturing "economies of series" in production.

2. It is likely that modules will be built at one national (or international) location and shipped in pieces for assembly at the site, thus allowing the internalization of factory learning (because of the smaller reactor vessel, it is assumed that there are competitive manufacturers of these reactor vessels; if there are few reactor vessel manufacturers, then much of the cost savings that would be attributable to learning could be captured by monopolistic equipment manufacturers). Construction crews could work nationally or internationally on modular, sequential sites, thus capturing "learning by doing."

3. There is unlikely to be competing Advanced Recycle Reactor designs (and thus monopoly pricing problems or bottlenecks could occur if there is a single manufacturer; this must be addressed as a potential deployment problem, including a discussion of international licensing agreements). There is likely to be an internationally certified standardized design, therefore capturing "economies of standardization."

4. It is likely that the construction industry will bid these jobs aggressively. However, to help align the incentives of all participants, equity positions in the plant could be held by a construction manager, the architect-engineer, the nuclear energy system supplier, the fuel supplier, and the plant owner and operator. This incentive structure maximizes the discovery of cost and risk reduction opportunities, thus helping to capture "economies of diversification and risk management."

5. And last, unfortunately if fast reactor deployment is well orchestrated with all regulatory bodies and most stakeholders are on board, as well as assured continuous government and corporate funding of research, development, demonstration, deployment, and commercialization, delays could be early and often. 
Therefore, following the University of Chicago suggestions (see Section 2.5), the rate of learning is bounded away from $5 \%$ (due to the high probability of delays). So, it could be as high as $4.55 \%$, as assumed in ANL (2004). However, to simplify the analysis, two learning rates are used in converting from NOAK to FOAK estimates: $4.5 \%$ as an upper and $3 \%$ as a lower bound.

Substituting these values into Equations (27) and (28):

$v c_{\mathrm{j}}=\$ 1,009 \cdot(1+0.045)^{[(\ln 20 / \ln 2)-(\ln 1 / \ln 2)]}=\$ 1,221$

$\underline{v c_{\mathrm{i}}}=\$ 359 \cdot(1+0.045)^{[(\ln 5 / \ln 2)-(\ln 1 / \ln 2)]}=\$ 398$

Therefore, the weighted average decline from FOAK to NOAK is $(\$ 1,221+\$ 398) /(\$ 1,009+359)$ equal to $18.35 \%$ (see Table 5). If the learning rate was 3\%, the weighted average decline would be $11.92 \%$. Table 5 presents estimates of the TCIC $(=K)$ with two costs of capital $(5 \%$ and $10 \%)$ and two learning rates $\left(3 \%\right.$ and $4.5 \%$ ), where $\mathrm{C}_{\mathrm{LEARN} 1}=\mathrm{C}_{\mathrm{LEARN} 2}$. FOAK capital costs vary from $\$ 3,052$ to $\$ 3,690$. The levelized capital costs vary from $\$ 23.60 / \mathrm{kWe}$ to $\$ 50.07 / \mathrm{kWe}$. And average (levelized unit energy) costs vary from $\$ 49.74 / \mathrm{kWe}$ to $\$ 77.71 / \mathrm{kWe}$.

Table 5. FOAK Costs for the "S-PRISM Mod B."

\begin{tabular}{|l|l|l|l|l|l|l|}
\hline \multicolumn{1}{|c|}{ FOAK Costs for the } & NOAK & \multicolumn{1}{c|}{ NOAK } & CLEARN & & FOAK & FOAK \\
\hline "S-PRISM Mod B" & $5 \%$ & $10 \%$ & Rate & Multiplier & $5 \%$ & $10 \%$ \\
\hline K/kWe & $\$ 2,727$ & $\$ 3,118$ & $3.00 \%$ & $111.92 \%$ & $\$ 3,052$ & $\$ 3,490$ \\
\hline From Table 4.4.1 & $\$ 2,727$ & $\$ 3,118$ & $4.50 \%$ & $118.35 \%$ & $\$ 3,227$ & $\$ 3,690$ \\
\hline Levelized K Cost & $\$ 21.09$ & $\$ 42.31$ & $3.00 \%$ & $111.92 \%$ & $\$ 23.60$ & $\$ 47.35$ \\
\hline From Table 4.4.1 & $\$ 21.09$ & $\$ 42.31$ & $4.50 \%$ & $118.35 \%$ & $\$ 24.96$ & $\$ 50.07$ \\
\hline Levelized AC $=\$ 23.35$ & $\$ 44.44$ & $\$ 65.66$ & $3.00 \%$ & $111.92 \%$ & $\$ 49.74$ & $\$ 73.48$ \\
\hline From Table 4.4.4 & $\$ 44.44$ & $\$ 65.66$ & $4.50 \%$ & $118.35 \%$ & $\$ 52.59$ & $\$ 77.71$ \\
\hline
\end{tabular}

\section{SUMMARY}

This attachment estimated the Levelized Unit Electricity Cost (or Average Cost, $A C$ ) for the Advanced Recycling Reactor following EMWG (2005), and its associated software, G4-ECONS. The cost economics methodology extends Rothwell's work on fuel cycle market structure analysis to nuclear power plants (see Attachment F). The methodology is applied to General Electric's NOAK cost estimate of the Super-PRISM (Power Reactor Innovative Small Module) with 1,520 MWe (net). This is compared with updated estimates of by Argonne National Laboratory NOAK cost estimate for the PRISM Mod B, a "burning" fast reactor with a conversion ratio of 0.80 . Two learning rates are assumed $(3-4.5 \%)$ in the decline in cost from FOAK to NOAK with each doubling of capacity to $8 \mathrm{GW}$, following EMWG (2005). With the "S-PRISM Mod B" four-reactor configuration, FOAK capital costs range from $\$ 3,052 / \mathrm{kWe}$ with a cost of capital of $5 \%$ and a learning rate of $3 \%$ to $\$ 3,690 / \mathrm{kWe}$ with a cost of capital of $10 \%$ and a learning rate of $4.5 \%$. Average (levelized) cost ranges from $\$ 49.74 / \mathrm{kWh}$ to $\$ 77.71 / \mathrm{kWh}$ for FOAK cost estimates. Given the great differences in the estimated back-end fuel cycle costs between the S-PRISM and the PRISM Mod B, more economic analysis must be done to model separations and transmutation fuel fabrication to better understand the costs of recycling nuclear fuel. 


\section{REFERENCES}

Boardman, C.E., M. Hui, D.G. Carroll, A.E. Dubberley (GE), 2000, "Economic Assessment of S-PRISM including Development and Generating Costs," General Electric, Nuclear Energy Division, San Jose, CA, 2000.

Council of Economic Advisers (CEA), 2007, Economic Report of the President, Table B-3, U.S. GDP deflator, http://www.gpoaccess.gov/eop/tables07.html, Web page accessed March 1, 2007

Economic Modeling Working Group (EMWG), 2005, Cost Estimating Guidelines for Generation IV Nuclear Energy Systems, EMWG of the Generation IV International Forum (GIF), http://nuclear.inl.gov/deliverables/docs/emwgguidelines rev2.pdf, Web page accessed November 1, 2005

Economic Crosscut Group (ECG) of the Generation IV Roadmap Committee, 2002, Crosscutting Economics R\&D Scope Report, Generation IV International Forum (GIF-007-00), http://gif.inel.gov/roadmap/pdfs/007_crosscutting_economics_r-d_scope_report.pdf, Web page accessed December 1, 2002.

Hoffman, Edward A., Robert N. Hill, and Phillip J. Finck (ANL), 2004, "Estimated Cost for Low Conversion Ratio Burners," Argonne National Laboratory, 2004.

Idaho National Laboratory (INL), 2007, Advanced Fuel Cycle Cost Basis, INL, Idaho Falls, Idaho, INLEXT-07-12107 (April), 2007.

International Atomic Energy Agency (IAEA), 2006, Nuclear Power Reactors of the World, Vienna: IAEA, IAEA-RDS-2/26, 2006.

Intriligator, M.D, 1978, Econometric Models, Techniques, \& Applications. Prentice-Hall, 1978.

Rothwell, G.S., (1986), "Steam-Electric Scale Economies and Construction Lead Times," California Institute of Technology, Social Science Working Paper No. 627 (December), 1986.

Rothwell, G.S., (1990), "Utilization and Service: Decomposing Nuclear Reactor Capacity Factors," Resources and Energy 12, 3, p. 215-229, 1990.

Rothwell, G.S., (1991), "The Optimal Time to Decommissioning Commercial Nuclear Reactors," The Energy Journal 12 Special Issue: p. 305-314, 1991.

Rothwell, G.S., (1996), “Organizational Structure and Expected Output for Nuclear Power Plants,” Review of Economics and Statistics 78: p. 482-488, August 1996.

Rothwell, G.S., (2005), "Cost Contingency as the Standard Deviation of the Cost Estimate," Cost Engineering 47, 7: p. 22-25, 2005.

Rothwell, G.S., (2006), “A Real Options Approach to Evaluating New Nuclear Power Plants,” The Energy Journal 27, 1, 2006.

Rothwell, G.S., (2007a), "IAEA's DEEP in Carlsbad: Co-Producing Energy and Water in Southern California," International Journal of Nuclear Desalination 2, 3: p. 265-279, 2007.

Rothwell, G.S., (2007b), "Cost Structure and Market Sustainability of the International Light Water Reactor Fuel Fabrication Industry," Stanford Institute for Economic Policy Research, Stanford University, July 2007.

Rothwell, G.S. and C. Braun, 2007, "International Uranium Enrichment Supply," Stanford Institute for Economic Policy Research, March 2007. 
Rothwell, G.S. and T. Gomez, 2003, Electricity Economics: Regulation and Deregulation (IEEE Press/John Wiley), 2003.

Rothwell, G.S. and K. Williams, 2006. "Is Nuclear Power Competitive Producing Electricity or Hydrogen?" International Journal of Nuclear Hydrogen Production and Applications 1, 2, p. 154-169, 2006.

Rothwell, G.S. and K. Williams, 2007, "The Costs of Developing and Commercializing the Advanced Burner Reactor," presented at the American Nuclear Society 2007 Annual Meeting, Boston, Massachusetts, June 27, 2007.

Williams, K. 2007, "G4-ECONS Economic Evaluation Tool for Generation IV Reactor Systems," presented at the American Nuclear Society 2007 Annual Meeting, Boston, Massachusetts, June 27, 2007.

University of Chicago, 2004, The Economic Future of Nuclear Power, Argonne National Laboratory, August, 2004. 
G-30

INL/EXT-09-15483 


\section{Attachment H}

\section{VISION Economic (VISION.ECON) Submodel Description and Methodology}

Jake Jacobson, Ann Marie Phillips, and David Shropshire Idaho National Laboratory

J'Tia Taylor

University of Illinois 
H-2

INL/EXT-09-15483 


\begin{abstract}
VISION (Verifiable Fuel Cycle Simulation Model) is a dynamic model that simulates the nuclear fuel cycle from cradle to grave, from mining of raw materials to disposition of waste after electricity generation. VISION.ECON was created as a submodel of VISION to provide economic analysis of the nuclear fuel cycle cases. The submodel produces relative economic comparisons rather than absolute value cost estimates. VISION.ECON extends the modeling capability beyond static equilibrium analysis tools by providing insight to dynamic modeling impacts to cost over time. The tool currently includes the functionality to evaluate cost and system uncertainties. Future capabilities will include feedback from economic factors into the main VISION model support system optimization. This report describes the VISION.ECON architecture, modeling methodology, functionality, uncertainty analysis algorithms, and the user interface. In addition, it is meant to give the user a basic understanding of the VISION.ECON submodel objectives and the methods used to meet those objectives.
\end{abstract}


H-4

INL/EXT-09-15483 


\section{CONTENTS}

ABSTRACT . H-3

ACRONYMS .

1. OBJECTIVES. H-11

2. COST MODELING PHILOSOPHY AND SOFTWARE DEVELOPMENT APPROACH.......H-11

3. VISION MODEL H-12

3.1 Other AFC Models $\mathrm{H}-14$

4. TRANSITION FROM STATIC TO DYNAMIC ANALYSIS H-14

5. VISION FUNCTIONALITY H-15

6. VISION ECONOMICS ARCHITECTURE H-15

7. ECONOMIC MODELING UNCERTAINTY ANALYSIS ALGORITHMS H-16

8. VISION ECONOMIC SUBMODEL H-17

8.1 Reactor Costs H-19

8.1.1 Capital Costs H-19

8.1.2 Operating Costs.... H-22

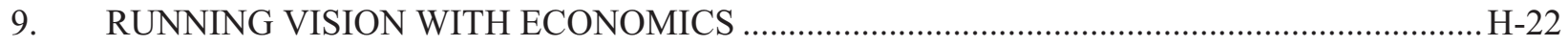

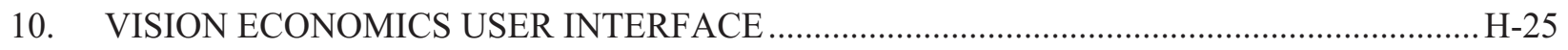

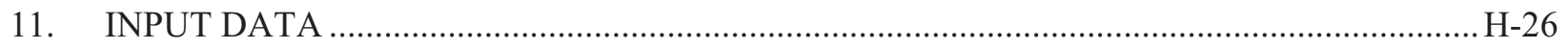

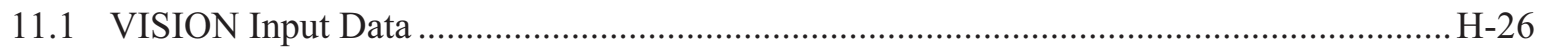

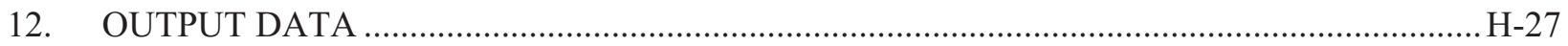

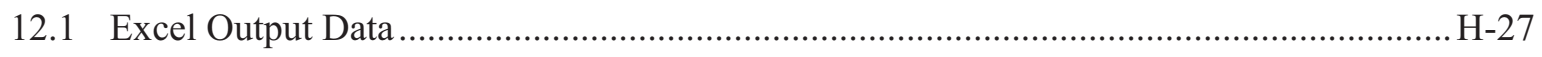

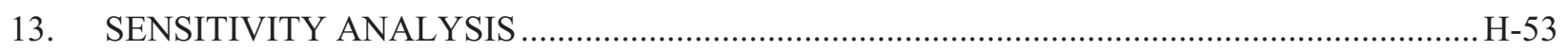

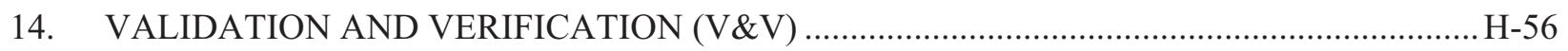

15. VISION.ECON FUTURE DEVELOPMENT PLANS …..........................................................

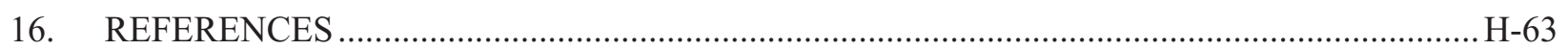




\section{FIGURES}

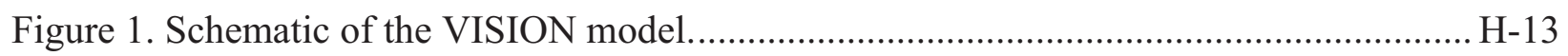

Figure 2. Relationships between Advanced Fuel Cycle Modeling Components....................... H-14

Figure 3. VISION economics architecture. Note: Economic feedback will be added in future revisions but is currently not activated. ....................................................... H-15

Figure 4. Example of a skewed triangular distribution............................................................ H-16

Figure 5. Example of a uniform distribution. ......................................................................

Figure 6. Pattern for design/construction/start-up cash flows. .............................................. H-2

Figure 7. Illustration of the VISION.ECON user interface. .................................................. H-26

Figure 8. Excel input file for distribution cost data. .......................................................... H-27

Figure 9. Base Case 1: 2000-2050 yearly results for Modules A through D1 ....................... H-28

Figure 10. Monte Carlo sampling results for fuel cycle costs and cost of electricity

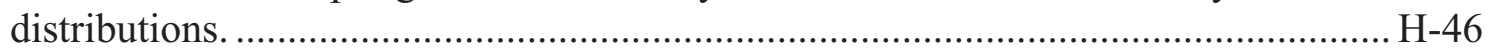

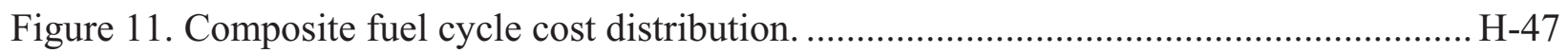

Figure 12. Distribution of composite cost of electricity at the end of the simulation............... H-48

Figure 13. Total annual fuel cycle cost.............................................................................

Figure 14. Total annual cost of electricity. ............................................................................

Figure 15. Annual unit cost breakdown. Fuel cycle costs do not include cost of reactor construction and operation where cost of electricity does include reactor costs........ H-49

Figure 16. Annual energy output by reactor type. ......................................................... H-50

Figure 17. Annual total costs broken down by front-end costs, back-end costs, recycling costs, reactor operation costs, and reactor capital costs. ........................................... H-50

Figure 18. Annual front-end cost breakdown by module .................................................... H-51

Figure 19. Annual back-end cost breakdown by module. ………………………….......... H-51

Figure 20. Annual recycle cost breakdown by module....................................................... H-52

Figure 21. Comparison of composite cost of electricity distribution for the five previous

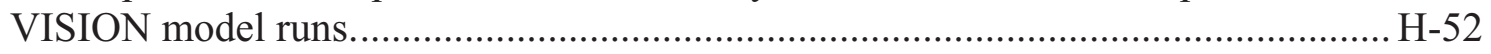

Figure 22. Risk Analysis Feature Analysis variable page for a sample run varying capacity factor and measuring effect on TCOE per year.

Figure 22. Risk Analysis results of TCOE per year for capacity factor variation for each time step outputted and graphed in Excel.

Figure 24. Tornado Diagram of Sensitivity Analysis performed on once through, one

LWR scenario with TCOE per year as effect variable.

Figure 23. Case 1: Thermal reactor once-through. ............................................................ H-56

Figure 24. Case 2: Thermal once-through fuel cycle with fast recycling.................................. H-57 
Figure 25. Case 3: Two-tier; thermal once-through fuel cycle with thermal and fast recycling. H-58

Figure 28. Economic modeling dynamics. (University of Texas-Austin developed a uranium resource module in FY-07).

Figure 29. Economic uncertainty analysis. (System affects to be studied as part of Simulation Institute for Nuclear Energy Modeling and Analysis (SINEMA), collaboration with Paul Turinsky at North Carolina State University). H-60

Figure 30. Tornado diagram outlining baseline government construct and operate H-61

Figure 31. Economic optimization. (Work with Paul Wilson at University WisconsinMadison). H-61

Figure 32. Regret concept example. H-62

\section{TABLES}

Table 1. List of Excel files that are related to the VISION Model. H-18

Table 2. Example of a What-It-Takes Table in the July 2007 "AFC Cost Basis" report (Shropshire, et al. 2007). H-19 
H-8

INL/EXT-09-15483 


\section{ACRONYMS}

ABR

AFC

AFCI

ALWR

ANNCAP

CAFCA

COSI

CRF

D\&D

DPL

DR

DYMOND

ECONS

EMWG

FR

GTCC

HLW

IDC

IMF

INL

IQTLY

IYRLY

LUEC

LWR

MOX

MRS

NOAK

O\&M

OCC

OECD

SINEMA

SNF

SNM
Advanced Burner Reactor

Advanced Fuel Cycle

Advanced Fuel Cycle Initiative

Advanced Light-Water Reactor

annual capital recovery cost

Code for Advanced Fuel Cycle Analysis

Commelini-Sicard

Capital Recovery Factor

Decommissioning and Decontamination

Decision Programming Language

discount rate

Dynamic Model of Nuclear Development

Economics

Economic Modeling Working Group

fast reactor

Greater than Class C

High-level Waste

interest during construction

inert matrix

Idaho National Laboratory

interest quarterly

interest yearly

Levelized Uniform Electricity Cost

Light-Water Reactor

mixed uranium-plutonium oxide

managed retrievable storage

Nth of a Kind

operations and maintenance

overnight capital cost

Organisation for Economic Co-operation and Development

Simulation Institute for Nuclear Energy Modeling and Analysis

spent nuclear fuel

special nuclear materials 


$\begin{array}{ll}\text { TCIC } & \text { total capital recovery factor } \\ \text { TCOE } & \text { Total Cost of Electricity } \\ \text { UOX } & \text { uranium oxide } \\ \text { V\&V } & \text { validation and verification } \\ \text { VISION } & \text { Verifiable Fuel Cycle Simulation } \\ \text { WIT } & \text { What-It-Takes }\end{array}$

$\mathrm{H}-10$

INL/EXT-09-15483 


\section{VISION Economic (VISION.ECON) Submodel Description and Methodology}

\section{OBJECTIVES}

The objective of the economic portion of the VISION (Verifiable Fuel Cycle $\underline{\text { Simulation) model, }}$ hereafter named as VISION.ECON, is to estimate the comparative economics of various nuclear fuel cycle scenarios. This report is intended to be a living document that will be expanded in lock step with the model development, so that a documented basis of the current functionality, inputs/outputs, modeling assumptions, and explanations for dynamic (perhaps non-intuitive) behavior will result from economic modeling. Future additions to the functionality of the economics model are described later in this document. Information on how to set up and run the economic submodel along with the VISION model is contained in the VISION User Guide (INL 2007).

\section{COST MODELING PHILOSOPHY AND SOFTWARE DEVELOPMENT APPROACH}

The economic data produced by the VISION.ECON submodel are consistent with and based on the information contained in the 2007 "Advanced Fuel Cycle (AFC) Cost Basis" (Shropshire, et al. 2007). The "AFC Cost Basis" report goals also apply to the VISION economic model. These goals are:

- Provide data for relative comparison of economic options rather than point value cost comparisons for determination of fuel cycle costs with great accuracy

- Show a meaningful understanding of the quality of the cost data, knowledge of the appropriate use of the cost data, and have a reasonable approach for using the data to provide comparisons given the inherent limitations of the data

- Use depth of knowledge to provide insight into the cost drivers and factors that can most influence the costs

- Document clearly the referenced cost data, assumptions, and relationships that have been developed

- Annualize cost estimates based on flows to each module

- Calculate final cash flow streams with uncertainty analysis at the end of the simulation for each module as well as for some summary data such as front-end costs, back-end costs, and total cost to generate electricity

- Perform peer reviews of the cost data.

The cost information included in this report may be used in conjunction with computer models to provide quantitative analysis of fuel cycle options. The costing procedure described in Section 4 of the "AFC Cost Basis" report is directly relevant to the use of cost data in the cost models. It is strongly recommended that the user become experienced with manually using the cost data in scenario studies before incorporating the data in a cost model. Manual checks on modeling results are recommended for verification.

Cost models can be useful timesaving analysis tools, but they may also provide misleading answers. Wrong conclusions will result from a number of sources. Such as:

1. Cost data were not intended for use in the type of scenario

2. Bounding capacities of the reference facility were exceeded 
3. Module capacities and mass flows were not properly calculated to account for recycling, blending, maximum versus operating capacities, etc.

4. Cost module uncertainties bounds were not considered

5. Misunderstanding of ownership (private versus government) and associated treatment of interest charges for capital, taxes, etc.

6. Inadequate account taken of the technology maturity and R\&D funds needed

7. Hidden/implicit assumptions

8. Impacts on processing efficiency resulting from future technologies.

The VISION.ECON development was performed using a spiral software development process, which included:

- Establishing economic modeling objectives and requirements

- Implementing, by the development team, the economic functionality into VISION based on satisfying a predetermined subset of the requirements

- Testing the economic model and comparing the results to verified cost data

- Taking actions to correct any model deficiencies as needed

- Repeating the cycle by building on the models' functionality by adding new capabilities to meet the next set of requirements

- Experiencing an iterated process until all objectives and requirements are satisfied.

The first development cycle of VISION.ECON was performed with the goal of creating a very simple, but working economic capability. This capability will be built upon by adding complexity one step at a time. Each step needs to be vigorously verified before moving on to the next level of complexity.

\section{VISION MODEL}

VISION is a dynamic model of the U.S. commercial nuclear fuel cycle developed at Idaho National Laboratory (INL). The objective of VISION is to serve as a broad systems analysis and study tool applicable to the Advanced Fuel Cycle Initiative (AFCI) and Generation IV reactor development studies. The model simulates the fuel cycle from cradle to grave-from mining of raw materials to the disposition of waste after electricity generation. VISION provides the capability to study the entire fuel cycle in detail for system level economics and trade-off studies, isotopic mass flow, and transportation and facility needs. Its flexibility allows for the selection of fuel type, reactor type, and fuel cycles. VISION also allows selection of facility options such as size and ordering based on energy or user defined demand. VISION can be ran on a desktop computer in five minutes or less. The current VISION model focuses on the U.S. reactor fleet, with planned expansion to handle the international power fleet in the future.

The document, Software Requirements Specification Verifiable Fuel Cycle Simulation (VISION) Model (INEEL 2005) was developed to define the objective, scope, and key assumptions of VISION. In addition, expectations and requirements were developed for model variables (flow model, cost model), analysis of estimates or measures, general model architecture elements, hardware/software, constraints, and use cases. Software quality is ensured through design requirements (e.g., code transparency), quality documentation (e.g., user manuals), and performance testing (e.g., independent verification and review). The model uses nonproprietary, off-the-shelf commercial software; has an open architecture; is readily usable by fuel cycle practitioners and technical experts; and supports communication of analysis and results to less technical audiences. The graphical user interface provides an intuitive understanding of the 
model functionality and the capability to trace though the causes of system behavior to identify the key variables driving the behavior within the system. The VISION User Guide (INL 2007) provides general user information, base case definitions, and default values. The economics section is included with the VISION User Guide for VISION Release 2.0.

The VISION model is constructed using Powersim Studio (http://www.powersim.com 2007), a commercial system dynamics tool. Powersim Studio provides the functionality to allow economics to be included as a separate submodel based on the flows in the core of the model. As a submodel, new versions can be easily plugged into the VISION model. In addition, development of the economics submodel can occur independently of the VISION model.

A schematic of the components in the VISION model is shown in Figure 1. The model is organized into a series of modules that include all of the major facilities and processes involved in the fuel cycle,

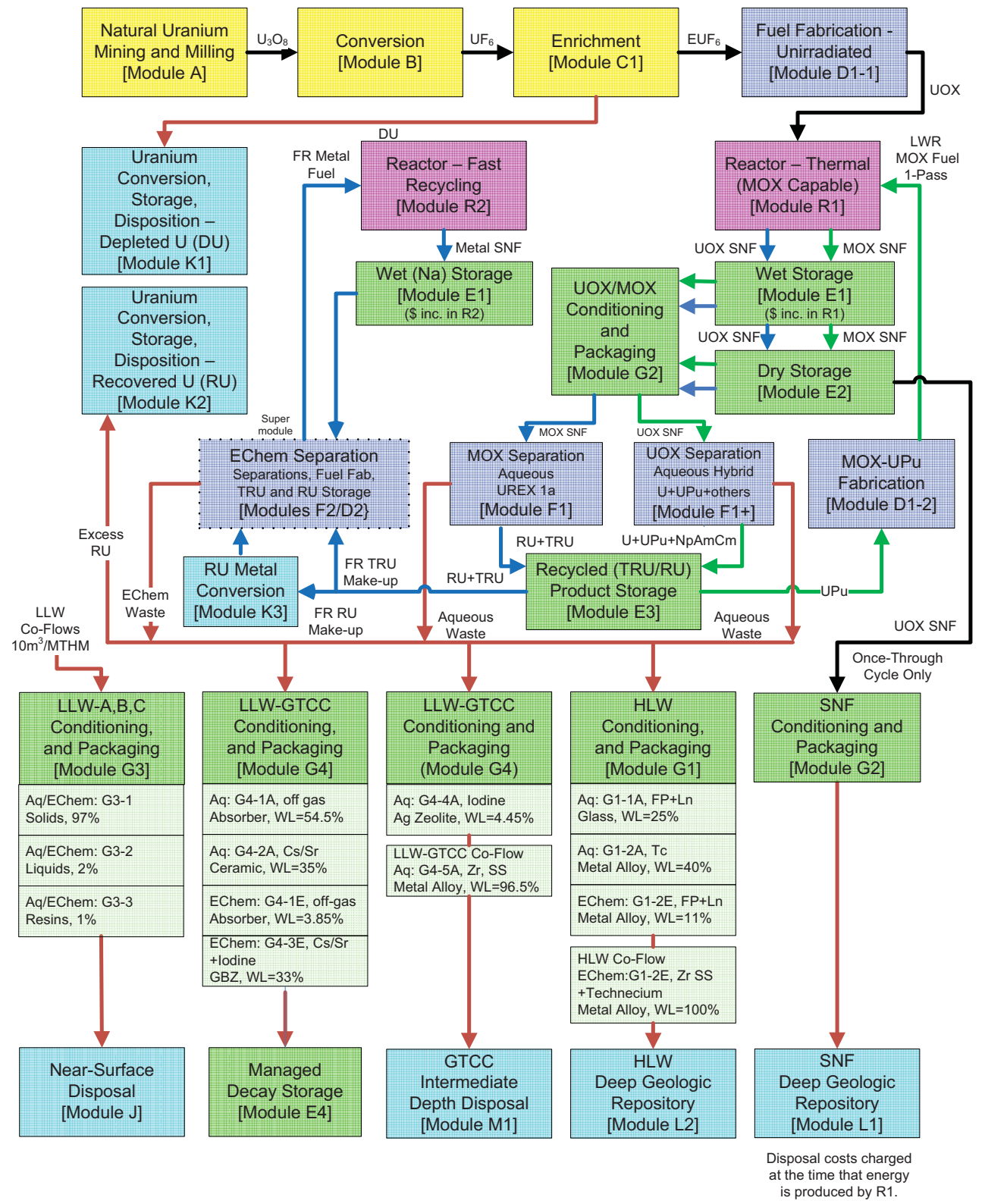

Figure 1. Schematic of the VISION model. 
starting with uranium mining and ending with waste management and disposal. The arrows in the diagram indicate the mass flow of the fuel; VISION provides an isotopic mass balance of fuel and an element mass balance of fuel by-products, such as cladding. Not shown, but included in each module, are the information, decision rules, and algorithms that control the flows among the modules that form the logic for the mass flow in VISION. In the economic submodel of VISION, the mass flows are combined with cost to provide insight into the economics of the fuel cycle.

\subsection{Other AFC Models}

During development of the "AFC Cost Basis" report (Shropshire, et al. 2007), a review of existing fuel cycle models including NFCSim, DYMOND/DANESS, and other fuel cycle cost models (e.g., NERAC) was performed (Schneider, et al. 2005, Yacout, et al. 2004). The VISION model is the successor to the Dynamic Model of Nuclear Development (DYMOND) model, which was originally developed for the Generation IV Fuel Cycle Cross Cut group and was used in the evaluation of the AFCI system options (Yacout, et al. 2004). VISION is backward compatible with DYMOND and has been checked versus DYMOND. VISION was tested against static calculations from the Economic Modeling Working Group's (EMWG) G4-Economics (ECONS) spreadsheet model (Williams and Shropshire 2007).

The VISION.ECON submodel was developed from scratch and contains unique capabilities resulting from the cost module structure, cost distributions, and modeling cost uncertainty algorithms.

\section{TRANSITION FROM STATIC TO DYNAMIC ANALYSIS}

The G4-ECONS spreadsheet has been used to perform static equilibrium analyses (a "snapshot" in time) of fuel cycle costs (Williams and Shropshire 2007). The G4-ECONS spreadsheet is an excellent tool for evaluating fuel cycle costs at any single point in time. VISION.ECON represents a transition from static to dynamic economic analysis, as described graphically in Figure 2. VISION.ECON will provide insight into the dynamics of fuel cycle costs over time. VISION.ECON provides a time phasing of fuel cycle and reactor costs, providing a more accurate representation of fuel cycle costs over time.

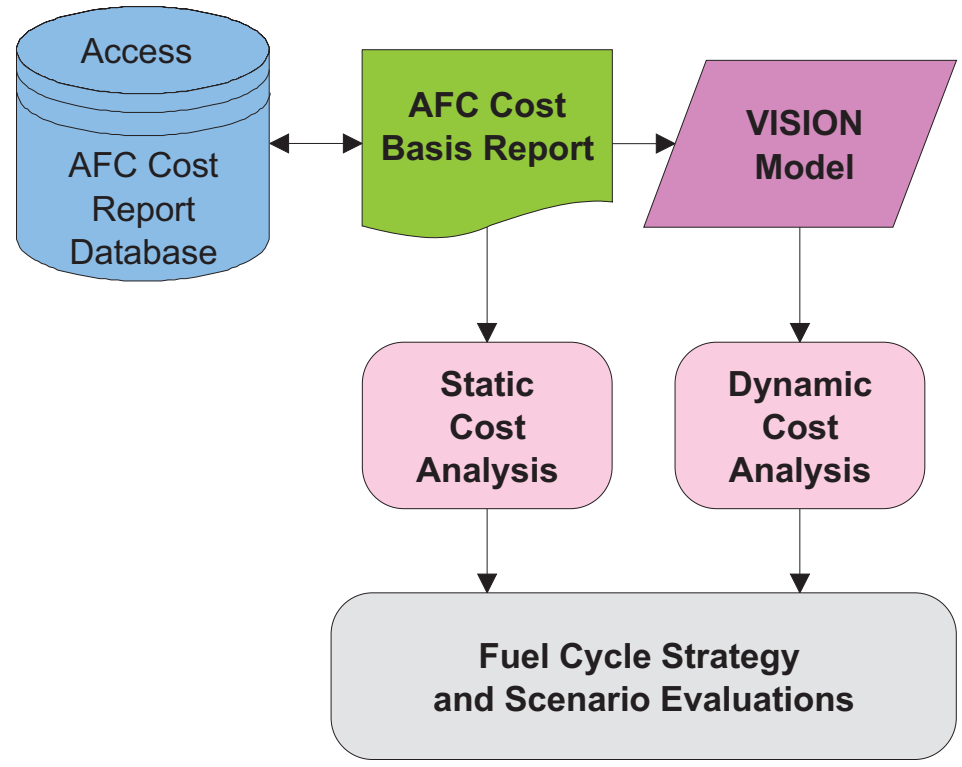

Figure 2. Relationships between Advanced Fuel Cycle Modeling Components. 


\section{VISION FUNCTIONALITY}

VISION currently supports three types of reactors: light water thermal reactors, which use only uranium oxide (UOX); light water thermal reactors that can use UOX, mixed uranium-plutonium oxide (MOX), or inert matrix (IMF) fuels; and fast reactors. Fast reactors may operate in breeder or burner mode. Multiple thermal and fast reactor fuel recipes are available in VISION. The fuel recipes specify the initial fuel isotopic composition and the fuel compositions at the time the fuel is removed from the reactors. The current version of the code estimates various metrics, such as heat load, radiotoxicity, proliferation metrics, and other parameters important for evaluating the nuclear fuel cycle. For separation and recycle of used fuel, the youngest (shortest time out of the reactor) and the least-cycled fuel has priority for the available capacity. The repository capacity is limited both in total mass, and the rate material can be sent to the repository. In contrast to separations, the oldest (longest time out of the reactor) and the most-cycled fuel has priority for disposition to the repository. The model tracks radioactive decay for all materials in the model when mass remains in a location for one or more years. VISION provides the capability to perform the mass flow analysis independent of the economic analysis, with the ability to turn economic capability on/off without influencing the balance of the model.

\section{VISION ECONOMICS ARCHITECTURE}

The VISION.ECON architecture is described graphically in Figure 3. The economics equations and calculations are contained in a separate submodel so they can be detached. The distinction between the economics submodel and the main VISION model is also maintained by the use of separate economics data files (input and output), which are used in addition to the standard VISION data files. The economic input data can be detached or zeroed in order to zero out any economic analyses. A button on the main VISION user interface screen is used to access the economics user interface, which is located in the economic submodel. Having a separate submodel for the economics also facilitates modular portability of

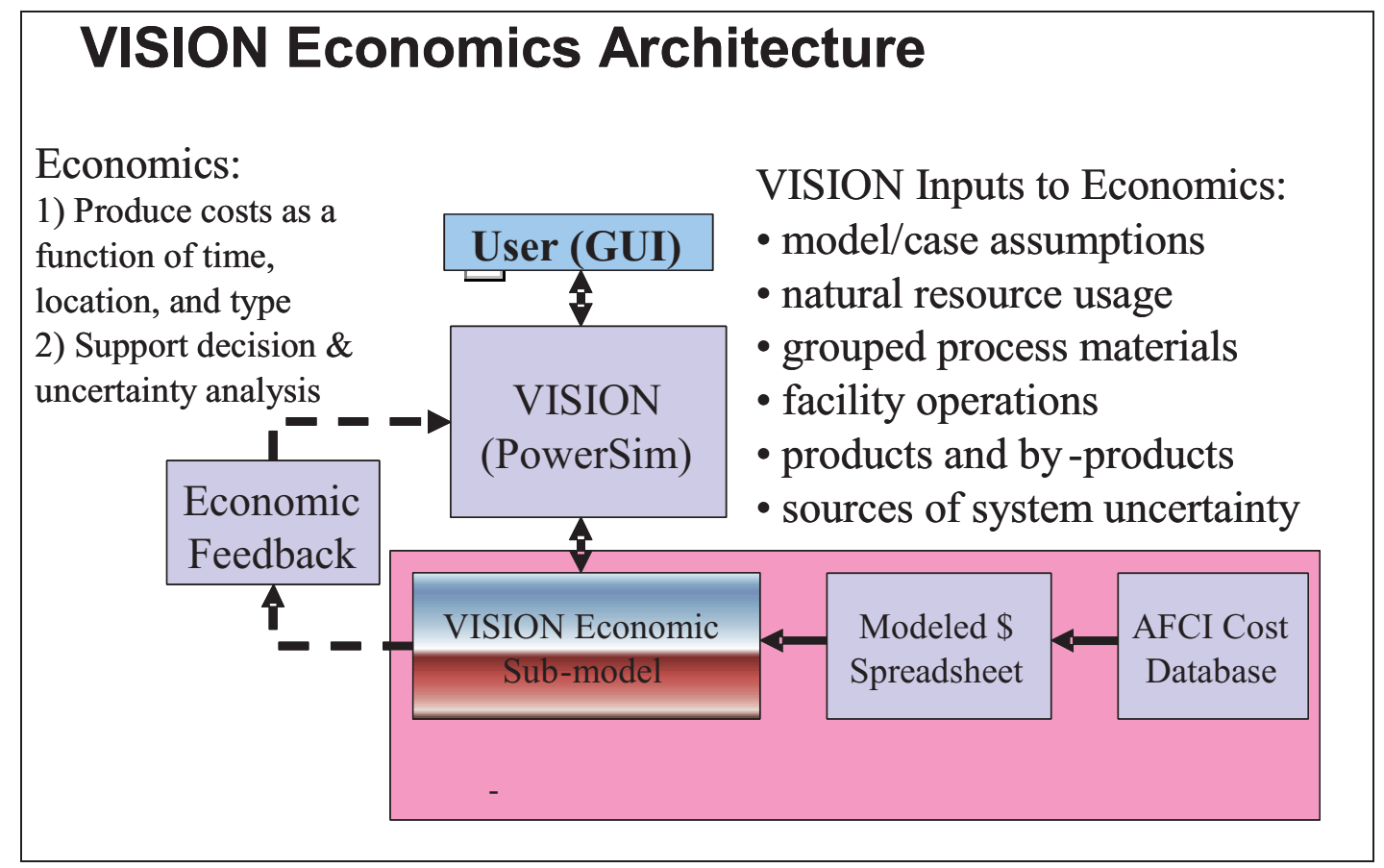

Figure 3. VISION economics architecture. Note: Economic feedback will be added in future revisions but is currently not activated. 
the economics submodel into different models in the future. There is no feedback from the economic submodel (cost model) into the main VISION model (flow model) at this time. Future functionality will include feedback of economic data into the main model to provide dynamic influences to facility schedules, capacities, and other modeling parameters. The economic submodel has variables that match those in the main VISION model for which mass flow output is currently available. These links facilitate the connections between the main model and the submodel. In the future, additional links will be added to the VISION economics submodel.

\section{ECONOMIC MODELING UNCERTAINTY ANALYSIS ALGORITHMS}

VISION.ECON supports simulations using probabilistic algorithms to account for module cost uncertainties. Powersim Studio (http://www.powersim.com 2007) can run uncertainty analyses, but in order to develop the distribution, the model must run multiple (typically $>100$ ) times varying specified input parameters. This would require a significantly-long run time to generate the necessary statistical parameters for the cost uncertainty. One solution is to generate economic statistical parameters in a post process mode. In this way, the model is ran once and the statistical parameters are estimated from the results (i.e., using the final total mass flows). The solution is implemented using Monte Carlo Method of sampling. The Monte Carlo method generates estimates of system parameters using a simple random sampling scheme. The sampling method uses a simple random number generator and then takes each random number processing it through an algorithm that samples from either a triangular distribution based on low, nominal, and high values or a uniform distribution based on low and high values, as shown in Figures 4 and 5. Each module has a distribution that can be used to estimate the range of possible outcomes for that module. An overall, cost and distribution is estimated by summing all the submodules and their distributions. The post processing approach allows VISION.ECON to produce statistical estimates in a single run rather than requiring multiple runs and significantly more time.

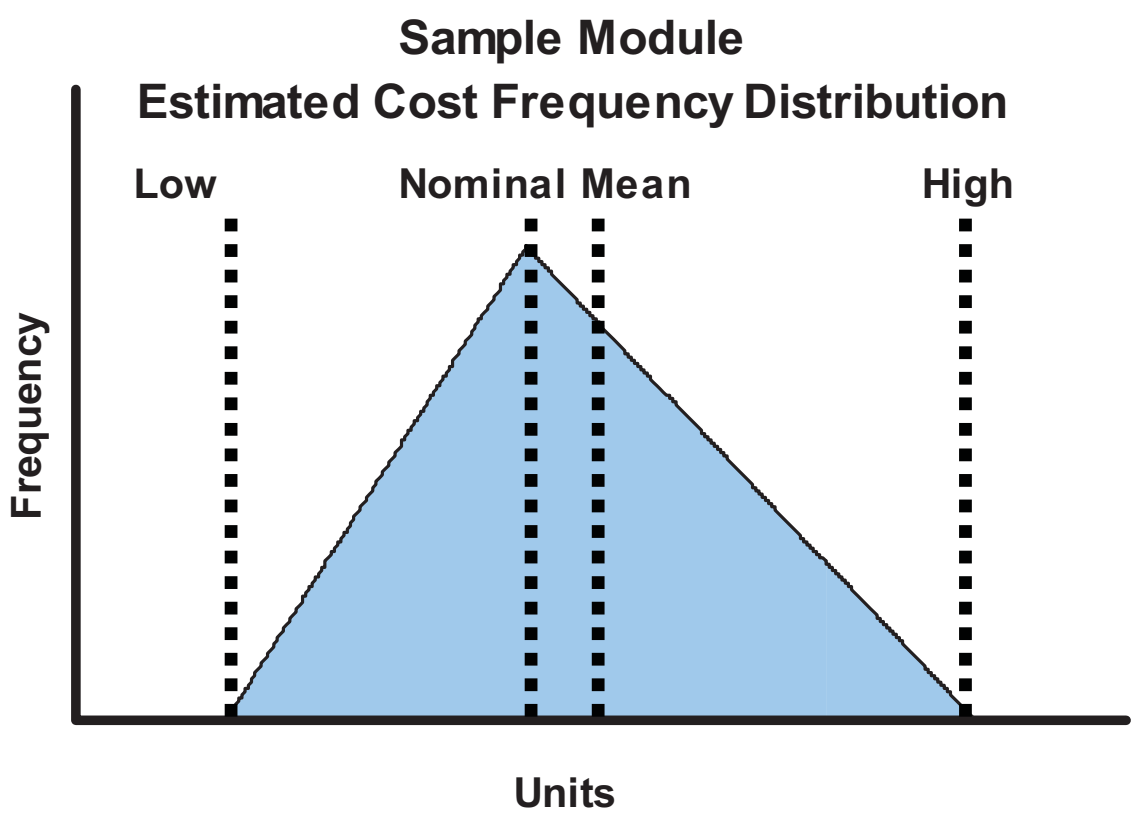

Figure 4. Example of a skewed triangular distribution. 


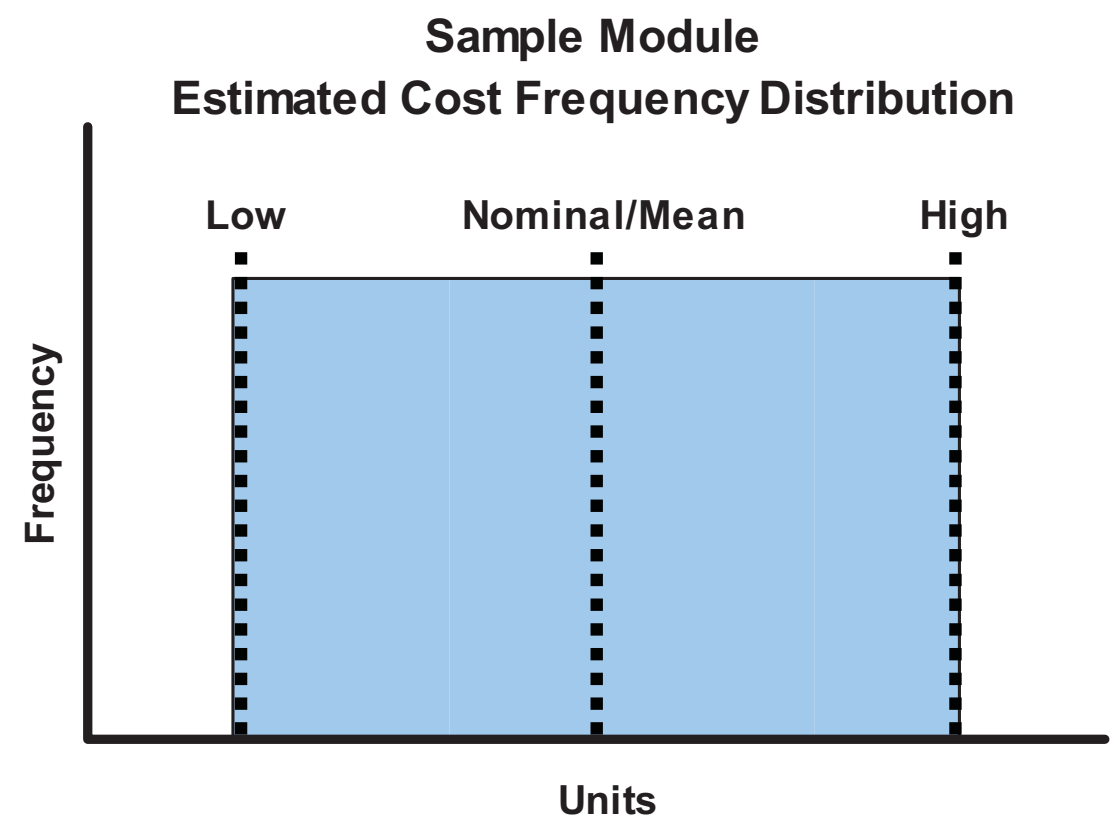

Figure 5. Example of a uniform distribution.

\section{VISION ECONOMIC SUBMODEL}

When VISION runs, mass flow rates for each module from the main VISION model are retrieved by the economic submodel at each time step. The specific modeling variable (e.g., U ore consumption, $\mathrm{kT} / \mathrm{yr}$ ) from the flow model is the input parameter for the cost calculation. There is a two step process for importing cost data into the VISION model. First, the cost data on the input spreadsheet, econ input data.xls, is imported from the "AFC 2007 Cost Basis" report. Second, cost data (e.g., cost of U ore mining, \$/yr) is automatically retrieved by VISION from the Excel spreadsheet (econ input data.xls).

In each module, two cost calculations are performed. First, annual costs are calculated. The mass flow rate for each time step (e.g., $\mathrm{U}$ ore consumption) is multiplied by the cost per unit (e.g., cost per unit $\mathrm{U}$ ore mining) for that module from the input spreadsheet (econ input data.xls) to produce a cost for that time step (e.g., cost of $U$ ore mining by year). These calculations allow us to track the costs of the entire system through time.

Second, cost distributions are calculated on the total final mass flows. The input data spreadsheet contains three columns: a low, nominal, and high cost value, which set the bounds for triangular (and in a few cases uniform) cost distributions. A Monte Carlo function is used to randomly select numbers from a uniform distribution from 0 to 1 which are then run through a set of equations that generate a number from a triangular distribution based on the low, nominal and high values. The cost estimate from each of the Monte Carlo runs is multiplied by the total final flow (sum of the mass flows from each year) for each module to create a cost distribution; each of the module costs are also summed to create a distribution for the total cost.

VISION.ECON is set up with links between Excel spreadsheets and the model that automatically input and output data (see Table 1). The cost data on the input spreadsheet, econ input data ver1.xls, is imported from the "AFC 2007 Cost Basis" report. VISION.ECON uses a table from the econ input data ver1.xls, vision base case settings ver1.xls, vision half-life ver1.xls, vision heatdosetox ver1.xls, and 
Table 1. List of Excel files that are related to the VISION Model.

\begin{tabular}{|c|c|c|}
\hline Table Name & Type & Connection \\
\hline Vision base case settings ver $1 . x 1 s$ & Input & Main Model \\
\hline Vision half-life ver1.xls & Input & Main Model \\
\hline Vision heatdosetox ver1.xls & Input & Main Model \\
\hline Vision recipes ver1.xls & Input & Main Model \\
\hline Econ input data ver1.xls & Input & Econ Submodel \\
\hline Vision validationdata ver1.xls & Output & Main Model \\
\hline Econ data output ver1.xls & Output & Econ Submodel \\
\hline Savable_output.xls & Output & Main Model \\
\hline Savable_output-2.xls & Output & Main Model \\
\hline Savable_output_econ.xls & Output & Econ Submodel \\
\hline
\end{tabular}

vision recipes ver1.xls when it runs. After each run, VISION.ECON automatically sends data to the econ data output.xls and validationdata ver1.xls files. These two files are linked to and automatically send data to the Savable_output.xls, Savable_output-2.xls, and Savable_output_econ.xls files. These files contain tabular data, automatically create graphs, and are easily saved under a new file name to archive results from VISION runs.

The current spreadsheet, econ input data ver1.xls containing the module cost data is illustrated in Figure 8. Only a subset of all the cost modules are used in VISION.ECON based on the current set of fuel cycles and reactor concepts being evaluated. A few modules (e.g., F1-C, COEX, and Aqueous Separation) are not currently used in the model, but will be used in future development, and can be easily added into the model in the future.

Note that the user can change the values of the input economic data in econ input data ver1.xls, but must leave the data in the exact same position (column and row), because VISION pulls the data by position location on the spreadsheet. Inserting columns or rows, or shifting data positions will result in erroneous results from VISION.ECON simulations.

Also note that during calculations in VISION.ECON, such as the uncertainty analysis, unit conversions are easily handled by Powersim Studio (http://www.powersim.com 2007). A unit equivalency is established in the model to automatically convert units when an algorithm is executed. For example, the primary mass flow unit in VISION is in kilo tonnes/year, but the primary economic mass flow unit is in kilograms/year. A relationship was established in VISION between the two units, so that conversions are made automatically.

The costs currently loaded into the Excel spreadsheet econ input data ver1.xls were taken from the What-It-Takes (WIT) tables (see Table 2) from the "AFC Cost Basis" report (Shropshire, et al. 2007). The low, nominal, and high values are loaded for each module. The "Distribution Level" selection on the Economics User Interface screen allows selection of which value (low, nominal, or high) is used for the annual cost calculations. All three values are used to define the limits of the distribution for the cost uncertainty calculations. Current-year (CY-2007) U.S. dollars are used for all comparisons. Future year escalation or discounting is not provided. 
Table 2. Example of a What-It-Takes Table in the July 2007 "AFC Cost Basis" report (Shropshire, et al. 2007).

\begin{tabular}{|c|c|c|c|}
\hline \multicolumn{4}{|c|}{ What-It-Takes (WIT) Table } \\
\hline $\begin{array}{c}\text { Reference Cost(s) } \\
\text { Based on Reference Capacity }\end{array}$ & $\begin{array}{l}\text { Upsides } \\
\text { (Low Cost) }\end{array}$ & $\begin{array}{l}\text { Downsides } \\
\text { (High Cost) }\end{array}$ & $\begin{array}{l}\text { Selected Values } \\
\text { (Nominal Cost) }\end{array}$ \\
\hline $\begin{array}{l}\text { Generic LWR in U.S.: (specific } \\
\text { overnight cost) Nth of a Kind } \\
\text { (NOAK) } \$ 2,100 / \mathrm{kWe}\end{array}$ & $\$ 1,800 / \mathrm{kWe}$ & $\$ 3,500 / \mathrm{kWe}$ & $\$ 2,300 / \mathrm{kWe}$ \\
\hline $\begin{array}{l}\text { (Specific total capital cost } \\
\text { including financing, NOAK) } \\
\$ 2,400 / \mathrm{kWe}(5 \% \mathrm{DR} \text { [discount } \\
\text { rate]) }\end{array}$ & $\begin{array}{l}\$ 2,000 / \mathrm{kWe}(\mathrm{low} \\
\text { risk financing) }\end{array}$ & $\begin{array}{l}\$ 4,700 / \mathrm{kWe}(\mathrm{high} \\
\text { risk financing) }\end{array}$ & $\begin{array}{l}\$ 2,600 / \mathrm{kWe} \text { (most } \\
\text { likely utility } \\
\text { financing at } 5 \% \text { real } \\
\text { DR) }\end{array}$ \\
\hline $\begin{array}{l}\text { Nonfuel O\&M including } \\
\text { contribution to } \\
\text { Decommissioning and } \\
\text { Decontamination (D\&D)fund: } \\
\text { fixed component } \\
62 \$ /(\mathrm{kWe}-\mathrm{yr}) \text { (w/o D\&D adj) }\end{array}$ & $\begin{array}{l}55 \$ / \mathrm{kWe}-\mathrm{yr} \\
\text { including D\&D fund } \\
\text { adj }\end{array}$ & $\begin{array}{l}75 \$ / k W e-y r \\
\text { including D\&D fund } \\
\text { adj }\end{array}$ & $\begin{array}{l}\$ 64 / \mathrm{kWe}-\mathrm{yr} \\
\text { including D\&D fund } \\
\text { adj }\end{array}$ \\
\hline $\begin{array}{l}\text { Nonfuel O\&M including capital } \\
\text { replacements: variable } \\
\text { component } \\
0.45 \text { mills/kWh (w/o capital } \\
\text { replacements adj) }\end{array}$ & $\begin{array}{l}0.8 \text { mills } / \mathrm{kWh} \\
\text { including capital } \\
\text { replacements adj }\end{array}$ & $\begin{array}{l}2.5 \mathrm{mills} / \mathrm{kWh} \\
\text { including capital } \\
\text { replacements adj }\end{array}$ & $\begin{array}{l}1.8 \text { mills } / \mathrm{kWh} \\
\text { including capital } \\
\text { replacements adj }\end{array}$ \\
\hline
\end{tabular}

\subsection{Reactor Costs}

\subsubsection{Capital Costs}

The total non-fuel related annualized and levelized reactor cost calculated in VISION.ECON is a sum of annual capital recovery (including interest) and the operations and maintenance (O\&M) costs. The capital recovery portion of the overall reactor annualized cost is calculated using a fixed charge rate (which in this case is a capital recovery factor) to account for interest charges from amortization of the estimated total capital investment cost (TCIC). The total capital investment cost includes two major parts: the overnight capital cost (OCC) and the interest during construction (IDC). (The IDC is different from the amortization interest; the IDC is essentially the interest on the construction loan.) The overnight cost is assumed to include a contingency amount. In addition, the estimated cost for D\&D is also included up from in the capital cost. In absence of detailed estimates, VISION uses a "rule of thumb" that the total constant dollar decommissioning cost is $33 \%$ of the total direct capital cost. The constant dollar levelized capital cost can be calculated as follows:

Total Overnight Capital Cost $(\mathrm{OCC})=$ Base costs + Owners costs + Contingency

The overnight cost is usually expressed a lump sum cost in \$M, but in the literature and in the "AFC Cost Basis" report it is expressed as a "specific" or normalized form in $\$ / \mathrm{KWe}$. The "specific" cost, also called the What-It-Takes (WIT) cost, is easily converted to a lump sum cost as follows:

Lump sum OCC $=$ Specific Cost $($ WIT $) \times 1,000 \times$ Net Power Level, for example:

$\$ 2,990 \mathrm{M}=2,300 \$ / \mathrm{KWe} \times 1,000 \mathrm{KWe} / \mathrm{MWe} \times 1,300 \mathrm{MWe}$ 
Now an interest during construction (or IDC) must be calculated and added to the OCC before amortization of the total capital investment costs (or TCIC):

TCIC (in \$M) $=$ OCC + IDC (both in \$M)

The IDC depends on the discount (interest rate), the total duration of the period up to commercial operation (i.e., the time it takes to design, construct, and startup the plant), and the timing of these expenditures. The most typical cumulative spending pattern is the S-curve (see Figure 6). G4-ECONS uses a somewhat complex "sine-wave" algorithm and quarterly partitioning of the OCC cash flows to calculate the IDC. This requires considerable bookkeeping for interest and principal amounts. For VISION.ECON modeling, a simpler algorithm using quarterly calculations was developed that still retains model fidelity and accuracy. The first simplification made is to assume that the OCC cash flows are the same (uniformly distributed) in the quarters prior to commercial operation. For a total 5-year duration consisting of the time to design, build, and start-up the reactor, this would be 20 quarters.

For example the OCC of $\$ 2,990 \mathrm{M}$ distributed over $\mathrm{n}=20$ quarters would be $\$ 149.5 \mathrm{M} / \mathrm{qtr}$

Now a quarterly interest rate equivalent to the base annual discount rate must be calculated:

$\left.\mathrm{IQTLY}=(1+\mathrm{IYRLY} / 4)^{\wedge} 4-1\right) / 4$

For a $10 \%$ annual discount rate, the quarterly rate amounts to $2.595 \% / \mathrm{QTR}$

where

IQTLY $=$ interest quarterly

$\operatorname{IYRLY}=$ interest yearly $($ default $=10 \%)$.

The annual discount rate can be adjusted as desired.

Now it is assumed that the loaned amounts $(\$ 149.5 \mathrm{M}$ in the example) are paid to the constructor at the midpoint of each quarter. Using the uniform payment future worth formula (based on year-end payments), and an adjustment for the half-year right before commercial operation, the "uniform distribution" cash flow IDC is calculated as:

$\mathrm{IDC}=\left[\left(\mathrm{QTRPYMT} \times\left\{\left[(1+\mathrm{IQTLY})^{\wedge} \mathrm{N}\right]-1\right\} / \mathrm{IQTLY}\right) \times(1+\mathrm{IQTLY} / 2)\right]-\mathrm{OCC}$

For QTRPYMT $=149.5 \$ \mathrm{M}, \mathrm{IQTLY}=2.595 \%, \mathrm{~N}=20$ quarters, and $\mathrm{OCC}=\$ 2,990 \mathrm{M}$ the IDC $=$ $\$ 915 \mathrm{M}$.

A "shape factor" can be used to convert the "uniform cash flow" IDC to a generic S-curve cumulative cash flow curve. For a cash flow distribution that peaks at the middle of the design/construct/startup duration, a value of 0.98 is appropriate.

In the example, the new S-curve-based IDC would be $915 \times 0.98$ or $\$ 898 \mathrm{M}$. This agrees with the G4ECONS value for the same inputs.

The TCIC can now be calculated as:

$\mathrm{TCIC}=\mathrm{OCC}+\mathrm{IDC}$

$\$ 3,798 \mathrm{M}=\$ 2,990 \mathrm{M}+\$ 898 \mathrm{M}$ 
This is the value that now must be amortized by a capital recovery factor, Capital Recovery Factor (CRF):

$\mathrm{CRF}=\frac{r^{*}(1+r)^{y r}}{\left((1+r)^{y r}-1\right)}=0.10033$ for $10 \% \mathrm{DR}$ and $60 \mathrm{yrs}$

where

$\mathrm{r}=$ Annual Cost of Capital (percentage)

(default $=10 \%$, same as for construction loan, IYRLY),

$\mathrm{yr}=$ Capital Recovery Period (years)(60 years in example)

The capital recovery period (economic or regulatory life of the plant) in years is assumed to be the same as the number or years of facility operation. This is currently set to 60 years in VISION.ECON and for most Gen IV reactors in G4-ECONS. The interest rate for the cost of capital is currently set at 10\% to reflect the interest rate for commercial facility financing (non-government reactors). The interest rates for government commercial facilities (e.g., for recycling facilities) should be set at lower rates (e.g., 5\%).

The TCIC, which is a sum of the OCC plus the cost of the construction loan (IDC), is being "rolled over" to a mortgage-type loan that recovers all of the capital investment (principal plus interest) over the operational or regulatory life of the plant. As more robust plants capable of $60+$ years of regulatory life are constructed, and as investors demand shorter payback periods, the future capital recovery period is likely to be considerable shorter than the actual plant operating or regulatory lifetimes. For levelization purposes, the payback time is assumed the same as the plant operating life; otherwise, the annual reactor costs and Levelized Uniform Electricity Cost (LUEC) would change after the plant is written-off. This would introduce un-needed complexity into the calculations.

The annual capital recovery cost (ANNCAP), usually expressed in $\$ \mathrm{M} / \mathrm{yr}$, is: $\mathrm{ANNCAP}=\mathrm{CRF} \mathrm{x}$ TCIC. Dividing this annual amount by the annual energy production (in $\mathrm{KWh} / \mathrm{yr}$ ) gives the capital component of the LUEC (expressed in mills/KWh or $\$ / M W h$ ).

$\$ 381 \mathrm{M}=0.10033 \times \$ 3,798 \mathrm{M}$, and the capital cost component is:

LUEC $($ capital only $)=\$ 381 \mathrm{M} /[(1,300 \mathrm{MWe}) \times 0.90 \times 1,000 \times 8,766]=37 \mathrm{mills} / \mathrm{KWh}$

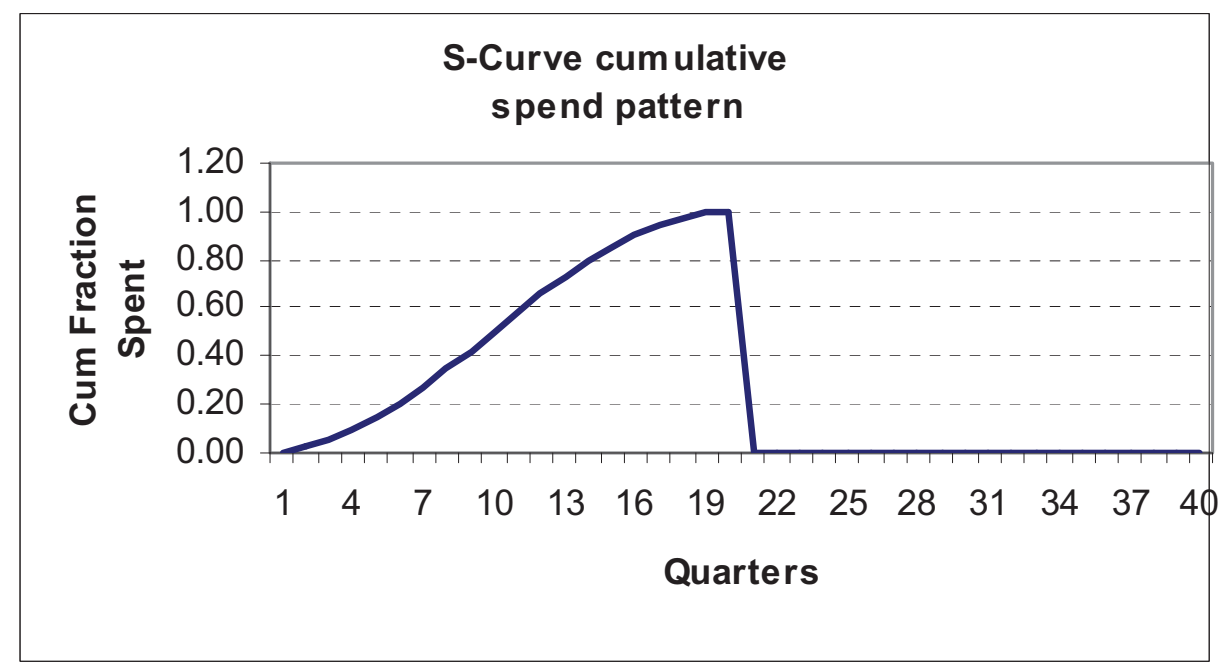

Figure 6. Pattern for design/construction/start-up cash flows. 


\subsubsection{Operating Costs}

Reactor non-fuel O\&M are separated into fixed and variable cost components (separately for each reactor type, fast, and thermal). Fixed O\&M costs are based on reactor net electrical capacity (size), are given in units of $\$ / \mathrm{kW}(\mathrm{e})$-yr and variable O\&M costs depending on annual electricity generation, and are given in units of mills/kW(e)-hr. The fixed and variable costs are normalized by their dependent factors and summed into the Reactor O\&M Cost per year.

For system scenarios where both fast and thermal reactors are used:

Total Reactor O\&M Variable Cost $=$ Variable Thermal O\&M Cost $\mathrm{x}$ Thermal Electricity Produced

+ Variable Fast O\&M Cost x Fast Electricity Produced

Total Reactor O\&M Fixed Cost $\quad=$ Fixed Fast O\&M Cost $\times$ Fast Reactor Power

+ Fixed Thermal O\&M Cost $x$ Thermal Reactor Power

Total Reactor O\&M Cost per year $=$ Total Variable O\&M Cost

+ Total Fixed O\&M Cost

The reactor specific capital cost $(\$ / \mathrm{kwe})$ and reactor operations cost components $(\$ / \mathrm{kwe}-\mathrm{yr}$ and mills/kwh) have separate uncertainty distributions for both reactor types calculated in VISION.ECON.

VISION also includes the functionality to accept exogenous (international) demand for light-water reactor (LWR) fuel services such as fuel fabrication and fuel take back (either for disposal or separations).

Operating costs are separated into fixed and variable cost for each reactor type: fast and thermal. Operating costs do not include the cost of fuel, but does include the cost of wet storage, operation, and maintenance. Fixed costs are given in units of $\$ / \mathrm{kW}(\mathrm{e})-\mathrm{yr}$ and variable costs are given in units of mills/kW(e)-hr. Fixed operations cost are dependent on reactor size while the variable costs are dependent on the electricity generation (output) of the reactor. The fixed and variable costs are normalized by their dependent factors and summed into the Reactor Operation Cost per year.

Total Reactor Operations Variable Cost $=$ Variable Thermal Operations Cost $\mathbf{x}$ Thermal Electricity Produced

+ Variable Fast Operations Cost x Fast Electricity Produced

Total Reactor Operation Fixed Cost $\quad=$ Fixed Fast Operations Cost x Fast Reactor Power

+ Fixed Thermal Operations Cost $x$ Thermal Reactor Power

Total Reactor Operation Cost Per Year $=$ Total Variable Operations Cost

+ Total Fixed Operations Cost

The reactor capital cost and reactor operation cost have separate uncertainty distributions calculated in VISION.ECON.

VISION also includes the functionality to accept exogenous (international) demand for LWR fuel services such as fuel fabrication and fuel take back (either for disposal or separations).

\section{RUNNING VISION WITH ECONOMICS}

Running VISION is simple. The program is designed to let the user run a range of base case scenarios simply by selecting a defined scenario from a dropdown list on the main user interface. There are 
currently over 60 different scenarios available in the model. VISION also has the flexibility to allow the user to develop additional scenarios.

Powersim is designed to allow the users to easily review the model structure and examine the linkages, decision rules, and equations that manage the fuel flow. This combination of transparency, simplicity, and flexibility is a key to the utility and power of VISION. In addition, the assumptions and calculations used in VISION are accessible through the user's guide. VISION is designed to be used by a variety of professionals, including researchers, technical managers, and policy makers to help evaluate options and make decisions.

VISION can be ran two ways: automatic or manual. In the automatic mode, the user selects from a set of predefined base cases and the model enters all of the input parameters automatically; they cannot be altered. Several new base cases, titled "User Defined," have been added to VISION recently. These base cases allow the user to define the parameters for a custom base case by modifying the Excel input files in the "User Defined" columns, allowing the user to save the selected input parameters for future reference or additional runs. Note that when using the User Defined base cases, the Excel files that have been modified (i.e., vision base case settings verl.xls, and vision recipes verl.xls) must be modified and saved before the model is advanced to the next run in a series or reset to start a new series of runs with VISION.ECON. When using user defined base cases, the basic order of steps is:

1. Edit input files

2. Save input files

3. Advance model to next run in series or reset to start new series

4. Select base case

5. Run model.

Caution should be taken in using the User Defined base case, the Excel files contain more than 200 inputs to VISION, which are detailed in the VISION User Guide (INL 2007). For assistance in learning how to use the User Defined mode, contact Gretchen Matthern at (208) 526-8747, or e-mail: gretchen.matthern@inl.gov. In the manual mode, the user enters all of the input parameters using the user interface screens. The automatic mode offers simplicity of operation, and the manual mode offers flexibility for developing different scenarios. In manual mode, if the user selects User Defined cases, the user is still required to set up the User Defined recipes in the VISION recipes excel file.

There are three key Powersim Studio (http://www.powersim.com 2007) buttons needed to run the model:

144

Reset (control-R) resets all the settings to their defaults and erases any data generated during the execution. The model will return to "run 1." Data already saved in Savable_output.xls, Savable_output2.xls, and Savable_output_econ.xls will not be erased, but will be written over as soon as additional runs are executed.

Play/Stop (control space) toggles between playing (running) the model and stop.

VII

Advanced simulation one step (control shift space) advances one time step. After completing a run, use this button to advance to the next run, to a maximum of "run 5." When you advance to a new run, the settings return to their defaults. 
There are a set of 12 files required to run the version of the VISION model with economics. If the user has Powersim Studio 2005 (http://www.powersim.com 2007), it is recommended that it be updated to service release 6. If the user does not have Powersim Studio 2005 software, then they can use the free Powersim player, which can be downloaded at http://www.powersim.com/download/player.asp.

The required files are as follows:

- econ data output ver1.xls (and output data file for economic data)

- econ input data ver1.xls (an input data file of costs from the "AFC Cost Basis" report [Shropshire et. al. 2007] for economic data)

- Savable_output-2.xls (a permanently savable data output file for VISION)

- Savable_output.xls (a permanently savable data output file for VISION)

- Savable_output_econ.xls (a permanently savable data output file for economic data)

- Savable_output-sjp.xls (a permanently savable data output file for VISION)

- vision base case settings ver1.xls (an input file)

- vision half life ver1.xls (an input file)

- vision heatdosetox ver1.xls (an input file)

- $\quad$ vision recipes ver1.xls (an input file)

- vision validationdata ver1.xls (a data output file for VISION)

- VISION Version 2.0.sip (the actual model)

- VISION_2.0_user_guide.doc (how to operate VISION).

The excel files must be in the same folder as the sip file. The user should launch Powersim Studio, and then open this sip file. Powersim will then open the Excel input data files. The output data files, Savable_output.xls, Savable_output-2.xls, and Savable_output_econ.xls, must be opened manually.

The system will store data for up to five runs in the excel output files. The files Savable_output.xls, Savable_output-2.xls, and Savable_output_econ.xls link to the output data in vision validationdata ver1.xls and econ data Output.xls (respectively) and provide the user with several graphs. Due to Microsoft Excel features, the links may have to be reset from Savable_output.xls and Savable_output2.xls to validationdata ver2.xls, or from Savable_output_econ.xls to econ data Output.xls. If so, go to "edit," then "links," click on "change source," and browse to the location of vision validationdata ver1.xls. Likewise, if the links have to be reset from Savable_output_econ.xls to econ data Output.xls, go to "edit," then "links," click on "change source," and browse to the location of econ data Output.xls.

After running up to five cases, the user should make copies of Savable_output.xls, Savable_output2.xls, and Savable_output_econ.xls by renaming them, and then breaking the links to the other files by going to "edit," then "links," click on "break links," and re-saving the files. The renamed files will then be an archive of the input settings and output of the five runs. The user needs to re-open the Savable_output.xls, Savable_output-2.xls, and Savable_output_econ.xls files prior to executing additional runs.

VISION is a dynamic model, so many input parameters can vary with time. The model is typically used to run scenarios starting in 2000 and ending in 2100, although either date can be changed. The model is currently set to use a 0.25 -year time step. There are three major periods in VISION: Phase 0 is the initial condition and lasts until the beginning of the user determined Phase 1, Phases 1 and 2 are the second and third periods and are set by the user. 
Phase 0 is the initial period; this phase starts in 2000 and always uses LWRs without recycle, which reflects the current U.S. reactor fleet. The end of this phase is set by the start time for Phase 1. Under default conditions, the initial U.S. fleet is assumed to have 104 light water reactors, of these, 35 reactors are assumed to be capable of only utilizing UOX fuel and are designated as LWRs in the model, while the remaining 69 reactors are assumed to be capable of utilizing UOX, MOX, or IMF fuel and are designated as Advanced Light-Water Reactors (ALWRs). Later in the setup, the total number of reactors and the relative proportion of LWR to ALWR reactors used can be varied. While no separation and recycle can occur during Phase 0, under many scenarios, the reactors present in Phase 0 will still be in the reactor fleet during Phases 1 and 2 when separation and recycle is possible.

Phase 1 is the second period; this phase starts between 2000 and 2100, as defined in the different base cases (may be modified in the manual mode by the slider bar). Phase 1 continues until the start of Phase 2 (the start of Phase 2 is defined by the user in manual mode by the slider bar). Phase 1 is and should be earlier than Phase 2. The start of Phase 1 and Phase 2 is NOT controlled by the slider bar while in base case mode. To select a reactor/fuel combination (only for RUN BASE CASE mode), click on the appropriate selection from the drop down list in the box entitled "phase 1 phase 2 ." The type of reactor and fuel utilized during this phase are set by the user choosing from the pre-determined list on the main page.

Phase 2 is the last period; this phase starts between 2000 and 2100. The end of Phase 1 is specified by the start time for Phase 2. Phase 1 always precedes Phase 2. The type of reactor and fuel utilized during this phase are set by the user choosing from a pre-determined list (see description of options presented in the Phase 1 discussion).

The Powersim Studio (http://www.powersim.com 2007) software functions on a presentation level or a modification level. If you are using VISION via a free reader, you only have access to the presentation level. If you have a full version of Powersim Studio, then you can access both levels. (Opening the model directly from the file name rather than opening the Powersim Studio software, and then opening the model file will access only the presentation level.)

Additional details about running VISION are available in the VISION User Guide (INL 2007).

\section{VISION ECONOMICS USER INTERFACE}

A separate user interface for economics is available in VISION. Regardless of whether the user runs a base case, user defined base case, or manual mode, the way to set the economics information is the same. Clicking on the "Economics" button on the main user interface screen takes the user to the economics user interface screen. This interface allows the user to select the "distribution type" (triangular or uniform) for each module. The user also makes one selection for the "distribution level," which applies to all of the modules. The distribution level determines whether the low, nominal, or high costs are used to calculate the point value annual costs. Scrolling to the left of the user interface screen on the economics submodel allows the user to view the logic and links of the VISION economic model, whether in the presentation or modification mode. In the modification mode, the code that implements the equations is also visible by double-clicking any icon in the model. 


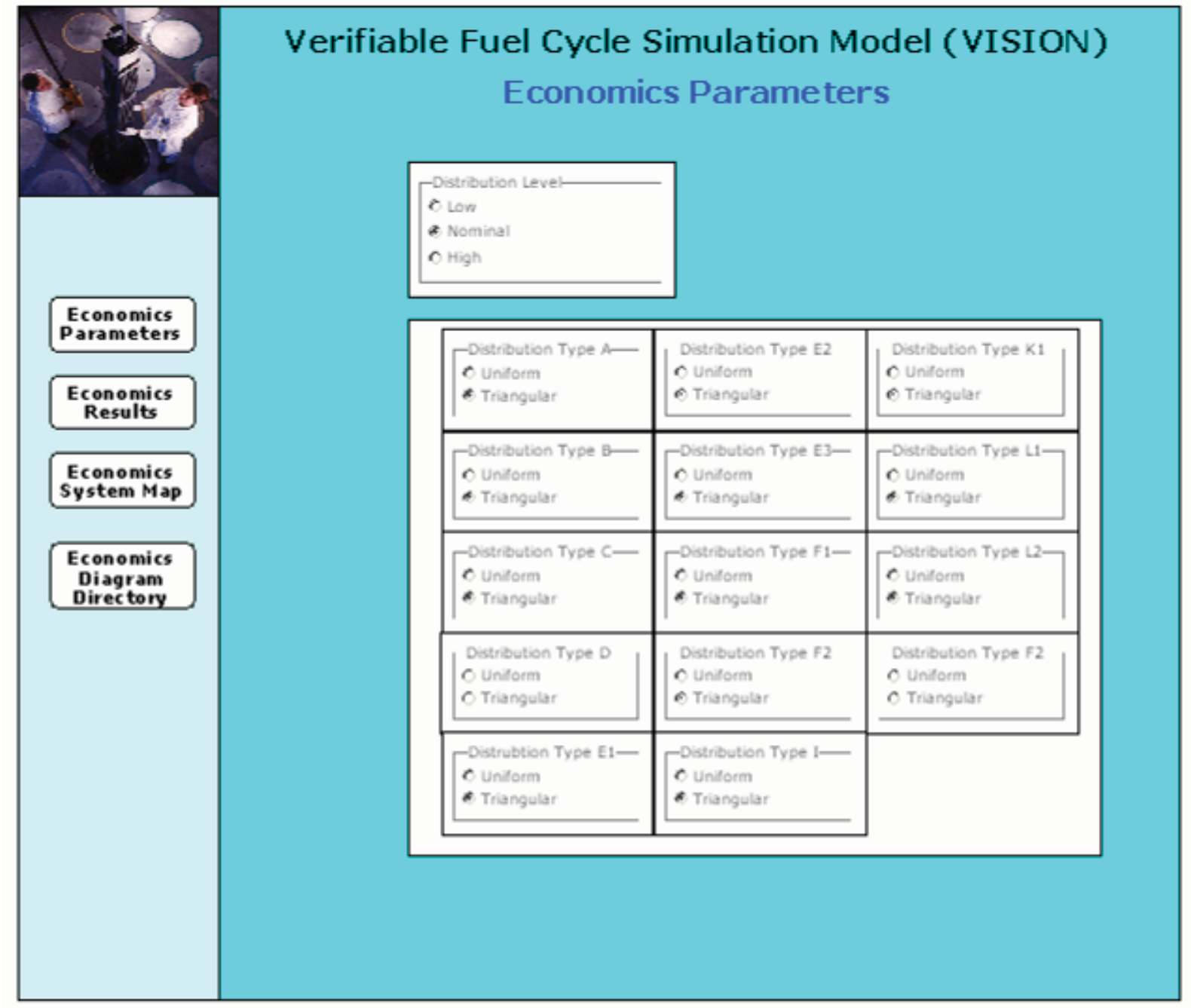

Figure 7. Illustration of the VISION.ECON user interface.

\section{INPUT DATA}

\subsection{VISION Input Data}

VISION.ECON input data is contained in the Excel file econ input data ver1.xls. This file contains the low, nominal, and high cost data to create distributions for each module, with units given. Low values in red denote modules where the low and nominal values are identical. The low values were lowered one unit to properly represent a triangular distribution. Figure 7 illustrates a sample economics input file.

Remote fast fuel fabrication is an integral part of the overall pyrochemical recycle system and the processes are usually housed in the same facility. In order to reflect this, the "AFC Cost Basis" report, which provides values to econ input data verl.xls, gives a single cost for fast fuel fabrication and reprocessing costs. The fabrication and the reprocessing steps are in different phases of the fuel cycle in the VISION.ECON input data. Fabrication is in the front-end phase of the fuel cycle and reprocessing is in the recycle phase of the fuel cycle. The submodel tracks the cost of each fuel cycle phase, so in order to resolve this discrepancy in phase costs, the combined costs of fast fuel fabrication and reprocessing are split equally between the fabrication module and the recycling module. 


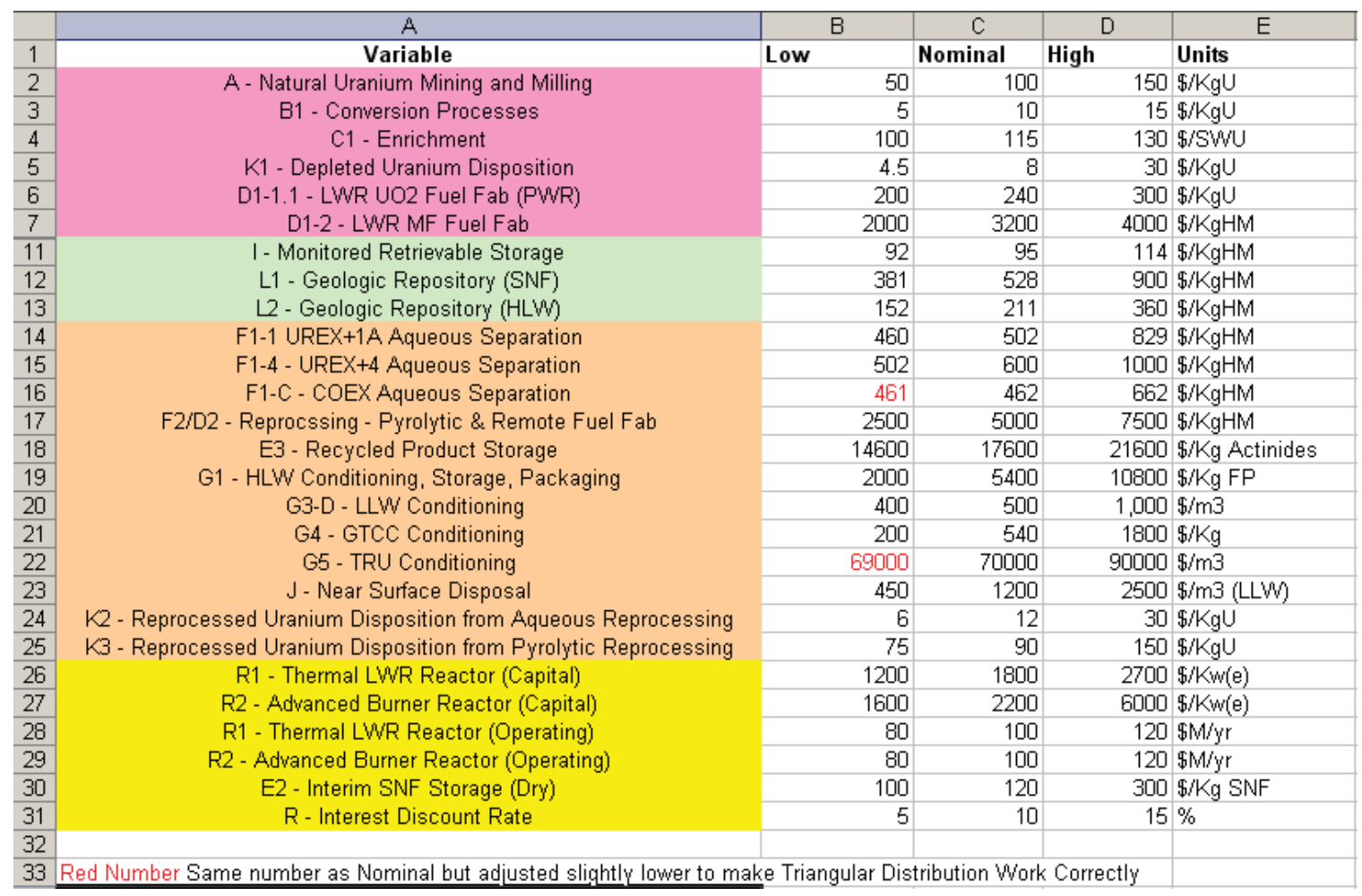

Figure 8. Excel input file for distribution cost data.

\section{OUTPUT DATA}

\subsection{Excel Output Data}

Data that is calculated in the VISION economics submodel and is automatically output to Excel in tabular form includes the:

- Flow and cost (\$) for each time step for each module

- Annual costs (\$) and cost distribution data for each module

- Summary level annual costs (\$) and cost distributions for:

- Front-end

- Recycling

- Back-end

- Capital

- Reactor operation

- Total fuel cycle

- Total reactor (including capital and operating)

- Total (fuel cycle and reactor)

- Total fuel cycle costs per unit electricity (\$ mills per kW-hr)

- Total reactor (including capital and operating) per unit electricity (mills per kW-hr)

- Total (fuel cycle and reactor) costs per unit electricity (mills per kW-hr) (i.e, Total Cost of Electricity). 
Figures 9 and 10 show the Excel output data contained in the savable output econ.xls file for a sample run using the AFCI 1.5\% base case. The columns are color coded according to their fuel cycle phase; pink for front end, yellow for reactor, green for back end, and tan for recycling, as diagrammed in Figure 7.

\begin{tabular}{|c|c|c|c|c|c|c|c|c|c|}
\hline & Case 1 & Base Case & & & & & & & \\
\hline & Module A & Module A & Module B & Module B & Module C & Module C & Module D1-1 & Module D2 & odule D1-2 \\
\hline & $\begin{array}{c}\mathrm{U} \text { ore } \\
\text { consumption LWR }\end{array}$ & $\begin{array}{c}\text { Cost of } \cup \text { Ore Mining by year } \\
(\$ / y r)\end{array}$ & $\begin{array}{l}\text { U conversion rate } \\
\text { LWR (kg U/yr) }\end{array}$ & Cost of U Conversion by year $(\$ / y r)$ & $\begin{array}{l}\text { SWU per year } \\
\text { (SWU/yr) }\end{array}$ & $\begin{array}{l}\text { Cost of } U \\
\text { Enrichment }\end{array}$ & Fuel Fab & rication Rate & $(\mathrm{kg} / \mathrm{yr})$ \\
\hline & & & & & & & LWR & FBR & LWRmf \\
\hline 2000 & $1.86 \mathrm{E}+07$ & 1.12E+09 & $0.00 E+00$ & $0.00 E+00$ & $1.28 \mathrm{E}+07$ & 1.35E+09 & $0.00 E+00$ & $0.00 E+00$ & $0.00 E+00$ \\
\hline 2001 & $1.85 E+07$ & $1.11 \mathrm{E}+09$ & $1.56 \mathrm{E}+07$ & $1.86 \mathrm{E}+08$ & $1.32 E+07$ & $1.39 \mathrm{E}+09$ & $0.00 \mathrm{E}+00$ & $0.00 \mathrm{E}+00$ & $0.00 \mathrm{E}+00$ \\
\hline 2002 & $1.84 \mathrm{E}+07$ & $1.11 \mathrm{E}+09$ & $1.55 \mathrm{E}+07$ & $1.85 E+08$ & $1.36 \mathrm{E}+07$ & 1.43E+09 & $2.56 \mathrm{E}+06$ & $0.00 E+00$ & $0.00 \mathrm{E}+00$ \\
\hline 2003 & $1.84 \mathrm{E}+07$ & 1.10E+09 & $1.54 \mathrm{E}+07$ & $1.84 \mathrm{E}+08$ & $1.39 \mathrm{E}+07$ & $1.46 \mathrm{E}+09$ & $2.29 \mathrm{E}+06$ & $0.00 E+00$ & $0.00 \mathrm{E}+00$ \\
\hline 2004 & $1.84 \mathrm{E}+07$ & $1.11 \mathrm{E}+09$ & $1.54 \mathrm{E}+07$ & $1.84 \mathrm{E}+08$ & $1.43 E+07$ & $1.50 \mathrm{E}+09$ & $2.07 E+06$ & $0.00 \mathrm{E}+00$ & $0.00 \mathrm{E}+00$ \\
\hline 2005 & $1.85 E+07$ & $1.11 \mathrm{E}+09$ & $1.54 \mathrm{E}+07$ & 1.84E+08 & $1.32 \mathrm{E}+07$ & $1.39 \mathrm{E}+09$ & $1.89 E+06$ & $0.00 E+00$ & $0.00 \mathrm{E}+00$ \\
\hline 2006 & $1.88 \mathrm{E}+07$ & 1.13E+09 & $1.55 \mathrm{E}+07$ & $2.22 \mathrm{E}+08$ & $1.39 \mathrm{E}+07$ & 1.45E+09 & 1.73E+06 & $0.00 \mathrm{E}+00$ & $0.00 \mathrm{E}+00$ \\
\hline 2007 & $1.89 \mathrm{E}+07$ & 1.14E+09 & $1.54 \mathrm{E}+07$ & $1.90 \mathrm{E}+08$ & $1.44 \mathrm{E}+07$ & $1.51 E+09$ & $2.41 E+06$ & $0.00 E+00$ & $0.00 \mathrm{E}+00$ \\
\hline 2008 & $1.93 \mathrm{E}+07$ & 1.16E+09 & $1.54 \mathrm{E}+07$ & $2.27 E+08$ & $1.50 \mathrm{E}+07$ & $1.57 \mathrm{E}+09$ & $2.23 E+06$ & $0.00 E+00$ & $0.00 \mathrm{E}+00$ \\
\hline 2009 & $2.31 E+07$ & $1.39 E+09$ & $1.54 \mathrm{E}+07$ & $1.95 E+08$ & $1.83 E+07$ & $1.92 E+09$ & $2.08 E+06$ & $0.00 \mathrm{E}+00$ & $0.00 \mathrm{E}+00$ \\
\hline 2010 & $1.98 \mathrm{E}+07$ & 1.19E+09 & 1.55E+07 & $1.99 \mathrm{E}+08$ & $1.46 \mathrm{E}+07$ & $1.54 \mathrm{E}+09$ & 1.95E+06 & $0.00 E+00$ & $0.00 \mathrm{E}+00$ \\
\hline 2011 & $2.02 \mathrm{E}+07$ & $1.21 \mathrm{E}+09$ & $1.54 \mathrm{E}+07$ & $2.36 \mathrm{E}+08$ & $1.53 E+07$ & $1.61 \mathrm{E}+09$ & $2.02 E+06$ & $0.00 E+00$ & $0.00 \mathrm{E}+00$ \\
\hline 2012 & $2.39 \mathrm{E}+07$ & $1.44 E+09$ & $1.54 \mathrm{E}+07$ & $2.04 \mathrm{E}+08$ & $1.86 \mathrm{E}+07$ & $1.95 E+09$ & $2.25 E+06$ & $0.00 E+00$ & $0.00 \mathrm{E}+00$ \\
\hline 2013 & $2.43 E+07$ & 1.46E+09 & $1.54 \mathrm{E}+07$ & $2.07 E+08$ & $1.93 \mathrm{E}+07$ & $2.02 \mathrm{E}+09$ & $2.09 E+06$ & $0.00 \mathrm{E}+00$ & $0.00 \mathrm{E}+00$ \\
\hline 2014 & $2.12 \mathrm{E}+07$ & $1.27 E+09$ & $1.55 \mathrm{E}+07$ & $2.45 E+08$ & $1.71 \mathrm{E}+07$ & $1.79 \mathrm{E}+09$ & $2.27 E+06$ & $0.00 \mathrm{E}+00$ & $0.00 \mathrm{E}+00$ \\
\hline 2015 & $2.14 \mathrm{E}+07$ & $1.29 \mathrm{E}+09$ & $1.55 \mathrm{E}+07$ & $2.49 E+08$ & $1.62 E+07$ & $1.70 \mathrm{E}+09$ & $1.82 \mathrm{E}+06$ & $0.00 \mathrm{E}+00$ & $0.00 \mathrm{E}+00$ \\
\hline 2016 & $2.52 \mathrm{E}+07$ & $1.51 \mathrm{E}+09$ & $1.54 \mathrm{E}+07$ & 2.16E+08 & $1.95 \mathrm{E}+07$ & $2.05 E+09$ & 1.72E+06 & $0.00 \mathrm{E}+00$ & $0.00 \mathrm{E}+00$ \\
\hline 2017 & $2.56 \mathrm{E}+07$ & $1.53 E+09$ & $1.54 \mathrm{E}+07$ & $2.20 \mathrm{E}+08$ & $2.02 \mathrm{E}+07$ & $2.13 E+09$ & $2.21 \mathrm{E}+06$ & $0.00 E+00$ & $0.00 \mathrm{E}+00$ \\
\hline 2018 & $2.26 \mathrm{E}+07$ & $1.36 \mathrm{E}+09$ & $1.55 \mathrm{E}+07$ & $2.26 \mathrm{E}+08$ & $1.82 \mathrm{E}+07$ & $1.91 E+09$ & $2.38 E+06$ & $0.00 \mathrm{E}+00$ & $0.00 \mathrm{E}+00$ \\
\hline 2019 & $2.32 E+07$ & $1.39 \mathrm{E}+09$ & $1.55 \mathrm{E}+07$ & $2.65 \mathrm{E}+08$ & $1.90 \mathrm{E}+07$ & $2.00 E+09$ & $2.34 E+06$ & $2.35 E+03$ & $0.00 \mathrm{E}+00$ \\
\hline 2020 & 2.34E+07 & $1.40 \mathrm{E}+09$ & $1.54 \mathrm{E}+07$ & $2.70 E+08$ & $1.81 \mathrm{E}+07$ & $1.90 \mathrm{E}+09$ & 2.13E+06 & $2.35 E+03$ & $0.00 \mathrm{E}+00$ \\
\hline 2021 & $2.36 \mathrm{E}+07$ & $1.42 E+09$ & $1.51 \mathrm{E}+07$ & $2.69 \mathrm{E}+08$ & $1.87 \mathrm{E}+07$ & $1.96 \mathrm{E}+09$ & $2.03 E+06$ & $2.35 E+03$ & $0.00 \mathrm{E}+00$ \\
\hline 2022 & $2.39 \mathrm{E}+07$ & $1.43 E+09$ & $1.49 \mathrm{E}+07$ & $2.72 \mathrm{E}+08$ & $1.92 \mathrm{E}+07$ & $2.02 E+09$ & $2.32 \mathrm{E}+06$ & $2.35 E+03$ & $0.00 E+00$ \\
\hline 2023 & $2.43 E+07$ & $1.46 \mathrm{E}+09$ & $1.50 \mathrm{E}+07$ & $2.76 \mathrm{E}+08$ & $1.99 \mathrm{E}+07$ & $2.09 \mathrm{E}+09$ & 2.12E+06 & $2.35 E+03$ & $0.00 \mathrm{E}+00$ \\
\hline 2024 & $2.47 E+07$ & $1.48 \mathrm{E}+09$ & $1.50 \mathrm{E}+07$ & $2.81 E+08$ & $2.05 \mathrm{E}+07$ & 2. $16 \mathrm{E}+09$ & $1.94 E+06$ & $2.35 E+03$ & $0.00 \mathrm{E}+00$ \\
\hline 2025 & $2.49 \mathrm{E}+07$ & $1.49 \mathrm{E}+09$ & $1.51 E+07$ & $2.85 \mathrm{E}+08$ & $1.97 \mathrm{E}+07$ & $2.07 E+09$ & $1.84 \mathrm{E}+06$ & $2.35 \mathrm{E}+03$ & $0.00 \mathrm{E}+00$ \\
\hline 2026 & $2.55 E+07$ & $1.53 E+09$ & $1.49 \mathrm{E}+07$ & $2.88 \mathrm{E}+08$ & $2.06 \mathrm{E}+07$ & 2.16E+09 & 1.75E+06 & $2.35 E+03$ & $0.00 \mathrm{E}+00$ \\
\hline 2027 & $2.95 E+07$ & 1.77E+09 & $1.50 \mathrm{E}+07$ & $2.92 \mathrm{E}+08$ & $2.43 E+07$ & $2.55 \mathrm{E}+09$ & $2.30 E+06$ & $2.35 E+03$ & $0.00 \mathrm{E}+00$ \\
\hline 2028 & $2.71 \mathrm{E}+07$ & $1.63 E+09$ & $1.49 \mathrm{E}+07$ & $3.04 E+08$ & $2.27 \mathrm{E}+07$ & $2.38 \mathrm{E}+09$ & $2.19 E+06$ & $9.41 E+03$ & $0.00 \mathrm{E}+00$ \\
\hline 2029 & $2.83 E+07$ & $1.70 E+09$ & $1.49 \mathrm{E}+07$ & $3.16 E+08$ & $2.40 \mathrm{E}+07$ & $2.52 E+09$ & $2.60 E+06$ & 1. $65 \mathrm{E}+04$ & $0.00 \mathrm{E}+00$ \\
\hline 2030 & $2.82 \mathrm{E}+07$ & $1.69 E+09$ & $1.41 \mathrm{E}+07$ & $3.19 E+08$ & $2.28 \mathrm{E}+07$ & $2.39 \mathrm{E}+09$ & $2.51 E+06$ & $2.59 E+04$ & $0.00 \mathrm{E}+00$ \\
\hline 2031 & $2.84 \mathrm{E}+07$ & $1.71 \mathrm{E}+09$ & 1.30E+07 & $3.17 E+08$ & $2.33 E+07$ & 2.45E+09 & $2.44 E+06$ & $3.53 E+04$ & $0.00 E+00$ \\
\hline 2032 & $2.87 E+07$ & $1.72 E+09$ & 1.22E+07 & $3.20 \mathrm{E}+08$ & $2.39 \mathrm{E}+07$ & $2.51 E+09$ & $2.60 E+06$ & 4. $47 \mathrm{E}+04$ & $0.00 \mathrm{E}+00$ \\
\hline 2033 & $2.88 \mathrm{E}+07$ & $1.73 E+09$ & $1.13 E+07$ & $3.21 \mathrm{E}+08$ & $2.43 E+07$ & $2.55 \mathrm{E}+09$ & $2.47 E+06$ & $6.35 E+04$ & $0.00 E+00$ \\
\hline 2034 & $3.23 E+07$ & $1.94 E+09$ & $1.04 E+07$ & $2.86 \mathrm{E}+08$ & $2.75 \mathrm{E}+07$ & $2.89 \mathrm{E}+09$ & $2.35 E+06$ & $8.00 \mathrm{E}+04$ & $0.00 \mathrm{E}+00$ \\
\hline 2035 & $2.90 \mathrm{E}+07$ & $1.74 \mathrm{E}+09$ & $9.56 \mathrm{E}+06$ & $2.92 E+08$ & $2.38 \mathrm{E}+07$ & $2.50 \mathrm{E}+09$ & $2.24 E+06$ & $8.23 E+04$ & $0.00 \mathrm{E}+00$ \\
\hline 2036 & $3.29 \mathrm{E}+07$ & $1.98 E+09$ & $8.58 \mathrm{E}+06$ & $2.93 E+08$ & $2.72 E+07$ & $2.86 \mathrm{E}+09$ & $2.64 E+06$ & $8.23 E+04$ & $0.00 \mathrm{E}+00$ \\
\hline 2037 & $3.32 E+07$ & $1.99 E+09$ & $7.70 \mathrm{E}+06$ & $2.95 E+08$ & $2.75 E+07$ & $2.89 \mathrm{E}+09$ & $2.70 E+06$ & $8.94 \mathrm{E}+04$ & $0.00 \mathrm{E}+00$ \\
\hline 2038 & $3.00 \mathrm{E}+07$ & $1.80 E+09$ & $6.81 E+06$ & $2.99 \mathrm{E}+08$ & $2.50 \mathrm{E}+07$ & $2.63 \mathrm{E}+09$ & $2.62 E+06$ & $9.88 \mathrm{E}+04$ & $0.00 \mathrm{E}+00$ \\
\hline 2039 & $3.40 \mathrm{E}+07$ & $2.04 E+09$ & $5.92 E+06$ & $3.03 E+08$ & $2.85 \mathrm{E}+07$ & $2.99 \mathrm{E}+09$ & $2.54 \mathrm{E}+06$ & $9.88 \mathrm{E}+04$ & $0.00 \mathrm{E}+00$ \\
\hline 2040 & $3.42 E+07$ & $2.05 E+09$ & $5.03 E+06$ & $3.07 E+08$ & $2.82 E+07$ & $2.96 \mathrm{E}+09$ & $2.47 E+06$ & $1.06 E+05$ & $0.00 \mathrm{E}+00$ \\
\hline 2041 & $3.42 E+07$ & $2.05 E+09$ & $4.12 E+06$ & $3.06 \mathrm{E}+08$ & $2.82 E+07$ & $2.96 \mathrm{E}+09$ & $2.90 E+06$ & $1.25 \mathrm{E}+05$ & $0.00 \mathrm{E}+00$ \\
\hline 2042 & $3.44 E+07$ & $2.06 \mathrm{E}+09$ & $3.22 E+06$ & $3.08 E+08$ & $2.84 \mathrm{E}+07$ & $2.98 \mathrm{E}+09$ & $2.86 \mathrm{E}+06$ & 1.36E+05 & $0.00 \mathrm{E}+00$ \\
\hline 2043 & $3.10 \mathrm{E}+07$ & $1.86 \mathrm{E}+09$ & 2.33E+06 & $3.44 \mathrm{E}+08$ & $2.56 \mathrm{E}+07$ & $2.69 \mathrm{E}+09$ & $2.80 E+06$ & $1.51 \mathrm{E}+05$ & $0.00 \mathrm{E}+00$ \\
\hline 2044 & $3.49 \mathrm{E}+07$ & $2.09 \mathrm{E}+09$ & $1.43 E+06$ & $3.13 E+08$ & $2.88 \mathrm{E}+07$ & $3.03 E+09$ & $2.73 E+06$ & 1.53E+05 & $0.00 E+00$ \\
\hline 2045 & $3.55 E+07$ & 2.13E+09 & $5.37 E+05$ & $3.19 E+08$ & $2.93 \mathrm{E}+07$ & $3.07 \mathrm{E}+09$ & 2. $67 \mathrm{E}+06$ & $1.53 E+05$ & $0.00 E+00$ \\
\hline 2046 & $3.60 \mathrm{E}+07$ & 2.16E+09 & $0.00 \mathrm{E}+00$ & $3.24 \mathrm{E}+08$ & $2.97 \mathrm{E}+07$ & $3.12 E+09$ & 2. $60 \mathrm{E}+06$ & $1.53 E+05$ & $0.00 \mathrm{E}+00$ \\
\hline 2047 & $3.29 \mathrm{E}+07$ & $1.98 \mathrm{E}+09$ & $0.00 E+00$ & $3.63 E+08$ & $2.72 E+07$ & $2.86 \mathrm{E}+09$ & $3.04 E+06$ & $1.53 E+05$ & $0.00 \mathrm{E}+00$ \\
\hline 2048 & $3.24 \mathrm{E}+07$ & $1.94 E+09$ & $0.00 \mathrm{E}+00$ & $3.58 E+08$ & $2.68 E+07$ & $2.81 E+09$ & $3.00 \mathrm{E}+06$ & 1. $60 \mathrm{E}+05$ & $0.00 \mathrm{E}+00$ \\
\hline 2049 & $3.17 E+07$ & $1.90 \mathrm{E}+09$ & $0.00 \mathrm{E}+00$ & $3.51 E+08$ & $2.62 E+07$ & $2.75 E+09$ & $2.74 E+06$ & $1.74 \mathrm{E}+05$ & $0.00 \mathrm{E}+00$ \\
\hline 2050 & $3.19 \mathrm{E}+07$ & $1.91 \mathrm{E}+09$ & $0.00 \mathrm{E}+00$ & $3.53 E+08$ & $2.63 \mathrm{E}+07$ & $2.76 \mathrm{E}+09$ & $2.34 \mathrm{E}+06$ & $1.88 \mathrm{E}+05$ & $0.00 \mathrm{E}+00$ \\
\hline
\end{tabular}

Figure 9. Base Case 1: 2000-2050 yearly results for Modules A through D1. 


\begin{tabular}{|c|c|c|c|c|c|c|c|c|c|}
\hline & Case 1 & Base Case & & & & & & & \\
\hline & Module A & Module A & Module B & Module B & Module C & Module C & Module D1-1 & Module D2 & lodule D1-2 \\
\hline & $\begin{array}{c}\mathrm{U} \text { ore } \\
\text { consumption LWR } \\
(\mathrm{kg} U / \mathrm{vr})\end{array}$ & $\begin{array}{l}\text { Cost of } U \text { Ore Mining by year } \\
\qquad(\$ / y r)\end{array}$ & $\begin{array}{l}\text { U conversion rate } \\
\text { LWR }(\mathrm{kg} \mathrm{U/yr)}\end{array}$ & Cost of U Conversion by year (\$/yr) & $\begin{array}{l}\text { SWU per year } \\
\text { (SWU/yr) }\end{array}$ & $\begin{array}{l}\text { Cost of U } \\
\text { Enrichment }\end{array}$ & Fuel Fab & rication Rate & (kg/yr) \\
\hline & & & & & & & LWR & FBR & LWRmf \\
\hline 2051 & $3.21 \mathrm{E}+07$ & $1.92 \mathrm{E}+09$ & $0.00 E+00$ & $3.55 E+08$ & 2. $65 \mathrm{E}+07$ & $2.78 \mathrm{E}+09$ & $2.29 \mathrm{E}+06$ & $2.05 E+05$ & $0.00 \mathrm{E}+00$ \\
\hline 2052 & $3.22 \mathrm{E}+07$ & $1.93 E+09$ & $0.00 \mathrm{E}+00$ & $3.56 \mathrm{E}+08$ & $2.66 \mathrm{E}+07$ & $2.79 \mathrm{E}+09$ & $2.30 E+06$ & 2. $19 \mathrm{E}+05$ & $0.00 \mathrm{E}+00$ \\
\hline 2053 & $3.24 \mathrm{E}+07$ & $1.94 \mathrm{E}+09$ & $0.00 E+00$ & $3.58 \mathrm{E}+08$ & $2.68 \mathrm{E}+07$ & $2.81 \mathrm{E}+09$ & $2.31 \mathrm{E}+06$ & $2.35 E+05$ & $0.00 \mathrm{E}+00$ \\
\hline 2054 & $3.26 \mathrm{E}+07$ & 1.96E+09 & $0.00 E+00$ & $3.60 \mathrm{E}+08$ & $2.69 \mathrm{E}+07$ & $2.82 \mathrm{E}+09$ & $2.33 E+06$ & $2.52 \mathrm{E}+05$ & $0.00 \mathrm{E}+00$ \\
\hline 2055 & $3.26 \mathrm{E}+07$ & $1.96 \mathrm{E}+09$ & $0.00 \mathrm{E}+00$ & $3.26 E+08$ & $2.69 \mathrm{E}+07$ & $2.82 E+09$ & $2.34 E+06$ & $2.73 E+05$ & $0.00 \mathrm{E}+00$ \\
\hline 2056 & $3.28 \mathrm{E}+07$ & $1.97 \mathrm{E}+09$ & $0.00 E+00$ & $3.28 \mathrm{E}+08$ & $2.71 \mathrm{E}+07$ & $2.84 E+09$ & $2.35 E+06$ & $2.89 E+05$ & $0.00 \mathrm{E}+00$ \\
\hline 2057 & $3.31 \mathrm{E}+07$ & $1.99 \mathrm{E}+09$ & $0.00 E+00$ & $3.31 E+08$ & $2.73 E+07$ & $2.87 E+09$ & $2.61 \mathrm{E}+06$ & $2.99 \mathrm{E}+05$ & $0.00 \mathrm{E}+00$ \\
\hline 2058 & $3.35 \mathrm{E}+07$ & $2.01 \mathrm{E}+09$ & $0.00 \mathrm{E}+00$ & $3.35 E+08$ & $2.76 \mathrm{E}+07$ & $2.90 \mathrm{E}+09$ & $2.64 E+06$ & $3.10 \mathrm{E}+05$ & $0.00 \mathrm{E}+00$ \\
\hline 2059 & $3.72 E+07$ & $2.23 E+09$ & $0.00 E+00$ & $3.37 \mathrm{E}+08$ & $3.07 \mathrm{E}+07$ & $3.23 E+09$ & $2.66 \mathrm{E}+06$ & $3.29 \mathrm{E}+05$ & $0.00 \mathrm{E}+00$ \\
\hline 2060 & $3.78 \mathrm{E}+07$ & 2.27E+09 & $0.00 \mathrm{E}+00$ & $3.42 E+08$ & $3.12 \mathrm{E}+07$ & $3.27 \mathrm{E}+09$ & $2.67 \mathrm{E}+06$ & $3.32 \mathrm{E}+05$ & $0.00 \mathrm{E}+00$ \\
\hline 2061 & $3.83 E+07$ & 2.30E+09 & $0.00 E+00$ & $3.47 \mathrm{E}+08$ & $3.16 E+07$ & $3.32 E+09$ & $2.71 \mathrm{E}+06$ & 3.36E+05 & $0.00 \mathrm{E}+00$ \\
\hline 2062 & $3.53 \mathrm{E}+07$ & $2.12 E+09$ & $0.00 E+00$ & $3.53 E+08$ & $2.91 E+07$ & $3.06 \mathrm{E}+09$ & $2.75 E+06$ & $3.41 \mathrm{E}+05$ & $0.00 \mathrm{E}+00$ \\
\hline 2063 & $3.55 \mathrm{E}+07$ & 2.13E+09 & $0.00 \mathrm{E}+00$ & $3.55 E+08$ & $2.93 E+07$ & $3.07 \mathrm{E}+09$ & $2.79 \mathrm{E}+06$ & $3.60 \mathrm{E}+05$ & $0.00 \mathrm{E}+00$ \\
\hline 2064 & $3.96 E+07$ & $2.37 E+09$ & $0.00 E+00$ & $3.60 \mathrm{E}+08$ & $3.27 \mathrm{E}+07$ & $3.43 E+09$ & $2.56 \mathrm{E}+06$ & $3.74 \mathrm{E}+05$ & $0.00 E+00$ \\
\hline 2065 & $3.65 \mathrm{E}+07$ & 2.19E+09 & $0.00 \mathrm{E}+00$ & $3.99 \mathrm{E}+08$ & $3.02 E+07$ & $3.17 E+09$ & $3.00 \mathrm{E}+06$ & $4.00 E+05$ & $0.00 \mathrm{E}+00$ \\
\hline 2066 & $4.40 \mathrm{E}+07$ & $2.64 \mathrm{E}+09$ & $0.00 \mathrm{E}+00$ & $3.69 \mathrm{E}+08$ & $3.64 E+07$ & $3.82 E+09$ & $2.98 \mathrm{E}+06$ & $4.07 E+05$ & $0.00 \mathrm{E}+00$ \\
\hline 2067 & 4.10E+07 & $2.46 E+09$ & $0.00 E+00$ & $3.76 E+08$ & $3.39 \mathrm{E}+07$ & $3.55 E+09$ & $3.00 E+06$ & $4.14 E+05$ & $0.00 \mathrm{E}+00$ \\
\hline 2068 & $4.15 \mathrm{E}+07$ & $2.49 E+09$ & $0.00 \mathrm{E}+00$ & $3.80 \mathrm{E}+08$ & $3.43 E+07$ & $3.60 \mathrm{E}+09$ & $3.00 E+06$ & $4.28 \mathrm{E}+05$ & $0.00 \mathrm{E}+00$ \\
\hline 2069 & $4.91 \mathrm{E}+07$ & $2.94 E+09$ & $0.00 E+00$ & $3.83 E+08$ & $4.05 E+07$ & 4.25E+09 & $3.00 E+06$ & $4.35 E+05$ & $0.00 E+00$ \\
\hline 2070 & $4.26 \mathrm{E}+07$ & $2.56 \mathrm{E}+09$ & $0.00 \mathrm{E}+00$ & $3.92 \mathrm{E}+08$ & $3.52 \mathrm{E}+07$ & $3.69 \mathrm{E}+09$ & $3.27 \mathrm{E}+06$ & $4.35 \mathrm{E}+05$ & $0.00 \mathrm{E}+00$ \\
\hline 2071 & $3.99 \mathrm{E}+07$ & $2.40 \mathrm{E}+09$ & $0.00 \mathrm{E}+00$ & $4.67 \mathrm{E}+08$ & 3. $30 E+07$ & $3.46 \mathrm{E}+09$ & $3.50 E+06$ & $4.40 \mathrm{E}+05$ & $0.00 \mathrm{E}+00$ \\
\hline 2072 & $4.73 E+07$ & $2.84 \mathrm{E}+09$ & $0.00 \mathrm{E}+00$ & $4.01 E+08$ & $3.90 \mathrm{E}+07$ & 4. $10 \mathrm{E}+09$ & $3.11 \mathrm{E}+06$ & $4.54 \mathrm{E}+05$ & $0.00 \mathrm{E}+00$ \\
\hline 2073 & $4.05 \mathrm{E}+07$ & $2.43 E+09$ & $0.00 \mathrm{E}+00$ & $4.06 \mathrm{E}+08$ & $3.34 E+07$ & $3.51 E+09$ & 3.15E+06 & $4.70 \mathrm{E}+05$ & $0.00 \mathrm{E}+00$ \\
\hline 2074 & 4.10E+07 & $2.46 E+09$ & $0.00 E+00$ & 4.10E+08 & $3.39 \mathrm{E}+07$ & $3.55 \mathrm{E}+09$ & $3.42 E+06$ & $4.87 E+05$ & $0.00 E+00$ \\
\hline 2075 & $4.49 \mathrm{E}+07$ & $2.70 E+09$ & $0.00 \mathrm{E}+00$ & $4.48 \mathrm{E}+08$ & $3.71 \mathrm{E}+07$ & $3.90 \mathrm{E}+09$ & $3.45 E+06$ & $5.06 \mathrm{E}+05$ & $0.00 \mathrm{E}+00$ \\
\hline 2076 & $4.23 E+07$ & $2.54 \mathrm{E}+09$ & $0.00 E+00$ & $4.91 \mathrm{E}+08$ & $3.49 \mathrm{E}+07$ & $3.66 \mathrm{E}+09$ & $3.50 \mathrm{E}+06$ & $5.10 \mathrm{E}+05$ & $0.00 E+00$ \\
\hline 2077 & $4.62 \mathrm{E}+07$ & $2.77 \mathrm{E}+09$ & $0.00 \mathrm{E}+00$ & $4.62 E+08$ & $3.81 \mathrm{E}+07$ & $4.00 \mathrm{E}+09$ & $3.50 E+06$ & $5.27 E+05$ & $0.00 \mathrm{E}+00$ \\
\hline 2078 & $5.03 E+07$ & $3.02 E+09$ & $0.00 \mathrm{E}+00$ & $5.03 E+08$ & $4.15 E+07$ & $4.36 \mathrm{E}+09$ & $3.50 E+06$ & $5.43 E+05$ & $0.00 \mathrm{E}+00$ \\
\hline 2079 & $5.10 \mathrm{E}+07$ & $3.06 \mathrm{E}+09$ & $0.00 \mathrm{E}+00$ & $4.75 E+08$ & $4.21 \mathrm{E}+07$ & $4.42 \mathrm{E}+09$ & $3.50 E+06$ & $5.50 \mathrm{E}+05$ & $0.00 \mathrm{E}+00$ \\
\hline 2080 & $4.82 \mathrm{E}+07$ & $2.89 \mathrm{E}+09$ & $0.00 E+00$ & $5.16 \mathrm{E}+08$ & $3.98 E+07$ & 4.18E+09 & $3.50 E+06$ & $5.50 \mathrm{E}+05$ & $0.00 \mathrm{E}+00$ \\
\hline 2081 & 4.87E+07 & $2.92 \mathrm{E}+09$ & $0.00 \mathrm{E}+00$ & $4.85 \mathrm{E}+08$ & $4.02 \mathrm{E}+07$ & $4.22 \mathrm{E}+09$ & $3.50 \mathrm{E}+06$ & $5.57 \mathrm{E}+05$ & $0.00 \mathrm{E}+00$ \\
\hline 2082 & $5.26 \mathrm{E}+07$ & $3.16 \mathrm{E}+09$ & $0.00 \mathrm{E}+00$ & 4. $55 E+08$ & $4.35 E+07$ & $4.56 \mathrm{E}+09$ & $3.75 E+06$ & $5.78 \mathrm{E}+05$ & $0.00 \mathrm{E}+00$ \\
\hline 2083 & $5.68 \mathrm{E}+07$ & $3.41 \mathrm{E}+09$ & $0.00 E+00$ & $4.60 \mathrm{E}+08$ & $4.69 \mathrm{E}+07$ & $4.92 \mathrm{E}+09$ & $3.79 E+06$ & $5.90 \mathrm{E}+05$ & $0.00 \mathrm{E}+00$ \\
\hline 2084 & $5.41 \mathrm{E}+07$ & $3.24 \mathrm{E}+09$ & $0.00 \mathrm{E}+00$ & $5.37 \mathrm{E}+08$ & $4.46 E+07$ & $4.69 \mathrm{E}+09$ & $4.00 E+06$ & $6.00 \mathrm{E}+05$ & $0.00 \mathrm{E}+00$ \\
\hline 2085 & $5.48 \mathrm{E}+07$ & $3.29 E+09$ & $0.00 \mathrm{E}+00$ & $5.10 \mathrm{E}+08$ & $4.52 \mathrm{E}+07$ & $4.75 E+09$ & $3.86 \mathrm{E}+06$ & $6.09 \mathrm{E}+05$ & $0.00 \mathrm{E}+00$ \\
\hline 2086 & $4.89 \mathrm{E}+07$ & $2.93 E+09$ & $0.00 E+00$ & $6.61 \mathrm{E}+08$ & $4.04 E+07$ & $4.24 \mathrm{E}+09$ & $3.68 \mathrm{E}+06$ & $6.28 \mathrm{E}+05$ & $0.00 E+00$ \\
\hline 2087 & $5.39 \mathrm{E}+07$ & $3.23 E+09$ & $0.00 E+00$ & $7.41 \mathrm{E}+08$ & $4.45 E+07$ & $4.67 \mathrm{E}+09$ & $3.71 \mathrm{E}+06$ & $6.47 \mathrm{E}+05$ & $0.00 \mathrm{E}+00$ \\
\hline 2088 & $5.44 \mathrm{E}+07$ & $3.27 \mathrm{E}+09$ & $0.00 \mathrm{E}+00$ & $7.22 E+08$ & $4.49 E+07$ & $4.72 E+09$ & $3.80 E+06$ & $6.61 \mathrm{E}+05$ & $0.00 \mathrm{E}+00$ \\
\hline 2089 & $5.89 \mathrm{E}+07$ & $3.53 E+09$ & $0.00 E+00$ & $7.31 E+08$ & $4.86 \mathrm{E}+07$ & $5.11 \mathrm{E}+09$ & 4.15E+06 & $6.75 E+05$ & $0.00 \mathrm{E}+00$ \\
\hline 2090 & $5.98 \mathrm{E}+07$ & $3.59 \mathrm{E}+09$ & $0.00 \mathrm{E}+00$ & $7.04 E+08$ & $4.94 \mathrm{E}+07$ & $5.18 \mathrm{E}+09$ & $4.46 \mathrm{E}+06$ & $6.84 \mathrm{E}+05$ & $0.00 \mathrm{E}+00$ \\
\hline 2091 & $6.07 \mathrm{E}+07$ & $3.64 E+09$ & $0.00 E+00$ & $7.13 E+08$ & $5.01 \mathrm{E}+07$ & $5.26 \mathrm{E}+09$ & $4.50 \mathrm{E}+06$ & $6.94 E+05$ & $0.00 E+00$ \\
\hline 2092 & $5.46 \mathrm{E}+07$ & $3.28 \mathrm{E}+09$ & $0.00 \mathrm{E}+00$ & $7.91 \mathrm{E}+08$ & $4.51 \mathrm{E}+07$ & $4.73 E+09$ & $4.63 E+06$ & $7.13 E+05$ & $0.00 \mathrm{E}+00$ \\
\hline 2093 & $5.62 \mathrm{E}+07$ & $3.37 E+09$ & $0.00 E+00$ & $9.42 E+08$ & $4.64 E+07$ & $4.87 \mathrm{E}+09$ & $4.41 \mathrm{E}+06$ & $7.27 \mathrm{E}+05$ & $0.00 E+00$ \\
\hline 2094 & $6.43 E+07$ & $3.86 E+09$ & $0.00 E+00$ & $7.82 E+08$ & $5.31 \mathrm{E}+07$ & $5.57 \mathrm{E}+09$ & $4.21 \mathrm{E}+06$ & $7.20 \mathrm{E}+05$ & $0.00 \mathrm{E}+00$ \\
\hline 2095 & $6.14 \mathrm{E}+07$ & $3.68 \mathrm{E}+09$ & $0.00 E+00$ & $8.29 \mathrm{E}+08$ & $5.07 \mathrm{E}+07$ & $5.32 E+09$ & $5.00 \mathrm{E}+06$ & $7.15 E+05$ & $0.00 \mathrm{E}+00$ \\
\hline 2096 & $6.16 \mathrm{E}+07$ & $3.70 E+09$ & $0.00 \mathrm{E}+00$ & $7.59 E+08$ & $5.08 \mathrm{E}+07$ & $5.34 \mathrm{E}+09$ & $4.85 \mathrm{E}+06$ & $7.48 \mathrm{E}+05$ & $0.00 \mathrm{E}+00$ \\
\hline 2097 & $5.89 \mathrm{E}+07$ & $3.53 E+09$ & $0.00 \mathrm{E}+00$ & $8.36 \mathrm{E}+08$ & $4.86 \mathrm{E}+07$ & $5.11 \mathrm{E}+09$ & $4.33 E+06$ & $7.69 \mathrm{E}+05$ & $0.00 \mathrm{E}+00$ \\
\hline 2098 & $6.63 E+07$ & $3.98 \mathrm{E}+09$ & $0.00 \mathrm{E}+00$ & $7.72 E+08$ & $5.47 \mathrm{E}+07$ & $5.74 \mathrm{E}+09$ & $4.72 E+06$ & $7.81 \mathrm{E}+05$ & $0.00 \mathrm{E}+00$ \\
\hline 2099 & $6.30 \mathrm{E}+07$ & $3.78 E+09$ & $0.00 \mathrm{E}+00$ & $8.08 \mathrm{E}+08$ & $5.20 \mathrm{E}+07$ & $5.46 \mathrm{E}+09$ & $4.59 E+06$ & $7.92 E+05$ & $0.00 E+00$ \\
\hline 2100 & $6.02 \mathrm{E}+07$ & $3.61 E+09$ & $0.00 \mathrm{E}+00$ & $8.85 E+08$ & $4.97 \mathrm{E}+07$ & $5.22 \mathrm{E}+09$ & 4.30E+06 & $8.30 E+05$ & $0.00 \mathrm{E}+00$ \\
\hline
\end{tabular}

Figure 9 (cont). Base Case 1: 2051-2100 yearly results for modules A through D1-2. 


\begin{tabular}{|c|c|c|c|c|c|c|c|c|c|c|c|}
\hline & Module D1-1 & Module D2 & Module D1-2 & & Module K1 & Module K1 & & Module E2 & Module E2 & Module I & Module I \\
\hline \multirow[b]{2}{*}{ Year } & \multicolumn{3}{|c|}{ Cost of U Fuel Fab by year ( $\$ / y r)$} & $\begin{array}{c}\text { Total Cost of } \\
\text { Fuel Fab } \\
\text { (\$/yr) }\end{array}$ & $\begin{array}{l}\text { total depleted } \\
\text { u disposition } \\
\text { rate }(\mathrm{kg} \mathrm{U} / \mathrm{yr})\end{array}$ & $\begin{array}{c}\text { Cost of DUD } \\
\text { by year } \\
\text { (\$/yr) }\end{array}$ & $\begin{array}{l}\text { Total Front End } \\
\text { Costs each year }\end{array}$ & $\begin{array}{l}\text { Rate of Dry } \\
\text { Storage } \\
\text { (kg/yr) }\end{array}$ & $\begin{array}{l}\text { Cost of SF } \\
\text { Dry Storage } \\
\text { by year } \\
(\$ / y r)\end{array}$ & $\begin{array}{c}\text { Total MRS } \\
\text { rate } \\
(\mathrm{kgHM} / \mathrm{yr})\end{array}$ & $\begin{array}{l}\text { Cost of MRS } \\
\text { by Year (\$/yr) }\end{array}$ \\
\hline & LWR & FBR & LWRmf & & & & & & & & \\
\hline 2000 & $0.00 \mathrm{E}+00$ & $0.00 \mathrm{E}+00$ & $0.00 E+00$ & $0.00 E+00$ & $0.00 \mathrm{E}+00$ & $0.00 E+00$ & $3.34 \mathrm{E}+09$ & $0.00 \mathrm{E}+00$ & $0.00 \mathrm{E}+00$ & $0.00 E+00$ & $0.00 E+00$ \\
\hline 2001 & $0.00 \mathrm{E}+00$ & $0.00 \mathrm{E}+00$ & $0.00 E+00$ & $0.00 \mathrm{E}+00$ & $0.00 \mathrm{E}+00$ & $0.00 E+00$ & $3.56 \mathrm{E}+09$ & $0.00 \mathrm{E}+00$ & $0.00 \mathrm{E}+00$ & $0.00 \mathrm{E}+00$ & $0.00 \mathrm{E}+00$ \\
\hline 2002 & $5.63 \mathrm{E}+08$ & $0.00 \mathrm{E}+00$ & $0.00 \mathrm{E}+00$ & $5.63 E+08$ & $1.63 E+07$ & $1.31 \mathrm{E}+08$ & $4.28 \mathrm{E}+09$ & $0.00 \mathrm{E}+00$ & $0.00 \mathrm{E}+00$ & $0.00 \mathrm{E}+00$ & $0.00 \mathrm{E}+00$ \\
\hline 2003 & $5.03 \mathrm{E}+08$ & $0.00 E+00$ & $0.00 E+00$ & $5.03 E+08$ & $1.64 \mathrm{E}+07$ & $1.31 E+08$ & $4.96 \mathrm{E}+09$ & $0.00 \mathrm{E}+00$ & $0.00 \mathrm{E}+00$ & $0.00 \mathrm{E}+00$ & $0.00 \mathrm{E}+00$ \\
\hline 2004 & $4.91 \mathrm{E}+08$ & $0.00 E+00$ & $0.00 E+00$ & $4.91 \mathrm{E}+08$ & $1.67 E+07$ & $1.34 E+08$ & $4.43 E+09$ & $0.00 \mathrm{E}+00$ & $0.00 \mathrm{E}+00$ & $0.00 \mathrm{E}+00$ & $0.00 \mathrm{E}+00$ \\
\hline 2005 & $4.44 \mathrm{E}+08$ & $0.00 \mathrm{E}+00$ & $0.00 E+00$ & $4.44 \mathrm{E}+08$ & $2.02 E+07$ & $1.62 E+08$ & $4.94 E+09$ & $0.00 \mathrm{E}+00$ & $0.00 \mathrm{E}+00$ & $0.00 \mathrm{E}+00$ & $0.00 \mathrm{E}+00$ \\
\hline 2006 & $4.29 \mathrm{E}+08$ & $0.00 \mathrm{E}+00$ & $0.00 E+00$ & $4.29 E+08$ & $1.68 \mathrm{E}+07$ & $1.34 \mathrm{E}+08$ & $4.36 \mathrm{E}+09$ & $2.56 \mathrm{E}+06$ & $3.07 \mathrm{E}+08$ & $0.00 \mathrm{E}+00$ & $0.00 \mathrm{E}+00$ \\
\hline 2007 & $5.31 \mathrm{E}+08$ & $0.00 \mathrm{E}+00$ & $0.00 \mathrm{E}+00$ & $5.31 \mathrm{E}+08$ & $1.74 \mathrm{E}+07$ & $1.39 E+08$ & $4.61 \mathrm{E}+09$ & $2.53 \mathrm{E}+06$ & $3.04 \mathrm{E}+08$ & $0.00 \mathrm{E}+00$ & $0.00 \mathrm{E}+00$ \\
\hline 2008 & $4.91 \mathrm{E}+08$ & $0.00 \mathrm{E}+00$ & $0.00 \mathrm{E}+00$ & $4.91 \mathrm{E}+08$ & $2.08 \mathrm{E}+07$ & $1.67 \mathrm{E}+08$ & $5.32 \mathrm{E}+09$ & $2.47 E+06$ & $2.96 \mathrm{E}+08$ & $0.00 \mathrm{E}+00$ & $0.00 \mathrm{E}+00$ \\
\hline 2009 & $5.67 \mathrm{E}+08$ & $0.00 \mathrm{E}+00$ & $0.00 \mathrm{E}+00$ & $5.67 \mathrm{E}+08$ & $1.81 \mathrm{E}+07$ & $1.45 \mathrm{E}+08$ & $4.82 E+09$ & $2.37 \mathrm{E}+06$ & $2.85 E+08$ & $0.00 \mathrm{E}+00$ & $0.00 \mathrm{E}+00$ \\
\hline 2010 & $4.92 \mathrm{E}+08$ & $0.00 \mathrm{E}+00$ & $0.00 \mathrm{E}+00$ & $4.92 E+08$ & $1.86 \mathrm{E}+07$ & $1.49 E+08$ & $4.71 \mathrm{E}+09$ & $2.27 \mathrm{E}+06$ & $2.72 \mathrm{E}+08$ & $0.00 \mathrm{E}+00$ & $0.00 \mathrm{E}+00$ \\
\hline 2011 & $3.94 \mathrm{E}+08$ & $0.00 \mathrm{E}+00$ & $0.00 E+00$ & $3.94 E+08$ & $2.14 \mathrm{E}+07$ & $1.72 \mathrm{E}+08$ & $5.35 E+09$ & $4.14 \mathrm{E}+06$ & $4.97 E+08$ & $0.00 \mathrm{E}+00$ & $0.00 \mathrm{E}+00$ \\
\hline 2012 & $5.16 \mathrm{E}+08$ & $0.00 \mathrm{E}+00$ & $0.00 E+00$ & $5.16 \mathrm{E}+08$ & $1.88 \mathrm{E}+07$ & $1.50 E+08$ & $5.57 \mathrm{E}+09$ & $6.70 \mathrm{E}+06$ & $8.04 \mathrm{E}+08$ & $0.00 \mathrm{E}+00$ & $0.00 \mathrm{E}+00$ \\
\hline 2013 & $5.55 \mathrm{E}+08$ & $0.00 \mathrm{E}+00$ & $0.00 \mathrm{E}+00$ & $5.55 \mathrm{E}+08$ & $1.92 \mathrm{E}+07$ & $1.54 \mathrm{E}+08$ & $5.06 \mathrm{E}+09$ & $9.17 \mathrm{E}+06$ & 1.10E+09 & $0.00 \mathrm{E}+00$ & $0.00 \mathrm{E}+00$ \\
\hline 2014 & $5.17 \mathrm{E}+08$ & $0.00 \mathrm{E}+00$ & $0.00 \mathrm{E}+00$ & $5.17 \mathrm{E}+08$ & $1.97 \mathrm{E}+07$ & $1.58 \mathrm{E}+08$ & $5.18 \mathrm{E}+09$ & $1.15 \mathrm{E}+07$ & $1.38 \mathrm{E}+09$ & $0.00 \mathrm{E}+00$ & $0.00 \mathrm{E}+00$ \\
\hline 2015 & $4.18 \mathrm{E}+08$ & $0.00 \mathrm{E}+00$ & $0.00 E+00$ & $4.18 E+08$ & $2.34 E+07$ & $1.87 E+08$ & $5.04 E+09$ & $1.38 \mathrm{E}+07$ & $1.65 E+09$ & $0.00 \mathrm{E}+00$ & $0.00 \mathrm{E}+00$ \\
\hline 2016 & $3.95 \mathrm{E}+08$ & $0.00 \mathrm{E}+00$ & $0.00 E+00$ & $3.95 E+08$ & $2.32 \mathrm{E}+07$ & $1.85 E+08$ & $5.13 E+09$ & $1.60 \mathrm{E}+07$ & $1.92 \mathrm{E}+09$ & $0.00 \mathrm{E}+00$ & $0.00 \mathrm{E}+00$ \\
\hline 2017 & $5.22 \mathrm{E}+08$ & $0.00 \mathrm{E}+00$ & $0.00 \mathrm{E}+00$ & $5.22 \mathrm{E}+08$ & $2.36 \mathrm{E}+07$ & $1.89 \mathrm{E}+08$ & $5.39 \mathrm{E}+09$ & $1.83 \mathrm{E}+07$ & $2.19 \mathrm{E}+09$ & $0.00 \mathrm{E}+00$ & $0.00 \mathrm{E}+00$ \\
\hline 2018 & $4.77 \mathrm{E}+08$ & $0.00 \mathrm{E}+00$ & $0.00 \mathrm{E}+00$ & $4.77 \mathrm{E}+08$ & $2.41 \mathrm{E}+07$ & $1.93 E+08$ & $5.47 \mathrm{E}+09$ & $2.05 \mathrm{E}+07$ & $2.46 \mathrm{E}+09$ & $0.00 \mathrm{E}+00$ & $0.00 \mathrm{E}+00$ \\
\hline 2019 & $5.15 \mathrm{E}+08$ & $0.00 \mathrm{E}+00$ & $0.00 \mathrm{E}+00$ & $5.15 E+08$ & $2.17 \mathrm{E}+07$ & $1.74 \mathrm{E}+08$ & $5.65 E+09$ & 2.27E+07 & $2.72 \mathrm{E}+09$ & $0.00 \mathrm{E}+00$ & $0.00 \mathrm{E}+00$ \\
\hline 2020 & $4.95 \mathrm{E}+08$ & $0.00 \mathrm{E}+00$ & $0.00 E+00$ & $4.95 E+08$ & $2.24 E+07$ & $1.79 E+08$ & $5.55 \mathrm{E}+09$ & $2.45 \mathrm{E}+07$ & $2.94 \mathrm{E}+09$ & $0.00 \mathrm{E}+00$ & $0.00 \mathrm{E}+00$ \\
\hline 2021 & $4.77 \mathrm{E}+08$ & $0.00 \mathrm{E}+00$ & $0.00 E+00$ & $4.77 \mathrm{E}+08$ & $2.23 E+07$ & $1.79 E+08$ & $5.62 E+09$ & $2.53 \mathrm{E}+07$ & $3.04 \mathrm{E}+09$ & $0.00 \mathrm{E}+00$ & $0.00 \mathrm{E}+00$ \\
\hline 2022 & $5.35 \mathrm{E}+08$ & $0.00 \mathrm{E}+00$ & $0.00 \mathrm{E}+00$ & $5.35 \mathrm{E}+08$ & $2.25 \mathrm{E}+07$ & $1.80 \mathrm{E}+08$ & $5.77 E+09$ & $2.55 \mathrm{E}+07$ & $3.06 \mathrm{E}+09$ & $0.00 \mathrm{E}+00$ & $0.00 \mathrm{E}+00$ \\
\hline 2023 & $5.09 E+08$ & $0.00 \mathrm{E}+00$ & $0.00 E+00$ & $5.09 E+08$ & $2.29 E+07$ & $1.83 E+08$ & $5.90 E+09$ & $2.55 \mathrm{E}+07$ & $3.06 \mathrm{E}+09$ & $0.00 E+00$ & $0.00 \mathrm{E}+00$ \\
\hline 2024 & $4.85 \mathrm{E}+08$ & $0.00 \mathrm{E}+00$ & $0.00 E+00$ & $4.85 E+08$ & $2.65 \mathrm{E}+07$ & $2.12 \mathrm{E}+08$ & $6.04 E+09$ & $2.55 \mathrm{E}+07$ & $3.06 \mathrm{E}+09$ & $0.00 E+00$ & $0.00 \mathrm{E}+00$ \\
\hline 2025 & $4.33 E+08$ & $0.00 \mathrm{E}+00$ & $0.00 E+00$ & $4.33 E+08$ & $2.71 \mathrm{E}+07$ & $2.17 \mathrm{E}+08$ & $5.90 \mathrm{E}+09$ & $2.54 \mathrm{E}+07$ & $3.05 E+09$ & $0.00 \mathrm{E}+00$ & $0.00 \mathrm{E}+00$ \\
\hline 2026 & $4.02 \mathrm{E}+08$ & $0.00 \mathrm{E}+00$ & $0.00 \mathrm{E}+00$ & $4.02 \mathrm{E}+08$ & $2.70 \mathrm{E}+07$ & $2.16 \mathrm{E}+08$ & $6.70 \mathrm{E}+09$ & $2.53 \mathrm{E}+07$ & $3.04 \mathrm{E}+09$ & $0.00 \mathrm{E}+00$ & $0.00 \mathrm{E}+00$ \\
\hline 2027 & $6.15 \mathrm{E}+08$ & $0.00 \mathrm{E}+00$ & $0.00 \mathrm{E}+00$ & $6.15 E+08$ & $2.44 \mathrm{E}+07$ & $1.95 E+08$ & $7.04 \mathrm{E}+09$ & $2.54 \mathrm{E}+07$ & $3.05 E+09$ & $0.00 \mathrm{E}+00$ & $0.00 \mathrm{E}+00$ \\
\hline 2028 & $5.30 \mathrm{E}+08$ & $0.00 \mathrm{E}+00$ & $0.00 \mathrm{E}+00$ & $5.30 \mathrm{E}+08$ & $2.49 \mathrm{E}+07$ & $2.00 \mathrm{E}+08$ & $7.95 E+09$ & $2.55 \mathrm{E}+07$ & $3.06 \mathrm{E}+09$ & $0.00 \mathrm{E}+00$ & $0.00 \mathrm{E}+00$ \\
\hline 2029 & $5.72 \mathrm{E}+08$ & $1.18 \mathrm{E}+07$ & $0.00 E+00$ & $5.84 \mathrm{E}+08$ & $2.62 \mathrm{E}+07$ & $2.10 \mathrm{E}+08$ & $6.96 \mathrm{E}+09$ & $2.55 \mathrm{E}+07$ & $3.06 \mathrm{E}+09$ & $0.00 \mathrm{E}+00$ & $0.00 \mathrm{E}+00$ \\
\hline 2030 & $5.52 \mathrm{E}+08$ & $1.18 \mathrm{E}+07$ & $0.00 \mathrm{E}+00$ & $5.64 \mathrm{E}+08$ & $2.78 \mathrm{E}+07$ & $2.22 \mathrm{E}+08$ & $8.21 \mathrm{E}+09$ & $2.54 \mathrm{E}+07$ & $3.05 E+09$ & $0.00 \mathrm{E}+00$ & $0.00 \mathrm{E}+00$ \\
\hline 2031 & $5.37 \mathrm{E}+08$ & $1.18 \mathrm{E}+07$ & $0.00 \mathrm{E}+00$ & $5.49 E+08$ & $2.77 E+07$ & $2.22 E+08$ & $8.34 E+09$ & $2.53 \mathrm{E}+07$ & $3.03 E+09$ & $0.00 \mathrm{E}+00$ & $0.00 \mathrm{E}+00$ \\
\hline 2032 & $5.73 E+08$ & $1.18 \mathrm{E}+07$ & $0.00 \mathrm{E}+00$ & $5.85 E+08$ & $2.79 E+07$ & $2.23 E+08$ & $7.15 E+09$ & $2.53 \mathrm{E}+07$ & $3.03 E+09$ & $0.00 E+00$ & $0.00 \mathrm{E}+00$ \\
\hline 2033 & $5.43 E+08$ & $1.18 \mathrm{E}+07$ & $0.00 E+00$ & $5.55 E+08$ & $2.86 \mathrm{E}+07$ & $2.29 E+08$ & $8.68 E+09$ & $2.52 \mathrm{E}+07$ & $3.03 E+09$ & $0.00 \mathrm{E}+00$ & $0.00 \mathrm{E}+00$ \\
\hline 2034 & $6.26 \mathrm{E}+08$ & $1.18 \mathrm{E}+07$ & $0.00 \mathrm{E}+00$ & $6.38 \mathrm{E}+08$ & $2.92 \mathrm{E}+07$ & $2.33 E+08$ & $7.62 E+09$ & $2.52 \mathrm{E}+07$ & $3.02 \mathrm{E}+09$ & $0.00 \mathrm{E}+00$ & $0.00 \mathrm{E}+00$ \\
\hline 2035 & $6.03 E+08$ & $1.18 \mathrm{E}+07$ & $0.00 \mathrm{E}+00$ & $6.15 \mathrm{E}+08$ & $3.65 \mathrm{E}+07$ & $2.92 \mathrm{E}+08$ & $8.84 \mathrm{E}+09$ & $2.51 \mathrm{E}+07$ & $3.01 \mathrm{E}+09$ & $0.00 \mathrm{E}+00$ & $0.00 \mathrm{E}+00$ \\
\hline 2036 & $5.82 \mathrm{E}+08$ & $1.18 \mathrm{E}+07$ & $0.00 \mathrm{E}+00$ & $5.94 \mathrm{E}+08$ & $2.99 \mathrm{E}+07$ & $2.39 \mathrm{E}+08$ & $7.62 E+09$ & $2.52 \mathrm{E}+07$ & $3.03 E+09$ & $0.00 \mathrm{E}+00$ & $0.00 \mathrm{E}+00$ \\
\hline 2037 & $5.95 \mathrm{E}+08$ & $1.18 \mathrm{E}+07$ & $0.00 E+00$ & $6.06 \mathrm{E}+08$ & $3.67 E+07$ & $2.93 E+08$ & $7.71 \mathrm{E}+09$ & $2.32 \mathrm{E}+07$ & $2.78 \mathrm{E}+09$ & $0.00 \mathrm{E}+00$ & $0.00 \mathrm{E}+00$ \\
\hline 2038 & $5.76 \mathrm{E}+08$ & $1.18 \mathrm{E}+07$ & $0.00 E+00$ & $5.88 E+08$ & $3.08 E+07$ & $2.46 \mathrm{E}+08$ & $9.15 E+09$ & $2.12 \mathrm{E}+07$ & $2.55 E+09$ & $0.00 \mathrm{E}+00$ & $0.00 \mathrm{E}+00$ \\
\hline 2039 & $6.69 E+08$ & $1.18 \mathrm{E}+07$ & $0.00 \mathrm{E}+00$ & $6.81 \mathrm{E}+08$ & $3.12 \mathrm{E}+07$ & $2.50 E+08$ & $8.09 E+09$ & $1.86 \mathrm{E}+07$ & $2.23 E+09$ & $0.00 \mathrm{E}+00$ & $0.00 \mathrm{E}+00$ \\
\hline 2040 & $6.53 E+08$ & $1.18 \mathrm{E}+07$ & $0.00 \mathrm{E}+00$ & $6.65 E+08$ & $3.84 \mathrm{E}+07$ & $3.07 E+08$ & $8.06 \mathrm{E}+09$ & $1.59 \mathrm{E}+07$ & $1.91 \mathrm{E}+09$ & $0.00 \mathrm{E}+00$ & $0.00 \mathrm{E}+00$ \\
\hline 2041 & $6.37 \mathrm{E}+08$ & $1.18 \mathrm{E}+07$ & $0.00 \mathrm{E}+00$ & $6.49 \mathrm{E}+08$ & $3.22 \mathrm{E}+07$ & $2.57 \mathrm{E}+08$ & $8.76 \mathrm{E}+09$ & $1.35 \mathrm{E}+07$ & $1.62 \mathrm{E}+09$ & $0.00 \mathrm{E}+00$ & $0.00 \mathrm{E}+00$ \\
\hline 2042 & $6.30 E+08$ & $1.18 \mathrm{E}+07$ & $0.00 E+00$ & $6.41 E+08$ & $3.24 E+07$ & $2.59 E+08$ & $8.17 E+09$ & $1.11 \mathrm{E}+07$ & $1.33 E+09$ & $0.00 \mathrm{E}+00$ & $0.00 \mathrm{E}+00$ \\
\hline 2043 & $6.15 \mathrm{E}+08$ & $2.35 \mathrm{E}+07$ & $0.00 \mathrm{E}+00$ & $6.39 E+08$ & $3.29 E+07$ & $2.63 E+08$ & $8.94 E+09$ & $8.63 E+06$ & $1.04 \mathrm{E}+09$ & $0.00 E+00$ & $0.00 \mathrm{E}+00$ \\
\hline 2044 & $7.11 \mathrm{E}+08$ & $2.35 \mathrm{E}+07$ & $0.00 \mathrm{E}+00$ & $7.35 \mathrm{E}+08$ & $3.32 \mathrm{E}+07$ & $2.66 \mathrm{E}+08$ & $9.15 E+09$ & $6.19 \mathrm{E}+06$ & $7.43 \mathrm{E}+08$ & $0.00 \mathrm{E}+00$ & $0.00 \mathrm{E}+00$ \\
\hline 2045 & $6.97 \mathrm{E}+08$ & $2.35 \mathrm{E}+07$ & $0.00 \mathrm{E}+00$ & $7.20 \mathrm{E}+08$ & $3.37 \mathrm{E}+07$ & $2.70 \mathrm{E}+08$ & $9.25 E+09$ & $3.88 \mathrm{E}+06$ & $4.66 \mathrm{E}+08$ & $0.00 \mathrm{E}+00$ & $0.00 \mathrm{E}+00$ \\
\hline 2046 & $6.83 E+08$ & $2.35 \mathrm{E}+07$ & $0.00 \mathrm{E}+00$ & $7.06 \mathrm{E}+08$ & $3.42 \mathrm{E}+07$ & $2.74 \mathrm{E}+08$ & $9.35 E+09$ & $3.12 \mathrm{E}+06$ & $3.74 \mathrm{E}+08$ & $0.00 \mathrm{E}+00$ & $0.00 \mathrm{E}+00$ \\
\hline 2047 & $6.69 E+08$ & $2.35 \mathrm{E}+07$ & $0.00 \mathrm{E}+00$ & $6.92 \mathrm{E}+08$ & $3.47 E+07$ & $2.78 \mathrm{E}+08$ & $9.45 E+09$ & $2.67 \mathrm{E}+06$ & $3.20 \mathrm{E}+08$ & $0.00 E+00$ & $0.00 \mathrm{E}+00$ \\
\hline 2048 & $6.60 \mathrm{E}+08$ & $2.35 \mathrm{E}+07$ & $0.00 \mathrm{E}+00$ & $6.84 \mathrm{E}+08$ & $3.52 E+07$ & $2.82 E+08$ & $9.40 E+09$ & $2.71 \mathrm{E}+06$ & $3.26 \mathrm{E}+08$ & $0.00 \mathrm{E}+00$ & $0.00 \mathrm{E}+00$ \\
\hline 2049 & $6.60 \mathrm{E}+08$ & $2.35 E+07$ & $0.00 \mathrm{E}+00$ & $6.84 E+08$ & $3.80 E+07$ & $3.04 E+08$ & $9.35 E+09$ & $2.75 \mathrm{E}+06$ & $3.30 \mathrm{E}+08$ & $0.00 \mathrm{E}+00$ & $0.00 \mathrm{E}+00$ \\
\hline 2050 & $6.60 \mathrm{E}+08$ & $3.53 E+07$ & $0.00 \mathrm{E}+00$ & $6.95 E+08$ & $3.77 \mathrm{E}+07$ & $3.02 E+08$ & $9.47 E+09$ & $2.79 \mathrm{E}+06$ & $3.35 E+08$ & $0.00 \mathrm{E}+00$ & $0.00 \mathrm{E}+00$ \\
\hline
\end{tabular}

Figure 9 (cont). Base Case 1: 2000-2050 yearly results for Modules D1-1 through I. 


\begin{tabular}{|c|c|c|c|c|c|c|c|c|c|c|c|}
\hline & Module D1-1 & Module D2 & Module D1-2 & & Module K1 & Module K1 & & Module E2 & Module E2 & Module I & Module I \\
\hline \multirow{2}{*}{ Year } & \multicolumn{3}{|c|}{ Cost of U Fuel Fab by year (\$/yr) } & $\begin{array}{c}\text { Total Cost of } \\
\text { Fuel Fab } \\
\text { (\$/yr) }\end{array}$ & $\begin{array}{c}\text { total depleted } \\
\mathrm{u} \text { disposition } \\
\text { rate }(\mathrm{kg} \mathrm{U} / \mathrm{yr})\end{array}$ & $\begin{array}{c}\text { Cost of DUD } \\
\text { by year } \\
(\$ / y r)\end{array}$ & $\begin{array}{l}\text { Total Front End } \\
\text { Costs each year }\end{array}$ & $\begin{array}{c}\text { Rate of Dry } \\
\text { Storage } \\
(\mathrm{kg} / \mathrm{yr})\end{array}$ & $\begin{array}{l}\text { Cost of SF } \\
\text { Dry Storage } \\
\text { by year } \\
(\$ / y r)\end{array}$ & $\begin{array}{c}\text { Total MRS } \\
\text { rate } \\
(\mathrm{kgHM} / \mathrm{yr})\end{array}$ & $\begin{array}{l}\text { Cost of MRS } \\
\text { by Year }(\$ / y r)\end{array}$ \\
\hline & LWR & FBR & LWRmf & & & & & & & & \\
\hline 2051 & $6.60 \mathrm{E}+08$ & $3.53 E+07$ & $0.00 E+00$ & $6.95 E+08$ & $3.82 E+07$ & $3.06 \mathrm{E}+08$ & $9.59 E+09$ & $2.83 E+06$ & $3.39 E+08$ & $0.00 \mathrm{E}+00$ & $0.00 \mathrm{E}+00$ \\
\hline 2052 & $6.60 \mathrm{E}+08$ & $3.53 E+07$ & $0.00 \mathrm{E}+00$ & $6.95 E+08$ & $3.87 E+07$ & $3.10 \mathrm{E}+08$ & $9.67 E+09$ & $2.87 \mathrm{E}+06$ & $3.44 \mathrm{E}+08$ & $0.00 \mathrm{E}+00$ & $0.00 \mathrm{E}+00$ \\
\hline 2053 & $6.60 \mathrm{E}+08$ & $3.53 E+07$ & $0.00 \mathrm{E}+00$ & $6.95 E+08$ & $3.61 \mathrm{E}+07$ & $2.88 \mathrm{E}+08$ & $9.83 E+09$ & $2.91 \mathrm{E}+06$ & $3.49 E+08$ & $0.00 \mathrm{E}+00$ & $0.00 \mathrm{E}+00$ \\
\hline 2054 & $6.60 \mathrm{E}+08$ & $3.53 E+07$ & $0.00 \mathrm{E}+00$ & $6.95 E+08$ & $3.99 \mathrm{E}+07$ & $3.19 E+08$ & $9.97 E+09$ & $2.93 E+06$ & $3.52 E+08$ & $0.00 \mathrm{E}+00$ & $0.00 \mathrm{E}+00$ \\
\hline 2055 & $7.70 \mathrm{E}+08$ & $3.53 E+07$ & $0.00 \mathrm{E}+00$ & $8.05 E+08$ & $4.04 \mathrm{E}+07$ & $3.23 \mathrm{E}+08$ & $1.02 \mathrm{E}+10$ & $2.99 \mathrm{E}+06$ & $3.59 \mathrm{E}+08$ & $0.00 \mathrm{E}+00$ & $0.00 \mathrm{E}+00$ \\
\hline 2056 & $6.99 \mathrm{E}+08$ & $3.53 E+07$ & $0.00 \mathrm{E}+00$ & $7.35 E+08$ & $3.77 \mathrm{E}+07$ & $3.02 \mathrm{E}+08$ & $1.02 E+10$ & $3.01 \mathrm{E}+06$ & $3.61 \mathrm{E}+08$ & $0.00 \mathrm{E}+00$ & $0.00 \mathrm{E}+00$ \\
\hline 2057 & $7.08 \mathrm{E}+08$ & $3.53 E+07$ & $0.00 \mathrm{E}+00$ & $7.43 E+08$ & $4.15 \mathrm{E}+07$ & $3.32 \mathrm{E}+08$ & $1.04 E+10$ & $2.99 \mathrm{E}+06$ & $3.59 \mathrm{E}+08$ & $0.00 \mathrm{E}+00$ & $0.00 \mathrm{E}+00$ \\
\hline 2058 & $6.62 E+08$ & $3.53 E+07$ & $0.00 \mathrm{E}+00$ & $6.98 E+08$ & $4.20 \mathrm{E}+07$ & $3.36 \mathrm{E}+08$ & $1.05 E+10$ & $2.66 \mathrm{E}+06$ & $3.19 E+08$ & $0.00 \mathrm{E}+00$ & $0.00 \mathrm{E}+00$ \\
\hline 2059 & $7.28 \mathrm{E}+08$ & $3.53 E+07$ & $0.00 \mathrm{E}+00$ & $7.63 E+08$ & $4.27 E+07$ & $3.42 \mathrm{E}+08$ & $1.00 \mathrm{E}+10$ & $2.70 \mathrm{E}+06$ & $3.24 \mathrm{E}+08$ & $0.00 \mathrm{E}+00$ & $0.00 \mathrm{E}+00$ \\
\hline 2060 & $7.39 \mathrm{E}+08$ & $3.53 E+07$ & $0.00 \mathrm{E}+00$ & $7.74 \mathrm{E}+08$ & $4.34 \mathrm{E}+07$ & $3.47 \mathrm{E}+08$ & $1.08 \mathrm{E}+10$ & $2.74 \mathrm{E}+06$ & $3.29 \mathrm{E}+08$ & $0.00 \mathrm{E}+00$ & $0.00 \mathrm{E}+00$ \\
\hline 2061 & $7.48 \mathrm{E}+08$ & $3.53 E+07$ & $0.00 \mathrm{E}+00$ & $7.83 E+08$ & $4.39 E+07$ & $3.51 \mathrm{E}+08$ & $1.11 \mathrm{E}+10$ & $2.78 \mathrm{E}+06$ & $3.34 \mathrm{E}+08$ & $0.00 \mathrm{E}+00$ & $0.00 \mathrm{E}+00$ \\
\hline 2062 & $7.59 \mathrm{E}+08$ & $3.53 E+07$ & $0.00 \mathrm{E}+00$ & $7.94 \mathrm{E}+08$ & $4.78 \mathrm{E}+07$ & $3.83 E+08$ & $1.13 E+10$ & $2.83 E+06$ & $3.39 E+08$ & $0.00 \mathrm{E}+00$ & $0.00 \mathrm{E}+00$ \\
\hline 2063 & $8.80 E+08$ & $4.70 \mathrm{E}+07$ & $0.00 \mathrm{E}+00$ & $9.27 E+08$ & $4.55 \mathrm{E}+07$ & $3.64 \mathrm{E}+08$ & 1.16E+10 & $2.87 E+06$ & $3.44 E+08$ & $0.00 \mathrm{E}+00$ & $0.00 \mathrm{E}+00$ \\
\hline 2064 & $7.88 \mathrm{E}+08$ & $4.70 \mathrm{E}+07$ & $0.00 \mathrm{E}+00$ & $8.35 \mathrm{E}+08$ & $4.95 \mathrm{E}+07$ & $3.96 \mathrm{E}+08$ & $1.17 E+10$ & $2.91 \mathrm{E}+06$ & $3.49 \mathrm{E}+08$ & $0.00 \mathrm{E}+00$ & $0.00 \mathrm{E}+00$ \\
\hline 2065 & $7.99 \mathrm{E}+08$ & $4.70 \mathrm{E}+07$ & $0.00 \mathrm{E}+00$ & $8.46 \mathrm{E}+08$ & $5.02 E+07$ & $4.01 \mathrm{E}+08$ & $1.25 E+10$ & $2.96 \mathrm{E}+06$ & $3.55 E+08$ & $0.00 \mathrm{E}+00$ & $0.00 \mathrm{E}+00$ \\
\hline 2066 & $8.80 \mathrm{E}+08$ & $4.70 \mathrm{E}+07$ & $0.00 \mathrm{E}+00$ & $9.27 E+08$ & $4.77 \mathrm{E}+07$ & $3.81 \mathrm{E}+08$ & $1.20 E+10$ & $3.00 \mathrm{E}+06$ & $3.60 \mathrm{E}+08$ & $0.00 \mathrm{E}+00$ & $0.00 \mathrm{E}+00$ \\
\hline 2067 & $8.22 \mathrm{E}+08$ & $4.70 \mathrm{E}+07$ & $0.00 \mathrm{E}+00$ & $8.69 E+08$ & $5.15 \mathrm{E}+07$ & $4.12 \mathrm{E}+08$ & $1.22 \mathrm{E}+10$ & $3.05 E+06$ & $3.66 \mathrm{E}+08$ & $0.00 \mathrm{E}+00$ & $0.00 \mathrm{E}+00$ \\
\hline 2068 & $8.43 E+08$ & $4.70 \mathrm{E}+07$ & $0.00 \mathrm{E}+00$ & $8.90 \mathrm{E}+08$ & $5.22 \mathrm{E}+07$ & $4.17 \mathrm{E}+08$ & $1.30 \mathrm{E}+10$ & $3.09 \mathrm{E}+06$ & $3.71 \mathrm{E}+08$ & $0.00 \mathrm{E}+00$ & $0.00 \mathrm{E}+00$ \\
\hline 2069 & $8.80 \mathrm{E}+08$ & $4.70 \mathrm{E}+07$ & $0.00 \mathrm{E}+00$ & $9.27 \mathrm{E}+08$ & $4.97 \mathrm{E}+07$ & $3.97 \mathrm{E}+08$ & $1.24 \mathrm{E}+10$ & $3.14 \mathrm{E}+06$ & $3.77 \mathrm{E}+08$ & $0.00 \mathrm{E}+00$ & $0.00 \mathrm{E}+00$ \\
\hline 2070 & $8.80 E+08$ & $1.65 E+08$ & $0.00 \mathrm{E}+00$ & $1.04 E+09$ & $5.03 E+07$ & $4.03 E+08$ & $1.19 E+10$ & $3.21 \mathrm{E}+06$ & $3.85 E+08$ & $0.00 \mathrm{E}+00$ & $0.00 \mathrm{E}+00$ \\
\hline 2071 & $8.54 \mathrm{E}+08$ & $4.00 E+08$ & $0.00 \mathrm{E}+00$ & $1.25 E+09$ & $4.73 E+07$ & $3.79 E+08$ & $1.20 \mathrm{E}+10$ & $3.33 E+06$ & $4.00 \mathrm{E}+08$ & $0.00 \mathrm{E}+00$ & $0.00 \mathrm{E}+00$ \\
\hline 2072 & 8.07E+08 & $6.00 \mathrm{E}+08$ & $0.00 \mathrm{E}+00$ & $1.41 \mathrm{E}+09$ & $4.70 \mathrm{E}+07$ & $3.76 \mathrm{E}+08$ & $1.21 \mathrm{E}+10$ & $3.38 \mathrm{E}+06$ & $4.06 \mathrm{E}+08$ & $0.00 \mathrm{E}+00$ & $0.00 \mathrm{E}+00$ \\
\hline 2073 & $8.02 E+08$ & $8.35 E+08$ & $0.00 \mathrm{E}+00$ & $1.64 \mathrm{E}+09$ & $4.68 \mathrm{E}+07$ & $3.75 \mathrm{E}+08$ & $1.23 E+10$ & $3.50 \mathrm{E}+06$ & $4.20 \mathrm{E}+08$ & $0.00 \mathrm{E}+00$ & $0.00 \mathrm{E}+00$ \\
\hline 2074 & $7.70 \mathrm{E}+08$ & $1.01 \mathrm{E}+09$ & $0.00 \mathrm{E}+00$ & $1.78 \mathrm{E}+09$ & $4.65 \mathrm{E}+07$ & $3.72 \mathrm{E}+08$ & $1.39 \mathrm{E}+10$ & $3.55 E+06$ & $4.26 \mathrm{E}+08$ & $0.00 \mathrm{E}+00$ & $0.00 \mathrm{E}+00$ \\
\hline 2075 & $8.50 \mathrm{E}+08$ & $1.02 \mathrm{E}+09$ & $0.00 \mathrm{E}+00$ & $1.87 E+09$ & $4.97 \mathrm{E}+07$ & $3.97 \mathrm{E}+08$ & $1.41 \mathrm{E}+10$ & $3.54 \mathrm{E}+06$ & $4.24 E+08$ & $0.00 \mathrm{E}+00$ & $0.00 \mathrm{E}+00$ \\
\hline 2076 & $8.80 \mathrm{E}+08$ & $1.05 \mathrm{E}+09$ & $0.00 \mathrm{E}+00$ & $1.93 E+09$ & $5.03 E+07$ & $4.03 E+08$ & $1.32 \mathrm{E}+10$ & $3.65 E+06$ & $4.39 E+08$ & $0.00 \mathrm{E}+00$ & $0.00 \mathrm{E}+00$ \\
\hline 2077 & $8.70 \mathrm{E}+08$ & $1.12 \mathrm{E}+09$ & $0.00 \mathrm{E}+00$ & $1.99 \mathrm{E}+09$ & $6.41 \mathrm{E}+07$ & $5.13 \mathrm{E}+08$ & $1.41 \mathrm{E}+10$ & $3.71 \mathrm{E}+06$ & $4.45 \mathrm{E}+08$ & $0.00 \mathrm{E}+00$ & $0.00 \mathrm{E}+00$ \\
\hline 2078 & $9.38 \mathrm{E}+08$ & $1.15 E+09$ & $0.00 \mathrm{E}+00$ & $2.09 \mathrm{E}+09$ & $5.83 E+07$ & $4.67 \mathrm{E}+08$ & $1.43 E+10$ & $3.69 \mathrm{E}+06$ & $4.42 \mathrm{E}+08$ & $0.00 \mathrm{E}+00$ & $0.00 \mathrm{E}+00$ \\
\hline 2079 & $8.98 \mathrm{E}+08$ & $1.25 \mathrm{E}+09$ & $0.00 E+00$ & $2.14 E+09$ & $5.93 E+07$ & $4.74 \mathrm{E}+08$ & $1.36 \mathrm{E}+10$ & $3.74 \mathrm{E}+06$ & $4.49 \mathrm{E}+08$ & $0.00 \mathrm{E}+00$ & $0.00 \mathrm{E}+00$ \\
\hline 2080 & $9.64 \mathrm{E}+08$ & $1.35 E+09$ & $0.00 \mathrm{E}+00$ & $2.32 \mathrm{E}+09$ & $5.00 \mathrm{E}+07$ & $4.00 \mathrm{E}+08$ & $1.37 \mathrm{E}+10$ & $3.72 \mathrm{E}+06$ & $4.47 \mathrm{E}+08$ & $0.00 \mathrm{E}+00$ & $0.00 \mathrm{E}+00$ \\
\hline 2081 & $9.90 \mathrm{E}+08$ & $1.54 \mathrm{E}+09$ & $0.00 \mathrm{E}+00$ & $2.53 E+09$ & $5.02 \mathrm{E}+07$ & $4.01 \mathrm{E}+08$ & $1.39 E+10$ & $3.70 \mathrm{E}+06$ & $4.44 \mathrm{E}+08$ & $0.00 \mathrm{E}+00$ & $0.00 \mathrm{E}+00$ \\
\hline 2082 & $9.07 \mathrm{E}+08$ & $1.73 E+09$ & $0.00 \mathrm{E}+00$ & $2.64 E+09$ & $4.98 \mathrm{E}+07$ & $3.99 E+08$ & $1.40 \mathrm{E}+10$ & $3.62 \mathrm{E}+06$ & $4.34 \mathrm{E}+08$ & $0.00 \mathrm{E}+00$ & $0.00 \mathrm{E}+00$ \\
\hline 2083 & $9.07 \mathrm{E}+08$ & $1.92 \mathrm{E}+09$ & $0.00 \mathrm{E}+00$ & $2.82 E+09$ & $4.95 \mathrm{E}+07$ & $3.96 \mathrm{E}+08$ & $1.63 E+10$ & $3.71 \mathrm{E}+06$ & $4.45 E+08$ & $0.00 \mathrm{E}+00$ & $0.00 \mathrm{E}+00$ \\
\hline 2084 & $9.07 \mathrm{E}+08$ & $1.96 \mathrm{E}+09$ & $0.00 \mathrm{E}+00$ & $2.87 E+09$ & $4.97 \mathrm{E}+07$ & $3.97 E+08$ & $1.53 E+10$ & $3.76 \mathrm{E}+06$ & $4.51 \mathrm{E}+08$ & $0.00 \mathrm{E}+00$ & $0.00 \mathrm{E}+00$ \\
\hline 2085 & $9.69 \mathrm{E}+08$ & $2.01 \mathrm{E}+09$ & $0.00 \mathrm{E}+00$ & $2.98 \mathrm{E}+09$ & $6.01 \mathrm{E}+07$ & $4.81 \mathrm{E}+08$ & $1.62 \mathrm{E}+10$ & $3.83 E+06$ & $4.59 \mathrm{E}+08$ & $0.00 \mathrm{E}+00$ & $0.00 \mathrm{E}+00$ \\
\hline 2086 & $9.80 \mathrm{E}+08$ & $2.06 \mathrm{E}+09$ & $0.00 \mathrm{E}+00$ & $3.04 E+09$ & $5.45 \mathrm{E}+07$ & $4.36 \mathrm{E}+08$ & $1.60 \mathrm{E}+10$ & $4.01 \mathrm{E}+06$ & $4.82 \mathrm{E}+08$ & $0.00 \mathrm{E}+00$ & $0.00 \mathrm{E}+00$ \\
\hline 2087 & $9.44 \mathrm{E}+08$ & $2.08 \mathrm{E}+09$ & $0.00 \mathrm{E}+00$ & $3.03 E+09$ & $7.51 \mathrm{E}+07$ & $6.01 \mathrm{E}+08$ & $1.66 \mathrm{E}+10$ & $4.00 \mathrm{E}+06$ & $4.79 \mathrm{E}+08$ & $0.00 \mathrm{E}+00$ & $0.00 \mathrm{E}+00$ \\
\hline 2088 & $9.84 \mathrm{E}+08$ & $2.22 \mathrm{E}+09$ & $0.00 \mathrm{E}+00$ & $3.21 \mathrm{E}+09$ & $7.66 \mathrm{E}+07$ & $6.13 \mathrm{E}+08$ & $1.60 \mathrm{E}+10$ & $4.00 \mathrm{E}+06$ & $4.80 \mathrm{E}+08$ & $0.00 \mathrm{E}+00$ & $0.00 \mathrm{E}+00$ \\
\hline 2089 & $1.10 \mathrm{E}+09$ & $2.32 \mathrm{E}+09$ & $0.00 \mathrm{E}+00$ & $3.42 E+09$ & $6.83 E+07$ & $5.46 \mathrm{E}+08$ & $1.64 \mathrm{E}+10$ & $3.94 \mathrm{E}+06$ & $4.73 E+08$ & $0.00 \mathrm{E}+00$ & $0.00 \mathrm{E}+00$ \\
\hline 2090 & $1.06 \mathrm{E}+09$ & $2.48 \mathrm{E}+09$ & $0.00 \mathrm{E}+00$ & $3.54 E+09$ & $7.51 \mathrm{E}+07$ & $6.01 \mathrm{E}+08$ & $1.66 \mathrm{E}+10$ & $3.93 E+06$ & $4.71 \mathrm{E}+08$ & $0.00 \mathrm{E}+00$ & $0.00 \mathrm{E}+00$ \\
\hline 2091 & 1.10E+09 & $2.61 \mathrm{E}+09$ & $0.00 \mathrm{E}+00$ & $3.71 E+09$ & $7.21 \mathrm{E}+07$ & $5.77 \mathrm{E}+08$ & $1.75 \mathrm{E}+10$ & $3.87 E+06$ & $4.64 E+08$ & $0.00 \mathrm{E}+00$ & $0.00 \mathrm{E}+00$ \\
\hline 2092 & $1.08 \mathrm{E}+09$ & $2.76 \mathrm{E}+09$ & $0.00 \mathrm{E}+00$ & $3.84 E+09$ & $7.24 \mathrm{E}+07$ & $5.79 \mathrm{E}+08$ & $1.90 E+10$ & $3.96 \mathrm{E}+06$ & $4.75 E+08$ & $0.00 \mathrm{E}+00$ & $0.00 \mathrm{E}+00$ \\
\hline 2093 & $1.07 \mathrm{E}+09$ & $2.77 \mathrm{E}+09$ & $0.00 \mathrm{E}+00$ & $3.85 E+09$ & $6.96 \mathrm{E}+07$ & $5.57 \mathrm{E}+08$ & $1.86 \mathrm{E}+10$ & $4.03 E+06$ & $4.84 \mathrm{E}+08$ & $0.00 \mathrm{E}+00$ & $0.00 \mathrm{E}+00$ \\
\hline 2094 & $1.03 E+09$ & $2.85 \mathrm{E}+09$ & $0.00 \mathrm{E}+00$ & $3.87 E+09$ & $7.99 E+07$ & $6.39 \mathrm{E}+08$ & $2.02 \mathrm{E}+10$ & $4.21 \mathrm{E}+06$ & $5.05 E+08$ & $0.00 \mathrm{E}+00$ & $0.00 \mathrm{E}+00$ \\
\hline 2095 & $1.04 \mathrm{E}+09$ & $2.85 \mathrm{E}+09$ & $0.00 \mathrm{E}+00$ & $3.89 E+09$ & $7.43 \mathrm{E}+07$ & $5.94 \mathrm{E}+08$ & $1.91 \mathrm{E}+10$ & $4.19 \mathrm{E}+06$ & $5.03 E+08$ & $0.00 \mathrm{E}+00$ & $0.00 \mathrm{E}+00$ \\
\hline 2096 & $1.11 \mathrm{E}+09$ & $3.00 \mathrm{E}+09$ & $0.00 \mathrm{E}+00$ & $4.11 \mathrm{E}+09$ & $8.51 \mathrm{E}+07$ & $6.80 \mathrm{E}+08$ & $1.87 E+10$ & $4.63 E+06$ & $5.56 \mathrm{E}+08$ & $0.00 \mathrm{E}+00$ & $0.00 \mathrm{E}+00$ \\
\hline 2097 & $1.21 \mathrm{E}+09$ & $3.10 E+09$ & $0.00 \mathrm{E}+00$ & $4.31 \mathrm{E}+09$ & $7.28 \mathrm{E}+07$ & $5.82 \mathrm{E}+08$ & 2.10E+10 & $4.72 \mathrm{E}+06$ & $5.66 \mathrm{E}+08$ & $0.00 \mathrm{E}+00$ & $0.00 \mathrm{E}+00$ \\
\hline 2098 & $1.11 \mathrm{E}+09$ & $3.21 \mathrm{E}+09$ & $0.00 \mathrm{E}+00$ & $4.32 \mathrm{E}+09$ & $7.33 E+07$ & $5.86 \mathrm{E}+08$ & $1.92 \mathrm{E}+10$ & $4.69 \mathrm{E}+06$ & $5.63 \mathrm{E}+08$ & $0.00 \mathrm{E}+00$ & $0.00 \mathrm{E}+00$ \\
\hline 2099 & $1.10 \mathrm{E}+09$ & $3.45 \mathrm{E}+09$ & $0.00 \mathrm{E}+00$ & $4.55 \mathrm{E}+09$ & $8.02 \mathrm{E}+07$ & $6.42 \mathrm{E}+08$ & $1.93 E+10$ & $4.71 \mathrm{E}+06$ & $5.65 \mathrm{E}+08$ & $0.00 \mathrm{E}+00$ & $0.00 \mathrm{E}+00$ \\
\hline 2100 & $1.21 \mathrm{E}+09$ & $3.55 \mathrm{E}+09$ & $0.00 \mathrm{E}+00$ & $4.76 \mathrm{E}+09$ & $6.76 \mathrm{E}+07$ & $5.41 \mathrm{E}+08$ & $1.97 \mathrm{E}+10$ & $4.80 \mathrm{E}+06$ & $5.77 \mathrm{E}+08$ & $0.00 \mathrm{E}+00$ & $0.00 \mathrm{E}+00$ \\
\hline
\end{tabular}

Figure 9 (cont). Base Case 1: 2051-2100 yearly results for Modules D1-1 through I. 


\begin{tabular}{|c|c|c|c|c|c|c|c|c|c|c|c|c|}
\hline \multirow{3}{*}{ Year } & \multirow{2}{*}{\begin{tabular}{|l|} 
Module L1 \\
total sf to \\
repository rate \\
(kgHM/yr)
\end{tabular}} & Module L1 & \begin{tabular}{|l|l|} 
Module L2 & \multicolumn{1}{|c|}{} \\
\end{tabular} & \multicolumn{2}{|c|}{\begin{tabular}{|l|l|l|l|} 
Module L2 & Module L2 \\
\end{tabular}} & Module L2 & \multicolumn{2}{|c|}{\begin{tabular}{|l|l|} 
Module L2 & Module L2 \\
\end{tabular}} & 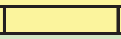 & \multicolumn{2}{|c|}{ Module F1-4 } & Module F1-4 \\
\hline & & $\begin{array}{l}\text { Cost of SNF } \\
\text { in Repository } \\
\text { by year (\$/yr) }\end{array}$ & Total HLV & $\begin{array}{l}\text { W in Reposi } \\
(\mathrm{kgHM} / \mathrm{yr})\end{array}$ & & Cost of $\mathrm{H}$ & $\begin{array}{l}\text { HLW in Repo } \\
\text { Year (\$/yr) }\end{array}$ & & $\begin{array}{c}\text { Total Cost } \\
\text { of HLW in } \\
\text { Repository } \\
\text { (\$/yr) }\end{array}$ & $\begin{array}{c}\text { Total Back } \\
\text { End Costs } \\
\text { Each Year } \\
\text { (\$/yr) }\end{array}$ & $\begin{array}{l}\text { Aqueous } \\
\text { Reprocessing } \\
\text { Rate F1-4 } \\
\text { (kgHM/yr) }\end{array}$ & $\begin{array}{c}\text { Aqueous } \\
\text { Reprocessin } \\
\text { g Cost F1-4 } \\
(\$ / y r)\end{array}$ \\
\hline & & & UREX+4 & Pyro & UREX-1A & UREX+4 & Pyro & UREX-1A & & & & \\
\hline 2000 & $0.00 \mathrm{E}+00$ & $0.00 \mathrm{E}+00$ & $0.00 \mathrm{E}+00$ & $0.00 \mathrm{E}+00$ & $0.00 \mathrm{E}+00$ & $0.00 \mathrm{E}+00$ & $0.00 \mathrm{E}+00$ & $0.00 \mathrm{E}+00$ & $0.00 \mathrm{E}+00$ & $0.00 \mathrm{E}+00$ & $0.00 \mathrm{E}+00$ & $0.00 \mathrm{E}+00$ \\
\hline 2001 & $0.00 \mathrm{E}+00$ & $0.00 \mathrm{E}+00$ & $0.00 \mathrm{E}+00$ & $0.00 \mathrm{E}+00$ & $0.00 \mathrm{E}+00$ & $0.00 \mathrm{E}+00$ & $0.00 \mathrm{E}+00$ & $0.00 \mathrm{E}+00$ & $0.00 \mathrm{E}+00$ & $0.00 \mathrm{E}+00$ & $0.00 \mathrm{E}+00$ & $0.00 \mathrm{E}+00$ \\
\hline 2002 & $0.00 \mathrm{E}+00$ & $0.00 \mathrm{E}+00$ & $0.00 \mathrm{E}+00$ & $0.00 \mathrm{E}+00$ & $0.00 \mathrm{E}+00$ & $0.00 \mathrm{E}+00$ & $0.00 \mathrm{E}+00$ & $0.00 \mathrm{E}+00$ & $0.00 \mathrm{E}+00$ & $0.00 \mathrm{E}+00$ & $0.00 \mathrm{E}+00$ & $0.00 \mathrm{E}+00$ \\
\hline 2003 & $0.00 \mathrm{E}+00$ & $0.00 \mathrm{E}+00$ & $0.00 \mathrm{E}+00$ & $0.00 \mathrm{E}+00$ & $0.00 \mathrm{E}+00$ & $0.00 \mathrm{E}+00$ & $0.00 \mathrm{E}+00$ & $0.00 \mathrm{E}+00$ & $0.00 \mathrm{E}+00$ & $0.00 \mathrm{E}+00$ & $0.00 \mathrm{E}+00$ & $0.00 \mathrm{E}+00$ \\
\hline 2004 & $0.00 \mathrm{E}+00$ & $0.00 \mathrm{E}+00$ & $0.00 \mathrm{E}+00$ & $0.00 \mathrm{E}+00$ & $0.00 \mathrm{E}+00$ & $0.00 \mathrm{E}+00$ & $0.00 \mathrm{E}+00$ & $0.00 \mathrm{E}+00$ & $0.00 \mathrm{E}+00$ & $0.00 \mathrm{E}+00$ & $0.00 \mathrm{E}+00$ & $0.00 \mathrm{E}+00$ \\
\hline 2005 & $0.00 \mathrm{E}+00$ & $0.00 \mathrm{E}+00$ & $0.00 \mathrm{E}+00$ & $0.00 \mathrm{E}+00$ & $0.00 \mathrm{E}+00$ & $0.00 \mathrm{E}+00$ & $0.00 \mathrm{E}+00$ & $0.00 \mathrm{E}+00$ & $0.00 \mathrm{E}+00$ & $0.00 \mathrm{E}+00$ & $0.00 \mathrm{E}+00$ & $0.00 \mathrm{E}+00$ \\
\hline 2006 & $0.00 \mathrm{E}+00$ & $0.00 \mathrm{E}+00$ & $0.00 \mathrm{E}+00$ & $0.00 \mathrm{E}+00$ & $0.00 \mathrm{E}+00$ & $0.00 \mathrm{E}+00$ & $0.00 \mathrm{E}+00$ & $0.00 \mathrm{E}+00$ & $0.00 \mathrm{E}+00$ & 3.07E+08 & $0.00 \mathrm{E}+00$ & $0.00 \mathrm{E}+00$ \\
\hline 2007 & $0.00 \mathrm{E}+00$ & $0.00 \mathrm{E}+00$ & $0.00 \mathrm{E}+00$ & $0.00 \mathrm{E}+00$ & $0.00 \mathrm{E}+00$ & $0.00 \mathrm{E}+00$ & $0.00 \mathrm{E}+00$ & $0.00 \mathrm{E}+00$ & $0.00 \mathrm{E}+00$ & $3.04 \mathrm{E}+08$ & $0.00 \mathrm{E}+00$ & $0.00 \mathrm{E}+00$ \\
\hline 2008 & $0.00 \mathrm{E}+00$ & $0.00 \mathrm{E}+00$ & $0.00 \mathrm{E}+00$ & $0.00 \mathrm{E}+00$ & $0.00 \mathrm{E}+00$ & $0.00 \mathrm{E}+00$ & $0.00 \mathrm{E}+00$ & $0.00 \mathrm{E}+00$ & $0.00 \mathrm{E}+00$ & $2.96 \mathrm{E}+08$ & $0.00 \mathrm{E}+00$ & $0.00 \mathrm{E}+00$ \\
\hline 2009 & $0.00 \mathrm{E}+00$ & $0.00 \mathrm{E}+00$ & $0.00 \mathrm{E}+00$ & $0.00 \mathrm{E}+00$ & $0.00 \mathrm{E}+00$ & $0.00 \mathrm{E}+00$ & $0.00 \mathrm{E}+00$ & $0.00 \mathrm{E}+00$ & $0.00 \mathrm{E}+00$ & $2.85 \mathrm{E}+08$ & $0.00 \mathrm{E}+00$ & $0.00 \mathrm{E}+00$ \\
\hline 2010 & $0.00 \mathrm{E}+00$ & $0.00 \mathrm{E}+00$ & $0.00 \mathrm{E}+00$ & $0.00 \mathrm{E}+00$ & $0.00 \mathrm{E}+00$ & $0.00 \mathrm{E}+00$ & $0.00 \mathrm{E}+00$ & $0.00 \mathrm{E}+00$ & $0.00 \mathrm{E}+00$ & $2.72 \mathrm{E}+08$ & $0.00 \mathrm{E}+00$ & $0.00 \mathrm{E}+00$ \\
\hline 2011 & $0.00 \mathrm{E}+00$ & $0.00 \mathrm{E}+00$ & $0.00 \mathrm{E}+00$ & $0.00 \mathrm{E}+00$ & $0.00 \mathrm{E}+00$ & $0.00 \mathrm{E}+00$ & $0.00 \mathrm{E}+00$ & $0.00 \mathrm{E}+00$ & $0.00 \mathrm{E}+00$ & $4.97 \mathrm{E}+08$ & $0.00 \mathrm{E}+00$ & $0.00 \mathrm{E}+00$ \\
\hline 2012 & $0.00 \mathrm{E}+00$ & $0.00 \mathrm{E}+00$ & $0.00 \mathrm{E}+00$ & $0.00 \mathrm{E}+00$ & $0.00 \mathrm{E}+00$ & $0.00 \mathrm{E}+00$ & $0.00 \mathrm{E}+00$ & $0.00 \mathrm{E}+00$ & $0.00 \mathrm{E}+00$ & $8.04 \mathrm{E}+08$ & $0.00 \mathrm{E}+00$ & $0.00 \mathrm{E}+00$ \\
\hline 2013 & $0.00 \mathrm{E}+00$ & $0.00 \mathrm{E}+00$ & $0.00 \mathrm{E}+00$ & $0.00 \mathrm{E}+00$ & $0.00 \mathrm{E}+00$ & $0.00 \mathrm{E}+00$ & $0.00 \mathrm{E}+00$ & $0.00 \mathrm{E}+00$ & $0.00 \mathrm{E}+00$ & 1.10E+09 & $0.00 \mathrm{E}+00$ & $0.00 \mathrm{E}+00$ \\
\hline 2014 & $0.00 \mathrm{E}+00$ & $0.00 \mathrm{E}+00$ & $0.00 \mathrm{E}+00$ & $0.00 \mathrm{E}+00$ & $0.00 \mathrm{E}+00$ & $0.00 \mathrm{E}+00$ & $0.00 \mathrm{E}+00$ & $0.00 \mathrm{E}+00$ & $0.00 \mathrm{E}+00$ & $1.38 \mathrm{E}+09$ & $0.00 \mathrm{E}+00$ & $0.00 \mathrm{E}+00$ \\
\hline 2015 & $0.00 \mathrm{E}+00$ & $0.00 \mathrm{E}+00$ & $0.00 \mathrm{E}+00$ & $0.00 \mathrm{E}+00$ & $0.00 \mathrm{E}+00$ & $0.00 \mathrm{E}+00$ & $0.00 \mathrm{E}+00$ & $0.00 \mathrm{E}+00$ & $0.00 \mathrm{E}+00$ & $1.65 \mathrm{E}+09$ & $0.00 \mathrm{E}+00$ & $0.00 \mathrm{E}+00$ \\
\hline 2016 & $0.00 \mathrm{E}+00$ & $0.00 \mathrm{E}+00$ & $1.10 \mathrm{E}+06$ & $0.00 \mathrm{E}+00$ & $0.00 \mathrm{E}+00$ & $2.32 \mathrm{E}+08$ & $0.00 \mathrm{E}+00$ & $0.00 \mathrm{E}+00$ & $2.32 \mathrm{E}+08$ & $E+09$ & $1.10 \mathrm{E}+06$ & $6.60 \mathrm{E}+08$ \\
\hline 2017 & $0.00 \mathrm{E}+00$ & $0.00 \mathrm{E}+00$ & $1.20 \mathrm{E}+06$ & $0.00 \mathrm{E}+00$ & $0.00 \mathrm{E}+00$ & $2.53 \mathrm{E}+08$ & $0.00 \mathrm{E}+00$ & $0.00 \mathrm{E}+00$ & $2.53 E+08$ & $2.44 \mathrm{E}+09$ & $1.20 \mathrm{E}+06$ & $7.20 \mathrm{E}+08$ \\
\hline 2018 & $0.00 \mathrm{E}+00$ & $0.00 \mathrm{E}+00$ & $1.40 \mathrm{E}+06$ & $0.00 \mathrm{E}+00$ & $0.00 \mathrm{E}+00$ & $2.95 \mathrm{E}+08$ & $0.00 \mathrm{E}+00$ & $0.00 \mathrm{E}+00$ & $2.95 \mathrm{E}+08$ & $E+09$ & $1.40 \mathrm{E}+06$ & $8.40 E+08$ \\
\hline 2019 & $0.00 E+00$ & $0.00 E+00$ & $1.60 \mathrm{E}+06$ & $0.00 \mathrm{E}+00$ & $0.00 \mathrm{E}+00$ & $3.38 \mathrm{E}+08$ & $0.00 E+00$ & $0.00 \mathrm{E}+00$ & $3.38 \mathrm{E}+08$ & $E+09$ & $1.60 E+06$ & $9.60 E+08$ \\
\hline 2020 & $0.00 E+00$ & $0.00 E+00$ & $2.00 \mathrm{E}+06$ & $0.00 E+00$ & $0.00 E+00$ & $4.22 E+08$ & $0.00 E+00$ & $0.00 \mathrm{E}+00$ & $4.22 E+08$ & $=+09$ & $2.00 E+06$ & $1.20 E+09$ \\
\hline 2021 & $3.00 E+06$ & $1.58 \mathrm{E}+09$ & $2.00 \mathrm{E}+06$ & $0.00 E+00$ & $0.00 \mathrm{E}+00$ & $4.22 E+08$ & $0.00 E+00$ & $0.00 E+00$ & $4.22 E+08$ & $E+09$ & $2.00 E+06$ & $1.20 E+09$ \\
\hline 2022 & $3.00 E+06$ & $1.58 \mathrm{E}+09$ & $2.00 E+06$ & $0.00 \mathrm{E}+00$ & $0.00 \mathrm{E}+00$ & $4.22 E+08$ & $0.00 E+00$ & $0.00 E+00$ & $4.22 E+08$ & $E+09$ & $2.00 E+06$ & $1.20 E+09$ \\
\hline 2023 & $3.00 E+06$ & $1.58 \mathrm{E}+09$ & $2.00 E+06$ & $0.00 E+00$ & $0.00 E+00$ & $4.22 E+08$ & $0.00 E+00$ & $0.00 E+00$ & $4.22 E+08$ & $=09$ & $2.00 E+06$ & $1.20 E+09$ \\
\hline 2024 & $3.00 E+06$ & $1.58 \mathrm{E}+09$ & $2.00 E+06$ & $0.00 E+00$ & $0.00 \mathrm{E}+00$ & $4.22 E+08$ & $0.00 E+00$ & $0.00 E+00$ & $4.22 E+08$ & $5.06 E+09$ & $2.00 E+06$ & $1.20 E+09$ \\
\hline 2025 & $3.00 E+06$ & $1.58 \mathrm{E}+09$ & $2.00 E+06$ & $0.00 E+00$ & $0.00 E+00$ & $4.22 E+08$ & $0.00 E+00$ & $0.00 E+00$ & $4.22 E+08$ & & $2.00 E+06$ & $1.20 E+09$ \\
\hline 2026 & $3.00 \mathrm{E}+06$ & $1.58 \mathrm{E}+09$ & $2.00 \mathrm{E}+06$ & $0.00 \mathrm{E}+00$ & $0.00 E+00$ & $4.22 E+08$ & $0.00 E+00$ & $0.00 E+00$ & $4.22 E+08$ & $5.05 E+09$ & $2.00 E+06$ & $1.20 E+09$ \\
\hline 2027 & $3.00 \mathrm{E}+06$ & $1.58 \mathrm{E}+09$ & $2.00 \mathrm{E}+06$ & $0.00 \mathrm{E}+00$ & $0.00 \mathrm{E}+00$ & $4.22 \mathrm{E}+08$ & $0.00 \mathrm{E}+00$ & $0.00 \mathrm{E}+00$ & $4.22 \mathrm{E}+08$ & +09 & $2.00 \mathrm{E}+06$ & $1.20 \mathrm{E}+09$ \\
\hline 2028 & $3.00 E+06$ & $1.58 E+09$ & $2.00 \mathrm{E}+06$ & $0.00 E+00$ & $0.00 E+00$ & $4.22 E+08$ & $0.00 E+00$ & $0.00 E+00$ & $4.22 E+08$ & +09 & $2.00 E+06$ & $1.20 E+09$ \\
\hline 2029 & $3.00 E+06$ & $1.58 E+09$ & $2.00 \mathrm{E}+06$ & $0.00 E+00$ & $0.00 \mathrm{E}+00$ & $4.22 E+08$ & $0.00 E+00$ & $0.00 E+00$ & $4.22 E+08$ & +09 & $2.00 E+06$ & $1.20 E+09$ \\
\hline 2030 & $3.00 E+06$ & $1.58 \mathrm{E}+09$ & $2.00 \mathrm{E}+06$ & $0.00 E+00$ & $0.00 \mathrm{E}+00$ & $4.22 E+08$ & $0.00 E+00$ & $0.00 E+00$ & $4.22 E+08$ & $5.06 \mathrm{E}+09$ & $2.00 E+06$ & $1.20 E+09$ \\
\hline 2031 & $3.00 E+06$ & $1.58 \mathrm{E}+09$ & $2.00 \mathrm{E}+06$ & $0.00 \mathrm{E}+00$ & $0.00 E+00$ & $4.22 E+08$ & $0.00 E+00$ & $0.00 E+00$ & $4.22 E+08$ & $5.04 \mathrm{E}+09$ & $2.00 E+06$ & $1.20 E+09$ \\
\hline 2032 & $3.00 E+06$ & $1.58 \mathrm{E}+09$ & $2.00 \mathrm{E}+06$ & $0.00 \mathrm{E}+00$ & $0.00 \mathrm{E}+00$ & $4.22 \mathrm{E}+08$ & $0.00 \mathrm{E}+00$ & $0.00 E+00$ & $4.22 E+08$ & $5.04 \mathrm{E}+09$ & $2.00 E+06$ & $1.20 E+09$ \\
\hline 2033 & $3.00 E+06$ & $1.58 \mathrm{E}+09$ & $2.00 \mathrm{E}+06$ & $0.00 E+00$ & $0.00 E+00$ & $4.22 E+08$ & $0.00 E+00$ & $0.00 E+00$ & $4.22 E+08$ & $5.04 \mathrm{E}+09$ & $2.00 E+06$ & $1.20 E+09$ \\
\hline 2034 & $3.00 E+06$ & $1.58 \mathrm{E}+09$ & $2.00 \mathrm{E}+06$ & $0.00 \mathrm{E}+00$ & $0.00 E+00$ & $4.22 E+08$ & $0.00 E+00$ & $0.00 E+00$ & $4.22 E+08$ & $5.03 E+09$ & $2.00 E+06$ & $1.20 E+09$ \\
\hline 2035 & $3.00 E+06$ & $1.58 \mathrm{E}+09$ & $2.00 \mathrm{E}+06$ & $0.00 \mathrm{E}+00$ & $0.00 E+00$ & $4.22 E+08$ & $0.00 \mathrm{E}+00$ & $0.00 E+00$ & $4.22 E+08$ & $5.02 E+09$ & $2.00 E+06$ & $1.20 E+09$ \\
\hline 2036 & $3.00 E+06$ & $1.58 \mathrm{E}+09$ & $2.00 \mathrm{E}+06$ & $1.76 \mathrm{E}+03$ & $0.00 E+00$ & $4.22 E+08$ & $3.72 E+05$ & $0.00 \mathrm{E}+00$ & $4.22 E+08$ & $5.03 E+09$ & $2.00 E+06$ & $1.20 E+09$ \\
\hline 2037 & $3.00 E+06$ & $1.58 \mathrm{E}+09$ & $2.00 E+06$ & $2.35 \mathrm{E}+03$ & $0.00 \mathrm{E}+00$ & $4.22 E+08$ & $4.96 \mathrm{E}+05$ & $0.00 \mathrm{E}+00$ & $4.22 E+08$ & $4.79 E+09$ & $2.00 E+06$ & $1.20 E+09$ \\
\hline 2038 & $3.00 E+06$ & $1.58 \mathrm{E}+09$ & $2.00 \mathrm{E}+06$ & $2.35 \mathrm{E}+03$ & $0.00 \mathrm{E}+00$ & $4.22 \mathrm{E}+08$ & $4.96 \mathrm{E}+05$ & $0.00 \mathrm{E}+00$ & $4.22 \mathrm{E}+08$ & $4.55 \mathrm{E}+09$ & $2.00 E+06$ & $1.20 \mathrm{E}+09$ \\
\hline 2039 & $3.00 E+06$ & $1.58 \mathrm{E}+09$ & $2.00 \mathrm{E}+06$ & $2.35 \mathrm{E}+03$ & $0.00 \mathrm{E}+00$ & $4.22 E+08$ & $4.96 \mathrm{E}+05$ & $0.00 \mathrm{E}+00$ & $4.22 \mathrm{E}+08$ & $4.23 E+09$ & $2.00 E+06$ & $1.20 E+09$ \\
\hline 2040 & $3.00 E+06$ & $1.58 \mathrm{E}+09$ & $2.00 \mathrm{E}+06$ & $2.35 \mathrm{E}+03$ & $0.00 \mathrm{E}+00$ & $4.22 \mathrm{E}+08$ & $4.96 \mathrm{E}+05$ & $0.00 \mathrm{E}+00$ & $4.22 \mathrm{E}+08$ & $3.92 E+09$ & $2.00 E+06$ & $1.20 E+09$ \\
\hline 2041 & $3.00 E+06$ & $1.58 E+09$ & $2.00 E+06$ & $2.35 \mathrm{E}+03$ & $0.00 E+00$ & $4.22 E+08$ & $4.96 \mathrm{E}+05$ & $0.00 E+00$ & $4.22 E+08$ & $3.63 E+09$ & $2.00 E+06$ & $1.20 E+09$ \\
\hline 2042 & $3.00 E+06$ & $1.58 E+09$ & $2.00 E+06$ & $2.35 \mathrm{E}+03$ & $0.00 \mathrm{E}+00$ & $4.22 E+08$ & $4.96 \mathrm{E}+05$ & $0.00 E+00$ & $4.22 E+08$ & $3.33 E+09$ & $2.00 E+06$ & $1.20 E+09$ \\
\hline 2043 & $3.00 E+06$ & $1.58 \mathrm{E}+09$ & $2.00 \mathrm{E}+06$ & $2.35 \mathrm{E}+03$ & $0.00 \mathrm{E}+00$ & $4.22 E+08$ & $4.96 \mathrm{E}+05$ & $0.00 E+00$ & $4.22 E+08$ & $3.04 \mathrm{E}+09$ & $2.00 E+06$ & $1.20 E+09$ \\
\hline 2044 & $3.00 E+06$ & $1.58 \mathrm{E}+09$ & $2.00 E+06$ & $2.35 \mathrm{E}+03$ & $0.00 E+00$ & $4.22 E+08$ & $4.96 \mathrm{E}+05$ & $0.00 E+00$ & $4.22 E+08$ & $2.75 E+09$ & $2.00 E+06$ & $1.20 E+09$ \\
\hline 2045 & $2.89 E+06$ & $1.52 E+09$ & $2.00 E+06$ & $2.35 \mathrm{E}+03$ & $0.00 \mathrm{E}+00$ & $4.22 E+08$ & $4.96 \mathrm{E}+05$ & $0.00 E+00$ & $4.22 E+08$ & $2.41 E+09$ & $2.00 E+06$ & $1.20 E+09$ \\
\hline 2046 & $1.35 E+06$ & $7.12 \mathrm{E}+08$ & $2.00 \mathrm{E}+06$ & $2.35 \mathrm{E}+03$ & $0.00 E+00$ & $4.22 E+08$ & $4.96 \mathrm{E}+05$ & $0.00 E+00$ & $4.22 E+08$ & $1.51 \mathrm{E}+09$ & $2.00 E+06$ & $1.20 E+09$ \\
\hline 2047 & $6.66 \mathrm{E}+05$ & $3.51 \mathrm{E}+08$ & $7.82 E+05$ & $2.35 \mathrm{E}+03$ & $1.22 \mathrm{E}+06$ & $1.65 \mathrm{E}+08$ & $4.96 \mathrm{E}+05$ & $2.57 E+08$ & $4.22 \mathrm{E}+08$ & $1.09 \mathrm{E}+09$ & $2.00 E+06$ & $1.20 E+09$ \\
\hline 2048 & $7.14 \mathrm{E}+05$ & $3.77 \mathrm{E}+08$ & $7.19 \mathrm{E}+05$ & $2.35 \mathrm{E}+03$ & $1.28 \mathrm{E}+06$ & $1.52 \mathrm{E}+08$ & $4.96 \mathrm{E}+05$ & $2.70 E+08$ & $4.22 \mathrm{E}+08$ & $1.12 \mathrm{E}+09$ & $2.00 E+06$ & $1.20 E+09$ \\
\hline 2049 & $7.54 \mathrm{E}+05$ & $3.98 \mathrm{E}+08$ & $6.56 \mathrm{E}+05$ & 4.12E+03 & $1.34 \mathrm{E}+06$ & $1.38 \mathrm{E}+08$ & $8.68 E+05$ & $2.84 E+08$ & $4.23 E+08$ & $1.15 E+09$ & $2.00 E+06$ & $1.20 E+09$ \\
\hline 2050 & $6.89 \mathrm{E}+05$ & $3.64 \mathrm{E}+08$ & $5.93 E+05$ & $4.70 \mathrm{E}+03$ & $1.41 \mathrm{E}+06$ & $1.25 \mathrm{E}+08$ & $9.92 \mathrm{E}+05$ & $2.97 E+08$ & $4.23 \mathrm{E}+08$ & $1.12 E+09$ & $2.00 \mathrm{E}+06$ & $1.20 \mathrm{E}+09$ \\
\hline
\end{tabular}

Figure 9 (cont). Base Case 1: 2000-2050 yearly results for Modules L1 through F1-4. 


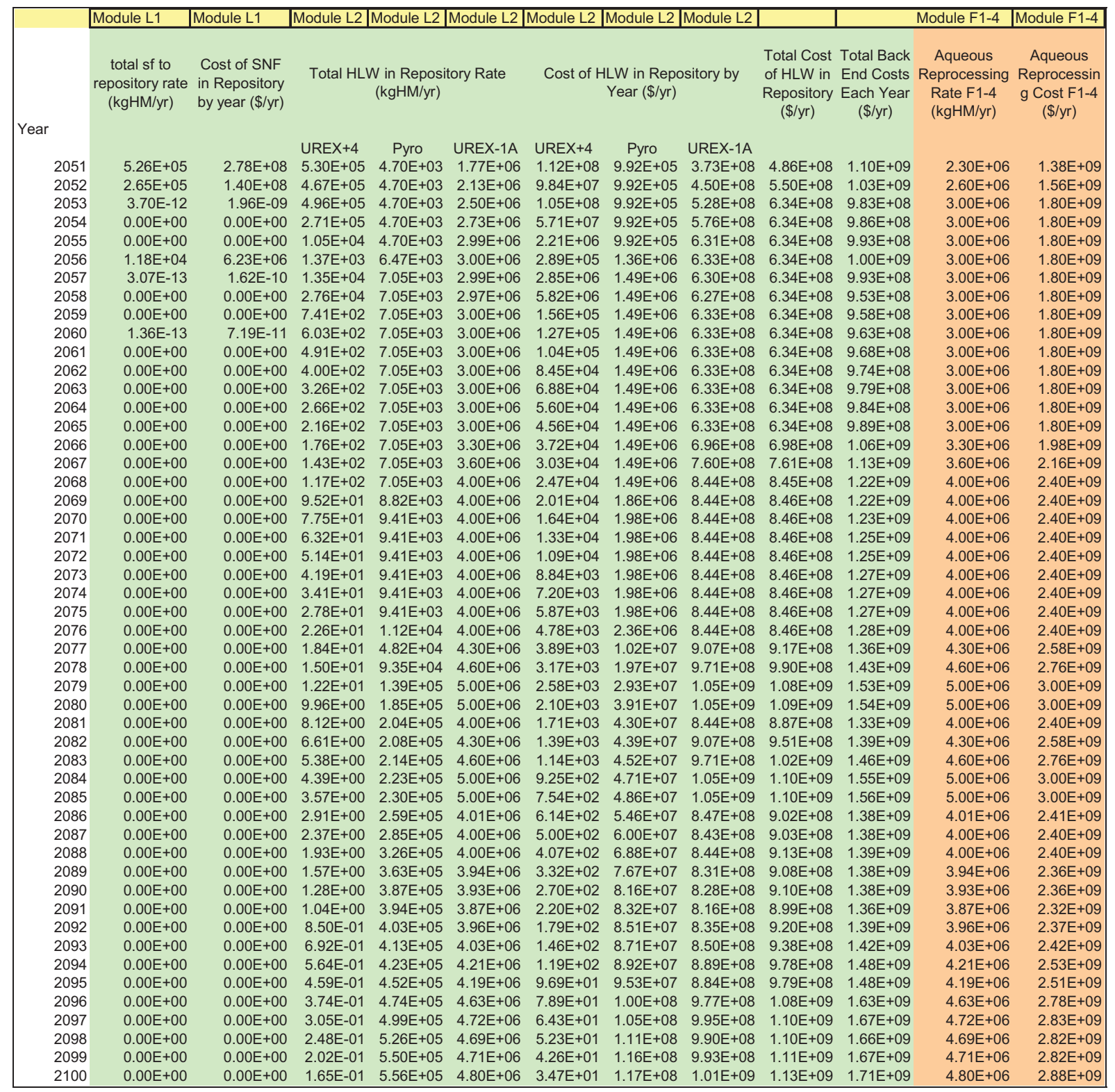

Figure 9 (cont). Base Case 1: 2051-2100 yearly results for Modules L1 through F1-4. 


\begin{tabular}{|c|c|c|c|c|c|c|c|c|c|c|}
\hline \multirow[b]{2}{*}{ Year } & Module F1-1 & Module F1-1 & Module F2 & Module F2 & & Module E3 & Module E3 & Module G1 & Module G1 & Module G1 \\
\hline & $\begin{array}{c}\text { Aqueous } \\
\text { Reprocessing Rate } \\
\text { F1-1 (kgHM/yr) }\end{array}$ & $\begin{array}{l}\text { Aqueous } \\
\text { Reprocessing } \\
\text { Cost F1-1 } \\
(\$ / y r)\end{array}$ & $\begin{array}{l}\text { Pyrolytic } \\
\text { reprocessing rate } \\
(\mathrm{kgHM} / \mathrm{yr})\end{array}$ & $\begin{array}{c}\text { Cost of Pyrolytic } \\
\text { Reprocessing by } \\
\text { Year (\$/yr) }\end{array}$ & $\begin{array}{l}\text { Total Reprocessing } \\
\text { Cost }(\$ / y r)\end{array}$ & $\begin{array}{c}\text { Recycled } \\
\text { Product Storage } \\
\text { Rate LWR } \\
(\mathrm{kg} / \mathrm{yr})\end{array}$ & $\begin{array}{l}\text { Cost of Recycled } \\
\text { Product Storage } \\
\text { by Year }(\$ / y r)\end{array}$ & \multicolumn{3}{|c|}{ HLW Conditioning (kg/yr) } \\
\hline & & & & & & & & UREX+4 & Pyro & UREX-1A \\
\hline 2000 & $0.00 \mathrm{E}+00$ & $0.00 \mathrm{E}+00$ & $0.00 \mathrm{E}+00$ & $0.00 E+00$ & $0.00 \mathrm{E}+00$ & $0.00 \mathrm{E}+00$ & $0.00 \mathrm{E}+00$ & $0.00 E+00$ & $0.00 \mathrm{E}+00$ & $0.00 \mathrm{E}+00$ \\
\hline 2001 & $0.00 \mathrm{E}+00$ & $0.00 \mathrm{E}+00$ & $0.00 \mathrm{E}+00$ & $0.00 \mathrm{E}+00$ & $0.00 \mathrm{E}+00$ & $0.00 \mathrm{E}+00$ & $0.00 \mathrm{E}+00$ & $0.00 E+00$ & $0.00 \mathrm{E}+00$ & $0.00 \mathrm{E}+00$ \\
\hline 2002 & $0.00 \mathrm{E}+00$ & $0.00 \mathrm{E}+00$ & $0.00 E+00$ & $0.00 E+00$ & $0.00 \mathrm{E}+00$ & $0.00 \mathrm{E}+00$ & $0.00 E+00$ & $0.00 E+00$ & $0.00 \mathrm{E}+00$ & $0.00 \mathrm{E}+00$ \\
\hline 2003 & $0.00 \mathrm{E}+00$ & $0.00 \mathrm{E}+00$ & $0.00 \mathrm{E}+00$ & $0.00 \mathrm{E}+00$ & $0.00 \mathrm{E}+00$ & $0.00 \mathrm{E}+00$ & $0.00 E+00$ & $0.00 E+00$ & $0.00 \mathrm{E}+00$ & $0.00 \mathrm{E}+00$ \\
\hline 2004 & $0.00 E+00$ & $0.00 \mathrm{E}+00$ & $0.00 E+00$ & $0.00 E+00$ & $0.00 E+00$ & $0.00 \mathrm{E}+00$ & $0.00 E+00$ & $0.00 E+00$ & $0.00 \mathrm{E}+00$ & $0.00 \mathrm{E}+00$ \\
\hline 2005 & $0.00 \mathrm{E}+00$ & $0.00 E+00$ & $0.00 E+00$ & $0.00 E+00$ & $0.00 E+00$ & $0.00 \mathrm{E}+00$ & $0.00 E+00$ & $0.00 E+00$ & $0.00 \mathrm{E}+00$ & $0.00 \mathrm{E}+00$ \\
\hline 2006 & $0.00 E+00$ & $0.00 \mathrm{E}+00$ & $0.00 E+00$ & $0.00 E+00$ & $0.00 E+00$ & $0.00 \mathrm{E}+00$ & $0.00 E+00$ & $0.00 E+00$ & $0.00 \mathrm{E}+00$ & $0.00 \mathrm{E}+00$ \\
\hline 2007 & $0.00 \mathrm{E}+00$ & $0.00 \mathrm{E}+00$ & $0.00 E+00$ & $0.00 E+00$ & $0.00 E+00$ & $0.00 \mathrm{E}+00$ & $0.00 E+00$ & $0.00 E+00$ & $0.00 \mathrm{E}+00$ & $0.00 \mathrm{E}+00$ \\
\hline 2008 & $0.00 \mathrm{E}+00$ & $0.00 \mathrm{E}+00$ & $0.00 \mathrm{E}+00$ & $0.00 E+00$ & $0.00 \mathrm{E}+00$ & $0.00 \mathrm{E}+00$ & $0.00 \mathrm{E}+00$ & $0.00 \mathrm{E}+00$ & $0.00 \mathrm{E}+00$ & $0.00 \mathrm{E}+00$ \\
\hline 2009 & $0.00 \mathrm{E}+00$ & $0.00 \mathrm{E}+00$ & $0.00 \mathrm{E}+00$ & $0.00 \mathrm{E}+00$ & $0.00 \mathrm{E}+00$ & $0.00 \mathrm{E}+00$ & $0.00 \mathrm{E}+00$ & $0.00 \mathrm{E}+00$ & $0.00 \mathrm{E}+00$ & $0.00 \mathrm{E}+00$ \\
\hline 2010 & $0.00 E+00$ & $0.00 E+00$ & $0.00 \mathrm{E}+00$ & $0.00 E+00$ & $0.00 E+00$ & $0.00 E+00$ & $0.00 E+00$ & $0.00 E+00$ & $0.00 \mathrm{E}+00$ & $0.00 E+00$ \\
\hline 2011 & $0.00 \mathrm{E}+00$ & $0.00 \mathrm{E}+00$ & $0.00 \mathrm{E}+00$ & $0.00 \mathrm{E}+00$ & $0.00 \mathrm{E}+00$ & $0.00 \mathrm{E}+00$ & $0.00 \mathrm{E}+00$ & $0.00 E+00$ & $0.00 \mathrm{E}+00$ & $0.00 \mathrm{E}+00$ \\
\hline 2012 & $0.00 \mathrm{E}+00$ & $0.00 \mathrm{E}+00$ & $0.00 \mathrm{E}+00$ & $0.00 E+00$ & $0.00 \mathrm{E}+00$ & $0.00 \mathrm{E}+00$ & $0.00 E+00$ & $0.00 E+00$ & $0.00 \mathrm{E}+00$ & $0.00 \mathrm{E}+00$ \\
\hline 2013 & $0.00 E+00$ & $0.00 E+00$ & $0.00 \mathrm{E}+00$ & $0.00 E+00$ & $0.00 \mathrm{E}+00$ & $0.00 \mathrm{E}+00$ & $0.00 E+00$ & $0.00 E+00$ & $0.00 \mathrm{E}+00$ & $0.00 \mathrm{E}+00$ \\
\hline 2014 & $0.00 \mathrm{E}+00$ & $0.00 \mathrm{E}+00$ & $0.00 \mathrm{E}+00$ & $0.00 E+00$ & $0.00 E+00$ & $0.00 \mathrm{E}+00$ & $0.00 \mathrm{E}+00$ & $0.00 E+00$ & $0.00 \mathrm{E}+00$ & $0.00 \mathrm{E}+00$ \\
\hline 2015 & $0.00 \mathrm{E}+00$ & $0.00 \mathrm{E}+00$ & $0.00 \mathrm{E}+00$ & $0.00 E+00$ & $0.00 E+00$ & $0.00 \mathrm{E}+00$ & $0.00 E+00$ & $0.00 \mathrm{E}+00$ & $0.00 \mathrm{E}+00$ & $0.00 \mathrm{E}+00$ \\
\hline 2016 & $0.00 \mathrm{E}+00$ & $0.00 \mathrm{E}+00$ & $0.00 \mathrm{E}+00$ & $0.00 E+00$ & $6.60 \mathrm{E}+08$ & $1.45 E+04$ & $2.61 E+08$ & $5.80 \mathrm{E}+04$ & $0.00 \mathrm{E}+00$ & $0.00 \mathrm{E}+00$ \\
\hline 2017 & $0.00 E+00$ & $0.00 \mathrm{E}+00$ & $0.00 \mathrm{E}+00$ & $0.00 E+00$ & $7.20 \mathrm{E}+08$ & $1.57 \mathrm{E}+04$ & $2.83 E+08$ & $6.29 E+04$ & $0.00 \mathrm{E}+00$ & $0.00 \mathrm{E}+00$ \\
\hline 2018 & $0.00 \mathrm{E}+00$ & $0.00 \mathrm{E}+00$ & $0.00 \mathrm{E}+00$ & $0.00 \mathrm{E}+00$ & $8.40 E+08$ & $1.93 \mathrm{E}+04$ & $3.48 \mathrm{E}+08$ & $7.84 \mathrm{E}+04$ & $0.00 \mathrm{E}+00$ & $0.00 \mathrm{E}+00$ \\
\hline 2019 & $0.00 \mathrm{E}+00$ & $0.00 \mathrm{E}+00$ & $0.00 \mathrm{E}+00$ & $0.00 E+00$ & $9.60 \mathrm{E}+08$ & $2.32 E+04$ & $4.18 \mathrm{E}+08$ & $9.56 \mathrm{E}+04$ & $0.00 \mathrm{E}+00$ & $0.00 \mathrm{E}+00$ \\
\hline 2020 & $0.00 \mathrm{E}+00$ & $0.00 E+00$ & $0.00 \mathrm{E}+00$ & $0.00 E+00$ & $1.20 \mathrm{E}+09$ & $3.00 \mathrm{E}+04$ & $5.40 \mathrm{E}+08$ & $1.24 \mathrm{E}+05$ & $0.00 \mathrm{E}+00$ & $0.00 \mathrm{E}+00$ \\
\hline 2021 & $0.00 E+00$ & $0.00 E+00$ & $0.00 E+00$ & $0.00 \mathrm{E}+00$ & $1.20 \mathrm{E}+09$ & $2.66 \mathrm{E}+04$ & $4.78 \mathrm{E}+08$ & $1.06 \mathrm{E}+05$ & $0.00 \mathrm{E}+00$ & $0.00 \mathrm{E}+00$ \\
\hline 2022 & $0.00 E+00$ & $0.00 E+00$ & $0.00 E+00$ & $0.00 E+00$ & $1.20 \mathrm{E}+09$ & $2.73 E+04$ & $4.92 E+08$ & $1.11 E+05$ & $0.00 E+00$ & $0.00 E+00$ \\
\hline 2023 & $0.00 E+00$ & $0.00 E+00$ & $0.00 E+00$ & $0.00 E+00$ & $1.20 E+09$ & $2.83 E+04$ & $5.09 E+08$ & 1.16E+05 & $0.00 \mathrm{E}+00$ & $0.00 E+00$ \\
\hline 2024 & $0.00 \mathrm{E}+00$ & $0.00 E+00$ & $0.00 E+00$ & $0.00 \mathrm{E}+00$ & $1.20 \mathrm{E}+09$ & $2.91 E+04$ & $5.24 \mathrm{E}+08$ & $1.20 E+05$ & $0.00 \mathrm{E}+00$ & $0.00 \mathrm{E}+00$ \\
\hline 2025 & $0.00 \mathrm{E}+00$ & $0.00 E+00$ & $0.00 \mathrm{E}+00$ & $0.00 E+00$ & $1.20 E+09$ & $2.99 \mathrm{E}+04$ & $5.38 E+08$ & $1.24 E+05$ & $0.00 \mathrm{E}+00$ & $0.00 E+00$ \\
\hline 2026 & $0.00 \mathrm{E}+00$ & $0.00 \mathrm{E}+00$ & $2.35 \mathrm{E}+03$ & $6.35 \mathrm{E}+06$ & $1.21 \mathrm{E}+09$ & $2.72 \mathrm{E}+04$ & $4.89 \mathrm{E}+08$ & $1.10 \mathrm{E}+05$ & $9.94 \mathrm{E}+02$ & $0.00 \mathrm{E}+00$ \\
\hline 2027 & $0.00 \mathrm{E}+00$ & $0.00 E+00$ & $2.35 \mathrm{E}+03$ & $6.35 \mathrm{E}+06$ & $1.21 \mathrm{E}+09$ & $2.81 E+04$ & $5.05 \mathrm{E}+08$ & 1.15E+05 & $9.94 \mathrm{E}+02$ & $0.00 \mathrm{E}+00$ \\
\hline 2028 & $0.00 \mathrm{E}+00$ & $0.00 \mathrm{E}+00$ & $2.35 \mathrm{E}+03$ & $6.35 \mathrm{E}+06$ & $1.21 E+09$ & $2.91 E+04$ & $5.24 \mathrm{E}+08$ & $1.20 E+05$ & $9.94 \mathrm{E}+02$ & $0.00 \mathrm{E}+00$ \\
\hline 2029 & $0.00 \mathrm{E}+00$ & $0.00 E+00$ & $2.35 \mathrm{E}+03$ & $6.35 \mathrm{E}+06$ & $1.21 E+09$ & $2.99 E+04$ & $5.37 E+08$ & $1.24 \mathrm{E}+05$ & $9.94 \mathrm{E}+02$ & $0.00 \mathrm{E}+00$ \\
\hline 2030 & $0.00 \mathrm{E}+00$ & $0.00 E+00$ & $2.35 E+03$ & $6.35 E+06$ & $1.21 E+09$ & $3.05 E+04$ & $5.49 E+08$ & $1.28 E+05$ & $9.94 \mathrm{E}+02$ & $0.00 E+00$ \\
\hline 2031 & $0.00 E+00$ & $0.00 E+00$ & $2.35 E+03$ & $6.35 E+06$ & $1.21 E+09$ & $2.78 \mathrm{E}+04$ & $5.00 E+08$ & 1.13E+05 & $9.94 \mathrm{E}+02$ & $0.00 \mathrm{E}+00$ \\
\hline 2032 & $0.00 \mathrm{E}+00$ & $0.00 E+00$ & $2.35 E+03$ & $6.35 \mathrm{E}+06$ & $1.21 E+09$ & $2.88 \mathrm{E}+04$ & $5.18 \mathrm{E}+08$ & 1.18E+05 & $9.94 \mathrm{E}+02$ & $0.00 \mathrm{E}+00$ \\
\hline 2033 & $0.00 E+00$ & $0.00 E+00$ & $2.35 \mathrm{E}+03$ & $6.35 \mathrm{E}+06$ & $1.21 E+09$ & $2.96 \mathrm{E}+04$ & $5.34 \mathrm{E}+08$ & $1.23 E+05$ & $9.94 \mathrm{E}+02$ & $0.00 \mathrm{E}+00$ \\
\hline 2034 & $0.00 E+00$ & $0.00 E+00$ & $3.53 E+03$ & $9.52 \mathrm{E}+06$ & $1.21 E+09$ & $3.04 \mathrm{E}+04$ & $5.48 E+08$ & $1.27 E+05$ & $1.49 E+03$ & $0.00 \mathrm{E}+00$ \\
\hline 2035 & $0.00 \mathrm{E}+00$ & $0.00 E+00$ & $1.06 E+04$ & $2.86 \mathrm{E}+07$ & $1.23 E+09$ & $3.11 \mathrm{E}+04$ & $5.60 \mathrm{E}+08$ & $1.31 E+05$ & $4.47 E+03$ & $0.00 \mathrm{E}+00$ \\
\hline 2036 & $0.00 \mathrm{E}+00$ & $0.00 E+00$ & $1.88 E+04$ & $5.08 \mathrm{E}+07$ & $1.25 E+09$ & $2.86 \mathrm{E}+04$ & $5.15 E+08$ & 1.18E+05 & $7.95 \mathrm{E}+03$ & $0.00 \mathrm{E}+00$ \\
\hline 2037 & $0.00 \mathrm{E}+00$ & $0.00 E+00$ & $2.82 E+04$ & $7.62 \mathrm{E}+07$ & $1.28 \mathrm{E}+09$ & $2.91 E+04$ & $5.25 E+08$ & $1.21 E+05$ & 1.19E+04 & $0.00 \mathrm{E}+00$ \\
\hline 2038 & $0.00 \mathrm{E}+00$ & $0.00 E+00$ & $3.76 E+04$ & $1.02 E+08$ & $1.30 E+09$ & $3.10 \mathrm{E}+04$ & $5.57 E+08$ & $1.30 E+05$ & $1.59 \mathrm{E}+04$ & $0.00 \mathrm{E}+00$ \\
\hline 2039 & $0.00 E+00$ & $0.00 E+00$ & $4.94 E+04$ & $1.33 E+08$ & $1.33 E+09$ & $3.14 \mathrm{E}+04$ & $5.65 E+08$ & 1.33E+05 & $2.09 E+04$ & $0.00 E+00$ \\
\hline 2040 & $0.00 E+00$ & $0.00 E+00$ & $6.76 \mathrm{E}+04$ & $1.83 E+08$ & $1.38 E+09$ & $3.16 E+04$ & $5.70 E+08$ & $1.34 E+05$ & $2.86 \mathrm{E}+04$ & $0.00 E+00$ \\
\hline 2041 & $0.00 E+00$ & $0.00 \mathrm{E}+00$ & $8.17 \mathrm{E}+04$ & $2.21 \mathrm{E}+08$ & $1.42 E+09$ & $2.94 \mathrm{E}+04$ & $5.28 \mathrm{E}+08$ & $1.22 \mathrm{E}+05$ & $3.46 \mathrm{E}+04$ & $0.00 E+00$ \\
\hline 2042 & $0.00 \mathrm{E}+00$ & $0.00 E+00$ & $8.23 E+04$ & $2.22 \mathrm{E}+08$ & $1.42 E+09$ & $2.94 \mathrm{E}+04$ & $5.29 E+08$ & $1.22 E+05$ & $3.48 E+04$ & $0.00 \mathrm{E}+00$ \\
\hline 2043 & $0.00 E+00$ & $0.00 E+00$ & $8.52 E+04$ & $2.30 E+08$ & $1.43 E+09$ & $2.94 \mathrm{E}+04$ & $5.29 E+08$ & $1.22 E+05$ & $3.60 E+04$ & $0.00 \mathrm{E}+00$ \\
\hline 2044 & $0.00 E+00$ & $0.00 E+00$ & $9.29 \mathrm{E}+04$ & $2.51 E+08$ & $1.45 E+09$ & $2.94 \mathrm{E}+04$ & $5.28 E+08$ & $1.22 E+05$ & $3.93 E+04$ & $0.00 E+00$ \\
\hline 2045 & $0.00 E+00$ & $0.00 E+00$ & $9.88 \mathrm{E}+04$ & $2.67 E+08$ & $1.47 E+09$ & $2.93 E+04$ & $5.27 E+08$ & $1.22 E+05$ & $4.18 E+04$ & $0.00 E+00$ \\
\hline 2046 & $0.00 E+00$ & $0.00 E+00$ & $1.02 E+05$ & $2.75 E+08$ & $1.47 E+09$ & $3.26 \mathrm{E}+04$ & $5.87 E+08$ & $5.84 E+04$ & $4.30 E+04$ & $7.99 E+04$ \\
\hline 2047 & $0.00 E+00$ & $0.00 E+00$ & $1.12 E+05$ & $3.02 E+08$ & $1.50 E+09$ & $3.26 \mathrm{E}+04$ & $5.87 E+08$ & $5.41 E+04$ & $4.72 E+04$ & $8.42 E+04$ \\
\hline 2048 & $0.00 E+00$ & $0.00 E+00$ & $1.29 E+05$ & $3.48 E+08$ & $1.55 E+09$ & $3.26 E+04$ & $5.87 E+08$ & $4.97 E+04$ & $5.44 E+04$ & $8.85 E+04$ \\
\hline 2049 & $0.00 E+00$ & $0.00 E+00$ & $1.41 E+05$ & $3.81 E+08$ & $1.58 E+09$ & $3.26 \mathrm{E}+04$ & $5.87 E+08$ & $4.54 E+04$ & $5.97 E+04$ & $9.29 E+04$ \\
\hline 2050 & $0.00 \mathrm{E}+00$ & $0.00 E+00$ & $1.51 \mathrm{E}+05$ & $4.06 E+08$ & $1.61 E+09$ & $3.26 \mathrm{E}+04$ & $5.87 E+08$ & $4.10 E+04$ & $6.36 \mathrm{E}+04$ & $9.73 E+04$ \\
\hline
\end{tabular}

Figure 9 (cont). Base Case 1: 2000-2050 yearly results for Modules F1-1 through G1. 


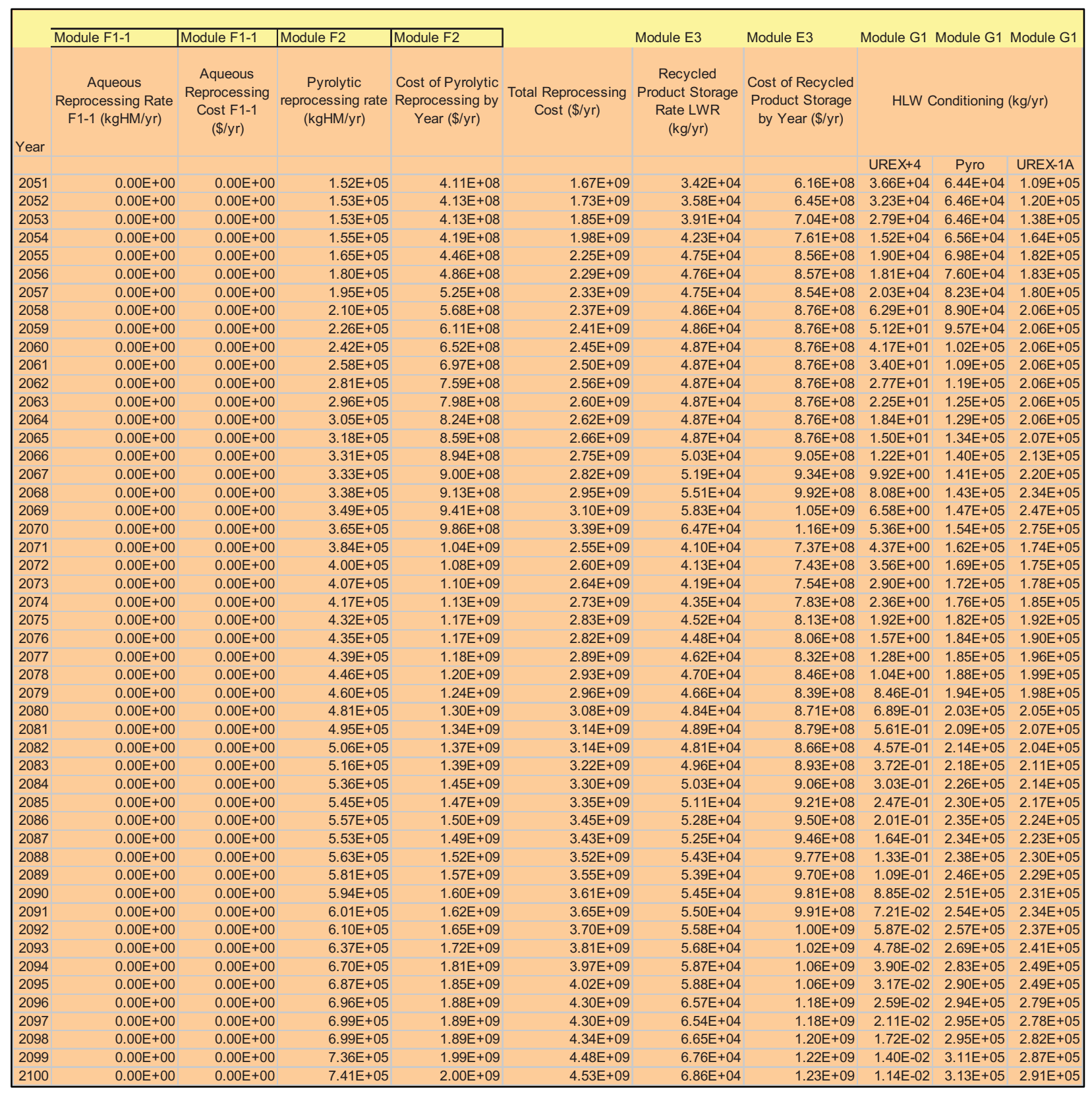

Figure 9 (cont). Base Case 1: 2051-2100 yearly results for Modules F1-1 through G1. 


\begin{tabular}{|c|c|c|c|c|c|c|c|c|c|c|c|c|c|c|}
\hline \multirow{3}{*}{ Year } & \multicolumn{4}{|c|}{ Module G1 Module G1 Module G1 } & \multirow{2}{*}{\multicolumn{3}{|c|}{$\begin{array}{l}\text { Module G3 Module G3 Module G3 } \\
\text { LLW Conditioning (m3/yr) }\end{array}$}} & \multirow{2}{*}{\multicolumn{3}{|c|}{$\begin{array}{l}\text { Module G3 Module G3 Module G3 } \\
\text { Cost of LLW Conditioning ( } \$ / y r)\end{array}$}} & \multirow{3}{*}{$\begin{array}{c}\text { Total LLW } \\
\text { Conditioning } \\
(\$ / y r)\end{array}$} & \multicolumn{3}{|c|}{\begin{tabular}{|l|l|l|} 
Module G4 & Module G4 & Module G4 \\
\end{tabular}} \\
\hline & \multicolumn{3}{|c|}{ Cost of HLW Conditioning (\$/yr) } & \multirow{2}{*}{$\begin{array}{l}\text { Total HLW } \\
\text { Conditioning } \\
\quad(\$ / y r)\end{array}$} & & & & & & & & Cladding ar & ind GTCC Ra & ate $(\mathrm{kg} / \mathrm{yr})$ \\
\hline & UREX+4 & Pyro & UREX-1A & & UREX+4 & Pyro & UREX-1A & UREX+4 & Pyro & UREX-1A & & UREX+4 & Pyro & UREX-1A \\
\hline 2000 & $0.00 \mathrm{E}+00$ & $0.00 \mathrm{E}+00$ & $0.00 \mathrm{E}+00$ & $0.00 \mathrm{E}+00$ & $0.00 \mathrm{E}+00$ & $0.00 \mathrm{E}+00$ & $0.00 \mathrm{E}+00$ & $0.00 \mathrm{E}+00$ & $0.00 \mathrm{E}+00$ & $0.00 \mathrm{E}+00$ & $0.00 \mathrm{E}+00$ & $0.00 \mathrm{E}+00$ & $0.00 E+00$ & $0.00 E+00$ \\
\hline 2001 & $.00 E+00$ & $0.00 \mathrm{E}+00$ & & & & & & & & & & $0.00 \mathrm{E}+00$ & $0.00 E+00$ & $0.00 E+00$ \\
\hline 02 & $0.00 \mathrm{E}+00$ & $0.00 \mathrm{E}+00$ & & & & & & & & & & $0.00 \mathrm{E}+00$ & $0.00 \mathrm{E}+00$ & $0.00 \mathrm{E}+00$ \\
\hline 03 & $0.00 \mathrm{E}+00$ & $0.00 \mathrm{E}+00$ & $0.00 \mathrm{E}+00$ & & $.00 \mathrm{E}+00$ & & & & & & & $0.00 \mathrm{E}+00$ & $0.00 E+00$ & $0.00 \mathrm{E}+00$ \\
\hline & $0.00 E+00$ & $0.00 \mathrm{E}+00$ & & & & & & & & & & $0.00 E+00$ & $0.00 E+00$ & $0.00 E+00$ \\
\hline 05 & $0.00 E+00$ & & & & & & & & & & & $0.00 \mathrm{E}+00$ & $0.00 E+00$ & $00 E+00$ \\
\hline & 0.00 & +00 & & & & & & & & & & $0.00 E+00$ & $0.00 E+00$ & $.00 E+00$ \\
\hline 07 & 0.0 & & & & & & & & & & & $0.00 \mathrm{E}+00$ & & $.00 E+00$ \\
\hline 08 & -00 & & & & & & & & & & & $0 \mathrm{E}+00$ & +00 & $\mathrm{E}+00$ \\
\hline & & & & & & & & & & & & $0 \mathrm{E}+00$ & & $\mathrm{E}+00$ \\
\hline 10 & 00 & & & & & & & & & & & $0.00 \mathrm{E}+00$ & & $E+00$ \\
\hline 11 & 00 & & & & & & & & & & & $0.00 \mathrm{E}+00$ & & $E+00$ \\
\hline 12 & 00 & & & & & & & & & & & $E+00$ & & $E+00$ \\
\hline 13 & 00 & & & & & & & & & & & & & \\
\hline & 0 & & & & & & & & & & & & & \\
\hline & $00 E+00$ & & & & & & & & & & & & & \\
\hline & $13 E+08$ & & & & & & & & & & & & & $0.00 E+00$ \\
\hline 017 & $40 \mathrm{E}+08$ & $0.00 E+00$ & & & & & & & & & & & & $0.00 E+00$ \\
\hline & $23 E+08$ & & & & & & & & & & & & & $0.00 E+00$ \\
\hline 19 & $16 \mathrm{E}+08$ & $.00 E+00$ & $0.00 E+00$ & & & & & & & & & $8.00 E+05$ & $E+00$ & $0.00 E+00$ \\
\hline 20 & $.72 E+08$ & & & & & & & & & & & $1.00 \mathrm{E}+06$ & & $0.00 \mathrm{E}+00$ \\
\hline & & & & & & & & & & & & & & $\mathrm{DE}+00$ \\
\hline & & & & & & & & & & & & & & $\mathrm{DE}+00$ \\
\hline & & & & & & & & & & & & & & $\mathrm{DE}+00$ \\
\hline & & & & & & & & & & & & & & $E+00$ \\
\hline & & & & & & & & & & & & & & $E+00$ \\
\hline & & & & & & & & & & & & & & +00 \\
\hline & & & & & & & & & & & & & & +00 \\
\hline & & & & & & & & & & & & & & \\
\hline & & & & & & & & & & & & 06 & & T \\
\hline & -08 & & & & & & & & & & & 06 & & +00 \\
\hline & & & & & & & & & & & & & & \\
\hline & & & & & & & & & & & & 06 & & \\
\hline & $6.65 \mathrm{E}+08$ & $5.37 \mathrm{E}+06$ & UUETU & & & & & & +02 & & & $1.00 \mathrm{E}+06$ & $E+02$ & $E+00$ \\
\hline & $88 \mathrm{E}+08$ & $8.05 E+06$ & & & & & & & & & & $1.00 E+06$ & $E+02$ & $E+00$ \\
\hline & $7.09 E+08$ & $2.42 \mathrm{E}+07$ & $00 E+00$ & & & & & & & & & $1.00 E+06$ & $=03$ & $E+00$ \\
\hline 36 & $6.36 \mathrm{E}+08$ & $4.30 \mathrm{E}+07$ & $00 \mathrm{E}+00$ & & $43 E+00$ & & & & +02 & 7.17E+02 & & $1.00 E+06$ & $E+03$ & $0 \mathrm{E}+00$ \\
\hline 37 & $6.51 \mathrm{E}+08$ & $6.44 \mathrm{E}+07$ & $00 E+00$ & & $48 E+00$ & & & & $8 \mathrm{E}+02$ & $7.38 \mathrm{E}+02$ & & $1.00 \mathrm{E}+06$ & $E+03$ & $0.00 E+00$ \\
\hline 38 & $7.03 E+08$ & $8.59 \mathrm{E}+07$ & $0.00 E+00$ & $39 E+08$ & $1.61 \mathrm{E}+00$ & $1.61 \mathrm{E}+00$ & $1.61 E+00$ & $8.06 \mathrm{E}+02$ & $8.06 \mathrm{E}+02$ & $8.06 \mathrm{E}+02$ & $42 E+03$ & $1.00 E+06$ & $7.53 E+03$ & $0.00 \mathrm{E}+00$ \\
\hline 2039 & $7.16 \mathrm{E}+08$ & 1.13E+08 & $0.00 \mathrm{E}+00$ & $29 \mathrm{E}+08$ & $1.65 E+00$ & $1.65 \mathrm{E}+00$ & $1.65 \mathrm{E}+00$ & $8.26 \mathrm{E}+02$ & $8.26 \mathrm{E}+02$ & $8.26 \mathrm{E}+02$ & $8 \mathrm{E}+03$ & $1.00 \mathrm{E}+06$ & $9.88 \mathrm{E}+03$ & $0.00 \mathrm{E}+00$ \\
\hline 40 & $7.26 \mathrm{E}+08$ & $1.54 \mathrm{E}+08$ & $0.00 \mathrm{E}+00$ & $\mathrm{DE}+08$ & $1.69 \mathrm{E}+00$ & $1.69 \mathrm{E}+00$ & $9 \mathrm{E}+00$ & $8.44 \mathrm{E}+02$ & $8.44 \mathrm{E}+02$ & $8.44 \mathrm{E}+02$ & & $0 \mathrm{E}+06$ & $1.35 \mathrm{E}+04$ & $0.00 E+00$ \\
\hline 41 & $6.57 E+08$ & $1.87 E+08$ & $0.00 E+00$ & $\mathrm{HE}+08$ & $54 \mathrm{E}+00$ & $1.54 \mathrm{E}+00$ & $E+00$ & $8 \mathrm{E}+02$ & $7.68 E+02$ & $7.68 \mathrm{E}+02$ & $E+03$ & $1.00 E+06$ & $1.63 E+04$ & $0.00 E+00$ \\
\hline 42 & $6.59 \mathrm{E}+08$ & $1.88 \mathrm{E}+08$ & $0.00 \mathrm{E}+00$ & $7 E+08$ & $54 \mathrm{E}+00$ & $1.54 \mathrm{E}+00$ & & $9 \mathrm{E}+02$ & $7.69 E+02$ & $7.69 \mathrm{E}+02$ & & $1.00 \mathrm{E}+06$ & $1.65 E+04$ & $0.00 E+00$ \\
\hline & $6.59 E+08$ & $1.95 E+08$ & $0.00 E+00$ & & $1.54 \mathrm{E}+00$ & $1.54 \mathrm{E}+00$ & & & $7.70 \mathrm{E}+02$ & $7.70 \mathrm{E}+02$ & & $1.00 E+06$ & $1.70 E+04$ & $0.00 E+00$ \\
\hline 044 & $6.59 E+08$ & $2.12 E+08$ & $0.00 E+00$ & $71 \mathrm{E}+08$ & $1.54 \mathrm{E}+00$ & $1.54 \mathrm{E}+00$ & & $7.71 \mathrm{E}+02$ & $7.71 \mathrm{E}+02$ & $7.71 \mathrm{E}+02$ & $1 E+03$ & $1.00 \mathrm{E}+06$ & $1.86 \mathrm{E}+04$ & $0.00 E+00$ \\
\hline & & $2.26 \mathrm{E}+08$ & & & & & & & & & & $1.00 \mathrm{E}+06$ & $1.98 E+04$ & $0.00 E+00$ \\
\hline & $3.16 \mathrm{E}+08$ & $2.32 E+08$ & $4.31 \mathrm{E}+08$ & $79 E+08$ & & & & & $8.92 \mathrm{E}+02$ & & & $4.23 E+05$ & $2.03 E+04$ & $5.77 E+05$ \\
\hline & $2.92 E+08$ & $2.55 E+08$ & $4.55 E+08$ & $1.00 \mathrm{E}+09$ & $1.79 \mathrm{E}+00$ & $1.79 \mathrm{E}+00$ & $1.79 \mathrm{E}+00$ & $8.96 \mathrm{E}+02$ & $8.96 \mathrm{E}+02$ & $8.96 \mathrm{E}+02$ & $2.69 \mathrm{E}+03$ & $3.91 \mathrm{E}+05$ & $2.23 E+04$ & $6.09 E+05$ \\
\hline & $2.69 \mathrm{E}+08$ & $2.94 \mathrm{E}+08$ & $4.78 \mathrm{E}+08$ & $1.04 \mathrm{E}+09$ & $1.81 E+00$ & & & $9.03 E+02$ & $9.03 E+02$ & & & & $2.58 \mathrm{E}+04$ & $6.40 \mathrm{E}+05$ \\
\hline & $2.45 E+08$ & $3.22 E+08$ & $5.02 E+08$ & 1.07E+09 & $1.82 \mathrm{E}+00$ & $1.82 \mathrm{E}+00$ & & $9.09 \mathrm{E}+02$ & $9.09 \mathrm{E}+02$ & $9.09 \mathrm{E}+02$ & & $3.28 \mathrm{E}+05$ & $2.82 E+04$ & $6.72 E+05$ \\
\hline & $2.21 \mathrm{E}+08$ & $3.44 \mathrm{E}+08$ & $5.25 E+08$ & $1.09 E+09$ & $1.82 E+00$ & $1.82 E+00$ & $1.82 \mathrm{E}+00$ & $9.12 \mathrm{E}+02$ & $9.12 E+02$ & $9.12 E+02$ & $2.74 \mathrm{E}+03$ & $2.97 E+05$ & $3.01 E+04$ & $7.03 E+05$ \\
\hline
\end{tabular}

Figure 9 (cont). Base Case 1: 2000-2050 yearly results for Modules G1 through G4. 


\begin{tabular}{|c|c|c|c|c|c|c|c|c|c|c|c|c|c|c|}
\hline \multirow{3}{*}{ 'ear } & \multicolumn{4}{|c|}{ Module G1 Module G1 Module G1 } & \multirow{2}{*}{\multicolumn{3}{|c|}{$\begin{array}{l}\text { Module G3 Module G3 Module G3 } \\
\text { LLW Conditioning (m3/yr) }\end{array}$}} & \multirow{2}{*}{\multicolumn{3}{|c|}{$\begin{array}{l}\text { Module G3 Module G3 Module G3 } \\
\text { Cost of LLW Conditioning ( } \$ / y r)\end{array}$}} & \multirow{3}{*}{$\begin{array}{c}\text { Total LLW } \\
\text { Conditioning } \\
\text { (\$/yr) }\end{array}$} & \multicolumn{3}{|c|}{\begin{tabular}{|l|l|l|l} 
Module G4 & Module G4 & Module G4 \\
\end{tabular}} \\
\hline & \multicolumn{3}{|c|}{ Cost of HLW Conditioning (\$/yr) } & \multirow{2}{*}{$\begin{array}{l}\text { Total HLW } \\
\text { Conditioning } \\
\quad(\$ / y r)\end{array}$} & & & & & & & & \multicolumn{3}{|c|}{ Cladding and GTCC Rate (kg/yr) } \\
\hline & UREX+4 & Pyro & UREX-1A & & UREX+4 & Pyro & UREX-1A & UREX+4 & Pyro & UREX-1A & & UREX+4 & Pyro & UREX-1A \\
\hline 2051 & $1.98 \mathrm{E}+08$ & $3.48 \mathrm{E}+08$ & $5.86 \mathrm{E}+08$ & 1.13E+09 & $1.91 \mathrm{E}+00$ & $1.91 \mathrm{E}+00$ & $1.91 \mathrm{E}+00$ & $9.56 \mathrm{E}+02$ & $9.56 \mathrm{E}+02$ & $9.56 \mathrm{E}+02$ & $2.87 \mathrm{E}+03$ & $2.65 E+05$ & $3.05 E+04$ & $7.85 \mathrm{E}+05$ \\
\hline 2052 & $1.74 \mathrm{E}+08$ & $3.49 E+08$ & $6.47 \mathrm{E}+08$ & & $2.00 \mathrm{E}+00$ & $2.00 \mathrm{E}+00$ & $2.00 \mathrm{E}+00$ & & $9.98 \mathrm{E}+02$ & $9.98 \mathrm{E}+02$ & & $2.33 E+05$ & $3.06 \mathrm{E}+04$ & $8.67 E+05$ \\
\hline 2053 & $1.51 \mathrm{E}+08$ & $3.49 \mathrm{E}+08$ & $7.46 \mathrm{E}+08$ & & $17 \mathrm{E}+00$ & 2.17E+00 & 2.17E+00 & $1.08 \mathrm{E}+03$ & $1.08 \mathrm{E}+03$ & $1.08 \mathrm{E}+03$ & & $2.02 \mathrm{E}+05$ & $3.06 \mathrm{E}+04$ & $9.98 \mathrm{E}+05$ \\
\hline 2054 & $8.22 E+07$ & $3.54 \mathrm{E}+08$ & $8.87 E+08$ & & $33 E+00$ & $2.33 E+00$ & & 1.17E+03 & 1.17E+03 & $1.17 \mathrm{E}+03$ & $0 \mathrm{E}+03$ & $1.13 E+05$ & $3.10 E+04$ & 1.19E+06 \\
\hline 2055 & $1.02 E+08$ & $3.77 \mathrm{E}+08$ & $9.81 E+08$ & $6 E+09$ & $2.59 \mathrm{E}+00$ & $2.59 \mathrm{E}+00$ & $2.59 \mathrm{E}+00$ & $1.30 \mathrm{E}+03$ & $1.30 \mathrm{E}+03$ & 1.30E+03 & $E+03$ & $1.86 \mathrm{E}+05$ & $3.30 E+04$ & $1.31 E+06$ \\
\hline 2056 & $9.76 \mathrm{E}+07$ & $4.11 \mathrm{E}+08$ & $9.88 \mathrm{E}+08$ & $0 \mathrm{E}+09$ & $2.61 \mathrm{E}+00$ & $2.61 \mathrm{E}+00$ & $2.61 \mathrm{E}+00$ & $1.30 \mathrm{E}+03$ & $1.30 \mathrm{E}+03$ & $1.30 \mathrm{E}+03$ & $E+03$ & $1.77 \mathrm{E}+05$ & $3.60 E+04$ & $1.32 E+06$ \\
\hline 2057 & 1.10E+08 & $4.44 \mathrm{E}+08$ & $9.72 E+08$ & & $61 \mathrm{E}+00$ & & $2.61 \mathrm{E}+00$ & & & & & $1.99 \mathrm{E}+05$ & $3.89 E+04$ & $1.30 E+06$ \\
\hline 2058 & $3.40 \mathrm{E}+05$ & $4.80 \mathrm{E}+08$ & $1.11 \mathrm{E}+09$ & +09 & $.70 \mathrm{E}+00$ & $2.70 \mathrm{E}+00$ & & & & & & $4.55 \mathrm{E}+02$ & $4.21 \mathrm{E}+04$ & $1.50 E+06$ \\
\hline 2059 & $2.77 E+05$ & $5.17 \mathrm{E}+08$ & $1.11 \mathrm{E}+09$ & $E+09$ & $2.71 \mathrm{E}+00$ & & & & & & & $3.70 \mathrm{E}+02$ & $4.53 E+04$ & $1.50 \mathrm{E}+06$ \\
\hline 2060 & $2.25 E+05$ & $5.52 E+08$ & $1.11 \mathrm{E}+09$ & & & & & & & & & $3.02 \mathrm{E}+02$ & $4.83 E+04$ & $1.50 \mathrm{E}+06$ \\
\hline 061 & $1.83 \mathrm{E}$ & $5.89 \mathrm{E}+08$ & +09 & & & & & & & & & $2.46 \mathrm{E}+02$ & $E+04$ & $0 \mathrm{E}+06$ \\
\hline 2062 & 1.49E+05 & 6.41 & & & 00 & & & & & & & $E+02$ & $E+04$ & $1.50 \mathrm{E}+06$ \\
\hline 2063 & $1.22 \mathrm{E}$ & 6.75 & 09 & & +00 & & & & & & & $E+02$ & $E+04$ & $1.50 \mathrm{E}+06$ \\
\hline 2064 & $9.92 \mathrm{E}$ & 6.9 & +09 & 09 & +00 & & & & 03 & & & $E+02$ & $E+04$ & $1.50 \mathrm{E}+06$ \\
\hline 665 & $8.08 \mathrm{E}+04$ & $E+08$ & +09 & & +00 & & & & & & & $3 E+02$ & $E+04$ & $1.50 \mathrm{E}+06$ \\
\hline 66 & $6.58 \mathrm{E}+04$ & $7.55 E+08$ & +09 & & $89 E+00$ & $2.89 \mathrm{E}-$ & & & 03 & & & $8.81 \mathrm{E}+01$ & $6.62 E+04$ & $1.55 E+06$ \\
\hline 67 & $5.36 \mathrm{E}+04$ & $7.61 \mathrm{E}+08$ & $E+09$ & 09 & $7 \mathrm{E}+00$ & $2.97 \mathrm{E}$ & 2.97 & 03 & +03 & $1.49 \mathrm{E}$ & & 7.17E+01 & $6.67 \mathrm{E}+04$ & $1.60 \mathrm{E}+06$ \\
\hline 68 & 4. $36 \mathrm{E}+04$ & +08 & $1.26 \mathrm{E}+09$ & 09 & $E+00$ & & & & & & & $E+01$ & +04 & $1.70 \mathrm{E}+06$ \\
\hline 69 & $3.55 \mathrm{E}+04$ & & & & & & & & & & & $E+01$ & +04 & $1.80 \mathrm{E}+06$ \\
\hline 70 & $2.90 \mathrm{E}+04$ & $8.33 E+08$ & $1.48 \mathrm{E}+09$ & & $3.66 \mathrm{E}+00$ & $3.66 \mathrm{E}+00$ & & & & & & $3.88 \mathrm{E}+01$ & $E+04$ & $2.00 E+06$ \\
\hline 071 & $2.36 \mathrm{E}+04$ & $8.76 \mathrm{E}+08$ & $9.39 \mathrm{E}+08$ & & $2.46 \mathrm{E}+00$ & $2.46 \mathrm{E}+00$ & & & & $1.23 E+03$ & & $3.16 \mathrm{E}+01$ & $E+04$ & $1.26 \mathrm{E}+06$ \\
\hline 2072 & $1.92 \mathrm{E}+04$ & $9.12 \mathrm{E}+08$ & $9.46 \mathrm{E}+08$ & & & & & & +03 & & & $2.57 \mathrm{E}+01$ & $E+04$ & $1.27 \mathrm{E}+06$ \\
\hline 2073 & $1.56 \mathrm{E}+04$ & $9.28 \mathrm{E}+08$ & $9.60 \mathrm{E}+08$ & & $2.52 \mathrm{E}+00$ & & & & $=03$ & & & $2.09 \mathrm{E}+01$ & $E+04$ & $1.29 \mathrm{E}+06$ \\
\hline 2074 & 1.27E+04 & $9.52 E+08$ & $9.97 \mathrm{E}+08$ & $5 E+09$ & $2.62 \mathrm{E}+00$ & $2.62 E+00$ & $2.62 \mathrm{E}+00$ & $=03$ & $1.31 \mathrm{E}+03$ & $1.31 E+03$ & $=03$ & $1.71 \mathrm{E}+01$ & $8.35 E+04$ & 1.34E+06 \\
\hline 2075 & $1.04 \mathrm{E}+04$ & $9.85 \mathrm{E}+08$ & $1.04 \mathrm{E}+09$ & $2 E+09$ & $2.71 \mathrm{E}+00$ & $2.71 \mathrm{E}+00$ & & +03 & $1.36 \mathrm{E}+03$ & $1.36 \mathrm{E}+03$ & +03 & $1.39 \mathrm{E}+01$ & $8.63 E+04$ & 1.39E+06 \\
\hline 2076 & $8.45 E+03$ & $9.93 E+08$ & 1.03E+09 & $2 E+09$ & & & & & $=03$ & & & $1.13 E+01$ & $E+04$ & 1.37E+06 \\
\hline 077 & $6.89 \mathrm{E}+03$ & $1.00 \mathrm{E}+09$ & $1.06 \mathrm{E}+09$ & $\mathrm{E}+09$ & & & & & & & & $9.22 \mathrm{E}+00$ & $E+04$ & $1.42 \mathrm{E}+06$ \\
\hline 2078 & $5.61 \mathrm{E}+03$ & $1.02 E+09$ & $1.08 \mathrm{E}+09$ & $E+09$ & $2.82 \mathrm{E}+00$ & $2.82 E+00$ & & & $=03$ & & & $7.51 \mathrm{E}+00$ & $E+04$ & $1.44 \mathrm{E}+06$ \\
\hline 579 & $4.57 \mathrm{E}+03$ & & & & & & & & & & & $E+00$ & $E+04$ & $1.43 E+06$ \\
\hline 80 & & & & & & & & & & & & $E+00$ & +04 & $9 \mathrm{E}+06$ \\
\hline 2081 & & & & & & & & & & & & 00 & & $E+06$ \\
\hline 82 & & & & & & & & & & & & 00 & & +06 \\
\hline 83 & & & & & & & & & & & & & & +06 \\
\hline & & & & & & & & & & & & & & +06 \\
\hline 85 & & & & & & & & & & & & +00 & & $=+06$ \\
\hline 86 & $.09 E+03$ & & & & & & & & & & & & & 1.62E+06 \\
\hline 87 & $8.85 E+02$ & $1.26 \mathrm{E}+09$ & $1.20 \mathrm{E}+09$ & & $20 \mathrm{E}+00$ & $E+00$ & & & $=+03$ & & & $=+00$ & +05 & $1.61 \mathrm{E}+06$ \\
\hline 88 & $7.21 \mathrm{E}+02$ & $1.28 \mathrm{E}+09$ & $1.24 \mathrm{E}+09$ & & $30 E+00$ & $3.30 \mathrm{E}+00$ & $3.30 \mathrm{E}+00$ & +03 & $5 E+03$ & $1.65 E+03$ & & $E-01$ & $E+05$ & $1.67 \mathrm{E}+06$ \\
\hline 89 & $5.87 \mathrm{E}+02$ & & & & & $3.29 \mathrm{E}+00$ & & & & $1.65 \mathrm{E}+$ & & $E-01$ & $E+05$ & $1.65 E+06$ \\
\hline 990 & $4.78 \mathrm{E}+02$ & 1.35E+09 & $1.25 \mathrm{E}+09$ & $60 \mathrm{E}+09$ & $3.34 \mathrm{E}+00$ & 3. $34 \mathrm{E}+00$ & $3.34 \mathrm{E}+00$ & 1.67E+03 & 1.67E+03 & 1.67E+03 & $5.00 \mathrm{E}+03$ & $6.40 \mathrm{E}-01$ & $1.19 \mathrm{E}+05$ & 1.67E+06 \\
\hline 091 & $3.89 \mathrm{E}+02$ & 1.37E+09 & $1.26 \mathrm{E}+09$ & $63 E+09$ & 3. $37 \mathrm{E}+00$ & 3.37E+00 & $3.37 \mathrm{E}+00$ & $1.68 \mathrm{E}+03$ & $1.68 \mathrm{E}+03$ & $1.68 \mathrm{E}+03$ & $.05 E+03$ & $5.22 \mathrm{E}-01$ & $1.20 \mathrm{E}+05$ & $1.69 \mathrm{E}+06$ \\
\hline 2092 & $3.17 \mathrm{E}+02$ & 1.39E+09 & $1.28 \mathrm{E}+09$ & $67 E+09$ & $3.41 \mathrm{E}+00$ & $3.41 \mathrm{E}+00$ & $3.41 \mathrm{E}+00$ & $1.71 \mathrm{E}+03$ & $1.71 \mathrm{E}+03$ & $1.71 \mathrm{E}+03$ & $12 \mathrm{E}+03$ & 4.25E-01 & $1.22 \mathrm{E}+05$ & $1.71 \mathrm{E}+06$ \\
\hline 2093 & $2.58 \mathrm{E}+02$ & $1.45 \mathrm{E}+09$ & 1.30E+09 & $2.76 \mathrm{E}+09$ & $3.49 E+00$ & $3.49 E+00$ & $3.49 \mathrm{E}+00$ & $1.75 E+03$ & $1.75 E+03$ & $1.75 E+03$ & $5.24 \mathrm{E}+03$ & 3.46E-01 & 1.27E+05 & $1.74 \mathrm{E}+06$ \\
\hline 2094 & 2.10E+02 & $1.53 E+09$ & 1.35E+09 & $2.87 E+09$ & $3.62 E+00$ & $3.62 E+00$ & $3.62 E+00$ & $1.81 \mathrm{E}+03$ & $1.81 \mathrm{E}+03$ & $1.81 E+03$ & $5.43 E+03$ & 2.82E-01 & $1.34 \mathrm{E}+05$ & $1.80 \mathrm{E}+06$ \\
\hline 2095 & $1.71 \mathrm{E}+02$ & $1.57 \mathrm{E}+09$ & 1.35E+09 & $2.91 \mathrm{E}+09$ & $3.63 E+00$ & $3.63 E+00$ & $3.63 \mathrm{E}+00$ & $1.82 E+03$ & $1.82 E+03$ & $1.82 \mathrm{E}+03$ & $5.45 E+03$ & 2.30E-01 & $1.37 \mathrm{E}+05$ & $1.80 \mathrm{E}+06$ \\
\hline 2096 & 1.40E+02 & 1.59E+09 & $1.50 \mathrm{E}+09$ & $3.09 E+09$ & $4.00 \mathrm{E}+00$ & $4.00 \mathrm{E}+00$ & $4.00 \mathrm{E}+00$ & $2.00 \mathrm{E}+03$ & $2.00 \mathrm{E}+03$ & $2.00 \mathrm{E}+03$ & $6.00 \mathrm{E}+03$ & 1.87E-01 & $1.39 \mathrm{E}+05$ & $2.02 E+06$ \\
\hline 2097 & 1.14E+02 & 1.59E+09 & $1.50 E+09$ & $3.09 E+09$ & $3.99 \mathrm{E}+00$ & $3.99 \mathrm{E}+00$ & $3.99 E+00$ & $1.99 E+03$ & $1.99 \mathrm{E}+03$ & 1.99E+03 & $5.98 \mathrm{E}+03$ & 1.52E-01 & $1.40 E+05$ & $2.01 E+06$ \\
\hline 098 & $9.26 \mathrm{E}+01$ & 1.59E+09 & $1.53 E+09$ & $3.12 E+09$ & $4.05 E+00$ & $4.05 E+00$ & $4.05 E+00$ & $2.02 E+03$ & $2.02 E+03$ & $2.02 E+03$ & $6.07 E+03$ & 1.24E-01 & $1.40 \mathrm{E}+05$ & $2.04 E+06$ \\
\hline 2099 & 7.54E+01 & $1.68 \mathrm{E}+09$ & $1.55 \mathrm{E}+09$ & $3.23 E+09$ & $4.13 E+00$ & $4.13 E+00$ & $4.13 E+00$ & $2.07 E+03$ & $2.07 \mathrm{E}+03$ & $2.07 E+03$ & $6.20 \mathrm{E}+03$ & $1.01 \mathrm{E}-01$ & $1.47 \mathrm{E}+05$ & $2.07 E+06$ \\
\hline 2100 & $6.14 \mathrm{E}+01$ & 1. $69 \mathrm{E}+09$ & $1.57 \mathrm{E}+09$ & $3.26 \mathrm{E}+09$ & $4.19 \mathrm{E}+00$ & 4. $19 \mathrm{E}+00$ & 4. $19 \mathrm{E}+00$ & $2.09 E+03$ & $2.09 E+03$ & $2.09 E+03$ & $6.28 \mathrm{E}+03$ & 8.23E-02 & $1.48 \mathrm{E}+05$ & 2. $10 \mathrm{E}+06$ \\
\hline
\end{tabular}

Figure 9 (cont). Base Case 1: 2051-2100 yearly results for Modules G1 through G4. 


\begin{tabular}{|c|c|c|c|c|c|c|c|c|c|c|c|c|c|c|}
\hline \multirow{3}{*}{ Year } & \multicolumn{3}{|c|}{\begin{tabular}{|l|l|l|} 
Module G4 & Module G4 & Module G4 \\
\end{tabular}} & & Module $\mathrm{J}$ & Module J & Module J & & \multicolumn{3}{|l|}{\begin{tabular}{|l|l} 
Module K2 \\
\end{tabular}} & \multicolumn{3}{|c|}{\begin{tabular}{|l|l|} 
Module K2 & Module K2
\end{tabular}} \\
\hline & \multicolumn{3}{|c|}{ Cost of Cladding and GTCC (\$/yr) } & $\begin{array}{l}\text { Total } \\
\text { Cladding \& }\end{array}$ & \multicolumn{3}{|c|}{$\begin{array}{l}\text { Cost of Near Surface Disposal } \\
\qquad(\$ / y r)\end{array}$} & $\begin{array}{l}\text { Total Near } \\
\text { Surface Displ }\end{array}$ & \multicolumn{3}{|c|}{ REPU Rate (kg U/yr) } & \multicolumn{3}{|c|}{ Cost of REPU (\$/yr) } \\
\hline & & & & & & & & & & & & & & \\
\hline & & & & & & & & & & & & & & \\
\hline & & & & & +00 & E+ & +00 & $=+00$ & & & & $00 \mathrm{E}+00$ & $0.00 \mathrm{E}+0$ & $0.00 \mathrm{E}+00$ \\
\hline & $0.00 \mathrm{E}+00$ & $0.00 E+00$ & $0.00 \mathrm{E}+00$ & $.00 E+00$ & $0.00 \mathrm{E}+00$ & $0.00 \mathrm{E}+00$ & $0.00 \mathrm{E}+00$ & $10 \mathrm{E}+00$ & $0.00 E+00$ & $0.00 \mathrm{E}+00$ & $0.00 \mathrm{E}+00$ & $0.00 \mathrm{E}+00$ & $0.00 E+00$ & $0.00 \mathrm{E}+00$ \\
\hline 02 & $0.00 \mathrm{E}+00$ & $0.00 \mathrm{E}+00$ & $0.00 \mathrm{E}+00$ & $.00 \mathrm{E}+00$ & $0.00 \mathrm{E}+00$ & $0.00 E+00$ & $0.00 \mathrm{E}+00$ & $0 \mathrm{E}+00$ & $0.00 \mathrm{E}+00$ & $0.00 \mathrm{E}+00$ & $0.00 \mathrm{E}+00$ & $0.00 \mathrm{E}+00$ & $0.00 E+00$ & $0.00 \mathrm{E}+00$ \\
\hline 03 & $0.00 \mathrm{E}+00$ & $0.00 \mathrm{E}+00$ & $0.00 \mathrm{E}+00$ & $0.00 E+00$ & $0.00 \mathrm{E}+00$ & $0.00 E+00$ & $0.00 \mathrm{E}+00$ & $0 \mathrm{E}+00$ & $0.00 \mathrm{E}+00$ & $0.00 \mathrm{E}+00$ & $0.00 \mathrm{E}+00$ & $0.00 E+00$ & $0.00 \mathrm{E}+00$ & $0.00 \mathrm{E}+00$ \\
\hline 04 & $0.00 \mathrm{E}+00$ & $0.00 \mathrm{E}+00$ & $0.00 \mathrm{E}+00$ & $.00 \mathrm{E}+00$ & $0.00 \mathrm{E}+00$ & $0.00 E+00$ & $0.00 \mathrm{E}+00$ & $0 \mathrm{E}+00$ & $0.00 E+00$ & $0.00 \mathrm{E}+00$ & $0.00 \mathrm{E}+00$ & $0.00 \mathrm{E}+00$ & $0.00 \mathrm{E}+00$ & $0.00 \mathrm{E}+00$ \\
\hline 05 & $0.00 \mathrm{E}+00$ & $0.00 E+00$ & $0.00 E+00$ & & $0.00 \mathrm{E}+00$ & $0.00 E+00$ & $0.00 \mathrm{E}+00$ & & $0.00 \mathrm{E}+00$ & $0.00 \mathrm{E}+00$ & $0.00 \mathrm{E}+00$ & $0.00 E+00$ & $0.00 E+00$ & $0.00 \mathrm{E}+00$ \\
\hline 006 & $0.00 \mathrm{E}+00$ & $0.00 \mathrm{E}+00$ & $0.00 E+00$ & & $0.00 \mathrm{E}+00$ & $0.00 E+00$ & $0.00 \mathrm{E}+00$ & & $0.00 \mathrm{E}+00$ & $0.00 \mathrm{E}+00$ & $0.00 \mathrm{E}+00$ & $0.00 E+00$ & $0.00 E+00$ & $0.00 \mathrm{E}+00$ \\
\hline 007 & $0.00 \mathrm{E}+00$ & $0.00 E+00$ & $0.00 \mathrm{E}+00$ & & $0.00 \mathrm{E}+00$ & $0.00 E+00$ & $0.00 \mathrm{E}+00$ & & $0.00 \mathrm{E}+00$ & +00 & $0.00 \mathrm{E}+00$ & $0.00 \mathrm{E}+00$ & $0.00 E+00$ & $0.00 \mathrm{E}+00$ \\
\hline 08 & $0.00 \mathrm{E}+00$ & $0.00 \mathrm{E}+00$ & $0.00 \mathrm{E}+00$ & & $0.00 \mathrm{E}+00$ & $0.00 \mathrm{E}+00$ & $0.00 \mathrm{E}+00$ & & $0.00 \mathrm{E}+00$ & +00 & $0.00 \mathrm{E}+00$ & $0.00 \mathrm{E}+00$ & $0.00 \mathrm{E}+00$ & $0.00 \mathrm{E}+00$ \\
\hline 09 & $0.00 \mathrm{E}+00$ & +00 & $0.00 \mathrm{E}+00$ & & $0.00 \mathrm{E}+00$ & $0.00 \mathrm{E}+00$ & $0.00 \mathrm{E}+00$ & & $0.00 \mathrm{E}+00$ & +00 & $0 \mathrm{E}+00$ & $\mathrm{E}+00$ & $.00 \mathrm{E}+00$ & $0.00 \mathrm{E}+00$ \\
\hline 10 & +00 & +00 & $0.00 \mathrm{E}+00$ & & $0.00 \mathrm{E}+00$ & $0.00 \mathrm{E}+00$ & $\mathrm{E}+00$ & & $E+00$ & & $\mathrm{E}+00$ & $E+00$ & $0 \mathrm{E}+00$ & $0 \mathrm{E}+00$ \\
\hline 11 & $0.00 \mathrm{E}+00$ & +00 & $0.00 \mathrm{E}+00$ & & $0.00 \mathrm{E}+00$ & $0.00 \mathrm{E}+00$ & $0.00 \mathrm{E}+00$ & & $0.00 \mathrm{E}+00$ & +00 & $0 \mathrm{E}+00$ & $\mathrm{OE}+00$ & $0.00 \mathrm{E}+00$ & $0.00 \mathrm{E}+00$ \\
\hline 12 & $0.00 E+00$ & +00 & $0.00 E+00$ & & $0.00 \mathrm{E}+00$ & $0.00 E+00$ & $0.00 E+00$ & & $0.00 \mathrm{E}+00$ & +00 & $0 \mathrm{E}+00$ & $0.00 E+00$ & $0.00 E+00$ & $0.00 \mathrm{E}+00$ \\
\hline 13 & +00 & +00 & $0.00 \mathrm{E}+00$ & & $0.00 \mathrm{E}+00$ & $0.00 E+00$ & $0.00 E+00$ & & $E+00$ & & $E+00$ & $E+00$ & $0.00 \mathrm{E}+00$ & $\mathrm{DE}+00$ \\
\hline 14 & $0.00 \mathrm{E}+00$ & $0.00 \mathrm{E}+00$ & $0.00 \mathrm{E}+00$ & & $0.00 \mathrm{E}+00$ & $0.00 \mathrm{E}+00$ & $0.00 \mathrm{E}+00$ & & $0.00 \mathrm{E}+00$ & 00 & $\mathrm{DE}+00$ & $0 \mathrm{E}+00$ & $0.00 \mathrm{E}+00$ & $0.00 \mathrm{E}+00$ \\
\hline 015 & $0.00 E+00$ & $0.00 E+00$ & $0.00 \mathrm{E}+00$ & & $0.00 \mathrm{E}+00$ & $0.00 \mathrm{E}+00$ & $0.00 \mathrm{E}+00$ & & $E+00$ & +00 & $0.00 \mathrm{E}+00$ & $E+00$ & $0.00 E+00$ & $0.00 E+00$ \\
\hline 016 & $2.97 E+08$ & $0.00 E+00$ & $0.00 E+00$ & & $8.76 \mathrm{E}+02$ & $8.76 \mathrm{E}+02$ & $8.76 \mathrm{E}+02$ & & $1.03 E+06$ & $=+00$ & $0.00 \mathrm{E}+00$ & $\mathrm{E}+07$ & $0.00 E+00$ & $0.00 E+00$ \\
\hline 017 & $3.24 \mathrm{E}+08$ & $0.00 \mathrm{E}+00$ & $0.00 \mathrm{E}+00$ & & $9.50 \mathrm{E}+02$ & $9.50 \mathrm{E}+02$ & $9.50 \mathrm{E}+02$ & & 1.12E+06 & $E+00$ & $0.00 E+00$ & $1.35 \mathrm{E}+07$ & $0.00 \mathrm{E}+00$ & $0.00 \mathrm{E}+00$ \\
\hline 18 & $3.78 \mathrm{E}+08$ & $0.00 \mathrm{E}+00$ & $0.00 \mathrm{E}+00$ & & 1.19E+03 & 1.19E+03 & 1.19E+03 & & $1.30 \mathrm{E}+06$ & $E+00$ & $0.00 \mathrm{E}+00$ & $1.56 \mathrm{E}+07$ & $0.00 E+00$ & $0.00 \mathrm{E}+00$ \\
\hline 19 & $4.32 E+08$ & $0.00 E+00$ & $0.00 \mathrm{E}+00$ & $E+08$ & $1.46 \mathrm{E}+03$ & $1.46 \mathrm{E}+03$ & $1.46 E+03$ & $E+03$ & $1.48 \mathrm{E}+06$ & $0.00 \mathrm{E}+00$ & $0.00 \mathrm{E}+00$ & $1.78 \mathrm{E}+07$ & $0.00 E+00$ & $0.00 \mathrm{E}+00$ \\
\hline 20 & $5.40 \mathrm{E}+08$ & $0.00 \mathrm{E}+00$ & $0.00 \mathrm{E}+00$ & $40 E+08$ & $1.90 \mathrm{E}+03$ & $1.90 \mathrm{E}+03$ & $1.90 \mathrm{E}+03$ & $E+03$ & $1.85 E+06$ & $0.00 \mathrm{E}+00$ & $0.00 \mathrm{E}+00$ & $2.21 \mathrm{E}+07$ & $0.00 \mathrm{E}+00$ & $0.00 \mathrm{E}+00$ \\
\hline 2021 & $5.40 \mathrm{E}+08$ & $0.00 \mathrm{E}+00$ & $0.00 \mathrm{E}+00$ & $0 \mathrm{E}+08$ & $1.61 \mathrm{E}+03$ & $1.61 \mathrm{E}+03$ & $1.61 \mathrm{E}+03$ & $E+03$ & 1.87E+06 & $0.00 \mathrm{E}+00$ & $0.00 \mathrm{E}+00$ & $2.24 \mathrm{E}+07$ & $0.00 \mathrm{E}+00$ & $0.00 \mathrm{E}+00$ \\
\hline 2022 & $5.40 \mathrm{E}+08$ & $0.00 \mathrm{E}+00$ & $0.00 \mathrm{E}+00$ & $40 E+08$ & $1.67 \mathrm{E}+03$ & $1.67 \mathrm{E}+03$ & $1.67 E+03$ & $E+03$ & $1.86 \mathrm{E}+06$ & $0.00 \mathrm{E}+00$ & $0.00 E+00$ & $2.23 \mathrm{E}+07$ & $0.00 \mathrm{E}+00$ & $0.00 E+00$ \\
\hline 2023 & $5.40 \mathrm{E}+08$ & $0.00 E+00$ & $0.00 \mathrm{E}+00$ & $40 \mathrm{E}+08$ & $1.75 \mathrm{E}+03$ & $1.75 E+03$ & $1.75 E+03$ & +03 & $1.86 \mathrm{E}+06$ & $=00$ & $0.00 \mathrm{E}+00$ & $2.23 \mathrm{E}+07$ & $0.00 \mathrm{E}+00$ & $0.00 \mathrm{E}+00$ \\
\hline 2024 & $5.40 \mathrm{E}+08$ & $0.00 E+00$ & $0.00 \mathrm{E}+00$ & $40 \mathrm{E}+08$ & $1.82 \mathrm{E}+03$ & $1.82 \mathrm{E}+03$ & $1.82 E+03$ & $E+03$ & $1.85 \mathrm{E}+06$ & $0.00 E+00$ & $0.00 \mathrm{E}+00$ & $2 E+07$ & $0.00 \mathrm{E}+00$ & $0.00 \mathrm{E}+00$ \\
\hline 2025 & $5.40 \mathrm{E}+08$ & $0.00 \mathrm{E}+00$ & $0.00 \mathrm{E}+00$ & $40 E+08$ & $1.89 \mathrm{E}+03$ & $1.89 \mathrm{E}+03$ & $1.89 \mathrm{E}+03$ & $E+03$ & $E+06$ & $0.00 \mathrm{E}+00$ & $0.00 \mathrm{E}+00$ & $1 \mathrm{E}+07$ & $0.00 \mathrm{E}+00$ & $0.00 \mathrm{E}+00$ \\
\hline 2026 & $5.40 \mathrm{E}+08$ & $2.54 \mathrm{E}+05$ & $0.00 \mathrm{E}+00$ & $40 E+08$ & $1.65 \mathrm{E}+03$ & $1.65 E+03$ & $1.65 \mathrm{E}+03$ & & +06 & $=03$ & $E+00$ & $E+07$ & 1.36E+05 & $0.00 \mathrm{E}+00$ \\
\hline 2027 & $5.40 \mathrm{E}+08$ & $2.54 \mathrm{E}+05$ & $0.00 \mathrm{E}+00$ & $40 E+08$ & $1.73 E+03$ & $1.73 E+03$ & $1.73 E+03$ & $E+03$ & $1.86 \mathrm{E}+06$ & 1.47E+03 & $0.00 \mathrm{E}+00$ & $E+07$ & 1.36E+05 & $0.00 \mathrm{E}+00$ \\
\hline 2028 & $5.40 \mathrm{E}+08$ & $2.54 \mathrm{E}+05$ & $0.00 \mathrm{E}+00$ & $40 \mathrm{E}+08$ & $1.82 \mathrm{E}+03$ & $1.82 E+03$ & $1.82 \mathrm{E}+03$ & $E+03$ & $E+06$ & 1.47E+03 & $0.00 \mathrm{E}+00$ & $2 E+07$ & $1.36 \mathrm{E}+05$ & $0.00 E+00$ \\
\hline 2029 & $5.40 \mathrm{E}+08$ & $2.54 \mathrm{E}+05$ & $0.00 \mathrm{E}+00$ & $40 \mathrm{E}+08$ & $1.88 \mathrm{E}+03$ & $1.88 \mathrm{E}+03$ & $1.88 \mathrm{E}+03$ & $E+03$ & $5 \mathrm{E}+06$ & $E+03$ & $0.00 \mathrm{E}+00$ & $2 \mathrm{E}+07$ & 1.36E+05 & $0.00 E+00$ \\
\hline 2030 & $5.40 \mathrm{E}+08$ & $2.54 \mathrm{E}+05$ & $0.00 \mathrm{E}+00$ & $40 E+08$ & $1.94 \mathrm{E}+03$ & $1.94 \mathrm{E}+03$ & $1.94 \mathrm{E}+03$ & $E+03$ & $1.84 \mathrm{E}+06$ & 1.47E+03 & $0.00 \mathrm{E}+00$ & $E+07$ & 1.36E+05 & $0.00 E+00$ \\
\hline 2031 & $5.40 \mathrm{E}+08$ & $2.54 \mathrm{E}+05$ & $0.00 \mathrm{E}+00$ & $40 E+08$ & $1.70 \mathrm{E}+03$ & $1.70 E+03$ & 1.70E+03 & $E+03$ & 1.86E+06 & $1.47 \mathrm{E}+03$ & $0.00 \mathrm{E}+00$ & $3 E+07$ & 1.36E+05 & $0.00 E+00$ \\
\hline 2032 & $5.40 \mathrm{E}+08$ & $2.54 \mathrm{E}+05$ & $0.00 \mathrm{E}+00$ & $.40 \mathrm{E}+08$ & 1.79E +03 & $1.79 E+03$ & $1.79 \mathrm{E}+03$ & $6 \mathrm{E}+03$ & 1.85E+06 & $1.46 \mathrm{E}+03$ & $0.00 \mathrm{E}+00$ & $2.22 \mathrm{E}+07$ & 1.36E+05 & $0.00 E+00$ \\
\hline 2033 & $5.40 \mathrm{E}+08$ & $2.54 \mathrm{E}+05$ & $0.00 \mathrm{E}+00$ & $40 E+08$ & $1.86 \mathrm{E}+03$ & $1.86 \mathrm{E}+03$ & $1.86 \mathrm{E}+03$ & $9 \mathrm{E}+03$ & $1.85 E+06$ & $1.46 \mathrm{E}+03$ & $0.00 \mathrm{E}+00$ & $2.22 \mathrm{E}+07$ & $1.36 \mathrm{E}+05$ & $0.00 E+00$ \\
\hline 34 & $5.40 \mathrm{E}+08$ & $E+05$ & $0.00 \mathrm{E}+00$ & $E+08$ & $1.93 E+03$ & $1.93 E+03$ & $1.93 E+03$ & & $1.84 \mathrm{E}+06$ & $2.20 \mathrm{E}+03$ & $0.00 \mathrm{E}+00$ & $2.21 \mathrm{E}+07$ & $2.04 \mathrm{E}+05$ & $0.00 \mathrm{E}+00$ \\
\hline 35 & $5.40 E+08$ & 1.14E+06 & $0.00 E+00$ & & $2.00 \mathrm{E}+03$ & $2.00 \mathrm{E}+03$ & $2.00 \mathrm{E}+03$ & +03 & $1.84 \mathrm{E}+06$ & $6.59 \mathrm{E}+03$ & $0.00 \mathrm{E}+00$ & $2.21 \mathrm{E}+07$ & $6.13 E+05$ & $0.00 E+00$ \\
\hline 36 & $5.40 E+08$ & +06 & $E+00$ & & $1.79 \mathrm{E}+03$ & $1.79 \mathrm{E}+03$ & $1.79 E+03$ & & $E+06$ & +04 & $0 E+00$ & $2 E+07$ & $1.09 E+06$ & $0 \mathrm{E}+00$ \\
\hline 37 & $5.40 \mathrm{E}$ & $=06$ & $E+00$ & & $1.84 \mathrm{E}+03$ & $1.84 E+03$ & $1.84 \mathrm{E}+03$ & & $E+06$ & +04 & $\mathrm{DE}+00$ & $E+07$ & $4 \mathrm{E}+06$ & $0.00 \mathrm{E}+00$ \\
\hline 338 & $5.40 E+08$ & $.06 E+06$ & $0.00 E+00$ & & $2.02 E+03$ & $2.02 E+03$ & $2.02 E+03$ & & 1.84E+06 & +04 & $0 \mathrm{E}+00$ & $E+07$ & $8 E+06$ & $0.00 E+00$ \\
\hline 039 & $5.40 \mathrm{E}+08$ & $E+06$ & $E+00$ & & $2.07 E+03$ & $2.07 \mathrm{E}+03$ & $2.07 E+03$ & & +06 & & $E+00$ & $E+07$ & $6 \mathrm{E}+06$ & $E+00$ \\
\hline 2040 & $5.40 \mathrm{E}+08$ & $E+06$ & $E+00$ & & $2.11 \mathrm{E}+03$ & $2.11 \mathrm{E}+03$ & $E+03$ & & +06 & & $E+00$ & $E+07$ & $3.92 E+06$ & $0.00 \mathrm{E}+00$ \\
\hline 2041 & $5.40 \mathrm{E}+08$ & $8.83 E+06$ & $0.00 E+00$ & $E+08$ & $1.92 \mathrm{E}+03$ & $1.92 \mathrm{E}+03$ & $1.92 \mathrm{E}+03$ & $E+03$ & $E+06$ & $E+04$ & $0 \mathrm{E}+00$ & $2.22 \mathrm{E}+07$ & $4.74 \mathrm{E}+06$ & $0.00 E+00$ \\
\hline 2042 & $5.40 \mathrm{E}+08$ & $8.89 \mathrm{E}+06$ & $E+00$ & $E+08$ & $1.92 \mathrm{E}+03$ & $1.92 \mathrm{E}+03$ & $1.92 \mathrm{E}+03$ & & $E+06$ & $5.13 E+04$ & $\mathrm{E}+00$ & $2.22 \mathrm{E}+07$ & 4.77E+06 & $0.00 \mathrm{E}+00$ \\
\hline 2043 & $5.40 \mathrm{E}+08$ & $9.21 \mathrm{E}+06$ & $0.00 \mathrm{E}+00$ & $E+08$ & $1.92 \mathrm{E}+03$ & $1.92 \mathrm{E}+03$ & $1.92 \mathrm{E}+03$ & & $E+06$ & $5.31 \mathrm{E}+04$ & $E+00$ & $2.22 \mathrm{E}+07$ & $4.94 \mathrm{E}+06$ & $0.00 \mathrm{E}+00$ \\
\hline 2044 & $5.40 \mathrm{E}+08$ & $1.00 \mathrm{E}+07$ & $0.00 \mathrm{E}+00$ & $5.50 \mathrm{E}+08$ & $1.93 \mathrm{E}+03$ & $1.93 E+03$ & $1.93 E+03$ & $9 \mathrm{E}+03$ & $1.85 \mathrm{E}+06$ & $5.79 \mathrm{E}+04$ & $0.00 \mathrm{E}+00$ & $2.22 \mathrm{E}+07$ & $5.38 \mathrm{E}+06$ & $0.00 \mathrm{E}+00$ \\
\hline 2045 & $5.40 \mathrm{E}+08$ & 1.07E+07 & $0.00 \mathrm{E}+00$ & $5.51 \mathrm{E}+08$ & $1.93 E+03$ & $1.93 E+03$ & $1.93 E+03$ & $78 \mathrm{E}+03$ & $1.85 E+06$ & $6.16 E+04$ & $0.00 \mathrm{E}+00$ & $2.22 \mathrm{E}+07$ & $5.73 E+06$ & $0.00 \mathrm{E}+00$ \\
\hline 2046 & $2.28 \mathrm{E}+08$ & $1.10 \mathrm{E}+07$ & $3.12 E+08$ & $5.51 \mathrm{E}+08$ & $2.23 E+03$ & $2.23 E+03$ & $2.23 E+03$ & $69 E+03$ & $7.73 E+05$ & $6.34 \mathrm{E}+04$ & 1.06E+06 & $9.27 E+06$ & $5.90 \mathrm{E}+06$ & 1.27E+07 \\
\hline 2047 & $2.11 \mathrm{E}+08$ & $1.21 \mathrm{E}+07$ & $3.29 E+08$ & $5.52 E+08$ & $2.24 \mathrm{E}+03$ & $2.24 \mathrm{E}+03$ & $2.24 \mathrm{E}+03$ & $.72 E+03$ & 7.15E+05 & $6.96 \mathrm{E}+04$ & 1.11E+06 & $8.59 E+06$ & $6.47 E+06$ & $1.34 \mathrm{E}+07$ \\
\hline 2048 & $1.94 \mathrm{E}+08$ & 1.39E+07 & $3.46 \mathrm{E}+08$ & $5.54 \mathrm{E}+08$ & $2.26 \mathrm{E}+03$ & $2.26 \mathrm{E}+03$ & $2.26 \mathrm{E}+03$ & $6.78 \mathrm{E}+03$ & $6.58 \mathrm{E}+05$ & $8.02 E+04$ & 1.17E+06 & $7.90 \mathrm{E}+06$ & $7.46 \mathrm{E}+06$ & $1.41 E+07$ \\
\hline 2049 & 1.77E+08 & $1.52 E+07$ & $3.63 E+08$ & $5.55 E+08$ & $2.27 \mathrm{E}+03$ & $2.27 \mathrm{E}+03$ & $2.27 \mathrm{E}+03$ & $6.81 \mathrm{E}+03$ & $6.00 \mathrm{E}+05$ & $8.78 E+04$ & $1.23 E+06$ & $7.20 E+06$ & $8.16 \mathrm{E}+06$ & $1.47 E+07$ \\
\hline 2050 & $1.60 \mathrm{E}+08$ & $1.63 E+07$ & $3.80 \mathrm{E}+08$ & $5.56 \mathrm{E}+08$ & $2.28 \mathrm{E}+03$ & $2.28 \mathrm{E}+03$ & $2.28 \mathrm{E}+03$ & $6.84 \mathrm{E}+03$ & $5.42 \mathrm{E}+05$ & $9.35 E+04$ & $1.29 \mathrm{E}+06$ & $6.51 \mathrm{E}+06$ & $8.69 \mathrm{E}+06$ & $1.54 \mathrm{E}+07$ \\
\hline
\end{tabular}

Figure 9 (cont). Base Case 1: 2000-2050 yearly results for Modules G4 through K2. 


\begin{tabular}{|c|c|c|c|c|c|c|c|c|c|c|c|c|c|c|}
\hline \multirow{3}{*}{ Year } & \multicolumn{3}{|c|}{\begin{tabular}{|l|l|l|} 
Module G4 & Module G4 & Module G4 \\
\end{tabular}} & \multicolumn{3}{|c|}{\begin{tabular}{|l|l|l|} 
Module J & Module J \\
\end{tabular}} & Module J & \multicolumn{7}{|c|}{\begin{tabular}{|l|l|l|l|l|l|} 
Module K2 & Module K2 & Module K2 & Module K2 & Module K2 & Module K2 \\
\end{tabular}} \\
\hline & \multicolumn{3}{|c|}{ Cost of Cladding and GTCC (\$/yr) } & $\begin{array}{l}\text { Total } \\
\text { Cladding \& } \\
\text { GTCC }(\$ / v r)\end{array}$ & \multicolumn{3}{|c|}{$\begin{array}{l}\text { Cost of Near Surface Disposal } \\
\qquad(\$ / y r)\end{array}$} & \multirow{2}{*}{$\begin{array}{c}\text { Total Near } \\
\text { Surface Displ } \\
(\$ / y r)\end{array}$} & \multicolumn{3}{|c|}{ REPU Rate (kg U/yr) } & \multicolumn{3}{|c|}{ Cost of REPU (\$/yr) } \\
\hline & & & & & & & & & & & & & & \\
\hline & & & & & & & & & & & & & & \\
\hline & $1.43 E+08$ & $1.64 \mathrm{E}+07$ & $4.24 \mathrm{E}+08$ & $5.83 E+08$ & $2.39 \mathrm{E}+03$ & $2.39 \mathrm{E}+03$ & $2.39 E+03$ & $.17 E+03$ & $4.85 E+05$ & $9.45 \mathrm{E}+04$ & $1.44 \mathrm{E}+06$ & $5.82 E+06$ & $79 E+06$ & $1.72 E+07$ \\
\hline 2052 & $1.26 \mathrm{E}+08$ & $1.65 E+07$ & $4.68 \mathrm{E}+08$ & & $2.50 \mathrm{E}+03$ & $2.50 \mathrm{E}+03$ & $2.50 \mathrm{E}+03$ & & $4.27 \mathrm{E}+05$ & $9.48 \mathrm{E}+04$ & $1.59 \mathrm{E}+06$ & $5.12 E+06$ & $81 E+06$ & $1.90 \mathrm{E}+07$ \\
\hline 2053 & $1.09 \mathrm{E}+08$ & $1.65 E+07$ & $5.39 E+08$ & & $2.71 \mathrm{E}+03$ & $2.71 \mathrm{E}+03$ & $2.71 \mathrm{E}+03$ & & $3.69 \mathrm{E}+05$ & $9.47 \mathrm{E}+04$ & $1.83 E+06$ & $4.42 E+06$ & $81 \mathrm{E}+06$ & 2. $19 \mathrm{E}+07$ \\
\hline 2054 & $6.09 \mathrm{E}+07$ & $1.68 \mathrm{E}+07$ & $6.41 \mathrm{E}+08$ & & $2.92 \mathrm{E}+03$ & $2.92 \mathrm{E}+03$ & $2.92 E+03$ & & $2.07 \mathrm{E}+05$ & $9.61 \mathrm{E}+04$ & $2.17 \mathrm{E}+06$ & $2.48 \mathrm{E}+06$ & $94 \mathrm{E}+06$ & $2.61 \mathrm{E}+07$ \\
\hline 2055 & $.00 \mathrm{E}+08$ & $1.78 \mathrm{E}+07$ & $7.10 \mathrm{E}+08$ & & $3.24 \mathrm{E}+03$ & $3.24 \mathrm{E}+03$ & $3.24 \mathrm{E}+03$ & & $3.48 \mathrm{E}+05$ & $=05$ & $2.40 \mathrm{E}+06$ & 4.18E+06 & $.52 E+06$ & $2.88 \mathrm{E}+07$ \\
\hline 56 & $E+07$ & $=+07$ & 7.14E+08 & & $3.26 \mathrm{E}+03$ & $3.26 \mathrm{E}+03$ & $E+03$ & & $3.32 \mathrm{E}+05$ & $=+05$ & $2.42 \mathrm{E}+06$ & $8 \mathrm{E}+06$ & 1.04E+07 & $2.90 \mathrm{E}+07$ \\
\hline 57 & $07 \mathrm{E}+08$ & $2.10 \mathrm{E}+07$ & $7.03 E+08$ & & $3.26 \mathrm{E}+03$ & $3.26 \mathrm{E}+03$ & $E+03$ & & $\mathrm{E}+05$ & +05 & $8 E+06$ & $7 E+06$ & 1.12E+07 & $2.86 \mathrm{E}+07$ \\
\hline 58 & $46 \mathrm{E}+05$ & $27 \mathrm{E}+07$ & $8.10 \mathrm{E}+08$ & & $3.38 \mathrm{E}+03$ & $3.38 \mathrm{E}+03$ & +03 & & $\mathrm{E}+02$ & +05 & $4 \mathrm{E}+06$ & $3 E+03$ & $1.21 \mathrm{E}+07$ & $3.29 \mathrm{E}+07$ \\
\hline 59 & +05 & +07 & $8.10 E+08$ & & $3.39 E+03$ & $3.39 \mathrm{E}+03$ & $E+03$ & & $E+02$ & +05 & $E+06$ & $\mathrm{E}+03$ & $1.30 \mathrm{E}+07$ & $9 \mathrm{E}+07$ \\
\hline 660 & $63 E+05$ & +07 & $8.10 E+08$ & & $3.41 \mathrm{E}+03$ & $3.41 \mathrm{E}+03$ & $E+03$ & & $E+02$ & +05 & $E+06$ & $E+03$ & $1.39 \mathrm{E}+07$ & $9 \mathrm{E}+07$ \\
\hline 61 & +05 & +07 & $E+08$ & & $3.43 E+03$ & $3.43 E+03$ & +03 & & $E+02$ & & $E+06$ & $\mathrm{E}+03$ & $.49 \mathrm{E}+07$ & $9 \mathrm{E}+07$ \\
\hline 62 & $08 \mathrm{E}+05$ & +07 & $E+08$ & & $3.45 \mathrm{E}+03$ & $3.45 \mathrm{E}+03$ & $3.45 \mathrm{E}+03$ & & $E+02$ & +05 & $E+06$ & $E+03$ & $1.62 \mathrm{E}+07$ & $9 \mathrm{E}+07$ \\
\hline 63 & $80 E+04$ & +07 & $8.10 E+08$ & & $3.47 \mathrm{E}+03$ & $3.47 \mathrm{E}+03$ & $3.47 \mathrm{E}+03$ & & $\mathrm{E}+02$ & +05 & $4 E+06$ & $8 E+03$ & $1.70 \mathrm{E}+07$ & $3.29 \mathrm{E}+07$ \\
\hline & $17 \mathrm{E}+04$ & +07 & $E+08$ & & $3.48 \mathrm{E}+03$ & $3.48 \mathrm{E}+03$ & 3.48 & & $E+02$ & +05 & $E+06$ & $E+03$ & $1.76 \mathrm{E}+07$ & $29 \mathrm{E}+07$ \\
\hline 2065 & $84 \mathrm{E}+04$ & $3.44 \mathrm{E}+07$ & $8.10 \mathrm{E}+08$ & & $3.49 \mathrm{E}+03$ & $3.49 \mathrm{E}+03$ & $3.49 \mathrm{E}+03$ & & $E+02$ & +05 & $4 \mathrm{E}+06$ & $E+03$ & $1.83 E+07$ & $3.29 \mathrm{E}+07$ \\
\hline 2066 & $4.76 \mathrm{E}+04$ & $3.57 \mathrm{E}+07$ & $8.37 E+08$ & & $3.61 \mathrm{E}+03$ & $3.61 \mathrm{E}+03$ & $3.61 \mathrm{E}+03$ & & $1.61 \mathrm{E}+02$ & $=05$ & $2.84 \mathrm{E}+06$ & $3 E+03$ & $1.90 \mathrm{E}+07$ & $3.40 \mathrm{E}+07$ \\
\hline 2067 & $3.87 \mathrm{E}+04$ & $3.60 \mathrm{E}+07$ & $8.64 E+08$ & $E+08$ & $3.71 \mathrm{E}+03$ & $3.71 \mathrm{E}+03$ & $3.71 \mathrm{E}+03$ & & $E+02$ & +05 & $3 E+06$ & $E+03$ & $1.92 \mathrm{E}+07$ & $3.51 \mathrm{E}+07$ \\
\hline 2068 & 3.16E+04 & $3.65 E+07$ & $9.18 E+08$ & $55 \mathrm{E}+08$ & $3.92 \mathrm{E}+03$ & $3.92 \mathrm{E}+03$ & $3.92 E+03$ & & $1.07 \mathrm{E}+02$ & $E+05$ & $3.11 \mathrm{E}+06$ & $3 E+03$ & $1.94 \mathrm{E}+07$ & $3.73 E+07$ \\
\hline 2069 & $2.57 E+04$ & $3.77 \mathrm{E}+07$ & $9.72 E+08$ & $1 E+09$ & $4.14 \mathrm{E}+03$ & $4.14 \mathrm{E}+03$ & $4.14 \mathrm{E}+03$ & & $1 \mathrm{E}+01$ & +05 & $E+06$ & $E+03$ & $2.00 \mathrm{E}+07$ & 3.95E+07 \\
\hline 2070 & $2.09 E+04$ & $E+07$ & $1.08 E+09$ & $E+09$ & $4.57 \mathrm{E}+03$ & $4.57 \mathrm{E}+03$ & $4.57 \mathrm{E}+03$ & & $E+01$ & +05 & $E+06$ & $E+02$ & 2. $10 \mathrm{E}+07$ & $4.39 \mathrm{E}+07$ \\
\hline 2071 & $.71 \mathrm{E}+04$ & $E+07$ & $6.79 \mathrm{E}+08$ & $\mathrm{E}+08$ & 3. $07 \mathrm{E}+03$ & 3.07E+03 & 3.07E+03 & & $E+01$ & & $E+06$ & $E+02$ & $E+07$ & $2.76 \mathrm{E}+07$ \\
\hline 2072 & $39 \mathrm{E}+04$ & $4.32 \mathrm{E}+07$ & $6.84 \mathrm{E}+08$ & $27 E+08$ & 3.11E+03 & $3.11 \mathrm{E}+03$ & $E+03$ & & +01 & +05 & $E+06$ & $E+02$ & $9 \mathrm{E}+07$ & $2.78 \mathrm{E}+07$ \\
\hline 2073 & 1.13E+04 & $4.39 E+07$ & $6.95 E+08$ & $38 \mathrm{E}+08$ & $3.15 E+03$ & $3.15 E+03$ & $E+03$ & & +01 & +05 & $E+06$ & $E+02$ & $3 \mathrm{E}+07$ & $2.82 E+07$ \\
\hline 2074 & $21 \mathrm{E}+03$ & +07 & $7.21 \mathrm{E}+08$ & & $3.27 \mathrm{E}+03$ & $3.27 \mathrm{E}+03$ & +03 & & +01 & & $4 E+06$ & $E+02$ & $E+07$ & $3 \mathrm{E}+07$ \\
\hline 2075 & $.51 \mathrm{E}+03$ & $4.66 \mathrm{E}+07$ & $7.49 \mathrm{E}+08$ & $E+08$ & $3.39 E+03$ & $3.39 \mathrm{E}+03$ & +03 & & +01 & +05 & $4 \mathrm{E}+06$ & $E+02$ & $7 E+07$ & $4 E+07$ \\
\hline 2076 & $11 \mathrm{E}+03$ & $4.70 \mathrm{E}+07$ & $7.42 \mathrm{E}+08$ & $E+08$ & $3.37 \mathrm{E}+03$ & 3. $37 \mathrm{E}+03$ & +03 & & +01 & +05 & $E+06$ & $E+02$ & $\mathrm{E}+07$ & $2 \mathrm{E}+07$ \\
\hline 2077 & $4.98 \mathrm{E}+03$ & $=07$ & $7.66 \mathrm{E}+08$ & $E+08$ & $3.47 \mathrm{E}+03$ & $3.47 \mathrm{E}+03$ & $E+03$ & & +01 & +05 & $\mathrm{E}+06$ & $E+02$ & $E+07$ & $E+07$ \\
\hline 2078 & $4.06 \mathrm{E}+03$ & $4.81 \mathrm{E}+07$ & $7.79 \mathrm{E}+08$ & $7 \mathrm{E}+08$ & $3.53 E+03$ & $3.53 E+03$ & $3.53 E+03$ & & $=01$ & +05 & $2.64 \mathrm{E}+06$ & $E+02$ & $2.55 \mathrm{E}+07$ & $E+07$ \\
\hline 2079 & $30 \mathrm{E}+03$ & $4.97 \mathrm{E}+07$ & $7.73 E+08$ & & $3.52 \mathrm{E}+03$ & $3.52 \mathrm{E}+03$ & $3.52 E+03$ & & $E+01$ & $E+05$ & $2.62 \mathrm{E}+06$ & $E+02$ & $2.63 E+07$ & $E+07$ \\
\hline 80 & $2.69 \mathrm{E}+03$ & $19 \mathrm{E}+07$ & $8.02 E+08$ & & $3.65 \mathrm{E}+03$ & $3.65 E+03$ & $3.65 E+03$ & & +00 & $E+05$ & $2.72 \mathrm{E}+06$ & $E+02$ & $2.75 E+07$ & $\mathrm{E}+07$ \\
\hline 81 & 2. $19 \mathrm{E}+03$ & $5.35 E+07$ & $8.10 E+08$ & $E+08$ & $3.70 \mathrm{E}+03$ & $3.70 \mathrm{E}+03$ & $3.70 E+03$ & & $E+00$ & $3.04 \mathrm{E}+05$ & $2.74 \mathrm{E}+06$ & $E+01$ & $2.83 E+07$ & $3.29 \mathrm{E}+07$ \\
\hline 082 & $E+03$ & $5.46 \mathrm{E}+07$ & $E+08$ & & $3.66 \mathrm{E}+03$ & $3.66 \mathrm{E}+03$ & $3.66 \mathrm{E}+03$ & & $E+00$ & +05 & $\mathrm{E}+06$ & $\mathrm{E}+01$ & $2.89 \mathrm{E}+07$ & $\mathrm{E}+07$ \\
\hline 83 & $E+03$ & $=07$ & $E+08$ & & 3.77E+03 & 3.77E+03 & 3.7 & & $E+00$ & +05 & $E+06$ & $E+01$ & $2.95 \mathrm{E}+07$ & $\mathrm{E}+07$ \\
\hline 84 & +03 & +07 & +08 & & $3.84 E+03$ & $E+03$ & & & +00 & & $E+06$ & +01 & +07 & $E+07$ \\
\hline 85 & & +07 & +08 & & $3.90 \mathrm{E}+03$ & $E+03$ & & & +00 & & +06 & +01 & -07 & $E+07$ \\
\hline 86 & +02 & +07 & +08 & +08 & $4.02 E+03$ & $4.02 \mathrm{E}+03$ & & & +00 & & $E+06$ & $E+01$ & +07 & $E+07$ \\
\hline & & +07 & +08 & & $4.00 E+03$ & $E+03$ & & & +00 & & +06 & +01 & 07 & $E+07$ \\
\hline & & & & & $=03$ & +03 & & & +00 & & +06 & +01 & 07 & $E+07$ \\
\hline 2089 & $E+02$ & $E+07$ & $E+08$ & $E+08$ & $4.12 E+03$ & $4.12 E+03$ & +03 & & +00 & +05 & $E+06$ & $E+01$ & $=07$ & $3 E+07$ \\
\hline 2090 & & $6.41 \mathrm{E}+07$ & $E+08$ & $E+08$ & 4.17E+03 & 4.17E+03 & & & +00 & $E+05$ & $E+06$ & +01 & +07 & $7 E+07$ \\
\hline 2091 & $.82 E+02$ & $6.49 \mathrm{E}+07$ & $9.12 E+08$ & $.77 E+08$ & $4.21 \mathrm{E}+03$ & $4.21 \mathrm{E}+03$ & $4.21 \mathrm{E}+03$ & & $\mathrm{E}-01$ & $E+05$ & $\mathrm{E}+06$ & $E+01$ & $E+07$ & $3.71 \mathrm{E}+07$ \\
\hline 2092 & $2.29 \mathrm{E}+02$ & $6.58 \mathrm{E}+07$ & $9.24 \mathrm{E}+08$ & $.90 E+08$ & $4.27 E+03$ & $4.27 E+03$ & $4.27 E+03$ & & 7E-01 & $3.72 E+05$ & $3.13 E+06$ & $2 E+00$ & $3.46 \mathrm{E}+07$ & $3.76 \mathrm{E}+07$ \\
\hline 2093 & 1.87E+02 & $6.88 \mathrm{E}+07$ & $9.41 \mathrm{E}+08$ & $1.01 \mathrm{E}+09$ & $4.36 \mathrm{E}+03$ & $4.36 \mathrm{E}+03$ & $4.36 \mathrm{E}+03$ & & $3 \mathrm{E}-01$ & $3.89 E+05$ & $3.19 \mathrm{E}+06$ & $9 \mathrm{E}+00$ & $3.62 E+07$ & $3.83 E+07$ \\
\hline 2094 & $1.52 E+02$ & $7.23 E+07$ & $9.73 E+08$ & $1.05 E+09$ & $4.52 \mathrm{E}+03$ & $4.52 \mathrm{E}+03$ & $4.52 E+03$ & $6 E+04$ & 5.15E-01 & $4.09 E+05$ & $3.30 E+06$ & $6.19 E+00$ & $3.80 E+07$ & $3.96 \mathrm{E}+07$ \\
\hline 2095 & $1.24 \mathrm{E}+02$ & $7.42 \mathrm{E}+07$ & $9.74 \mathrm{E}+08$ & $1.05 E+09$ & $4.54 \mathrm{E}+03$ & $4.54 \mathrm{E}+03$ & $4.54 \mathrm{E}+03$ & $6 \mathrm{E}+04$ & 4.20E-01 & 4.19E+05 & $3.30 \mathrm{E}+06$ & $5.04 \mathrm{E}+00$ & $3.90 \mathrm{E}+07$ & $3.96 \mathrm{E}+07$ \\
\hline 2096 & $1.01 \mathrm{E}+02$ & $7.52 \mathrm{E}+07$ & $1.09 E+09$ & 1.16E+09 & $5.00 \mathrm{E}+03$ & $5.00 \mathrm{E}+03$ & $5.00 \mathrm{E}+03$ & 1.50E+04 & 3.42E-01 & $4.24 \mathrm{E}+05$ & $3.69 \mathrm{E}+06$ & $4.10 \mathrm{E}+00$ & $3.95 E+07$ & $4.42 \mathrm{E}+07$ \\
\hline 2097 & $8.22 E+01$ & $7.55 E+07$ & $1.08 E+09$ & 1.16E+09 & $4.99 \mathrm{E}+03$ & $4.99 E+03$ & $4.99 E+03$ & $1.50 \mathrm{E}+04$ & 2.79E-01 & $4.26 \mathrm{E}+05$ & $3.67 \mathrm{E}+06$ & $3.34 \mathrm{E}+00$ & $3.96 \mathrm{E}+07$ & $4.41 \mathrm{E}+07$ \\
\hline 2098 & $6.70 \mathrm{E}+01$ & $7.55 \mathrm{E}+07$ & $1.10 E+09$ & $1.18 \mathrm{E}+09$ & $5.06 \mathrm{E}+03$ & $5.06 \mathrm{E}+03$ & $5.06 \mathrm{E}+03$ & $1.52 E+04$ & 2.27E-01 & $4.25 E+05$ & $3.74 \mathrm{E}+06$ & $2.72 \mathrm{E}+00$ & $3.95 \mathrm{E}+07$ & $4.48 \mathrm{E}+07$ \\
\hline 2099 & $5.46 \mathrm{E}+01$ & $7.95 \mathrm{E}+07$ & $1.12 E+09$ & $1.20 E+09$ & $5.17 E+03$ & 5.17E+03 & $5.17 E+03$ & $1.55 E+04$ & 1.85E-01 & 4.47E+05 & $3.79 \mathrm{E}+06$ & $2.22 \mathrm{E}+00$ & $4.16 \mathrm{E}+07$ & $4.55 E+07$ \\
\hline 2100 & $4.44 \mathrm{E}+01$ & $8.00 \mathrm{E}+07$ & 1.14E+09 & $1.22 E+09$ & $5.24 \mathrm{E}+03$ & $5.24 \mathrm{E}+03$ & $5.24 \mathrm{E}+03$ & 1.57E+04 & 1.51E-01 & $4.50 \mathrm{E}+05$ & 3.85E+06 & $1.81 \mathrm{E}+00$ & $4.19 \mathrm{E}+07$ & $4.62 \mathrm{E}+07$ \\
\hline
\end{tabular}

Figure 9 (cont). Base Case 1: 2051-2100 yearly results for Modules G4 through K2. 


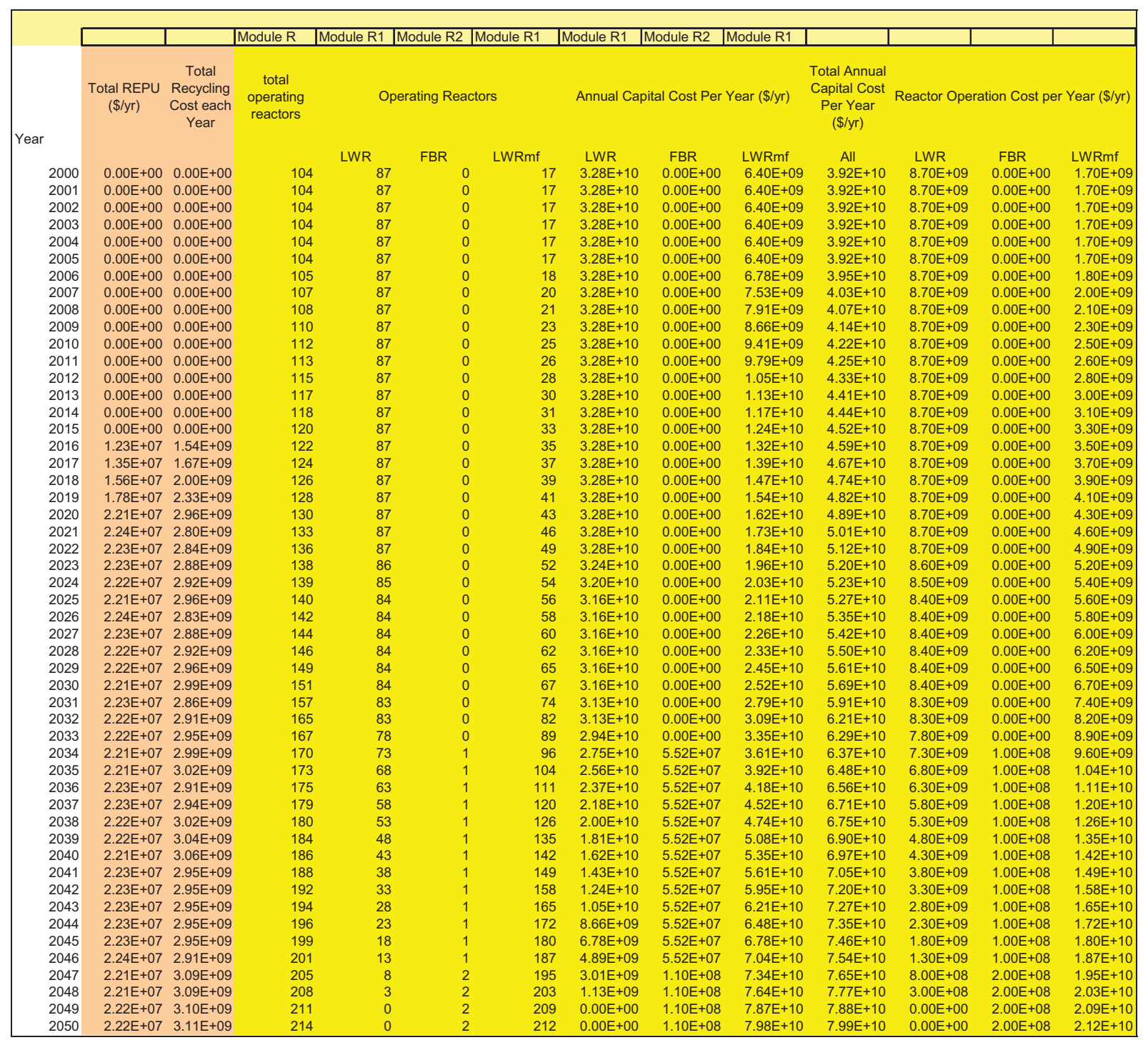

Figure 9 (cont). Base Case 1: 2000-2050 yearly results for Modules R1/R2. 


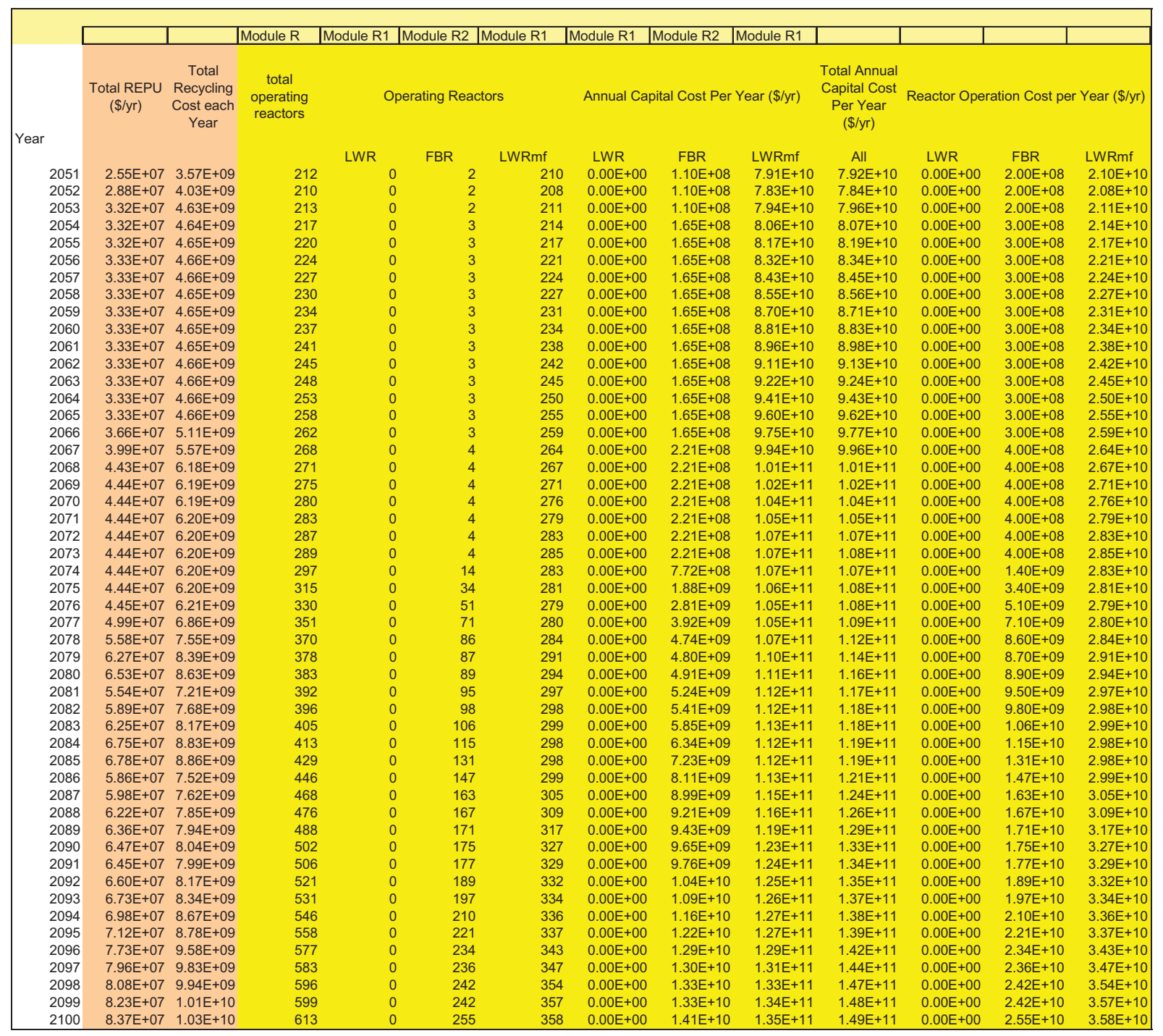

Figure 9 (cont). Base Case 1: 2051-2100 yearly results for Modules R1/R2. 


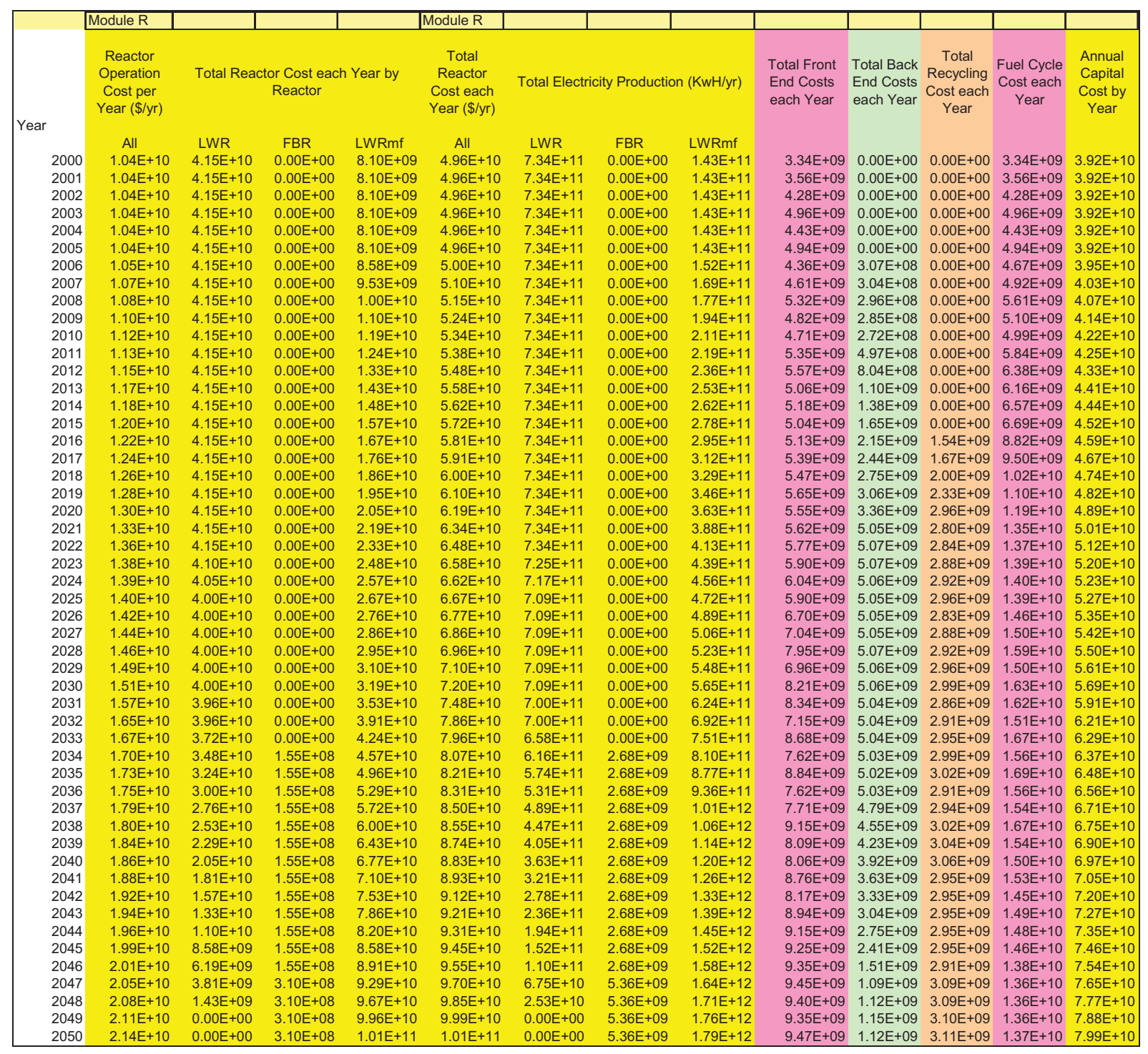

Figure 9 (cont). Base Case 1: 2000-2050 yearly results for output calculations. 


\begin{tabular}{|c|c|c|c|c|c|c|c|c|c|c|c|c|c|}
\hline \multirow{3}{*}{ Year } & Module R & & & & Module R & & & & & & & & \\
\hline & $\begin{array}{l}\text { Reactor } \\
\text { Operation } \\
\text { Cost per } \\
\text { Year (\$/yr) }\end{array}$ & \multicolumn{3}{|c|}{$\begin{array}{l}\text { Total Reactor Cost each Year by } \\
\text { Reactor }\end{array}$} & $\begin{array}{c}\text { Total } \\
\text { Reactor } \\
\text { Cost each } \\
\text { Year (\$/yr) }\end{array}$ & \multicolumn{3}{|c|}{ Total Electricity Production (KwH/yr) } & $\begin{array}{l}\text { Total Front } \\
\text { End Costs } \\
\text { each Year }\end{array}$ & $\begin{array}{l}\text { Total Back } \\
\text { End Costs } \\
\text { each Year }\end{array}$ & $\begin{array}{c}\text { Total } \\
\text { Recycling } \\
\text { Cost each } \\
\text { Year }\end{array}$ & $\begin{array}{c}\text { Fuel Cycle } \\
\text { Cost each } \\
\text { Year }\end{array}$ & $\begin{array}{c}\text { Annual } \\
\text { Capital } \\
\text { Cost by } \\
\text { Year }\end{array}$ \\
\hline & All & LWR & FBR & LWRmf & All & LWR & FBR & LWRmf & & & & & \\
\hline 2051 & $2.12 \mathrm{E}+10$ & $0.00 \mathrm{E}+00$ & $3.10 E+08$ & $1.00 \mathrm{E}+11$ & $1.00 E+11$ & $0.00 E+00$ & $5.36 \mathrm{E}+09$ & $1.77 \mathrm{E}+12$ & $9.59 E+09$ & 1.10E+09 & $3.57 \mathrm{E}+09$ & $1.43 E+10$ & $7.92 E+10$ \\
\hline 2052 & $2.10 E+10$ & $0.00 E+00$ & $3.10 E+08$ & $9.91 E+10$ & $9.94 E+10$ & $0.00 E+00$ & $5.36 \mathrm{E}+09$ & $1.75 E+12$ & $9.67 E+09$ & $1.03 E+09$ & $4.03 E+09$ & $1.47 \mathrm{E}+10$ & $7.84 E+10$ \\
\hline 2053 & $2.13 E+10$ & $0.00 E+00$ & $3.10 E+08$ & $1.01 \mathrm{E}+11$ & $1.01 \mathrm{E}+11$ & $0.00 E+00$ & $5.36 \mathrm{E}+09$ & $1.78 \mathrm{E}+12$ & $9.83 E+09$ & $9.83 E+08$ & $4.63 E+09$ & $1.54 \mathrm{E}+10$ & $7.96 \mathrm{E}+10$ \\
\hline 2054 & $2.17 \mathrm{E}+10$ & $0.00 E+00$ & $4.65 E+08$ & $1.02 \mathrm{E}+11$ & $1.02 E+11$ & $0.00 E+00$ & $8.04 E+09$ & $1.81 \mathrm{E}+12$ & $9.97 E+09$ & $9.86 \mathrm{E}+08$ & $4.64 E+09$ & $1.56 \mathrm{E}+10$ & $8.07 E+10$ \\
\hline 2055 & $2.20 \mathrm{E}+10$ & $0.00 E+00$ & $4.65 E+08$ & $1.03 E+11$ & $1.04 E+11$ & $0.00 E+00$ & $8.04 E+09$ & $1.83 E+12$ & $1.02 \mathrm{E}+10$ & $9.93 E+08$ & $4.65 E+09$ & $1.58 \mathrm{E}+10$ & $8.19 E+10$ \\
\hline 2056 & $2.24 \mathrm{E}+10$ & $0.00 E+00$ & $4.65 E+08$ & $1.05 E+11$ & $1.06 \mathrm{E}+11$ & $0.00 E+00$ & $8.04 \mathrm{E}+09$ & $1.86 \mathrm{E}+12$ & $1.02 \mathrm{E}+10$ & $1.00 \mathrm{E}+09$ & $4.66 \mathrm{E}+09$ & $1.59 \mathrm{E}+10$ & $8.34 E+10$ \\
\hline 2057 & $2.27 \mathrm{E}+10$ & $0.00 \mathrm{E}+00$ & $4.65 E+08$ & $1.07 \mathrm{E}+11$ & $1.07 E+11$ & $0.00 E+00$ & $8.04 \mathrm{E}+09$ & $1.89 \mathrm{E}+12$ & $1.04 \mathrm{E}+10$ & $9.93 \mathrm{E}+08$ & $4.66 \mathrm{E}+09$ & $1.60 \mathrm{E}+10$ & $8.45 E+10$ \\
\hline 2058 & $2.30 \mathrm{E}+10$ & $0.00 E+00$ & $4.65 E+08$ & $1.08 \mathrm{E}+11$ & $1.09 \mathrm{E}+11$ & $0.00 E+00$ & $8.04 \mathrm{E}+09$ & $1.91 \mathrm{E}+12$ & $1.05 E+10$ & $9.53 \mathrm{E}+08$ & $4.65 \mathrm{E}+09$ & $1.61 \mathrm{E}+10$ & $8.56 E+10$ \\
\hline 2059 & $2.34 \mathrm{E}+10$ & $0.00 \mathrm{E}+00$ & $4.65 E+08$ & $1.10 \mathrm{E}+11$ & $1.11 \mathrm{E}+11$ & $0.00 E+00$ & $8.04 \mathrm{E}+09$ & $1.95 E+12$ & $1.00 \mathrm{E}+10$ & $9.58 \mathrm{E}+08$ & $4.65 \mathrm{E}+09$ & $1.56 \mathrm{E}+10$ & $8.71 E+10$ \\
\hline 2060 & $2.37 E+10$ & $0.00 E+00$ & $4.65 E+08$ & $1.12 \mathrm{E}+11$ & $1.12 E+11$ & $0.00 E+00$ & $8.04 \mathrm{E}+09$ & $1.97 \mathrm{E}+12$ & $1.08 E+10$ & $9.63 \mathrm{E}+08$ & $4.65 \mathrm{E}+09$ & $1.65 E+10$ & $8.83 E+10$ \\
\hline 2061 & $2.41 \mathrm{E}+10$ & $0.00 \mathrm{E}+00$ & 4.65E+08 & $1.13 E+11$ & $1.14 \mathrm{E}+11$ & $0.00 \mathrm{E}+00$ & $8.04 \mathrm{E}+09$ & $2.01 \mathrm{E}+12$ & $1.11 \mathrm{E}+10$ & $9.68 \mathrm{E}+08$ & $4.65 \mathrm{E}+09$ & $1.67 E+10$ & $8.98 \mathrm{E}+10$ \\
\hline 2062 & $2.45 E+10$ & $0.00 E+00$ & $4.65 \mathrm{E}+08$ & $1.15 E+11$ & $1.16 \mathrm{E}+11$ & $0.00 E+00$ & $8.04 E+09$ & $2.04 \mathrm{E}+12$ & $1.13 E+10$ & $9.74 \mathrm{E}+08$ & $4.66 \mathrm{E}+09$ & $1.69 E+10$ & $9.13 E+10$ \\
\hline 2063 & $2.48 E+10$ & $0.00 \mathrm{E}+00$ & 4.65E+08 & $1.17 \mathrm{E}+11$ & $1.17 \mathrm{E}+11$ & $0.00 \mathrm{E}+00$ & $8.04 \mathrm{E}+09$ & $2.07 \mathrm{E}+12$ & $1.16 \mathrm{E}+10$ & $9.79 E+08$ & $4.66 \mathrm{E}+09$ & $1.72 \mathrm{E}+10$ & $9.24 \mathrm{E}+10$ \\
\hline 2064 & $2.53 E+10$ & $0.00 E+00$ & $4.65 E+08$ & $1.19 \mathrm{E}+11$ & 1. $20 \mathrm{E}+11$ & $0.00 E+00$ & $8.04 \mathrm{E}+09$ & $2.11 \mathrm{E}+12$ & $1.17 E+10$ & $9.84 \mathrm{E}+08$ & $4.66 \mathrm{E}+09$ & $1.73 E+10$ & $9.43 E+10$ \\
\hline 2065 & $2.58 \mathrm{E}+10$ & $0.00 \mathrm{E}+00$ & $4.65 \mathrm{E}+08$ & $1.22 \mathrm{E}+11$ & $1.22 \mathrm{E}+11$ & $0.00 \mathrm{E}+00$ & $8.04 \mathrm{E}+09$ & $2.15 \mathrm{E}+12$ & $1.25 \mathrm{E}+10$ & $9.89 \mathrm{E}+08$ & $4.66 \mathrm{E}+09$ & $1.81 \mathrm{E}+10$ & $9.62 \mathrm{E}+10$ \\
\hline 2066 & $2.62 E+10$ & $0.00 E+00$ & $4.65 E+08$ & $1.23 E+11$ & $1.24 \mathrm{E}+11$ & $0.00 E+00$ & $8.04 \mathrm{E}+09$ & $2.18 \mathrm{E}+12$ & $1.20 E+10$ & $1.06 \mathrm{E}+09$ & $5.11 \mathrm{E}+09$ & $1.82 \mathrm{E}+10$ & $9.77 E+10$ \\
\hline 2067 & $2.68 \mathrm{E}+10$ & $0.00 \mathrm{E}+00$ & $6.21 \mathrm{E}+08$ & $1.26 \mathrm{E}+11$ & $1.26 \mathrm{E}+11$ & $0.00 \mathrm{E}+00$ & $1.07 \mathrm{E}+10$ & $2.23 \mathrm{E}+12$ & $1.22 \mathrm{E}+10$ & 1.13E+09 & $5.57 \mathrm{E}+09$ & $1.89 E+10$ & $9.96 \mathrm{E}+10$ \\
\hline 2068 & $2.71 \mathrm{E}+10$ & $0.00 \mathrm{E}+00$ & $6.21 \mathrm{E}+08$ & $1.27 \mathrm{E}+11$ & $1.28 \mathrm{E}+11$ & $0.00 \mathrm{E}+00$ & $1.07 \mathrm{E}+10$ & $2.25 \mathrm{E}+12$ & $1.30 \mathrm{E}+10$ & $1.22 \mathrm{E}+09$ & $6.18 \mathrm{E}+09$ & $2.04 \mathrm{E}+10$ & $1.01 \mathrm{E}+11$ \\
\hline 2069 & $2.75 \mathrm{E}+10$ & $0.00 \mathrm{E}+00$ & $6.21 \mathrm{E}+08$ & $1.29 \mathrm{E}+11$ & $1.30 \mathrm{E}+11$ & $0.00 \mathrm{E}+00$ & $1.07 \mathrm{E}+10$ & $2.29 \mathrm{E}+12$ & $1.24 \mathrm{E}+10$ & $1.22 \mathrm{E}+09$ & $6.19 E+09$ & $1.99 \mathrm{E}+10$ & $1.02 \mathrm{E}+11$ \\
\hline 2070 & $2.80 \mathrm{E}+10$ & $0.00 \mathrm{E}+00$ & $6.21 \mathrm{E}+08$ & $1.32 \mathrm{E}+11$ & $1.32 \mathrm{E}+11$ & $0.00 \mathrm{E}+00$ & $1.07 \mathrm{E}+10$ & $2.33 \mathrm{E}+12$ & $1.19 \mathrm{E}+10$ & $1.23 \mathrm{E}+09$ & $6.19 \mathrm{E}+09$ & $1.93 E+10$ & $1.04 \mathrm{E}+11$ \\
\hline 2071 & $2.83 E+10$ & $0.00 \mathrm{E}+00$ & $6.21 \mathrm{E}+08$ & $1.33 \mathrm{E}+11$ & $1.34 \mathrm{E}+11$ & $0.00 \mathrm{E}+00$ & $1.07 \mathrm{E}+10$ & $2.35 E+12$ & $1.20 \mathrm{E}+10$ & $1.25 \mathrm{E}+09$ & $6.20 E+09$ & $1.95 \mathrm{E}+10$ & $1.05 E+11$ \\
\hline 2072 & $2.87 E+10$ & $0.00 E+00$ & $6.21 \mathrm{E}+08$ & $1.35 \mathrm{E}+11$ & $1.35 E+11$ & $0.00 E+00$ & $1.07 E+10$ & $2.39 E+12$ & $1.21 \mathrm{E}+10$ & 1.25E+09 & $6.20 E+09$ & $1.95 E+10$ & $1.07 E+11$ \\
\hline 2073 & $2.89 \mathrm{E}+10$ & $0.00 \mathrm{E}+00$ & $6.21 \mathrm{E}+08$ & $1.36 \mathrm{E}+11$ & $1.36 \mathrm{E}+11$ & $0.00 \mathrm{E}+00$ & $1.07 \mathrm{E}+10$ & $2.40 \mathrm{E}+12$ & $1.23 \mathrm{E}+10$ & 1.27E+09 & $6.20 \mathrm{E}+09$ & $1.97 \mathrm{E}+10$ & $1.08 \mathrm{E}+11$ \\
\hline 2074 & $2.97 E+10$ & $0.00 E+00$ & $2.17 E+09$ & $1.35 E+11$ & $1.37 E+11$ & $0.00 E+00$ & $3.75 E+10$ & $2.39 E+12$ & $1.39 \mathrm{E}+10$ & $1.27 \mathrm{E}+09$ & $6.20 \mathrm{E}+09$ & $2.13 E+10$ & $1.07 E+11$ \\
\hline 2075 & $3.15 \mathrm{E}+10$ & $0.00 \mathrm{E}+00$ & $5.28 \mathrm{E}+09$ & $1.34 \mathrm{E}+11$ & $1.39 \mathrm{E}+11$ & $0.00 \mathrm{E}+00$ & $9.11 \mathrm{E}+10$ & $2.37 \mathrm{E}+12$ & $1.41 \mathrm{E}+10$ & 1.27E+09 & $6.20 \mathrm{E}+09$ & 2.16E+10 & $1.08 \mathrm{E}+11$ \\
\hline 2076 & $3.30 \mathrm{E}+10$ & $0.00 \mathrm{E}+00$ & $7.91 \mathrm{E}+09$ & $1.33 E+11$ & $1.41 \mathrm{E}+11$ & $0.00 E+00$ & $1.37 E+11$ & $2.35 E+12$ & $2 E+10$ & $1.28 \mathrm{E}+09$ & $6.21 \mathrm{E}+09$ & $2.07 E+10$ & $1.08 \mathrm{E}+11$ \\
\hline 2077 & $3.51 \mathrm{E}+10$ & $0.00 \mathrm{E}+00$ & 1.10E+10 & $1.33 \mathrm{E}+11$ & $1.44 \mathrm{E}+11$ & $0.00 \mathrm{E}+00$ & $1.90 \mathrm{E}+11$ & $2.36 \mathrm{E}+12$ & $1.41 \mathrm{E}+10$ & $1.36 \mathrm{E}+09$ & $6.86 \mathrm{E}+09$ & $2.23 \mathrm{E}+10$ & $1.09 \mathrm{E}+11$ \\
\hline 2078 & $3.70 \mathrm{E}+10$ & $0.00 E+00$ & $1.33 E+10$ & $1.35 \mathrm{E}+11$ & $1.49 \mathrm{E}+11$ & $0.00 E+00$ & $2.31 \mathrm{E}+11$ & $2.40 \mathrm{E}+12$ & $1.43 E+10$ & $1.43 \mathrm{E}+09$ & $7.55 \mathrm{E}+09$ & $2.32 E+10$ & $1.12 \mathrm{E}+11$ \\
\hline 2079 & $3.78 \mathrm{E}+10$ & $0.00 E+00$ & $1.35 E+10$ & $1.39 \mathrm{E}+11$ & $1.52 E+11$ & $0.00 E+00$ & $2.33 E+11$ & $2.45 E+12$ & $1.36 \mathrm{E}+10$ & $1.53 \mathrm{E}+09$ & $8.39 E+09$ & $2.35 E+10$ & $1.14 \mathrm{E}+11$ \\
\hline 2080 & $3.83 E+10$ & $0.00 E+00$ & $1.38 \mathrm{E}+10$ & $1.40 \mathrm{E}+11$ & $1.54 \mathrm{E}+11$ & $0.00 E+00$ & $2.39 E+11$ & $2.48 \mathrm{E}+12$ & $1.37 \mathrm{E}+10$ & $1.54 \mathrm{E}+09$ & $8.63 E+09$ & $2.39 E+10$ & $1.16 \mathrm{E}+11$ \\
\hline 2081 & $3.92 \mathrm{E}+10$ & $0.00 E+00$ & $1.47 \mathrm{E}+10$ & $1.42 \mathrm{E}+11$ & $1.56 \mathrm{E}+11$ & $0.00 \mathrm{E}+00$ & $2.55 E+11$ & $2.51 \mathrm{E}+12$ & $1.39 \mathrm{E}+10$ & $1.33 \mathrm{E}+09$ & $7.21 \mathrm{E}+09$ & $2.24 \mathrm{E}+10$ & $1.17 E+11$ \\
\hline 2082 & $3.96 \mathrm{E}+10$ & $0.00 \mathrm{E}+00$ & $1.52 \mathrm{E}+10$ & $1.42 \mathrm{E}+11$ & $1.57 \mathrm{E}+11$ & $0.00 \mathrm{E}+00$ & $2.63 \mathrm{E}+11$ & $2.51 \mathrm{E}+12$ & $1.40 \mathrm{E}+10$ & $1.39 \mathrm{E}+09$ & $7.68 \mathrm{E}+09$ & $2.30 \mathrm{E}+10$ & $1.18 \mathrm{E}+11$ \\
\hline 2083 & $4.05 \mathrm{E}+10$ & $0.00 \mathrm{E}+00$ & $1.64 \mathrm{E}+10$ & $1.42 \mathrm{E}+11$ & $1.59 \mathrm{E}+11$ & $0.00 \mathrm{E}+00$ & $2.84 \mathrm{E}+11$ & $2.52 \mathrm{E}+12$ & $1.63 \mathrm{E}+10$ & $1.46 \mathrm{E}+09$ & 8.17E+09 & $2.59 \mathrm{E}+10$ & $1.18 \mathrm{E}+11$ \\
\hline 2084 & $4.13 \mathrm{E}+10$ & $0.00 \mathrm{E}+00$ & $1.78 \mathrm{E}+10$ & $1.42 \mathrm{E}+11$ & $1.60 \mathrm{E}+11$ & $0.00 \mathrm{E}+00$ & $3.08 \mathrm{E}+11$ & $2.51 \mathrm{E}+12$ & $1.53 \mathrm{E}+10$ & $1.55 \mathrm{E}+09$ & $8.83 E+09$ & $2.56 \mathrm{E}+10$ & $1.19 \mathrm{E}+11$ \\
\hline 2085 & $4.29 \mathrm{E}+10$ & $0.00 E+00$ & $2.03 E+10$ & $1.42 \mathrm{E}+11$ & $1.62 E+11$ & $0.00 E+00$ & $3.51 \mathrm{E}+11$ & $2.51 \mathrm{E}+12$ & 1. $62 \mathrm{E}+10$ & $1.56 \mathrm{E}+09$ & $8.86 \mathrm{E}+09$ & $2.67 E+10$ & $1.19 E+11$ \\
\hline 2086 & $4.46 \mathrm{E}+10$ & $0.00 \mathrm{E}+00$ & $2.28 \mathrm{E}+10$ & $1.42 \mathrm{E}+11$ & $1.65 \mathrm{E}+11$ & $0.00 \mathrm{E}+00$ & $3.94 \mathrm{E}+11$ & $2.52 \mathrm{E}+12$ & 1. $60 \mathrm{E}+10$ & $1.38 \mathrm{E}+09$ & $7.52 \mathrm{E}+09$ & $2.49 E+10$ & $1.21 \mathrm{E}+11$ \\
\hline 2087 & $4.68 \mathrm{E}+10$ & $0.00 E+00$ & $2.53 E+10$ & $1.45 E+11$ & $1.71 \mathrm{E}+11$ & $0.00 E+00$ & $4.37 E+11$ & $2.57 E+12$ & $1.66 \mathrm{E}+10$ & $1.38 \mathrm{E}+09$ & $7.62 E+09$ & $2.56 E+10$ & $1.24 E+11$ \\
\hline 2088 & $4.76 \mathrm{E}+10$ & $0.00 \mathrm{E}+00$ & $2.59 \mathrm{E}+10$ & $1.47 \mathrm{E}+11$ & $1.73 E+11$ & $0.00 \mathrm{E}+00$ & $4.48 \mathrm{E}+11$ & $2.61 \mathrm{E}+12$ & $1.60 \mathrm{E}+10$ & $1.39 \mathrm{E}+09$ & $7.85 \mathrm{E}+09$ & $2.53 E+10$ & $1.26 \mathrm{E}+11$ \\
\hline 2089 & $4.88 \mathrm{E}+10$ & $0.00 E+00$ & $2.65 E+10$ & $1.51 \mathrm{E}+11$ & $1.78 \mathrm{E}+11$ & $0.00 E+00$ & $4.58 \mathrm{E}+11$ & $2.67 E+12$ & $1.64 \mathrm{E}+10$ & $1.38 \mathrm{E}+09$ & $7.94 E+09$ & $2.57 E+10$ & $1.29 E+11$ \\
\hline 2090 & $5.02 \mathrm{E}+10$ & $0.00 \mathrm{E}+00$ & $2.72 \mathrm{E}+10$ & $1.56 \mathrm{E}+11$ & $1.83 \mathrm{E}+11$ & $0.00 \mathrm{E}+00$ & $4.69 \mathrm{E}+11$ & $2.76 \mathrm{E}+12$ & 1.66E +10 & $1.38 \mathrm{E}+09$ & $8.04 \mathrm{E}+09$ & $2.60 \mathrm{E}+10$ & $1.33 \mathrm{E}+11$ \\
\hline 2091 & $5.06 \mathrm{E}+10$ & $0.00 \mathrm{E}+00$ & $2.75 \mathrm{E}+10$ & $1.57 \mathrm{E}+11$ & $1.84 \mathrm{E}+11$ & $0.00 \mathrm{E}+00$ & $4.74 \mathrm{E}+11$ & $2.78 \mathrm{E}+12$ & $1.75 \mathrm{E}+10$ & $1.36 \mathrm{E}+09$ & $7.99 \mathrm{E}+09$ & $2.68 \mathrm{E}+10$ & $1.34 \mathrm{E}+11$ \\
\hline 2092 & $5.21 \mathrm{E}+10$ & $0.00 \mathrm{E}+00$ & $2.93 \mathrm{E}+10$ & $1.58 \mathrm{E}+11$ & $1.88 \mathrm{E}+11$ & $0.00 \mathrm{E}+00$ & $5.07 \mathrm{E}+11$ & $2.80 \mathrm{E}+12$ & $1.90 \mathrm{E}+10$ & $1.39 \mathrm{E}+09$ & $8.17 E+09$ & $2.86 \mathrm{E}+10$ & $1.35 \mathrm{E}+11$ \\
\hline 2093 & $5.31 \mathrm{E}+10$ & $0.00 E+00$ & $3.06 E+10$ & $1.59 \mathrm{E}+11$ & $1.90 E+11$ & $0.00 E+00$ & $5.28 \mathrm{E}+11$ & $2.82 \mathrm{E}+12$ & $1.86 \mathrm{E}+10$ & $1.42 \mathrm{E}+09$ & $8.34 E+09$ & $2.84 \mathrm{E}+10$ & $1.37 E+11$ \\
\hline 2094 & $5.46 \mathrm{E}+10$ & $0.00 \mathrm{E}+00$ & $3.26 \mathrm{E}+10$ & $1.60 \mathrm{E}+11$ & $1.93 E+11$ & $0.00 \mathrm{E}+00$ & $5.63 E+11$ & $2.83 \mathrm{E}+12$ & $2.02 E+10$ & $1.48 \mathrm{E}+09$ & $8.67 \mathrm{E}+09$ & $3.04 \mathrm{E}+10$ & $1.38 \mathrm{E}+11$ \\
\hline 2095 & $5.58 \mathrm{E}+10$ & $0.00 \mathrm{E}+00$ & $3.43 \mathrm{E}+10$ & $1.61 \mathrm{E}+11$ & $1.95 \mathrm{E}+11$ & $0.00 \mathrm{E}+00$ & $5.92 \mathrm{E}+11$ & $2.84 \mathrm{E}+12$ & $1.91 \mathrm{E}+10$ & $1.48 \mathrm{E}+09$ & $8.78 \mathrm{E}+09$ & $2.94 \mathrm{E}+10$ & $1.39 \mathrm{E}+11$ \\
\hline 2096 & $5.77 \mathrm{E}+10$ & $0.00 \mathrm{E}+00$ & 3.63E+10 & $1.63 E+11$ & $2.00 \mathrm{E}+11$ & $0.00 \mathrm{E}+00$ & $6.27 \mathrm{E}+11$ & $2.89 \mathrm{E}+12$ & $1.87 \mathrm{E}+10$ & $1.63 E+09$ & $9.58 \mathrm{E}+09$ & $2.99 \mathrm{E}+10$ & $1.42 \mathrm{E}+11$ \\
\hline 2097 & $5.83 E+10$ & $0.00 E+00$ & $3.66 \mathrm{E}+10$ & $1.65 E+11$ & $2.02 E+11$ & $0.00 \mathrm{E}+00$ & $6.33 E+11$ & $2.93 E+12$ & $2.10 E+10$ & $1.67 E+09$ & $9.83 E+09$ & 3. $25 \mathrm{E}+10$ & $1.44 \mathrm{E}+11$ \\
\hline 2098 & $5.96 \mathrm{E}+10$ & $0.00 \mathrm{E}+00$ & $3.75 \mathrm{E}+10$ & $1.69 \mathrm{E}+11$ & $2.06 \mathrm{E}+11$ & $0.00 \mathrm{E}+00$ & $6.49 \mathrm{E}+11$ & $2.99 \mathrm{E}+12$ & $1.92 \mathrm{E}+10$ & $1.66 \mathrm{E}+09$ & $9.94 \mathrm{E}+09$ & $3.08 \mathrm{E}+10$ & $1.47 \mathrm{E}+11$ \\
\hline 2099 & $5.99 \mathrm{E}+10$ & $0.00 \mathrm{E}+00$ & $3.75 E+10$ & $1.70 \mathrm{E}+11$ & $2.08 E+11$ & $0.00 \mathrm{E}+00$ & $6.49 \mathrm{E}+11$ & $3.01 \mathrm{E}+12$ & $1.93 E+10$ & $1.67 E+09$ & $1.01 \mathrm{E}+10$ & $3.11 \mathrm{E}+10$ & $1.48 \mathrm{E}+11$ \\
\hline 2100 & $6.13 \mathrm{E}+10$ & $0.00 E+00$ & $3.96 \mathrm{E}+10$ & $1.71 \mathrm{E}+11$ & $2.10 E+11$ & $0.00 E+00$ & $6.84 E+11$ & $3.02 E+12$ & $1.97 \mathrm{E}+10$ & $1.71 \mathrm{E}+09$ & $1.03 E+10$ & 3. $17 \mathrm{E}+10$ & $1.49 \mathrm{E}+11$ \\
\hline
\end{tabular}

Figure 9 (cont). Base Case 1: 2051-2100 yearly results for output calculations. 


\begin{tabular}{|c|c|c|c|c|c|c|}
\hline ear & $\begin{array}{l}\text { Total Cost } \\
\text { of Reactor } \\
\text { Operation } \\
\text { s by Year }\end{array}$ & $\begin{array}{c}\text { Total } \\
\text { Reactor } \\
\text { Cost each } \\
\text { Year }\end{array}$ & $\begin{array}{l}\text { Total Cost } \\
\text { each Year }\end{array}$ & $\begin{array}{c}\text { Total } \\
\text { Electricity } \\
\text { Produced } \\
\text { Yearly } \\
(\mathrm{KwH} / \mathrm{Yr})\end{array}$ & $\begin{array}{l}\text { Fuel Cycle } \\
\text { (mills/KwH) }\end{array}$ & $\begin{array}{c}\text { Cost of } \\
\text { Electricity } \\
\text { (mills/KwH) }\end{array}$ \\
\hline 2000 & $1.04 \mathrm{E}+10$ & $4.96 \mathrm{E}+10$ & $5.29 \mathrm{E}+10$ & $8.77 \mathrm{E}+11$ & $6.03 E+01$ & $3.81 \mathrm{E}+00$ \\
\hline 2001 & $1.04 \mathrm{E}+10$ & $4.96 \mathrm{E}+10$ & $5.31 \mathrm{E}+10$ & $8.77 \mathrm{E}+11$ & $6.05 E+01$ & $4.05 E+00$ \\
\hline 2002 & $1.04 \mathrm{E}+10$ & $4.96 \mathrm{E}+10$ & $5.38 E+10$ & $8.77 \mathrm{E}+11$ & $6.14 \mathrm{E}+01$ & $4.88 \mathrm{E}+00$ \\
\hline 2003 & $1.04 \mathrm{E}+10$ & $4.96 \mathrm{E}+10$ & $5.45 E+10$ & $8.77 \mathrm{E}+11$ & $6.21 \mathrm{E}+01$ & $5.66 \mathrm{E}+00$ \\
\hline 2004 & $1.04 \mathrm{E}+10$ & $4.96 \mathrm{E}+10$ & $5.40 \mathrm{E}+10$ & $8.77 \mathrm{E}+11$ & $6.15 \mathrm{E}+01$ & $5.05 \mathrm{E}+00$ \\
\hline 2005 & $1.04 \mathrm{E}+10$ & $4.96 \mathrm{E}+10$ & $5.45 E+10$ & $8.77 \mathrm{E}+11$ & $6.21 \mathrm{E}+01$ & $5.64 \mathrm{E}+00$ \\
\hline 2006 & $1.05 \mathrm{E}+10$ & $5.00 \mathrm{E}+10$ & $5.47 E+10$ & $8.86 \mathrm{E}+11$ & $6.18 \mathrm{E}+01$ & $5.27 \mathrm{E}+00$ \\
\hline 2007 & $1.07 \mathrm{E}+10$ & $5.10 \mathrm{E}+10$ & $5.59 \mathrm{E}+10$ & $9.03 E+11$ & $6.19 \mathrm{E}+01$ & $5.45 \mathrm{E}+00$ \\
\hline 2008 & $1.08 \mathrm{E}+10$ & $5.15 \mathrm{E}+10$ & $5.71 \mathrm{E}+10$ & $9.11 \mathrm{E}+11$ & $6.26 \mathrm{E}+01$ & $6.16 \mathrm{E}+00$ \\
\hline 2009 & $1.10 \mathrm{E}+10$ & $5.24 \mathrm{E}+10$ & $5.75 \mathrm{E}+10$ & $9.28 \mathrm{E}+11$ & $6.20 \mathrm{E}+01$ & $5.50 \mathrm{E}+00$ \\
\hline 2010 & $1.12 \mathrm{E}+10$ & $5.34 \mathrm{E}+10$ & $5.84 \mathrm{E}+10$ & $9.45 \mathrm{E}+11$ & $6.18 \mathrm{E}+01$ & $5.28 \mathrm{E}+00$ \\
\hline 2011 & $1.13 \mathrm{E}+10$ & $5.38 \mathrm{E}+10$ & $5.97 \mathrm{E}+10$ & $9.53 E+11$ & $6.26 \mathrm{E}+01$ & $6.13 E+00$ \\
\hline 2012 & $1.15 E+10$ & $5.48 \mathrm{E}+10$ & $6.12 \mathrm{E}+10$ & $9.70 \mathrm{E}+11$ & $6.31 E+01$ & $6.57 \mathrm{E}+00$ \\
\hline 2013 & $1.17 \mathrm{E}+10$ & $5.58 \mathrm{E}+10$ & $6.19 E+10$ & $9.87 E+11$ & $6.27 E+01$ & $6.25 E+00$ \\
\hline 2014 & $1.18 \mathrm{E}+10$ & $5.62 E+10$ & $6.28 E+10$ & $9.95 E+11$ & $6.31 E+01$ & $6.60 \mathrm{E}+00$ \\
\hline 2015 & $1.20 E+10$ & $5.72 E+10$ & $6.39 E+10$ & $1.01 \mathrm{E}+12$ & $6.31 \mathrm{E}+01$ & $6.61 E+00$ \\
\hline 2016 & $1.22 \mathrm{E}+10$ & $5.81 E+10$ & $6.70 \mathrm{E}+10$ & $1.03 E+12$ & $6.51 \mathrm{E}+01$ & $8.57 E+00$ \\
\hline 2017 & $1.24 \mathrm{E}+10$ & $5.91 E+10$ & $6.86 \mathrm{E}+10$ & $1.05 E+12$ & $6.56 \mathrm{E}+01$ & $9.09 \mathrm{E}+00$ \\
\hline 2018 & $1.26 \mathrm{E}+10$ & $6.00 E+10$ & $7.03 E+10$ & $1.06 \mathrm{E}+12$ & $6.61 \mathrm{E}+01$ & $9.62 E+00$ \\
\hline 2019 & $1.28 E+10$ & $6.10 E+10$ & $7.20 E+10$ & $1.08 \mathrm{E}+12$ & $6.67 E+01$ & $1.02 E+01$ \\
\hline 2020 & $1.30 E+10$ & $6.19 E+10$ & $7.38 \mathrm{E}+10$ & $1.10 E+12$ & $6.73 E+01$ & $1.08 E+01$ \\
\hline 2021 & $1.33 E+10$ & $6.34 E+10$ & $7.68 E+10$ & $1.12 E+12$ & $6.85 E+01$ & $1.20 E+01$ \\
\hline 2022 & $1.36 E+10$ & $6.48 E+10$ & $7.85 E+10$ & $1.15 \mathrm{E}+12$ & $6.84 \mathrm{E}+01$ & $1.19 E+01$ \\
\hline 2023 & $1.38 E+10$ & $6.58 E+10$ & $7.96 \mathrm{E}+10$ & $1.16 \mathrm{E}+12$ & $6.84 \mathrm{E}+01$ & $1.19 E+01$ \\
\hline 2024 & $1.39 E+10$ & $6.62 E+10$ & $8.03 E+10$ & 1.17E+12 & $6.84 \mathrm{E}+01$ & $1.20 E+01$ \\
\hline 2025 & $1.40 E+10$ & $6.67 E+10$ & $8.06 \mathrm{E}+10$ & $1.18 \mathrm{E}+12$ & $6.83 E+01$ & $1.18 E+01$ \\
\hline 2026 & $1.42 \mathrm{E}+10$ & $6.77 \mathrm{E}+10$ & $8.22 \mathrm{E}+10$ & $1.20 \mathrm{E}+12$ & $6.87 E+01$ & $1.22 \mathrm{E}+01$ \\
\hline 2027 & $1.44 \mathrm{E}+10$ & $6.86 \mathrm{E}+10$ & $8.36 \mathrm{E}+10$ & $1.21 \mathrm{E}+12$ & $6.88 \mathrm{E}+01$ & $1.23 \mathrm{E}+01$ \\
\hline 2028 & $1.46 \mathrm{E}+10$ & $6.96 \mathrm{E}+10$ & $8.55 \mathrm{E}+10$ & $1.23 \mathrm{E}+12$ & $6.94 \mathrm{E}+01$ & $1.29 \mathrm{E}+01$ \\
\hline 2029 & $1.49 \mathrm{E}+10$ & $7.10 \mathrm{E}+10$ & $8.60 E+10$ & $1.26 \mathrm{E}+12$ & $6.84 \mathrm{E}+01$ & $1.19 E+01$ \\
\hline 2030 & $1.51 \mathrm{E}+10$ & $7.20 E+10$ & $8.82 E+10$ & $1.27 E+12$ & $6.92 E+01$ & $1.28 \mathrm{E}+01$ \\
\hline 2031 & $1.57 E+10$ & $7.48 \mathrm{E}+10$ & $9.11 \mathrm{E}+10$ & $1.32 \mathrm{E}+12$ & $6.87 E+01$ & $1.23 \mathrm{E}+01$ \\
\hline 2032 & $1.65 E+10$ & $7.86 \mathrm{E}+10$ & $9.37 E+10$ & $1.39 E+12$ & $6.73 E+01$ & $1.08 E+01$ \\
\hline 2033 & $1.67 E+10$ & $7.96 \mathrm{E}+10$ & $9.62 E+10$ & $1.41 \mathrm{E}+12$ & $6.83 E+01$ & $1.18 E+01$ \\
\hline 2034 & $1.70 \mathrm{E}+10$ & $8.07 E+10$ & $9.63 E+10$ & $1.43 E+12$ & $6.74 E+01$ & $1.09 \mathrm{E}+01$ \\
\hline 2035 & $1.73 \mathrm{E}+10$ & $8.21 \mathrm{E}+10$ & $9.90 \mathrm{E}+10$ & $1.45 \mathrm{E}+12$ & $6.81 \mathrm{E}+01$ & $1.16 \mathrm{E}+01$ \\
\hline 2036 & $1.75 E+10$ & $8.31 E+10$ & $9.86 \mathrm{E}+10$ & 1.47E+12 & $6.71 E+01$ & $1.06 \mathrm{E}+01$ \\
\hline 2037 & $1.79 \mathrm{E}+10$ & $8.50 E+10$ & $1.00 \mathrm{E}+11$ & $1.50 \mathrm{E}+12$ & $6.68 E+01$ & $1.03 E+01$ \\
\hline 2038 & $1.80 E+10$ & $8.55 E+10$ & $1.02 \mathrm{E}+11$ & $1.51 \mathrm{E}+12$ & $6.75 E+01$ & $1.11 \mathrm{E}+01$ \\
\hline 2039 & $1.84 \mathrm{E}+10$ & $8.74 E+10$ & $1.03 E+11$ & $1.55 \mathrm{E}+12$ & $6.64 \mathrm{E}+01$ & $9.93 E+00$ \\
\hline 2040 & $1.86 E+10$ & $8.83 E+10$ & $1.03 E+11$ & $1.56 \mathrm{E}+12$ & $6.61 E+01$ & $9.62 E+00$ \\
\hline 2041 & $1.88 E+10$ & $8.93 E+10$ & $1.05 E+11$ & $1.58 \mathrm{E}+12$ & $6.62 E+01$ & $9.71 E+00$ \\
\hline 2042 & $1.92 E+10$ & $9.12 E+10$ & $1.06 E+11$ & $1.61 \mathrm{E}+12$ & $6.54 \mathrm{E}+01$ & $8.95 E+00$ \\
\hline 2043 & $1.94 \mathrm{E}+10$ & $9.21 E+10$ & $1.07 E+11$ & $1.63 E+12$ & $6.56 \mathrm{E}+01$ & $9.16 E+00$ \\
\hline 2044 & $1.96 \mathrm{E}+10$ & $9.31 E+10$ & $1.08 E+11$ & $1.65 E+12$ & $6.55 E+01$ & $9.01 E+00$ \\
\hline 2045 & $1.99 \mathrm{E}+10$ & $9.45 E+10$ & $1.09 E+11$ & $1.67 \mathrm{E}+12$ & $6.52 E+01$ & $8.73 E+00$ \\
\hline 2046 & $2.01 \mathrm{E}+10$ & $9.55 \mathrm{E}+10$ & $1.09 \mathrm{E}+11$ & $1.69 \mathrm{E}+12$ & $6.46 \mathrm{E}+01$ & $8.15 \mathrm{E}+00$ \\
\hline 2047 & $2.05 E+10$ & $9.70 \mathrm{E}+10$ & $1.11 \mathrm{E}+11$ & $1.72 \mathrm{E}+12$ & $6.44 \mathrm{E}+01$ & $7.94 \mathrm{E}+00$ \\
\hline 2048 & $2.08 E+10$ & $9.85 E+10$ & $1.12 \mathrm{E}+11$ & $1.74 \mathrm{E}+12$ & $6.43 E+01$ & $7.81 \mathrm{E}+00$ \\
\hline 2049 & $2.11 \mathrm{E}+10$ & $9.99 E+10$ & $1.14 \mathrm{E}+11$ & 1.77E+12 & $6.42 E+01$ & $7.69 E+00$ \\
\hline 2050 & $2.14 \mathrm{E}+10$ & $1.01 \mathrm{E}+11$ & $1.15 E+11$ & $1.79 \mathrm{E}+12$ & $6.41 \mathrm{E}+01$ & $7.64 \mathrm{E}+00$ \\
\hline
\end{tabular}

Figure 9 (cont). Base Case 1: 2000-2050 yearly results for output calculations continued. 


\begin{tabular}{|c|c|c|c|c|c|c|}
\hline Year & $\begin{array}{l}\text { Total Cost } \\
\text { of Reactor } \\
\text { Operation } \\
\text { s by Year }\end{array}$ & $\begin{array}{c}\text { Total } \\
\text { Reactor } \\
\text { Cost each } \\
\text { Year }\end{array}$ & $\begin{array}{l}\text { Total Cost } \\
\text { each Year }\end{array}$ & $\begin{array}{l}\text { Total } \\
\text { Electricity } \\
\text { Produced } \\
\text { Yearly } \\
\text { (KwH/Yr) }\end{array}$ & $\begin{array}{l}\text { Fuel Cycle } \\
\text { (mills/KwH) }\end{array}$ & $\begin{array}{c}\text { Cost of } \\
\text { Electricity } \\
\text { (mills/KwH) }\end{array}$ \\
\hline 2051 & $2.12 E+10$ & 1.00E+11 & 1.15E+11 & 1.78E+12 & $6.45 E+01$ & $8.02 E+00$ \\
\hline 2052 & $2.10 E+10$ & $9.94 E+10$ & $1.14 \mathrm{E}+11$ & $1.76 \mathrm{E}+12$ & $6.49 E+01$ & 8.37E+00 \\
\hline 2053 & $2.13 E+10$ & $1.01 \mathrm{E}+11$ & $1.16 E+11$ & $1.79 E+12$ & $6.51 E+01$ & $8.65 E+00$ \\
\hline 2054 & 2.17E+10 & $1.02 E+11$ & $1.18 \mathrm{E}+11$ & $1.81 \mathrm{E}+12$ & $6.51 \mathrm{E}+01$ & $8.60 E+00$ \\
\hline 2055 & $2.20 E+10$ & $1.04 E+11$ & $1.20 \mathrm{E}+11$ & 1.84E+12 & $6.51 \mathrm{E}+01$ & $8.59 E+00$ \\
\hline 2056 & $2.24 E+10$ & 1.06E+11 & $1.22 E+11$ & 1.87E+12 & $6.50 \mathrm{E}+01$ & $8.49 E+00$ \\
\hline 2057 & $2.27 E+10$ & 1.07E+11 & $1.23 E+11$ & $1.90 \mathrm{E}+12$ & $6.49 E+01$ & $8.45 E+00$ \\
\hline 2058 & $2.30 E+10$ & $1.09 \mathrm{E}+11$ & $1.25 E+11$ & $1.92 E+12$ & $6.49 \mathrm{E}+01$ & 8.37E+00 \\
\hline 2059 & $2.34 \mathrm{E}+10$ & $1.11 \mathrm{E}+11$ & $1.26 \mathrm{E}+11$ & 1.96E+12 & $6.45 E+01$ & $7.99 \mathrm{E}+00$ \\
\hline 2060 & $2.37 E+10$ & $1.12 \mathrm{E}+11$ & $1.28 \mathrm{E}+11$ & $1.98 \mathrm{E}+12$ & $6.48 \mathrm{E}+01$ & $8.31 \mathrm{E}+00$ \\
\hline 2061 & $2.41 \mathrm{E}+10$ & $1.14 \mathrm{E}+11$ & $1.31 \mathrm{E}+11$ & $2.02 E+12$ & $6.48 E+01$ & $8.28 \mathrm{E}+00$ \\
\hline 2062 & $2.45 E+10$ & $1.16 \mathrm{E}+11$ & $1.33 E+11$ & $2.05 E+12$ & $6.47 E+01$ & $8.24 E+00$ \\
\hline 2063 & $2.48 E+10$ & 1.17E+11 & $1.34 \mathrm{E}+11$ & 2.07E+12 & $6.48 E+01$ & $8.29 E+00$ \\
\hline 2064 & $2.53 E+10$ & $1.20 \mathrm{E}+11$ & 1.37E+11 & $2.12 E+12$ & $6.47 E+01$ & $8.18 E+00$ \\
\hline 2065 & $2.58 E+10$ & 1.22E+11 & $1.40 \mathrm{E}+11$ & $2.16 \mathrm{E}+12$ & $6.49 \mathrm{E}+01$ & $8.39 E+00$ \\
\hline 2066 & $2.62 E+10$ & $1.24 \mathrm{E}+11$ & $1.42 E+11$ & $2.19 E+12$ & $6.48 E+01$ & $8.30 E+00$ \\
\hline 2067 & $2.68 E+10$ & $1.26 \mathrm{E}+11$ & $1.45 E+11$ & $2.24 \mathrm{E}+12$ & $6.49 \mathrm{E}+01$ & $8.43 E+00$ \\
\hline 2068 & $2.71 E+10$ & $1.28 \mathrm{E}+11$ & $1.48 \mathrm{E}+11$ & $2.26 \mathrm{E}+12$ & $6.55 \mathrm{E}+01$ & $9.00 \mathrm{E}+00$ \\
\hline 2069 & $2.75 E+10$ & $1.30 \mathrm{E}+11$ & $1.50 \mathrm{E}+11$ & $2.30 \mathrm{E}+12$ & $6.51 \mathrm{E}+01$ & $8.64 \mathrm{E}+00$ \\
\hline 2070 & $2.80 E+10$ & $1.32 \mathrm{E}+11$ & $1.51 \mathrm{E}+11$ & $2.34 \mathrm{E}+12$ & $6.48 E+01$ & $8.26 E+00$ \\
\hline 2071 & $2.83 E+10$ & $1.34 \mathrm{E}+11$ & $1.53 E+11$ & $2.36 \mathrm{E}+12$ & $6.47 E+01$ & $8.23 E+00$ \\
\hline 2072 & 2.87E+10 & $1.35 E+11$ & $1.55 E+11$ & $2.40 \mathrm{E}+12$ & $6.46 \mathrm{E}+01$ & $8.15 E+00$ \\
\hline 2073 & $2.89 E+10$ & 1.36E+11 & $1.56 \mathrm{E}+11$ & $2.41 E+12$ & $6.47 E+01$ & $8.17 E+00$ \\
\hline 2074 & 2.97E+10 & 1.37E+11 & $1.58 \mathrm{E}+11$ & $2.42 E+12$ & $6.53 E+01$ & $8.80 \mathrm{E}+00$ \\
\hline 2075 & $3.15 E+10$ & 1.39E+11 & $1.61 \mathrm{E}+11$ & $2.46 \mathrm{E}+12$ & $6.53 E+01$ & 8.77E+00 \\
\hline 2076 & $3.30 E+10$ & $1.41 \mathrm{E}+11$ & $1.62 E+11$ & $2.49 E+12$ & $6.49 E+01$ & $8.30 E+00$ \\
\hline 2077 & $3.51 \mathrm{E}+10$ & 1.44E+11 & $1.67 E+11$ & $2.55 E+12$ & $6.53 E+01$ & $8.74 \mathrm{E}+00$ \\
\hline 2078 & $3.70 E+10$ & $1.49 E+11$ & $1.72 E+11$ & $2.63 E+12$ & $6.55 E+01$ & $8.85 E+00$ \\
\hline 2079 & $3.78 E+10$ & $1.52 \mathrm{E}+11$ & $1.76 \mathrm{E}+11$ & $2.69 E+12$ & $6.53 E+01$ & $8.74 \mathrm{E}+00$ \\
\hline 2080 & $3.83 E+10$ & $1.54 \mathrm{E}+11$ & $1.78 \mathrm{E}+11$ & $2.72 E+12$ & $6.54 \mathrm{E}+01$ & $8.78 E+00$ \\
\hline 2081 & $3.92 E+10$ & $1.56 \mathrm{E}+11$ & $1.79 E+11$ & $2.76 \mathrm{E}+12$ & $6.47 E+01$ & $8.12 E+00$ \\
\hline 2082 & $3.96 E+10$ & $1.57 \mathrm{E}+11$ & $1.80 \mathrm{E}+11$ & $2.78 \mathrm{E}+12$ & $6.49 E+01$ & $8.30 E+00$ \\
\hline 2083 & $4.05 E+10$ & $1.59 \mathrm{E}+11$ & $1.85 E+11$ & $2.81 E+12$ & $6.59 \mathrm{E}+01$ & $9.23 E+00$ \\
\hline 2084 & $4.13 E+10$ & $1.60 \mathrm{E}+11$ & $1.85 E+11$ & $2.82 E+12$ & $6.57 E+01$ & $9.09 E+00$ \\
\hline 2085 & $4.29 E+10$ & $1.62 E+11$ & $1.89 E+11$ & 2.87E+12 & $6.60 \mathrm{E}+01$ & $9.30 \mathrm{E}+00$ \\
\hline 2086 & $4.46 E+10$ & $1.65 E+11$ & $1.90 \mathrm{E}+11$ & $2.92 E+12$ & $6.52 E+01$ & $8.55 E+00$ \\
\hline 2087 & $4.68 \mathrm{E}+10$ & $1.71 \mathrm{E}+11$ & $1.96 \mathrm{E}+11$ & $3.01 \mathrm{E}+12$ & $6.52 E+01$ & $8.49 E+00$ \\
\hline 2088 & $4.76 E+10$ & $1.73 E+11$ & $1.98 \mathrm{E}+11$ & $3.05 E+12$ & $6.50 \mathrm{E}+01$ & $8.28 E+00$ \\
\hline 2089 & $4.88 E+10$ & $1.78 \mathrm{E}+11$ & 2.03E+11 & $3.13 E+12$ & $6.49 \mathrm{E}+01$ & $8.20 E+00$ \\
\hline 2090 & $5.02 E+10$ & 1.83E+11 & 2.09E+11 & $3.23 E+12$ & 6.47E+01 & $8.06 E+00$ \\
\hline 2091 & $5.06 \mathrm{E}+10$ & $1.84 \mathrm{E}+11$ & 2.11E+11 & $3.25 E+12$ & $6.50 \mathrm{E}+01$ & $8.26 \mathrm{E}+00$ \\
\hline 2092 & $5.21 E+10$ & $1.88 \mathrm{E}+11$ & $2.16 \mathrm{E}+11$ & 3.31E+12 & $6.53 E+01$ & $8.65 E+00$ \\
\hline 2093 & $5.31 \mathrm{E}+10$ & $1.90 \mathrm{E}+11$ & $2.18 E+11$ & $3.35 E+12$ & $6.52 E+01$ & $8.49 E+00$ \\
\hline 2094 & $5.46 \mathrm{E}+10$ & 1.93E+11 & 2.23E+11 & $3.40 E+12$ & $6.57 E+01$ & $8.94 E+00$ \\
\hline 2095 & $5.58 \mathrm{E}+10$ & $1.95 E+11$ & 2.24E+11 & $3.44 \mathrm{E}+12$ & $6.53 E+01$ & $8.56 E+00$ \\
\hline 2096 & 5.77E+10 & $2.00 E+11$ & $2.30 \mathrm{E}+11$ & $3.52 E+12$ & $6.52 E+01$ & $8.50 E+00$ \\
\hline 2097 & $5.83 E+10$ & $2.02 E+11$ & $2.34 \mathrm{E}+11$ & $3.56 E+12$ & $6.59 \mathrm{E}+01$ & $9.12 E+00$ \\
\hline 2098 & $5.96 E+10$ & $2.06 \mathrm{E}+11$ & 2.37E+11 & $3.63 E+12$ & $6.52 E+01$ & $8.47 E+00$ \\
\hline 2099 & $5.99 E+10$ & $2.08 E+11$ & 2.39E+11 & $3.66 E+12$ & $6.52 E+01$ & $8.49 E+00$ \\
\hline 2100 & $6.13 E+10$ & $2.10 \mathrm{E}+11$ & $2.42 E+11$ & $3.70 \mathrm{E}+12$ & $6.53 E+01$ & $8.56 \mathrm{E}+00$ \\
\hline
\end{tabular}

Figure 9 (cont). Base Case 1: 2050-2100 yearly results for output calculations continued. 


\begin{tabular}{|c|c|c|c|c|}
\hline \multirow[t]{2}{*}{ Case 1} & \multicolumn{4}{|l|}{ Base Case } \\
\hline & Probability & $\begin{array}{c}\text { Cost of } \\
\text { Electricity }\end{array}$ & Probability & Fuel Cycle Costs \\
\hline Bin 1 & 0 & 78.11704692 & 0 & 6.680674004 \\
\hline Bin 2 & 0.001 & 78.43784744 & 0.001 & 6.874909969 \\
\hline Bin 3 & 0.002 & 78.75864795 & 0 & 7.069145934 \\
\hline Bin 4 & 0.004 & 79.07944847 & 0 & 7.263381898 \\
\hline Bin 5 & 0.007 & 79.40024899 & 0.003 & 7.457617863 \\
\hline Bin 6 & 0.016 & 79.7210495 & 0.004 & 7.651853828 \\
\hline Bin 7 & 0.021 & 80.04185002 & 0.004 & 7.846089793 \\
\hline Bin 8 & 0.032 & 80.36265053 & 0.006 & 8.040325758 \\
\hline Bin 9 & 0.047 & 80.68345105 & 0.019 & 8.234561723 \\
\hline Bin 10 & 0.054 & 81.00425156 & 0.032 & 8.428797687 \\
\hline Bin 11 & 0.057 & 81.32505208 & 0.04 & 8.623033652 \\
\hline Bin 12 & 0.079 & 81.64585259 & 0.048 & 8.817269617 \\
\hline Bin 13 & 0.074 & 81.96665311 & 0.07 & 9.011505582 \\
\hline Bin 14 & 0.077 & 82.28745363 & 0.075 & 9.205741547 \\
\hline Bin 15 & 0.058 & 82.60825414 & 0.086 & 9.399977512 \\
\hline Bin 16 & 0.062 & 82.92905466 & 0.082 & 9.594213476 \\
\hline Bin 17 & 0.061 & 83.24985517 & 0.093 & 9.788449441 \\
\hline Bin 18 & 0.055 & 83.57065569 & 0.082 & 9.982685406 \\
\hline Bin 19 & 0.048 & 83.8914562 & 0.087 & 10.17692137 \\
\hline Bin 20 & 0.049 & 84.21225672 & 0.062 & 10.37115734 \\
\hline Bin 21 & 0.035 & 84.53305723 & 0.067 & 10.5653933 \\
\hline Bin 22 & 0.027 & 84.85385775 & 0.048 & 10.75962927 \\
\hline Bin 23 & 0.032 & 85.17465827 & 0.03 & 10.95386523 \\
\hline Bin 24 & 0.023 & 85.49545878 & 0.013 & 11.14810119 \\
\hline Bin 25 & 0.021 & 85.8162593 & 0.022 & 11.34233716 \\
\hline Bin 26 & 0.022 & 86.13705981 & 0.007 & 11.53657312 \\
\hline Bin 27 & 0.012 & 86.45786033 & 0.007 & 11.73080909 \\
\hline Bin 28 & 0.006 & 86.77866084 & 0.006 & 11.92504505 \\
\hline Bin 29 & 0.009 & 87.09946136 & 0.003 & 12.11928102 \\
\hline Bin 30 & 0.004 & 87.42026187 & 0.001 & 12.31351698 \\
\hline Bin 31 & 0.002 & 87.74106239 & 0.001 & 12.50775295 \\
\hline Bin 32 & 0.002 & 88.06186291 & 0 & 12.70198891 \\
\hline Bin 33 & 0.001 & 88.38266342 & 0.001 & 12.89622488 \\
\hline Bin 34 & 0 & 88.70346394 & 0 & 13.09046084 \\
\hline
\end{tabular}

Figure 10. Monte Carlo sampling results for fuel cycle costs and cost of electricity distributions. 
In the savable output econ.xls file, output charts have been developed to support economic analysis. These charts are automatically created after each VISION run, from the numeric data that is sent to the savable output econ.xls file automatically from VISION. Figures 11-20 show all output charts for a single sample run. Charts in Figure 11 and 12 show an example of cost distributions for the fuel cycle and cost of electricity in mills $/ \mathrm{kWh}$. Charts in Figures 13 and 14 illustrate the annual fuel cycle cost and annual cost of electricity from 2000 to 2100 in mills/kWh. The chart in Figure 15 shows the annual unit breakdown of fuel cycle cost and cost of electricity. The chart in Figure 16 contains the annual energy output for each reactor type in $\mathrm{kWh} / \mathrm{yr}$.

Charts that show the stacked costs for the front-end, recycling, back-end, capital, and reactor operating costs (in \$) annually for each run are available in the savable output econ.xls file. Examples of stacked annual cost charts from the Excel savable output econ.xls file are shown in Figures 17-20. Figure 17 shows annual energy total costs with respect to the front end, back end, recycling, reactor operation, and annual capital costs. Figure 17 gives the annual front-end cost breakdown by front-end fuel cycle step including, mining, conversion, fuel fabrication, enrichment, and depleted uranium disposition. Figure 19 gives the annual back-end cost breakdown by back-end fuel cycle step, including dry fuel storage, managed retrievable storage (MRS), High-Level Waste (HLW)in repository, fuel fabrication, and depleted uranium disposition. Figure 20 gives the annual recycling cost breakdown by recycling fuel cycle step including, separations, recycled product storage, HLW conditioning, LLW conditioning, Cladding and Greater than Class C (GTCC, near surface disposal, and reprocessed uranium. In addition to charts with single run information, there are also charts that show comparative data between runs. Figure 21 gives an example of a comparison of the composite cost of electricity distribution for a range of recycling process losses. Other output charts are available in the savable output econ.xls file comparing data gathered from the five most recent runs of VISION, and the two most recent runs.

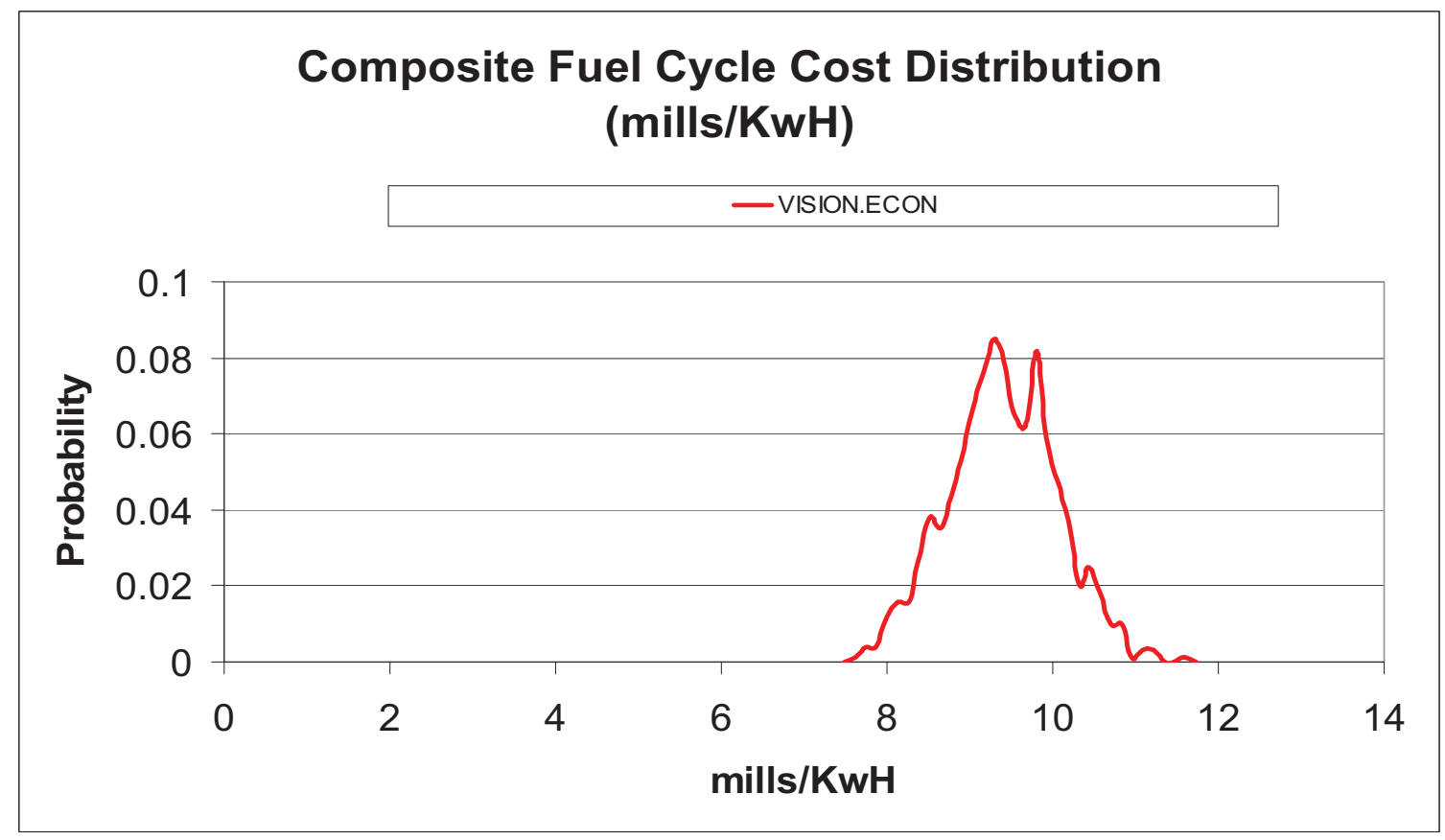

Figure 11. Composite fuel cycle cost distribution. 


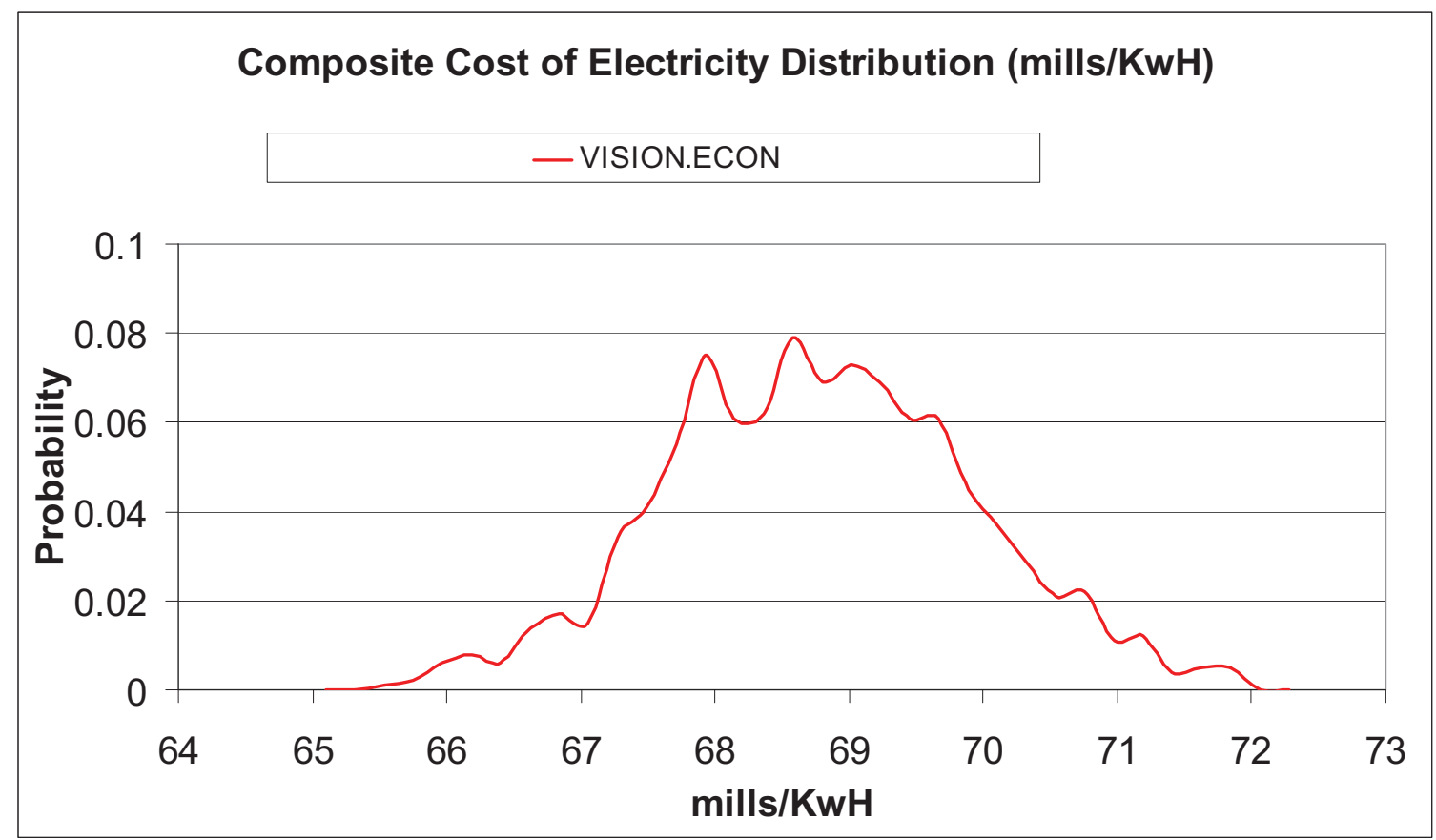

Figure 12. Distribution of composite cost of electricity at the end of the simulation.

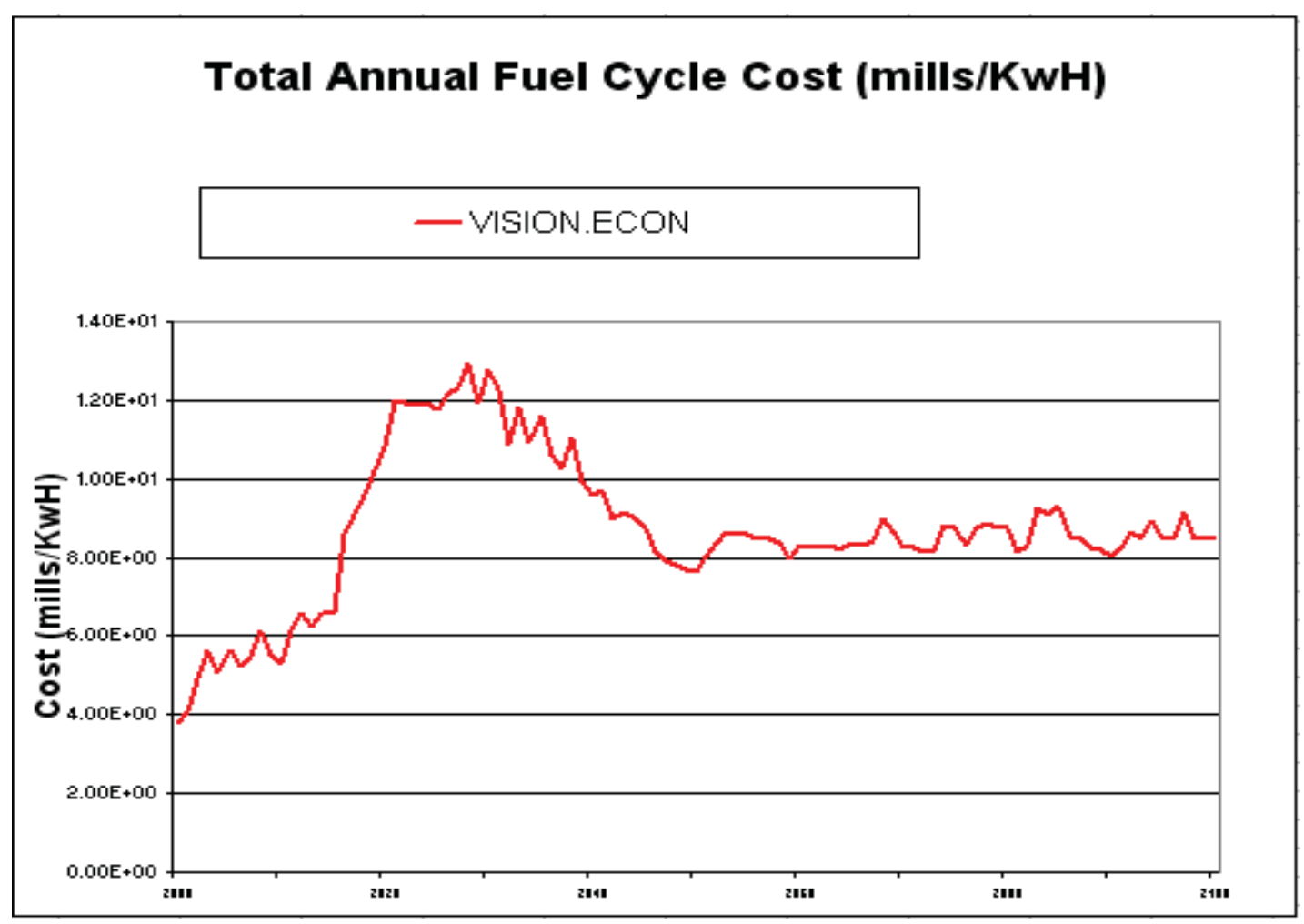

Figure 13. Total annual fuel cycle cost. 


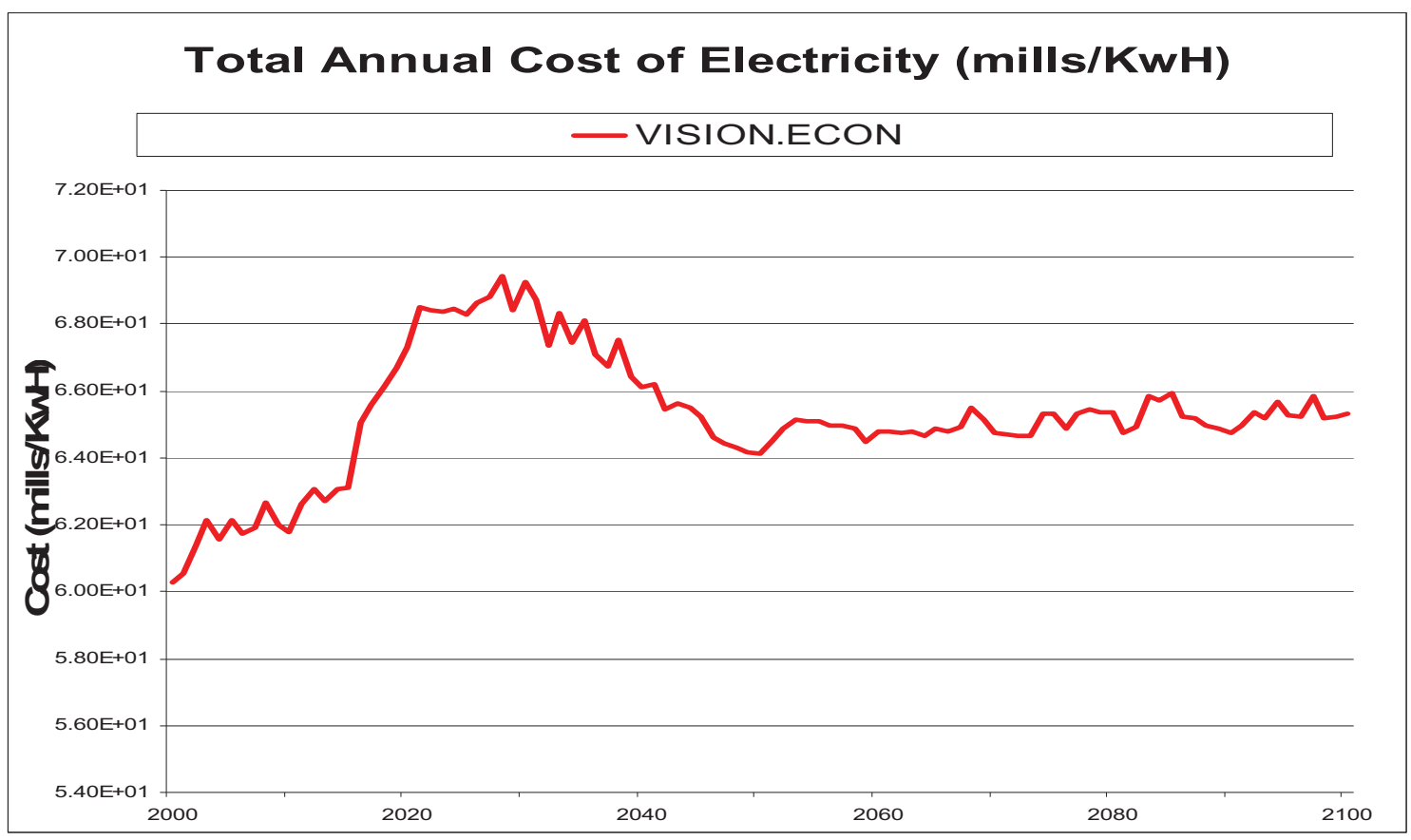

Figure 14. Total annual cost of electricity.

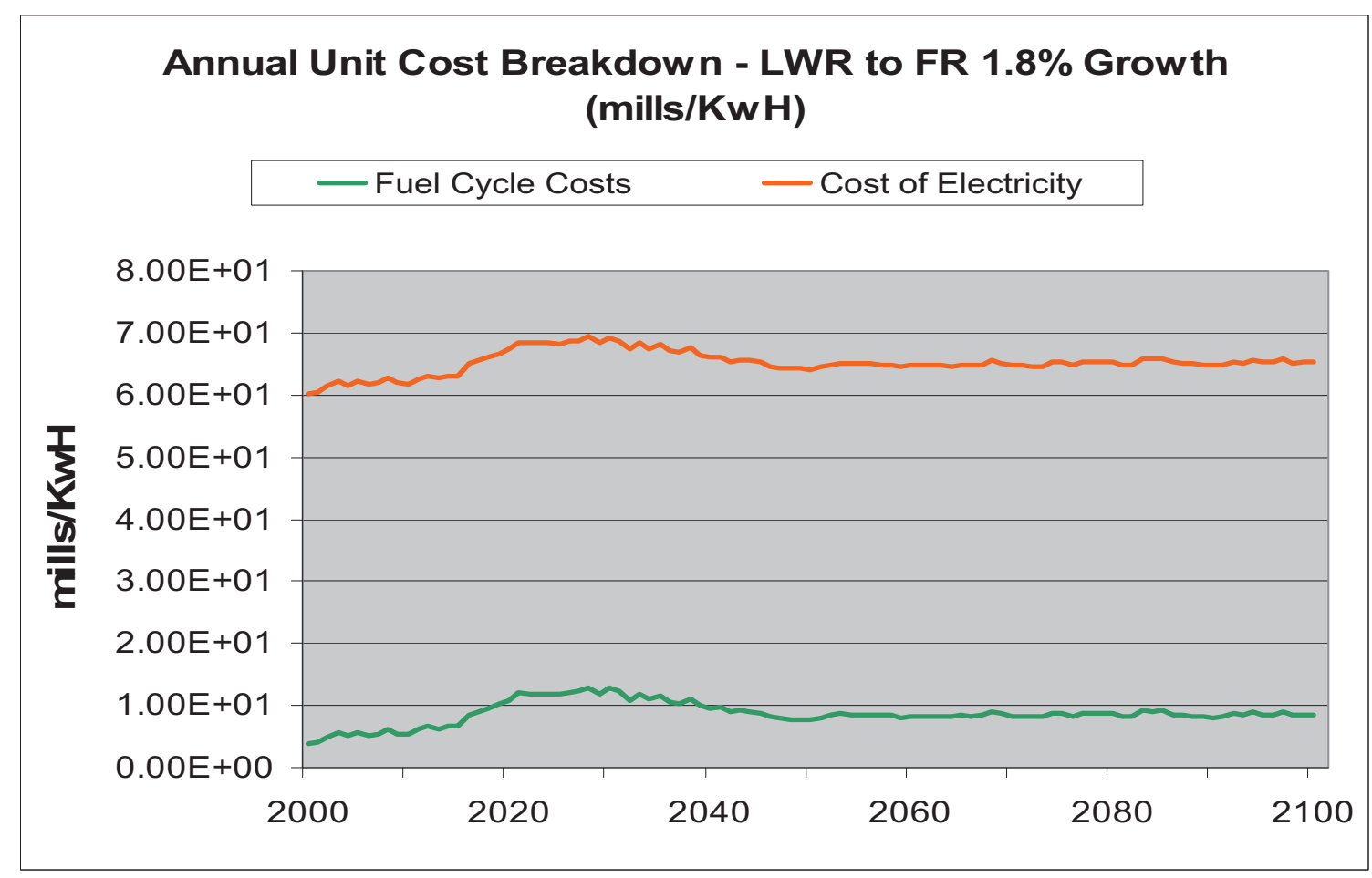

Figure 15. Annual unit cost breakdown. Fuel cycle costs do not include cost of reactor construction and operation where cost of electricity does include reactor costs. 


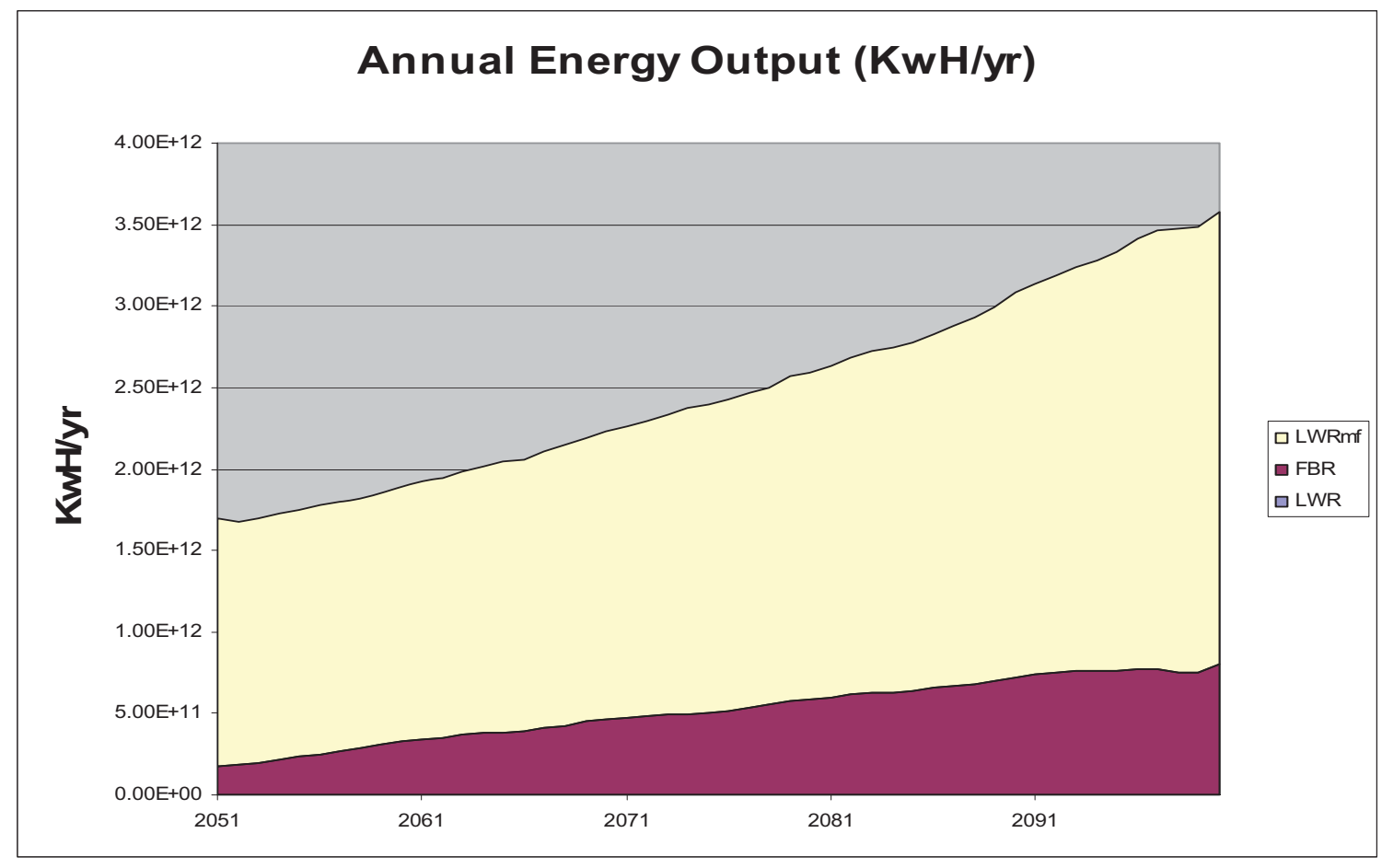

Figure 16. Annual energy output by reactor type.

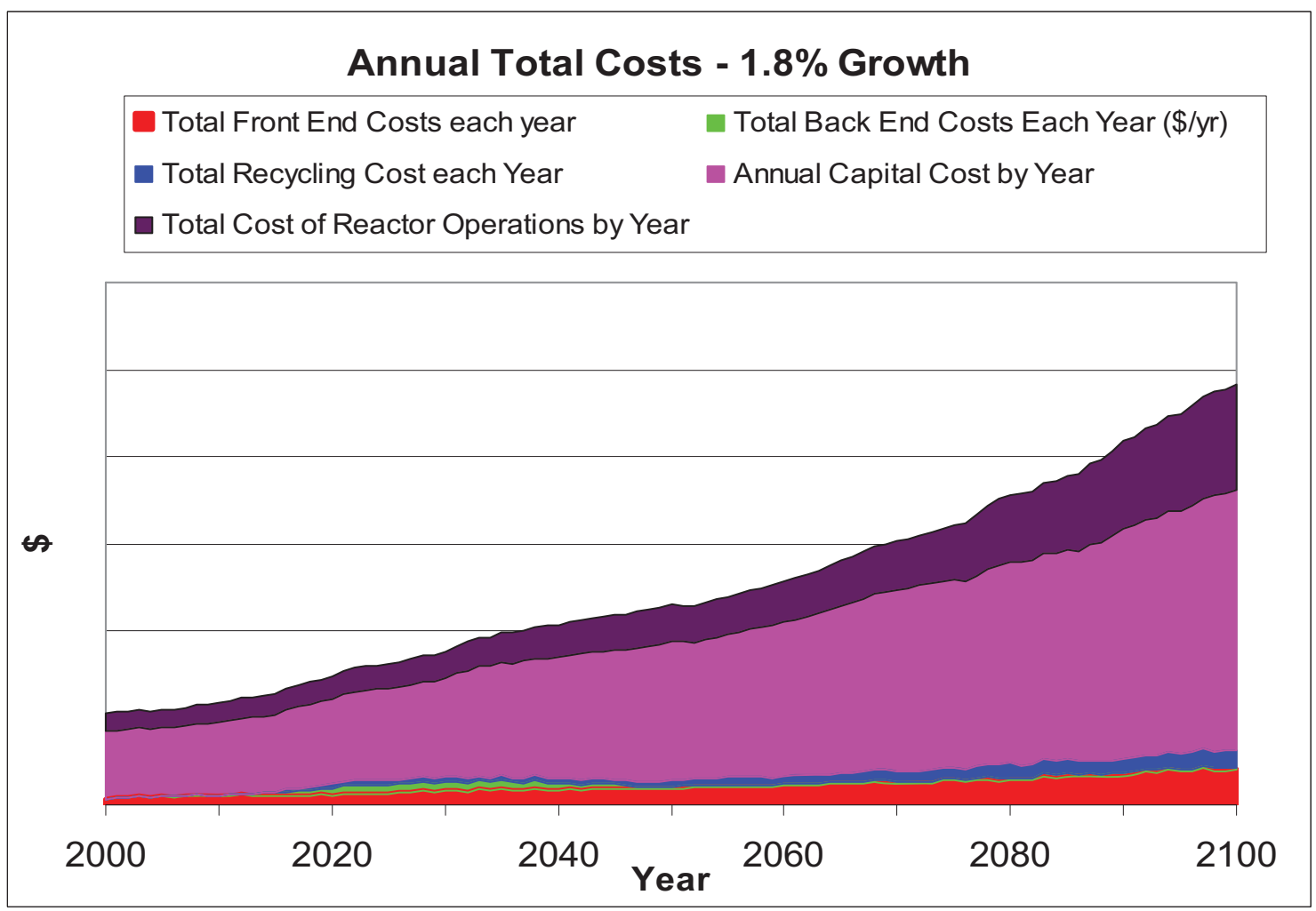

Figure 17. Annual total costs broken down by front-end costs, back-end costs, recycling costs, reactor operation costs, and reactor capital costs. 


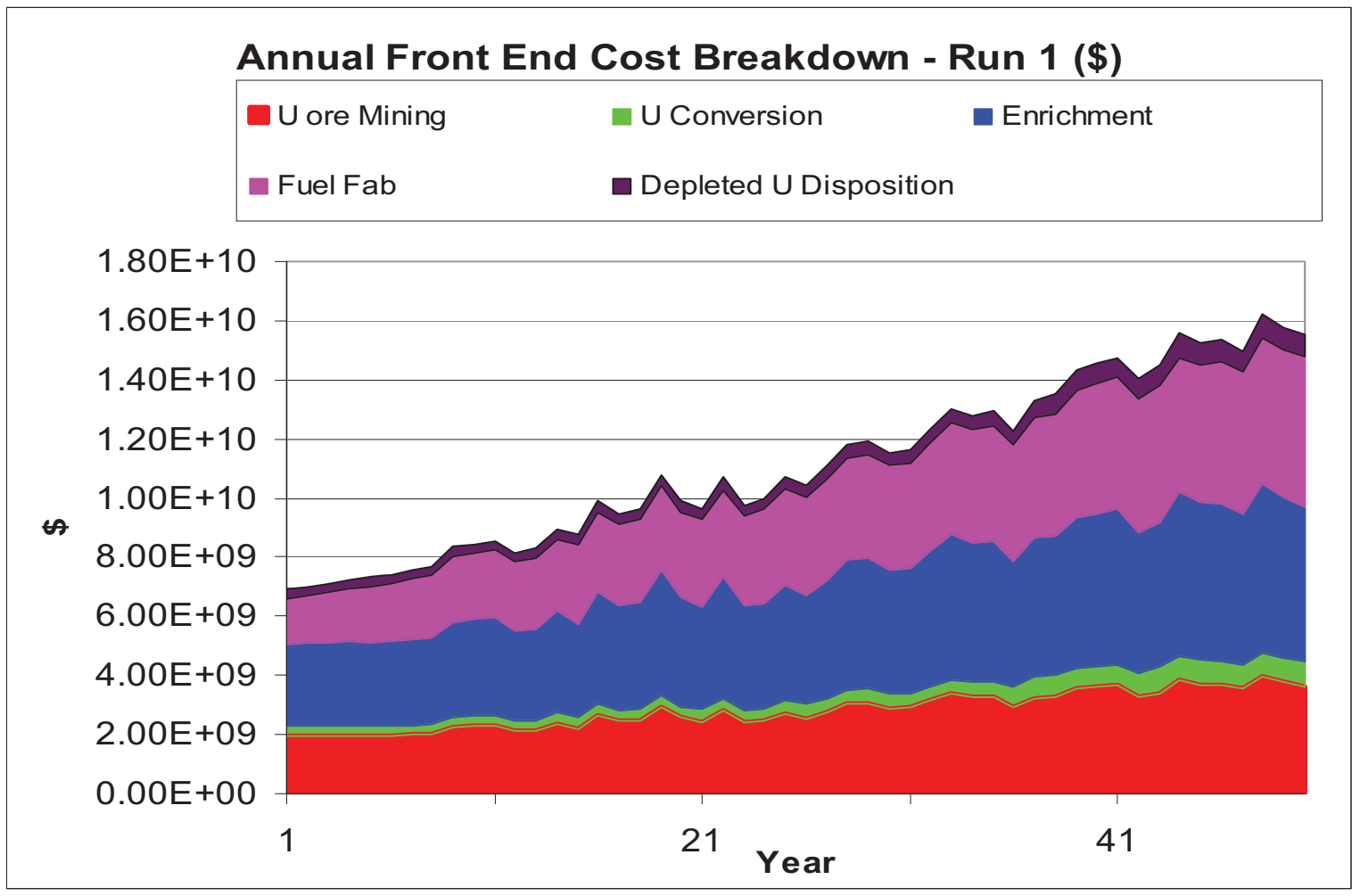

Figure 18. Annual front-end cost breakdown by module.

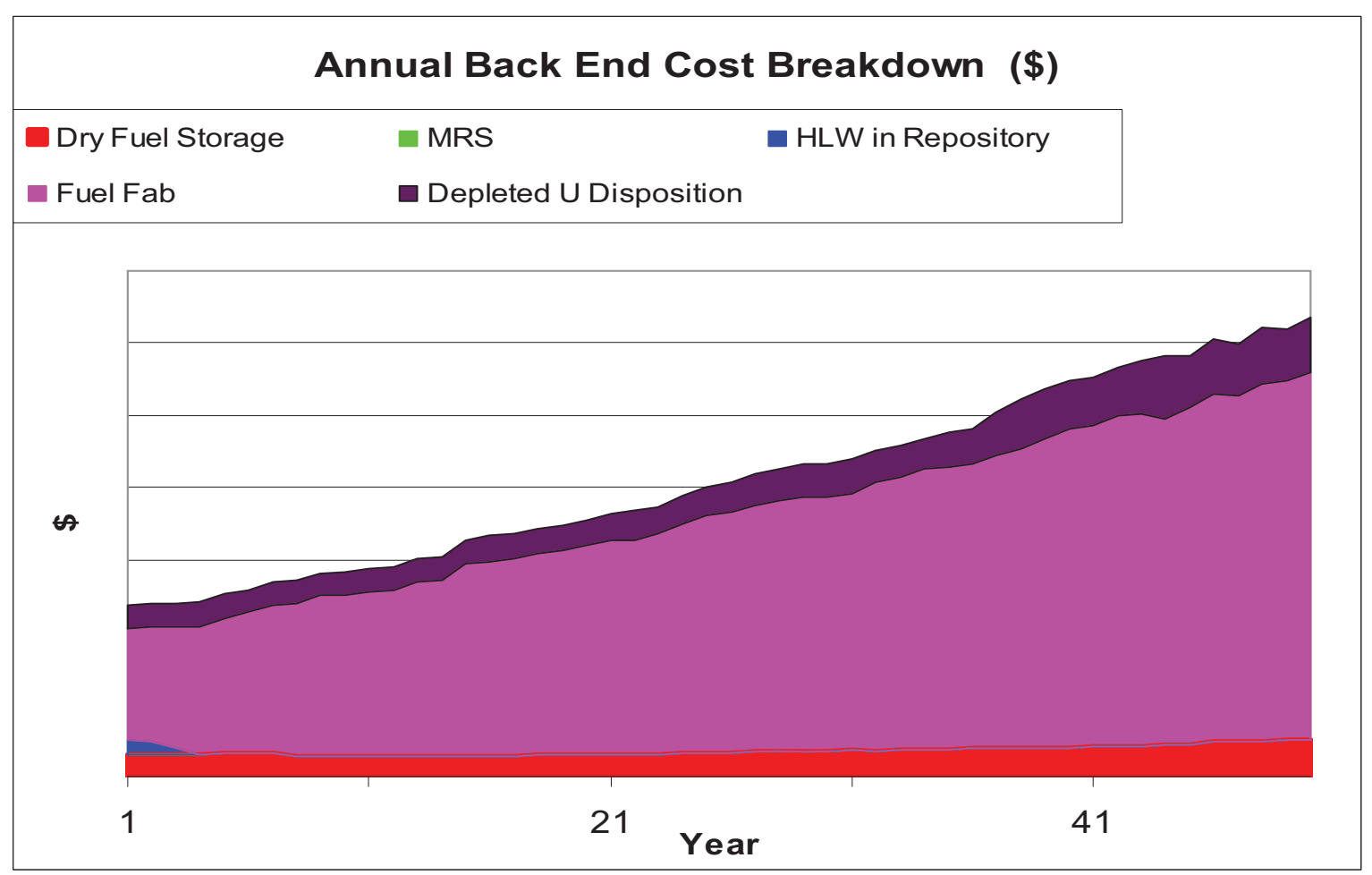

Figure 19. Annual back-end cost breakdown by module. 


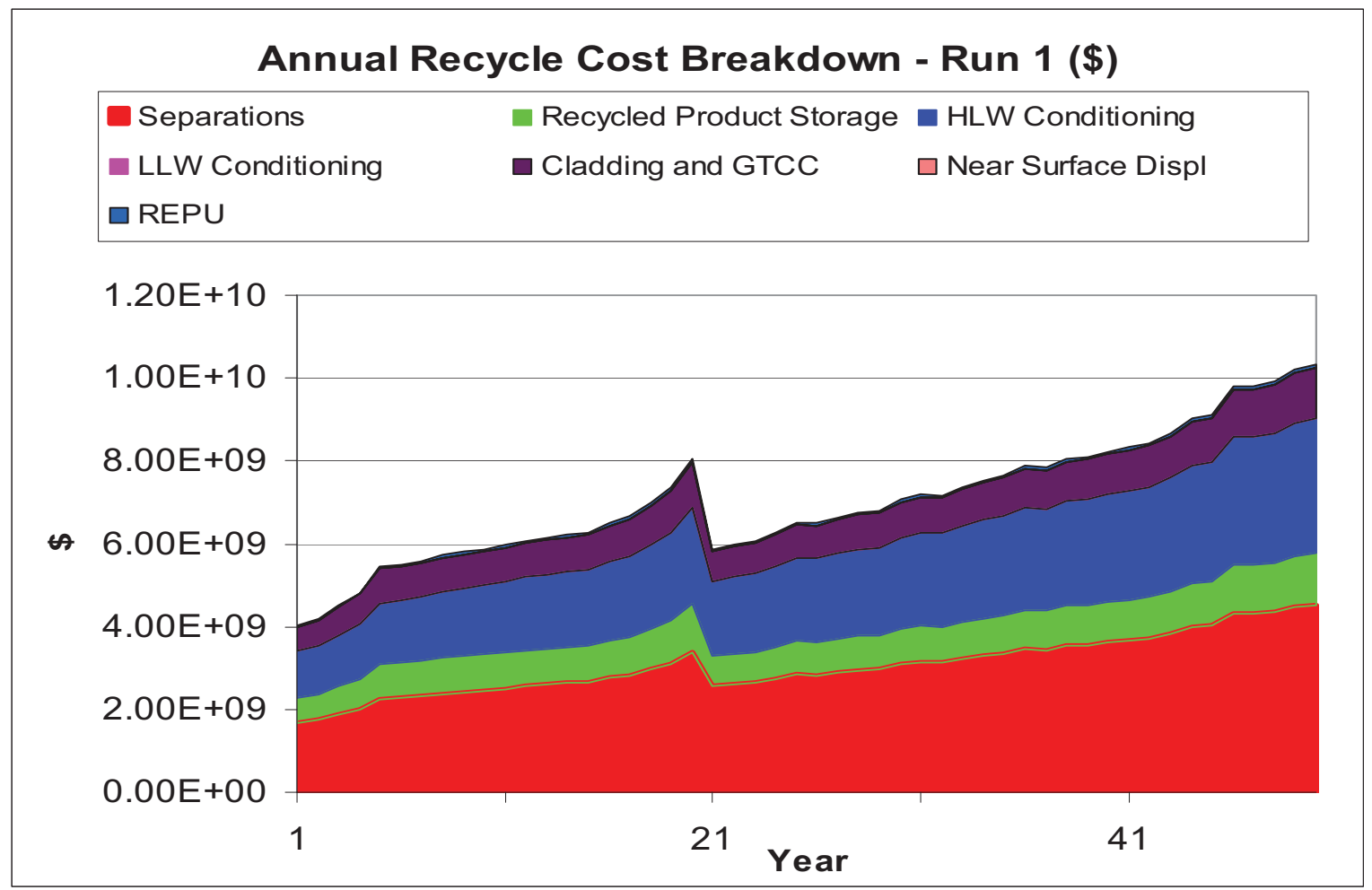

Figure 20. Annual recycle cost breakdown by module.

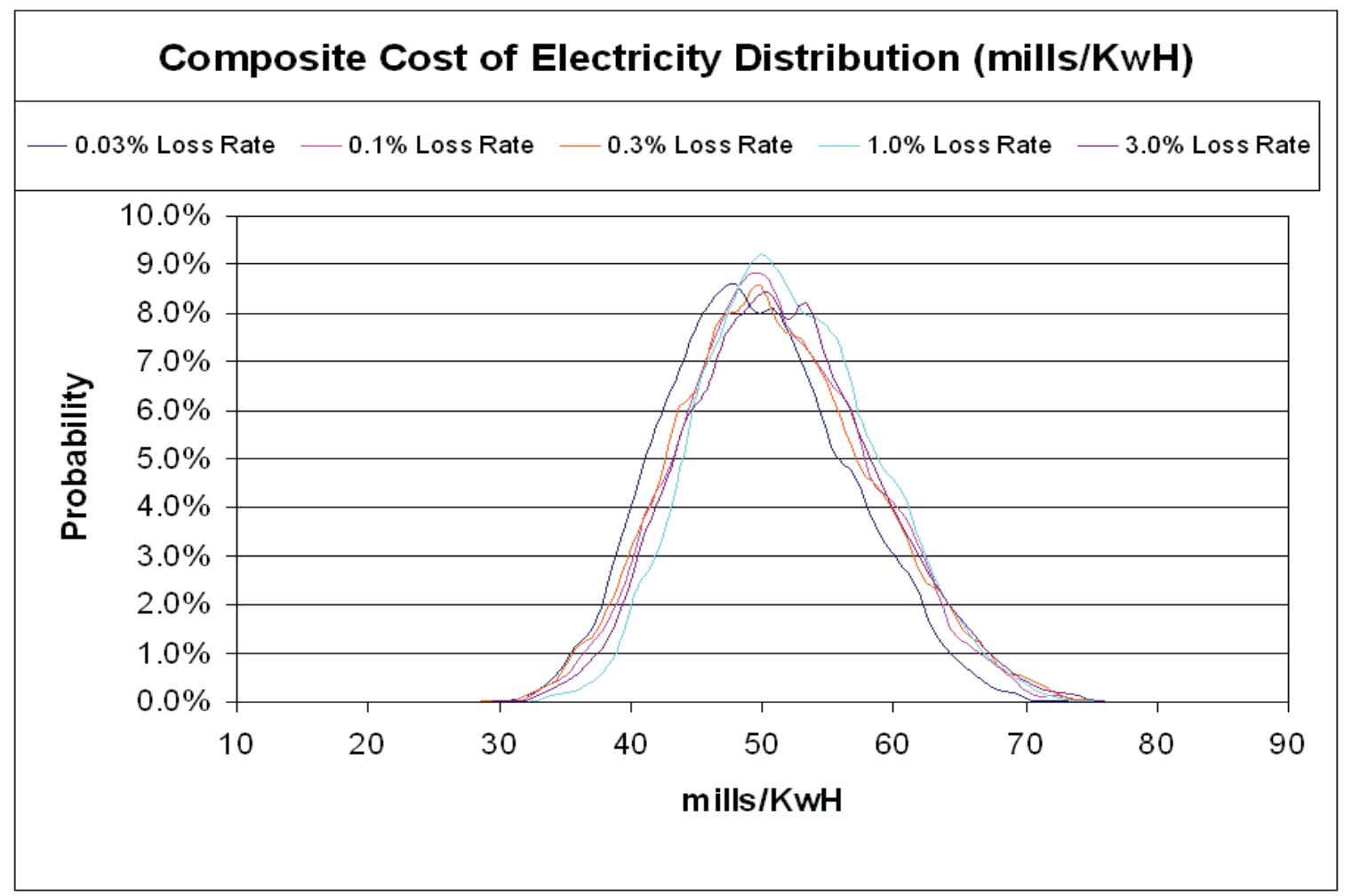

Figure 21. Comparison of composite cost of electricity distribution for the five previous VISION model runs. 


\section{SENSITIVITY ANALYSIS}

The Powersim platform on which VISION was built contains a tool for sensitivity analysis. This section details how to set up a sensitivity analysis and gives a sample setup and results. The user will first create a risk analysis clone after opening the VISION program in the Advanced Mode. This is done by right clicking the Simulation Controls under the VISION Flow Model heading in the sidebar and choosing the "Add Risk Analysis Clone" option. This will create a copy of the entire VISION model. After opening the Risk Analysis heading, click on the Analysis Variable heading to open its window.

The Analysis Variable window should display four categories: assumptions, decisions, objectives, and effects. Assumptions are parameters that the user would like to vary. Only one assumption may be selected for each run, and the parameters must be a level or constant. Additional information about Powersim variables including levels, constants, and auxiliaries can be found in the help section of the program. The assumption is sampled from a user-selected distribution, which includes normal, triangular, and uniform distributions among choices. Decisions are parameters that the user changes from the set value in the model. These parameters must be constants and the user can define the time that the decision value will be in affect. Objectives are computed variables that are a target for optimization and are not utilized in the Risk Analysis. The variable selected under the effects heading is the variable that is analyzed due to changes in the assumption and decision variables. Multiple effects can be chosen per each Risk Analysis run. Percentile, average, and standard deviation values can be selected as output data under effects properties.

Simulation settings must also be defined before the Risk Analysis can be ran. The Risk Analysis tab in the simulation settings lets the user input the Risk Analysis method: Monte Carlo or Latin Hyper Cube; the run count; and the seed type: random or fixed. Latin Hypercube is the preferred method and requires a minimum run count of ten or five depending on the Powersim version the user is running. Powersim recommends a run count of at least 40 for final results. Risk Analysis results may be duplicated for different runs by using an identical random seed on the same computer. The use of a different computer may produce a different random seed, although it uses the same random seed number due to computer configuration. Other tabs in the simulation settings may be modified to change the time settings of the Risk Analysis to differ from the simulation time settings.

Figure 22 below illustrates a sample Analysis Variables window. The sample VISION run uses a once through fuel cycle with a lone LWRmf reactor. The USA growth rate is zero for this user-defined run. The assumption variable is the capacity factor variable named "capacity factor2." Capacity factor, as originally defined in the model, is an auxiliary with information inputted from an Excel file. All auxiliaries are manually replaced with the renamed constant variable "capacity factor2." The assumption variable varies the capacity factor for all reactors. This only affects the LWRmf since it is the only reactor type available for this user-defined run and has a uniform distribution within the range of 0.8 to 0.95 .

The effect variable is the Total Cost of Electricity (TCOE) per year and is defined as the ratio of the total cost to the total electricity produced for the specified year with the units mills $/ \mathrm{kWh}$. The effect variable has output data for the $5^{\text {th }}, 25^{\text {th }}, 50^{\text {th }}, 75^{\text {th }}, 90^{\text {th }}$ percentiles and the average. In the time step, start and stop time are the same as the simulation. The output data, for the last time step of the Risk Analysis run, is displayed in the Analysis Variable page at the conclusion of the run. Opening the effects properties displays the output data for each time step. This data can be exported into a text file or copied to a clipboard to be pasted into a data manipulation file, such as Excel. Figure 22 illustrates the results of the Risk Analysis run. 


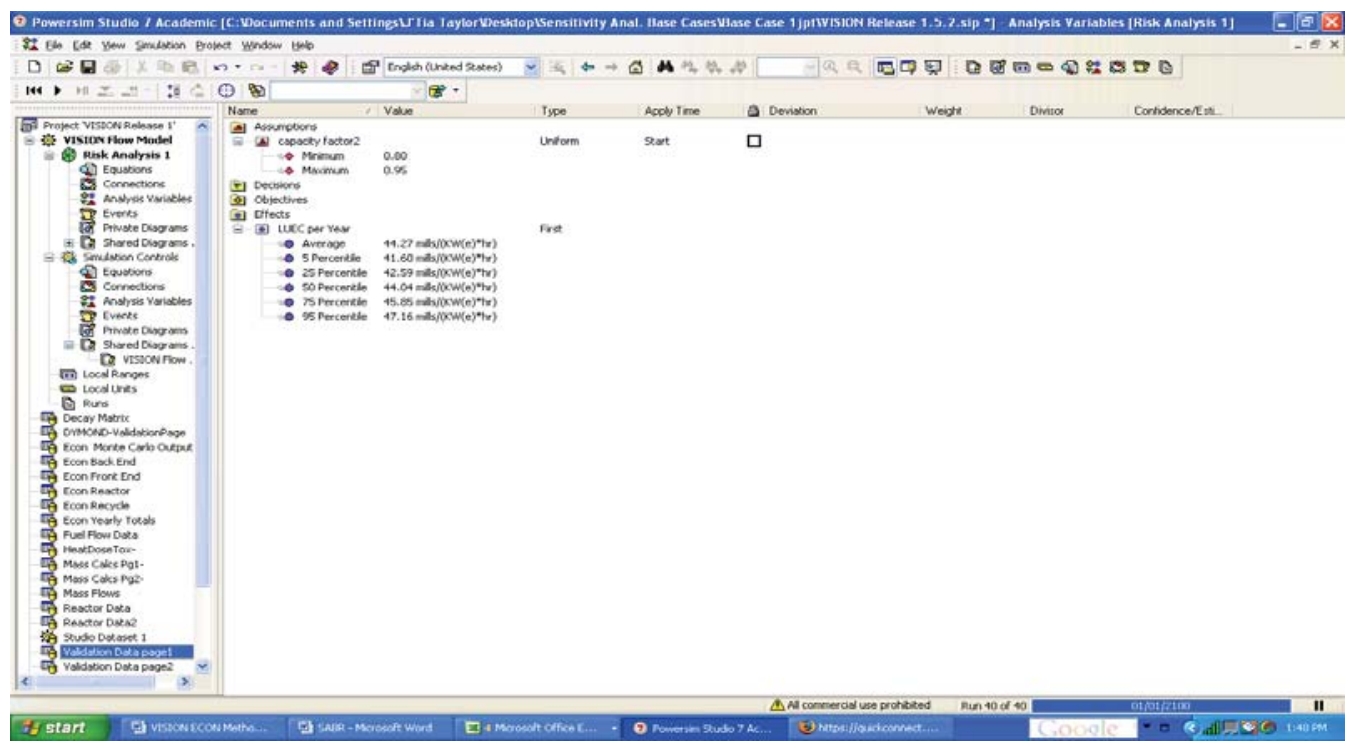

Figure 22. Risk Analysis Feature Analysis variable page for a sample run varying capacity factor and measuring effect on TCOE per year.

Users must be cautious in interpreting the results of the Risk Analysis tool. Risks Analysis runs, which are not at equilibrium, can introduce a dynamic system parameter influence on the effect variable. Data illustrated in Figure 23 shows that the Risk Analysis reaches equilibrium at the July 2005 time step. Subsequent time steps only fluctuate due to sampling of the capacity factor distribution. Thus in an analysis, only the equilibrium data should be compared. The $5^{\text {th }}$ percentile value for this run is 41.60 mills $/ \mathrm{kWh}$ and the $95^{\text {th }}$ percentile value for this run is 47.16 mills $/ \mathrm{kWh}$ at equilibrium.

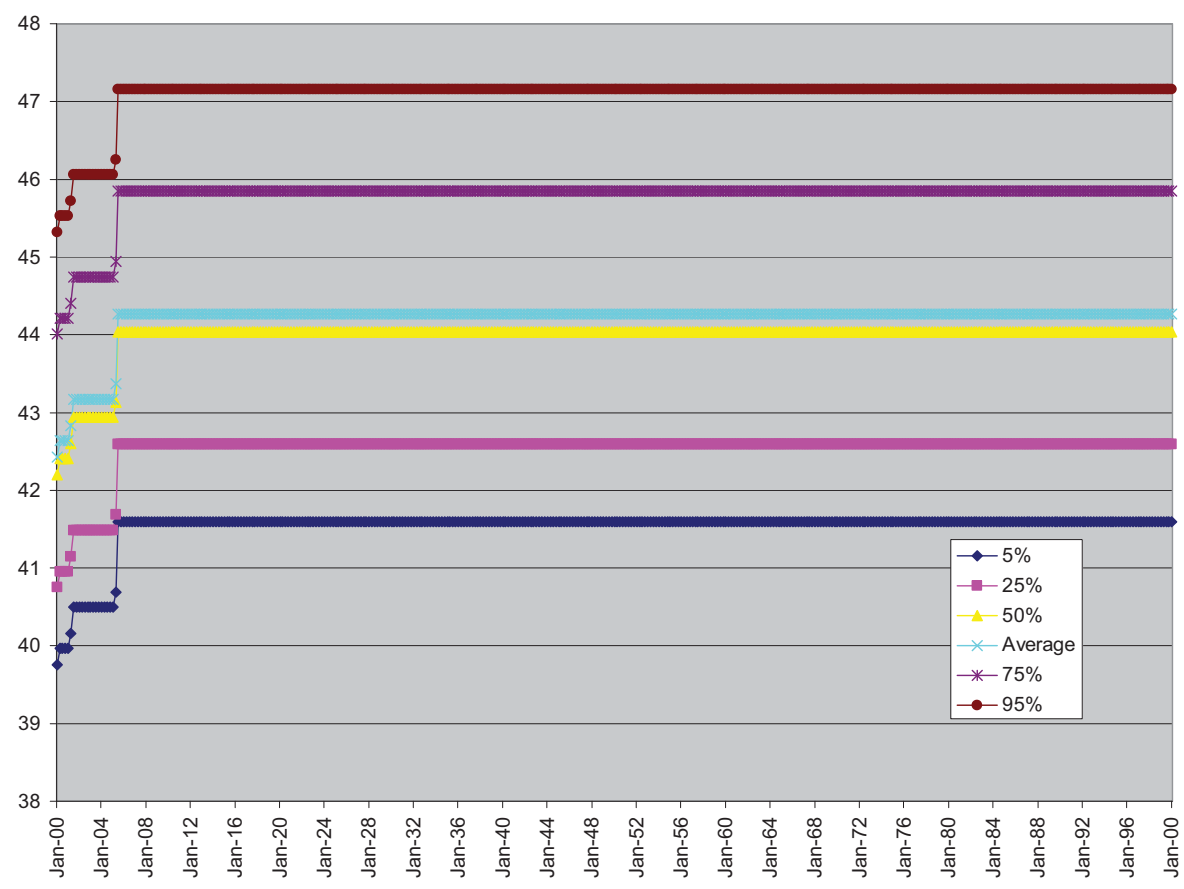

Figure 22. Risk Analysis results of TCOE per year for capacity factor variation for each time step outputted and graphed in Excel. 
Risk analysis runs on this user-defined base case have also been performed with burnup and reactor power as assumption variables. The tornado diagram, located in Figure 24, details the results of the risk analyses. The tornado diagrams give a range encompassing the $5^{\text {th }}$ to the $95^{\text {th }}$ percentile values for the three variables. The $5^{\text {th }}$ percentile TCOE per year values corresponds to the higher reactor power, burnup, and capacity factor values.

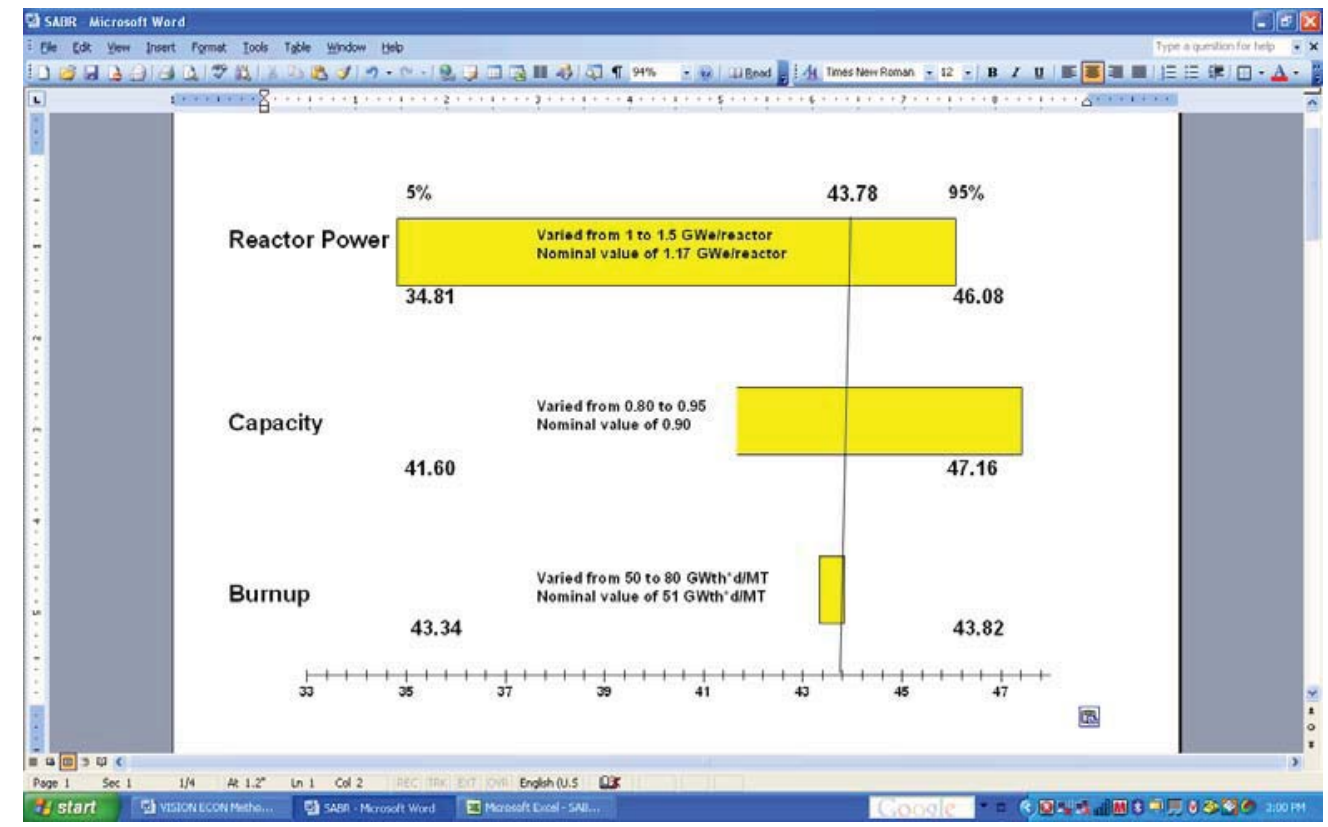

Figure 24. Tornado Diagram of Sensitivity Analysis performed on once through, one LWR scenario with TCOE per year as effect variable.

Reactor power varies from 1 to $1.5 \mathrm{GWe}$ from a nominal value of $1.17 \mathrm{GWe}$ using the uniform distribution. As reactor power increases from its nominal value, the TCOE decreases. The increase in reactor power results in an increase in the reactor costs due to higher capital costs, which are based on a cost per capacity $(\$ / \mathrm{KWe})$. However, operations costs are unchanged because they are based on a fixed costs per year (e.g., $\$ 100 \mathrm{M} /$ year), regardless of the reactor size. The increase in capital costs is significant because of there high contribution to the total costs associated with electricity production. However the increase in total cost is outpaced by the increase in electricity production (from the larger reactor) causing their ratio defined as the TCOE per year to decrease.

Capacity factor varies from a low value of 0.80 to a high value of 0.95 and from a nominal value of 0.90. Capacity factor defines the availability of the reactor to produce electricity. As the capacity factor increases toward 1.00 (or 100\%), the reactor has higher availability to produce power without incurring any additional cost, hence, the TCOE per year decreases.

Burnup varies from 50 to $80 \mathrm{MWd} / \mathrm{MT}$ from a nominal value of $51 \mathrm{MWd} / \mathrm{MT}$. As burnup increases from the nominal value, the TCOE decreases. In summary, to obtain higher burnup, there is an increase in front-end costs, whereas the back-end costs decrease and the reactor costs remain steady. Front-end costs increase with burnup due to higher costs for uranium resources, conversion, and enrichment to produce fuels at higher enrichments. Back-end costs decline because less fuel mass flows out of reactor/per year due to longer refueling cycles (e.g., 18 months extend to 24 months). Reactor costs remain unchanged because the reactor power does not vary despite burnup changes. The decline in back-end costs outpaces the rise in front-end costs causing the TCOE per year to decline with the increasing burnup. In other words, more energy is produced with a less amount (tons of heavy metal) of fuel. 


\section{VALIDATION AND VERIFICATION (V\&V)}

A limited validation and verification $(\mathrm{V} \& \mathrm{~V})$ has been performed currently. The development team has concentrated on implementing the basic economic modeling functionality into the model and creating sufficient input variable screens and output charts to enable troubleshooting and support future V\&V activities. The complexity of the $\mathrm{V} \& \mathrm{~V}$ is high because of the close coupling between the dynamic flow model and the economic model. Modeling behavior may be generated from the flow model and/or from the economic algorithms. All V\&V efforts must start with an evaluation of the mass flows and when satisfied that they are reasonable, delve into the economic calculations and economic outputs that are produced. As this model is further developed with more complex algorithms, and especially when feedback from the economic model is linked into the flow model, the V\&V will become much more difficult. Hence, there is a strong need to maintain a structured, step-by-step approach to model development, documentation, and $\mathrm{V} \& \mathrm{~V}$.

As described previously in the section on the software modeling approach, a spiral development approach is being used in the economic submodel development. Using this approach, the model developers will perform $\mathrm{V} \& \mathrm{~V}$ with each cycle of software development. Initially, the $\mathrm{V} \& \mathrm{~V}$ is being performed by case comparisons with the G4-ECONS spreadsheet model pre-run equilibrium cases for the open through cycle. The VISION economics cases were ran with the current U.S. fleet of reactors (104 LWRs), with $0 \%$ growth and $1.8 \%$ growth from 2000 to 2100 . The growth rate is defined as the "rate of growth of nuclear power demand" (INEEL 2005). Zero growth means that new reactors are only added to replace reactors at the end of their lives. The zero-growth case was most similar to the equilibrium case that was ran on the G4-ECONS spreadsheet. From this comparison, it was assessed that similar costs per unit (mills/kwh) were being produced when new reactors were built to replace retiring LWRs. It was found that the unit energy costs for the current fleet of LWRs were essentially half of what they are when new reactors are being built that maintain a constant growth or $1.8 \%$ growth. The differences in cost were attributed to the additional capital cost (plus interest) required for the new reactors coming online.

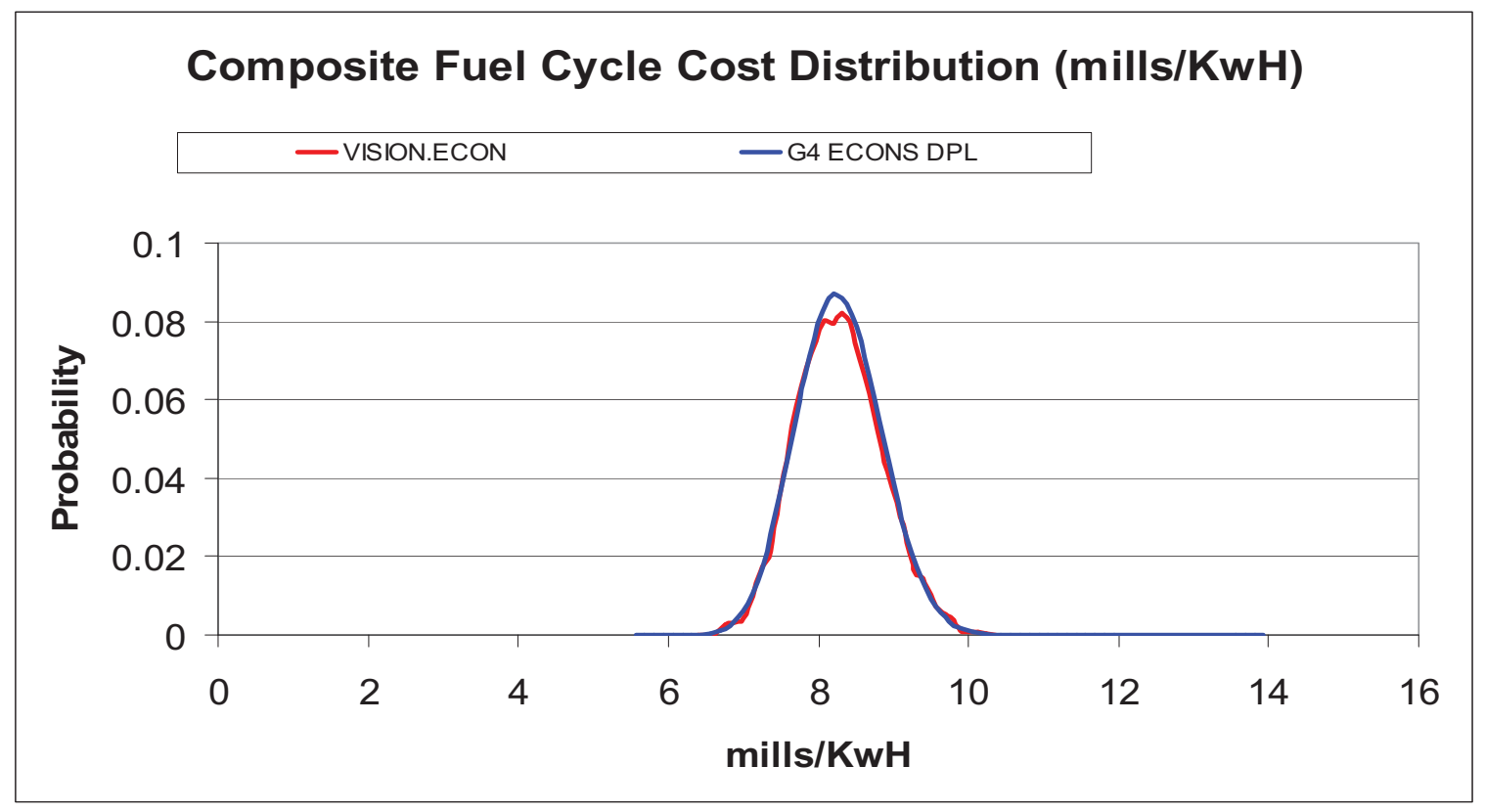

Figure 23. Case 1: Thermal reactor once-through. 
The next V\&V case is a one-tier case. Advanced recycling reactors come online as soon as SNF is available, legacy fuel is used (legacy fuel is spent nuclear fuel [SNF] that was created before the beginning of the simulation and is ready for recycle), and with growth rates of $0 \%$ and $1.8 \%$. (Note that in VISION, Advanced Burner Reactors [ABRs] are $600 \mathrm{MWe}$ reactors, while ALWRs are 1,000 MWe reactors. So even in a zero-growth case, the total number of reactors increases, since $0 \%$ growth means no increase in energy demand, rather than a set number of reactors.) Zero growth was selected to limit the dynamics of the cycle and approach equilibrium. The verification was performed jointly with the VISION model development team to ensure the V\&V scenarios accurately mimic the case from the Excel spreadsheet, that the parameters entered were manipulating VISION as desired, and they were compliant with VISION requirements. The initial V\&V resulted in a close comparison between the VISION.ECON costs and the G4-ECONS spreadsheet.

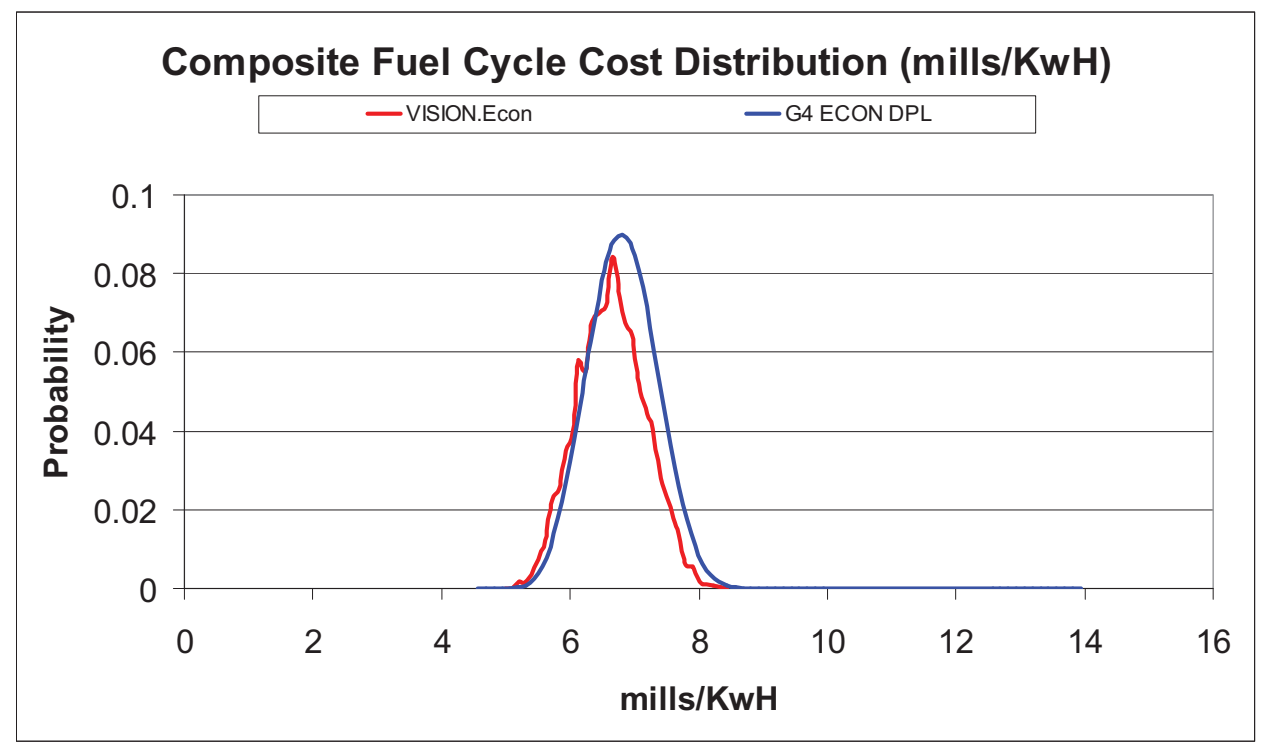

Figure 24. Case 2: Thermal once-through fuel cycle with fast recycling.

In February 2007, additional modules for fuel fabrication facilities, fast reactor recycle, and additional waste streams were added. With these additions, two-tier cases can be ran on VISION.ECON. V\&V of the two-tier functionality was performed by comparing the VISION.ECON results to G4-ECONS results. In order to do this, the VISION reactor parameters were scaled down to match the power output of the G4-ECON run for one reactor. The results matched closely, validating the two-tier case on VISION.ECON.

Before adding additional capabilities to VISION.ECON, more runs are needed to check the model integrity under dynamic modeling conditions. The economic model developers will note deficiencies for future development and improvements. Some of the needed additions anticipated are included in the future development plans, but other changes are likely to become more apparent as modeling experience is gained.

As a means to record and disposition modeling issues, including VISION.ECON issues, a VISION "bug list" has been created. The current VISION Bug List will be issued with each new VISION release. A VISION Capabilities list, which contains a prioritized list of desired VISION enhancements, will also include VISION.ECON desired capabilities. 


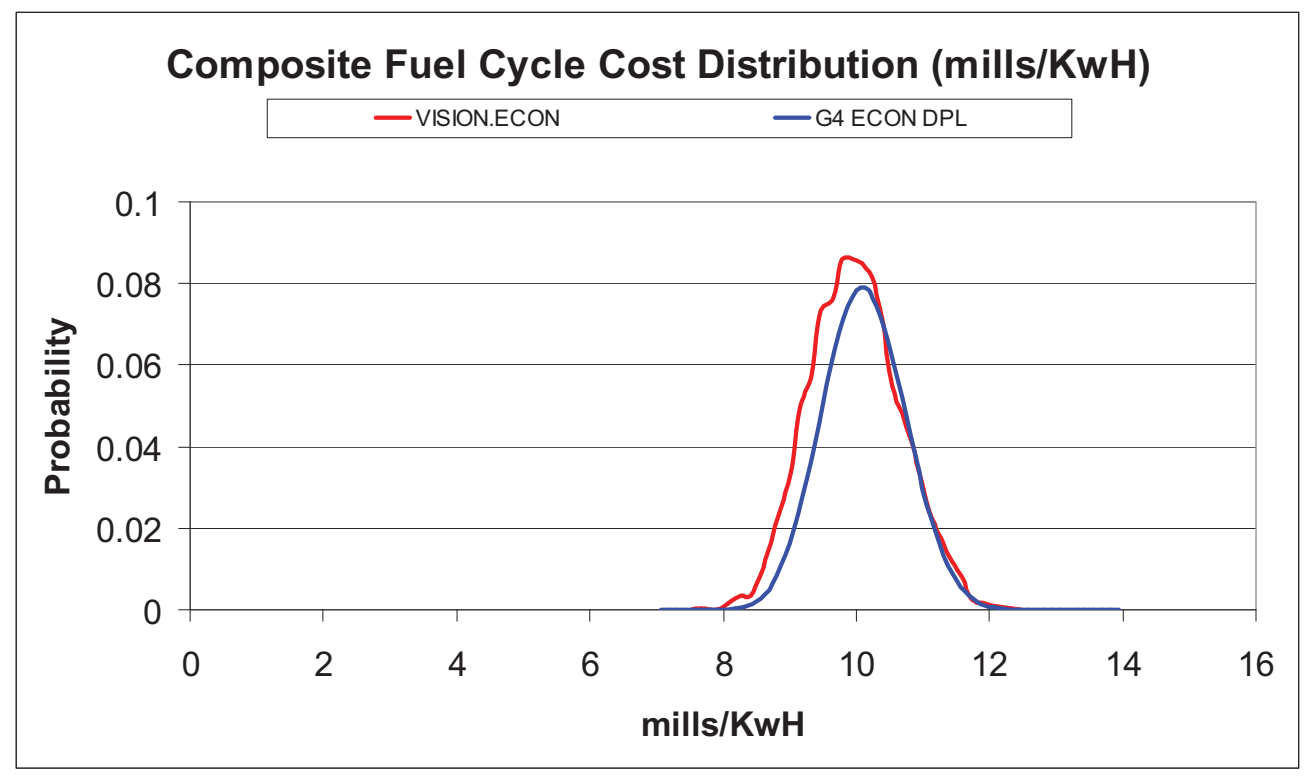

Figure 25. Case 3: Two-tier; thermal once-through fuel cycle with thermal and fast recycling.

In 2008, the Economic Analysis Working Group can perform a comparison between the AFCI Economic Analysis and other studies, such as the Organisation for Economic Co-operation and Development (OECD) 2006 study. VISION and VISION.ECON could also be benchmarked against other codes, such as the French CEA code, COSI (Commelini-Sicard). COSI is used to calculate costs including an optimized balance between reactor and fuel cycle facilities (Grouiller, et al. 1991, Bathke and Schneider 2003).

\section{VISION.ECON FUTURE DEVELOPMENT PLANS}

VISION and VISION.ECON are works in progress. There are a variety of activities planned for both components over the next several years. Modeling improvements will be made in VISION.ECON based on the priority of the new functionality, cost to implement, and value of new capability to identify areas of cost reduction or develop useful intuition about the system economics. The following list describes future development plans.

Cost Module Refinement and Expansion

- The economics data has been prepared for additional modules than ones currently being used in VISION. As new scenarios require these modules, they can easily be added to the model structure.

- Cost submodules will also be developed, as needed, to further specify costs. For example, in the "AFC Cost Basis" report, Module L, repository costs are discriminated between HLW and SNF in the VISION submodel but need more sophisticated algorithms for costing of storage. Also new submodules may be needed to address different waste form options in Module $G$ (waste forms would be different if from F1 rather than F2 Modules).

- Additional modeling algorithms may be needed to assess cost differences due to key processing parameters that can drive costs (e.g., fuel type, gamma field, neutron emission rate, heat rate, and facility size). Also, different separation options, fuel fabrication technologies, and waste treatment/storage and disposition alternatives may need additional algorithms for cost analysis.

Breakout facility capital and O\&M for fuel cycle facilities (already completed for reactors). 
Support calculations of the economic present worth.

- This functionality will require a specificity of costs and expenditures beyond the data currently available and creates a bias toward no-action in the near term.

Extend VISION flow constraints. (Default capacities area currently defined.)

- Keep costs consistent with the range of capacities/assumptions in the "AFC Cost Basis" report

- Levelize facility module capacities over the facility life times

- Levelize back-end disposal based on transportation and/or repository loading

- Acquire additional buffer storage (Modules R, G, E, and I), if needed, to accumulate carryover processing demands or other system constraints

- Define algorithms to determine when additional wet or dry storage costs are needed beyond what costs are included with the reactor

- Define international materials flow considerations accounting for transportation, storage, etc. in fuel bank and fuel take back schemes.

Facility Ownership Options. (Methodology was developed in FY-06.)

- Evaluate potential facility ownership (i.e., government, regulated, private, or hybrid) algorithms to assess the costs of future fuel cycle and reactor ownership choices. The analysis will incorporate impacts from various interest rates and taxes.

- Evaluate international ownership conditions.

The Figure 28 shows the cost sensitivity to operational and financial conditions.

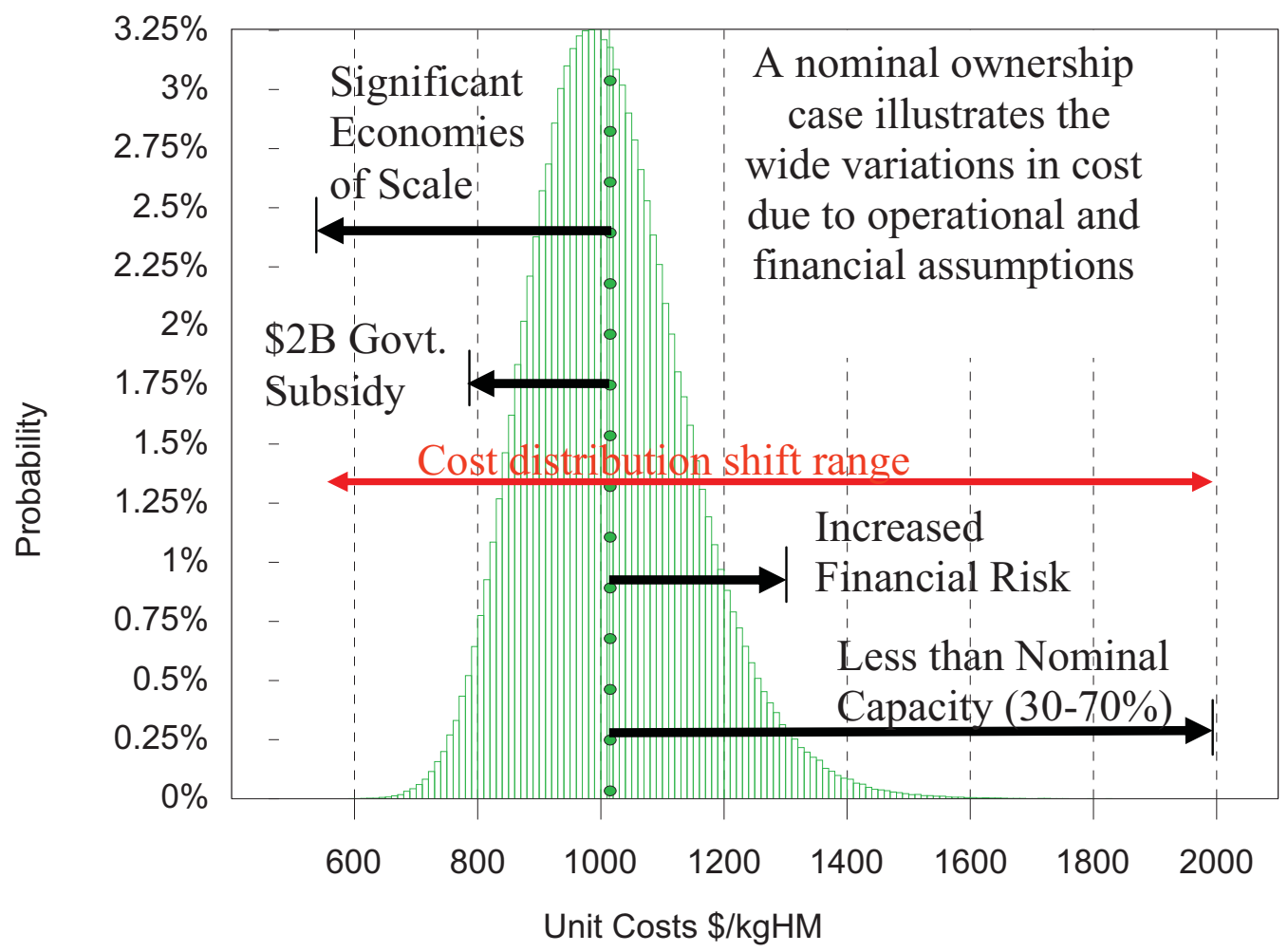

Figure 28. Economic modeling dynamics. (University of Texas-Austin developed a uranium resource module in FY-07). 
- Include feedback of economic data into the main model for future functionality to provide dynamic influences to facility schedules, capacities, and other modeling parameters.

- Provide front-end fuel cycle modeling dynamics. This will include feedback from VISION.ECON to VISION (e.g., tails depletion).

Facility Deployment Cost Scaling. (Stanford has developed a first-of-a-kind to nth-of-a-kind methodology in FY-07.)

- Provide algorithms to account for economies of scale and production.

- Define the potential for follow-on build learning and scaling effects based on technology maturity and assumptions of R\&D funding requirements. (See the following example for the combined affects of scaling and uncertainty analysis.)

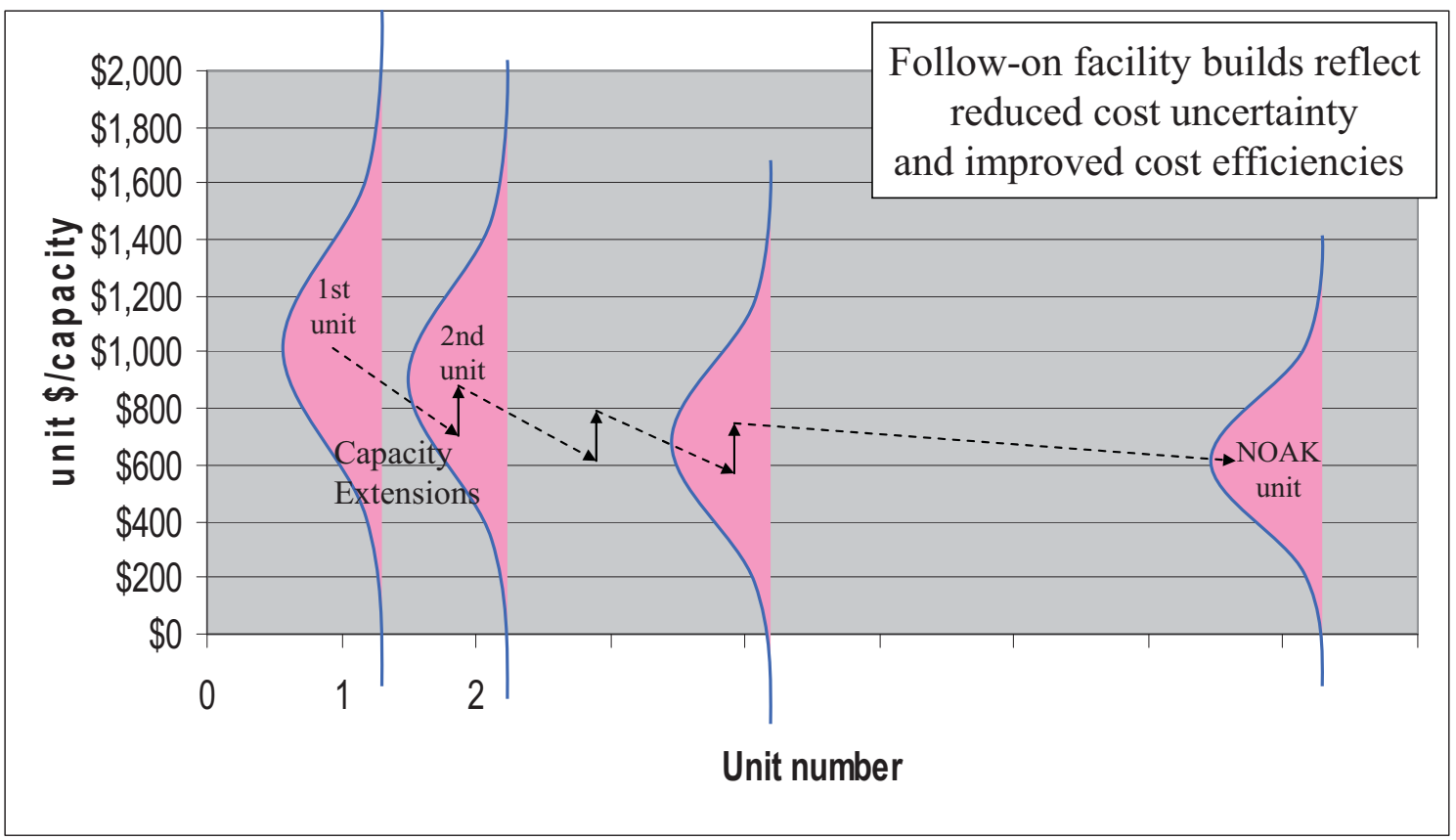

Figure 29. Economic uncertainty analysis. (System affects to be studied as part of Simulation Institute for Nuclear Energy Modeling and Analysis (SINEMA), collaboration with Paul Turinsky at North Carolina State University).

- Provide functionality to perform (Decision Programming Language [DPL] like) cost uncertainty analysis and provide Tornado (Figure 30) and Rainbow diagrams of cost variables that have significant impacts on the costs. 


\section{Baseline Government Construct and Operate}

Expected Value: Annual Capacity 800,000 kgHM/year, Overnight Costs $\$ 8000 \mathrm{M}$, Gov Forgives 0\%, Annual O\&M Costs $\$ 396 \mathrm{M}$, Lifetime $30 y e a r s$

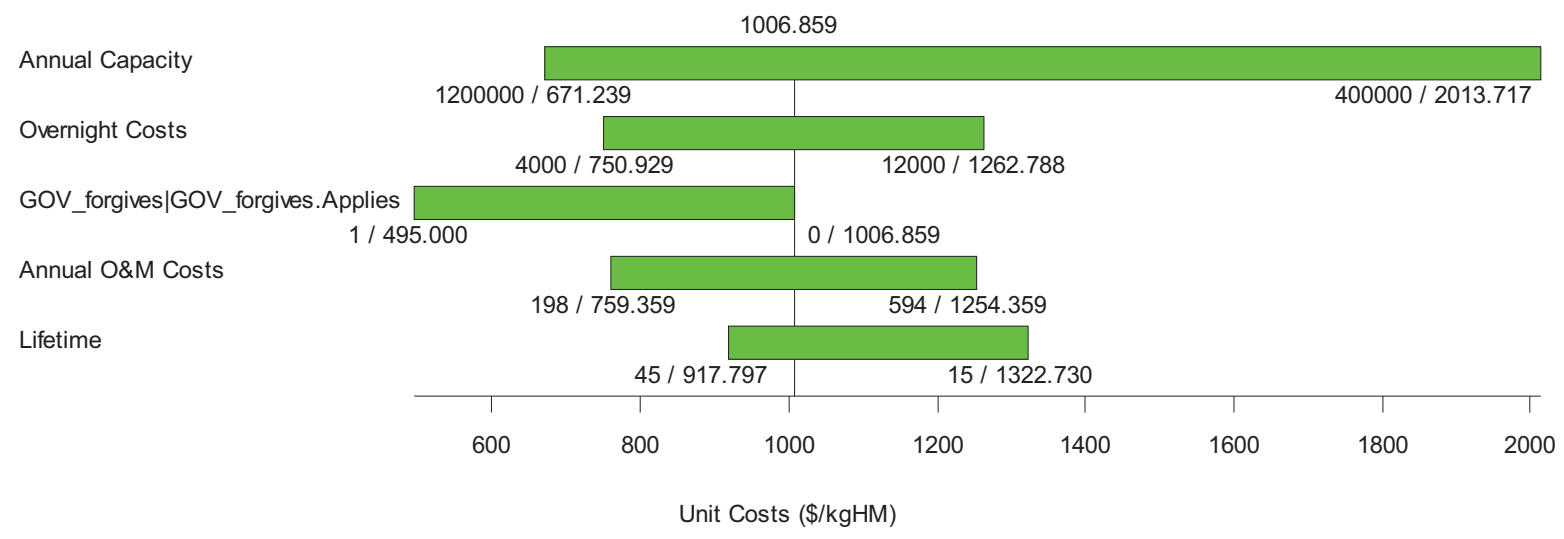

Figure 30. Tornado diagram outlining baseline government construct and operate.

- Incorporation of system (e.g., reactor, reprocessing parameter) economic uncertainty analysis. Work in FY-06 using Maple software showed how 3-D simulations could be used to visualize combined system and cost uncertainty changes over time. Figure 31 shows the type of visualization possible using Maple. Future analysis could also show dynamic coupling of uncertainties over time.

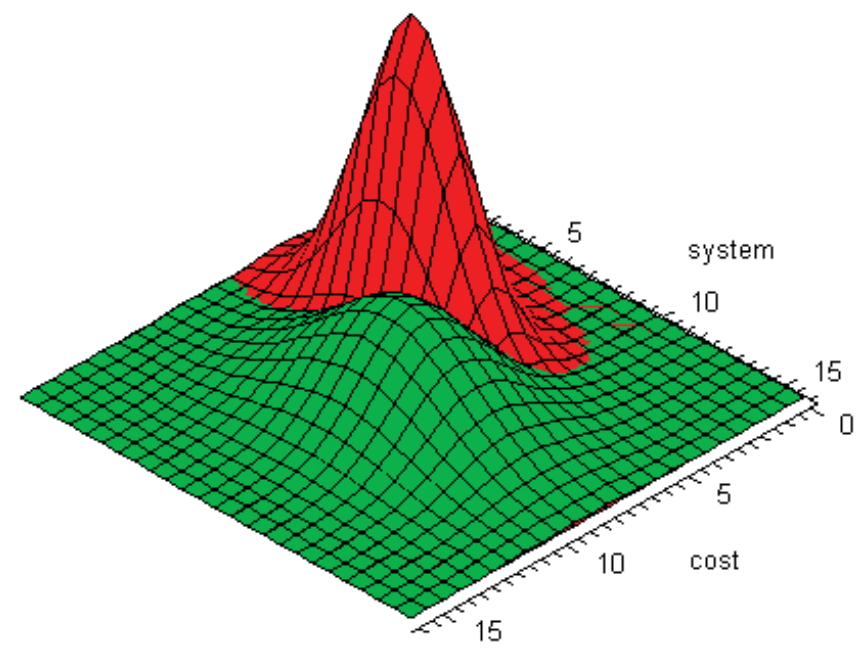

Figure 31. Economic optimization. (Work with Paul Wilson at University Wisconsin-Madison).

- Define economic objective functions and cost variables.

- Develop innovative approaches to creating solution spaces and utilizing concepts such as Regret. Concepts developed by RAND Corporation, which could be applied to VISION.ECON; an example is shown in Figure 32. 


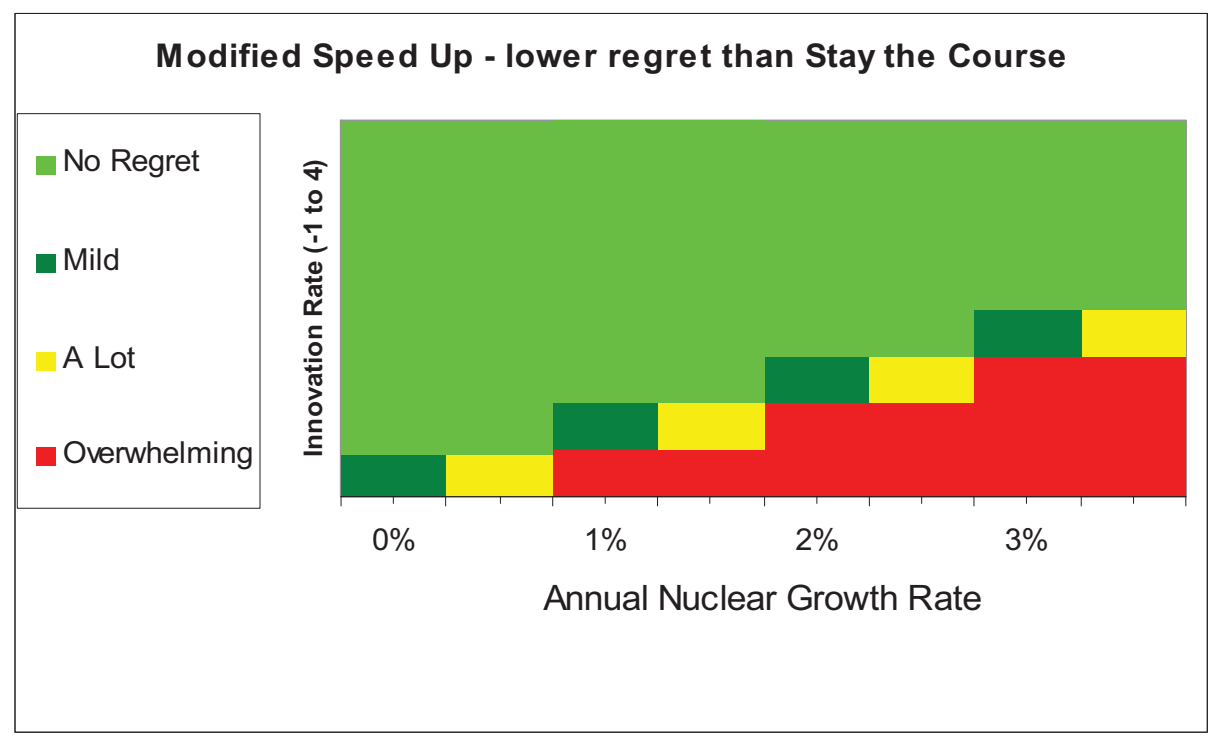

Figure 32. Regret concept example.

Economic measures of proliferation resistance

- Discriminate economically between various levels of security category facilities.

Reactor Modeling

Economic analysis of low conversion ratio fast reactors (FRs) will be evaluated for the advanced recycling reactor.

- Add possible additional cost modules (e.g., heavy water) and economic algorithms for new reactor systems (heavy water, high temperature gas reactors, etc.).

- Analyze reactor SNF storage analysis for capacity of wet/dry storage.

- Implement fixed rate charges for capital cost allocations in VISION.ECON, but alternative algorithms (accelerated depreciation) could be developed.

MRS and Repository Modeling

- Consider interim SNF storage (Module I) for private or government facilities.

- Analyze impacts from reconfiguration of the repository.

Transportation Economics

- Integrate transportation into the flow analysis, which will require verification of packaging, waste densities, waste form, for consistency between the stream flows, module assumptions, and transportation assumptions.

- Transport SNF/HLW (will involve multiple variables such as selection of location scenarios, $\mathrm{road} / \mathrm{rail}$, and conversion factors from mass to volumes as applicable, definition of all flow paths [matrix], calculations to determine number of packages, shipments, etc.). The packaging cost must be verified against Module $\mathrm{G}$ costs.

- Analyze the transportation of special nuclear materials (SNM), such as the transuranic materials, which may require separate modeling due to security implications. 


\section{Modeling V\&V}

- Duplicate assumptions for other cost models (e.g., Code for Advanced Fuel Cycle Analysis [CAFCA], COSI, NFCSim, Harvard report) and evaluate model cost differences.

\section{REFERENCES}

AFCI Economic Benefits and Systems Analysis Team, Software Requirements Specification Verifiable Fuel Cycle Simulation (VISION) Model, INEEL/EXT-05-02643, Rev. 1, November 2005.

Cost Estimating Guidelines for Generation IV Nuclear Energy Systems, Generation IV International Forum Rev 3.01, August 23, 2006.

Grouiller, J., G. Glamenbaum, B. Sicard, M. Mus, J. Martin, J. Devezeaux de Lavergne, O. Comellini. COSI, "A Simulation Software for a Pool of Reactors and Fuel Cycle Plants: Application to the Study of the Deployment of Fast Breeder Reactors," Proceedings of the International Conference on Fast Reactors and Related Fuel Cycles, Kyoto, Japan, October 1991.

OECD 2006, Advanced Nuclear Fuel Cycles and Radioactive Waste Management, NEA No. 5990, 2006.

Powersim Software, http://www.powersim.com, Web page accessed September 2007.

Schneider, E. A., C. G. Bathke, M. R. James. NFCSim: A Dynamic Fuel Burnup and Fuel Cycle Simulation Tool. Advances in Nuclear Fuel Management—Core Physics and Fuel Management Methods, Analytical Tools, and Benchmarks, Vol 151, No 1, July 2005.

Shropshire, D. E., et al., 2007 Advanced Fuel Cycle Cost Basis, INL/EXT-07-12107, July 2007.

User Guide, VISION (Verifiable Fuel Cycle Simulation Model) Version 2.0, INL, INL/MIS-07-13102, August 2007.

Williams, K.A., and Shropshire, D. E., "Fuel Cycle Economic Analysis Using an Excel Spreadsheet," ANS Summer meeting Transactions, Boston, MA, 2007.

Yacout A. M., Hill, R. N., Van Den Durpel, L., Finck, P. J., Schneider, E. A., Bathke, C. G., and Herring, J. S., "Dynamic Analysis of the AFCI Scenarios," PHYSOR 2004, Chicago, Illinois, April 25-29, 2004. 
H-64

INL/EXT-09-15483 


\section{Attachment I}

\section{The Static Analysis and Uncertainty Analysis Toolbox for the Spreadsheet Economic Evaluation of Reactor/Fuel Cycle Scenarios}

Kent A. Williams

Oak Ridge National Laboratory 
I-2

INL/EXT-09-15483 


\begin{abstract}
This report describes a versatile economic evaluation tool that will be used to perform economic analysis of Advanced Fuel Cycle Initiative (AFCI) options. The Generation IV Excel Calculation of Nuclear Systems (G4-ECONS) spreadsheet model will be used to analyze "snapshots-in-time" or "static scenarios." Even though the model is "static" in time, uncertainty analysis is used to understand the cost risks associated with AFCI fuel cycles at a particular point in time. This report provides a detailed description of the "single-reactor" G4ECONS-R (reactor) model and the associated algorithms, cost components, and data requirements. The report also describes how complex (static) scenarios are analyzed and the techniques and tools used to apply uncertainty analysis.
\end{abstract}


I-4

INL/EXT-09-15483 


\section{PREFACE}

History. In late 2002, the Generation IV Reactor International Forum (GIF) saw the need to develop an economic evaluation methodology and a model for comparison of the systems (reactors and their fuel cycles) to be considered under this International Reactor Program. An Economic Modeling Working Group (EMWG) was established for this purpose, and the GIF nations were given the opportunity to be represented on this group. William Rasin, Geoffrey Rothwell, and Kent Williams were the first U.S. representatives to this group and were supported by the United States Department of Energy's Office of Nuclear Energy (DOE-NE). The first meeting of the group was held at Stanford University in February 2003, and 17 meetings have been held in various locations as of August 2007. The first task undertaken by the EMWG was to assume the development of Cost Estimating Guidelines (to be referred to as Guidelines) document (EWMG 2006) for use by the Generation IV reactor development teams in preparing cost estimates for their systems. If the teams utilize such Guidelines, their estimates will essentially be on an "apples-to-apples", basis, thus allowing useful comparisons between systems to be made. The Guidelines also assure "level playing field analysis" of the various options. The Guidelines document also presents useful methodology and data for preparation of either detailed "bottomup" or less detailed "top-down" estimates based on scaling from other designs. The Guidelines document is now undergoing its fourth revision, and the third revision is publicly available on the Generation IV Web site. Shortly after the first version of the Guidelines was drafted (November 2003) work began by Oak Ridge National Laboratory (ORNL) on the preparation of an Excel-based reactor economic model which implements the methodology spelled out in the Guidelines. The intent was to prepare a transparent, simple, an internally consistent model for calculating the levelized unit electricity cost (LUEC) for a reactor system, including the cost of its fuel cycle. This model is now known as

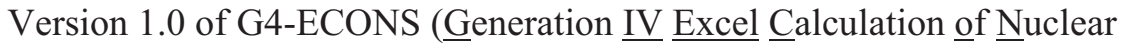
Systems).

Evolution of AFCI "Static" Models from G4-ECONS. As both the AFCI and Generation IV work progressed it soon became apparent that the AFCI modeling requirements were diverging from the simple use of the fuel cycle model within the "single reactor" G4-ECONS code (a.k.a. G4-ECONS-R), which has only three "hard-wired" fuel cycles built into it. It became apparent that the fuel cycle model within G4-ECONS had to morph into a different and more interactive "module-by-module" modeling system for AFCI use, but also keep the same basic algorithmic structure used in G4-ECONS. This was especially important in light of the fact that symbiotic and much more complex fuel cycles consisting of fleets of differing reactor types were becoming the main scenarios for consideration under the AFCI.

A common consideration was that all of these models would be analyzing "snapshots-in-time" over the course of the AFCI deployment. This differentiates these G4-ECONS-based Excel models from the "dynamic" simulation models such as Verifiable Fuel Cycle Simulation (VISION) or Dynamic Analysis of Nuclear Energy System Strategies (DANESS), which model the flows of materials and dollars in time; hence, the term "static" is used to describe the former. Even though the models to be described here are "static" in time, 
uncertainty analysis can still be used with these Excel models to understand the cost risks associated with AFCI fuel cycles at a particular point in time.

Organization of the Attachment. This attachment treats the G4-ECONSderived modeling systems as a "toolbox" from which various modeling tools can be selected. It is divided into three parts:

Part 1: A detailed description of the "single-reactor" G4-ECONS-R model and its algorithms as developed for the Generation IV Reactor Systems Program. Version 1.0 of G4-ECONS-R develops the LUEC from its four major cost components: capital recovery, non-fuel operations and maintenance (O\&M), fuel cycle, and decontamination and decommissioning (D\&D), each of which has their own set of calculational algorithms. A submodel called G4-ECONS-FCF (Fuel Cycle Facility) is also described. This model calculates the unit cost of a fuel cycle material or service from available facility data, such as capital cost, O\&M, D\&D, and annual projected production. The algorithms are basically the same as those used for the reactor model.

Part 2: A description of how the more complex AFCI scenarios, which cannot be modeled directly within the "single-reactor" G4-ECONS-R model, are developed in spreadsheet fashion. An example of one such scenario is presented in this section.

Part 3: A description of how uncertainty analysis is applied within these models. Some commercially available software tools, which allow Monte Carlo, Latin Hypercube, or other types of stochastic analysis to be undertaken with Excel spreadsheets, are mentioned. An example output from a 2006 study is shown (Shropshire, et al. 2006).

\section{Relationship to Other Models}

The G4-ECONS-related models described here relate most closely to the dynamic VISION model. Many of the economic algorithms described here have been incorporated into a module of VISION called VISION.ECON. In the future, many of the "snapshot-in-time" cases to be ran with these G4-ECONS models will have their inputs derived directly from VISION output. For example, VISION can produce material balance, facility requirement, separation "recipes," and reactor "mixes" for any year over the span of the AFCI (2010-2100). It is anticipated that "snapshots" will be needed for years such as 2025, 2050, 2075, and 2100. For each of these years, a unit fuel cycle cost and unit cost of electricity can be calculated for the overall symbiotic AFCI system at that future time.

Some of the assumptions used in G4-ECONS can flow from other models, such as the $\$ / \mathrm{kWe}$ values required for "competitive" nuclear power. The "Nuclear Energy Market Assessment" and "Comparison of Energy Options and Technology Challenges" efforts can provide useful data. Facility-related data can be gleaned from the "Nuclear Materials Exchange" database and the "Market Structure Economics" efforts. The "Facility Economic Liaison" section defines how useful facility data might flow from the three major AFCI Projects:

Consolidated Fuel Treatment Center (CFTC), Advanced Burner Reactor (ABR), and Advanced Fuel Cycle Facility (AFCF). The Uranium Supply study and the "FOAK/NOAK" study will also influence the inputs to the G4-ECONS based methodologies described here. 


\section{CONTENTS}

ABSTRACT

PREFACE

ACRONYMS

1. THE G4-ECONS ECONOMIC EVALUATION TOOL FOR GENERATION IV REACTOR SYSTEMS AND ITS PROPOSED APPLICATION TO REACTOR/FUEL CYCLE SYSTEMS

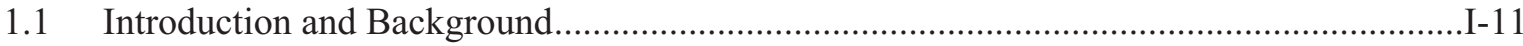

1.2 Basic Model Structure and the Concept of Cost Levelization .............................................

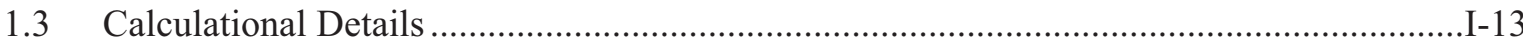

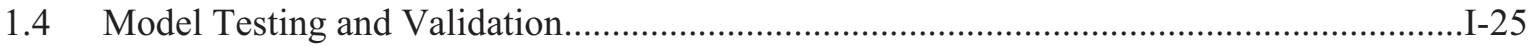

1.5 Costing of Fuel Cycle Services and Materials Not Available Commercially - the

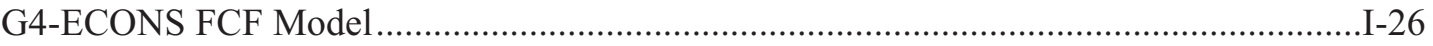

1.6 Plans for Version 2 of G4-ECONS Reactor Model ............................................................26

2. THE MODULE-BY-MODULE “SNAPSHOT-IN-TIME” ECONOMIC EVALUATION TOOL FOR FUEL CYCLES PROPOSED FOR THE Advanced Fuel Cycle Initiative (AFCI)

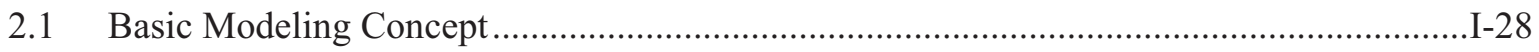

2.2 Additional Considerations and Calculational Details ........................................................

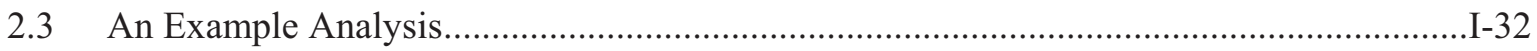

3. USE OF UNCERTAINTY ANALYSIS WITHIN THE G4-ECONS DERIVED

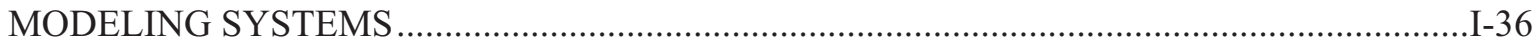

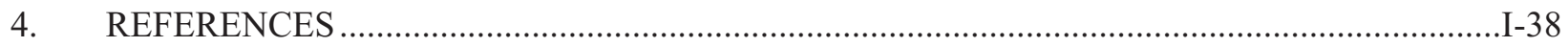

\section{FIGURES}

Figure 1. Concept of cost levelization. $\mathrm{I}-12$

Figure 2. "Sine-wave" pattern for quarterly cash flows comprising the overnight cost.

Figure 3. "S-Curve" pattern for timing of cumulative quarterly overnight cost expenditure (5-year project example).

Figure 4. Typical cost categories for annual nonfuel O\&M costs. .................................................... I-16

Figure 5. Modular representation of fuel cycle steps...................................................................... I-17

Figure 6. Simplified algorithm for fuel cycle cost derivation......................................................... I-18

Figure 7. Example flowchart produced by the G4-ECONS fuel cycle model for an open cycle............. I-21

Figure 8. Example flowchart produced by the G4-ECONS fuel cycle model for a partially closed fuel cycle. 
Figure 9. Example flowchart produced by the G4-ECONS fuel cycle model for a totally closed fuel cycle.

Figure 10. G4-ECONS output table for typical PWR (year 2001 fuel cycle prices). ${ }^{\mathrm{a}}$

Figure 11. Output table from G4-ECONS FCF showing breakdown of the unit cost.

Figure 12. Nuclear energy products.

Figure 13. Statistics on "AFC Cost Basis" report.

Figure 14. A Generic AFCI Symbiotic Fuel Cycle.

Figure 15a. Example of complex flows associated with hybrid or symbiotic fuel cycle (Example is the front end LWR portion of Case 2 from December 2006 Advanced Fuel Cycle Sensitivity Analysis [Shropshire and Williams 2006].).

Figure 15b. Example of complex flows associated with hybrid or symbiotic fuel cycle (Example is the back end LWR portion of Case 2 from December 2006 Advanced Fuel Cycle Sensitivity Analysis.[Shropshire and Williams 2006]).

Figure 15c. Example of complex flows associated with hybrid or symbiotic fuel cycle (Example is the fast reactor actinide recycle portion of Case 2 from December 2006 Advanced Fuel Cycle Sensitivity Analysis. [Shropshire and Williams 2006])

Figure 16. Example of single-value sensitivity study output.

Figure 17. Example of multivariable sensitivity study output (probabilistic analysis). 


\section{ACRONYMS}

\begin{tabular}{|c|c|}
\hline ABR & Advanced Burner Reactor \\
\hline $\mathrm{AFC}$ & Advanced Fuel Cycle \\
\hline $\mathrm{AFCF}$ & Advanced Fuel Cycle Facility \\
\hline AFCI & Advanced Fuel Cycle Initiative \\
\hline ANNCAP & annual capital cost \\
\hline ANNFC & annual fuel cycle cost \\
\hline ANNOM & annual O\&M cost \\
\hline ANS & American Nuclear Society \\
\hline CDIRECT & direct cost \\
\hline CFTC & Consolidated Fuel Cycle Facility \\
\hline CINDIRECT & indirect costs \\
\hline CONT & contingency \\
\hline COVNT & overnight cost \\
\hline COWNER & owner's costs \\
\hline D\&D & decontamination and decommissioning \\
\hline DANESS & Dynamic Analysis of Nuclear Energy System Strategies \\
\hline DOE-NE & United States Department of Energy's Office of Nuclear Energy \\
\hline DPL & Decision Programming Language \\
\hline FCF & Fuel Cycle Facility \\
\hline G4-ECONS & Generation IV Excel Calculations of Nuclear Systems \\
\hline G4-ECONS-R & Generation IV Excel Calculations of Nuclear Systems Single Reactor \\
\hline GARS & grid-appropriate reactor systems \\
\hline GIF & Generation IV Reactor International Forum \\
\hline ICAPP & International Congress on Advances in Nuclear Power Plants \\
\hline IDC & interest during construction \\
\hline JSFR & Japanese Sodium-Cooled Fast Reactor \\
\hline LUEC & leveled unit electricity cost \\
\hline LWR & light-water reactor \\
\hline M-by-M & module-by-module \\
\hline MIT & Massachusetts Institute of Technology \\
\hline MONOMOX & once recycled mixed uranium-plutonium oxide \\
\hline MOX & mixed uranium-plutonium oxide \\
\hline O\&M & operations and maintenance \\
\hline
\end{tabular}


ORNL Oak Ridge National Laboratory

PBMR pebble-bed modular reactor

PRISM Power Reactor Innovative Small Module

PT partitioning/transmutation

PUREX plutonium-uranium extraction

PWR pressurized-water reactor

REPU reprocessed uranium

SFF sinking fund factor

SMA Spreadsheet Modeling Analysis

SWU separative work unit

TLCC total capital cost

VISION Verifiable Fuel Cycle Simulation 


\title{
The Static Analysis and Uncertainty Analysis Toolbox for the Spreadsheet Economic Evaluation of Reactor/Fuel Cycle Scenarios
}

\author{
1. THE G4-ECONS ECONOMIC EVALUATION TOOL FOR \\ GENERATION IV REACTOR SYSTEMS AND ITS PROPOSED \\ APPLICATION TO REACTOR/FUEL CYCLE SYSTEMS
}

\subsection{Introduction and Background}

At the outset of the International Generation IV Program, it was decided that the six candidate reactor systems will ultimately be evaluated on the basis of safety, sustainability, nonproliferation attributes, technical readiness, and projected economics. It is likely that the same factors will influence the evaluation of grid-appropriate reactor systems (GARS) and new fuel cycle facilities, such as reprocessing plants that are being considered under the more recent Advanced Fuel Cycle Initiative (AFCI). This document describes how the development of an economic modeling system has evolved to address the issue of economic competitiveness for both the Generation IV and AFCI programs.

In 2004, the Generation IV Economic Modeling Working Group (EMWG) commissioned the development of a Microsoft ${ }^{\mathrm{a}}$ Excel-based model capable of calculating the Levelized Unit Electricity Cost (LUEC) in mills $/ \mathrm{kW} \cdot \mathrm{h}$ or $\$ / \mathrm{MWh}$ for multiple types of reactor systems being developed under the Generation IV program. This overall modeling system is now called G4-ECONS (Generation IV-Excel

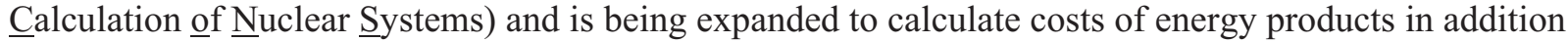
to electricity, such as hydrogen and desalinated water. A version (G4-ECONS-FCF) has also been developed to evaluate the costs of products or services from fuel-cycle facilities. The cost estimating methodology and algorithms are explained in detail in the Generation IV Cost Estimating Guidelines (EMWG, 2006a), for which the latest revision resides on the Web site http://www.gen4.org/Technology/horizontal/economics.htm and in the G4_ECONS User's Manual (EMWG, 2006b).

The model was constructed with relatively simple economic algorithms such that it could be used by most any nation without regard to country-specific taxation, cost accounting, depreciation, or capital cost recovery methodologies. It was also designed with transparency to the user in mind (i.e., all algorithms and cell contents are visible to the user). A short description of the Version 1.0 G4-ECONS-R (reactor economics model) also has been published in the Proceedings of the June 2007 Meeting of the American Nuclear Society (ANS) (Williams and Shropshire 2007). It is the purpose of this section to expand upon this ANS summary, which dealt mainly with Generation IV applications, and explain the levelized cost algorithms in more detail with the hope that they can be applied to evaluate the AFCI facilities such as GARs, fuel-cycle facilities, and a demonstration advanced recycle reactor.

\subsection{Basic Model Structure and the Concept of Cost Levelization}

Each section of the reactor economics model computes a component of the total LUEC, which can be divided into four life cycle components: recovery of capital (including financing costs), nonfuel

\section{a. PRODUCT DISCLAIMER}

References herein to any specific commercial product, process, or service by trade name, trademark, manufacturer, or otherwise, does not necessarily constitute or imply its endorsement, recommendation, or favoring by the U.S. Government, any agency thereof, or any company affiliated with Idaho National Laboratory. 
operations and maintenance (O\&M) costs, fuel cycle costs, and annual funding of decontamination and decommissioning (D\&D) costs via an escrow fund. All costs are calculated on a constant-dollar levelized annual cost basis, and it is assumed that capital and financing costs are repaid over the operating life of the plant. Annual electrical production is also considered at a constant value over the life of the plant. Each component of the LUEC is calculated by dividing the annualized $(\$ \mathrm{M} /$ year) cost for that component by the annual production ( $\mathrm{kW} \cdot \mathrm{h} /$ year). An average capacity factor is also assumed over the life of the plant to relate electrical energy production (plant performance) to the net installed capacity of the plant.

Figure 1 illustrates the concept of levelization, which is central to this type of economic modeling. The left side of the figure shows how typical cash flows (\$M/year) actually occur over the life cycle of a power plant. During the design/construction phase, annual costs rise to a peak and taper off into the startup phase. Annual O\&M and fuel costs are nearly constant (assuming constant dollar costing) with an occasional "blip" for a major capital replacement item, such as a steam generator. At end-of-life, there is another blip for the decontamination and decommissioning of the plant. Power production also has a ramp-up and ramp-down period. For actual power plant projects, utilities typically use "business models" where such annual cash flows and annual power production (revenue steam) projections are entered into a complex spreadsheet in order to calculate revenue requirements and project financing needs. For technology comparison purposes, however, such as the Generation IV and AFCI applications, such cash flow models are too complex and the input data does not exist at a fine enough detail level to support that "business model" type of modeling. For this reason G4-ECONS was designed to treat the costs in the "levelized" manner as shown on the right side of Figure 1. Essentially all front-end costs (design, construction, startup, and financing) are rolled-up into a single total capital cost or TLCC. This TLCC is then recovered over the life of the plant by means of a capital recovery factor, which in turn depends on the assumed interest or discount rate. The reverse of the capital recovery algorithm (a sinking fund equation) is used to recover the future D\&D cost over the plant operating life. Other annual costs, such as fuel, nonfuel O\&M, and capital replacements are calculated or entered into the model as average

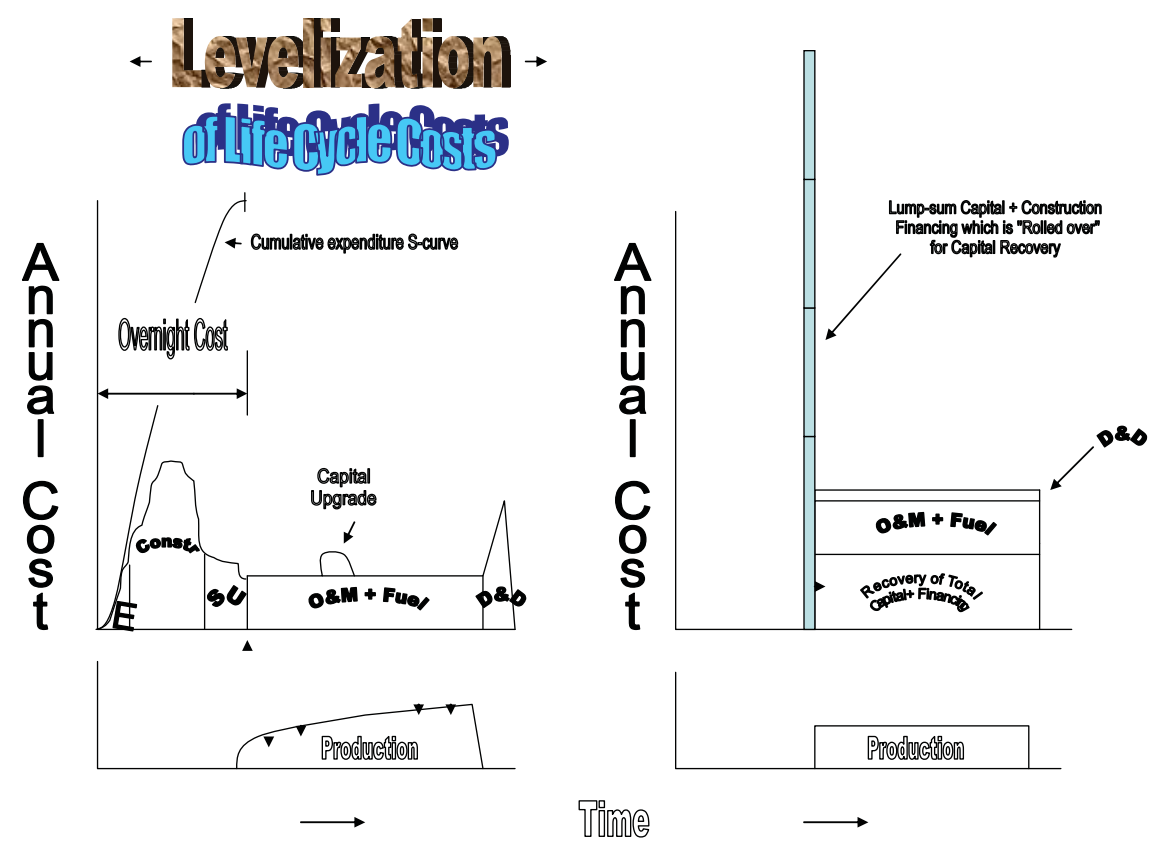

Figure 1. Concept of cost levelization. 
(typically $\$ M /$ year) values that are the same over all years of the operating life. An average assumed power production also has a constant value over the plant operating life and represents the "revenue" to the utility. It is believed that this simpler representation of economics will minimize the amount of data that the project proponents must develop during the R\&D phase of the Generation IV and AFCI programs.

\subsection{Calculational Details}

Capital Cost. The first step is the calculation of the TLCC, which has two major components: the "overnight" cost (COVNT) and the interest during construction (IDC). The overnight cost consists of a base cost (direct plus indirect plus owner's costs) plus a contingency (CONT) to account for items that may not be accounted for and other cost risks. The contingency generally decreases with increasing detail of the level of the underlying estimate.

The direct cost (CDIRECT) inputs can be entered at the subsystem level (i.e., separate cost [code-ofaccounts] lines for the civil, nuclear island, electrical, heat management, and other subsystems). If these subsystem costs can be linked to a separate reactor design/cost scaling model, G4-ECONS can be used in conjunction with an optimization tool to minimize the LUEC for a given reactor technology concept. It is the intent of the EMWG that this model be used by the design teams for the six reactor systems, as well as providing a "level playing field" means of comparing the six concepts. Indirect costs (CINDIRECT) are also partitioned by a code-of-accounts system that separate home office and site-located management and support categories. Owner's costs (COWNER), such as startup and training, are then added to this basecost sum. In summary:

- $\quad$ CBASE $=$ CDIRECT + CINDIRECT + COWNER

- $\mathrm{COVNT}=\mathrm{CBASE}+\mathrm{CONT}$

- $\quad \mathrm{TLCC}=\mathrm{COVNT}+\mathrm{IDC}$

In G4-ECONS, there is also the option of adding the reactor first core fuel load to the TLCC. In the United States, the first core is normally carried in the fuel cycle cost; however, in a smaller nation the first core might be included in the reactor purchase and financing structure. In order to derive the lump sum costs defined above, a type of cost estimate must be prepared. The Generation IV Cost Estimating Guidelines present in detail methodologies and a standard code-of-accounts for reactor systems (EMWG 2006a). Both the traditional "bottom-up" cost estimating method and the more subjective "top-down" method (based on scaling from other estimates) are described in detail.

The IDC component of the TLCC depends on the duration of the front end activities, their timing, plus the discount rate. 


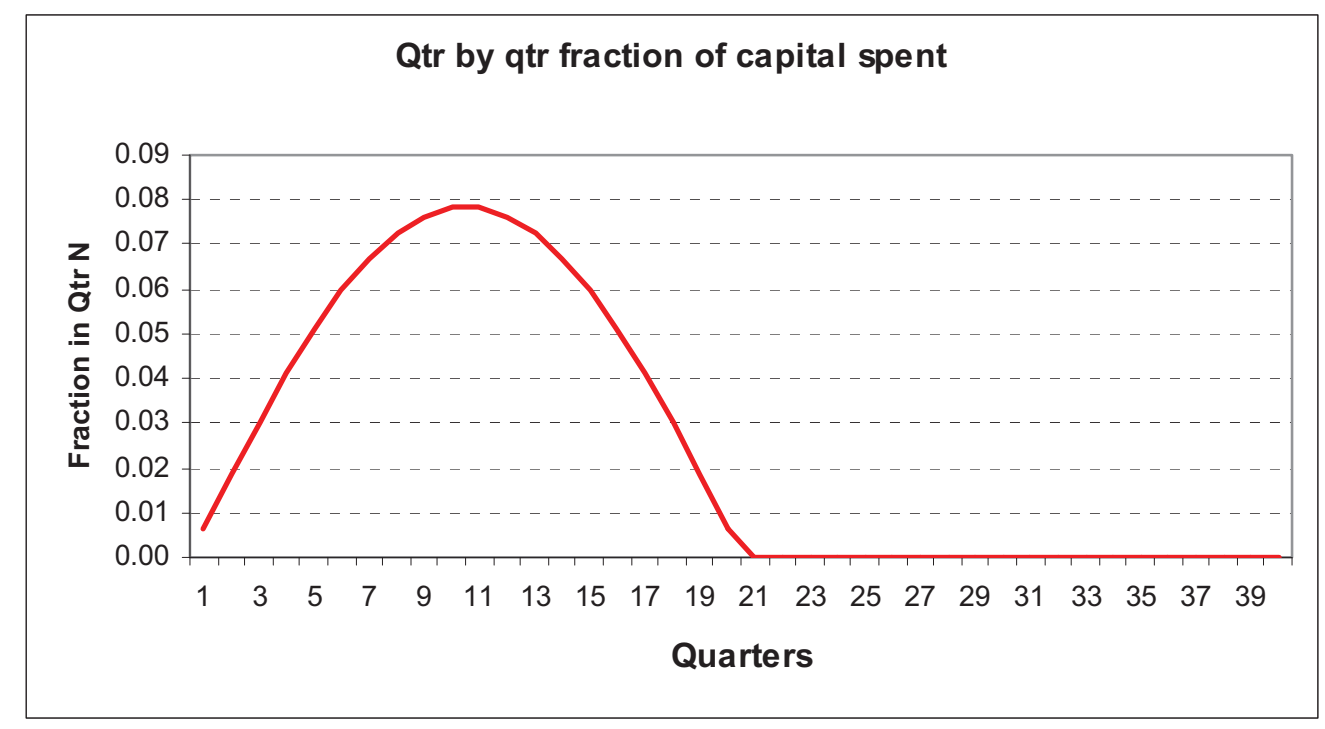

Figure 2. "Sine-wave" pattern for quarterly cash flows comprising the overnight cost.

For model simplicity, it is assumed that spending peaks in the middle of the front-end project capital campaign and that a sine-wave function spread over the total front-end project duration provides an acceptable mathematical approximation. Cumulative expenditures can then be represented by an "Sshaped curve" or "S-Curve" for purposes of interest calculation. In order to provide more modeling accuracy and fidelity, the interest payments are assumed to be made on a quarterly basis; hence, a quarterly discount or interest rate must be calculated. Interest is accumulated from the midpoint of each quarter until the beginning of commercial electricity production. The sum of all the interest payments is the total IDC. The use of the generic "S-curve" was selected because it is typical for many projects, and it prevents the model user from having to derive and manually enter capital cash flow information.

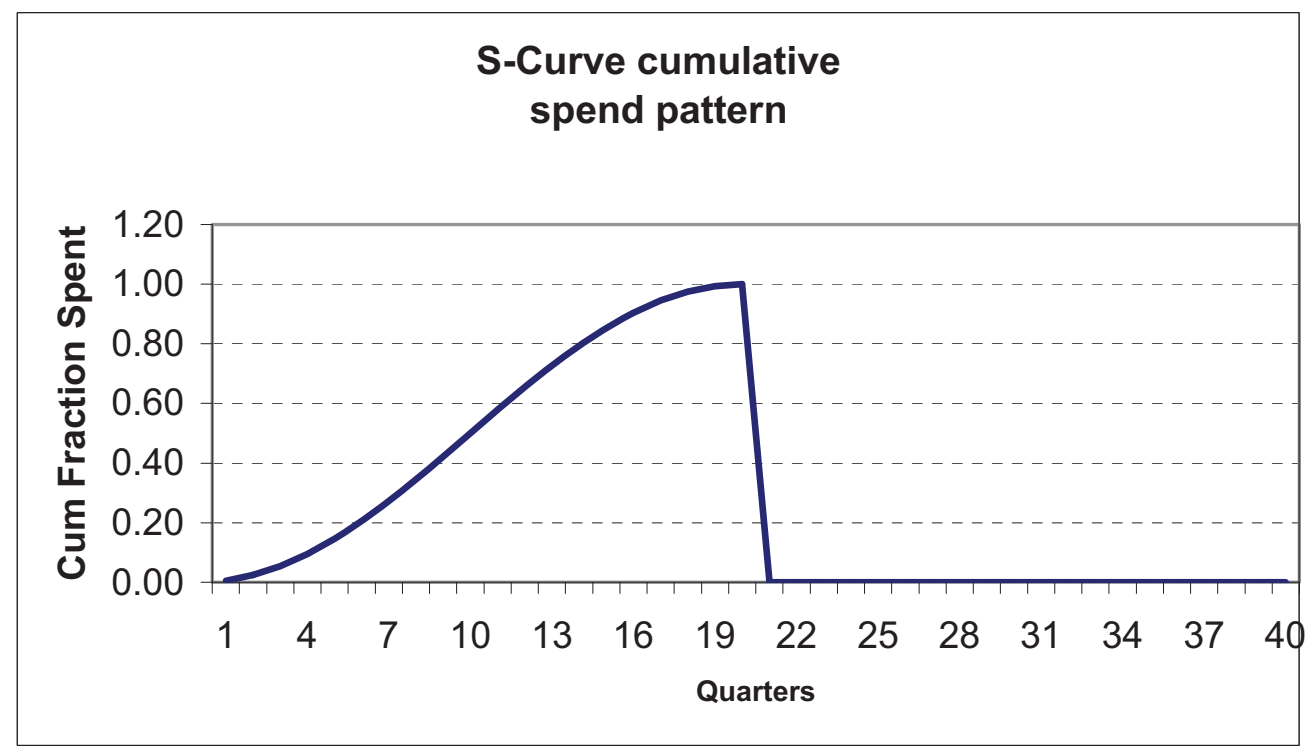

Figure 3. "S-Curve" pattern for timing of cumulative quarterly overnight cost expenditure (5-year project example). 
Amortization/Capital Recovery. The G4-ECONS must now convert the sum of the overnight and IDC (i.e., the TLCC) into an annual cash stream that recovers the TLCC over the life of the plant. In essence, the "construction loan principal + interest" must be amortized in the same manner a home loan is amortized in the United States. The factor that accomplishes this calculation is called a "simple fixed charge rate" and is calculated as:

$\mathrm{CRF}=\mathrm{i} /\left[1-(1+\mathrm{i})^{\wedge}(-\mathrm{L})\right]$

where

$\mathrm{i}=$ the real discount rate (annual)

$\mathrm{L}=$ the plant operating life in years.

In this model, the plant economic life is assumed to be the same as the operational life. This allows the calculation of a LUEC that is the same over the entire plant life and does not change after the plant is amortized, as would be the case if the plant economic life were shorter than the operating life. Actually this latter "shorter write-off" case is more realistic in practice; however, this model is designed for comparison of technologies, not financial planning for a particular project. The levelized annual capital charge, ANNCAP, typically expressed in \$M/year, is calculated as follows:

$\mathrm{ANNCAP}=\mathrm{CRF} * \mathrm{TLCC}$.

Nonfuel O\&M Costs. Nonfuel O\&M costs are also assigned specific cost code-of-accounts categories (i.e., staffing, regulation, maintenance, overhead, etc.) for data input. The way the numbers are rolled up into these categories is highly subjective and often depends on corporate and national industry practice. Figure 4 shows some categories and a code-of-accounts structure used in an example G4ECONS case for a 1,300 MW(e) U.S. pressurized-water reactor (PWR) (values in 2001 dollars).

The model user simply enters the projected average annual nonfuel O\&M costs for each category, and the model sums them to obtain the total annual O\&M cost (ANNOM), typically also expressed in $\$ \mathrm{M} /$ year.

Fuel Cycle Cost. The fuel cycle cost calculation is the most complex part of the G4-ECONS model. When development of G4-ECONS began it was realized that amount of detailed fuel cycle information the EMWG would receive from the Generation IV development teams was likely to be very small. In some cases all that might be available would be physical and chemical definition of the fuel material, the enrichment of the fissile material therein, its projected burnup or cycle time, and the total fuel mass for an assembly or the entire reactor core. It was soon realized that many steps in some advanced fuel cycles, particularly those that involve fuel recycle or actinide partitioning/transmutation $(\mathrm{P} / \mathrm{T})$, are not commercially available, and that for such systems, new fuel cycle facilities involving new processes would have to be designed, built, and operated. There would be no information readily available on prices, process losses, timing of purchases, or even optimum facility size for many steps. This was the same problem encountered in DOE's Advanced Fuel Cycle Initiative (AFCI) Program, and is still true for the AFCI into which AFCI has evolved. It became apparent that the best option for both the Gen IV and AFCI programs was to develop "snapshot-in-time" models based on projected fuel material balances for the reactor systems of interest. The modeler could, for example, take an "equilibrium" cycle and divide it up into definable fuel cycle steps for which unit cost information was available or derivable. Figure 5 shows in modular fashion the list of fuel cycle steps from which nearly any type of reactor fuel cycle can be constructed. Open, partially closed, totally closed, and P/T fuel cycles can all be constructed from constituent modules. (For the AFCI work, each module is given a designated letter for identification.) 


\begin{tabular}{|c|c|c|c|}
\hline & REACTOR COST DATA & & \\
\hline 7 & OPERATONS COST CATEGORY & & Units \\
\hline \multicolumn{4}{|l|}{70 series } \\
\hline $71+72$ & On-site Staffing Cost (71: Non-Management 72 : Management) & 9.51 & \$MYear \\
\hline 73 & Pensions and Benefits & 0 & \$MYear \\
\hline 76,74 & Consumables & 0 & \$MYear \\
\hline 75 & Repair costs including spare parts & 25.46 & \$MYear \\
\hline 93 & Charges on working capital & 33.63 & \$MYear \\
\hline 84 & Purchased services induding refuelling crews & 0 & \$MYear \\
\hline 78 & Insurance Premiums \& Taxes & 3.85 & \$MYear \\
\hline & & & \\
\hline$?$ & Regulatory Fees & 0 & \$MYear \\
\hline$?$ & Radioactive Waste Management (non-spent fuel) & 0 & \$MYear \\
\hline$?$ & Other General and Administrative (G\&A) & 26.89 & \$MYear \\
\hline 77 & Capital replacements/upgrades (levelized) & 0 & \$MYear \\
\hline 79 & Contingency on O\&M & 0 & \$MYear \\
\hline 7 & Total & 99.34 & \$MYear \\
\hline & & & \\
\hline & Annualized O\&M cost per kwh & 0.00840 & $\$ / k w h$ \\
\hline & & 8.397 & mills/kwh \\
\hline & & & or $\$ / M M h$ \\
\hline
\end{tabular}

Figure 4. Typical cost categories for annual nonfuel O\&M costs. 


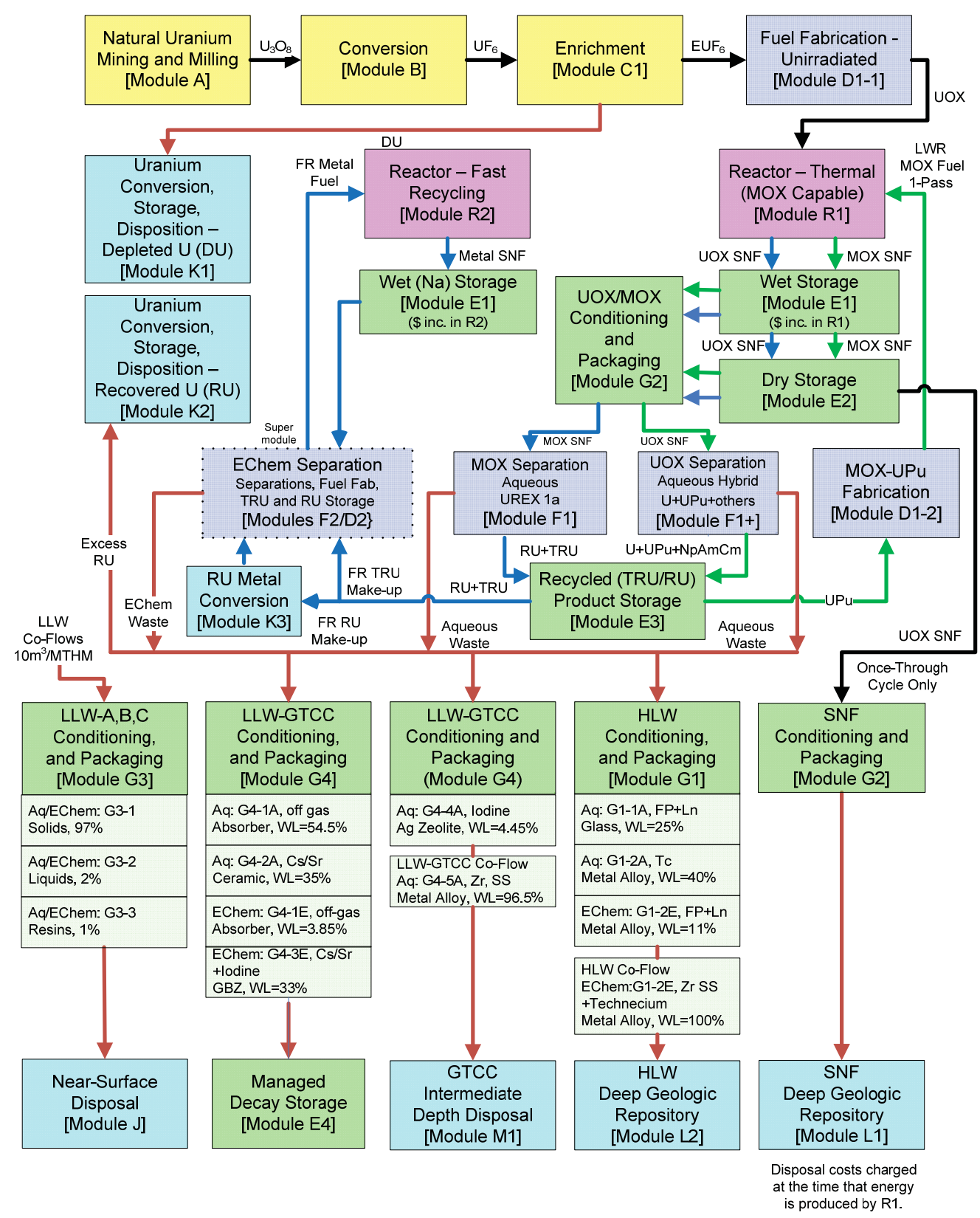

Figure 5. Modular representation of fuel cycle steps.

Working backwards and forwards from the reactor module (R1 or R2), the necessary front-end and back-end fuel cycle steps are identified and a material balance developed for each step depending on the annual mass flow requirements from the previous step (in terms of flow directionality). In order to keep this model simple, material losses between steps are ignored. (Since most nuclear materials have high value, these losses tend to be minimal or the materials are recycled internally within a step.) Once the annual flow (typically in kg/year) into a module or "box" is identified, the annual flow is multiplied by the unit cost of that step to obtain an annual cost for that step. Figure 6 shows how all the relevant annual costs for the required steps can be summed to a total, annual fuel cycle cost (ANNFC), and then divided by the amount of electricity produced by the reactor to obtain an average mills $/ \mathrm{kW} \cdot \mathrm{h}$ or $\$ / \mathrm{MWh}$ fuel cycle cost. 

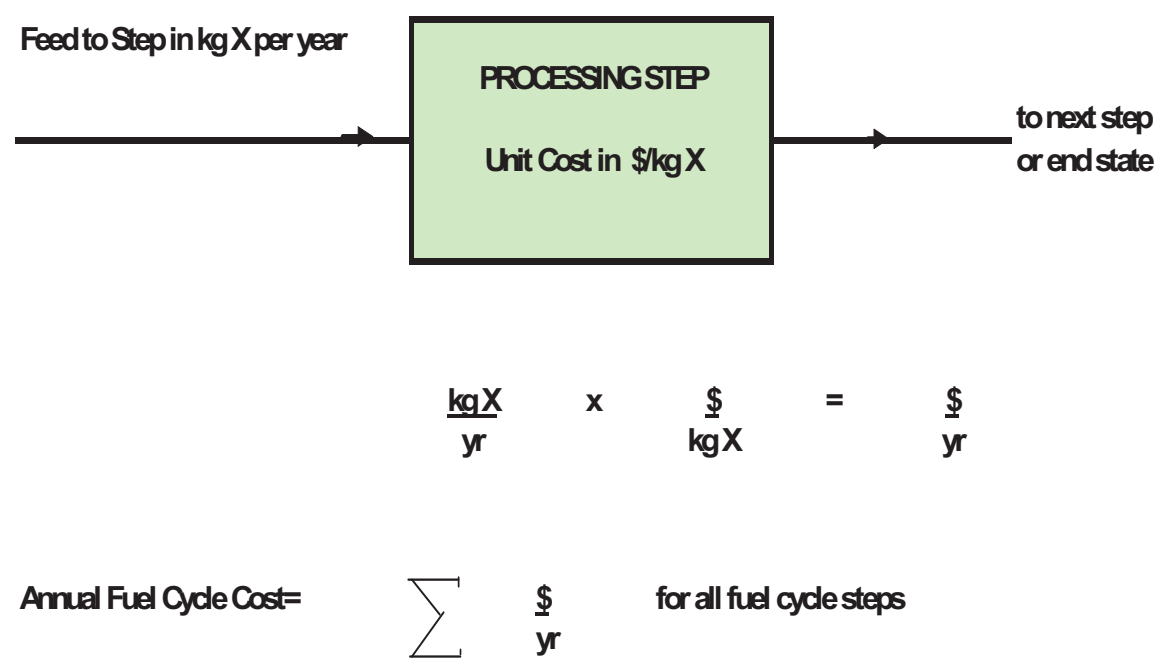

Contribution to Levelized Unit Bectricity Cost $=$

\section{Annual Fuel Cycle Cost / Klowett hours generated per year}

\section{Usually expressed in mills/kwh or \$MWh}

Figure 6. Simplified algorithm for fuel cycle cost derivation.

The unit cost inputs ( $\$ \mathrm{~kg}$ of material or service) that are required for the model and addressed in this chapter depend on the following factors:

- Fissile/fertile materials used (natural uranium, low-enrichment uranium, highly-enriched uranium, mixed oxide fuel, uranium-thorium, etc.)

- Enrichment of fissile materials

- Other materials in the fuel assemblies (zirconium, graphite, etc.)

- Services required to produce the needed materials (mining, milling, conversion, enrichment, fabrication)

- Costs of spent-fuel disposal or reprocessing, and low and high-level waste (including transuranic waste) disposal

- Storage of critical materials.

The availability of existing fuel infrastructure or the need to create new infrastructure is a key driver of fuel cycle unit costs. For infrastructure that does not yet exist, the EMWG recommends that sufficient fuel-cycle facility capacity be priced such that $32 \mathrm{GW}$ of fleet capacity for the given Generation IV reactor type can be supported. At this level of production, it is likely that competitive economics based on process learning and experience will have been realized. The calculation of projected unit costs from such presently nonexistent fuel cycle facilities will be discussed below.

Before considering individual fuel cycle steps, it should be noted that the U.S. AFCI Program has created a report and database on nuclear fuel cycle processes and cost information for all of the fuel cycle steps shown on Figure 5 (Shropshire, et al. 2007). This publicly available document is available on the 
Idaho National Laboratory Publications Web site as is a report documenting its use for comparison of some fuel cycles (Shropshire and Williams 2006). This document should be helpful to the G4-ECONS user in selecting input unit cost values for all fuel cycle steps. Typical fuel cycle-related inputs to the G4ECONS fuel cycle module include the following, and the choice of inputs depends on the nature of the fuel cycle evaluated.

$\begin{array}{ll}\text { Mining and milling } & \$ / 1 \mathrm{~b} \mathrm{U} \mathrm{O}_{8} \\ \mathrm{U}_{3} \mathrm{O}_{8} \text { to } \mathrm{UF}_{6} \text { conversion } & \$ / \mathrm{kgU} \\ \text { Uranium enrichment } & \$ / \mathrm{SWU} \\ \text { Fuel fabrication } & \$ / \mathrm{kgHM} \\ \text { Spent fuel storage } & \$ / \mathrm{kgHM} \\ \text { Repository disposition of spent fuel } & \$ / \mathrm{kgHM} \text { or mills } / \mathrm{kW} \bullet \mathrm{h} \\ \text { Reprocessing } & \$ / \mathrm{kgHM} \\ \text { Repository disposition of high-level waste } & \$ / \mathrm{kgHM} \text { equivalent }\end{array}$

Fuel Cycles Explicitly Modeled by G4-ECONS. Using the methodology outlined above, G4ECONS has the capability to model three "hard-wired" fuel cycles. By "hard-wired," it is meant that the program predetermines which steps constitute the particular fuel cycle option (three options are available), and the program automatically fills out the flowcharts/summary diagrams and displays the fuel cycle component of the LUEC. All three flowchart examples will be shown below. The three fuel cycle options are:

Fuel Cycle Code 1: Open fuel cycle (no recycle and planned geologic repository disposal of spent fuel). This option describes today's light-water reactor (LWR) reactor systems in the United States and can also be used for gas-cooled reactors for which fuel recycle is less likely.

Fuel Cycle Code 2: Partial recycle (meant for thermal reactors; reprocessed uranium (REPU) is reconverted, re-enriched, and refabricated to produce LWR fuel assemblies. The separated plutonium is diluted with $\mathrm{DUO}_{2}$ to produce thermal mixed uranium-plutonium oxide (MOX) fuel assemblies. The fuel assemblies produced from this single recycle mode are credited back to the fuel cycle at a unit (per assembly) value equivalent to an original virgin $\mathrm{EUO}_{2}$ fuel assembly. There is also the option to store or dispose of the REPU instead of recycling it.

Fuel Cycle Code 3: Total recycle - this option is for fast reactor systems that operate in the highconversion ratio or breeder mode. Make-up uranium is supplied to the system to account for the fission products that are removed. There is also the option to store any excess plutonium produced.

Note that the fuel cycle model in the G4-ECONS reactor model is designed to consider "one-reactorat-a-time." It is not designed to model symbiotic systems, such as those proposed in the U.S. AFCI Program, where actinide products from reprocessing of fuel from many LWRs becomes the make-up feed for a series of actinide-burning fast reactors. These cases have to be modeled with stand-alone spreadsheets/flow diagrams (see Module C-2) where the user selects fuel cycle steps from different reactor systems and integrates them manually (i.e., flow sheets are not created automatically as is the case with G4-ECONS). The December 2006 Advanced Fuel Cycle Economic Sensitivity Analysis report shows two cases (single tier thermal and fast recycle of actinides) where symbiotic fuel cycles were modeled in order to effect thermal and fast reactor destruction of actinides (Shropshire and Williams 2007). See Section C-2 for an example.

Figure 7 shows the fuel cycle module output from G4-ECONS for an open cycle. The example reactor is a Generation III+ ABB-CE System $80+$ design for which cost and fuel cycle material balance information was available. The unit cost values selected for input are the "most-likely" values from the 
2007 “Advanced Fuel Cycle (AFC) Cost Basis” report (Shropshire, et al. 2007). The reactor is assumed to undergo refueling every 18 months and has a fuel burnup of $\sim 47,000 \mathrm{MWd} / \mathrm{MTHM}$. It should be noted that G4-ECONS has an internal enrichment calculator in order to calculate the separative work unit (SWU) requirements to produce $\mathrm{EUO}_{2}$ fuel of a specified ${ }^{235} \mathrm{U}$ content. The program can also automatically find the optimal tails assay that minimizes the cost of $\mathrm{EUF}_{6}$ to the front end of the fuel cycle. The spent fuel repository cost can be entered in terms of $\$ / \mathrm{kgHM}$ or in mills $/ \mathrm{kW} \cdot \mathrm{h}$. For the burnup shown in the diagram in Figure 8, a $1 \mathrm{mill} / \mathrm{kW} \cdot \mathrm{h}$ waste fee would translate to just under $\$ 400 / \mathrm{kgHM}$. The ultimate long-term cost of repository spent fuel disposition is still a major unknown.

Figure 8 represents "Fuel Cycle Code 2," where the LWR fuel is assumed to be reprocessed, in this case by a plutonium-uranium extraction (PUREX) system, and the separated REPU and plutonium are utilized to produce energy-equivalent fuel assemblies, which can displace $\mathrm{EUO}_{2}$ assemblies. In this "partial recycle" mode, which assumes one-time-only use of the recycled MOX/REPU assemblies, approximately $20 \%$ of the original $\mathrm{EUO}_{2}$ number of fuel assemblies reloaded are "returned" for credit as recycle assemblies. (This cycle is sometimes called "MONOMOX," since the MOX is assumed to undergo only one recycle.) In the case shown, the front end of the fuel cycle is nearly identical to the open cycle in Figure 7. This partial recycle option also has a switch that can be activated to store or dispose of the reprocessed uranium instead of recycling it. There are also costs associated with these paths. Again, the input unit costs are taken from the July 2007 "AFC Cost Basis" report (Shropshire and Williams 2006).

Figure 9 shows the schematic for an almost totally closed fuel cycle (i.e., Fuel Cycle Code 3). The reactor and fuel cycle information were supplied to the Generation IV EMWG by its Japanese participants. The reactor is a large sodium-cooled fast reactor utilizing $(\mathrm{Pu}, \mathrm{U}) \mathrm{O}_{2} \mathrm{MOX}$ fuel. The Japanese Sodium-Cooled Fast Reactor (JSFR) represents the major development item in the Japanese Generation IV program. This reactor is a heterogeneous system; hence, drivers and blankets are utilized. However, in the G4-ECONS representation, the uranium in the blankets is combined with the plutonium and uranium in the driver fuel for purposes of analysis. Aqueous reprocessing of fast reactor drivers and blankets is assumed. Depleted uranium is supplied to the fuel fabrication facility as makeup to the overall recycle system. The unit costs used in Figure 9 were provided by Japanese members of the EMWG. It should be possible to run similar cases for other fast reactor systems such as the Power Reactor Innovative Small Module (PRISM) system being proposed by General Electric in the United States.

Future efforts in EMWG G4-ECONS fuel cycle modeling will be positioned toward creating a fuel cycle specifically oriented toward actinide burning, where lower fast reactor conversion ratios will be needed. It will also be necessary to modify the closed cycle model such that drivers, blankets, and targets can be accounted for separately. The European "Red Impact" program is also considering actinide burning, $\mathrm{P} / \mathrm{T}$ cycles, and using a methodology similar to that described in this chapter (Lauferts, et al. 2007). 


\section{Draft}

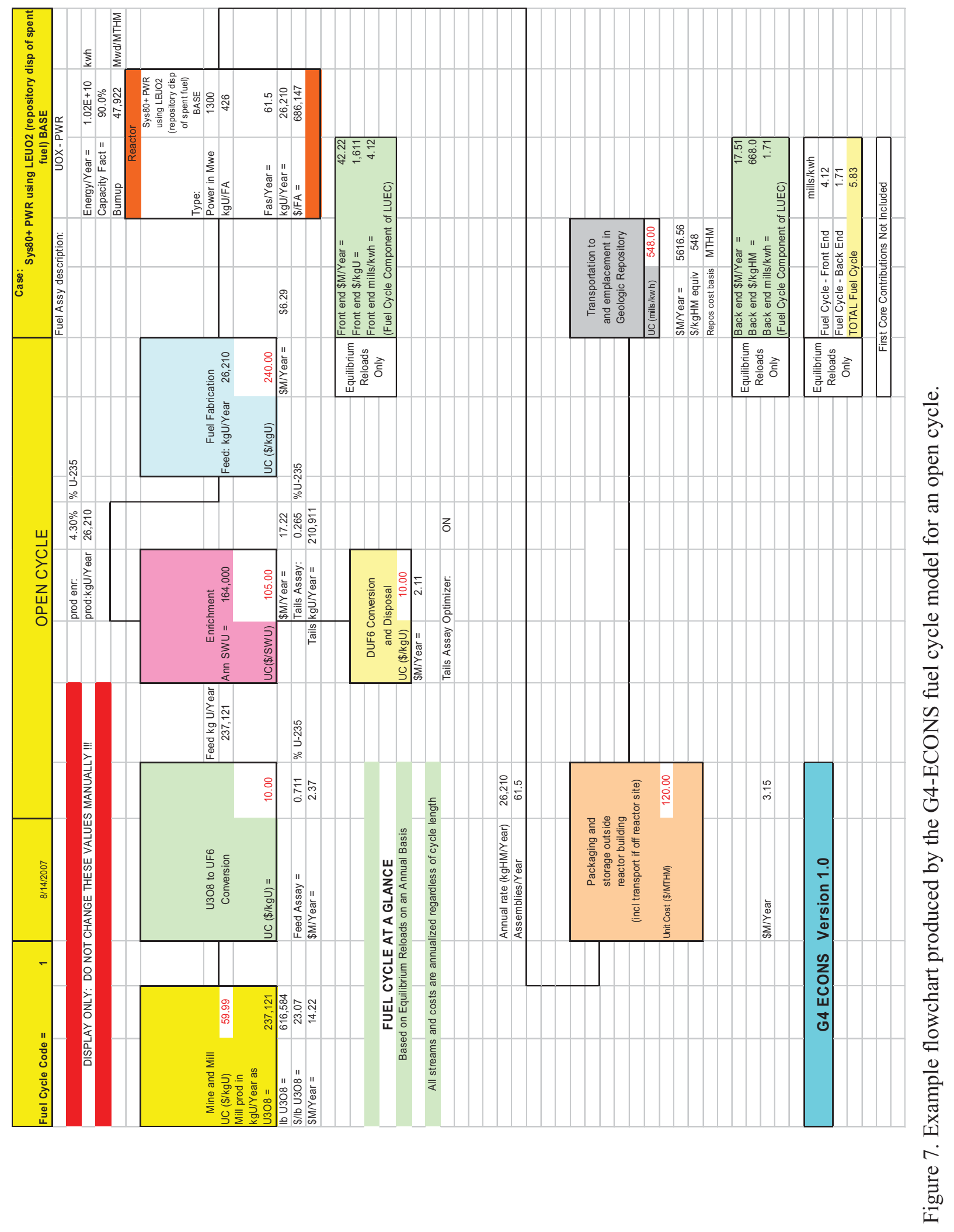




\section{Draft}

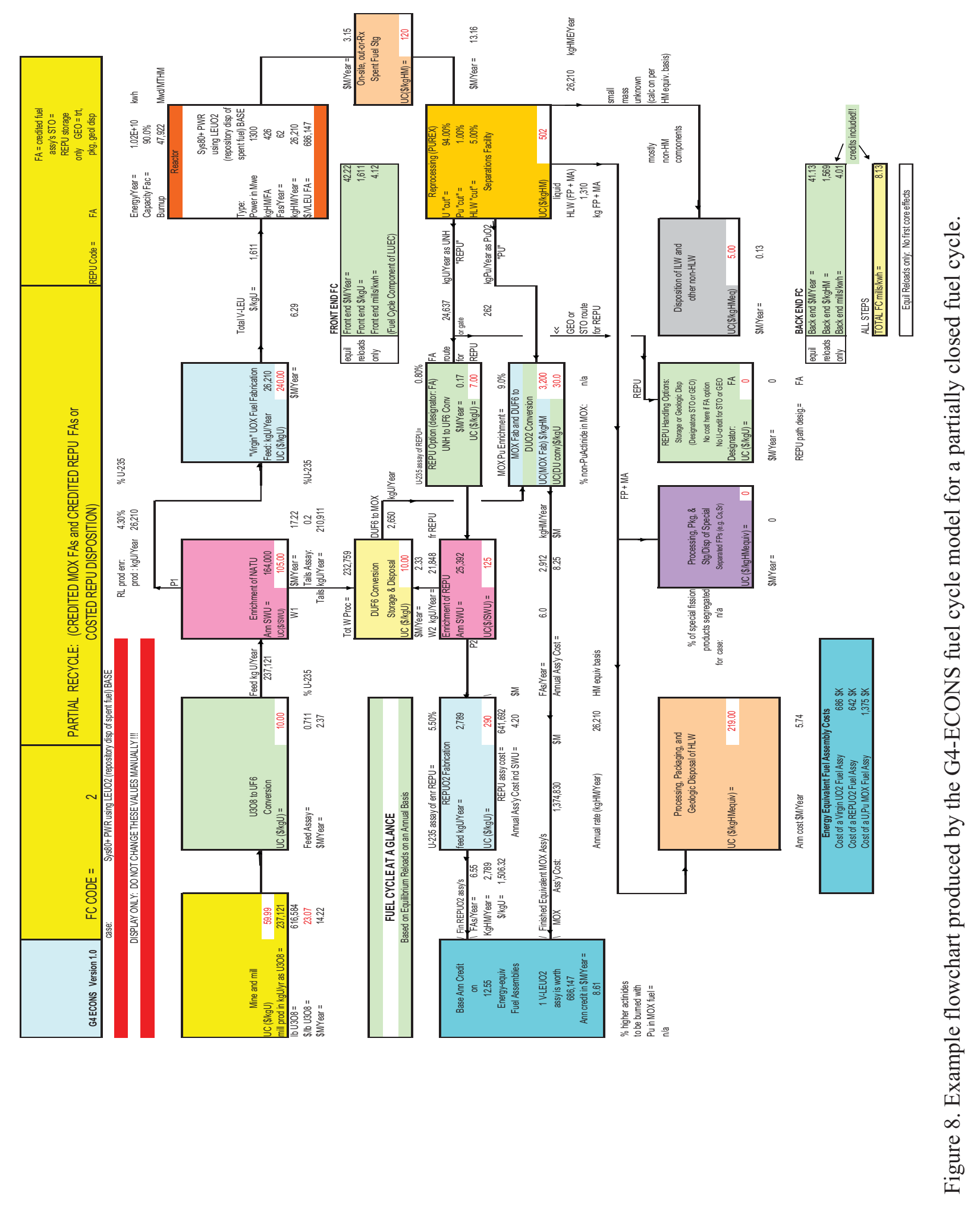




\section{Draft}

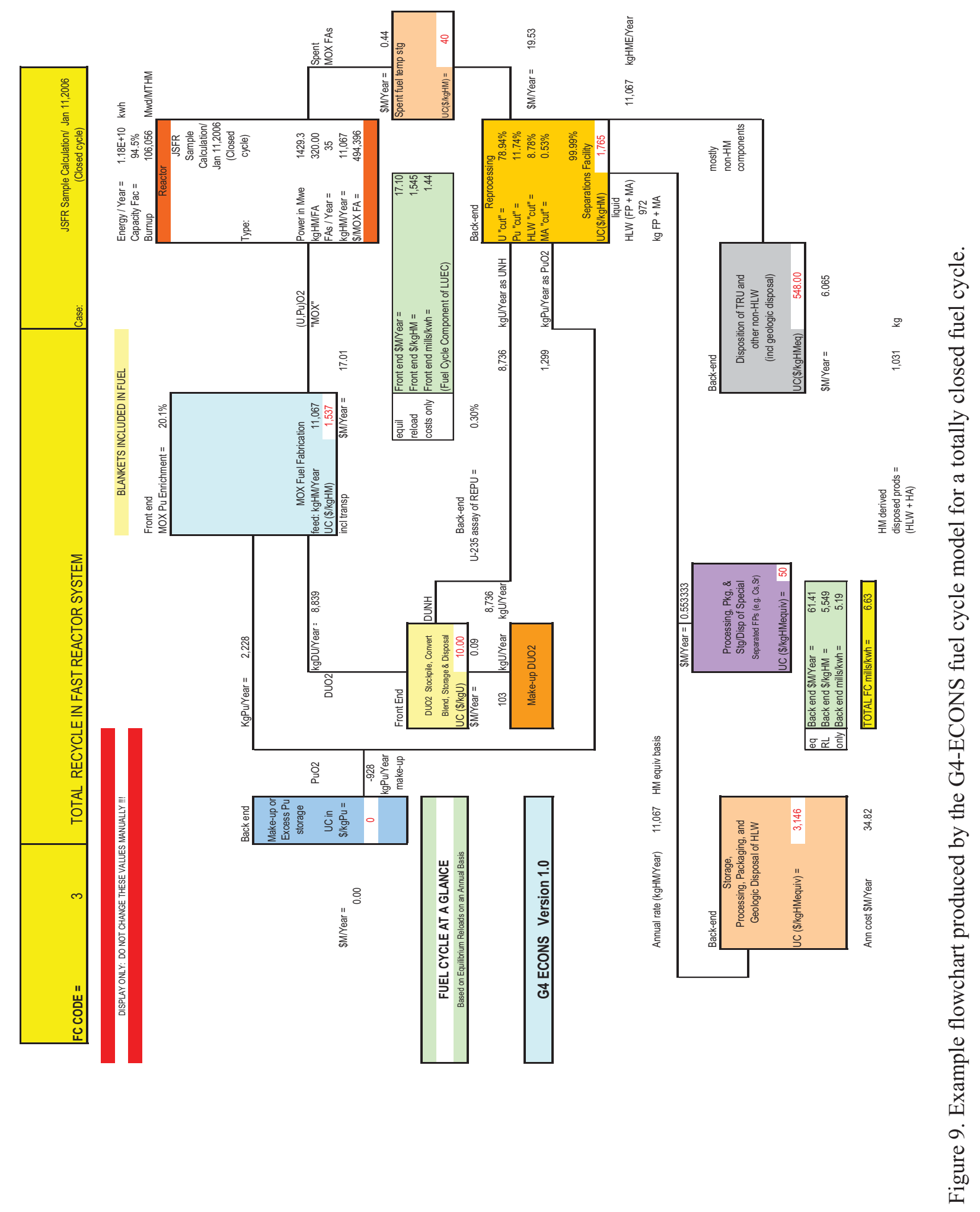


Reactor Decontamination and Decommissioning Cost. The D\&D cost is annualized by use of a sinking fund calculation, with the calculated annual payment based on the projected D\&D funding requirement at end of life and the discount rate. The sinking fund factor, SFF, is calculated as follows:

$\mathrm{SFF}=\mathrm{i} /\left[\left((1+\mathrm{i})^{\wedge} \mathrm{L}\right)-1\right]$,

where:

$\mathrm{SFF}=$ the sinking fund factor

$\mathrm{i}=$ the real discount rate

$\mathrm{L}=$ the plant operating life.

The annual amount which must be set aside every year is:

$\mathrm{ANNDD}=\mathrm{SFF} \times \mathrm{CDD}$

where

ANNDD $=$ the annual payment into the sinking fund, typically in \$M/year

$\mathrm{CDD}=$ the constant dollar lump sum estimate of what is required at the end of plant life to decontaminate and decommission the plant to whatever regulatory requirements allow.

Components of the LUEC. The model has now calculated four annual costs, which in constant dollars, is the same each year over the life of the plant. These are:

ANNCAP The annual capital recovery cost

ANNOM The annual nonfuel O\&M cost

ANNFC The annual fuel cycle cost

ANNDD The annual payment to the D\&D sinking fund.

In order to convert these to components of the LUEC, typically in mills $/ \mathrm{kW} \cdot \mathrm{h}$ or $\$ / \mathrm{MWh}$, one merely divides each of the components above by the annual power production. The electrical power production in kilowatt-hours/year is calculated as:

ANNENERGY $=$ NETCAP $\times 1000 \times 8766 \times$ CAPFAC

where

NETCAP = the NPP's net power capacity in MW(e)

$\mathrm{CAPFAC}=$ the average projected plant capacity factor over the entire plant life

$8,766=$ the average number of hours in a year (including effect of leap years)

$1,000=$ the number of kilowatts per megawatt.

The four LUEC components are therefore:

Capital LCAP $=$ ANNCAP/ ANNENERGY

Nonfuel O\&M LOM = ANNOM/ ANNENERGY 
Fuel cycle $\quad$ LFC $=$ ANNFC/ANNENERGY

D\&D $\quad$ LDD $=$ ANNDD/ANNENERGY.

And the total LUEC:

$\mathrm{LUEC}=\mathrm{LCAP}+\mathrm{LOM}+\mathrm{LFC}+\mathrm{LDD}$.

Figure 10 shows the LUEC components from an actual G4-ECONS-R run for a PWR. The fuel cycle LUEC for this case has been partitioned into both its front end (ore, conversion, enrichment, and fuel fabrication) and back end (spent fuel storage and repository disposition) components.

\subsection{Model Testing and Validation}

The G4-ECONS model has been tested on the following systems for which cost input was availablethe System 80+ PWR, a Massachusetts Institute of Technology (MIT) design for a pebble-bed modular reactor (PBMR), and the JSFR. It can also be used to evaluate small and medium reactor concepts.

The System 80+ case and the JSFR case were run with other more complex generation cost models, and good agreement of the output results was found when the same input values were submitted to each model. Details of this validation are discussed in the G4-ECONS User's Manual Version 1.0 (EMWG 2006b).

\begin{tabular}{|c|c|c|}
\hline \multicolumn{3}{|c|}{ Summary of Model Results } \\
\hline \multicolumn{3}{|c|}{ Discount Rate $=10 \%$} \\
\hline & $\begin{array}{c}\text { Annualized } \\
\text { cost in } \$ \mathrm{M} / \text { year }\end{array}$ & $\begin{array}{l}\text { Mills } / \mathrm{kW} \cdot \mathrm{h} \text { or } \\
\text { \$/MWh }\end{array}$ \\
\hline $\begin{array}{l}\text { Capital (including first } \\
\text { core and financing) }\end{array}$ & 327.19 & 35.91 \\
\hline Operations cost & 78.47 & 8.61 \\
\hline Fuel cycle-front end & 29.07 & 3.19 \\
\hline Fuel cycle_-back end & 9.90 & 1.09 \\
\hline D\&D sinking fund & 0.68 & 0.07 \\
\hline TOTAL LUEC & 445.31 & 48.88 \\
\hline
\end{tabular}

Figure 10. G4-ECONS output table for typical PWR (year 2001 fuel cycle prices). ${ }^{\mathrm{a}}$ 


\subsection{Costing of Fuel Cycle Services and Materials Not Available Commercially-the G4-ECONS FCF Model}

For some Generation IV concepts, fuel cycle cost information will be required for fuel types or fuel services that are not commercially available. These services may have little cost or price information accessible. Estimating teams should still able to calculate the levelized unit costs for these fuels $(\$ / \mathrm{kgHM})$ or services (\$/unit of fabrication, reprocessing, etc.) initially with a top-down cost estimating approach plus the appropriate levelizing algorithms. The estimate should start with information from the Generation IV fuel cycle system designers and sources within the DOE/NE Advanced Fuel Cycle Initiative program, such as the 2007 "AFC Cost Basis" report (Shropshire, et al. 2007). A unit cost can be built from the following data:

- Fuel cycle facility base and owner's costs (for capital component of fuel cycle cost)

- Design/construction duration (for IDC calculation)

- Contingency (part of the overnight cost)

- Annual production from the plant, for example, $\mathrm{kgHM} / \mathrm{year}$ (assumed constant over life of plant)

- Number of years of commercial operation (for recovery of capital)

- Annual operating costs $(\$ \mathrm{M} /$ year)

- An interim replacement rate for capital equipment (treated as an annual average cost like O\&M and included in the O\&M annual cost summation)

- The cost of plant D\&D (recoverable by use of a sinking fund)

- The number of years the D\&D fund is to be collected.

The cost summation and levelization algorithms required for this calculation are basically the same as for the reactor as described above, except that no fuel cycle component is calculated; only capital recovery, O\&M, and D\&D are calculated. A special generic version of G4-ECONS, called G4-ECONS FCF, will be available specifically to address the economics of new fuel cycle process facilities. Most facility concepts will need to start with top-down estimating based on alteration of reference processes to accommodate new fuel cycles. The most likely fuel cycles to need this type of analysis are fuel fabrication facilities for advanced reactor types, fuel reprocessing facilities, and special $\mathrm{P} / \mathrm{T}$ separation facilities, such as for actinides. As mentioned earlier, the estimator should assume that sufficient fuel cycle capacity be designed and estimated to service $32 \mathrm{GW}$ of reactor capacity. Figure 11 shows the actual output from a run of G4-ECONS FCF for a hypothetical fast reactor spent fuel reprocessing facility. Data was provided by Japanese members of the Generation IV EMWG.

\subsection{Plans for Version 2 of G4-ECONS Reactor Model}

Development of Version 2.0 of G4-ECONS is now under way. This revised model will allow for the calculation of the levelized unit cost of energy for products other than electricity from the reactor or coproduction of other products and electricity. Among such products are hydrogen, process heat, desalinated water, and, ultimately, actinide destruction services. Figure 12 shows some of these products. 


\begin{tabular}{|c|c|c|c|c|}
\hline Summary & for Process Plant including Levelized Unit Pro & duct Cost (LUPC) & & \\
\hline $\begin{array}{l}\text { Plant/Facility Name } \\
\text { Product word desription }\end{array}$ & $\begin{array}{l}\text { Japanese Fabrication Plant for JSFR MOX } \\
\text { Metric Tons of Heavy Metal Processed }\end{array}$ & & & \\
\hline Facility Capacity & 250 & MTHM /yr & & \\
\hline Capacity factor & $80.0 \%$ & & & \\
\hline Average Annual Throughput & 200.0 & MTHM /yr & & \\
\hline Overnight Cost & 1778 & $\$ M(U S)$ & & \\
\hline Plant Total Capital Cost & 1870 & $\$ M(U S)$ & & \\
\hline Discount rate for amortization & $3.75 \%$ & & & \\
\hline Plant life & 40 & & & \\
\hline Fixed Charge Rate for amortization & $4.8659 \%$ & & & \\
\hline Reference year for const $\$$ costing & 2003 & & & \\
\hline $\begin{array}{l}\text { Specific Capital Cost } \\
\text { Int During Constr as \% of Overn't Cost }\end{array}$ & $\begin{array}{r}\$ 7,480 \\
5.2 \%\end{array}$ & $\$ / \mathrm{kgHM} / \mathrm{yr}$ & & \\
\hline \multicolumn{5}{|c|}{ Levelized \& Annualized Cost Components: } \\
\hline & & $\$ M(U S) / y r$ & $\$ / k g H M$ & \multirow{6}{*}{ "LUPC" } \\
\hline Capital & & 91.0 & 454.98 & \\
\hline O\&M (Production) & & 177.6 & 887.85 & \\
\hline D\&D Fund & & $\underline{26.9}$ & $\underline{134.52}$ & \\
\hline Total & & 295.5 & 1477.35 & \\
\hline \multicolumn{3}{|c|}{$\begin{array}{l}\text { Plant uses pellet technology to handle } \mathrm{PuO} 2 \\
\text { from reprocessing }\end{array}$} & $\begin{array}{l}1516 \text { is } \\
\text { value from } \\
\text { Japanese } \\
\text { model }\end{array}$ & \\
\hline
\end{tabular}

Figure 11. Output table from G4-ECONS FCF showing breakdown of the unit cost.

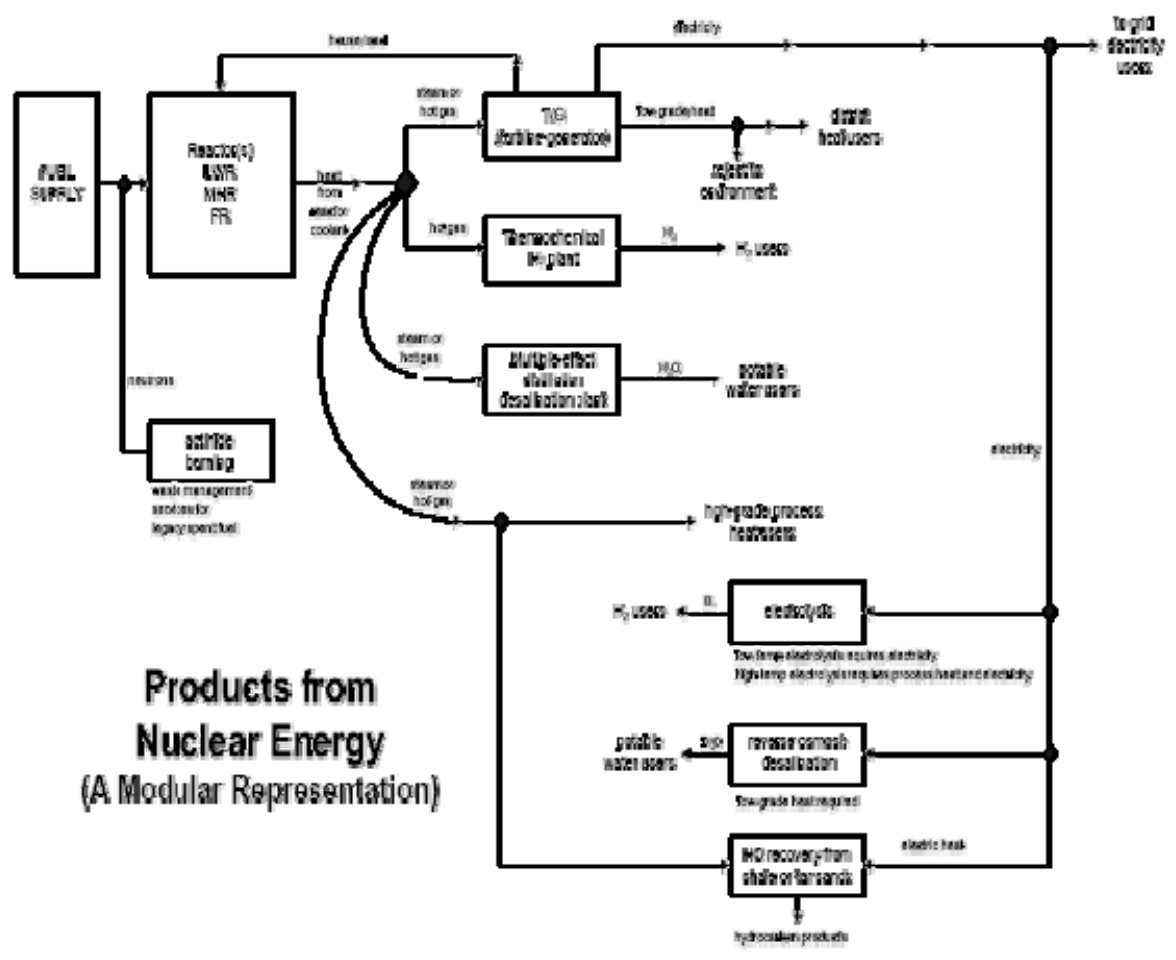

Figure 12. Nuclear energy products. 


\section{THE MODULE-BY-MODULE "SNAPSHOT-IN-TIME" ECONOMIC EVALUATION TOOL FOR FUEL CYCLES PROPOSED FOR THE Advanced Fuel Cycle Initiative (AFCl)}

\subsection{Basic Modeling Concept}

The module-by-module spreadsheet approach to AFCI fuel cycle economic analysis evolved from the fuel cycle part of the Version 1.0 G4-ECONS-R model (Module C-1). As initial AFCI recycle scenarios were developed, it soon became apparent that the G4-ECONS-R model could not be directly applied to most of the $\mathrm{P} / \mathrm{T}$ fuel cycles of interest. This is true mainly for the reason that in G4-ECONS the three fuel cycles available for analysis (open, one-pass MOX and REPU recycle, and totally closed) are "hardwired," (i.e. nearly all fuel steps are pre-selected and there is no opportunity to model symbiotic fuel cycles involving more than one reactor type). (G4-ECONS can only handle one reactor type at a time, which meets the needs of Generation IV program users.)

For this reason, a more flexible modeling approach was deemed necessary for the symbiotic AFCI fuel cycles of interest. The development of a single input/output spreadsheet model to handle all fuel cycle possibilities ( $25+$ steps, multiple reactors, and possible permutations/combinations) was deemed to be too costly and time consuming. The input/output bookkeeping necessary would have required hundreds of hours of programming time and would not have advanced the cause of understanding the economic implications of fuel cycle choices. It was decided that each AFCI scenario would require its own spreadsheet constructed on a "module-by-module" (M-by-M) basis (Spreadsheet Modeling Analysis [SMA]). The M-by-M method requires significantly more analyst interaction, and requires much more than simply entering a series of numbers into a column of cells. The main P/T fuel cycles investigated under AFCI must be pieced together from over 25 possible fuel cycle steps or "modules," shown in the figure in Module C-1, as well as being able to assimilate the associated unit cost for each step. This requires that the analyst be able to link the modules via the appropriate "mass flow" or "material balance" information that flows from the reactors' annual fuel requirements. As an example (for symbiotic fuel cycles using two reactor types), the reactor "fleet sizes" are defined by the fast reactor conversion ratio, which specifies how much makeup fissile material to the fast reactor closed cycle must be derived from the reprocessing of LWR spent fuel. Figure 13 shows a "generic" AFCI P/T cycle involving two reactor types.

The basic calculational algorithms in Excel are mainly the same as those in G4-ECONS-R and described in Module C-1. A unit cost for a particular step is multiplied by the annual flow rate (units/year) to obtain an annual cost. All annual costs (for all steps) are summed to obtain the overall annual cost $(\$ \mathrm{M} / \mathrm{yr})$ for the fuel cycle. This value is then divided by the number of kilowatt-hours produced annually by all reactors in the scenario to obtain the "mills $/ \mathrm{kW} \cdot \mathrm{h}$ " for the fuel cycle.

The unit cost inputs ( $\$ / \mathrm{kg}$ of material or service), required for the M-by-M analysis, depend on the following factors:

- Fissile/fertile materials used (natural uranium, low-enrichment uranium, highly-enriched uranium, MOX, uranium-thorium, etc.)

- Enrichment of fissile materials

- Other materials in the fuel assemblies (zirconium, graphite, etc.)

- Services required to produce the needed materials (mining, milling, conversion, enrichment, fabrication) 


\section{Report Stats}

- 556 Pages ( Over 600 in July Revision )

- In hardback or PDF format (11MB)

- Contains information on 26 cost modules, 24 on the fuel cycle and 2 for reactors

- AFCI Cost Collection Database contains $\sim 300$ reference citations (over 400 in July rev)

- Provides the source of cost data used in system cost models (e.g., VISION and G4ECONS based models) to perform relative economic comparisons of options.

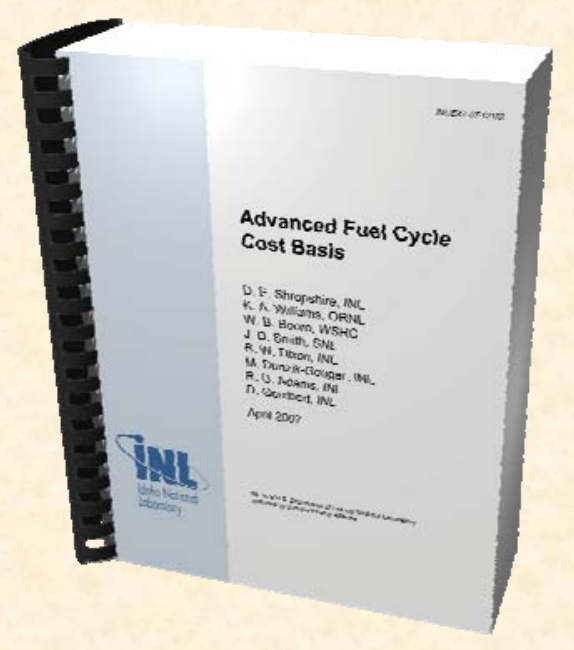

OAK RIDGE NATIONAL LABORATORY

U. S. DEPARTMENT OF ENERGY

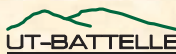

Figure 13. Statistics on "AFC Cost Basis" report.

- Costs of spent-fuel disposal or reprocessing and costs of low and high-level waste (including transuranic waste) disposal

- Storage of critical materials.

The M-by-M method should make use of the most recent "AFC Cost Basis" report (Figure 13 below) as its major resource for such input cost data.

Definition of the material balance which links the modules depends on other data provided by the AFCI Systems Analysis Working Group:

- Reactor mix

- "Recipes" for separations in recycle facilities

- Fuel definitions

- Waste definitions

- Fuel burnups in both reactor types

- Conversion ratio. 


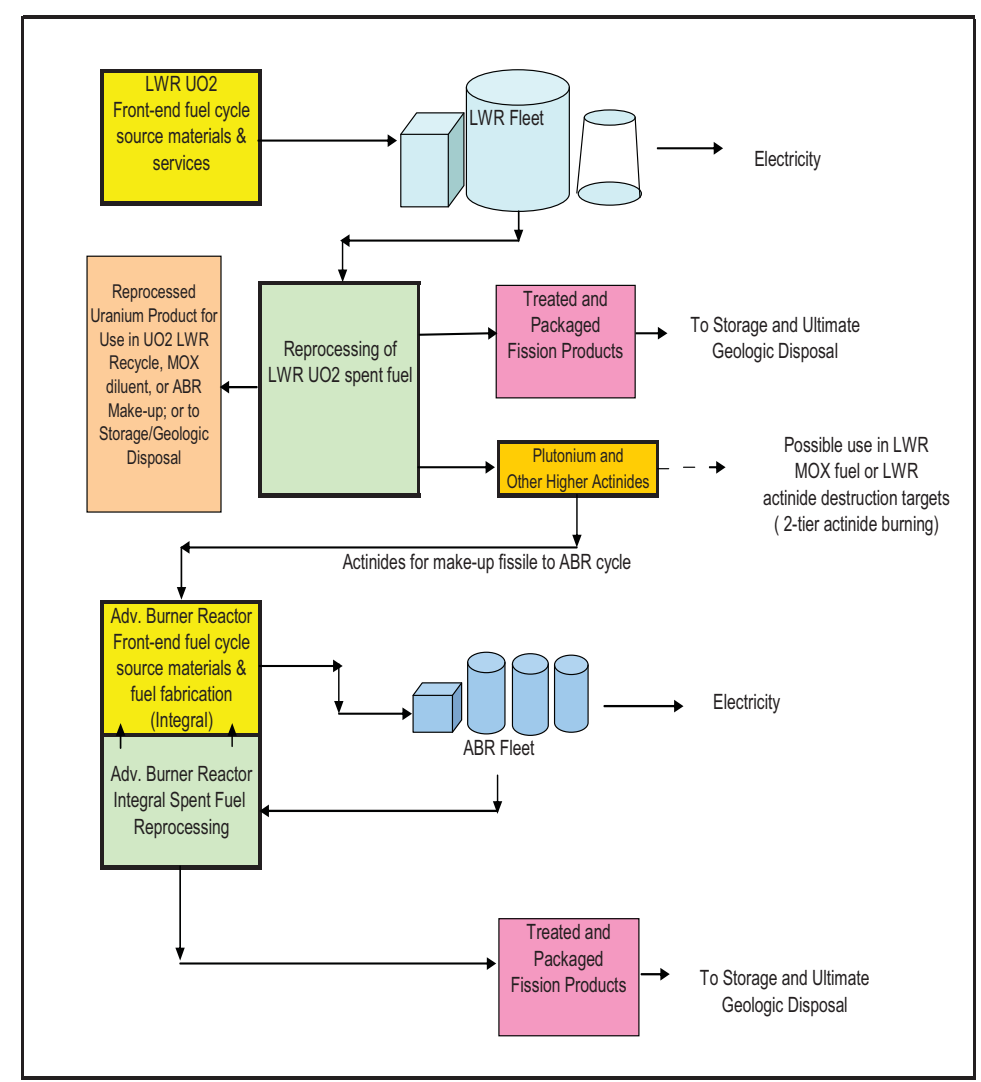

Figure 14. A Generic AFCI Symbiotic Fuel Cycle.

\subsection{Additional Considerations and Calculational Details}

The "M-by-M" methodology described here produces "snapshot-in-time" analyses based on projected fuel cycle material balances for the symbiotic reactor systems of interest to the AFCI. The modeler could, for example, select an "equilibrium" cycle for analysis or utilize a "snapshot" material balance from the dynamic VISION model for particular years of interest during the $21^{\text {st }}$ Century span envisioned for the AFCI. It should be realized that many P/T-type fuel cycles may not reach equilibrium until many decades or even hundreds of years have elapsed.

As initial AFCI analyses were prepared, it became apparent that the overall busbar electricity cost (LUEC) from particular scenarios needed to be calculated in addition to the fuel cycle cost. This meant that the non-fuel cycle costs for the reactors, such as capital amortization, O\&M, and D\&D, needed to be added to the fuel cycle component of the LUEC. The reactor (or fleets of reactors of the two types) now had to be treated as another module (R1 [LWR] and/or R2 [FR]) in the overall fuel cycle scheme. The Mby-M analysis had to be adapted to include levelized, annualized reactor-related costs such as capital, O\&M, and D\&D into the cost data for the "R" modules, but at a detail level much less than that incorporated in the G4-ECONS-R model. A "mini-model" for each reactor type (with many of the features of G4-ECONS-R) had to be prepared that had much simpler inputs. It was decided that the following simplified cost-related inputs for each reactor type would be specified and ranges defined in the R1 and R2 Modules of the July 2007 Advanced Fuel Cycle Cost Basis Report:

- The reactor-specific capital cost in $\$ / \mathrm{kWe}$ (including any interest during construction and contingency). 
- The fixed component of the non-fuel annual O\&M cost in $\$ / \mathrm{kWe}-y r$ (including a slight "plus-up" to include the small annual contribution to the D\&D fund).

- The variable component of the non-fuel annual O\&M cost in mills $/ \mathrm{kW} \cdot \mathrm{h}$ or $\$ / \mathrm{MWh}$ (including a small contribution for capital replacements anticipated over the operating life of the reactor).

- The reactor lifetime in years and the discount rate needed to calculate a fixed charge rate for capital recovery. The fixed charge rate is calculated in same way as described in Module C-1.

The capital component of the LUEC for a given reactor type or a fleet of reactors of the same type ( $\mathrm{R} 1$ or $\mathrm{R} 2)$ is calculated in mills $/ \mathrm{kW} \cdot \mathrm{h}$ or $\$ / \mathrm{MWe}$ as:

LUECCAP $=$ SPECCOST $\times$ RXCAP $\times 1 . E 6 \times$ FIXCHG $/$ EL

where

SPECCOST $=$ specific capital cost in $\$ / \mathrm{kWe}$

$\mathrm{RXCAP}=$ reactor(s) net power capacity in MWe

$\mathrm{FIXCHG}=$ annual fixed charge rate

$\mathrm{EL}=$ annual electricity production in Kilowatt-hr/yr for single reactor or fleet

The non-fuel O\&M component of the LUEC is the sum of the fixed and variable components as follows (in mills/kW•h or $\$ / M W h$ ):

Fixed Component:

LUECFOM $=$ FIXOM $\times$ RXCAP $\times 1 . E 6 / E L$

where

FIXOM $=$ fixed O\&M component in $\$ / \mathrm{kWe}$

$\mathrm{RXCAP}=$ net power capacity of reactor or fleet in MWe

$\mathrm{EL}=$ electricity production of reactor or Fleet in $\mathrm{kW} \cdot \mathrm{h} / \mathrm{year}$

Variable Component:

LUECVOM $=$ VAROM, which is already in mills $/ \mathrm{kW} \cdot \mathrm{h}$ or $\$ / M W h$.

The total nonfuel cycle levelized electricity cost for the reactor(s) of a given type is thus LUECCAP + LUECFOM + LUECVOM. If an AFCI scenario involves two or more reactor types, it should be calculated separately for each. The LUECs so obtained (for R1 and R2) are then multiplied by the electricity production from each fleet (R1 and R2) to obtain the total annual non-fuel cycle related cost for the whole scenario. To this is added the total annual fuel cycle cost $(\$ \mathrm{M} / \mathrm{yr})$ for the whole scenario to obtain the "all-in" costs for the AFCI scenario in a given year. Dividing this by the electrical production for all fleets (modules R1+R2) of reactors gives the levelized annual LUEC for the entire symbiotic system. This is the value that should be compared to the LUEC from the open cycle LWR system that is currently operating. So far all studies have shown that closed, partially closed, or symbiotic fuel cycles will have LUECs higher than those for the open cycle. The difference, likely to be a few mills $/ \mathrm{kW} \bullet \mathrm{h}$, represents the amount that might have to be "subsidized" or treated in a manner similar to the "carbon taxes" that are likely to be required in the future for fossil fuel electricity production to meet its sustainability and environmental requirements. 


\subsection{An Example Analysis}

The following is a list of reports which include scenarios (listed below) analyzed by the M-by-M spreadsheet method:

- December 2006 “AFC Economic Sensitivity Analysis Report” (INL/EXT-06-11947)

- Open cycle

- One-tier AFCI cycle (recycle fuel loaded in fast reactors only)

- Fully-closed ABR cycle

- $\quad$ LWR thermal recycle using drivers and targets

- "SNF Recycling Alternatives Assessment" (December 2006) [unpublished: preparation stimulated by BCG/AREVA report]

- Open cycle

- AFCI single-tier cycle

- COEX cycle

- “AFCI Comparison Report” (May 2007: unpublished)

- Open cycle

- Thermal recycle only

- $\quad$ Two-tier recycle (recycle fuel loaded in both LWRs and fast reactors)

- $\quad$ AFCI single-tier

- $\quad$ Sustained fast reactor recycle.

Figures $15 \mathrm{a}, 15 \mathrm{~b}$, and $15 \mathrm{c}$ show an example of a complete symbiotic scenario where actinides derived from LWR spent fuel provide the make-up fissile material to a fast reactor recycle system based on metal fuel/pyroprocessing technology. This is not the "official" AFCI scenario, just one of many that have been examined. It is expected that many new cases for such "static" analysis will flow from the VISION studies now being undertaken by the Systems Analysis Working group. 


\section{Draft}

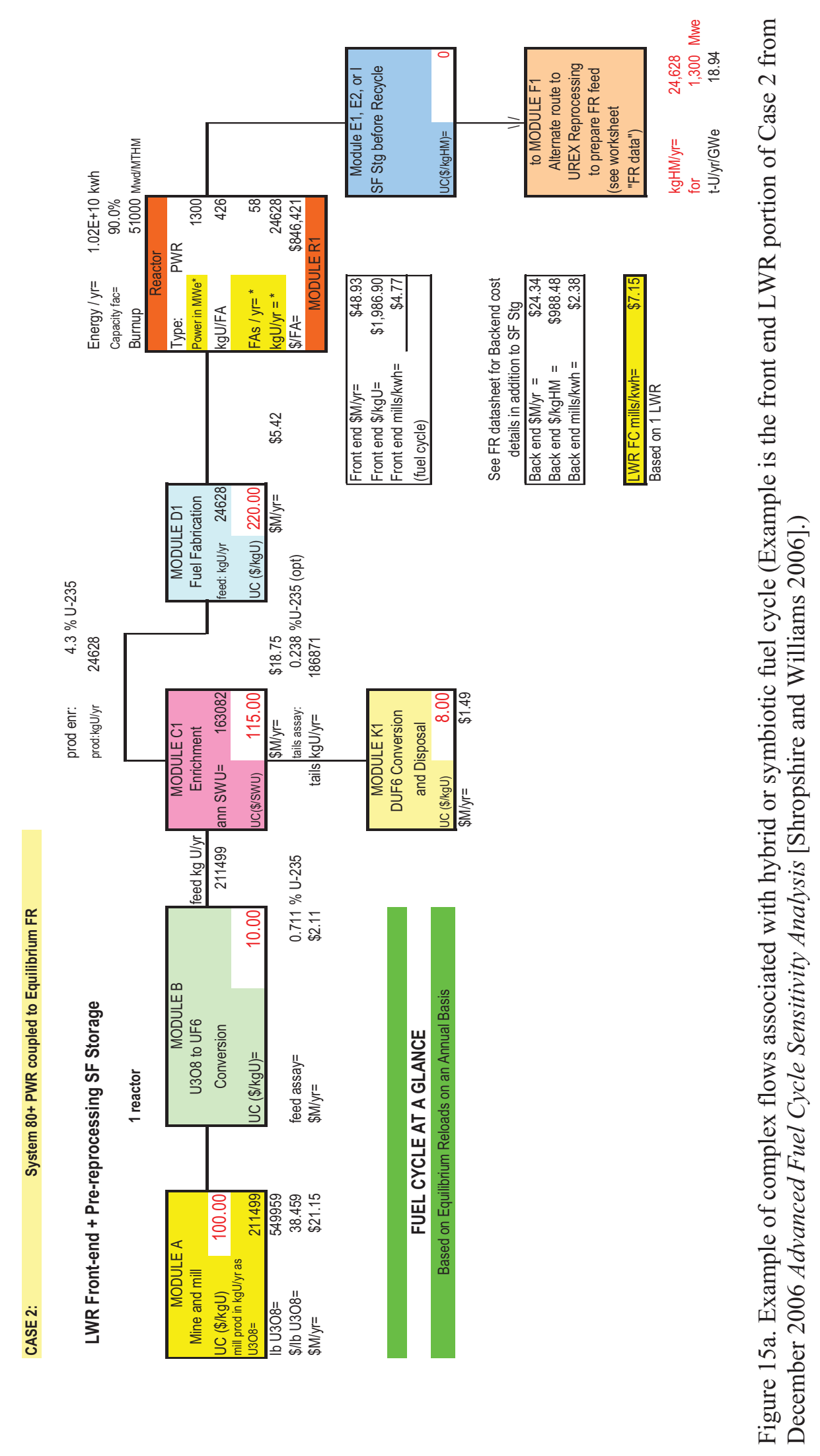




\section{Draft}

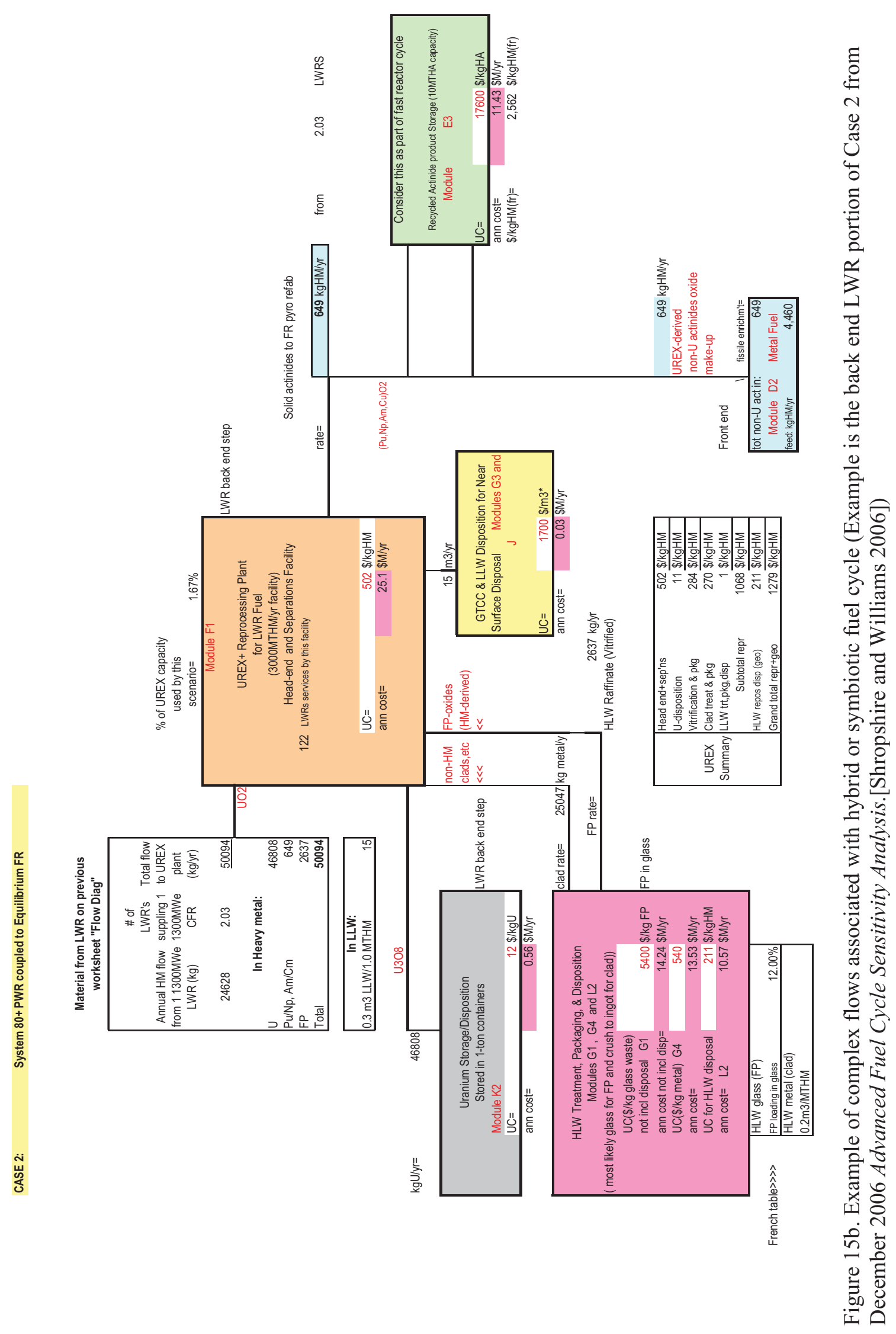




\section{Draft}

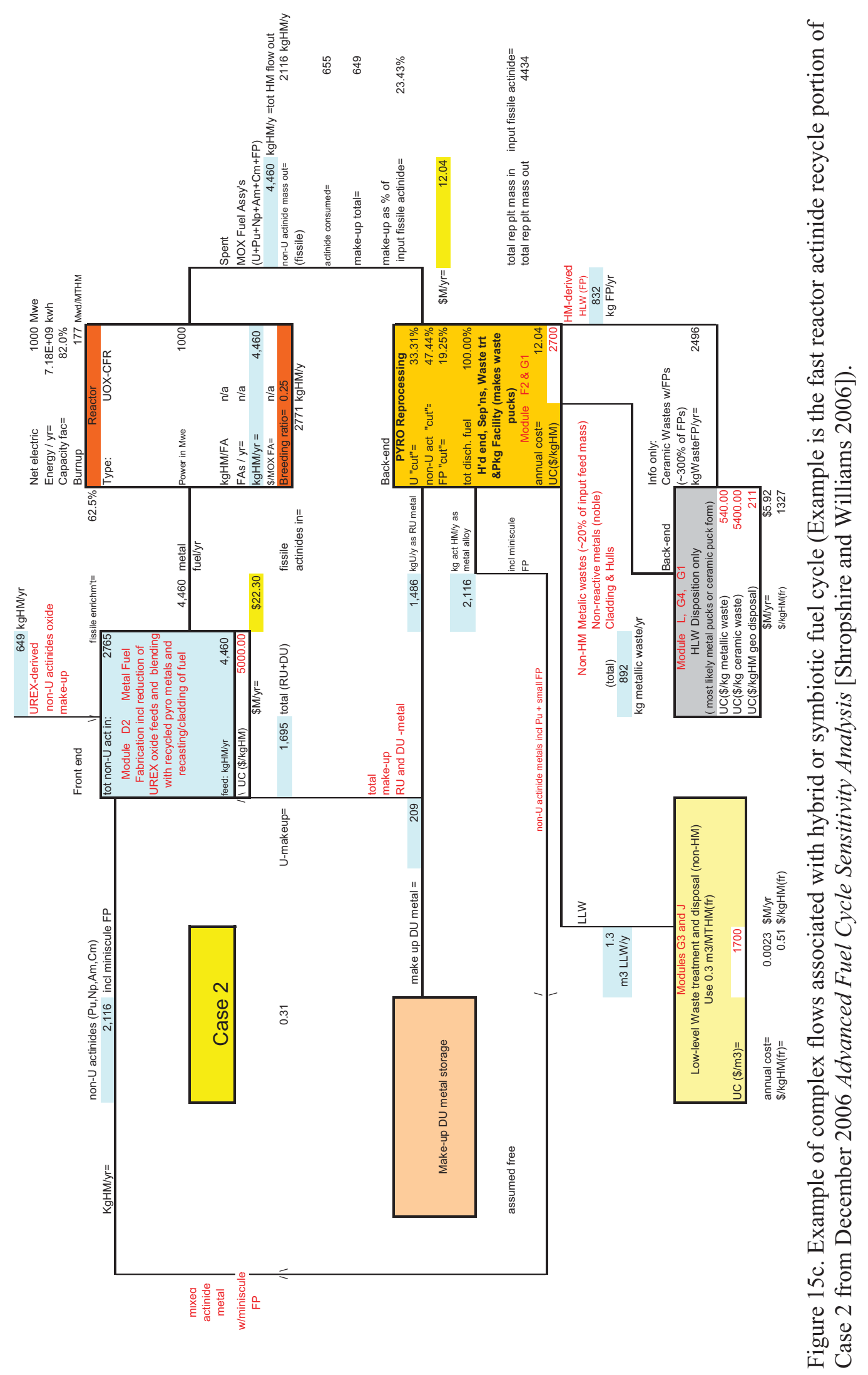




\section{USE OF UNCERTAINTY ANALYSIS WITHIN THE G4-ECONS DERIVED MODELING SYSTEMS}

Since the AFCI program is dealing with hypothetical deployment of advanced nuclear technologies over several future decades, there are many uncertainties associated with future costs. For this reason it is prudent to present not only "single-point" or deterministic values, but also ranges or probabilities associated with modeling results. Presenting and comparing cost figures of merit, such as "mills/kW·h" fuel cycle cost or generation cost, in the form of probability distributions or ranges has the value of allowing the analyst to compare the relative cost risk of technology alternatives. The use of probabilistic analysis for such application has now become the norm for preparing credible and meaningful comparative economic analyses.

There are several commercially available software tools that allow the user to associate ranges or probability distributions with input cells of an Excel spreadsheet. These programs essentially "drive" the user's spreadsheet model by drawing samples, using Monte Carlo or Latin Hypercube methods, from each designated input cell distribution. The program runs the Excel spreadsheet multiple times and performs the "bookkeeping" function of accumulating the multiple values calculated for the selected output (cost figure-of-merit) cells. After sufficient samples and runs have been completed, the programs do a statistical analysis on the desired outputs (figures-of-merit) and present the results in terms of the typical "bell-shaped" relative probability distribution plots or S-curve shaped cumulative distribution plots. Among the software brands which can be utilized with Excel spreadsheets are Crystal Ball, @ RISK, and DPL (Decision Programming Language).

Most of these software packages can also perform "single-value" or "one-variable-at-a-time" sensitivity studies, where all spreadsheet inputs, except one, are held constant at their "baseline" values. The user specifies the credible range for the single variable of interest. The results are often displayed in the form of "tornado" or "Pareto" diagrams. As an example, Figure 16 below shows the result of sensitivity studies on eight different fuel cycle module unit costs on the overall fuel cycle cost in $\mathrm{mills} / \mathrm{kW} \cdot \mathrm{h}$. (The baseline deterministic figure of merit is the single $6.36 \mathrm{mills} / \mathrm{kW} \cdot \mathrm{h}$ value represented by the vertical line). The green horizontal bars display both the input and output ranges for the input variable (a unit cost for a particular fuel cycle step or material) and the fuel cycle cost component of the levelized unit cost of electricity. This example is taken from the December 2006 Advanced Fuel Cycle Economic Sensitivity Analysis report (Shropshire, et al. 2006).

Figure 17 show the relative probability distributions on the fuel cycle component of the LUEC for four different fuel cycle scenarios. These were prepared by the DPL software and preparation of the Advanced Fuel Cycle Economic Sensitivity Analysis report (Shropshire, et al. 2006). The location of each curve on the cost axis and its relative "spread" or standard deviation give the user some indication of the comparative economic risk of each scenario in relation to the others. This is much more meaningful than considering only the locations of the four vertical bars (deterministic results) on the cost axis.

These diagrams and results are shown as examples of methodology application only. These by no means represent the current official AFCI scenarios. The scenarios which will inform the Secretary of Energy's June 2008 decision are still in the process of definition. 


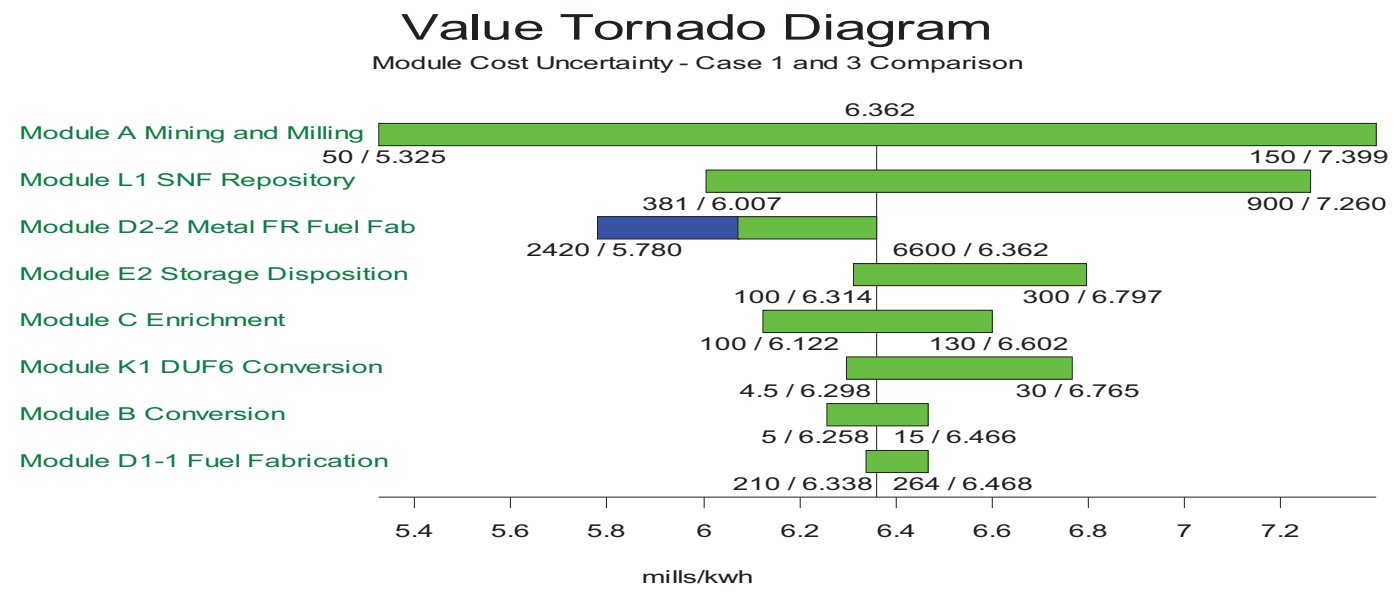

Figure 16. Example of single-value sensitivity study output.

\section{Frequency Risk Profile}

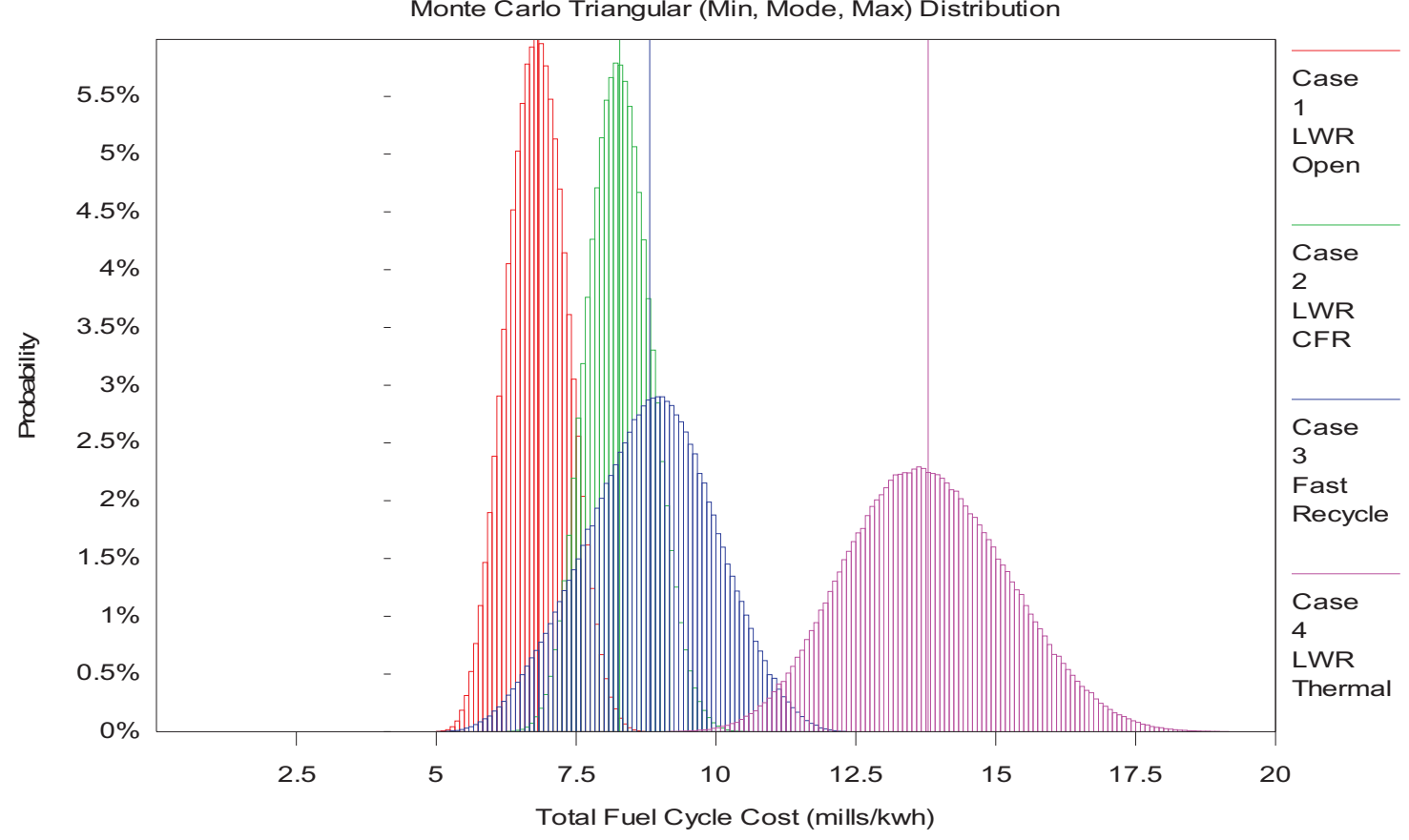

Figure 17. Example of multivariable sensitivity study output (probabilistic analysis). 


\section{REFERENCES}

EMWG (2006a), "Cost Estimating Guidelines for Generation IV Nuclear Energy Systems-Rev. 3," Generation IV Economic Modeling Working Group, November 30, 2006, http://www.gen4.org/Technology/horizontal/economics.htm, Web site accessed September 2007.

EMWG (2006b), A User's Manual for G4-ECONS, Generation IV Economic Modeling Working Group, May 2006, (to be issued along with G4-ECONS software in 2007).

EMWG, Cost Estimating Guidelines for Generation IV Nuclear Energy Systems-Rev 3, Generation IV Economic Modeling Working Group, November 30, 2006, http://www.gen4.org/Technology/horizontal/economics.htm, Web page accessed September 2007.

Lauferts, U., et al., "Economic Assessment of Partitioning, Transmutation, and Waste Reduction Technologies," Proceeding of ICAPP 2007, Nice, France, Paper 7382, May 13-18, 2007.

Shropshire, D. E., and Williams, K. A., Advanced Fuel Cycle Sensitivity Analysis, INL/EXT-06-11947, December 2006.

Shropshire, D. E., Williams, K. A., et al., Advanced Fuel Cycle Cost Basis, INL/EXT-07-12107, July 2007.

Shropshire, D., Williams, K. et al., Advanced Fuel Cycle Economic Sensitivity Analysis, INL/EXT-0611947, December 2006.

Williams, K. A., and Shropshire, D. E., "Fuel Cycle Economic Analysis Using an Excel Spreadsheet," ANS Summer Meeting, Boston, MA (June 24-28, 2007) to be published. 